\title{
Continuo e infinito Influencias y génesis del tratamiento leibniziano del laberinto del continuo
}

Federico Raffo Quintana

Tesis para optar por el grado de Doctor en Filosofía

Director Oscar M. Esquisabel, Universidad Nacional de La Plata

La Plata, Noviembre de 2016 

Resumen: En esta tesis analizaremos el tratamiento del problema del continuo y del infinito en el pensamiento de juventud de Leibniz. Mostraremos que, en su abordaje, el filósofo de Leipzig entremezcla problemas físicos, metafísicos y matemáticos. Dividiremos este trabajo en tres partes: en la primera de ellas examinaremos algunos aspectos generales del trasfondo científico y filosófico del siglo XVII. Luego, nos detendremos en algunas importantes concepciones históricas que, de una u otra manera, influyeron en la evolución del pensamiento de Leibniz, como por ejemplo, entre otras, las de Aristóteles, Froidmont, Galileo y Gassendi. En la segunda parte abordaremos el tratamiento de Leibniz sobre el continuo y el infinito entre 1669 y 1672 . Veremos que en este período, en el que hubo una gran evolución interna, Leibniz planteó algunas nociones muy importantes, como por ejemplo, las de lo indivisible y lo infinitamente pequeño. En la tercera parte nos centraremos en algunos escritos redactados por Leibniz entre 1675 y 1676, en los que propuso algunas ideas novedosas en el dominio de la matemática, de la física y de la metafísica. Algunas de ellas son, por ejemplo, la distinción entre infinito con término y sin término, las nociones de forma simple, agregado, todo y uno.

Palabras clave: continuo / infinito / indivisible / infinitesimal / agregado / forma simple

\begin{abstract}
In this thesis we will analyze the approach to the problem of the continuum and the infinite in young Leibniz's thought. We will show that in his treatment, Leibniz considers physical, metaphysical and mathematical questions altogether. Our work will be divided in three parts: in the first one, we will examine some general aspects of the scientific and philosophical background of the seventeenth century. After this, we will analyze some decisive historical conceptions, which in some way influenced in the evolution of Leibniz's thought, such as those of Aristotle, Froidmont, Galileo and Gassendi. In the second part, we will deal with Leibniz approach to the continuum and the infinite between 1669 and 1672. We will see that in this period, as a result of his internal evolution, Leibniz introduced some significant notions, such as those of the indivisible and of the infinitely small. In the third part, we will focus on some texts written by Leibniz between 1675 and 1676, in which he proposed some novel ideas in the mathematical, physical and metaphysical domain. Among these ideas, the distinction between bounded and unbounded infinite, the notions of simple form, aggregate, whole and unit, stand out.
\end{abstract}

Key-words: continuum / infinite / indivisible / infinitesimal / aggregate / simple form 



\section{ÍNDICE GENERAL}

INTRODUCCIÓN GENERAL

Primera PARTe: ConteXto Y ANTECEDentes

CAPÍTULO 1: LEIBNIZ Y SU CONTEXTO INTELECTUAL

1. Crisis del esquema epistemológico $\quad 4$

2. Cambios en el abordaje de la física $\quad 7$

3. Cambios lógico-metodológicos 10

4. El mecanicismo como modelo de explicación física 16

CAPÍTULO 2: TEORÍAS DEL CONTINUO Y DEL INFINITO PRE-LEIBNIZIANAS 23

INTERPRETACIONES ARISTOTÉLICAS DEL CONTINUO 24

1. Continuo e infinito en Aristóteles 24

2. Francisco Suárez y los extremos como veras res 33

3. Continuo e infinito en Froidmont: Labyrinthus sive de compositione continui 36

3.1. 'Indivisibilistas' versus 'divisibilistas' 39

3.2. Ejemplos de argumentos geométricos contra el atomismo 41

3.3. La división infinita del continuo según una ratio constante 45

INTERPRETACIONES ATOMISTAS DEL CONTINUO 51

4. La oposición finito-divisible e infinito-indivisible de Galileo $\quad 51$

5. El 'método de los indivisibles' de Cavalieri 61

6. Los átomos físicos de Gassendi $\quad 65$

SEgunda PARTe: PRimer abordaje leibniziano del CONTINUO Y El INFINITO 73

CAPÍTULO 3: EL INFINITO ACTUAL EN LA MATERIA 75

1. La actualidad de partes en el continuo $\quad 76$

2. Hacia la infinitud de partes en el continuo: el examen de la materia 79

2.1. Las notas esenciales de la materia $\quad 80$

2.2. Materia y movimiento $\quad 86$

2.3. Movimiento e infinitas partes actuales $\quad 92$

2.4. El problema de la indefinición cartesiana 95 
1. Modelos de comprensión del infinito y la infinitud actual de partes del continuo 108

2. Los extremos del continuo $\quad 118$

3. Los extremos indivisibles de $1671 \quad 120$

3.1. Existencia y naturaleza de los extremos indivisibles $\quad 120$

3.2. Discusión de otras interpretaciones sobre el continuo leibniziano de 1671

4. De los indivisibles a las partes infinitamente pequeñas 135

CAPÍTULO 5: ASPECTOS FÍSICOS DEL TRATAMIENTO DEL CONTINUO 149

1. La explicación de la diferencia de velocidades en el siglo XVII 150

2. Conatos, movimientos y diferencia de velocidades en Leibniz 155

3. Presupuestos y justificación de la cohesión de los cuerpos 166

4. Algunas consecuencias de la explicación leibniziana de la cohesión de los cuerpos 171

CAPÍTULO 6: LO MÍNIMO Y LO MÁXIMO EN EL CONTINUO 179

1. El infinito actual y los mínimos en el continuo 180

2. El número infinito de todas las unidades 191

2.1. El abordaje filosófico: la demostración del axioma 194

2.2. El abordaje aritmético: la equiparación con el cero 201

Tercera Parte: Continuo e infinito en DE SUMma Rerum 215

CAPÍTULO 7: EL INFINITO ENTRE LA MATEMÁTICA Y LA METAFÍSICA 217

1. Los diversos grados de infinito $\quad 217$

2. El infinito 'como la asíntota de una hipérbola' 219

3. In minima divisum esse y sine fine divisum esse 224

4. Cantidades ficticias infinitas e infinitamente pequeñas 230

4.1. La cuadratura del círculo y el método de exhaución 232

4.2. Los fundamentos del método infinitesimal de Leibniz 235

4.3. La introducción de cantidades ficticias 241

4.4. Las cantidades infinitamente pequeñas desde el punto de vista metafísico 252

CAPÍTULO 8: FORMAS, MODOS Y EL CONTINUO 259

1. El infinito como la suma de todos los requisitos 260 
2. 'Cosas extensas' y 'extensión’ 268

3. 'La extensión' o 'lo inmenso' 271

4. Otros atributos relacionados con el problema del continuo 279

4.1. Tiempo y eternidad 280

4.2. Mentes individuales e intelecto agente universal 282

4.2.1. Pluralismo de entes en DSR 283

4.2.2. Mentes y omnisciencia 285

5. Conocimiento y clasificación de las formas 293

CAPÍTULO 9: MATERIA, MOVIMIENTO Y ACCIÓN EN DSR 301

1. La naturaleza de la materia 301

1.1. La congruencia de las sensaciones 303

1.2. La flexibilidad de todos los cuerpos 306

1.3. La materia, mole o masa: sobre la variedad de cosas en lo inmenso 309

2. Individuación y cohesión de los cuerpos 314

2.1. El problema de la continuidad de los agregados 315

2.2. Los cuerpos que se resisten a la disipación: la unidad de los agregados 324

3. Naturaleza del movimiento 333

4. La formulación leibniziana de la ley de conservación 343

5. Naturaleza de la acción 347

CONCLUSIONES 355

1. Conclusiones generales: la transversalidad del problema del continuo y del infinito 355

2. Trazando puentes: de la multiplicidad a la unidad 365 



\section{INTRODUCCIÓN GENERAL}

El problema de la composición del continuo es, por su propia naturaleza, muy complejo. El abordaje que Leibniz hizo de él es especialmente intrincado, al menos por dos motivos. En primer lugar, porque hay distintas tradiciones, que Leibniz no siempre menciona explícitamente, en las que el filósofo de Leipzig sustenta su concepción y a las que también cuestiona. Por otro lado, porque su tratamiento entremezcla reflexiones filosóficas o, si se quiere, metafísicas, con otras pertenecientes al dominio de la física e incluso, más importante aún, de la matemática. En este sentido, para Leibniz, así como también para algunos de sus contemporáneos, el problema del continuo no estaba limitado a la cuestión de la composición de las entidades puramente matemáticas, pues comprendía todas las cantidades en general, es decir, también las físicas. ${ }^{1}$ No obstante, hay algo que atraviesa toda esta variedad de ámbitos como un pilar fundamental del tratamiento de Leibniz, a saber, el concepto de infinito. Como señala Ph. Beeley, infinito y continuo, nociones cuyos tratamientos dieron lugar a tradiciones, fueron para Leibniz “(...) la clave para armonizar o al menos conectar tres pilares centrales de su sistema: la matemática, la física y, por supuesto, la metafísica misma".2

Si bien durante toda su vida Leibniz consideró que el problema "de la Composición del continuo, el tiempo, el lugar, el movimiento, los átomos, lo indivisible y lo infinito" 3 es uno de los dos 'laberintos' para la mente humana (siendo el otro el de la libertad), los tratamientos más minuciosos fueron concebidos especialmente en sus años formativos de juventud. ${ }^{4}$ Esto explica, al mismo tiempo, la presencia de distintas tradiciones a la que nos referimos antes. En este trabajo nos proponemos reconstruir los primeros pasos del

\footnotetext{
${ }^{1}$ Arthur, 1998: 110.

${ }^{2}$ Beeley, 2015: 23. "For infinity and the intimately related concept of continuity, while having an ancient philosophical tradition of their own, were for him always also the key to harmonizing or at least connecting the three central pillars of his system: mathematics, physics, and indeed metaphysics itself'.

${ }^{3}$ Guilielmi Pacidii de rerum arcanis, A VI 3, 527. "Labyrinthus posterior, seu de Compositione continui, tempore, loco, motu, atomis, indivisibili et infinito". Es célebre la referencia a los dos laberintos que se encuentra en Theodicée, GP VI, 29.

${ }^{4}$ Como veremos, la masa de escritos en los que Leibniz abordó como tal el problema del continuo data especialmente de entre los años 1671 y 1676, aunque en algunos aspectos es posible remontarse hasta 1669. Si bien posteriormente se refirió al laberinto del continuo, no hay tratamientos sistemáticos, excepto en Geschichte des Kontinuumproblems de 1693, que fue editado por Manuel Luna Alcoba (Leibniz, 1996).
} 
tratamiento realizado por Leibniz del problema del continuo y del infinito, así como también las teorías más significativas que, de una u otra manera, influyeron en su desarrollo.

El hecho de referirnos a 'pasos' de un 'desarrollo' implica que en los escritos de juventud de Leibniz no hubo un único tratamiento, sino más bien una evolución. El límite inicial de este proceso se encuentra, históricamente, en los últimos años de la década de 1660. A pesar de ello, el primer tratado en el que podemos hallar un desarrollo relativamente sistemático del problema de la composición del continuo data de los primeros años de la década de 1670, a saber, la Theoria motus abstracti. En este escrito, en el que abordó las razones de los movimientos de un modo -dicho en términos actualescinemático, Leibniz presentó sumariamente una primera concepción general del continuo y del infinito. Si tenemos en cuenta las dos tradiciones generales del problema del continuo, una de naturaleza atomista y otra inspirada en el pensamiento de Aristóteles, podríamos decir que la concepción de Leibniz fue, en términos generales, aristotélica. No obstante, no fue un repetidor de las ideas del célebre filósofo griego ni de sus continuadores. La diferencia más destacada es, sin dudas, que Leibniz afirmó infinitas partes actuales en el continuo. Ahora bien, un año después de presentar este breve tratado, Leibniz viajó a París, donde se estableció hasta fines de 1676. Si bien el motivo formal de su viaje estuvo relacionado con cuestiones de naturaleza diplomática, en 1679 reconoció que la razón por la que permaneció tanto tiempo en París fue la búsqueda de conocimiento matemático. ${ }^{5}$ La dedicación que tuvo hacia las matemáticas no hizo mermar el tratamiento del problema del continuo, sino que más bien sucedió todo lo contrario: la intensidad con la que lo abordó se acrecentó notablemente.

La piedra angular del desarrollo del laberinto del continuo en el período parisino de Leibniz es el concepto de infinito. La centralidad de esta noción se vio potenciada primero por algunos exámenes aritméticos relativos a la suma de series infinitas y luego por el desarrollo de un método infinitesimal para abordar el problema de la cuadratura del círculo y de las restantes secciones cónicas. No obstante, la manera como Leibniz concibió el continuo en el período parisino no fue unívoca. En un primer momento, discutió intensamente algunas ideas del célebre matemático italiano Galileo Galilei y arribó, entre muchas otras conclusiones, a la visión de que en el continuo hay en acto cosas

\footnotetext{
${ }^{5}$ Leibniz a Johann Friedrich, A II 1, 490. Beeley, 2015: 29.
} 
infinitamente pequeñas. Los desarrollos sobre series infinitas del comienzo de sus días en París fueron decisivos para el surgimiento y la profundización de esta concepción. No obstante, en los últimos años del período parisino, Leibniz defendió que las cantidades que tienen la propiedad de ser infinitamente pequeñas no existen realmente, sino que son ficciones. En el marco de un tratado sobre geometría, Leibniz estableció algunas aclaraciones relativas al concepto de infinito, como la distinción entre el infinito 'sin término' y 'terminado', que también fueron fundamentales para su concepción del continuo. Más allá de estas vinculaciones con la matemática, las reflexiones sobre el problema del continuo de 1675/1676 están también estrechamente conectadas con una incipiente concepción metafísica que tiene algunos aspectos verdaderamente novedosos en relación con sus planteos previos. Esta visión metafísica estuvo influenciada fundamental, aunque no exclusivamente, por el pensamiento spinozista. A pesar de que con el tiempo muchos de los aspectos spinozistas que tuvo la concepción metafísica de 1675/1676 fueron desapareciendo, en la visión sobre el continuo de este período ya se encuentran presentes numerosos elementos por cuya evolución Leibniz arribó a su planteo de madurez.

Nuestro trabajo está dividido en tres partes que, en total, suman nueve capítulos. En la primera parte abordaremos algunos aspectos del contexto intelectual de Leibniz, así como también algunas de las teorías sobre el problema del continuo que influyeron, directa o indirectamente, en la concepción del filósofo de Leipzig. En la segunda parte analizaremos las primeras reflexiones de Leibniz sobre el problema del continuo y el infinito entre 1669 y 1672. Si bien hay algunas grandes constantes teóricas a lo largo de esos años, hay también, y especialmente, una evolución interna muy significativa. Finalmente, en la tercera parte examinaremos la concepción leibniziana del continuo y del infinito de los últimos años del período parisino, es decir, entre 1675 y 1676. Si bien hay conexiones entre los desarrollos de este período en relación con el que abordaremos en la segunda parte, hay también ideas novedosas tanto matemáticas como metafísicas. Los primeros dos capítulos corresponden a la primera parte de nuestra tesis, mientras que la segunda parte comprende del tercer al sexto capítulo y la tercera del séptimo al noveno. A continuación haremos una breve síntesis de los objetivos y de los temas que serán abordados en cada uno de los capítulos. 
En el primer capítulo examinaremos algunos aspectos del contexto intelectual del siglo de Leibniz. Especialmente, analizaremos los cambios epistemológicos que tuvieron lugar en el siglo XVII en relación con el paradigma aristotélico de las ciencias. La división entre tipos de ciencias, como si se tratara de géneros de conocimiento perfectamente delimitados y cerrados, dejó lugar a una concepción según la cual la física debía hallar sus fundamentos en la geometría. Esto explica en buena parte el surgimiento del modelo mecanicista de explicación de la física. Al mismo tiempo, veremos que los pensadores del siglo XVII encontraron que la lógica aristotélica, cuya utilidad para demostrar resultados es indiscutible, es insuficiente en relación con el descubrimiento de nuevas verdades.

En el segundo capítulo haremos una presentación de las concepciones sobre el continuo y el infinito de algunos pensadores que, de una u otra manera, han influido en Leibniz. Sin pretender hacer una historia completa de la cuestión, buscaremos recopilar los lineamientos centrales de las interpretaciones que nos permitirán reconstruir el marco teórico dentro del cual se desarrolla el pensamiento leibniziano del problema del continuo. Habiendo distinguido entre dos líneas interpretativas históricas generales del problema del continuo, una inspirada en el pensamiento de Aristóteles y la otra de naturaleza atomista, examinaremos las ideas centrales del estagirita, Francisco Suárez y Libert Froidmont (entre los aristotélicos), así como también de Galileo, Bonaventura Cavalieri y Pierre Gassendi (entre los que genéricamente pueden denominarse como 'atomistas').

En el tercer capítulo reconstruiremos el contexto en el que Leibniz formuló una de sus tesis más peculiares sobre el problema del continuo, a saber, que hay infinitas partes en acto. En primer lugar, veremos que, al afirmar el carácter 'actual' de las partes, el filósofo de Leipzig se opuso a la concepción de Thomas White. Luego, veremos que, al afirmar la existencia en acto de 'infinitas' partes, Leibniz se opuso a la visión de Descartes según la cual la materia se divide 'indefinidamente'. Así, estableceremos un paralelismo entre los pensamientos de Descartes y Leibniz sobre la materia, que atraviesa el examen de las notas esenciales que definen al cuerpo, la importancia del movimiento en relación con la materia, la afirmación de infinitas partes y, en consecuencia, el cuestionamiento de la concepción del autor de las Meditaciones metafisicas.

En el cuarto capítulo abordaremos el modo como Leibniz entendió la estructura de la composición del continuo en los años delimitados en la segunda parte de nuestro trabajo. 
Al mismo tiempo, veremos que hubo una evolución en su planteo. Primero, discutiremos la interpretación según la cual en la Theoria motus abstracti Leibniz sostuvo que el continuo se compone de 'indivisibles', y mostraremos que defendió una concepción de orientación más bien aristotélica según la cual los indivisibles son los extremos de las partes, aunque no las partes mismas. Los escritos sobre aritmética de 1672 nos servirán para que nos representemos el modo como Leibniz habría concebido una infinitud actual de partes, sin que eso signifique, al mismo tiempo, sostener indivisibles. Luego, veremos que, apenas arribó a la capital francesa, Leibniz modificó su manera de entender la composición del continuo: no se compone de indivisibles (como sostuvo Galileo), sino de cosas infinitamente pequeñas (que pueden ser unas menores que otras, incluso al infinito).

En el quinto capítulo trataremos algunos problemas físicos abordados por Leibniz en el marco del problema del continuo. En primer lugar, tras hacer una breve reconstrucción del estado de la cuestión en el siglo XVII, examinaremos la manera en que el filósofo de Leipzig resolvió el problema de la desigualdad de las velocidades de los movimientos. Esta cuestión, que se vincula estrechamente con los desarrollos del capítulo anterior, evidencia que uno de los sentidos de 'continuo' mantenido por Leibniz se enmarca en el contexto de la teoría del movimiento. Luego, abordaremos la manera como el filósofo de Leipzig resolvió el problema de la unidad o cohesión de los cuerpos, así como también algunas de las consecuencias que tuvo su propuesta. Este planteo, que para Leibniz fue uno de sus grandes aportes, manifiesta otro de los sentidos de 'continuo' sostenidos por el autor, en este caso enmarcado en la teoría del cuerpo.

En el sexto capítulo veremos la concepción leibniziana sobre lo 'mínimo' y lo 'máximo'. Primero, veremos qué entendió Leibniz por 'mínimo' y cuáles fueron los argumentos por los que los mínimos quedan excluidos de la composición del continuo. Luego, haremos lo propio respecto de lo 'máximo'. Para este caso, veremos que, desde un punto de vista filosófico, Leibniz justificó que el axioma según el cual 'el todo es mayor que una parte' vale para cualquier conjunto de cosas, es decir, sea finito o infinito (en contra de los presupuestos de Galileo). Una vez demostrado el axioma, Leibniz concluyó que el número infinito lo contradiría. No obstante, por otro lado, también llevó a cabo un abordaje aritmético en el cual mostró que el número infinito se equipararía con el cero, es decir, la nada. Dicha conclusión se extrae como consecuencia de la aplicación de una regla 
formulada por Leibniz para sumar las series infinitas del triángulo armónico a las series de las fracciones naturales y de las unidades.

En el séptimo capítulo analizaremos el tratamiento realizado por Leibniz en 1675/1676 de un 'grado de infinito' en el que se vinculan los estudios matemáticos y la cuestión de la composición del continuo. Primero, veremos que, en un escrito de geometría en el que presentó un método infinitesimal para la cuadratura de las secciones cónicas, Leibniz llevó a cabo una distinción entre el infinito 'sin término' y ‘terminado' que tuvo grandes repercusiones en el dominio de sus estudios geométricos, así como también en relación con el problema del continuo. En efecto, la afirmación de que el continuo se divide 'sin fin' (y no 'en mínimos') se vale de la noción de infinito sin término. Luego, examinaremos la compleja cuestión de la introducción de cantidades ficticias infinitas e infinitamente pequeñas en el procedimiento matemático ideado por Leibniz. Esto nos llevará a reconocer que Leibniz mantuvo dos sentidos de lo infinitamente pequeño, a saber, como propiedad (en las cantidades ficticias infinitamente pequeñas) y como relación (en las cosas que son infinitamente pequeñas en relación con otras, aunque haya cosas más pequeñas que ellas).

En el octavo capítulo reconstruiremos la concepción metafísica que Leibniz mantuvo en 1675/1676 y la vincularemos con el desarrollo del problema del continuo. En primer lugar, examinaremos el grado de infinito según el cual en Dios están los requisitos de existencia de todas las cosas. Veremos que Leibniz consideró que el denominado 'argumento ontológico' requirió de un suplemento con el que se muestre que el Ente que tenga todos los atributos absolutos afirmativos es posible. Luego, abordaremos el examen de los atributos o formas simples, en el que puede observarse una inspiración de tipo spinozista. Para esto, examinaremos el atributo divino de la extensión, concebido como esencia o naturaleza según la cual las cosas se dicen extensas, y su vinculación con las nociones de 'lugar', como modificación de la extensión, y de 'espacio universal', como agregado de todos los lugares. Posteriormente, haremos lo propio a propósito de otros atributos o formas simples. Nos detendremos especialmente en la vinculación entre el atributo de la omnisciencia y las mentes particulares, para mostrar que Leibniz defendió un pluralismo de entes tipo mentes que poseen de un modo limitado la omnisciencia que en 
Dios se encuentra absolutamente. Las consideraciones sobre las mentes son esenciales para lo que veremos en el siguiente capítulo.

En el noveno capítulo consideraremos las reflexiones leibnizianas sobre la materia, el movimiento y la acción en el contexto circunscrito en la tercera parte de nuestra tesis. En primer lugar, abordaremos los exámenes sobre la naturaleza de la materia, para detenernos inicialmente en la concepción según la cual la existencia de las cosas materiales no es otra cosa que la congruencia de las sensaciones. Luego, veremos que Leibniz sostuvo que no hay cuerpos perfectamente sólidos, como defendió Gassendi, ni cuerpos perfectamente fluidos, como la 'materia líquida' de Descartes, sino que todos son flexibles, es decir, son susceptibles de una nueva subdivisión, pero mantienen también una cierta coherencia. ${ }^{6}$ En siguiente lugar, examinaremos la noción de 'materia', 'mole' o 'masa', como aquello gracias a lo cual se dan las modificaciones en el atributo divino de la extensión. A continuación, veremos el modo como Leibniz abordó el problema de la cohesión de los cuerpos. Tras considerar que su interpretación previa lleva a inconsistencias, Leibniz juzgó que los cuerpos no son 'todos' sino solamente 'agregados', que mantienen la unidad porque hay una mente implantada en la materia. Tras presentar el modo como Leibniz concibió la naturaleza del movimiento en este período, veremos que cuestionó la formulación cartesiana de la ley de conservación, pues consideró que no se conserva la misma cantidad de movimiento, sino de acción. Para finalizar, veremos que en el Pacidius Philalethi consideró que no hay acción en los cuerpos que se mueven. En este sentido, la materia es recreada constantemente, lo que se explica por el atributo divino de la omnipotencia.

Luego de los capítulos, presentaremos las conclusiones de nuestro trabajo, que se dividirán en dos partes: en primer lugar, extraeremos las conclusiones generales que recorren todo nuestro estudio; en segundo lugar, buscaremos mostrar de manera sintética la conexión entre los desarrollos del período delimitado en esta tesis y el pensamiento maduro de Leibniz.

Para finalizar esta introducción, haremos algunas indicaciones en relación con la bibliografía. Con respecto a las traducciones, tanto de los escritos de Leibniz como de Descartes, Froidmont, Gassendi, Hobbes, Pascal, Suárez, entre otros, salvo que se indique

\footnotetext{
${ }^{6}$ Como veremos, esto no implica una contradicción dado que para Leibniz un cuerpo es divisible porque está dividido en acto.
} 
lo contrario, son de nuestra autoría. Por esta razón, consideramos necesario introducir el texto original en nota al pie, a saber, para ofrecerle al lector la posibilidad de contrastar directamente con los textos originales. La gran mayoría de los escritos que Leibniz redactó en su juventud no están aún traducidos al español. Inclusive, de algunos no hay traducciones conocidas tampoco a ninguna otra lengua. Recientemente han sido publicadas traducciones de algunos de los escritos que tendremos en cuenta en nuestro trabajo en el marco de la edición de las Obras filosóficas y científicas que la Sociedad Española Leibniz ha comenzado laboriosamente a llevar a cabo. A esto hay que añadirle que hace poco se publicó una traducción de la Accessio ad arithmeticam infinitorum de nuestra autoría, realizada en el marco del trabajo que llevó a la realización de esta tesis doctoral. Siempre que nos fue posible, contrastamos y corroboramos nuestras traducciones con aquellas publicadas, sea en español, inglés o francés. En este sentido, hay dos grandes compilaciones de traducciones al inglés que son relevantes para nuestro trabajo. Por un lado, las realizadas por George H. R. Parkinson de los textos metafísicos de 1675-1676 que, acompañadas por una introducción, fueron publicadas como De summa rerum. Metaphysical Papers, 1675-1676 en 1992. Por otro lado, y aún más importante para nuestro estudio, Richard T. W. Arthur ha seleccionado y traducido numerosos textos que tratan sobre el problema del continuo que, acompañados de una extensa introducción, fueron publicados en el año 2001 como The Labyrinth of the Continuum. Writings on the Continuum Problem, 1672-1686. En menor medida, también han sido útiles las traducciones editadas por Leroy E. Loemker en la edición titulada Philosophical Papers and Letters. Por su parte, también es valiosa la traducción al francés realizada por Marc Parmentier del tratado de geometría redactado en 1675/1676 De quadratura arithmetica circuli, ellipseos et hyperbolae, cujus corollarium est trigonometria sine tabulis, que Eberhard Knobloch editó por primera vez en el año 1993.

Por otro lado, debemos mencionar que tendremos fundamentalmente en cuenta la edición canónica de los escritos de Leibniz llevada a cabo por la Berlin-Brandenburgische Akademie der Wissenschaften y la Akademie der Wissenschaften zu Göttingen bajo el título de Sämtliche Schriften und Briefe. En algunas ocasiones, también nos valdremos de textos presentes en las ediciones de Carl I. Gerhardt, Die Philosophischen Schriften von Gottfried Wilhelm Leibniz y Leibnizen Mathematische Schriften. No obstante, en ningún 
caso los textos por los que nos refiramos a las ediciones de Gerhardt son centrales para nuestro trabajo. El único texto fundamental del que no hemos seguido la edición canónica antes mencionada es De quadratura arithmetica circuli, ellipseos et hyperbolae, cujus corollarium est trigonometria sine tabulis. Como dijimos, en el caso de este texto nos remitiremos a la edición bilingüe (latín-francés) compuesta por la edición de Knobloch y la traducción de Parmentier. Nos referiremos a todas estas ediciones con las abreviaturas que se indican en el apartado de la bibliografía.

Para finalizar, indicaremos algunas abreviaturas de los escritos de Leibniz a los que nos referiremos recurrentemente en nuestro trabajo.

TMA Theoria motus abstracti seu Rationes Motuum universales, a sensu et Phaenomenis independentes

DMM De minimo et maximo. De corporibus et mentibus

Accessio Accessio ad arithmeticam infinitorum, ubi et ostenditur Numerum maximum seu numerum omnium numerorum impossibilem esse sive nullum; item quae pro axiomatis habentur, demonstrabilia esse evincitur exemplis

DSR Con esta abreviatura nos referiremos a los escritos metafísicos que los editores de la edición crítica agruparon bajo la denominación de De summa rerum (A VI 3, 459-588).

DQA De quadratura arithmetica circuli, ellipseos et hyperbolae, cujus corollarium est trigonometria sine tabulis

Quiero agradecer a todos los que, de una u otra manera, me han ayudado en mi trabajo. En especial, a Oscar Esquisabel, sin cuya dedicada y paciente dirección este trabajo no hubiese sido posible en absoluto. Asimismo, quiero agradecer a los colegas de la Red Iberoamericana Leibniz por el intercambio en general y por sus comentarios, críticas y consejos, en especial a Rodolfo Fazio, Griselda Gaiada, Maximiliano Escobar Viré, así como también a Juan Antonio Nicolás, Manuel Sánchez Rodríguez, Miguel Palomo, Miguel Escribano y Laura Herrera. También quiero agradecerle a Richard T. W. Arthur por las generosas respuestas a mis correos electrónicos y por las valiosas sugerencias contenidas en ellos. Por último, agradezco también a Lucía, mi mujer, por su apoyo y paciencia durante los años que me tomó realizar este trabajo. 

Primera PARTe:

CONTEXTO Y ANTECEDENTES 



\section{CAPÍTULO 1: LEIBNIZ Y SU CONTEXTO INTELECTUAL}

Leibniz no estaba especialmente familiarizado con la física y la matemática de su siglo antes de que viajara a Francia en $1672 .{ }^{1}$ No obstante, como quedará en evidencia en la segunda parte de esta tesis, disponía de algunos conocimientos elementales. En su primera formación, decisiva para el pensamiento anterior al de su estadía en París, ha tenido especial importancia el pensamiento de los clásicos en general y en especial de Aristóteles. ${ }^{2}$ Sus conocimientos de la obra de este gran filósofo griego superaban notablemente los que tenía de sus contemporáneos. En ese momento histórico, lo que hoy conocemos como Alemania no estaba en el centro de la escena intelectual como ha sabido estarlo posteriormente, y precisamente por esto el conocimiento de obras y pensadores contemporáneos por parte de Leibniz era elemental e indirecto. Esto no quita, no obstante, que en la década de 1660 se haya interesado por el pensamiento de su época (fundamentalmente por el de la filosofía natural). En este capítulo intentaremos sintetizar algunos aspectos del contexto histórico del siglo de Leibniz que fueron importantes como marco en el que se desarrollaron sus reflexiones. Evidentemente una presentación exhaustiva del trasfondo científico y filosófico del siglo XVII excede nuestro objetivo. Por eso, nos centraremos en algunos aspectos especialmente seleccionados en virtud del hecho de que son todos relevantes, directa o indirectamente, para los desarrollos leibnizianos relativos al problema del continuo. Asimismo, los autores que analizaremos fueron importantes, como veremos, en vistas a la génesis del pensamiento leibniziano sobre este laberinto. En algunos casos las conexiones serán explicitadas en el presente capítulo y en otros se irán mencionando según sea oportuno en los capítulos siguientes.

Los distintos aspectos que analizaremos fueron pensados como productos de una tensión dada en la temprana filosofía moderna en relación con el pensamiento aristotélico. En efecto, en primer lugar veremos que el esquema epistemológico de Aristóteles, cuya vitalidad hasta la edad moderna de la filosofía es indiscutible, recibió fuertes cuestionamientos por verse imposibilitado de ofrecer un fundamento matemático para la ciencia física. Uno de los elementos más destacados de la pretensión de fundamentar la

\footnotetext{
${ }^{1}$ Brown, 1999b: 11-12.

${ }^{2}$ Mercer, 1999: 35 y ss, y Mercer, 2004: capítulo 1.
} 
física en la matemática fue, por ejemplo, el concepto cartesiano de 'materia' que se define de acuerdo con notas geométricas. Como veremos en el tercer capítulo, estas reflexiones cartesianas están vinculadas con el punto de partida del examen leibniziano del problema del continuo y del infinito. A continuación, examinaremos el cuestionamiento que llevaron a cabo algunos pensadores modernos, como por ejemplo Galileo, a la falta de experimentación en los exámenes físicos de Aristóteles. Veremos, a su vez, que esta controversia no significó necesariamente la prevalencia del conocimiento empírico frente al racional. Esto es particularmente manifiesto en el caso de Leibniz, dado que, como veremos, entendió que entre un abordaje empírico y otro racional debe haber una complementariedad. En tercer lugar, examinaremos el reconocimiento por parte de los filósofos modernos de la insuficiencia de la lógica aristotélica, en la medida en que no facilitaba un procedimiento para el descubrimiento de nuevos conocimientos. A modo de ejemplo, consideraremos la propuesta metodológica de Hobbes que ha sido muy significativa para Leibniz, como quedará en evidencia en los capítulos siguientes. En último lugar, examinaremos el rechazo por parte de los filósofos modernos de la pretensión aristotélica -aunque particularmente escolástica- de explicar los fenómenos físicos basándose en tendencias naturales de los cuerpos. En este punto mostraremos que, aunque Leibniz disienta de los exámenes de los escolásticos y esté de acuerdo con cierta pauta común entre los modernos, tiene en alta estima los desarrollos de la física aristotélica. Como resultado de esto (que veremos recurrentemente en los capítulos siguientes), Leibniz sintetizó elementos de la física aristotélica con los de la moderna.

\section{Crisis del esquema epistemológico}

A lo largo de la historia, fue célebre la demarcación entre las ciencias presentada por Aristóteles en el escrito que hoy conocemos como Metafísica. En efecto, en dicha obra se manifiesta la preocupación del célebre filósofo griego, entre otras muchas cosas, por señalar cuál es la ubicación de la 'ciencia del ser en cuanto ser' (uno de los diversos 
aspectos considerados por la 'filosofía primera') ${ }^{3}$ en el organigrama de las ciencias. Con el objetivo de distinguirla de otras ciencias, Aristóteles señaló:

Hay una ciencia que estudia lo que es, en tanto que algo que es, y los atributos que, por sí mismo, le pertenecen. Esta ciencia, por lo demás, no se identifica con ninguna de las denominadas particulares. Ninguna de las otras [ciencias], en efecto, se ocupa universalmente de lo que es, en tanto que algo que es, sino que tras seccionar de ello una parte, estudia los accidentes de ésta: así, por ejemplo, las ciencias matemáticas. ${ }^{4}$

Para Aristóteles, la ciencia del ser en cuanto ser se diferencia de las restantes por el hecho de no seleccionar un dominio de objetos en particular, sino por considerar algo que es universal, es decir, común a todas las cosas. ${ }^{5}$ Las ciencias particulares, inversamente, se caracterizan por delimitar un determinado género de objetos especiales e indagar, cada una por su parte, las propiedades y atributos que pertenecen a las cosas incluidas en cada dominio. En este sentido, cada ciencia es una especie de conocimiento cerrado que gira en torno al objeto considerado y a los principios y causas propios de ese género en concreto. Así, para Aristóteles, una ciencia, tras circunscribir el género de objetos que le corresponde, “(...) investiga ciertos principios y causas concernientes a todas las cosas cuyo conocimiento le corresponde". 6 Un ejemplo paradigmático de esta tajante circunscripción se encuentra en la distinción entre las ciencias consideradas como 'teóricas', esto es, la física, la matemática y la ciencia del ser en cuanto ser. La física, de acuerdo con Aristóteles, estudia los principios y las causas de las entidades que poseen tanto una existencia independiente como un principio intrínseco de movimiento y de reposo (y precisamente por ello están sometidas al cambio). La matemática, por su parte, versa sobre aquellos objetos que, sin estar separados de la materia, no están sometidos al cambio. Tanto en la física como en la matemática se estudia no el ser en general sino desde una determinada perspectiva que es especifica precisamente de cada ciencia. ${ }^{7}$ En la medida en que estos son los objetos de estudio de cada una de las ciencias y dado que en cada una de ellas se

\footnotetext{
${ }^{3}$ En general los intérpretes del pensamiento de Aristóteles entendieron que éste es uno de los cuatro grandes temas considerados en la Metaphysika, junto con el estudio de las causas, de la sustancia en general y de la teología. Véase, por ejemplo, Barnes, 1999b y Reale, 1985: 43-68.

${ }^{4}$ Aristóteles, Metaphysika, Г 1003a19-25. Tomamos las traducciones de esta obra de Aristóteles, 1994.

${ }^{5}$ No trataremos aquí de la compleja discusión sobre lo que implica la 'ciencia del ser en cuanto ser' en el pensamiento aristotélico. Para esto, véase Jaeger, 1923, Owens, 1978 y Reale, 1993.

${ }^{6}$ Aristóteles, Metaphysika, K 1063b35-1064a9.

${ }^{7}$ Véase Aristóteles, Metaphysika, Г 1003a-1012b, E 1025b-1028a y K 1059a-1069a. Asimismo, Barnes, 1999b: 68-69.
} 
estudian las causas y principios propios de cada región de objetos, en consecuencia, es imposible valerse de principios de un género para establecer los de otro. Justificar, por ejemplo, geométricamente la física era entendido como un sinsentido o bien como una

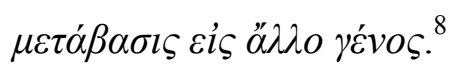

El esquema epistemológico aristotélico resultó insuficiente para las pretensiones del pensamiento moderno. La imposibilidad de cruzar regiones de conocimiento no permitía satisfacer una de las demandas de un pensamiento moderno que intentó fundar la física en la geometría. Uno de los filósofos modernos que combatió esta idea aristotélica fue Descartes. Cuando el filósofo francés declara que no admite en la física otros principios que los de las matemáticas "ya que así se explican todos los fenómenos de la naturaleza y pueden darse demostraciones ciertas sobre ellos", 9 presupone que la física y la matemática no son ámbitos inconfundibles. En este sentido, se requiere que haya cierta homogeneidad entre estos tipos de conocimiento. La única manera de hacer sensato este intento era instituyendo un nuevo tipo de delimitación epistemológica tal que sea admisible esta remisión de la física a la geometría. Esto significó que, para fundar la física en principios geométricos, Descartes necesitó encontrar algo que le permita articular estas regiones. Una de las claves, en este sentido, está en su noción de cuerpo o sustancia extensa, pues se trata de un concepto que vale unívocamente para referirse al cuerpo geométrico y al cuerpo físico o, mejor dicho, que no reconoce una distinción real entre géneros de cuerpos. ${ }^{10} \mathrm{De}$ allí que el filósofo francés mencione: “[p]ues confieso abiertamente que la única materia de

\footnotetext{
${ }^{8}$ Gaukroger, 2002a: 56.

9 Principia Philosophiae, AT, VIII, 2, § 64. "Non alia principia in Physica, quam in Geometria, vel in Mathesi abstracta, a me admitti, nec optari, quia sic omnia naturae phaenomena explicantur, et certae de iis demonstrationes dari possunt". Asimismo, y en el mismo parágrafo, indica: "Et quia sic omnia Naturae Phaenomena possunt explicari, ut in sequentibus apparebit, nulla alia Physicae principia puto esse admittenda, nec alia etiam optanda". Tendremos en cuenta la traducción de Descartes y Leibniz (1989), aunque ocasionalmente introduciremos modificaciones. Garber, 2000: 113-127, muestra, a partir de la correspondencia, algunos elementos de la física matemática de Descartes.

${ }^{10}$ Compartimos, en este sentido, la interpretación de Gaukroger, quien, en 2002b: 70, indica: "Descartes argumenta que el único tipo de mundo físico sobre cuya existencia puedo inteligiblemente investigar es uno que pueda concebir clara y distintamente, y que la única manera en que podemos satisfacer este criterio es pensando acerca del mundo en términos cuantitativos - eso es, en términos de una materia inerte cuya única propiedad sea la extensión espacial- y caracterizándolo de un modo puramente geométrico. De este modo, arribamos a una explicación mecánica del universo como la única opción posible”. La traducción es nuestra.
} 
las cosas corpóreas que reconozco es aquella absolutamente divisible, configurable y móvil que los geómetras llaman cantidad, y que toman como objeto de sus demostraciones". ${ }^{11}$

Debido a la imposibilidad de remitir las explicaciones de un género de objetos a otro, la física aristotélica no apelaba en su fundamentación a la geometría sino a otro tipo de entidades en cuya naturaleza los filósofos modernos no veían bases lo suficientemente sólidas en las que fundamentar la física. Este cuestionamiento, por cierto, solía hacerse más a los escolásticos que a Aristóteles mismo. Por eso, por ejemplo, Descartes se esforzó por señalar la notable diferencia que yace entre su noción de 'materia' y la 'materia prima' de los escolásticos: esta última, que es pura potencialidad y que, al margen de la forma, permanece indeterminada, en última instancia no significa nada que pueda ser comprendido con claridad. ${ }^{12}$ Leibniz mismo, por su parte, indicó que, a partir de una explicación física fundada en formas, facultades o en general en entes incorporales, no se aprende nada. ${ }^{13}$ Como vemos, en buena medida, algunos autores modernos plantearon sus reflexiones a través de una crítica a las viejas formas de pensar el conocimiento de la naturaleza. ${ }^{14}$

\section{Cambios en el abordaje de la física}

La física aristotélica fue cuestionada también en otro aspecto decisivo para la ciencia moderna. En efecto, las explicaciones físicas de Aristóteles no exigían necesariamente de experimentación. Como veremos, en la modernidad se valoró la experimentación, aunque también fue central el conocimiento racional deductivo. ${ }^{15}$ En

\footnotetext{
${ }^{11}$ AT, VIII, 2, § 64. "Nam plane profiteor me nullam aliam rerum corporearum materiam agnoscere, quàm illam omnimodè divisibilem, figurabilem \& mobilem, quam Geometrae quantitatem vocant, \& pro obiecto suarum demonstrationum assumunt".

${ }^{12}$ AT, XI, 33.

${ }^{13}$ Leibniz a Thomasius, A II 1, 26. Más tarde, en su Nuevo sistema de la naturaleza y de la comunicación de las sustancias así como de la unión que hay entre el alma y el cuerpo de 1695, dirá refiriéndose a la filosofía mecánica: “[m]e encantó su hermosa manera de explicar mecánicamente la naturaleza y desprecié con razón el método de los que sólo emplean formas o facultades con las que nada se aprende" (Traducción: De Olaso, 1982: 528).

${ }^{14}$ Shapin, 2000: 35-89. Dentro de las críticas que se dieron en la modernidad a las ideas de la antigüedad, se destacan (además de las que ya mencionamos y de otras que veremos más adelante) las observaciones de Galileo de manchas solares, que desafiaron la filosofía natural de Aristóteles, la astronomía que dio lugar al sistema heliocéntrico, que se opuso al geocentrismo de Ptolomeo, y la distinción entre cualidades primarias y secundarias, relativamente extendida en el siglo XVII.

${ }^{15}$ Suele señalarse que, en la filosofía moderna, la experimentación fue uno de los procedimientos por excelencia para producir conocimientos. No obstante, como muestran Shapin y Shaffer, 2005 (en especial, pp. 163-182), ya en la modernidad algunos pensadores, como Hobbes, señalaron que la experimentación no era
} 
relación con lo primero, fueron paradigmáticas las objeciones de Galileo frente a la falta de experimentación implícita en los argumentos que Aristóteles presentó para negar la existencia del vacío. En efecto, frente a aquellos que introdujeron el vacío para justificar el movimiento, Aristóteles señaló inversamente, mediante dos razonamientos, que la mera existencia del movimiento niega la del vacío. ${ }^{16}$ En el primer argumento, Aristóteles supone que un mismo móvil se movería con distintas velocidades en diversos medios, en tanto que la consistencia del medio retardaría más o menos al cuerpo móvil. Suponiendo un cuerpo A y dos medios distintos, B (el aire) y D (el agua), Aristóteles mencionó, a modo de ejemplo, que: "si el aire es dos veces más sutil que el agua, A pasará a través de B en el doble de tiempo que a través de $\mathrm{D}$, y por tanto el tiempo C [en el que A pasa a través de D] será el doble que el tiempo $\mathrm{E}$ [en el que pasa a través de B]". ${ }^{17}$ Como la retardación del movimiento depende del medio, no hay, entonces, un vacío. En el segundo argumento, Aristóteles supone que las velocidades de dos cuerpos móviles en un mismo medio serían proporcionales a sus respectivos pesos. Consecuentemente, un cuerpo que pese, por ejemplo, diez veces más que otro, en el mismo medio se movería diez veces más rápido. Ahora bien, como en este caso hay una proporción entre peso y velocidad, si el cuerpo más veloz se moviera en el vacío, debería también moverse diez veces más rápido que el otro. No obstante, señala Aristóteles que "esto es imposible; pues, ¿por qué habrían de desplazarse más rápidamente? En las cosas que están llenas tiene que ser así, ya que el cuerpo que sea mayor divide el medio más rápidamente por su fuerza. (...) Por tanto, si se admitiese el vacío, todos los cuerpos tendrían la misma velocidad; pero esto es imposible". ${ }^{18}$ Analizando estos argumentos, Galileo denuncia que Aristóteles no parece haber sometido su argumentación a la experimentación, pues ésta permite concluir que no se da dicha proporcionalidad entre peso y velocidad. Si se diera, arrojados desde la misma altura dos cuerpos de los cuales uno sea diez veces más pesado que el otro, cuando el

capaz de generar los conocimientos que se creía que podía producir. Abordaremos sintéticamente la propuesta de Hobbes en la siguiente sección. Asimismo, véase Shapin y Shaffer, 2005: 200-205.

${ }^{16}$ Aristóteles, Physika, 215a24-216a21. Las traducciones de esta obra serán tomadas de Aristóteles, 1995a. Galileo analiza los argumentos aristotélicos en EN, VIII, 95-96.

${ }^{17}$ Aristóteles, Physika, 215b7-9.

${ }^{18}$ Aristóteles, Physika, 216a17-22. 
cuerpo más veloz alcance el suelo, el otro habría recorrido solamente el diez por ciento de la distancia dada. Sin embargo, esto no sucede. ${ }^{19}$

Sostener la importancia de la experimentación no significó necesariamente la prevalencia del conocimiento empírico por sobre los argumentos racionales. Galileo mismo, en el caso recién mencionado, muestra la incorrección de las tesis aristotélicas mediante un escrutinio de sus argumentaciones $\mathrm{y}$, por consiguiente, mediante razonamientos. ${ }^{20}$ Por su parte, Leibniz ha reconocido la importancia de distinguir los dos tipos de abordaje de los que el movimiento es susceptible. En sus primerísimos escritos físicos que le sirvieron como preparatorios para su TMA de 1671, en donde consideró el problema de la composición del continuo por primera vez, Leibniz reconoció que el movimiento admite un doble análisis, esto es, uno sensible y otro racional. ${ }^{21}$ Entre ellos, debe haber una complementariedad tal que, aunque muchas veces se manifiesten como incompatibles, no lo sean en realidad. De darse una aparente contradicción, el análisis sensible debe dejar lugar a las explicaciones racionales, pues en dicho caso debe reconocerse que hay algo que subyace a lo sensible y que, aunque no sea sensible, tal vez puede serlo algún efecto suyo. ${ }^{22}$ Por ejemplo: supóngase que un cuerpo pequeño golpea a otro grande. A partir del análisis sensible de dicho fenómeno, debería concluirse que el cuerpo menor no puede mover al mayor: "en efecto, vemos que una casa no es demolida por el lanzamiento de una piedra". ${ }^{23}$ Sin embargo, desde el punto de vista racional o abstracto, se reconoce que el cuerpo menor, sin importar cuán pequeño sea, mueve al mayor con un movimiento que, del mismo modo, puede ser cuanto pequeño se quiera. ${ }^{24} \mathrm{La}$ conclusión a la que Leibniz quiere arribar, y cuya justificación se encontrará en los capítulos siguientes, es que el reposo absoluto es imposible, ${ }^{25} \mathrm{y}$ en este sentido un

\footnotetext{
${ }^{19} \mathrm{EN}, \mathrm{VIII}, 106$.

${ }^{20}$ EN, VIII, 106.

${ }^{21}$ De rationibus motus, A VI 2, 159.

${ }^{22}$ De rationibus motus, A VI 2, 159. En términos similares, Leibniz señala, en 1676, que el conocimiento por experiencia sólo alcanza resultados satisfactorios si anteriormente el razonamiento ha allanado el terreno. Por ejemplo: Pacidius Philalethi, A VI 3, 531: "Non dubito quin regia sit via per experimenta, sed nisi ratiocinatio eam complanaverit, tarde proficiemus et post multa secula in initiis haerebimus". OFC, 8, 118.

${ }^{23}$ De rationibus motus, A VI 2, 159. “(...) videmus enim iactu lapidis domum non convelli”.

${ }^{24}$ De rationibus motus, A VI 2, 159.

${ }^{25}$ Leibniz explícitamente menciona que sus objeciones hacen referencia al reposo si se lo considera absolutamente, aunque, sin embargo, esto no significa que no sea comprensible un reposo relativo. En este sentido, no es incorrecto decir que un cuerpo se mueve hacia otro que reposa, si por esta expresión se entiende que los cuerpos tienden entre sí recíprocamente. De rationibus motus, A VI 2, 161.
} 
movimiento, en la medida en que no está interrumpido por reposos, es continuo. ${ }^{26}$ Pero además de la explicación del movimiento continuo y de la inexistencia de un reposo absoluto, Leibniz cree que hay otras cosas que no se les pueden confiar a las experiencias sensibles:

Hay cuatro cosas por las que no puede tenerse confianza en las experiencias sensitivas: 1) porque ningún cuerpo que es sentido reposa, 2) porque es incierto si un cuerpo que es sentido propiamente es 'un cuerpo' o 'cuerpos', 3) porque es incierto si un cuerpo que es sentido es discontiguo o contiguo, 4) porque es incierto si dos cuerpos que se tocan, se tocan en las superficies, o si solamente en líneas y puntos. Suponiendo o ignorando estas cosas, es imposible que los primeros principios del movimiento se establezcan sólidamente por los sentidos. Pues es muy importante si un cuerpo reposa, si es 'muchos cuerpos', si es discontiguo, si toca a otro en un punto, línea o superficie; esto, sin embargo, no puede ser explorado por los sentidos. ${ }^{27}$

Considérese, por ejemplo, la segunda cuestión mencionada. Como se mostrará en los siguientes capítulos, para Leibniz un cuerpo posee infinitas partes en acto. Sin embargo, en la percepción sensible no se tiene experiencia de una multiplicidad infinita de ellas sino que por el contrario se presentan unitariamente. En este sentido, la explicación abstracta debe ser tal que justifique, como efecto suyo, la percepción unitaria. Así, una explicación abstracta, además de dilucidar la estructura de los hechos considerados, debe contribuir a salvar los fenómenos, es decir, a hacer racional el comportamiento observable. ${ }^{28}$

\section{Cambios lógico-metodológicos}

Además de los cuestionamientos al esquema epistemológico general y a las explicaciones físicas en particular, el pensamiento aristotélico fue objeto de controversias

${ }^{26}$ TMA, A VI 2, 265. OFC, 8, 80.

${ }^{27}$ De rationibus motus, A VI 2, 166. "Tria sunt, ob quae sensualibus experimentis fidi non potest: 1) quia nullum corpus quod sentitur quiescit, 2) quia incertum est an corpus quod sentitur, proprie sit corpus an corpora, 3) quia incertum est an corpus quod sentitur sit discontiguum an contiguum, 4) quia incertum est an corpora se contingentia, contingant superficiebus, an vero tantum lineis et punctis. Quibus suppositis vel ignoratis, impossibile est prima motus principia sensu constabilire. Quia multum refert an corpus quiescat, an sit corpora multa an sit discontiguum, an puncto vel linea vel superficie aliud contingat, quod tamen sensu explorari non potest". Como se ve, originalmente el texto comienza señalando que "son tres las cosas..."; hemos modificado el original asumiendo que se trata de un error.

${ }^{28}$ De rationibus motus, A VI 2, 164. Luego de dilucidar que un cuerpo discontiguo resiste más que uno contiguo, dice: "Huius paragraphi ope multa in phaenomenis motum vulgo apparentibus salvari possunt". Sobre el significado original de la expresión 'salvar los fenómenos', Duhem, 1908: 1-27. Más aún, en dicha obra puede encontrarse la historia de esta expresión desde la antigüedad hasta la modernidad. 
también en la lógica y la metodología de las ciencias. Sin embargo, hay una diferencia: la lógica aristotélica no fue vista en la modernidad necesariamente como incorrecta, sino más bien como insuficiente. A esta lógica, capaz de exposición y enjuiciamiento, se le cuestionaba su incapacidad de alcanzar el descubrimiento de nuevas verdades. El pensamiento del siglo XVII demandó, además de un arte para juzgar la corrección o incorrección de lo ya conocido, un arte de descubrimiento. ${ }^{29}$

Ya desde la Dissertatio de arte combinatoria (1666) Leibniz había indicado algunos elementos que son importantes para el método de la filosofía en general y que, como veremos en el tercer capítulo, son particularmente relevantes en sus indagaciones físicas. Como dijo unos pocos años más tarde, aunque éste haya sido un trabajo pueril, hay allí algunas indicaciones que son de lo más valederas. Por ejemplo, allí señaló, en concordancia con Pascal, que las proposiciones de las ciencias puras, es decir, de las no empíricas, no hacen más que enunciar una definición o una parte de una definición sobre lo definido. ${ }^{30}$ Las definiciones son el punto más importante de la nueva metodología. Como veremos especialmente en el capítulo sexto, en los análisis leibnizianos se hará presente recurrentemente la idea de que todo lo que pueda deducirse de una noción ha de estar ya contenido en su definición. Dicho de otro modo: el definiendum ha de estar en el definiens, bajo el presupuesto de que no haya nada sin causa. ${ }^{31}$ En estas cuestiones metodológicas, Leibniz ha tenido a Thomas Hobbes (1588-1679) como un autor de referencia, sin que esto signifique necesariamente, como veremos más adelante, que haya adoptado la totalidad de las ideas del británico. ${ }^{32}$ Ya desde la Dissertatio, por ejemplo, Leibniz reconoce y hace

\footnotetext{
${ }^{29}$ Esquisabel, 1999a: 304-305.

${ }^{30}$ Leibniz a Jean Gallois, A II 1, 354. Sobre esta cuestión, véase Esquisabel, 2012b.

${ }^{31}$ Por ejemplo, a propósito del análisis de la materia (que analizaremos en detalle más adelante), dice Leibniz en Leibniz a Thomasius, A II 1, 36: "Ex his patet, naturam Corporis constitui per Extensionem et Antitypiam, cumque nihil sit in rebus sine causa, nihil etiam poni debet in corporibus, cujus causa reddi non possit ex primis eorum constitutivis". Garber, 2009: 14-16, destaca la relevancia de esta cuestión para la física.

32 McDonald Ross, 2007: 21-22, discute este asunto a propósito de la confrontacion entre Ferdinand Tönnies y Louis Couturat sobre esta cuestión. Mientras que para el primero el arte combinatorio y el proyecto de una característica universal podrían remontarse a Hobbes, para el segundo esto es incorrecto. McDonald Ross sostiene una posición intermedia: si bien no pueden remontarse directamente hasta Hobbes, no debe desestimarse la influencia que pudo tener en británico en Leibniz. Una indicación similar hace Leroy Loemker, 1989: 105: "La influencia temprana de Hobbes en Leibniz es evidente, aunque Couturat refutó adecuadamente el esfuerzo de Tönnies por rastrear el origen del método lógico hasta el pensador inglés (...). Leibniz se impresionó mucho tanto con el De corpore como con el De cive, pero intentó complementarlos, el primero con Elementa de mente, el segundo con argumentos teológicos sobre la justicia como la voluntad del más poderoso, es decir, Dios". La traducción es nuestra.
} 
propia una de las ideas centrales de Hobbes, a saber, aquella según la cual el razonamiento ha de ser comprendido como computatio:

El profundísimo examinador de los principios de todas las cosas, Thomas Hobbes, ha afirmado con razón que todo trabajo de nuestra mente es computación y que en ésta se comprende tanto añadir una suma como sustraer una diferencia. ${ }^{33}$

Para Hobbes la comprensión del raciocinio en estos términos es fundamental, en la medida en que la filosofía, como conocimiento de causas a partir de los efectos o de los efectos a partir de causas, debe ser alcanzada precisamente mediante la adición y la sustracción. ${ }^{34}$ No es de extrañar, entonces, que la primera parte de su De corpore se titule “computación o lógica". ${ }^{35}$ Una de las preocupaciones centrales de Hobbes corresponde a la manera como debe entenderse el método de la filosofía, esto es, "el camino más corto para hallar los efectos por sus causas conocidas o las causas por sus efectos conocidos". ${ }^{36}$ En la medida en que el raciocinio se define por la adición o sustracción, consecuentemente, el método deberá ser o bien compositivo o bien resolutivo, o bien parcialmente compositivo y parcialmente resolutivo. De acuerdo a la terminología usual, Hobbes denomina al compositivo 'método sintético' y al resolutivo 'analítico'. 37

El análisis y la síntesis son los pilares de los métodos de descubrimiento y de demostración o enseñanza. El descubrimiento y la demostración no se diferencian por tener métodos radicalmente distintos sino en que el segundo carece de un aspecto del primero. En el descubrimiento se parte de los efectos, esto es, de los "fantasmas de la sensación o imaginación", los cuales no son conocidos por raciocinio sino por las capacidades

\footnotetext{
${ }^{33}$ Dissertatio de arte combinatoria, A VI 1, 194. "Profundissimus principiorum in omnibus rebus scrutator Th. Hobbes merito posuit omne opus mentis nostrae esse computationem, sed hac vel summam addendo vel subtrahendo differentiam colligi".

${ }^{34}$ Hobbes, De corpore, I, 1, 1. Allí define a la filosofía en estos términos en 1. 2.: "La Filosofía es el conocimiento de los efectos o apariencias tal como los adquirimos por el verdadero raciocinio a partir del conocimiento que tenemos primero de sus causas o generación: Y nuevamente, de las causas o generaciones tal como pueda ser a partir de conocer primero sus efectos". También dice en 6.1.: "(...) La filosofía es el conocimiento que adquirimos de las apariencias o efectos aparentes por el verdadero raciocinio a partir del conocimiento que tenemos de algunas producciones o causas posibles de esas mismas cosas; y de la producción, tal como haya sido o como pueda ser, a partir del conocimiento que tenemos de los efectos". Las traducciones son nuestras.

${ }^{35}$ Hobbes, De corpore, I, 1, 1 .

${ }^{36}$ Hobbes, De corpore, I, 6, 1. "Method, therefore, in the study of philosophy, is the shortest way of finding out effects by their known causes, or of causes by their known effects".

${ }^{37}$ Hobbes, De corpore, I, 6, 1. De alguna manera, esta distinción entre métodos se remonta a Aristóteles. Sobre esta cuestión, véase Gilbert, 1963: 7-11 y 39-42.
} 
naturales. ${ }^{38}$ Esto implica, ante todo, que mediante la experiencia sensible y la imaginación no se obtiene un conocimiento causal ni, por tanto, filosófico. En este sentido, mediante las capacidades naturales se 'conoce que', haciéndose indispensable para la ciencia lograr alcanzar el conocimiento del 'por qué. ${ }^{39}$ De allí que, si bien parte de la experiencia sensible, en el descubrimiento se pretende arribar a los principios que explican causalmente dichos fenómenos. Y este proceder es justamente analítico. De este aspecto se carece, consecuentemente, en las demostraciones, las cuales parten de los principios sintéticamente. De este modo, a la síntesis la antecede el análisis, así como a la demostración el descubrimiento. Como indica Hobbes, el método a partir del cual se procede de los sentidos a los principios es analítico, mientras que el que procede de los principios a los efectos es sintético. ${ }^{40}$

Hobbes toma a modo de ejemplo la idea de un cuadrado cualquiera. Resolutivamente, el cuadrado se descompone en un plano determinado por un cierto número de líneas rectas iguales y ángulos rectos. De este modo, se han obtenido analíticamente las nociones contenidas en el cuadrado: línea, plano, ángulo, rectitud, igualdad, etc. ${ }^{41}$ Como el conocimiento que se pretende es causal, debe establecerse, como principio, el procedimiento de generación o producción del cuadrado (supuesto, ciertamente, que ya se han establecido las causas de aquellas nociones que componen el cuadrado). Así, "si podemos hallar las causas de éstas, podremos componerlas juntas en la causa de un cuadrado". ${ }^{42}$ Similarmente, si partiéramos de un círculo determinado, podríamos establecer que su causa es la circunducción de un cuerpo del cual un extremo permanece inmóvil (supuesto primero el análisis que arribaría a las nociones de ‘cuerpo', 'término', ‘inmóvil', 'circunducción', etc.). De este modo surge la definición de círculo

\footnotetext{
${ }^{38}$ Hobbes, De corpore, I, 6, 1. "The first beginning, therefore, of knowledge, are the phantasms of sense and imagination; and that there be such phantasms we know well enough by nature".

${ }^{39}$ De Jong, 1986: punto 7: "Science and method".

${ }^{40}$ Hobbes, De corpore, I, 6, 7. De allí que Douglas Jesseph, 1996: 94, identifique el análisis como método de descubrimiento y la síntesis con el de demostración, en la medida en que así como el análisis antecede a la síntesis, así también el descubrimiento a la demostración. Sin embargo, como indica De Jong, 1986: punto 7, no es incorrecto concebir que el descubrimiento mismo es parcialmente analítico y parcialmente sintético, de acuerdo con la indicación de Hobbes según la cual la demostración carece de la primera parte del descubrimiento.

${ }^{41}$ Hobbes, De corpore, I, 6, 4 .

${ }^{42}$ Hobbes, De corpore, I, 6, 4. "and if we can find out the causes of these, we may compound them altogether into the cause of a square".
} 
conteniendo la causa de su generación. ${ }^{43}$ Evidentemente este tipo de ejemplos comportan una gran ventaja: en la medida en que los objetos geométricos son producidos por el hombre, el conocimiento de su causa es ejemplar, cosa que no sucede tratándose de entidades físicas cuya producción no es análoga. De allí precisamente que Hobbes comprenda a la geometría como modelo de ciencia, ya que las ciencias físicas no tratan con causas exactas sino probables, esto es, hipótesis o conjeturas causales. ${ }^{44}$

Como se dijo, el descubrimiento comienza con las imágenes sensibles para proceder, analíticamente, a descomponer sus partes. La noción de 'parte' aplicada al análisis no refiere a los elementos de la cosa misma sentida sino de su naturaleza. Así, las partes del cuadrado no son los lados concretos que tienen un determinado largo sino precisamente las nociones antes descritas que componen la naturaleza misma del cuadrado. ${ }^{45}$ El objetivo del análisis es, como se ha indicado, la obtención de principios. Estos, dado que son evidentes por naturaleza, no necesitan ser demostrados. Precisamente por esto, ellos son el punto de partida de las demostraciones: mientras que el procedimiento analítico a partir del cual se ha arribado a ellos no puede enseñarse (pues, en primera instancia, no pueden enseñarse las imágenes ofrecidas por las capacidades naturales de cada uno), sí se puede a partir de los principios. ${ }^{46}$

Para que los principios sirvan en las demostraciones, ante todo deben poder ser comprendidos por otros hombres. Esto conlleva al menos dos consecuencias. Por una parte, que las palabras o términos lingüísticos tengan diferentes funciones en el descubrimiento y en la demostración: mientras que en el primero las palabras son marcas para recordar lo hallado previamente (y en este sentido auxilian a la memoria), en las demostraciones sirven como signos que, entendidos por todos, permiten la enseñanza. ${ }^{47}$ En este sentido, cumplen una función intersubjetiva. Por otra parte, conlleva que los principios mismos utilizados en

\footnotetext{
${ }^{43}$ Hobbes, De corpore, I, 1, 5.

${ }^{4}$ Seguimos aquí a Jesseph, 1996, fundamentalmente los puntos "Geometry and natural philosophy" y "Analysis, synthesis, and natural science". Sobre la importancia de la geometría en el pensamiento de Hobbes, véase también Grant, 1996.

${ }^{45}$ Hobbes, De corpore, I, 6, 2.

${ }^{46}$ Hobbes, De corpore, I, 6, 12.

${ }^{47}$ Hobbes, De corpore, I, 6, 11. Acerca de los nombres como marcas o signos, puede verse Jesseph, 1996 y De Jong, 1986, fundamentalmente los puntos 2, 3, 4 y 5 ("The traditional model of languaje", "Significare and nominare", "Names as marks and names as signs" y "Language and science").
} 
las demostraciones deban ser entendidos como definiciones de nombres. ${ }^{48}$ Cuando se trata de nombres que signifiquen cosas que tienen una causa concebible (como 'cuerpo', 'materia', 'cantidad', 'movimiento', etc.), ${ }^{49}$ una buena definición será aquella que consista de nombres que expresen la causa o forma en que se genera lo definido. ${ }^{50}$ De este modo, por ejemplo, dadas las definiciones de punto y movimiento, puede procederse a demostrar causalmente una línea o una superficie: "una línea es producida por el movimiento de un punto, las superficies por el movimiento de una línea". 51

La manera como Hobbes entiende la demostración en general y la importancia de las definiciones en ellas coincide con la de Leibniz: todo lo que pueda deducirse en una demostración o cadena de demostraciones ha de estar contenido ya en alguna de las definiciones involucradas. ${ }^{52} \mathrm{Si}$, como entiende Hobbes, una demostración es un silogismo o cadena de silogismos que parten de definiciones de nombres hasta una última conclusión, ${ }^{53}$ entonces aquello que se concluya ha de estar de alguna manera contenido en las definiciones que están en la base del primer silogismo. Si la causa no se halla allí, no se encontraría en ninguno de los otros que dependen de él y, por consiguiente, no se alcanzaría

\footnotetext{
${ }^{48}$ Hobbes, De corpore, I, 6, 13. Zarka 1996, por su parte, señala que aquellos conceptos más universales y simples que se alcanzan mediante el análisis constituirán el objeto de la 'filosofia primera' hobbesiana, como principios que ofician de fundamentos del conocimiento. Entre ellos indica, al menos tentativamente, los de espacio, tiempo, cuerpo, accidente, causa, efecto, poder y acción.

${ }^{49}$ No tienen una causa concebible nombres como 'este cuerpo', 'este movimiento', etc., en virtud de que, siguiendo el ejemplo anterior, la causa expresa la generación del 'cuadrado' y no de 'este cuadrado'.

${ }^{50}$ Hobbes, De corpore, I, 6, 13.

${ }^{51}$ Hobbes, De corpore, I, 6, 6. "(...) a line is made by the motion of a point, superficies by the motion of a line". Esto remarca, asimismo, la importancia que tienen las definiciones para Hobbes, fundamentalmente en el ámbito geométrico. Una de las cosas en las que Hobbes creyó avanzar respecto de la geometría clásica ha sido precisamente redefiniendo varios de sus elementos. En este sentido, indica Grant 1996: "En un momento, para estar seguros, Hobbes prometió que comenzaría solamente donde dejaron Euclides, Arquímedes, Apolonio (...). Pero pensó haber visto en la herencia griega ciertos defectos que demandaron una corrección (...). Su desafío más insistente respecto del legado antiguo estuvo en sus fundamentos, las definiciones que subyacen a los Elementos. Una y otra vez, criticó la definición de Euclides de un punto como 'lo que no tiene partes'. Un punto geométrico (explicó) es una marca visible, y entonces tiene una cantidad, y así, es potencialmente divisible en partes, aunque tales partes 'no sean consideradas' en las demostraciones. Similarmente, se opuso a la definición de Euclides de una línea como 'longitud sin anchura'. Pues, 'las líneas no son trazadas sino por un movimiento, y el movimiento es solamente de un cuerpo', entonces una línea debe tener un ancho, aunque esto también sea insignificante en la práctica. Estos pronunciamientos encapsulan mucho de la filosofía de la matemática de Hobbes. Lo ubican en una aguda oposición a la visión principal de que los objetos de la geometría son abstracciones, idealizaciones de la experiencia sensible. Vio una ciencia cuasi-física del cuerpo extenso; su insistencia de que los objetos son producidos por movimientos físicos fue profundamente característica". La traducción es nuestra.

${ }_{52}$ Véase la cita referida en la nota 31.

${ }^{53}$ Hobbes, De corpore, I, 6, 16.
} 
nunca. ${ }^{54}$ En síntesis, en el concepto de demostración tanto de Hobbes como de Leibniz es esencial la idea de que toda deducción se realiza a partir de las definiciones implicadas. Ahora bien, hay también una diferencia entre los planteos de estos autores, pues para Leibniz las definiciones no son genéticas, sino que contienen las notas que componen un concepto. $^{55}$

\section{El mecanicismo como modelo de explicación física}

El cuestionamiento planteado a la física aristotélica generó, como una evidente consecuencia, un cambio en el modelo de explicación de la filosofía natural. Frente al modelo fundado en 'facultades' o 'formas', en la primera mitad del siglo XVII se instituyó el paradigma de explicación mecánica de los fenómenos físicos. El mecanicismo pretendió explicar todo acontecimiento relativo a la realidad corpórea apelando a la materia y al movimiento. En este sentido, por ejemplo, dice Descartes:

Y, si no me equivoco, no solamente estas cuatro Cualidades [a saber, el calor, el frio, la humedad y la sequedad] sino también todas las otras, así como todas las formas de los cuerpos inanimados, pueden ser explicadas sin que se necesite suponer para esto ninguna otra cosa en su materia que el movimiento, el tamaño, la figura y la disposición de sus partes. ${ }^{56}$

El mecanicismo no debe ser confundido con la ciencia mecánica que tanta importancia tuvo en el contexto inmediatamente anterior al que aquí consideramos. ${ }^{57}$ Entre ellas hubo, ante todo, una diferencia en cuanto al objeto de análisis: la ciencia mecánica tuvo un dominio de objetos a indagar mucho más acotado que la física, a saber, las máquinas. Evidentemente había una conexión entre física y ciencia mecánica, puesto que los objetos de ésta estaban constituidos de elementos físicos. Precisamente por eso se basaba relativamente en premisas físicas. Sin embargo, desde un punto de vista

\footnotetext{
${ }^{54}$ Hobbes, De corpore, I, 6, 13.

${ }^{55}$ Demonstratio propositionum primarum, A VI 2, 479. Veremos algunos ejemplos en el tercer capítulo.

${ }^{56}$ AT, XI, 26. "\& que, si je ne me trompe, non seulement ces quatre Qualitez, mais aussi toutes les autres, \& mesme toutes les Formes des corps inanimez, peuvent estre expliquées, sans qu'il soit besoin de supposer pour cet effet aucune autre chose en leur matiere, que le mouvement, la grosseur, la figure, \& l'arrangement de ses parties". El agregado que hemos introducido entre corchetes responde a lo que Descartes venía indicando antes de mencionar lo citado.

${ }^{57}$ Seguimos aquí a Garber, 2002: "Mechanics and Natural Philosophy: The Sixteenth-Century Tradition(s)". Especialmente, tomamos el sentido de 'mecánica fundacional' para referirnos a la diferencia entre ciencia mecánica y física mecánica.
} 
epistemológico, la ciencia mecánica formaba parte de las 'ciencias medias' que, junto con la astronomía, la óptica y la música, se ubicaron como una rama de la matemática. Cuando en la modernidad se pensó en una 'física mecánica' se realizó, en términos generales, una extrapolación de una propiedad de la ciencia mecánica a la física en general. El sentido de mecánica aplicado a la física da lugar a una 'mecánica fundacional', esto es, tal que funde toda explicación física. Así, el sentido de 'mecánica' que subyace a la intención de instituir una física de este tipo no es exactamente el mismo que el presente en la ciencia mecánica, pues la física mecánica fue no una ciencia particular sino una manera de entender la física misma. ${ }^{58} \mathrm{Al}$ identificar las leyes de la física con las leyes mecánicas, incluso la ciencia mecánica debió explicarse a partir de la física mecánica. ${ }^{59}$

Como ideal de ciencia enfrentado a la física aristotélica, el mecanicismo tuvo que renunciar a algunos de los supuestos que aquella mantenía. "Para un físico aristotélico señala D. Garber- la filosofía natural está en última instancia fundada en las tendencias irreductibles de los cuerpos a comportarse de una u otra manera", de acuerdo con lo cual "algunos cuerpos naturalmente caen y otros naturalmente se alzan". ${ }^{60}$ En los escritos de Galileo se pueden encontrar claros ejemplos del esfuerzo por mostrar que los supuestos de esta interpretación son incorrectos. ${ }^{61}$ La física mecánica, por su parte, no admite que los cuerpos se muevan hacia uno u otro lado por sí. En este sentido, todo movimiento de un cuerpo se explica por el movimiento de otro u otros. De allí, incluso, que una característica en general difundida en el mecanicismo haya sido la visión de la materia como inerte o inactiva por sí. Ya en la década de 1620 M. Mersenne, en sus Quaestiones celeberrimae (1623), había emprendido la tarea de presentar un modelo del mundo cuya cualidad definitoria sea precisamente la inactividad de la materia. La finalidad de esta propuesta

\footnotetext{
${ }^{58}$ De allí, ciertamente, que Descartes utilice expresiones tales como: "Quippe hactenus hanc Terram, totumque adeo hunc mundum aspectabilem, instar machinae descripsi, nihil praeter figuras \& motus in eo considerans" (AT, VIII, 4, § 188). También: "nullum enim aliud, inter ipsa et corpora naturalia, discrimen agnosco, nisi quod arte factorum operationes, ut plurimum, peraguntur instrumentis adeo magnis, ut sensu facile percipi possint: hoc enim requiritur, ut ab hominibus fabricari queant. Contra autem naturales effectus fere semper dependent ab aliquibus organis adeo minutis, ut omnem sensum effugiant" (AT, VIII, 4, § 203).

${ }^{59}$ Es significativo, en este sentido, que si bien antes de Descartes la ciencia mecánica se basaba, por ejemplo, en la gravedad como premisa física, la nueva física mecánica debe explicar inclusive también la gravedad mecánicamente. En Garber, 2002, el autor explora en detalle las características fundamentales de la nueva física mecánica a diferencia de la ciencia mecánica anterior, concluyendo que la nota distintiva es la ausencia de teleología, en el sentido de que el telos es aquí algo impuesto desde fuera, tanto en el caso de los objetos mecánicos como en el de los objetos naturales.

${ }^{60}$ Garber, 2002: 185. La traducción es nuestra.

${ }^{61}$ EN, VIII, 61-69.
} 
particular era ofrecer una interpretación que refute ciertas doctrinas heréticas que resurgieron en el Renacimiento, entre las cuales se incluían la brujería, la astrología o la doctrina de un 'alma del mundo', que se fundarían en el hecho de entender a la materia como esencialmente activa. ${ }^{62}$

Pero en la segunda mitad del siglo XVII surgió la tendencia a cuestionar algunos aspectos (o supuestos) de la física mecanicista. Por sobre todo, filósofos como Leibniz reconocieron que las explicaciones mecánicas para la física carecen de bases metafísicas sólidas. ${ }^{63}$ Ciertamente hubo intentos de establecer fundamentos metafísicos. Uno paradigmático fue el de Descartes, aunque hacia el final de su vida haya confesado que su máximo aporte para la filosofía no fue tanto su metafísica sino más bien su física o filosofía natural. ${ }^{64}$ En este sentido, la metafísica cartesiana puede verse como un intento de establecer un fundamento para la física apelando a expresiones típicas de la metafísica escolástica, como el concepto de 'sustancia'. ${ }^{65}$ Leibniz se vio atraído en su más temprana juventud por el pensamiento mecanicista, aunque luego, con el correr de los años, haya arribado a la conclusión de que sus explicaciones no son satisfactorias. En efecto, reconoció que no basta con el mero concepto de cuerpo, entendido como masa extensa, para dar razón de las leyes naturales. En su filosofía madura reconoce la necesidad del concepto metafísico de 'fuerza'. ${ }^{66}$ Aunque dicho concepto no aparece en su pensamiento de juventud, Leibniz

\footnotetext{
${ }^{62}$ Seguimos aquí las indicaciones de Gaukroger, 2002a: capítulo 5, "The Paris Years, 1625-1628”, apartado "Mersenne, Mechanism, and the Problem of Naturalism". Gaukroger incluso interpreta allí que lo radicalmente distintivo del mecanicismo del siglo XVII no es particularmente el hecho de fundar sus explicaciones en el tamaño, la figura y el movimiento de las partes, sino precisamente en el hecho de que la materia sea concebida inactivamente.

${ }^{63}$ De acuerdo con Racionero, 1980: 57-58, Leibniz conocía especialmente la variante del mecanicismo de Pierre Gassendi. Sobre el pensamiento de Gassendi, véase la sexta sección del próximo capítulo. El mismo intérprete señala, en la página 78: "[r]esulta, pues, que si, por una parte, la magnitud, la figura y el movimiento son nociones mecánicas (...), a cambio de ello, la base de legitimidad de tales nociones no puede ser mecánica o geométrica, sino que requiere, además, la postulación de un ordo metaphysicus como última razón de su consistencia explicativa". Esto se relaciona con lo que mencionaremos más adelante, especialmente en las notas 66 y 67.

${ }^{64}$ AT, V, 165. Del mismo modo, en una carta a Elizabeth de 1643 (AT III, 695), le indica que, una vez entendidos los principios de la metafísica, no debe perderse más tiempo en ellos, debiendo dedicarse en lo siguiente a la filosofía natural, en donde el intelecto coopera con la imaginación y los sentidos. Ambos pasajes son referidos en Gaukroger, 2002b: capítulo 1: "Before the Principia", punto "Metaphysics and the Legitimation of Natural Philosophy".

${ }^{65}$ Gaukroger, 2002b: 364 y ss.

${ }^{66}$ En conexión con lo que mencionamos en la nota 13, en su Nuevo sistema ..., Leibniz añadió: "Pero al tratar después de profundizar en los principios mismos de la mecánica para dar razón de las leyes de la naturaleza que conocíamos por experiencia, advertí que no bastaba con la consideración exclusiva de una masa extensa y que era preciso emplear además la noción de fuerza, que es muy inteligible, aunque pertenezca al dominio de la metafísica" (traducción: De Olaso, 1982: 528-529).
} 
había detectado los problemas metafísicos que le subyacen a la física mecánica. Como veremos en los próximos capítulos, en este período ya se observa un Leibniz que mantiene una actitud conciliadora en relación, por un lado, con la metafísica clásica, fundamentalmente aristotélica, y, por otro, con la filosofía natural mecanicista de su tiempo. ${ }^{67}$ Por esta razón, estuvo interesado en mostrar que la filosofía natural aristotélica puede y debe compatibilizarse con la física de los pensadores de su tiempo. ${ }^{68}$

En sus primeros análisis físicos, Leibniz también cuestionó el abordaje de los escolásticos. Similarmente a lo señalado por Descartes, para Leibniz las explicaciones de aquellos no son las más claras e inteligibles dado que imaginan o fingen entes incorporales. ${ }^{69}$ A pesar de ello, Leibniz valora de una manera absolutamente positiva la Física de Aristóteles. El filósofo de Leipzig indica, en este sentido, que Aristóteles mismo ha señalado que el objeto de la física es el 'ente móvil' (en el cual se hallan las nociones de magnitud, movimiento, espacio y tiempo, esto es, cosas claras e inteligibles), de modo que toda esta ciencia trata sobre la materia y el movimiento. ${ }^{70}$ Así, el problema para Leibniz es el abordaje que han hecho los escolásticos de la física, pero no las conclusiones de la física aristotélica, las cuales considera en general ciertas y demostradas. ${ }^{71}$ Las recurrentes menciones de nociones y argumentos aristotélicos en los siguientes capítulos serán prueba de esto. El problema aquí, entonces, no son tanto las conclusiones cuanto los procedimientos para obtenerlas. En este sentido, Leibniz encontró una fuente de inspiración en las explicaciones de sus contemporáneos.

Leibniz ha observado que el tipo de explicaciones dado por pensadores más recientes (recentiores) es más acorde con el objeto de la física que el de los escolásticos. Por esta razón, ha tomado una 'regla común' utilizada por los filósofos de su tiempo en la

\footnotetext{
${ }^{67}$ Seguimos la sugerencia de Ursula Goldenbaum (expuesta en su presentación del X. Internationaler LeibnizKongress titulada "Why Leibniz is No Eclectic?") de referirnos a una 'actitud conciliadora' más que a un 'eclecticismo conciliador', como propuso, por ejemplo, Mercer, 1999. Mercer señalan tres maestros de Leibniz que, en mayor o menor medida, formaron parte del grupo de los "eclécticos conciliadores": Johann Adam Scherzer (24-28), Jakob Thomasius (28-32) y Erhard Weigel (33-35). Según Mercer, el sistema filosófico de Weigel, por ejemplo, fue una "complicada mezcla de ideas Platónicas, Aristotélicas y Mecánicas" (34).

${ }^{68}$ Leibniz a Thomasius, A II 1, 26. Asimismo, A II 1, 30. Ambos pasajes marcan el aspecto no sólo de posibilidad de conciliación sino cierta necesidad de ello. Véase Garber, 1995: 271-273, quien, asimismo, también indica que Leibniz tiene la intención de ser consistente con el pensamiento de Aristóteles (aunque no necesariamente con el escolástico).

${ }^{69}$ Leibniz a Thomasius, A II 1, 26.

${ }^{70}$ Leibniz a Thomasius, A II 1, 30.

${ }^{71}$ Leibniz a Thomasius, A II 1, 25.
} 
que basar las explicaciones físicas, a saber, "que 'nada debe explicarse en los cuerpos, a no ser por magnitud, figura y movimiento"". ${ }^{72}$ De esta manera, como las explicaciones físicas basadas en esta regla son más claras e inteligibles que aquellas de los escolásticos, son preferibles las hipótesis de los pensadores más recientes. ${ }^{73}$ De acuerdo con esto, Leibniz reconoció tres núcleos conceptuales distintivos de la física aristotélica que deberían ser explicados recurriendo a la magnitud, la figura y el movimiento, a saber: las explicaciones abstractas de Aristóteles acerca de la materia, la forma y la mutación. ${ }^{74}$ El tratamiento que Leibniz hizo de estas nociones, particularmente de la de 'materia', fue muy importante para el problema del continuo. En efecto, como veremos en el tercer capítulo, a partir de un examen de dicha noción, se sigue la afirmación según la cual se dan infinitas partes en acto, tesis que es el punto de partida del laberinto del continuo en el pensamiento leibniziano.

Como mencionamos al comienzo, en este capítulo buscamos plantear algunos lineamientos fundamentales del trasfondo científico y filosófico del siglo XVII que manifiestan la tensión entre la nueva filosofía moderna y el pensamiento aristotélico y que, directa o indirectamente, son relevantes para el tratamiento leibniziano del problema del continuo. Para finalizar este capítulo, conectaremos los aspectos filosóficos generales que hemos expuesto aquí con algunas de las cuestiones que abordaremos en los capítulos siguientes, en especial los de la segunda parte. Por un lado, hemos visto que para el pensamiento moderno fue insuficiente el esquema clasificatorio de las ciencias de Aristóteles, pues no admite que un género de conocimientos tenga como fundamentos los principios de otro género. Como veremos, el pensamiento leibniziano presupone también que la clasificación aristotélica de las ciencias es obsoleta. Esto se verá especialmente en el tercer capítulo, cuando consideremos que, hacia finales de la década de 1660 y comienzos de la siguiente, Leibniz entendió que el espacio geométrico es una de las notas que definen a la materia, así como también en el cuarto capítulo, cuando mostremos que en los escritos

\footnotetext{
${ }^{72}$ Leibniz a Thomasius, A II 1, 25. "Regulam illam omnibus istis philosophiae Restauratoribus communem teneo, nihil explicandum in corporibus, nisi per magnitudinem, figuram et motum". Asimismo, véase Garber, 2009: 3-9.

${ }_{73}^{73}$ Leibniz a Thomasius, A II 1, 26.

${ }^{74}$ Leibniz a Thomasius, A II 1, 26.
} 
de 1671 y 1672 Leibniz se representó las infinitas partes actuales del continuo en fracciones. Por otro lado, hemos visto que en la modernidad se pensó que la experiencia y la experimentación cumplen un rol fundamental para el conocimiento físico. En este sentido, por ejemplo, Leibniz consideró que el movimiento admite tanto un análisis sensible como uno racional que no solamente no son contradictorios sino que deben ser complementarios. Como veremos, esto será muy relevante cuando examinemos el análisis abstracto del movimiento que Leibniz llevó a cabo al comienzo de la década de 1670. Así, en el tercer capítulo veremos que el filósofo de Leipzig ha justificado abstractamente la infinitud actual de partes en la materia, en el cuarto capítulo veremos varios elementos de la teoría abstracta del movimiento de Leibniz, del mismo modo que en el quinto capítulo veremos el modo en que Leibniz explicó abstractamente la diferencia de velocidades en los movimientos, así como también la explicación de la unidad de las infinitas partes de la materia. A continuación, hemos visto que, desde un punto de vista metodológico, en la temprana filosofía moderna se concibió a la lógica aristotélica como insuficiente. En efecto, carece de un procedimiento para descubrir verdades. En este sentido, para Leibniz fue especialmente importante el pensamiento de Hobbes. Esta cuestión será relevante para el capítulo tercero, cuando veamos que, en sus escritos físicos, Leibniz tomó la definición de cuerpo y luego dedujo de ella todo lo que puede deducirse, así como también, y especialmente, en el sexto capítulo, cuando veamos que Leibniz buscó demostrar el axioma según el cual 'el todo es mayor que una parte' analíticamente, es decir, a partir de definiciones. Finalmente, hemos visto que en la temprana filosofía moderna surgió el modelo de explicación de la física llamado 'mecanicismo', aunque también hubo quienes, como Leibniz, consideraron que el mecanicismo carece de explicaciones metafísicas sólidas. Si bien en la segunda parte de nuestra tesis ya hay algunos elementos que muestran la búsqueda por parte de Leibniz de una síntesis entre el pensamiento aristotélico y el moderno (como veremos por ejemplo en el tercer capítulo a propósito del examen de la materia), en la tercera parte de nuestro trabajo (especialmente en el octavo capítulo) veremos más detalladamente algunos elementos de la metafísica leibniziana de finales de su estancia en París. 



\section{CAPÍTULO 2: TEORÍAS DEL CONTINUO Y DEL INFINITO PRE-LEIBNIZIANAS}

La historia del problema del continuo es extensa y quizás tan complicada como el laberinto del continuo mismo. Las célebres paradojas de Zenón de Elea han sido la primera manifestación de la complejidad del tratamiento del infinito y de la división de magnitudes finitas. ${ }^{1}$ No obstante, el primer examen exhaustivo sobre el infinito y el continuo fue llevado a cabo por Aristóteles. Mediante la célebre teoría del carácter potencial del infinito y la definición del continuo como lo que es siempre divisible, Aristóteles no solamente ofreció una alternativa frente a las aporías propuestas por Zenón sino que también puso las bases sobre las que se apoyaron las investigaciones futuras sobre el problema del continuo. Esto no significa, por cierto, que todas las propuestas que vinieron después de Aristóteles hayan retomado su interpretación. Las variantes de la teoría atomista, como la de Epicuro entre los griegos o posteriormente la de Lucrecio entre los latinos, son esencialmente distintas de la de Aristóteles y en cierto sentido buscaron oponerse a ella. ${ }^{2}$ En última instancia, la oposición entre aristotelismo y atomismo ha persistido incluso hasta la época de Leibniz. No obstante, la situación en la temprana filosofía moderna es notablemente más compleja. Como veremos en lo que sigue, tanto entre los aristotélicos como entre los atomistas ha surgido una gran variedad de alternativas.

El objetivo de este capítulo es presentar algunas de las teorías del continuo anteriores a la leibniziana que fueron decisivas para el filósofo de Leipzig, sea por haberlas retomado parcialmente o por haberlas cuestionado. En este sentido, no es nuestra intención hacer una historia del problema del continuo sino sintetizar los lineamientos centrales de ciertas interpretaciones que en algún sentido son el marco dentro del cual se desarrolla la teoría de Leibniz. Dividiremos nuestro examen en dos partes: en la primera examinaremos algunas interpretaciones aristotélicas del continuo y en la segunda otras atomistas. Comenzaremos sintetizando los lineamientos fundamentales de la teoría del continuo y del infinito de Aristóteles tanto por la importancia que tuvo para Leibniz (esto se verá en los capítulos siguientes, fundamentalmente en el quinto) como para otros aristotélicos e incluso para los atomistas críticos del aristotelismo de la temprana filosofía moderna. A

\footnotetext{
${ }^{1}$ Sorabji, 1983: 321-335.

${ }^{2}$ Véase, por ejemplo, Sorabji, 1983: 371-377.
} 
continuación, y como consecuencia de algunas conclusiones de Aristóteles, examinaremos la tesis de Francisco Suárez según la cual los extremos indivisibles de las partes del continuo (en virtud de los que, según la propuesta del filósofo griego, se explica la continuidad) se dan positivamente. Como veremos en los capítulos siguientes, es posible que esta tesis haya tenido repercusiones en algún período del pensamiento de Leibniz. En tercer lugar, abordaremos sintéticamente el examen de Libert Froidmont, uno de los autores que presumiblemente más influyó en el pensamiento de Leibniz acerca del laberinto del continuo en su juventud. En este caso, examinaremos algunos argumentos geométricos de Froidmont empleados para negar una composición del continuo en términos de partículas puntuales, así como también algunas reflexiones suyas relativas a la naturaleza del infinito que lo condujeron a reconocer que en el continuo deben darse tantas partes proporcionales como puedan darse. Luego, pasaremos a examinar las interpretaciones atomistas del continuo. En esta perspectiva, tendremos en cuenta dos alternativas principales muy distintas entre sí que de alguna manera ofrecen un panorama de las posibles variantes de atomismo que se han dado: primero examinaremos el atomismo geométrico de Galileo, tras lo cual veremos algunos planteos de Cavalieri, y luego el atomismo físico de Gassendi. Estos autores han generado un fuerte impacto en Leibniz, aunque en general en un sentido crítico. Con respecto a Galileo, en el capítulo sexto veremos que la comprensión leibniziana del infinito se desarrolla en una explícita oposición a la interpretación del científico italiano. A su vez, en el próximo capítulo señalaremos las razones por las cuales para Leibniz los átomos de Gassendi no pueden sostenerse.

\section{INTERPRETACIONES ARISTOTÉLICAS DEL CONTINUO}

\section{Continuo e infinito en Aristóteles}

"Es evidente que todo continuo es divisible en partes que son siempre divisibles", 3 expresa Aristóteles en una de sus más concisas definiciones del continuo. La palabra 'siempre' hace referencia a uno de los aspectos más importantes de su examen, a saber, al

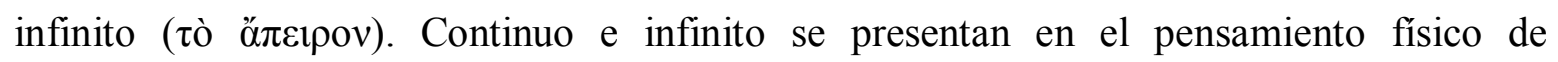

\footnotetext{
${ }^{3}$ Aristóteles, Physika, 231b16. Como mencionamos en el capítulo anterior, las traducciones de esta obra se tomarán de Aristóteles, 1995a.
} 
Aristóteles, al igual que sucederá muchos siglos después con Leibniz, como una par de conceptos íntimamente ligados. En este apartado buscaremos sintetizar los lineamientos fundamentales de la teoría del continuo y del infinito de Aristóteles, una de las primeras y más influyentes de la historia. Abordaremos en primer lugar el concepto de infinito y luego introduciremos algunas precisiones relativas al de continuo.

El examen de la naturaleza del infinito se desarrolla fundamentalmente en el centro de las investigaciones físicas de Aristóteles. La razón de la importancia del infinito en la física depende esencialmente de la naturaleza del objeto considerado por esta ciencia, pues

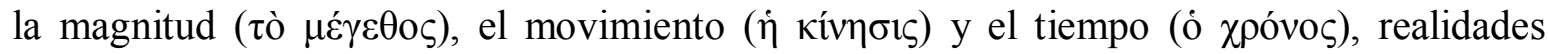
nucleares en el estudio de la física, son por necesidad o finitas o infinitas. ${ }^{4}$ Aristóteles reconoce múltiples razones por las cuales se ha creído en el infinito (en lo fundamental históricas, aunque para él también teóricas). Una de ellas ha sido la afirmación de que si el tiempo no tiene un comienzo ni un fin es porque en algún sentido es infinito, ${ }^{5}$ mientras que otra es el hecho de que los matemáticos hagan uso del infinito. ${ }^{6}$ No obstante, es importante tener en cuenta la diferencia (a la que sucintamente nos hemos referido en el primer capítulo) que Aristóteles supone entre el abordaje de los físicos y el de los matemáticos. En este sentido, aunque los cuerpos físicos posean cualidades que en lo fundamental son estudiadas en la matemática, como superficies, volúmenes o longitudes, el matemático las trata como objetos autónomos. Así, la diferencia en los abordajes físicos y matemáticos es una diferencia en el grado de abstracción o separación, en tanto que, aunque aquellos atributos se dan en los cuerpos físicos, el pensamiento matemático los considera separadamente. En este sentido, un geómetra puede estudiar una línea, pero no en tanto que es física (como sería, por ejemplo, el trayecto de un movimiento). ${ }^{7}$ Ahora bien, precisamente porque en la matemática se abstrae de la realidad física, hay propiedades y

\footnotetext{
${ }^{4}$ Aristóteles, Physika, 202b29-35. Esto no significa para Aristóteles que todo es por necesidad o finito o infinito. Hay cosas que, por su propia naturaleza, escapan a esta distinción. Ejemplo de esto son las afecciones, que no son cantidades sino cualidades, o los puntos, que, como veremos más adelante, tampoco son cantidades sino sus límites.

${ }^{5}$ Véase el libro VIII de la Physika.

${ }^{6}$ Aristóteles, Physika, 203b15-203b26.

${ }^{7}$ Aristóteles, Physika, 193b22-35.
} 
características consideradas en la física que también son objeto de estudio en la matemática, aunque no todas. Una de ellas es precisamente el infinito. ${ }^{8}$

Aunque el examen del infinito tenga un papel preponderante en la física, su consideración es radicalmente problemática. En este sentido, Aristóteles reconoce que “(...) la teoría del infinito plantea dificultades; porque tanto si suponemos que existe como que no existe se siguen muchas consecuencias imposibles". ${ }^{9}$ No obstante, el abordaje que lleva a cabo revela que las indeseables consecuencias que se siguen de negar el infinito son notablemente más críticas para la física que las que se siguen de afirmarlo. Las dos razones mencionadas anteriormente que justificaron la creencia en el infinito son decisivas en este sentido, pues como es sabido la ausencia de un comienzo y un fin del tiempo es una de las tesis más determinantes de la física de Aristóteles, así como también es innegable la importancia del empleo del infinito en la matemática. El objetivo de Aristóteles en cuanto al infinito es, por lo tanto, dilucidar su naturaleza, de manera tal que se eviten las contradicciones que se siguen de afirmarlo $\mathrm{y}$, al mismo tiempo, las que se siguen de negarlo:

Pero, por otra parte, es claro que la negación absoluta del infinito es una hipótesis que conduce a consecuencias imposibles. Porque en tal caso tendría que haber un comienzo y un fin del tiempo, las magnitudes no serían divisibles en magnitudes y el número no sería infinito. Y puesto que, según las distinciones establecidas, ninguna de estas alternativas parece aceptable, hace falta un árbitro que ponga de manifiesto en qué sentido el infinito es y en qué sentido no es. ${ }^{10}$

El punto de partida ineludible del examen de lo que es y lo que no es el infinito es una consideración del modo de existencia que le corresponde. Desde un punto de vista que, sin necesidad de ser inspeccionado en profundidad, puede denominarse como ontológico, hay al menos tres alternativas a considerar, esto es, si existe como sustancia, como un

\footnotetext{
${ }^{8}$ Seguimos las sugerencias de Hasper, 2006, puntos 1 y 4, quien argumenta que el hecho de que la matemática implique un grado de separación o abstracción mayor que el de la física le permite a Aristóteles concluir que lo que es imposible en la matemática lo es también en la física, aunque no se da necesariamente la recíproca. De esta manera, las características y propiedades estudiadas en la física son numéricamente más que las de la matemática. Como consecuencia para el problema que nos atañe, los razonamientos de Aristóteles a propósito del infinito (en el sentido que será dilucidado a continuación) tienen validez tanto para la matemática como para la física, aunque no obstante haya diferencias en el modo como deben entenderse algunos aspectos de la divisibilidad infinita en dichas ciencias (para esto, véase el punto 4 del trabajo de Hasper).

${ }^{9}$ Aristóteles, Physika, 203b32-33.

${ }^{10}$ Aristóteles, Physika, 206a10-15.
} 
atributo o bien de ninguna de estas maneras. ${ }^{11}$ El examen de estas alternativas no es menor, pues para Aristóteles el mayor problema que supone el infinito para la física es analizar si es posible que exista en acto un cuerpo, es decir, una sustancia, que sea infinita por aumento o extensión (esto es, en cuanto a un atributo suyo). ${ }^{12}$ No obstante, el examen del modo de existencia del infinito que realiza Aristóteles no parte de la dualidad sustanciaatributo sino de otra aún más profunda, implícita en las alternativas antes mencionadas, a

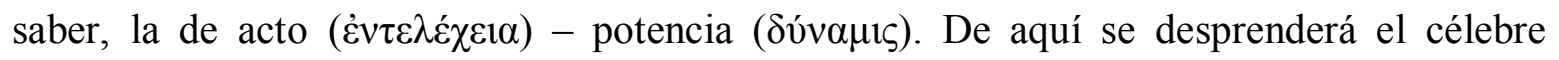
examen del infinito potencial aristotélico. ${ }^{13}$

Ahora bien, el ser se dice o de lo que es en potencia o de lo que es en acto, mientras que el infinito es o por adición o por división. Y ya se ha dicho que la magnitud no es actualmente infinita, aunque es infinitamente divisible (...). Nos queda, entonces, por mostrar que el infinito existe potencialmente. ${ }^{14}$

La distinción sugerida en la cita, y que será explorada en lo sucesivo, entre infinito

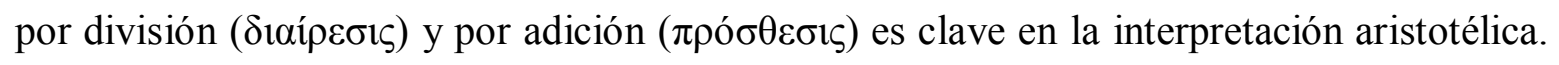
Ahora bien, el modo de ser en potencia del infinito posee un matiz absolutamente distintivo que lo diferencia de prácticamente cualquier otro tipo de potencialidad. Aristóteles reconoce que hay distintas maneras en que puede interpretarse la expresión 'existencia potencial'. El sentido usual es el que entiende la potencialidad de modo tal que pueda luego llegar a ser en acto (así, el bronce “(...) es potencialmente una estatua, y después será una estatua"). ${ }^{15}$ No obstante, este no es el significado de 'ser en potencia' que corresponde al infinito. ${ }^{16}$ El modo de ser en potencia propio del infinito, y que a su vez es el núcleo de esta

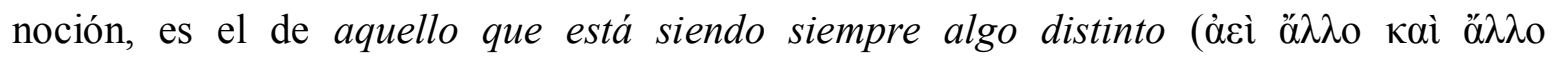
$\gamma^{\prime}(\gamma v \varepsilon \sigma \theta \alpha \imath) .{ }^{17}$ En este sentido, la potencialidad del infinito no debe ser entendida como la

\footnotetext{
${ }^{11}$ Aristóteles, Physika, 203b30-35.

12 Aristóteles, Physika, 204b1-5.

${ }^{13}$ Las razones por las cuales no existe ni puede existir en acto exceden la intención de esta presentación. Asimismo, la caracterización del infinito aristotélico, que señalaremos a continuación, hace imposible de hecho su existencia actual. Pueden encontrarse los argumentos aristotélicos en Aristóteles, Physika, 204a8$206 a 8$.

${ }^{14}$ Aristóteles, Physika, 206a14-18.

15 Aristóteles, Physika, 206 a19.

${ }^{16}$ Aristóteles, Physika, $206 \mathrm{a} 20$.

${ }^{17}$ Aristóteles, Physika, 206a20-25. Esta idea, que como se remarcará es la nota esencial del infinito potencial aristotélico, es reiteradamente mencionada por el autor. Así, por ejemplo (207a5-9): “en lo infinito también es preciso que la parte que se tome no sea jamás la misma", o bien "[a]sí pues, una cantidad es infinita si siempre se puede tomar una parte fuera de la que ya ha sido tomada". Bostock, 2006: 117, interpreta que, al referirse al infinito 'por división', Aristóteles tiene en mente el proceso de dividir continuamente una magnitud dada que no puede ser completado. Si esto se entendiera en un sentido estrecho, no obstante, parecería seguirse que
} 
que tiende a su realización plena, “(...) pues no hay un infinito tal que después sea en acto". ${ }^{18}$ Hay varios ejemplos utilizados por Aristóteles para graficar esta característica central del infinito, en todos los cuales se refleja la nota esencial antes mencionada, esto es, la de ser siempre algo distinto. Así, “(...) decimos que el infinito «es» en el sentido en que decimos «el día es» o «la competición es»", esto es, hay en ellos una existencia actual (lo que el día ahora es) y una potencial (lo distinto que eventualmente llegará a ser). ${ }^{19}$ Del mismo modo, de manera análoga se dice que existe potencialmente como la materia, la cual, a saber, está en potencia de adquirir diversas formas. ${ }^{20}$ En cualquiera de estos ejemplos, lo que es en acto es algo finito, mientras que lo infinito es sólo potencialmente. De allí que Aristóteles señale que "[e]n general, el infinito tiene tal modo porque lo que en cada caso se toma es siempre algo distinto y lo que se toma es siempre finito, aunque siempre distinto". 21

Es importante notar que el significado de infinito es para Aristóteles uno y el mismo, de manera tal que la distinción antes sugerida entre ‘infinito por división' e ‘infinito por adición' se refiere, en cierto sentido, a distintas subespecies complementarias de lo

el infinito se atribuye más a aquello que lleva a cabo el proceso que a lo que de hecho es divisible. De esta manera, ante todo el infinito por división en la física, en el sentido antes descrito, debe ser visto como una potencialidad de la cosa más que como un proceso efectuado por alguien. Esta es la idea que parece estar en la base de la interpretación de Sorabji, 1983: 210, pues entiende que el 'proceso' es el hecho de estar siendo siempre algo distinto.

${ }^{18}$ Aristóteles, Physika, 206a20. Hasper, 2006: 125-133, considera dos maneras, reconocidas por Aristóteles en De generatione et corruptione, 315a26-317a30, en las que podría entenderse el sentido de infinito como "ser siempre divisible": o bien el sentido que aquí presentamos, esto es, de ser siempre algo distinto, o bien en el sentido de poder ser dividido en todas partes, podría decirse, simultáneamente. En este segundo caso, de actualizarse la potencialidad, el continuo se dividiría en acto en partes indivisibles (pues se habría agotado la infinita divisibilidad ya que se ha supuesto que ha sido realizada 'en todas partes'). Como muestra Hasper, este segundo sentido es el supuesto en los argumentos de Demócrito para justificar la existencia de átomos, argumentos respecto de los cuales Aristóteles nota que se produce una falacia de ambigüedad de significado, pues se toma el "ser siempre divisible" en algunos casos en el primer sentido y en otros en el segundo. Esta diferenciación señalada por Hasper es importante tenerla en cuenta sobre todo en vistas de la crítica de Galileo al continuo aristotélico (véase la cuarta sección). Un tratamiento próximo al de Hasper, aunque menos exhaustivo, puede encontrarse en Charlton, 2003: 135-136.

${ }^{19}$ Aristóteles, Physika, 206a21-23. Es sabido que Aristóteles discute las paradojas de Zenón sobre la base de su comprensión del infinito como potencial. Como nuestra intención es ofrecer una presentación general de la propuesta de Aristóteles, dejaremos de lado la consideración de las paradojas. Para esto, véase Sorabji, 1983, cap. 21, White, 2002: 168-179, Charlton, 2003: 131-135 o Bostock, 2006: 116-127.

${ }_{20}$ Aristóteles, Physika, 206b13-14. Véase a su vez la nota 71 de la traducción (Aristóteles, 1995a).

${ }^{21}$ Aristóteles, Physika, 206a26-29. Seguimos la interpretación del infinito aristotélico de Sorabji, 1983: 210213. De acuerdo con él, como efecto de esta caracterización, el infinito se define siempre en términos de una finitud, a saber, pues (considerando el infinito por división) siempre pueden tomarse partes más pequeñas sin importar cuán grande sea el número finito de partes que ya se haya tomado. Sorabji entiende al infinito aristotélico, consecuentemente, como una "finitud extensible", en la medida en que la idea de "estar siendo siempre algo distinto" supone un número actualmente finito de divisiones. 
mismo. ${ }^{22}$ Esto significa que en ambos casos siempre se toma algo distinto, aunque la manera en que esto ocurre no es la misma: por división siempre se adquieren partes cada vez más pequeñas que las actuales, mientras que por adición siempre se obtienen resultados más grandes que los que actualmente se dan:

Hay también un infinito potencial por adición, el cual, como hemos dicho, es en cierto sentido de la misma manera que el infinito por división, pues siempre se podrá tomar algo fuera de él; pero lo que se tome nunca superará toda magnitud finita, a diferencia del infinito por división, en el que toda magnitud finita es superada en pequeñez y siempre quedará una parte más pequeña. ${ }^{23}$

La idea fundamental de la complementariedad entre la división y la adición puede verse de esta manera: supongamos que se divide infinitamente (recordemos, en el sentido aristotélico) una magnitud finita cualquiera en mitades. Lo que se tenga será siempre algo distinto, pues cada parte dividida sería una fracción de la precedente y por lo tanto nunca idéntica. La suma de dichas partes, consecuentemente, involucraría un número siempre finito de sumandos, aunque el número de sumandos sea siempre extensible. ${ }^{24}$ Es decir que podría siempre añadirse un nuevo sumando al número finito que actualmente se posee, de manera que el añadido sea distinto del anterior (pues, según se supuso, sería la mitad del precedente). Como consecuencia, simultáneamente, la suma -permítanos la expresióntenderá a una magnitud finita que nunca será superada: “(...) en la medida en que una magnitud se ve dividida hasta el infinito, en la misma medida aparecen las adiciones con respecto a una determinada magnitud". ${ }^{25}$ En este sentido, entonces, son complementarios:

\footnotetext{
${ }^{22}$ Bostock, 2006: 160-161 (y en general en todo el capítulo 10), reconoce acertadamente que en algún sentido el infinito por 'división' y por 'adición' son distintos y complementarios. A propósito de lo que se ha dicho en el trabajo, por cierto, Aristóteles señala que es claro que ningún cuerpo sensible puede ser infinito por adición, al modo como se dice que el tiempo es de este modo infinito. No obstante, el cuerpo reconoce una manera de entender el infinito potencial por adición "de una manera inversa a la del infinito por división" (206b25-27).

${ }^{23}$ Aristóteles, Physika, 206b16-20. Aristóteles admite, por cierto, que algo puede ser infinito por división, por adición o bien por ambos (204a7-8). El segundo caso sería, por ejemplo, el del tiempo: si se lo considera en relación con el movimiento de un cuerpo dado, en la mitad del tiempo requerido para alcanzar el punto final del movimiento el cuerpo recorrería la mitad del trayecto espacial, así como en una cuarta parte del tiempo una parte proporcional de espacio, y así sucesivamente. En este caso, el tiempo es infinito por división. Ahora bien, considerado en relación con el hecho de que para Aristóteles el tiempo carece de un comienzo y un final, siempre habrá un 'ahora' (en el sentido en que lo explica en capítulo 3 del libro VI) distinto del actualmente dado. En este caso, será infinito por adición.

${ }^{24}$ Seguimos a White, 2002: 137-148, quien, por otra parte, establece un muy interesante paralelo entre el método de exhaución empleado por Arquímedes (al que nos referiremos en el séptimo capítulo) y la distinción complementaria entre infinito por división y adición de Aristóteles a la que hemos hecho referencia. Al igual que Sorabji, White entiende el infinito aristotélico como una finitud extensible (véase la nota 21).

${ }^{25}$ Aristóteles, Física, 206b6-7.
} 
la división, que es infinita potencialmente aunque el número de partes actuales es finito (y siempre distinto), se corresponde con la suma de dichas partes, la cual suma es también infinita potencialmente, aunque el número actual de sumandos sea siempre finito ( $\mathrm{y}$ siempre distinto). ${ }^{26}$

Como se ha dicho al comienzo, el infinito es uno de los elementos centrales de la interpretación aristotélica del continuo. Es por ello que indica que “(...) lo que es continuo tiene partes distintas y puede ser dividido en esas partes, que son entonces diferentes y están separadas en cuanto al lugar", ${ }^{27}$ o señala que entiende por continuo "(...) lo que es divisible en divisibles siempre divisibles". ${ }^{28}$ De más está aclarar que es el infinito por división el que está incluido en la noción de continuo. No obstante, estas indicaciones no responden directamente a la pregunta por: ¿qué son las cosas continuas?, es decir, ¿cómo se explica la continuidad de lo continuo? De este interrogante se desprenden importantes reflexiones aristotélicas que, como se verá posteriormente, tienen un impacto muy importante en la teoría leibniziana. ${ }^{29}$

La manera como Aristóteles entiende el concepto de lo continuo ( $\tau$ ò $\sigma v v \varepsilon \chi \varepsilon ́ \varsigma$ ) le exige considerar previamente otras nociones que o están incluidas en o deben distinguirse

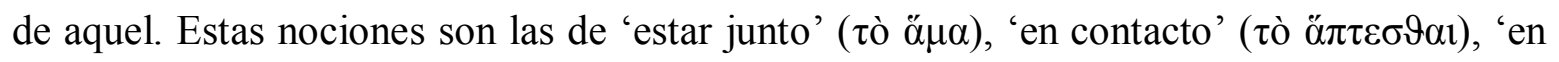

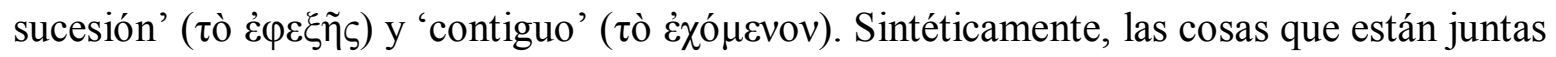
son aquellas que están en un mismo lugar, pudiendo estar luego separadas (a modo de ejemplo, como una estantería y un libro); las cosas en contacto, por su parte, son aquellas cuyos extremos ( $\tau \grave{\alpha}$ ö́ $\rho \alpha$ ) están juntos $;^{30}$ una cosa sucede a otra, por su lado, cuando cumple con dos condiciones: si, sea en posición o en algún otro respecto, está después de la anterior y si no hay otra cosa del mismo género entre ellas. En este sentido, por ejemplo, en la serie de los números naturales, entre dos números sucesivos, como el 1 y el 2, no hay

\footnotetext{
${ }^{26}$ Nótese, sin embargo, que en el marco del pensamiento aristotélico no tendríamos nunca una suma infinita, es decir, de infinitos términos, al menos en el sentido como lo entenderá en la modernidad filosófica Leibniz, de acuerdo con lo que veremos fundamentalmente en los capítulos 4 y 6 . Más aún, esto sería imposible, pues para una tal suma (nuevamente, al modo como la entendería Leibniz) se requieren los infinitos términos en acto, lo que la noción aristotélica de infinito potencial no permite: para Aristóteles los términos de una suma no son infinitos sino siempre finitos en número, aunque el número sea siempre extensible. Véase White, 2002: $10-13$.

${ }^{27}$ Aristóteles, Physika, 231b4-5.

${ }^{28}$ Aristóteles, Physika, 232b24-25.

${ }^{29}$ Véase, sobre todo, el quinto capítulo.

${ }^{30}$ Aristóteles, Physika, 226b20-25.
} 
otro número interpuesto. ${ }^{31}$ Estas tres nociones son fundamentales para comprender el concepto aristotélico de lo contiguo y, finalmente, también de lo continuo. Para el filósofo griego, una cosa es contigua con otra cuando la sucede y está en contacto con ella. ${ }^{32} \mathrm{~A}$ modo de ejemplo, supongamos, en términos abstractos, un círculo $A$ sobre una línea recta YZ (figura 1). El círculo está en contacto con la línea y al mismo tiempo la sucede (en el sentido de que está 'sobre ella'). Debido a que la noción de sucesión incluye la de 'estar junto', si posteriormente se moviera el círculo, de manera tal que medie un espacio entre él y la línea, dejarán de sucederse y, por lo mismo, dejarán de ser contiguas para pasar a ser discontiguas (figura 2$):^{33}$

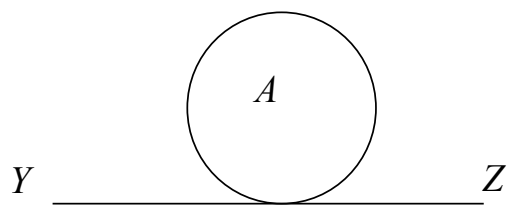

(Figura 1)

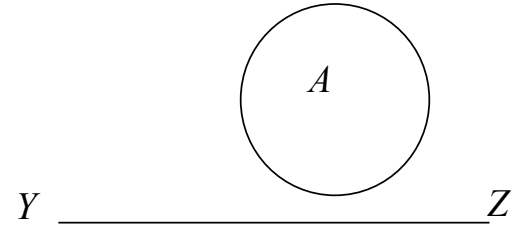

(Figura 2)

El hecho de que moviendo el círculo no se desplace simultáneamente la línea significa que los extremos de una y otra figura, aunque están juntos mientras permanecen contiguamente, no son el mismo. Esto es precisamente en lo que para Aristóteles se distingue lo contiguo de lo continuo: "digo que una cosa es continua con otra cuando sus límites que se tocan entre sí llegan a ser uno y lo mismo y, como indica la palabra, se «contienen» entre sí, pero si los extremos son dos no puede haber continuidad". 34 Lo continuo,

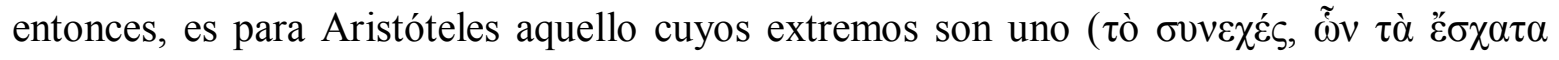
$\tilde{\varepsilon} v) .{ }^{35}$ Dado que los extremos, en este caso, serían no dos distintos que están juntos sino uno y el mismo, lo continuo se presenta como una variante especial de lo contiguo o, como dice Aristóteles, una subdivisión suya. ${ }^{36}$ De esta manera, la continuidad se presenta como una herramienta teórica para explicar la unidad de aquellas cosas que naturalmente están unidas por contacto. ${ }^{37}$ Como una consecuencia de lo anterior, y que nuevamente marca la

\footnotetext{
${ }^{31}$ Aristóteles, Physika, 226b34-227a4.

32 Aristóteles, Physika, 227a6-9.

${ }^{33}$ Hemos seleccionado este ejemplo porque fue empleado por Leibniz mismo precisamente para graficar la noción aristotélica de lo contiguo. Véase Pacidius Philalethi, A VI 3, 537. OFC, 8. 124-125.

${ }^{34}$ Aristóteles, Physika, 227a10-13.

${ }^{35}$ Aristóteles, Physika, $228 \mathrm{~b} 30$.

${ }^{36}$ Aristóteles, Physika, 227a10. Sorabji, 1983: 366.

37 Aristóteles, Physika, 227a13-19.
} 
diferencia entre lo continuo y lo contiguo, dado que las cosas continuas comparten un mismo extremo, el movimiento de una de ellas acarrearía necesariamente el de la otra. Por eso, para Aristóteles lo que es continuo es un todo, es decir, es algo uno. ${ }^{38}$ Desde el punto de vista físico, esto justifica, por ejemplo, la unión orgánica, esto es, la de los cuerpos físicos: cuando una parte de un cuerpo se mueve, no se separa de las restantes: ellas se contienen, esto es, se co-mueven: “(...) el movimiento de lo que es uno tiene que ser uno, ni de ninguna otra cosa, porque un movimiento continuo tiene que ser movimiento de cosas que sean continuas". 39

La teoría aristotélica conlleva, como una de sus consecuencias más importantes, la imposibilidad de que el continuo se componga de, o bien se divida en, partes que no admitan una nueva subdivisión. La imposibilidad de que se resuelva en última instancia en

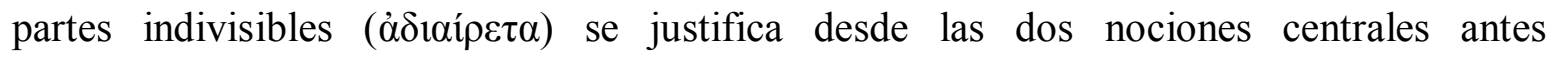
mencionadas, esto es, las de infinito y de continuo. Por un lado, si, como se ha dicho, es esencial al continuo ser divisible al infinito, es decir, en partes que son siempre nuevamente divisibles, entonces no es posible hallar un límite final de la división en partes que no sean susceptibles de ser nuevamente particionadas. Pero por otro lado, la manera de entender la continuidad, como una subespecie de lo contiguo, también conlleva para Aristóteles la necesidad de negar una sucesión de indivisibles. Esto significa, por ejemplo, que una línea, supuesto que sea algo continuo, no puede componerse de puntos (tomados precisamente como indivisibles). ${ }^{40}$

Para la presente discusión es fundamental el hecho de que Aristóteles interprete a los puntos como indivisibles. En este sentido, ellos no son magnitudes ni, por eso mismo, divisibles. ${ }^{41}$ Más bien, los puntos son los límites extremos entre los cuales hay siempre una línea, aunque no sus componentes o partes. ${ }^{42}$ Dada la naturaleza del punto, la suposición de que ellos son partes lleva a contradicciones. En efecto, si ellos no fueran extremos sino

\footnotetext{
${ }^{38}$ Aristóteles, Physika, 227a16-17.

${ }^{39}$ Aristóteles, Physika, 235a5-7.

${ }^{40}$ Aristóteles, Physika, 231a23-26. Puede encontrarse un detallado análisis de los argumentos contra una composición de puntos indivisibles en White, 2002, cap. 1.

${ }^{41}$ Aristóteles, Physika, 202b30-35. En efecto, como se ha visto, cuando Aristóteles justifica por qué es importante para la física el estudio del infinito, señala que si bien hay algunas entidades fundamentales para esta ciencia de las que cabe preguntarse si son o no infinitas, hay otras respecto de las cuales esta pregunta carece de sentido. Como ejemplo señala precisamente a los puntos.

${ }^{42}$ Aristóteles, Physika, 231b6-10. A propósito de la distinción entre las dos maneras de entender a los puntos, como límites o como componentes, y su relación con los argumentos aristotélicos contra el atomismo, véase Hasper, 2006, puntos 1 y 3 .
} 
partes, entonces para hacer algo continuo deberían unirse unos con otros en sus respectivos extremos. No obstante, como el punto no es una magnitud y por lo tanto no tiene partes, no hay extremos que sean distintos de aquello de lo que es extremo. ${ }^{43}$ De esta manera, como no tienen partes, los puntos indivisibles deberían tocarse entre ellos no en sus extremos sino como una totalidad con otra. ${ }^{44}$ Sin embargo, para Aristóteles es evidente que un indivisible añadido a otro no hace algo divisible y continuo ya que, como se ha dicho anteriormente, es esencial al continuo tener partes distintas en las que pueda dividirse y que, precisamente por eso, están separadas. ${ }^{45}$ Más aún, y como corolario de lo anterior, si una magnitud continua se compusiera de indivisibles, entonces podría dividirse en partes que no tienen partes (pues no serían magnitudes), contradiciendo la definición de continuo que ya ha sido alcanzada. ${ }^{46}$

\section{Francisco Suárez y los extremos como veras res}

Más allá de que Aristóteles mencione explícitamente la imposibilidad de que una línea se componga de puntos indivisibles, es claro que los puntos, en cuanto extremos de una línea, cumplen un papel muy importante en la interpretación aristotélica. En efecto, como se ha dicho, para el filósofo griego son continuas las cosas que tienen un extremo en común. Ahora bien, de la teoría del continuo de Aristóteles se sigue un interrogante que ha sido decisivo para la historia de su interpretación. En efecto, uno de los puntos de discusión relativo al problema de la composición del continuo entre los aristotélicos de la temprana filosofía moderna ha sido el del modo de existencia de dichos extremos, esto es, si existen como privación o positivamente. Libert Froidmont, cuyo pensamiento examinaremos en el apartado siguiente, se ha inclinado por la primera alternativa. Si bien considera que Aristóteles se ha decidido finalmente por considerarlos como privación, reconoce no obstante que su tratamiento da lugar a una variedad de interpretaciones. En efecto, el

\footnotetext{
${ }^{43}$ Aristóteles, Física, 231a26-30.

${ }^{44}$ No extenderemos en este punto en la tercera sección de este capítulo. Véanse fundamentalmente la nota 127, donde se observará la conexión con el desarrollo aquí presentado.

${ }^{45}$ Véase la cita referida en la nota 27. Como veremos más adelante en este capítulo, Libert Froidmont retoma este cuestionamiento de Aristóteles para justificar la imposibilidad de una composición atomista. Froidmont, 1631: 77.

${ }^{46}$ Aristóteles, Physika, 231b10-13.
} 
abordaje que ha hecho de los puntos, líneas y superficies en las Categorías puede sugerir que han de tomarse positivamente:

La línea es, en cambio, continua; es posible, en efecto, captar un límite común en el que las partes de ella se unen, [a saber,] el punto; y, de la superficie, la línea - pues las partes del plano se unen en un límite común-; de igual modo, también en el cuerpo podrías captar un límite común, [a saber,] o una línea o una superficie, en la que se unen las partes del cuerpo. ${ }^{47}$

No obstante, Froidmont considera que Aristóteles ha sido mucho más contundente a propósito de esta cuestión en otros escritos, como cuando en el De anima menciona que, “[p]or lo que se refiere al punto y, en general, a todo aquello que actúa como elemento divisorio siendo en sí indivisible, su intelección se realiza del mismo modo que la de la privación". ${ }^{48}$ Por eso, como se dijo, Froidmont concuerda con la que, a su parecer, es la correcta interpretación aristotélica. ${ }^{49}$ No obstante, esta manera de interpretar la concepción de Aristóteles no ha sido unánimemente aceptada. Otros, como Francisco Suárez, han entendido que el filósofo griego los ha tomado de manera positiva. ${ }^{50}$

El examen del problema del modo de existencia de los puntos por parte del Doctor Eximius es notablemente sutil, pero en algún sentido es también poco concluyente. En su análisis, Suárez comienza distinguiendo entre dos supuestas variedades de puntos indivisibles, a saber, en cuanto tomados como límites extremos de una línea o cuerpo (puncta terminantia) y en cuanto considerados como elementos que explican la continuidad de las partes (puncta continuantia). Si bien para el español no hay una diferencia real entre ellos (pues reconoce que la continuidad entre las partes se explica, al modo aristotélico, por tener un extremo en común), ${ }^{51}$ toma esta distinción dado que la variedad de interpretaciones posibles surge parcialmente de ella:

Por lo tanto, hay dos opiniones extremas: una que niega absolutamente que un punto, una línea y una superficie sean cosas positivas; otra que afirma simplemente que estas cosas son verdaderas [veras res], realmente distintas tanto entre sí como respecto del cuerpo y que existen no solamente en las extremidades de los cuerpos, sino también íntimamente en todo el cuerpo y

\footnotetext{
47 Aristóteles, Categorías, 5a1-14. Tomamos la traducción de Aristóteles, 2009. Los corchetes fueron introducidos por el traductor.

${ }^{48}$ Aristóteles, De anima, $430 \mathrm{~b} 20$ y ss. Tomamos la traducción de Aristóteles, 1978.

${ }^{49}$ Froidmont, 1631, 108.

${ }^{50}$ Suárez, Disp. XL, Sect. V, 553-554.

${ }^{51}$ Suárez, Disp. XL, Sect. V, 551.
} 
entre todas sus partes. Pero hay otras opiniones intermedias que de distintas maneras en parte [los] afirman y en parte [los] niegan. ${ }^{52}$

Para Suárez las posiciones intermedias son menos probables que las extremas, motivo por el cual la discusión se centra particularmente en estas últimas. ${ }^{53}$ No obstante, parecería que no encuentra razones concluyentes para justificar cuál de éstas es la correcta, pues “(...) las otras dos opiniones extremas están plagadas de dificultades”. ${ }^{4}$ Según esto, Suárez hace un balance de las razones a favor y en contra de negar o de afirmar los indivisibles como veras res. Sin demasiadas explicaciones, concluye que la negación se fundaría en inferencias difíciles de creer o que contienen inconveniencias. ${ }^{55} \mathrm{Sin}$ embargo, su afirmación tiene ciertas ventajas: por una parte, para Suárez es claro que ésta ha sido la posición de Aristóteles, así como de otros rigurosos filósofos, de la misma manera que es concordante con principios tanto de orden filosófico como geométrico. Según este criterio, el filósofo español sostiene que, "por eso, consideramos que ha de ser preferida la opinión común que afirma que se dan estos indivisibles tanto terminantia como continuantia en la cantidad". 56

Ahora bien, esta opción por una alternativa no resuelve todas las dificultades. Hay una particularmente relevante que consiste en examinar si debe decirse que los indivisibles están en acto o en potencia en el continuo. En este punto Suárez se aleja explícitamente de Aristóteles y de otros que afirman que solamente se dan en potencia para enseñar que han de tomarse en acto. ${ }^{57}$ No obstante, como las expresiones 'ser en acto' y 'ser en potencia' son locuciones muchas veces malinterpretadas, Suárez evalúa dos maneras de entenderlas y fundamentalmente de comprender la tensión que hay entre ellas. Por un lado, puede entenderse que la expresión 'en potencia' incluye la negación de la existencia actual.

\footnotetext{
${ }^{52}$ Suárez, Disp. XL, Sect. V, 553. "Duae ergo sunt extremae sententiae: una absolute negans, punctum, lineam et superficiem esse res positivas; alia simpliciter affirmans has esse veras res, et inter se et a corpore realiter distinctas, existentesque non tantum in extremitatibus corporum, sed etiam intime in toto corpore, et inter omnes partes eius. Aliae vero sunt opiniones mediae, quae variis modis partim affirmant, partim negant". ${ }^{53}$ Suárez, Disp. XL, Sect. V, 559. Suárez ha reconocido tres posiciones intermedias: la de aquellos que admiten indivisibles como términos aunque no como elementos que explican la continuidad de las partes; la de quienes admiten superficies indivisibles, aunque no puntos y líneas; y la de quienes admiten indivisibles únicamente en la superficie externa de un cuerpo, aunque no en el resto (es decir, internamente). Estas posiciones y las respectivas objeciones se encuentran en 554-559.

${ }^{54}$ Suárez, Disp. XL, Sect. V, 559. "Aliae vero duae opiniones extremae ambas sunt difficultatibus plenae".

${ }^{55}$ Suárez, Disp. XL, Sect. V, 559.

${ }^{56}$ Suárez, Disp. XL, Sect. V, 559. "Ideoque communem sententiam, quae affirmat dari haec indivisibilia, tum terminantia, tum continuantia, in quantitate, praeferendam censemus".

${ }^{57}$ Suárez, Disp. XL, Sect. V, 559.
} 
Precisamente de esta manera han entendido Aristóteles y muchos otros el modo de existencia de los indivisibles. No obstante, Suárez reconoce una inconsistencia en esta manera de verlo: si fuera imposible por definición que los indivisibles existan en acto, entonces su existencia sería siempre al modo de un ens rationis, esto es, serían entidades imaginadas $\mathrm{y}$, por lo tanto, en última instancia no se estarían afirmando como veras res, la cual era la hipótesis inicial. ${ }^{58}$ De aquí precisamente que Suárez haya distinguido un segundo modo en el que interpretar la expresión 'en potencia', a saber, el que dice negación no de la existencia sino de la división actual del continuo en los indivisibles. ${ }^{59}$ Según esta manera, los indivisibles terminantia y continuantia existen en acto, pero sin que esto signifique que el continuo está real y actualmente dividido en ellos: “(...) los puntos están en acto en el continuo, aunque están en potencia en otro sentido". ${ }^{60}$ Así, para Suárez se dice de los indivisibles lo mismo que se dice respecto de las partes del continuo en general, pues ellos no son otra cosa que los términos de las partes que explican su continuidad.

Por consiguiente, a partir de todas estas cosas parece manifestada y confirmada la opinión común, a saber, que los puntos, las líneas y las superficies son verdaderas entidades reales existentes en la magnitud o en los cuerpos, no solamente en las superficies externas o términos, sino también internamente entre todas las partes de la misma magnitud y entre todas sus dimensiones. ${ }^{61}$

\section{Continuo e infinito en Froidmont: Labyrinthus sive de compositione continui}

En los escritos en los que considera el problema del continuo, Leibniz recurrentemente remite a una obra en la que este laberinto es analizado de una manera muy rigurosa. Desde su juventud y hasta el final de su vida, y mediante expresiones tales como "véase el libro de Froidmont", Leibniz alude a la obra Labyrinthus sive de compositione continui (a la que nos referiremos como Labyrinthus). ${ }^{62} \mathrm{Su}$ autor, el teólogo belga Libert

\footnotetext{
${ }^{58}$ Suárez, Disp. XL, Sect. V, 559.

${ }^{59}$ Suárez, Disp. XL, Sect. V, 560-561.

${ }^{60}$ Suárez, Disp. XL, Sect. V, 561. “(...) sic puncta sint actu in continuo, etiamsi sint in potentia in alio sensu”.

61 Suárez, Disp. XL, Sect. V, 561. "Ex his ergo omnibus satis videtur declarata et confirmata communis sententia, nimirium, puncta, lineas et superficies esse veras entitates reales in magnitudinis vel in corporibus existentes, non tantum in externis superficiebus, seu terminis, sed etiam interne inter omnes partes ipsius magnitudinis, et inter omnes dimensiones eius".

${ }^{62}$ Así, por ejemplo, en una carta al duque Johann Friedrich de Hannover del 21 de mayo de 1671, A II 1, 111: "Cum ipsa motus Elementa, unde tamen omnis de his rebus ratiocinatio ducenda est, vix ac ne vix quidem nuperrime sint demonstrata, continui quoque compositio, sine qua intima mentis natura plene intelligi non
} 
Froidmont (1587-1653), amigo del padre Jansen de Port Royal, ${ }^{63}$ nació en Lieja y estudió en la universidad de Lovaina donde obtuvo su maîtrise en 1606, año desde el cual ejerció como profesor en la misma universidad, y donde se doctoró en teología en $1628 .{ }^{64}$ En general los escritos de Froidmont tratan sobre astronomía. ${ }^{65}$ No obstante, en su Labyrinthus de 1631 se propone hacer frente al atomismo que había encontrado una fuerte revitalización en la física del siglo XVII gracias, entre otros, a Pierre Gassendi y Jean Chrysostôme Magnen. ${ }^{66}$ Aunque propone algunas observaciones teológicas, ${ }^{67}$ la intención de Froidmont en esta obra es filosófica, pues se esfuerza por ofrecer un cuerpo conceptual y argumentativo que contribuya precisamente a mostrar lo incorrecto de la interpretación atomista del continuo. No sería de extrañar que la imagen del laberinto, utilizada por Leibniz para referirse no sólo al problema del continuo sino también al de la libertad, haya sido un préstamo conceptual del pensador flamenco. ${ }^{68}$

Cualquiera que, examinando el tratamiento leibniziano del continuo, llegue a abordar el pensamiento de Froidmont, está en deuda con el excelente examen llevado a cabo por Beeley en el capítulo 12 de su trabajo Kontinuität und Mechanismus. Zur Philosphie des jungen Leibniz in ihrem Ideengeschichtlichen Kontext (1996). En la reseña de la obra de Beeley que ha hecho R. Arthur, ${ }^{69}$ el autor señala que lo que movilizó a Beeley a dedicar buena parte de su libro a la obra de Froidmont fue una breve indicación que Leibniz realizó en el prefacio de la $T M A$ de 1671 al 'laberinto del continuo y el

potest, agnita ab omni aevo caligine (de quo videri potest elegans Lib. Fromondi liber, quem inscripsit Labyrinthum) mersa nunc aegre ad lucem aspiret". En este período temprano es común encontrar que Leibniz se refiera a este problema como un "laberinto", haciendo propia la expresión con la que Froidmont titula su trabajo. El teólogo lovaniense también es mencionado en el contexto de 1676: De arcanis sublimium vel de summa rerum, A VI 3, 475: "Evolvendus est quam rigorosissime omnis ille de compositione continui labyrinthus, videatur liber Fromondi (...)". No obstante, como se indicó, Leibniz se refiere a Froidmont incluso en su vejez, como por ejemplo en su Essais de Théodicée, GP VI, 65: "Libertus Fromondus, Théologien de Louvain (...) a aussi fait un livre expresès intitulé Labyrinthus de compositione continui, a bien expérimenté les difficultés de l'un et de l'autre".

${ }^{63}$ Essais de Théodicée, GP VI, 65, citado en Beeley, 1996: 287.

${ }^{64}$ Los datos biográficos son tomados de Pantin, 2001.

${ }^{65}$ Así, por ejemplo, Meteorologica o Meteorologicorum libri sex (Anvers, 1627) y Ant-Aristarchus sive orbisterrae immobilis (Anvers, 1634). Véase Pantin, 2001.

${ }^{66}$ De acuerdo con Magnen, el continuo se compone de un número finito de átomos interpretados como físicamente indivisibles e insensibles, aunque matemáticamente divisibles al infinito (Arthur, 2004, fundamentalmente el punto 3, "Leibniz and Chemical Atomism"). Sobre el pensamiento de Gassendi, véase la quinta sección de este capítulo.

${ }^{67}$ Froidmont, 1631, los primeros capítulos, fundamentalmente IV y V.

${ }^{68}$ Guilielmi Pacidii de rerum arcanis, A VI 3, 527.

${ }^{69}$ Arthur, Mercer, Smith, y Wilson, 1997: 27-28. 
movimiento', 70 aunque no obstante también indica que la primera vez que Leibniz explícitamente se refirió al libro de Froidmont tuvo lugar en el año 1676. No queremos dejar de señalar que Leibniz aludió explícitamente a la obra de Froidmont en el mismo año en que redactó la $T M A .^{71}$ El hecho de que Leibniz haya conocido el libro de Froidmont en este año deja abierta la posibilidad de que la influencia del teólogo lovaniense en Leibniz haya sido mucho mayor que la que hasta aquí se ha considerado.

La recurrente remisión por parte de Leibniz a la obra de Froidmont deja en evidencia que para el filósofo de Leipzig se trataba de un escrito valorado positivamente. No obstante, Leibniz no fue nunca lo suficientemente explícito sobre lo que particularmente estimó del escrito de Froidmont. En esta sección buscaremos sintetizar los lineamientos centrales de la obra de Froidmont que nos permitirán dejar en evidencia, en los capítulos siguientes, que hay puntos con los que el análisis leibniziano coincide. Veremos, en este sentido, que Leibniz no lo valoraba solamente por presentar un panorama general del problema del continuo, sino también por estar de acuerdo en algunas propuestas teóricas. Para cumplir con este objetivo, dividiremos el desarrollo del Labyrinthus en distintas partes. Aunque dicha obra formalmente consta de cincuenta capítulos, pueden distinguirse tres grandes bloques de acuerdo con los temas que se consideran: en el primero de ellos se delimitan las posiciones que históricamente se han dado sobre el laberinto del continuo; ${ }^{72}$ en el segundo se presenta una importante serie de argumentos que apuntan a demostrar que una composición del continuo de átomos finitos en número es contradictoria; ${ }^{73}$ en el último, finalmente, Froidmont intenta explicar, a partir de la disolución de los argumentos atomistas, su propia interpretación, precisando algunas nociones, como por ejemplo la de 'infinito', cuya falta de dilucidación ha sido la razón por la cual se ha generado toda la polémica relativa a la composición del continuo. ${ }^{74}$

\footnotetext{
${ }^{70} T M A$, A VI 2, 262. OFC, 8, 76.

${ }^{71}$ Véase la nota 62.

${ }_{73}^{72}$ Los primeros siete capítulos del Labyrinthus están dedicados a esta cuestión.

73 Dichos argumentos se presentan entre los capítulos 8 y 38. Se dividen, a su vez, en "argumentos geométricos" (capítulos 8-15) y "argumentos físicos" (capítulos 16-38).

${ }^{74}$ Esto corresponderá desde el capítulo 39 hasta el 50, que es el último.
} 


\section{1. 'Indivisibilistas' versus 'divisibilistas'}

El primer paso del examen de Froidmont es delimitar las dos maneras de abordar el problema de la composición del continuo que se han dado históricamente, a saber, una que entiende al continuo como divisible sin fin y otra como dividido en átomos:

En las escuelas de Filósofos ha sido célebre en otro tiempo, y lo es todavía ahora, el desacuerdo sobre las partes del continuo: habiéndolas estimado algunos divisibles sin fin, otros pusieron finalmente límites a toda división en ciertos átomos y partículas indivisibles, es decir, como dice Séneca, en migas. ${ }^{75}$

Esta indicación está vinculada con dos de las intenciones de la primera parte de su obra. Por un lado, Froidmont pretende reducir todos los tratamientos que se han dado a lo largo de la historia a uno u otro tipo de abordaje. Esto significa, consecuentemente, que los diversos pensadores de todas las épocas se pueden presentar o como 'indivisibilistas' (a saber, quienes defendieron átomos o en general partículas indivisibles) o como 'divisibilistas' (esto es, quienes entendieron que las partes son divisibles sin fin). Froidmont concibe al indivisibilismo que busca refutar en su libro como una postura que compone el continuo de un número finito de átomos. ${ }^{76}$ Esta concepción es una limitación de su análisis que luego será superada por Leibniz, como veremos en los capítulos siguientes. Por otro lado, para circunscribir la disputa relativa al continuo a aquellas dos posturas antitéticas, Froidmont aspira también a retrotraer estos abordajes a sus orígenes históricos. De acuerdo con esto, para él ni la postura divisibilista tiene sus verdaderas raíces en Aristóteles ni el atomismo en Epicuro: la primera remonta a la matemática de Pitágoras y Euclides, y la segunda fue inicialmente pronunciada por Leucipo. ${ }^{77}$

El examen del origen de la postura divisibilista llevado a cabo por Froidmont apunta inicialmente a vincular la negación del atomismo con el pensamiento matemático, fundamentalmente de Pitágoras y de Euclides. ${ }^{78}$ Como consecuencia de ello, no obstante, también apunta a justificar que puede constituirse un mismo frente anti-atomista compuesto, entre otros, por Aristóteles y por los miembros de la escuela platónica (gracias

\footnotetext{
${ }^{75}$ Froidmont, 1631: 1. "Celebre olim et nunc in Philosophorum scholis, de continui partibus dissidium fuit, aliis sine fine divisibiles eas existimantibus, ceteri in atomis quibusdam et individuis particulis, seu micis, ut Seneca appellat, omnem divisionem tandem finiebant".

${ }^{76}$ Beeley, 1996: 293-295.

${ }^{77}$ Froidmont, 1631: 1.

${ }^{78}$ Froidmont, 1631: 1-3.
} 
a Euclides), incluyendo a Platón mismo. Su intención es mostrar que esto revelaría un admirable consenso en lo que respecta a la crítica a una composición atomista y, consecuentemente, en la infinitud de partes del continuo. ${ }^{79}$ Dada la importancia histórica del platonismo, con esto Froidmont apunta a mostrar que los más grandes filósofos de todos los tiempos coinciden en su cuestionamiento del atomismo. De acuerdo con esto, en primer lugar Froidmont destaca que Pitágoras no fue atomista dado que concibió la composición de las figuras geométricas en términos no homogéneos, esto es, consideró que los cuerpos sólidos se generan a partir de superficies, éstas de líneas que se generan a partir de puntos y éstos de números. ${ }^{80}$ En segundo lugar, Froidmont recuerda que, de acuerdo con J. Kepler, "toda la Geometría de Euclides es Pitagórica", motivo por el cual Euclides tampoco fue atomista. ${ }^{81}$ Ahora bien, en tercer lugar justifica que Platón no fue atomista -a pesar de haber sido interpretado como defensor de una composición de indivisibles $-{ }^{82}$ señalando que Euclides perteneció a la Academia. Dada la conexión entre Euclides y la academia platónica, Froidmont articula una cadena desde Pitágoras, pasando por Platón, hasta Euclides, que en última instancia justifica que Platón no fue atomista: “[y] así, es segurísimo que ni Pitágoras, ni Platón han compuesto una magnitud de átomos". ${ }^{83}$

Con respecto, por su parte, al atomismo, cuyo origen atribuye a Leucipo, Froidmont también intenta agrupar a los indivisibilistas. Es muy sugestiva, en este sentido, la conexión que señala entre Leucipo y Zenón de Elea, como de discípulo y maestro. ${ }^{84}$ Froidmont cuenta, así, con una conexión histórica que justifica una intuición suya, a saber, la posibilidad de considerar las paradojas del filósofo de Elea en términos atomistas: "Zenón introdujo, en otro tiempo, cierto paralogismo a partir de la infinitud de partes del continuo (...), el más veloz nunca puede alcanzar a aquello que es llevado por un movimiento más

\footnotetext{
${ }^{79}$ Froidmont, 1631: 22.

${ }^{80}$ Froidmont, 1631: 2.

${ }^{81}$ Froidmont, 1631: 3. "Constat enim per se, tam ex Proclo interprete, ait alicubi Io. Keplerus, totam Euclidis Geometriam Pythagoricam esse".

${ }^{82}$ Para un desarrollo de la crítica aristotélica del continuo platónico, así como para la interpretación de Froidmont que indicaremos a continuación, véase Beeley, 1996: 288-293.

${ }^{83}$ Froidmont, 1631: 3. "Itaque compertissimum est, neque Pythagoram, neque Platonem composuisse magnitudinem ex atomis".

${ }^{84}$ Froidmont, 1631: 6-7.
} 
lento. (...) pero verdaderamente la misma demostración podría [darse] a partir de la finitud de átomos de Epicuro". ${ }^{85}$

A partir de estas consideraciones, Froidmont concluye que hay un " $[a]$ dmirable consenso entre todos los máximos ingenios de todo el género humano en la infinitud de partes del continuo". ${ }^{86}$ De allí que señale que, si se tratara de un asunto de autoridad, "San Agustín y toda aquella columna de Santos Padres, con las tres escuelas, de Tomistas, de Scotistas y de Nominalistas, y otros esparcidos fuera de ellas (...), las tres escuelas de Atenas, la Academia, el Liceo y la Stoa, sobresalen inmensamente a Epicuro, y, si se reunieran, lo derrotarían". ${ }^{87}$ Confiesa, sin embargo, que la autoridad no resuelve la cuestión. De este modo, ella debe dejar lugar a los argumentos.

\subsection{Ejemplos de argumentos geométricos contra el atomismo}

En el análisis de Froidmont se han puesto de manifiesto dos horizontes en los que se puede considerar el problema de los átomos, esto es, el geométrico y el físico. Precisamente por eso, Froidmont considera por separado los argumentos geométricos (esto es, los relativos a "la composición del continuo permanente") y físicos (los "del tiempo y el movimiento" ${ }^{88}$ contra el atomismo. A continuación presentaremos algunos de los argumentos geométricos propuestos por Froidmont, seleccionados por ser significativos tanto por ser ejemplares como en vistas a los desarrollos de Leibniz que se verán en el sexto capítulo. Por su parte, los argumentos físicos serán considerados en el capítulo quinto.

En el ámbito geométrico Froidmont se refiere a los átomos como 'puntos'. En este sentido, los argumentos geométricos aspiran a mostrar que las figuras geométricas en

\footnotetext{
${ }^{85}$ Froidmont, 1631: 57. " Zeno olim paralogismo quodam, ex infinitudine partium continui, intulit, (...), velocissimum numquam posse assequi id quod tardissimo fertur motu. (...) sed idem vera demonstratione poterat ex finitudine atomorum Epicuri".

${ }^{86}$ Froidmont, 1631: 22. "Admirabilis maximorum omnium totius humani generis ingeniorum consensus in infinitudine partium continui".

${ }^{87}$ Froidmont, 1631: 29. “(...) S. Augustinus, et tot illa SS. Patrum columina, cum tribus Thomistarum, Scotistarum, Nominalium scholis, aliisque extra eas spartim, par illud haereticorum, VVicleffum et Hussum, tres Athenarum scholae, Academia, Lyceum, Stoa, Epicurum immensum excedunt, et si componantur, oppriment".

${ }^{88}$ Froidmont, 1631: 29. "Et primum quidem compositionem continui permanentis, sive magnitudinis, deinde temporis et motus tractabimus".
} 
general no pueden componerse de puntos sin que se sigan contradicciones. ${ }^{89}$ Froidmont entiende por 'punto', en rasgos generales, una parte última absolutamente indivisible que carece a su vez de partes. ${ }^{90}$ Como veremos en el capítulo sexto, esta noción de punto se asemeja a la manera como Leibniz concibió los mínimos. Mediante sus argumentos, Froidmont pretende demostrar que "una magnitud no se compone en última instancia de meros puntos finitos". ${ }^{91}$ La sola consideración de los títulos de los argumentos geométricos revela que en todos ellos se pretende lo mismo. ${ }^{92}$ Así, por ejemplo, el primero de los argumentos sostiene que, si los círculos se componen de un número finito de puntos y supuestos dos círculos concéntricos, no sería posible trazar una línea recta desde un punto de la circunferencia del círculo mayor al centro.

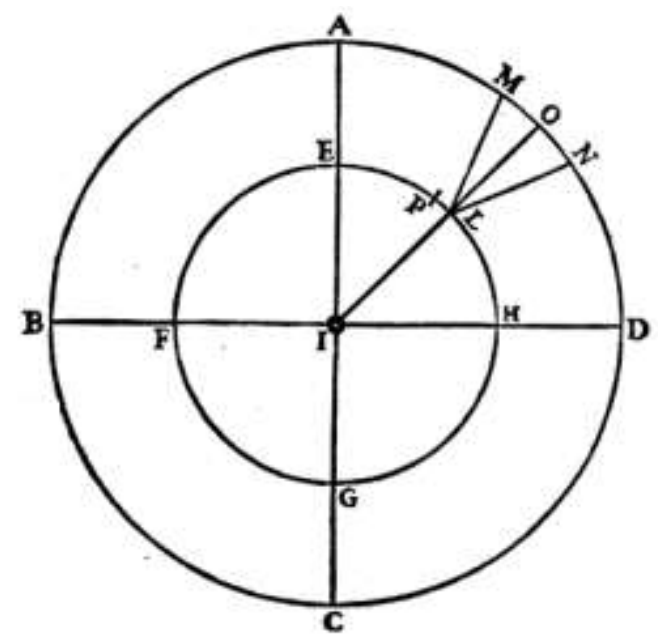

Según Froidmont, y de acuerdo a lo que enseñan los matemáticos, toda línea que se trace desde el diámetro del círculo mayor hacia el centro debe pasar por uno y sólo uno de los puntos del diámetro del círculo menor (como DHI en la imagen). A su vez, el círculo mayor, en tanto que es mayor, debe componerse de más puntos que el menor. En este sentido, supóngase que el segmento AD del círculo mayor se compone de 1000 puntos, mientras que el segmento correspondiente al círculo menor, EH, se compone de 500. Consecuentemente, si, desde cada uno de los 1000 puntos de AD, se puede trazar una línea

\footnotetext{
${ }^{89}$ Como atinadamente señala Beeley, 1996: 293-294, lo que buscará poner de manifiesto Froidmont es que la composición del continuo de mínimos es incompatible con la matemática.

${ }^{90}$ Froidmont, 1631: 40; 77, entre otros.

${ }^{91}$ Froidmont, 1631: 29. “(...) magnitudinem non componi ultimo ex solis punctis finitis".

${ }^{92}$ Así, el capítulo noveno: "Argumentum secundum Geometricum idem demonstrans" (Froidmont, 1631: 36); el capítulo décimo: "Argumentum tertium Geometricum idem demonstrans" (37); el onceavo: "Argumentum quartum Geometricum, quo Aristoteles idem demonstrat”(40), y así sucesivamente.
} 
recta hacia I pasando solamente por un punto de $\mathrm{EH}$, entonces los 500 puntos de $\mathrm{EH}$ serían iguales a los 1000 de AD. La contradicción es manifiesta: el todo sería igual a una parte. Por consiguiente, los círculos no se componen de un número finito de puntos. ${ }^{93}$ En la medida en que los siguientes argumentos intentan probar lo mismo, Froidmont entiende que éste es un esquema aplicable a propósito de otras figuras geométricas. Así, lo mismo sucede respecto de figuras rectilíneas. ${ }^{94}$ Consecuentemente, aquello que se concluya respecto de los círculos, en lo que respecta a la composición de puntos, vale igualmente para estas otras figuras. De este modo, ninguna magnitud geométrica se compone de puntos.

Froidmont apunta también a argumentar en contra del atomismo justificando que, bajo el supuesto de una composición de puntos, serían conmensurables un lado y la diagonal de un cuadrado. El teólogo flamenco se apoya aquí en la apócrifa proposición 117 del libro X de los Elementos de Euclides, así como en una conclusión presente en los Analíticos primeros de Aristóteles según la cual, supuesto que sean conmensurables, lo par se igualaría con lo impar. ${ }^{95}$ De acuerdo con Froidmont, el punto sería la medida común de la longitud de ambas líneas. ${ }^{96}$ Para justificar que esto acarrea contradicciones, traza un cuadrado compuesto de puntos finitos en número: $:^{97}$

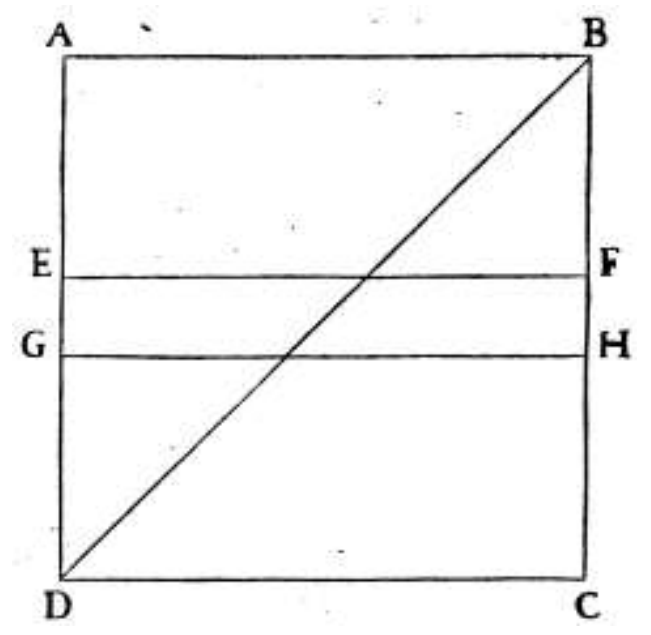

\footnotetext{
${ }^{93}$ Froidmont, 1631: 29-31.

${ }_{95}^{94}$ Esto lo explica en los capítulos X, XI y XII de Froidmont, 1631: 37 y siguientes.

95 Aristóteles, Prim. anal., 41a25-30. Las nociones de conmensurabilidad e inconmensurabilidad supuestas por Froidmont son las mismas presentes en las definiciones del décimo libro de los Elementos, esto es, dos magnitudes son 'conmensurables' si hay una medida común entre ellas, e 'inconmensurables' si no es posible que haya una tal medida. Euclides, Elementa, Lib. X, def. 1(1996: 9).

${ }^{96}$ Froidmont, 1631: 40.

${ }^{97}$ Froidmont, 1631: 43-44.
} 
En siguiente lugar, Froidmont traza todas las líneas rectas que puedan hacerse desde los puntos de un lado hacia los correspondientes del otro, como EF y GH. Se obtiene, así, una correspondencia biunívoca entre los lados $\mathrm{AD}$ y $\mathrm{BC}$, de manera tal que toda el área correspondiente al cuadrado ha quedado cubierta por las líneas rectas. Éstas, asimismo, deben necesariamente atravesar la diagonal BD.

Ahora bien, la manera como dos líneas (EF y GH) interceptan la diagonal puede interpretarse de dos modos: o bien la atraviesan en dos puntos próximos, esto es, tales que no haya nada entre ellos, o bien la interceptan de manera tal que permanece en la diagonal un punto sin ser tocado. ${ }^{98} \mathrm{Si}$ se considera la primera de las opciones, debería concluirse que la diagonal es igual a cualquiera de sus lados, lo cual es absurdo. ${ }^{99}$ De la segunda alternativa, no obstante, se sigue que la diagonal sería el doble que cualquiera de los lados (pues por cada punto atravesado permanece uno intacto). Sin embargo, Froidmont subraya que, si se le asignaran valores numéricos a la diagonal y al lado, se seguirían contradicciones. En efecto, entiende que si el lado es $\frac{1}{2}$ de la diagonal, entonces esta relación debería mantenerse independientemente de los números con los que se asignen las longitudes de las líneas. De esta manera, le asigna el número 3 al lado y 4 a la diagonal. ${ }^{100}$ Como consecuencia, los números deberían comportar la misma proporción que los cuadrados de las líneas. ${ }^{101}$ Así, determínense los respectivos cuadrados de 3 y 4, esto es, 9 y 16. El problema es manifiesto: como consecuencia de la relación entre el lado y la diagonal, la mitad de 16, 8, sería igual a 9, esto es, lo par sería igual a lo impar. ${ }^{102}$ Es claro, contra el supuesto, que la relación entre los cuadrados de estos números no es la de $\frac{1}{2} .{ }^{103}$ Se sigue entonces que las líneas no son longitudinalmente conmensurables. Dado que esto solamente era concebible bajo el supuesto de una composición atomista, la imposibilidad de la primera conlleva la de la segunda.

\footnotetext{
${ }^{98}$ La argumentación se desarrolla en Froidmont, 1631: 44. Véase también Beeley, 1996: 295-297.

${ }^{99}$ Froidmont, 1631: 44.

${ }^{100}$ En este caso la unidad sería la parte alícuota. Froidmont, 1631: 42-43.

${ }^{101}$ Véase la nota anterior y Froidmont, 1631: 41.

${ }^{102}$ Froidmont, 1631: 42.

${ }^{103}$ Froidmont, 1631: 42.
} 


\subsection{La división infinita del continuo según una ratio constante}

El intento de Froidmont de desarticular el atomismo tiene, como contracara, la necesidad de establecer precisiones respecto de la manera de entender la tesis divisibilista. Froidmont se esfuerza notablemente por esclarecer la naturaleza del continuo y, en particular, del concepto de infinito implicado. En este sentido, reconoce que todas las dificultades que dan lugar al laberinto provienen de su desconocimiento:

Además, toda la dificultad de nuestro pensamiento proviene de la ignorancia de la esencia del infinito. En efecto, éste obstruye nuestro intelecto por la multitud de sus partes. De otra manera, si observáramos claramente su naturaleza y todas sus condiciones, se resolvería y desaparecería toda la perplejidad que nos rodea. $^{104}$

En su esfuerzo por clarificar la esencia del infinito, Froidmont se distancia de varios planteos propios del pensamiento de Aristóteles y de los escolásticos. Uno de ellos atañe a la pregunta por la posibilidad de que se dé un infinito mayor que otro. La concepción estándar del aristotelismo, que era común entre los escolásticos, sostenía que, como el infinito es potencial, formalmente un infinito es siempre igual a otro. ${ }^{105}$ Para Froidmont, en cambio, puede darse un infinito mayor que otro. No obstante, su planteo, como se justificará en lo sucesivo, se distancia también de la tesis aristotélica según la cual el número de partes actuales en el continuo es finito. Esta conclusión supone, por cierto, que se ha demostrado la imposibilidad de una composición atomista, es decir, de un número finito de puntos, tal como se ha mostrado en el apartado anterior de este capítulo. En efecto, la tesis de Froidmont de que hay infinitos mayores que otros tiene lugar una vez que se ha concluido precisamente que el número de partes en el continuo no puede ser finito en términos atomistas. Para demostrar y ejemplificar estas conclusiones, propone trazar dos líneas que tengan los mismos puntos extremos, una curva, $\mathrm{ABC}$ (es decir, un semicírculo), y una recta, $\mathrm{AC}$ (es decir, un diámetro): ${ }^{106}$

\footnotetext{
${ }^{104}$ Froidmont, 1631: 171: "Porro tota difficultas nostrae imaginationis ex ignorantia rei infinitae provenit: haec enim partium suarum multitudine intellectum nostrum obruit. alias si naturam eius et omnes conditiones clare cerneremus, illico tota quae nos circumvenit perplexitas solveretur et evanesceret". Seguimos la interpretación de Beeley, 1996: 305, al traducir 'esencia del infinito'.

${ }^{105}$ Beeley, 1996: 295.

${ }^{106}$ El ejemplo se encuentra en Froidmont, 1631: 36-37.
} 


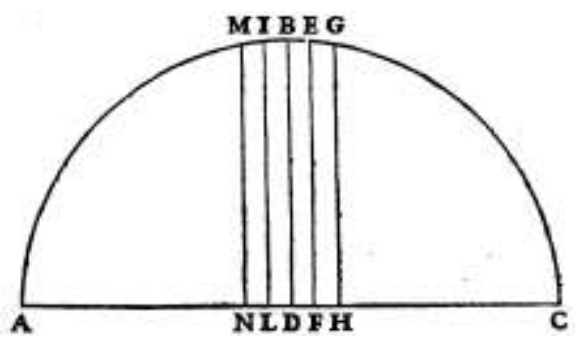

A continuación traza desde los puntos del semicírculo a los del diámetro todas las líneas rectas que puedan trazarse, como $\mathrm{MN}, \mathrm{IL}, \mathrm{BD}, \mathrm{EF}, \mathrm{GH}$, etc. Si las dos líneas que poseen los mismos puntos extremos, $\mathrm{ABC}$ y $\mathrm{AC}$, se compusieran de un número finito de partes, entonces, en virtud de la correspondencia biunívoca que puede establecerse entre los puntos de ambas líneas, debería concluirse con necesidad que ellas constan de la misma cantidad. ${ }^{107}$ No obstante, el número de partes del semicírculo debería ser evidentemente mayor que el del diámetro. Froidmont reconoció, así, que el número de partes no puede ser finito sino que debe ser necesariamente infinito. Ahora bien, del mismo modo, por extrapolación, reconoció el número infinito de partes en el semicírculo debe ser necesariamente mayor que el del diámetro:

Mas en la opinión de Aristóteles y de los Matemáticos alcanza con que en el diámetro los puntos o partes sean infinitos, aunque en la circunferencia del semicírculo se hallen más; lo cierto es que nada prohíbe que un infinito sea mayor que otro. Del mismo modo, en el número infinito de hombres posibles son infinitas no solamente las unidades sino también las centenas, aunque las unidades sean más que las centenas. ${ }^{108}$

El ejemplo de Froidmont es claro: en el número infinito de hombres posibles, son infinitos tanto los individuos como las colecciones de cien hombres; no obstante, el infinito de los individuos es mayor que el de las centenas, dado que una colección de hombres abarca una multitud de individuos. Dicho de otra manera, si por cada centena hay cien individuos, el número infinito de individuos es cien veces mayor que el número infinito de centenas. Para Froidmont, en síntesis, las líneas se componen de un número infinito de partes, aunque el número infinito de ellas en una línea sea mayor que en la otra. Con esto, incluso, lleva su abordaje del concepto de infinito más allá, permitiéndose afirmar que cada

\footnotetext{
${ }^{107}$ Froidmont, 1631: 36.

${ }^{108}$ Froidmont, 1631: 37. "In sententia vero Aristotelis et Mathematicorum, sufficit in diametro puncta, aut partes infinitas esse, licet in circumferentia semicirculi plures inveniantur: unum quippe infinitum alio maius esse nihil vetat; quemadmodum in numero hominum possibilium infinito, non tantum unitates, sed centenaris intiniti sunt, etsi unitates, quam centenaris, plures sint".
} 
parte de la línea posee una infinitud de partes menores. Dice Froidmont, como una notable síntesis de su planteo:

Pensemos, por lo tanto (...) que en un número infinito de partes del continuo se contienen no solamente infinitas unidades sino también infinitas centenas o millares (y cualquier número finito que tomes). (...) Puesto que en cualquier parte del continuo existen otras infinitas partículas menores y que cada una comprende infinitas unidades de otras partes, etc., es evidente, por consiguiente, que en cualquier parte existen otras infinitas partículas infinitésimas. Todas estas cosas se siguen muy cierta y evidentemente supuesta aquella admirable infinitud de partes. Finalmente, en un número infinito no puede asumirse ninguna unidad que no respondan a ella infinitas centenas, infinitos millares. Pues de otro modo, como se ha dicho antes, todo número de unidades sería finito. ${ }^{109}$

Evidentemente la tesis según la cual en el continuo hay un número infinito de partes no está exenta de problemas. Uno de ellos, particularmente importante y estrechamente ligado al mencionado anteriormente, consiste en explicar por qué una infinitud de partes no implica como consecuencia una magnitud infinita. Este planteo, que no es nuevo de la modernidad filosófica, se encontraba no obstante bastante difundido fundamentalmente entre los críticos del atomismo. Froidmont recuerda, en este sentido, un argumento de Gregorio de Rimini (ca. 1300-1358) ${ }^{110}$ quien, retomando la opinión de Juan Mayor, sostiene que una magnitud compuesta de infinitos puntos que se siguen próximamente, será infinita según la extensión:

Sin embargo, Gregorio Ariminense recuerda esta opinión (...) y refiere que una magnitud compuesta de puros puntos infinitos que se siguen próximamente, será infinita según la extensión: lo que de facto supongo que es falso. La consecuencia es manifiesta: pues tendría en sí partes recíprocamente iguales según la magnitud, infinitas en multitud (...) puesto que en una multitud infinita

\footnotetext{
${ }^{109}$ Froidmont, 1631: 171. "Cogitemus ergo (...) in numero partium continui infinito, non tantum infinitas unitates, sed centenarios, millenarios (et quemcumque finitum numerum capies) contineri infinitos. (...). Patet, quia in qualibet parte continui sunt aliae particulae minores infinitae, et singulae comprehendunt infinitas aliarum partium unitates, etc. igitur in quavis parte sunt particulae aliae infinities infinitae. Quae omnia certissimo et evidenter sequuntur posita illa admirabili partium infinitudine. Denique in numero infinito nulla potest sumi unitas, quin ei infiniti respodeant centenaris, infiniti millenaris. nam alias, ut ante dictum est, totus numerus unitatum esset finitus. Hac numeri infiniti quamvis nebulosa cogitatione instructis scintilla fortassis aliqua allucebit, qua allucinantes saltem et morose non paullatim ex hoc labyrintho extrahamus".

${ }^{110}$ Teólogo agustiniano que cumplió un gran papel en la trasmisión del pensamiento de Oxford en París. En lo que respecta al problema del continuo, sintéticamente, consideró que lo continuo se compone de infinitas partes extensas que se superponen (es decir, no se disponen contiguamente una al lado de la otra). Véase Zupko, 2002: 283-290.
} 
de indivisibles serán infinitos los cuaternarios y cualquier cuaternario será de igual magnitud que cualquier otro cuaternario. Esta razón, si se sopesa bien, es sin duda óptima. ${ }^{111}$

Sin duda este problema se evade parcialmente negando que las magnitudes se compongan de puntos. No debe olvidarse que, como se ha dicho, el atomismo considerado por Froidmont es aquel que sostiene partículas indivisibles finitas en número y que los puntos indivisibles ocuparían una extensión. ${ }^{112}$ Para Froidmont (así como también para Leibniz, como veremos en el cuarto capítulo) puede sostenerse una infinitud de partes no puntuales o mínimas sin que se siga una magnitud infinita. La clave para que un número infinito de partes no puntuales no sea contradictorio es llevar adelante una revisión del concepto de infinito. Como hemos visto anteriormente, para Froidmont en última instancia es nuestra ignorancia de este concepto lo que lleva a inconsistencias. El teólogo de Lovaina reconoce, ciertamente, que la objeción anterior no necesariamente contradice la afirmación de un número infinito de partes, con la condición de que no se las entienda como recíprocamente iguales en extensión:

Y no se enfrenta a la opinión de Aristóteles (como quizá alguien podría pensar), puesto que aunque introduce infinitas partes y quizá infinitos indivisibles continuados continuamente, sin embargo, no admite extensiones iguales entre sí infinitas en número. ${ }^{113}$

La revisión del concepto de infinito llevada a cabo por Froidmont conduce a reconocer que su planteo es estructuralmente distinto del atomista. El atomismo supone que una magnitud resulta del encadenamiento de un número de partes mínimas que, como tales, son iguales entre sí (y precisamente por ello es que la objeción de Gregorio de Rimini recae

\footnotetext{
${ }^{111}$ Froidmont, 1631: 98. "Huius tamen ante eum opinionis meminit Gregorius Ariminensis, et refellit: quia magnitudo ex puris punctis se proxime sequentibus infinitis composita, esset infinita secundum extensionem: quod de facto suppono esse falsum. Consequentia patet: nam haberet in se partes invicem aequales secundum magnitudinem, infinitas multitudine (utpote infinitas partes, quarum quaelibet esse ex quatuor indivisibilibus, vel decem indivisibilibus constituta:) quoniam in infinita multitudine indivisibilium essent infiniti quaternaris, et quilibet quaternarius esset cuilibet alis quaternario aequalis magnitudinis. Quae ratio, si bene perpendatur, est sane optima".

112 Más adelante en su obra considerará y criticará una composición a partir de indivisibles no-extensos. Si bien esto, el objetivo central de su obra es, como decíamos, un atomismo finitista que supone los indivisibles como extensos. Sobre esta cuestión puede verse Palmerino, 2011, punto 2. "Isomorphism of Space, Time and Matter: An Historical Account".

${ }^{113}$ Froidmont, 1631: 98. "Nec militat (quod quis forte existimare possit) contra sententiam Aristotelis: quia etsi partes infinitas, et fortassis indivisibilia continuantia infinita continuo inferciat, nullas tamen extensiones inter se aequales, numero infinitas admittit". Sobre la mención de los 'infinitos indivisibles', téngase presente lo mencionado en la nota 112 .
} 
sobre esta interpretación). Froidmont, por su lado, pone inicialmente el acento en la división de la que devienen las partes, de tal manera que se explique que ellas no son iguales unas con otras. De este modo, su análisis del infinito se encuentra, en este punto, relacionado con la manera en que entiende la división del continuo. Hay dos condiciones fundamentales con las que Froidmont piensa el infinito. De acuerdo con su clara postura anti-atomista, aunque mediante la división se obtengan partes cada vez más pequeñas, nunca se deberían alcanzar dos que sean iguales. En este sentido, dice:

Y así, toda la dificultad (o por lo menos la máxima) que nuestro intelecto experimenta al reducir infinitas partes dentro de términos finitos proviene de que se divida una cantidad en partes iguales o de una extensión visible. ${ }^{114}$

De esta manera, las partes del continuo nunca serían iguales entre sí, y por lo tanto ninguna sería atómica en este sentido. Como consecuencia de esto (y como segunda condición), Froidmont debe pensar un modelo con el cual representar una división infinita que no alcance aquellos últimos términos iguales entre sí. Un modelo de este tipo se encuentra si se procede dividiendo siempre de acuerdo a una misma ratio. Por ejemplo, dividiendo primero una magnitud cualquiera al medio, luego en una cuarta parte y así sucesivamente. La división, en este caso, se hace siempre bajo la razón de $\frac{1}{2}$, de modo que avanzando en ella, se obtendrían siempre partes proporcionalmente menores que las anteriores, pero sin llegar nunca a una que no admita una nueva subdivisión. De acuerdo con esto, indica Froidmont:

Verdaderamente, ya que se asumen partes proporcionales de tal modo que lo siguiente siempre sea dos veces menor que lo precedente, aquella infinitud no avanzará con pasos iguales o mayores, sino menores, y descenderá hacia lo mínimo pero no ascenderá a lo máximo. ${ }^{115}$

De acuerdo con esa proporción, y siguiendo las palabras de Froidmont, por división se obtienen partes proporcionales que descienden hacia lo mínimo, pero sin que el continuo se resuelva en partes mínimas. Si esto sucediera, como en el caso de la división atomista,

\footnotetext{
${ }^{114}$ Froidmont, 1631: 152: "Itaque tota, aut maxima saltem difficultas, quam intellectus noster experitur in redigendo infinitas partes intra terminos finitos, ex eo provenit, quod quantitatem in partes aequales, aut notabilis extensionis concidat: infinitas enim illas particularum minutias, quia imaginatio eum sequi non potest, vix concipit".

${ }^{115}$ Froidmont, 1631: 151-152. "iam vero, cum partes proportionales eiusmodi sumantur, ut sequens semper sit duplo minor praecedente, infinitudo illa non passibus aequis, aut maioribus, sed minoribus progreditur, ac versus minimum descendit, non ascendit versus maximum".
} 
las magnitudes compuestas serían infinitamente extensas. ${ }^{116}$ Por eso mismo, podría decirse que desciende 'hacia lo pequeño'. La división del continuo tal como la propone Froidmont, descendente según una ratio constante (entendida en un sentido matemático), conlleva la admisión de un infinito que, sin embargo, explica la división de una magnitud finita en infinitas partes que por eso mismo pueden ser comprendidas dentro de límites o términos finitos. $^{117}$

La propuesta de Froidmont está en desacuerdo, como se dijo, con la tesis aristotélica según la cual un infinito no puede ser mayor que otro. La división según una razón constante justifica, a su vez, cómo entender infinitas partes sin que se siga una extensión infinita. Así, Froidmont justifica, como se ha dicho, su desacuerdo respecto de la interpretación de Aristóteles según la cual el continuo, aunque pueda dividirse en un número infinito de partes, en acto está dividido en un número finito. Para Froidmont la división explica infinitas partes actualmente divididas según una razón constante o proporcional. Dicho de otra manera, para el teólogo de Lovaina en el continuo hay en acto tantas partes como partes proporcionales se puedan designar en él, esto es, no finitas en número sino infinitas. Así, si se dividiera una magnitud de acuerdo a la razón de $\frac{1}{2}$, no sólo estaría dividida ahora en dos mitades sino en infinitas partes que conservan, respecto de la anterior, la misma razón. De este modo, una magnitud se divide en infinitas partes proporcionales que, sumadas, dan lugar al todo. Si se quisiera expresar esto aritméticamente, debería decirse que, si la razón tomada es la de $\frac{1}{2}$, entonces $1=\frac{1}{2}+\frac{1}{4}+$ $\frac{1}{8}+$ etc., donde ' 1 ' es el todo, cada término respeta la misma razón respecto del anterior y el 'etc.' significa 'al infinito'. Como señala C. R. Palmerino respecto de Froidmont, “[m]ás bien, él argumenta que el espacio, el tiempo y la materia son divisibles en una infinidad actual de partes proportionales, procediendo hacia magnitudes incluso más pequeñas como $1,1 / 2,1 / 4$ y así sucesivamente". 118

\footnotetext{
${ }^{116}$ Froidmont, 1631: 151.

${ }^{117}$ Froidmont, 1631: 152.

${ }^{118}$ Palmerino, 2011: 32: "The author of the Labyrinthus was however not willing to endorse Aristotle's claim that these parts were finite in act and infinite in potency. Rather, he argued that space, time, and matter were divisible into an actual infinity of partes proportionales, proceeding towards ever smaller magnitudes as $1,1 / 2$, $1 / 4$, and so on".
} 


\section{INTERPRETACIONES ATOMISTAS DEL CONTINUO}

\section{La oposición finito-divisible e infinito-indivisible de Galileo}

El más completo y profundo análisis galileano del problema del continuo tiene lugar en su última obra escrita, Discorsi e dimostrazioni matematiche, intorno a due nuove scienze publicada en el año 1638. Como el título de este trabajo sugiere, la investigación de Galileo apunta a examinar argumentos y problemas relativos a dos nuevas ciencias, a saber, la de la resistencia de los materiales y la de los movimientos locales. ${ }^{119}$ Este escrito, redactado en forma de diálogo, se divide en una serie de episodios o jornadas, en el primero de los cuales tiene lugar un examen, entre otras cuestiones, sobre el problema del continuo, los indivisibles y el vacío. ${ }^{120} \mathrm{Al}$ igual que el resto de la obra, el tratamiento galileano de este problema guarda un fuerte acento crítico en relación con el pensamiento aristotélico. Un ejemplo es, como se ha mencionado en el primer capítulo, el cuestionamiento a los planteos físicos de Aristóteles por falta de experimentaciones que sustenten sus afirmaciones. Por esto Simplicio, el interlocutor aristotélico en el diálogo, cumple un papel muy importante en las discusiones del escrito. En el análisis de la composición del continuo, la situación no es distinta: Galileo ofrece una interpretación del continuo que es de principio a fin una alternativa a la aristotélica. En este apartado mostraremos cómo interpreta Galileo la composición del continuo a partir de la disolución de la tesis aristotélica.

La nueva manera de entender el continuo por parte de Galileo, esencialmente distinta de la de Aristóteles, encuentra no obstante su punto de partida precisamente en una tesis aristotélica. En efecto, examinando el concepto de infinito potencial que es nuclear en el abordaje de Aristóteles, Galileo reconoce ciertos inconvenientes. Recordemos que para Aristóteles el modo de ser del infinito es en potencia, mientras que en acto solamente puede encontrarse en el continuo un número finito de partes. Por esto, para el filósofo griego no hay un infinito que pueda ser actualizado. Ahora bien, cuando Galileo examina la concepción aristotélica del continuo, reconoce que esta conclusión lleva a inconsistencias

\footnotetext{
119 Solis Santos, 2007: 219-220.

${ }^{120}$ Sobre la estructura de esta obra, tanto de las partes que finalmente vieron la luz como de aquellas que lamentablemente no la han visto, véase Giusti, 2001, punto "La estructura de los discursos".
} 
en algunos casos. Si se toma una línea cualquiera, que como tal es infinitamente divisible, y se la pliega en cuatro (formando así un cuadrado), tendremos efectivamente que de las infinitas partes potenciales solamente cuatro han sido actualizadas. Lo mismo puede decirse cuando la línea se pliega no en cuatro sino ocho, mil, diez o cien mil partes, esto es, en un número finito cualquiera, formando un polígono de tantos lados como se haya doblado la línea. ${ }^{121}$ Pero Galileo propone un caso más, a saber, que se pliegue la línea de tal modo que se forme un polígono de infinitos lados o, lo que para él es lo mismo, un círculo. En este caso, las partes actualizadas ya no responderían a un número finito. Al igual que en los casos anteriores, aquí debería decirse que en el polígono infinitángulo están en acto las infinitas partes que en la línea estaban en potencia. ${ }^{122}$ Para Galileo, en síntesis, el problema de la interpretación aristotélica es que eventualmente no puede evitar una composición de infinitas partes que, como veremos a continuación, no implican una contradicción en la medida en que se entiendan como indivisibles:

(...) al admitir que la línea y todo continuo son divisibles en partes siempre divisibles, no veo cómo se podrá eludir el que su composición conste de infinitos indivisibles, porque una división y subdivisión que pueda proseguir perpetuamente, supone que las partes son infinitas, ya que de otro modo la subdivisión tendría un límite. ${ }^{123}$

No obstante, debe notarse que en su argumentación Galileo no responde a la noción aristotélica de infinito que hemos explicado anteriormente en este capítulo. Por una parte, es claro que en su argumentación no toma al infinito como lo que está siendo siempre algo distinto. Además, por otra parte, en el corpus aristotélico puede hallarse un examen de la posibilidad o imposibilidad de entender la división del continuo precisamente en los términos sugeridos por Galileo. Esto se encuentra en el De generatione et corruptione cuando Aristóteles analiza la manera como los atomistas comprendieron la generación y la corrupción de los cuerpos, a saber, por asociación o disociación de partículas atómicas. ${ }^{124}$ Aristóteles reconoce que para alcanzar dichos corpúsculos sería necesario que una magnitud sea totalmente divisible y además que dicha división sea posible. Esto último

\footnotetext{
${ }^{121}$ EN, VIII, 92.

${ }^{122}$ EN, VIII, 92. Jullien, 2015c: 94.

${ }^{123}$ EN, VIII, 80. “(...) che stante che la linea ed ogni continuo sian divisibili in sempre divisibili, non veggo come si possa sfuggire, la composizione essere di infiniti indivisibili, perchè una divisione e subdivisione che si possa proseguir perpetuamente, suppone che le parti siano infinite, perchè altramente la subdivisione sarebbe terminabile". Tomamos las traducciones de esta obra de Galilei, 2003: 63-64.

${ }^{124}$ Aristóteles, De generatione et corruptione, 315a32-35 y 315b7-15.
} 
significa, en efecto, que pueda ser actualizada, de modo que una magnitud esté dividida en acto, podría decirse, 'en todas partes'. ${ }^{125}$ Aristóteles reconoce, sin embargo, que la argumentación atomista comporta un serio problema. Ciertamente no es absurdo que un cuerpo sensible sea divisible en cualquier punto (entendiéndolo en el sentido explicado en la primera sección de este capítulo, esto es, como extremo o contacto); no obstante, sí lo sería que el cuerpo fuese divisible simultáneamente y en su totalidad, pues en dicho caso el cuerpo estaría dividido en acto en puntos, ${ }^{126}$ lo que, como vimos antes, para Aristóteles es absurdo. ${ }^{127}$ A pesar de esto, hay una diferencia entre el atomismo que considera el filósofo griego en su argumentación, que es físico, y el de Galileo, que es geométrico. ${ }^{128}$ Lo relevante en esta cuestión es que el modo como Galileo entendió la concepción aristotélica del continuo, aunque quizás haya sido incorrecta, determinó el modo como él mismo abordó el problema del infinito, es decir, pensando la actualización simultánea de las infinitas partes del continuo. La tensión aristotélica entre acto y potencia, en lo que respecta al infinito, pierde sentido en tanto que se considera que puede actualizarse no solamente un

\footnotetext{
${ }^{125}$ Aristóteles, De generatione et corruptione, 316a15-23.

${ }^{126}$ Aristóteles, De generatione et corruptione, 316b18-28. En efecto, allí menciona: "Pero, ya que debemos intentar resolver estos problemas, es preciso reformular la dificultad desde su origen. No es, en absoluto, absurdo que todo cuerpo sensible sea divisible en cualquier punto e indivisible: será, en efecto, divisible en potencia e indivisible en acto. Pero parecería imposible que el cuerpo fuese en potencia divisible simultáneamente y en su totalidad. Pues, si esto fuera posible, la división podría efectivamente llevarse a cabo, con la consecuencia de que el cuerpo no sería en acto simultáneamente indivisible y dividido, sino dividido en el punto en que se quiera. Mas, entonces, no restará nada, el cuerpo se disolverá en la incorporeidad y, nuevamente, se constituirá a partir de puntos o de nada en absoluto. ¿Y cómo es esto posible?". Tomamos la traducción de Aristóteles, 1987.

${ }^{127}$ Véanse las notas 42 y 43. También, Aristóteles, De generatione et corruptione, 317a2-17. Coincidimos, en este sentido, con la interpretación de White, 2002: 16-17, quien señala: "Cabe señalar que este argumento es simplemente un argumento en contra de que se resuelva una magnitud en puntos. Sobre la presuposición (...) de que las 'cosas' que están tocándose o que son contiguas, cuyo 'contacto' es un punto, no pueden ser ellas puntos, el argumento no depende de la ordenación no-sucesiva o no-discreta de los puntos en una magnitud. Los puntos tienen que ser puntos de cosas que no son ellas mismas puntos". La traducción es nuestra. De allí que White (en la página 19 del mismo trabajo) extraiga como un principio de Aristóteles que "Para cada punto $p$ anterior al punto medio $m$, hay una cantidad finita positiva $e$ tal que la distancia entre $p$ y $m$ es al menos $e$ ". Esta cuestión es también analizada por Hasper, 2006, y Charlton, 2003.

${ }^{128}$ Véase el pasaje citado en la nota 141. A lo largo de su vida Galileo ha sostenido siempre una interpretación atomista, aunque ha ido cambiando la manera de entender precisamente los átomos. De acuerdo con lo que explica Solis Santos, 2007, pueden distinguirse tres momentos atomistas en la vida de Galileo: el primero, entre 1611 y 1615, en el cual el científico italiano sostuvo un atomismo físico 'clásico' de átomos extensos (y vacíos igualmente 'extensos'); el segundo, entre 1615 y 1623, en el cual sostuvo un 'atomismo mixto', en la medida en que mantiene los átomos extensos en la física, pero comienza a hablar de átomos indivisibles en la geometría; finalmente, entre 1626 y 1648 (incluida la obra de 1638 que aquí tenemos en cuenta), Galileo sostuvo un atomismo geométrico incluso aplicado a la física. Shea, 2001: 267-268, sugiere que Galileo pudo haber adoptado la tesis atomista en Padua, donde era aprobada por una buena tradición de averroístas como A. Nifo y J. Zabarella.
} 
número finito de partes sino también uno infinito. ${ }^{129}$ En esto, el planteo de Galileo es sintomático de una época en que la tesis de la infinitud actual de partes del continuo estuvo bastante extendida. ${ }^{130}$

La afirmación de una composición de infinitos indivisibles lleva al científico italiano a tener que dilucidar cómo han de ser entendidos dichos indivisibles. En efecto, entendió inmediatamente que la afirmación de una infinitud de indivisibles, si éstos no son entendidos correctamente, puede llevar a una extensión infinita (siguiendo, por ejemplo, el argumento de Gregorio de Rimini que hemos presentado en la tercera sección). Galileo reconoce este problema, pero también que puede ser fácilmente evitado: basta con darse cuenta de que los indivisibles no tienen cantidad. Para Galileo se sigue como consecuencia inmediata del hecho de que las partes sean infinitas el que ellas no puedan tener cantidad: "y el que sean infinitas las partes, entraña como consecuencia el que no tengan cantidad [non quante], porque infinitas partes que tengan cantidad [quante] determinarían una extensión infinita". 131 "Y por lo tanto -concluye el autor- el continuo está compuesto de infinitos indivisibles". ${ }^{132}$

Puede observarse, a partir de lo anterior, que para Galileo hay una notable diferencia entre lo finito y lo infinito que no es puramente numérica. ${ }^{133}$ Por un lado, ellos difieren también en cuanto a la naturaleza de las partes dadas en número finito o infinito. En este sentido, siempre que nos refiramos a un número finito cualquiera de partes o lados

\footnotetext{
${ }^{129}$ Shea, 2001: 270 .

${ }^{130}$ Como hemos visto, incluso Froidmont entendió que se dan en acto todas las partes proporcionales que puedan darse, y por lo tanto infinitas. Leibniz mismo, al entender que en el continuo hay infinitas partes en acto (como veremos en el capítulo siguiente), entiende una actualidad simultánea de la multitud de partes (aunque, más allá de esta coincidencia, el modo de entender el infinito es diferente del de Galileo, como veremos en los capítulos 4 y 6). En consonancia con lo que aquí se ha dicho, señala Sellés García 2006: 114: "En la concepción euclídeo-aristotélica, el todo es anterior a sus partes. Estas partes nunca llegan a ser últimas: la magnitud continua es divisible en partes siempre divisibles. Por el contrario, dentro del espíritu mecanicista, sea atomista o plenista, del siglo XVII, los todos resultan de la agregación de sus partes - las partes son anteriores al todo- $y$, en definitiva, las magnitudes finitas que se presentan a nuestros sentidos - o a nuestra consideración matemática— son composiciones o resultados de sus elementos integrantes".

${ }^{131} \mathrm{EN}, \mathrm{VIII}, 80$. 'e 1' esser le parti infinite si tira in consequenza l' esser non quante, perchè quanti infiniti fanno un'estensione infinita”. Traducción: Galilei, 2003: 64, aunque hemos introducido modificaciones que se justifican en que allí se traduce respectivamente quanta y non quanta como 'extenso' e 'inextenso'. Como bien explica Knobloch, 1999, esto no es correcto, pues no son sinónimos. Por esta razón optamos hacer uso de expresiones como 'carentes de cantidad' o similares y aclarar entre paréntesis el concepto al que nos referimos.

${ }^{132}$ EN, VIII, 80. “e così abbiamo il continuo composto d'infiniti indivisibili”. Galilei, 2003: 64.

${ }^{133}$ En líneas generales seguimos la presentación de Knobloch, 1999. Levey, 2015, en general coincide con el examen de Knobloch, pero también presenta algunas diferencias, como veremos en la nota 135.
} 
(como en los polígonos, exceptuado el de infinitos lados), debemos consecuentemente tomarlos como poseyendo una cantidad (quanti) y como divisibles. Sin embargo, cuando nos refiramos a un número infinito de lados (como en los círculos o polígonos infinitángulos), debemos reconocer que la única manera de evitar las contradicciones antes señaladas es tomándolos no como poseyendo una cantidad y siendo divisibles sino como carentes de cantidad (non quanti) y como indivisibles. ${ }^{134}$ En este sentido, el número infinito de lados no se equipara con ningún número finito, por más grande que éste sea, así como tampoco se equiparan -en cuanto a su naturaleza- las partes que se dan en número finito con las que se dan infinitamente. ${ }^{135}$ Ahora bien, en el caso de los polígonos con un número finito de partes extensas, esto no significa que el número finito de ellas esté determinado. Si así lo fuera, sería imposible formar un polígono de un número finito de lados mayor que el determinado, lo que es absurdo. Bajo el supuesto de que las partes consideradas son extensas, el número de ellas no podría ser infinito (precisamente porque son extensas), pero tampoco habría un número finito determinado que las comprenda. De acuerdo con esto, Galileo señala que no son ni finitas ni infinitas sino tantas que corresponden a cada número dado: "para esto [que no sean ni finitas ni infinitas] es necesario que no estén comprendidas dentro de ningún número limitado, porque no corresponderían a uno mayor; pero tampoco es necesario que sean infinitas, porque ningún número asignado es infinito". ${ }^{136}$ Cuando Leibniz lee en 1672 la obra de Galileo, se refiere a esta interpretación como una composición 'indefinida' del continuo. ${ }^{137}$

\footnotetext{
${ }^{134}$ EN, VIII, 95.

${ }^{135}$ Knobloch, 1999: 88-94, ha atendido especialmente a estas nociones en virtud de tres criterios, a saber, mensurabilidad (lo quanti puede ser tomado como unidad de medida, lo non quanti no), calculabilidad (lo non quanti no puede ser sumado, precisamente por no ser una cantidad) y comparabilidad (como lo non quanti carece de las propiedades de lo mensurable (a diferencia de lo quanti), no puede ser comparado). Ahora bien, Levey, 2015, especialmente p. 162 y 165-172, entiende que Knobloch estaría considerando que tanto lo infinito como lo indivisible pertenecen al género o dominio de lo non quanti. No obstante, el examen de Knobloch no parecería orientarse en la dirección sugerida por Levey. Más bien, la intención de Knobloch parecería ser, siguiendo a Galileo, la de establecer un paralelismo entre considerar un número finito de lados (quanti y divisibles) y un número infinito de ellos (non quanti e indivisibles).

${ }^{136}$ EN, VIII, 81. "per il che fare é necessario che elle non siano comprese dentro a un limitato numero, perchè non risponderebbono ad un maggiore; ma nè anco è necessario che elle siano infinite, perchè niuno assegnato numero è infinito". Traducción: Galilei, 2003: 65-66. Modificamos ligeramente la traducción. Previamente había mencionado: "sì che, domandato, nel presente proposito, se le parti quante nel continuo siano finite o infinite, la più congrua risposta sia il dire, non esser né finite né infinite, ma tante che rispondono ad ogni segnato numero". Véanse también Sellés García, 2001: 446; 2006: 115-116 y Solis Santos, 2007: 224.

${ }^{137}$ Aus und zu Galileis Discorsi, A VI 3, 168. Levey, 2015: 183.
} 
Como hemos visto, la crítica galileana a la composición aristotélica del continuo parte de reconocer que una división que puede seguir perpetuamente no puede eludir una composición de infinitos indivisibles. Ahora bien, la manera como Galileo aborda la cuestión podría sugerir que los indivisibles se alcanzan mediante una división constante de lo que es divisible, esto es, llevando a cabo una tras otra todas las divisiones que puedan hacerse. De esta manera, realizada la última división, ya no se tendrían partes quanti y divisibles sino otras que, por su propia naturaleza, serían non quanti e indivisibles. Es claro, como hemos visto, que ninguna variante del aristotelismo admite esta última división. No obstante, es esencial al planteo galileano el hecho de que, dada la diferencia entre lo finito y lo infinito, tampoco sea admisible la tesis según la cual la división final es producto de una cadena de divisiones sucesivas. En efecto, para Galileo no se llega jamás a la división final que resuelve el continuo en indivisibles mediante la división en un número progresivamente mayor de partes. ${ }^{138}$ Como se ha dicho, ningún número finito asignable, por más grande que sea, se equipara con uno infinito. Dado que la divisibilidad es algo definitorio de lo quanti, no alcanzaría la eternidad para dividir hasta llegar a lo non quanti. ${ }^{139}$ Precisamente por esto, no es concebible el paso de lo divisible a lo indivisible como un proceso gradual. La distinción entre lo finito y lo infinito lo lleva a notar, consecuentemente, que la división de la que resultan partes finitas en número no es en absoluto idéntica a aquella de la que resultan infinitas. De esta manera, para alcanzar los indivisibles es preciso una suerte de quiebre en la división, un proceso distinto o, como dice Galileo, una metamorfosis. ${ }^{140}$ Así como a un número finito de partes se llega por una división finita, así el continuo se resuelve en infinitas partes 'de un solo golpe':

Pero haciendo uso del método que yo propongo, para separar y resolver toda la infinitud de un solo golpe (recurso que no debería negárseme), me parece que ellos [los peripatéticos] deberían conformarse y admitir que el continuo está compuesto de átomos absolutamente indivisibles, máxime siendo éste, quizá entre todos, el camino más apto para salir de intrincadísimos laberintos (...). ${ }^{141}$

\footnotetext{
${ }^{138} \mathrm{EN}, \mathrm{VIII}, 92-93$.

139 EN, VIII, 82.

${ }^{140} \mathrm{EN}, \mathrm{VIII}, 85$.

${ }^{141}$ EN, VIII, 93. "ma servendosi della maniera che propongo io, di distinguere e risolvere tutta la infinità in un tratto solo (artifizio che non mi dovrebbe esser negato), crederei che dovessero quietarsi, ed ammetter questa composizione del continuo di atomi assolutamente indivisibili, e massime essendo questa una strada forse più d'ogni altra corrente per trarci fuori di molto intrigati laberinti (...)”. Traducción: Galilei, 2003 : 79.
} 
Tenemos, por lo tanto, que en última instancia el continuo se compone de infinitos indivisibles. Como atinadamente señaló M. Sellés García, uno de los grandes interrogantes que toda interpretación que sostiene infinitos indivisibles debe responder corresponde a la manera como deben disponerse dichas partes para que den lugar a una extensión. ${ }^{142}$ Una aproximación en esta dirección, aunque quizás insuficiente, ${ }^{143}$ se halla en el tratamiento galileano de la paradoja de los círculos concéntricos que el pseudo-Aristóteles presentó en la vigesimocuarta de las cuestiones de la Mecánica ${ }^{144}$ La presentación galileana de la paradoja puede resumirse de este modo: ${ }^{145}$ supónganse dos círculos concéntricos como B (el menor) y C (el mayor) en la imagen.

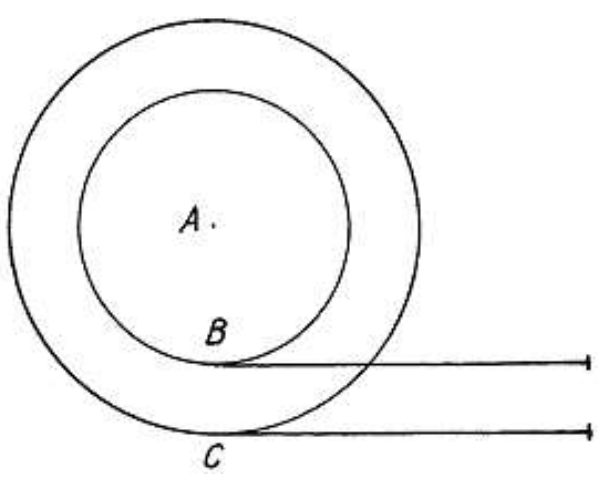

Supóngase, en siguiente lugar, que el círculo mayor $\mathrm{C}$ se mueve a lo largo de una línea recta que es idéntica al trazado producido por su revolución completa y que el círculo menor B se mueve solidariamente. Cuando el círculo mayor C complete la revolución y alcance consecuentemente el otro extremo de la línea recta, el círculo menor B habría recorrido el mismo trayecto en el mismo tiempo. No obstante, si se moviera el círculo menor B con independencia del movimiento del otro círculo, la línea recta resultante del trazado producido por su revolución completa, y que por eso mismo recorrería al cabo de dicha revolución, sería menor que la del círculo mayor C. La paradoja, entonces, se observa cuando se atiende a que en el primer caso el círculo menor B habría recorrido una línea igual a la de la circunferencia del círculo mayor $\mathrm{C}$, mientras que en el segundo caso

\footnotetext{
${ }^{142}$ Sellés García, 2006: 119.

${ }^{143}$ Coincidimos nuevamente con Sellés García, 2006: 120 y siguientes. Diremos algo más al respecto en la nota 147.

${ }^{144}$ Aristóteles, Mecánica, 855a28-856a39. La cuestión es: "No se sabe por qué el círculo mayor da la vuelta en una línea igual que el círculo menor cuando son concéntricos". Tomamos la traducción de Aristóteles y Euclides, 2000.

${ }^{145}$ Galileo desarrolla su examen en EN, VIII, 68-72. En líneas generales seguimos las presentaciones de Knobloch, 1999, y Sellés García, 2006.
} 
recorrería una menor pero que es igual a su propia circunferencia. En la medida en que entiende a los círculos como polígonos infinitángulos, ${ }^{146}$ en la búsqueda de una solución Galileo transforma la paradoja de los círculos en una paradoja de polígonos. Inicialmente, considera el problema analizando dos polígonos concéntricos cuyos lados son numéricamente finitos:

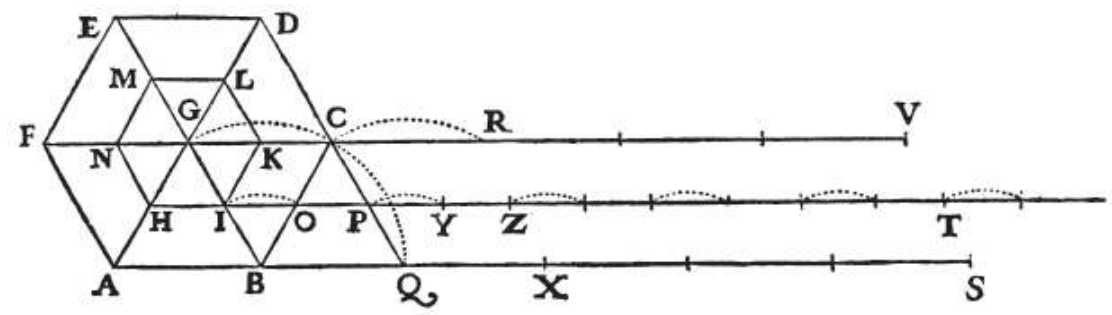

La estrategia de Galileo apunta a mostrar que la manera como se resuelva la paradoja a propósito del hexágono de la imagen sería la misma que como se resuelva para cualquier polígono, esto es, sea de un número finito de lados muy grande, como un polígono de cien mil lados, o de un número infinito de ellos. De esta manera, cuando el hexágono mayor gire, inicialmente la parte BC recaería sobre la sección BQ de la línea AS, luego de lo cual la parte CD recaería sobre QX y así sucesivamente hasta completar la revolución. Si el polígono menor se moviera independientemente del mayor, sucedería algo análogo. Ahora bien, si su movimiento es solidario con el del polígono mayor, lo que sucedería es que el lado IK no recaería sobre la sección IO de la línea HT correspondiente, sino sobre OP, de la misma manera que posteriormente KL no recaería sobre PY sino sobre YZ y así sucesivamente. De esta manera, pueden reconocerse en la línea recorrida por el polígono menor, en el movimiento que acompaña al polígono mayor, algunas secciones vacías (como IO, PY, etc.) y otras que no lo son (como OP, YZ, etc.). Como se ha dicho, la situación es la misma si el polígono considerado tiene cualquier otro número finito de lados o bien si tiene infinitos, esto es, si es un círculo:

(...) en los círculos (que son polígonos de infinitos lados) la línea recorrida por los infinitos lados del circulo grande, dispuestos consecutivamente, es igual en longitud a la recorrida por los infinitos lados del menor, pero en este último caso, con la interposición de otros tantos espacios vacíos entre esos lados; y así

\footnotetext{
${ }^{146}$ Véase la cita de la nota 147.
} 
como los lados no son cuantificables, sino infinitos, así también los vacíos interpuestos no son cuantificables, sino infinitos. ${ }^{147}$

Consecuentemente, el trayecto del círculo menor estaría compuesto de un número infinito de indivisibles y de un número también infinito de vacíos. La única diferencia respecto del caso de polígonos de un número finito de lados es que en dicha situación los vacíos interpuestos serían asignables (como también los lados), lo que no sucede tratándose de círculos (pues el infinito, como se ha dicho, no se equipara con ningún número asignable).

Es claro, por lo tanto, que la diferenciación entre el ámbito de lo finito y de lo infinito asumida por Galileo tiene importantes repercusiones en su teoría del continuo. Pero el campo de las consecuencias que se siguen de allí incluso excede el dominio en el que se incluyen estos 'intrincadísimos laberintos'. A continuación señalaremos una consecuencia que se sigue de aquí y que, como veremos, fue particularmente importante para Leibniz (al menos como punto de discusión). Se trata de un resultado que se sigue necesariamente de un aspecto más en el que se diferencian lo finito y lo infinito. Por este motivo, en primer lugar señalaremos en qué consiste esta nueva diferencia entre ellos que supone el examen de Galileo y luego la consecuencia. En efecto, el científico italiano reconoce que entre lo finito y lo infinito hay también una disimilitud desde el punto de vista del alcance cognoscitivo humano, pues mientras que la mente humana es capaz de entender lo finito y de reconocer cuando una magnitud finita es mayor que otra, no lo es respecto de lo infinito. "Pero no debemos olvidar -señala Galileo- que se trata de infinitos e indivisibles, unos y otros incomprensibles para nuestro entendimiento, aquéllos por grandeza, y éstos, por su

\footnotetext{
${ }^{147}$ EN, VIII, 71. “(...) ne i cerchi (che son poligoni di lati infiniti) la linea passata da gl' infiniti lati del cerchio grande, continuamente disposti, esser pareggiata in lunghezza dalla linea passata da gl' infiniti lati del minore, ma da questi con l' interposizion d' altrettanti vacui tra essi; e sì come i lati non son quanti, ma bene infiniti, così gl' interposti vacui non son quanti, ma infiniti”. Traducción: Galilei, 2003: 53. Modificamos ligeramente la traducción allí donde introducimos "cuantificables" (en lugar de "finitos en número") para traducir lo que en el original es quanti. Seguimos en esto la traducción de Sellés García, 2006: 121. En consonancia con lo que hemos dicho anteriormente (véase la nota 143), dice este intérprete (nota 19, página 123): "En ningún momento Galileo clarifica el modo de disposición de los puntos para formar el continuo. Si este silencio ante una conocida objeción a las teorías indivisibilistas escondía o no un problema de fundamentos, es algo que parece que no se puede dilucidar. Está claro que sus puntos no podían estar en contacto, pero tampoco separados por espacios extensos de tal modo que entre dos puntos sucesivos se pudiese tender una línea. Como se cuida de especificar, dichos espacios son inextensos y, además, no admiten razón entre sí, es decir, no son mayores, ni menores, ni iguales. Son tan indeterminados como el número de puntos que componen un segmento dado. En todo caso, el conjunto de puntos que componen el segmento es un conjunto denso, no numerable, pues corresponde a un infinito actual".
} 
pequeñez". ${ }^{148}$ La incomprensión de lo infinito, debida a la limitación del entendimiento humano, debe llevar a reconocer, para Galileo, que hay propiedades asignables a lo finito que no pueden ser extrapoladas a lo infinito. Particularmente importante, en este sentido, son las propiedades de 'ser mayor que', 'ser menor que' y 'ser igual a'. Estos atributos, comprensibles en lo finito, son inconvenientemente asignados a lo infinito. ${ }^{149}$ Dicho de otra manera, dada la naturaleza de lo infinito y la imposibilidad de asirlo con el pensamiento, no es posible determinar que un infinito sea mayor que otro ni, por la misma razón, que un infinito sea mayor que algo finito. ${ }^{150}$ Análogamente, como se ha dicho, lo indivisible es debido a su pequeñez inaprehensible para el entendimiento finito humano. En este sentido, así como no se alcanza lo infinito por una mera adición de cantidades finitas, tampoco se resuelve hasta lo indivisible dividiendo una cantidad divisible.

Como se ha dicho, hay una importante consecuencia que se sigue de esta tesis galileana. Es evidente, de acuerdo con las propiedades asignables a lo finito que no deben ser extrapoladas a lo infinito, que el axioma de Euclides según el cual "el todo es mayor que una parte" ${ }^{\prime 151}$ posee un ámbito restringido de aplicación. Analicemos el siguiente procedimiento teniendo en cuenta los presupuestos de Galileo: tómense dos conjuntos de números tales que uno de ellos sea a su vez un subconjunto del otro, por ejemplo, el conjunto de los números naturales y el de los números cuadrados (véase la imagen a continuación). Es claro, nuevamente, que los números cuadrados son un subconjunto de los naturales. Es evidente que, como forman un subconjunto, los números cuadrados son una parte de los números naturales. Sin embargo, como puede obtenerse el cuadrado de cualquier número natural, llevados los números al infinito, debería concluirse que hay tantos cuadrados como números naturales: ${ }^{152}$

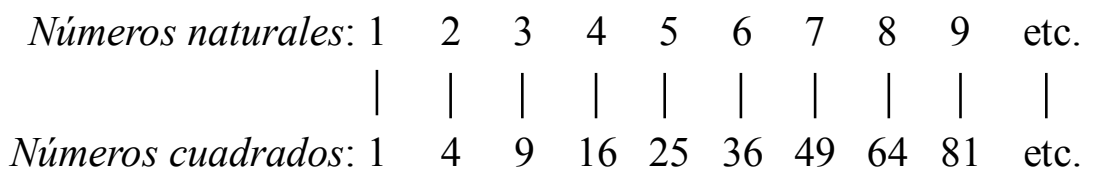

\footnotetext{
${ }^{148} \mathrm{EN}$, VIII, 73. “ma ricordiamoci che siamo tra gl'infiniti e gl'indivisibili, quelli incomprensibili dal nostro intelletto finito per la lor grandezza, e questi per la lor piccolezza". Traducción: Galilei, 2003: 55.

${ }^{149} \mathrm{EN}, \mathrm{VIII}, 77-78$.

${ }^{150}$ EN, VIII, 79.

${ }^{151}$ Euclides, Elementa, Lib. I, Noc. com. 8, (1991: 201).

${ }^{152}$ EN VIII, 78-79. Véase Sellés García, 2006: 123-127 y Levey, 2015: 158-160.
} 
Por lo tanto, el todo (el conjunto de los números naturales) sería igual a una parte (el de los cuadrados). Si no tuviéramos en cuenta los presupuestos del examen de Galileo, deberíamos concluir que este procedimiento contradice el axioma de Euclides según el cual el todo es mayor que una parte. De esta manera, parecería que no sería posible llevar los números al infinito, o mejor dicho, que no sería posible el número infinito de todos los números naturales. Ahora bien, si el infinito no admite las propiedades antes mencionadas, los números infinitos que expresarían el conjunto de los números naturales y el subconjunto de los cuadrados estarían fuera del alcance del axioma. ${ }^{153}$ Por eso, para Galileo el razonamiento anterior no tiene razón de ser. Como el axioma no vale en lo infinito, se sigue por un lado que el número infinito de todas las unidades no es contradictorio $\mathrm{y}$, por otro lado, que le es esencial a dicho número el hecho de estar por fuera del alcance del axioma. De allí que el número infinito deba cumplir con un requisito: en él, el todo debe ser igual a la parte, esto es, debe contener en sí tantos números naturales como cuadrados, cubos o cualquiera otra potencia. Ya que, tratándose de números finitos, este requisito solamente se cumple en el número 1 (pues cualquier potencia de este número es igual a sí), Galileo equipara el número infinito de todas las unidades con la unidad. ${ }^{154}$ Como veremos en el capítulo sexto, Leibniz discute intensamente esta conclusión de Galileo. Más aún, como en última instancia ésta es una consecuencia necesaria de la manera como el científico italiano entiende el concepto de infinito y el problema del continuo en general, la discusión de Leibniz se revela como un signo de que su manera de abordar estos 'intrincadísimos laberintos' es radicalmente distinta.

\section{EI 'método de los indivisibles' de Cavalieri}

Como veremos especialmente en el sexto capítulo, Galileo ha generado un fuerte impacto en Leibniz. No obstante, el ámbito de influencia del científico florentino ha sido mucho mayor. Por ejemplo, uno de sus más destacados seguidores ha sido el matemático italiano Bonaventura Cavalieri (1598-1647). El 'método de los indivisibles' que ha presentado en su trabajo Geometria indivisibilibus continuorum quadam nova ratione

\footnotetext{
${ }^{153}$ Como el infinito no es conmensurable, no sólo un infinito no puede ser mayor que otro sino que técnicamente tampoco puede decirse que es mayor que lo finito. EN VIII, 79.

${ }^{154}$ EN VIII, 83.
} 
promota, publicado en 1635 , ha sido muy influyente en el pensamiento del siglo XVII. Como veremos en el cuarto capítulo, algunos estudiosos del pensamiento de Leibniz consideran que en algún momento de su desarrollo intelectual él habría tomado la idea de una 'composición de indivisibles' de la obra de Cavalieri. Por la importancia que ha tenido para Leibniz, en esta sección nos limitaremos a abordar sintéticamente las ideas fundamentales del método de Cavalieri que más adelante nos permitirán discutir esta interpretación.

A finales del siglo XVI, la geometría se consolidó como una de las ramas de la investigación matemática más influyentes. Dentro de los problemas considerados por esta disciplina, tuvieron un papel importante las investigaciones de Arquímedes sobre el cálculo de áreas y volúmenes de las figuras geométricas, así como también, y en consecuencia, el método de exhaución. No obstante, este método fue insuficiente para los matemáticos del siglo XVII. ${ }^{155}$ Por esta razón, Cavalieri intentó proveer un procedimiento para cuadrar figuras, es decir, para hallar una razón entre dos figuras planas dadas. ${ }^{156}$ De acuerdo con el método, la obtención de esta razón no se conseguiría mediante una consideración directa de las figuras mismas sino de los 'indivisibles', esto es, la colección de líneas de dichas figuras. La determinación de la razón exacta que hay entre dos figuras, es decir, la cuadratura, se sirve del concepto de omnes lineae, esto es, de 'todas las líneas' (entendidas conjuntamente como una colección). ${ }^{157}$ En efecto, uno de los teoremas más importantes sobre los que se sostiene la propuesta metodológica de Cavalieri es precisamente que la razón entre dos figuras es igual a la razón entre sus respectivas colecciones de líneas, esto es, que dadas dos figuras cualesquiera 'Fig.' y 'Fig.2', $\frac{\text { Fig.1 }}{\text { Fig.2 }}=\frac{\text { colección de líneas de Fig.1 }}{\text { colección de líneas de Fig.2 }}{ }^{158}$ Ahora bien, para el funcionamiento del método, Cavalieri ha presentado una regla, que históricamente ha pasado a ser conocida como el 'principio de Cavalieri', que, dada su complejidad, descompondremos en una serie de enunciados acompañados del ejemplo que el mismo matemático italiano presenta. En primer lugar, tómense dos figuras planas que

\footnotetext{
${ }^{155}$ Andersen, Giusti y Jullien, 2015: 33-34. En el séptimo capítulo abordaremos los lineamientos centrales de este procedimiento.

${ }^{156}$ Andersen, 1986: 18 y 1985: 299. El método también proveía el procedimiento para hallar no sólo un cuadrado de igual área que una superficie dada sino también un cubo, dependiendo del caso.

${ }^{157}$ Seguimos la sugerencia de Andersen de referirnos a los indivisibles como 'colección' para acentuar que deben considerarse como una totalidad, esto es, unitariamente.

${ }^{158}$ Andersen, 1985: 302.
} 
tengan la misma altura, como CAM y CME en la imagen: ${ }^{159}$

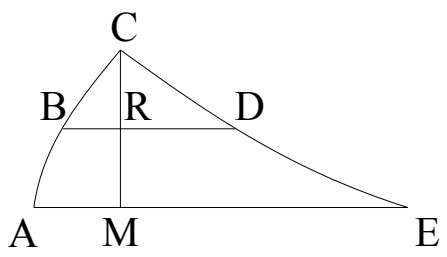

A continuación trácense, en estas figuras, líneas rectas que entre sí sean paralelas y conserven siempre la misma diferencia de altura, como AE y BD. Se obtendrían, de acuerdo con lo anterior, diversas secciones o porciones de las líneas trazadas que interceptarían a las figuras planas antes mencionadas, como AM y ME en relación con la línea $\mathrm{AE}$ y $\mathrm{BR}$ y $\mathrm{RD}$ en relación con la línea $\mathrm{BD}$. Cavalieri sostuvo que la figura CAM es a la figura CME como AM a ME o BR a RD (es decir, $\left.\frac{C A M}{C M E}=\frac{A M}{M E}\right) .{ }^{160}$ Dicho de otra manera, si las líneas correspondientes a cada figura, pensadas siempre en una correspondencia biunívoca, estuvieran en una misma razón, entonces las dos figuras serían también magnitudes proporcionales de acuerdo con esa misma razón. ${ }^{161} \mathrm{Si}$ en todas las líneas que se tracen paralelas a $\mathrm{AE}$ y $\mathrm{BD}$ que mantengan las mismas condiciones antes descritas se mantiene la misma razón, estamos en condiciones de decir que la colección de líneas de dichas figuras están en la misma razón que las figuras mismas. Como ha quedado en evidencia, las líneas $\mathrm{AE}$ y BD trazadas en las figuras, así como las colecciones de líneas, son esenciales para el método de Cavalieri. Como él ha denominado a dichas líneas como 'indivisibles', el método ha sido bautizado como 'método de los indivisibles'.

Como la obra de Cavalieri apunta a presentar un procedimiento geométrico, deja sin responder una multiplicidad de interrogantes que no tienen específicamente que ver con el carácter procedimental del método sino, por ejemplo, con cuestiones ontológicas. Aquellas que están relacionadas con el problema del continuo son evidentemente relevantes para nuestro examen, a saber, por ejemplo: ¿cómo se obtienen los indivisibles de una figura? O bien, ¿una figura se compone de indivisibles? Como se observa, son cuestiones relacionadas más con la teoría del método que con el método mismo. El primero de estos interrogantes tiene importancia precisamente desde el instante en que para Cavalieri la

\footnotetext{
159 Tomamos la imagen de Cavalieri, 1653: 115. El ejemplo presentado se encuentra en 115-116.

${ }^{160}$ Andersen 1985: 316.

${ }^{161}$ Cavalieri, 1653: 115.
} 
colección de líneas de una figura no se obtiene mediante su división. ${ }^{162}$ Para obtener todas las líneas de una figura dada, debe procederse de este modo: en primer lugar, dada una figura como BAC, deben trazarse dos tangentes (esto es, líneas que toquen a la figura en sus extremos) que sean paralelas entre sí, como EO y BC en la imagen adjunta: ${ }^{163}$

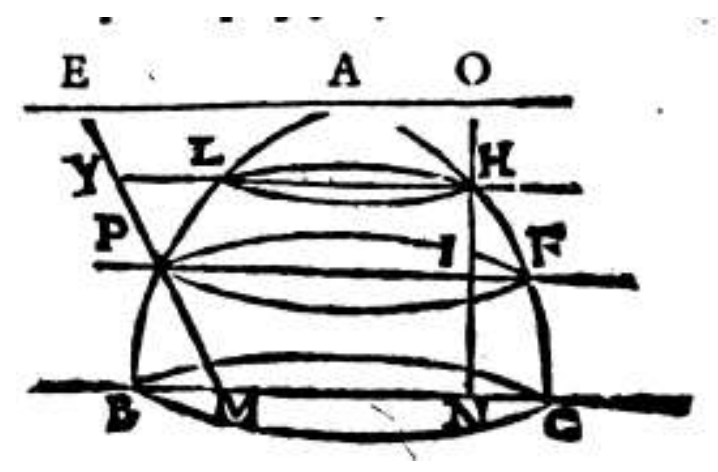

En siguiente lugar, muévase una de las tangentes asumidas (como EO) hacia la otra (es decir, BC), permaneciendo siempre paralela, hasta el punto de coincidir con ella. Se obtiene, en consecuencia, que durante su movimiento se ha producido un gran número de líneas rectas que resultan de la intersección entre la línea que se mueve y la figura dada, como por ejemplo LK y PF. Estas líneas consideradas conjuntamente son llamadas "todas las líneas", esto es, "omnes lineae" de la figura, tomando una de estas líneas como regla. ${ }^{164}$ Quizás podría decirse que la colección de líneas de una figura dada es el conjunto de 'cortes' posibles en ella. Las líneas indivisibles de una figura dada no se obtienen, así, por medio de la división de la figura correspondiente sino de un procedimiento que incluye el movimiento de una línea extrema hacia otra siguiendo una tercera como regla.

La cuestión de si para Cavalieri los indivisibles, esto es, omnes lineae de una figura, componen precisamente a la figura, fue apenas considerado en su trabajo. El hecho de que la colección de líneas de una figura no se obtenga por división permitiría inferir que la figura no es la suma de dichas líneas. Sin embargo, como la preocupación de Cavalieri fue esencialmente matemática, su aproximación a este problema filosófico fue escasa y vaga. ${ }^{165}$

\footnotetext{
162 Andersen, 1986: 18-19.

${ }^{163}$ La imagen se puede encontrar en Cavalieri, 1653: 105.

${ }^{164}$ Cavalieri, 1653: 99. "Si per oppositas tangentes cuiuscunque datae planae figurae ducantur duo plana invicem parallela, recta, sive inclinata ad planum datae figurae, hinc inde indefinite producta; quorum alterum moveatur versus reliquum eidem Semper aequidistans donec illi congruerit: singulae rectae lineae, quae in toto motu fiunt comunes sectiones plani moti, \& datae figurae, simul collectae vocentur: Omnes lineae talis figurae, sumptae regula una earundem".

${ }^{165}$ Andersen, 1985: 306-308. Allí se mencionan algunas cartas entre Cavalieri y Galileo de diversos años en las que se evidencia que Cavalieri no tiene una posición clara asumida respecto del laberinto del continuo.
} 
Sea como fuere, Cavalieri no tomó posición en relación con el problema de la composición del continuo, aunque haya dejado abierta la posibilidad de concebirlo como compuesto de indivisibles o como no compuesto de ellos. ${ }^{166} \mathrm{~K}$. Andersen sugiere que el hecho de que Cavalieri se haya referido en esta obra al 'método' de los indivisibles apunta también a subrayar su independencia respecto de cualquier teoría de la composición del continuo. ${ }^{167}$ En este sentido, el matemático italiano podría haber distinguido entre la teoría sobre cómo se compone el continuo y la pregunta por cómo funciona un método geométrico, esto es, cómo operar con indivisibles.

\section{Los átomos físicos de Gassendi}

La concepción galileana del continuo ha sido un síntoma del cambio de paradigma que se estaba generando en la temprana filosofía moderna en relación con las explicaciones físicas de cuño aristotélico que seguían interpretando la realidad corpórea en términos hilemórficos. No obstante, los indivisibles de Galileo no representaron todas las variantes de atomismo que han tenido lugar en el siglo XVII. Por ejemplo Daniel Sennert (15721637), inspirándose en investigaciones químicas, entendió a los átomos como partículas que, aunque posean una cierta complejidad interna, no son divisibles por procesos físicos o químicos. ${ }^{168}$ Otros atomistas, como el sacerdote francés Pierre Gassendi (1592-1655), han cuestionado las variantes geométricas del atomismo y, en general, todo intento de fundar la física en principios matemáticos, interpretando a los átomos, consecuentemente, como porciones diminutas e indivisibles de materia constitutivas de los cuerpos físicos. El objetivo de esta sección será analizar sucintamente los lineamientos centrales del atomismo físico de Gassendi.

\footnotetext{
${ }^{166}$ Andersen, 1985: 307 y 1986: 20; Jullien, 2015b: 3; 9.

${ }^{167}$ Andersen, 1985: 364. "Mi última indicación se refiere al nombre que CAVALIERI eligió para su teoría: el método de los indivisibles. Si el lector se pregunta por qué CAVALIERI utilizó esta expresión, he logrado uno de los objetivos de mi trabajo, a saber, mostrar que el método de CAVALIERI es independiente de las teorías sobre la composición del continuo: simplemente, decidió usar el término 'indivisible' como una alternativa para 'todas las líneas' y 'todos los planos”'. La traducción es nuestra. Jullien, 2015c: 95-97.

${ }^{168}$ Sennert ha dicho, por ejemplo, que "[los átomos o mínimos de la naturaleza] deben sus nombres al hecho de que no pueden ser divididos nuevamente a través de procesos naturales, e inversamente, forman los bloques de todas las cosas naturales. Son, sin embargo, tan pequeños que escapan a la detección de los sentidos". Citado en Leibniz, 2001: 371, nota 59. La traducción es nuestra. Véase Arthur, 2004, puntos 3 y 4 ; LoLordo, 2007: 131 y ss.; Blank, 2011.
} 
El núcleo de la concepción atomista de Gassendi se encuentra en el marco de un examen de los principios físicos necesarios para explicar la realidad corpórea. Gassendi aspira a mostrar que todo cambio supone algo constante que permanece invariante mientras se producen dichas alteraciones. Si no se diera algo permanente, se contradiría el antiguo principio aceptado por numerosos pensadores, incluidos Aristóteles y Epicuro, según el cual ex nihilo nihil fieri, in nihilum nihil abire. ${ }^{169} \mathrm{~A}$ todo cambio subyace, por lo tanto, una cierta materia, es decir, un principio material. No obstante, Gassendi no interpreta la materia como Aristóteles; más aún, no admite que los principios de la física sean la materia, la forma y la privación, sino más bien el espacio, el tiempo y el principio material que comprende los átomos que subyacen como lo invariante en cualquier cambio. ${ }^{170}$ Toda alteración, consecuentemente, se explica por agregación o sustracción de partículas atómicas. ${ }^{171}$

Asignando estos principios, Gassendi se opone a una concepción relativamente común entre sus contemporáneos, típicamente cartesiana, según la cual los principios explicativos de la física deben buscarse en la geometría. ${ }^{172}$ En efecto, el examen del sacerdote francés se esfuerza por señalar que no debe pasarse por alto el hecho de que el objeto de indagación no es aquí el cuerpo matemático sino el natural. ${ }^{173}$ La materia, es decir, todo cuerpo natural se caracteriza (al menos parcialmente) por la magnitud o cantidad que consiste en la extensión tridimensional -esto es, en largo, ancho y profundidad- que puede ser considerada por un matemático. No obstante, Gassendi señala que el examen que realiza un geómetra de las dimensiones es siempre fruto de una selección o elección por la cual se las separa de la materia, se las considera separadamente y por lo tanto se construyen demostraciones sobre lo abstractamente considerado. ${ }^{174}$ Precisamente por esto, el cuerpo geométrico pertenece a un orden distinto que el natural: mientras que este último

\footnotetext{
${ }^{169}$ Gassendi, Syntagma philosophicum, Pars. 2, Lib. 3, 232. Seguiremos como hilo conductor el libro tercero de la segunda parte de esta obra, en el que se examina "de materiali principio, sive materia prima rerum". La necesidad del principio materia se enfatiza en el primer capítulo de este libro, que se titula: "Quid sit, et qua necessitate Materiale Principium, Materiave prima exigatur" (229). Sobre la disposición de los temas físicos abordados por Gassendi en esta obra, véase Osler, 2002.

${ }^{170}$ Gassendi, Syntagma philosophicum, Pars. 2, Lib. 3, 230.

${ }^{171}$ LoLordo, 2007: 100. Sobre la argumentación de existencia de los átomos, véase Sumida Joy, 2002: 134136.

${ }^{172}$ Véase la primera sección del primer capítulo de este trabajo. Sobre esta cuestión puede verse también Sumida Joy, 2002: 83 y ss. y LoLordo, 2007: 138-139.

${ }_{173}$ Gassendi, Syntagma philosophicum, Pars. 2, Lib. 3, 231.

${ }^{174}$ Gassendi, Syntagma philosophicum, Pars. 2, Lib. 3, 232.
} 
corresponde al género de la sustancia, es decir, de la materia, el cuerpo geométrico, en cuanto objeto de una consideración abstracta de la mente, pertenece al género de la cantidad. ${ }^{175}$ De allí que sea posible para el geómetra, como consecuencia, considerar una línea como una cierta longitud que carece de anchura o una superficie como una cierta anchura carente de profundidad, aunque estas cosas no se den en la materia o en el cuerpo. ${ }^{176}$ Como consecuencia, Gassendi solicita que “(...) entendamos que no es lícito transferir continuamente a la Física todo lo que los Geómetras demuestras abstractamente". 177

Estas aclaraciones permiten comprender que el examen de Gassendi bajo ningún concepto permitiría una composición de indivisibles geométricos tal como había mantenido Galileo. Su examen del principio material lo llevó a una concepción epicúrea de los átomos radicalmente materialista. ${ }^{178} \mathrm{El}$ sacerdote francés entiende a los átomos, consecuentemente, como cuerpos pequeñísimos (exilissima corpora), esto es, corpúsculos absolutamente plenos (es decir, que no admiten un vacío interno), extremadamente sólidos y duros, y físicamente indivisibles. ${ }^{179}$ Dado su carácter indivisible, los primeros predicados de los átomos, la figura y el tamaño, permanecen constantes a lo largo del tiempo. ${ }^{180}$ En este sentido, sus primeras cualidades deben ser tan invariantes como los átomos mismos. ${ }^{181}$ En correlación con lo anterior, Gassendi diferencia los átomos físicos recién mencionados de los puntos geométricos, usualmente comprendidos en términos euclidianos, esto es, como carentes de partes:

Me agrada notar que 'A 'A $\mu_{0}$ v' se dice no como suponen vulgarmente (y como, por lo demás, interpretan algunos eruditos), lo que carece de partes y está desprovisto de toda magnitud, y por lo tanto no es otra cosa que un punto Matemático, sino lo que es sólido y, por decirlo así, duro y compacto, de modo que no hay lugar para una división o sección y corte, es decir, que no hay en la naturaleza ninguna fuerza que pueda dividirlo. ${ }^{182}$

\footnotetext{
${ }^{175}$ Gassendi, Syntagma philosophicum, Pars. 2, Lib. 3, 232.

176 Gassendi, Syntagma philosophicum, Pars. 2, Lib. 3, 232.

177 Gassendi, Syntagma philosophicum, Pars. 2, Lib. 3, 265. "Quod dico autem eo sensu, ac fine, ideo est, ut intelligamus non licere perpetuo transferre in Physicam quicquid Geometrae abstracte demonstrant".

178 Brundell, 1987: 113.

${ }^{179}$ Gassendi, Syntagma philosophicum, Pars. 2, Lib. 3, 263. Véase también p. 256.

${ }^{180}$ LoLordo, 2007: 138-139.

181 Sumida Joy, 2002: 136.

182 Gassendi, Syntagma philosophicum, Pars. 2, Lib. 3, 256. "Adnotare autem lubet dici 'Atopov', non ut vulgo putant, (et quidam alioquin eruditi interpretantur) quod partibus careat, et magnitudine omni destituatur,
} 
Presumiblemente una de las notas más importante de los átomos físicos de Gassendi sea el carácter absolutamente sólido y duro, pues de ella se sigue el hecho de ser indivisibles y de ser plenos. Ahora bien, esto no significa para Gassendi la negación del vacío; más bien, cuerpo y vacío son un par de contrarios mutuamente necesarios en el pensamiento del sacerdote francés: mientras que el cuerpo está dotado de masa, es táctil, capaz de acción, pasión y de resistencia, el vacío se caracteriza precisamente por carecer de masa $\mathrm{y}$, consecuentemente, por no ser táctil y por ser incapaz de acción, pasión y resistencia. ${ }^{183}$ La resistencia describe la impenetrabilidad que le es esencial a la materia tridimensional y la ausencia de ella es esencial al vacío que, siendo tridimensional, es sin embargo penetrable. ${ }^{184}$ En este sentido, aunque los átomos sean plenos, entre ellos se interponen las diminutas porciones espaciales vacías gracias a las cuales un cuerpo compuesto puede ser seccionado. ${ }^{185}$

Gassendi era consciente de que afirmar átomos físicamente indivisibles contradiría la definición aristotélica de 'continuo' como la de aquello que es divisible en partes siempre divisibles. ${ }^{186}$ El sacerdote francés no tiene inconvenientes en reconocer que ciertamente los cuerpos son divisibles en la medida en que haya un vacío entre las partes que permita su separación. No obstante, ya que los átomos mismos son plenos, esto es, que no admiten un vacío en su constitución, la división del continuo se ve imposibilitada de seguir ad infinitum: ella alcanza un límite precisamente donde arriba a los indivisibles. ${ }^{187} \mathrm{El}$ argumento de Gassendi es, en este caso, idéntico al utilizado por Epicuro para justificar que los átomos deben poseer cierta magnitud: si un cuerpo finito fuera divisible ad infinitum, entonces eventualmente se resolvería en partículas cuya magnitud sería cero, es decir, en cosas inexistentes, contradiciendo aquel principio mencionado anteriormente según el cual de la nada no procede nada. ${ }^{188}$ De allí que la conclusión de Gassendi sea: "[p]or

sitque proinde aliud nihil, quam punctum Mathematicum; sed quod ita solida, et, ut si sicam, dura, compactaque sit; ut divisioni, sectionive, et plagae nullum locum faciat, seu quod nulla vis in natura sit, quae dividere illam possit". Brundell, 1987: 113-114.

${ }_{183}$ Gassendi, Syntagma philosophicum, Pars. 2, Lib. 3, 256.

${ }^{184}$ LoLordo, 2007: 102-103 y 139-140.

${ }^{185}$ Sobre el vacío en Gassendi, véase Brundell, 1987: 61-62 y LoLordo, 2007: 101-102.

${ }^{186}$ Gassendi, Syntagma philosophicum, Pars. 2, Lib. 3, 258.

${ }^{187}$ Gassendi, Syntagma philosophicum, Pars. 2, Lib. 3, 258. Sobre la negación gassendiana de la infinita divisibilidad, Sumida Joy, 2002: 150 y ss.

${ }^{188}$ Sumida Joy, 2002: 136-137, 146-147, 150 y ss. 
consiguiente, hecha la resolución extrema, deben quedar partículas diminutísimas que sean invencibles". 189

El hecho de que el continuo no sea para Gassendi divisible al infinito tiene una importante consecuencia: por la misma razón, una división infinita actual sería contradictoria, de manera tal que el número de átomos no podría ser jamás infinito. Gassendi se distancia en este punto incluso de algunos célebres atomistas antiguos, como Lucrecio, que los afirmaron en número infinito. ${ }^{190}$ Para el sacerdote francés, en efecto, la división infinita de una magnitud es una opinión paradójica y absurda que contradice a los sentidos, aunque haya sido sorprendentemente aceptada por una gran variedad de pensadores. ${ }^{191}$ No obstante, para Gassendi -así como previamente para Epicuro- si el continuo o, lo que es lo mismo, una magnitud finita se dividiera en infinitas partes alícuotas, no podría evitarse que de su agregación resulte una magnitud infinita. ${ }^{192}$ Toda magnitud finita, en efecto, posee partes extremas que la delimitan, esto es, entre las cuales se da. Supuesta la división infinita, no obstante, las partes extremas se dividirían infinitamente, de manera tal que formalmente no existirían como tales. ${ }^{193}$ De esta manera, es esencial al atomismo gassendiano el rechazo de la división infinita actual. Ahora bien, entre la divisibilidad infinita y la división actual infinita, Gassendi reconoce una tercera alternativa, a saber, la de Aristóteles, esto es, aquella que sostiene que, aunque el continuo sea infinitamente divisible, el número de partes actuales en él es siempre y necesariamente finito. ${ }^{194}$ No obstante, para Gassendi el planteo de Aristóteles evade el núcleo auténtico del problema. ${ }^{195}$ En efecto, omite considerar que, si por 'partes en acto' se entienden aquellas en las que el continuo está actualmente dividido, entonces ellas permanecerían indivisas (en contra de la divisibilidad infinita). En efecto, si se dice que dichas partes en acto, finitas en número, pueden ser nuevamente divididas, entonces el mismo procedimiento se aplicaría al

\footnotetext{
189 Gassendi, Syntagma philosophicum, Pars. 2, Lib. 3, 259. "Superesse igitur debent, extrema facta resolutione, particulae minutissima, quae inexorables sint".

${ }^{190}$ Gassendi, Syntagma philosophicum, Pars. 2, Lib. 3, 260. Brundell, 1987: 56.

191 Gassendi, Syntagma philosophicum, Pars. 2, Lib. 3, 261.

192 Gassendi, Syntagma philosophicum, Pars. 2, Lib. 3, 261. Sumida Joy, 2002: 138-139.

193 Gassendi, Syntagma philosophicum, Pars. 2, Lib. 3, 261. Sumida Joy, 2002: 137-138, señala que la división de los extremos sería algo admitido por Epicuro, pues si los átomos son menores que cualquier magnitud perceptible, entonces es posible seguir dividiendo los extremos siempre que creamos observar un límite.

${ }^{194}$ Véase la primera sección de este capítulo.

195 Gassendi, Syntagma philosophicum, Pars. 2, Lib. 3, 262.
} 
infinito, de manera tal que serían infinitas en acto. ${ }^{196}$ En consecuencia, como una composición infinita acarrea consecuencias inadmisibles, el número de átomos físicos debe ser necesariamente finito.

El examen gassendiano del problema de la composición del continuo está estrechamente vinculado con su negación del atomismo geométrico que hemos mencionado anteriormente. En efecto, Gassendi reconoce que entre los antiguos algunos han mantenido que la división de una magnitud finita cualquiera se termina en ciertos puntos matemáticos, así como entre los pensadores contemporáneos a él otros han mantenido una composición heterogénea, esto es, tal que los cuerpos se componen de superficies, las que a su vez se componen de líneas que finalmente están compuestas de puntos. ${ }^{197}$ Gassendi, en efecto, conocía los planteos sobre el infinito y lo indivisible que eran comunes en su tiempo, y precisamente por eso se esfuerza por recordar que las conclusiones extraídas en la geometría no necesariamente tienen validez en la física. ${ }^{198}$ Incluso, presenta una serie de argumentos geométricos que mostrarían que una composición de puntos matemáticos sería inconsistente, ${ }^{199}$ aunque en la física no lo sea una composición de puntos físicos: "[y] en efecto, aquello mínimo o Indivisible [Insectile] que admite Epicuro es Físico y es tal por otra razón en grado sumo distinta de lo que es Matemático, es decir, como éstos suponen al punto". ${ }^{200}$ Para Gassendi, en efecto, los argumentos de Aristóteles contra la posibilidad de que una línea se componga de indivisibles eran matemáticos, de modo que, en el caso de la física, no serían concluyentes. ${ }^{201}$

A modo de conclusión, a continuación haremos una breve síntesis de los principales lineamientos anteriormente expuestos. En este capítulo hemos presentado algunos autores representativos de los dos modelos de abordaje del problema del continuo, a saber, el

\footnotetext{
${ }^{196}$ Gassendi, Syntagma philosophicum, Pars. 2, Lib. 3, 262.

${ }_{197}$ Gassendi, Syntagma philosophicum, Pars. 2, Lib. 3, 263-264.

198 Gassendi, Syntagma philosophicum, Pars. 2, Lib. 3, 264-265. LoLordo, 2007: 139.

199 Gassendi, Syntagma philosophicum, Pars. 2, Lib. 3, 264. Sumida Joy, 2002: 160.

${ }^{200}$ Gassendi, Syntagma philosophicum, Pars. 2, Lib. 3, 264. "Etenim illud minimum, seu Insectile, quod Epicurus admittit, et Physicum est, est alterius longe rationis, quam sit Mathematicum, seu quale isti supponunt punctum".

${ }^{201}$ Sumida Joy, 2002: 87-89.
} 
'aristotélico' y el 'atomista'. Los representantes de la interpretación aristotélica que hemos visto han sido Aristóteles, quien fue el precursor de este modelo interpretativo, Francisco Suárez y Libert Froidmont. Con respecto al pensamiento de Aristóteles, es importante resaltar tres cosas: en primer lugar, la noción de infinito potencial, como la de aquello que está siendo siempre algo distinto; en segundo lugar, la noción de 'cosas continuas' como aquellas que poseen un extremo en común; en tercer lugar, el hecho de concebir como imposible la división del continuo 'simultáneamente y en todas partes', es decir, una división en indivisibles. En lo que respecta al planteo de Suárez, su concepción de que los puntos son cosas reales, tanto concebidos como límites extremos como tomados como elementos que explican la continuidad, podría ser relevante a la hora de explorar el abordaje leibniziano. En siguiente lugar, el planteo de Froidmont se destaca al menos por dos cosas: primero, por la multiplicidad de argumentos propuestos para señalar las contradicciones que se siguen de suponer una composición del continuo de un número finito de átomos; segundo, por su concepción de que en el continuo hay infinitas partes actuales, que no deben concebirse como puntos sino como partes proporcionales. Con respecto a los atomistas, hemos presentado el pensamiento de Galileo, tras lo cual introdujimos algunas precisiones sobre el método de los indivisibles de Cavalieri, y finalmente abordamos el atomismo físico de Gassendi. Con respecto al planteo de Galileo, quien como veremos fue uno de los autores más discutidos por Leibniz, resaltaremos tres cuestiones: por un parte, su propuesta de un atomismo geométrico según el cual hay infinitos indivisibles en acto; por otra parte, las diferencias que concibió entre lo finito y divisible y lo infinito e indivisible; finalmente, la indicación de que hay propiedades de lo finito que no pueden extrapolarse a lo infinito, motivo por el cual el alcance del axioma del todo y la parte es limitado. En siguiente lugar, hemos hecho una sintética reconstrucción de los pasos fundamentales del método de los indivisibles propuesto por Cavalieri para establecer la razón entre dos figuras. Finalmente, hemos visto que el atomismo de Gassendi se caracteriza por no fundar las explicaciones físicas en la geometría, por concebir a los átomos como cuerpos pequeñísimos, duros y físicamente indivisibles y por aceptar solamente un número finito de átomos. 



\section{Segunda PaRTe:}

PRIMER ABORDAJE LEIBNIZIANO DEL CONTINUO Y EL INFINITO 



\section{CAPÍTUlO 3: El INFINITO ACTUAL EN LA MATERIA}

El examen del problema del continuo se centra fundamentalmente en un reducido número de cuestiones estrechamente vinculadas entre sí, que, por eso mismo, son muy difíciles de abordar. Una de ellas consiste en determinar si el número de partes en el continuo es finito, infinito o si permanece indeterminado. Ahora bien, no basta con la mera consideración cuantitativa de las partes para la solución del problema del continuo. Además de esto, es necesario, por lo menos, precisar si ellas se dan actualmente o sólo en potencia. Como hemos visto anteriormente, no han faltado quienes, como Aristóteles, entendieron que, aunque en potencia haya un número infinito de partes, en acto hay solamente un número finito, pues no hay un infinito que pueda alcanzar la actualidad. ${ }^{1}$ La propuesta que Leibniz presentó en la década de 1670 no deja margen a dudas. En efecto, desde la TMA de 1671 en adelante, el filósofo de Leipzig sostuvo dos enunciados que, considerados en conjunto, llamaremos la tesis leibniziana del 'infinito actual':

(1) Se dan en acto partes en el continuo, contra lo que piensa el agudísimo Thomas White, (2) y ellas son infinitas en acto; en efecto, lo indefinido de Descartes no existe en la cosa $\left[\right.$ in re] sino en el pensante. ${ }^{2}$

En el marco del examen de la naturaleza corpórea, la tesis del infinito actual significa que para Leibniz hay infinitas partes que actualmente componen la materia. Como ha sugerido Richard Arthur, Leibniz habría arribado a esta conclusión tras un cuestionamiento de la concepción cartesiana según la cual en la materia hay un número indeterminado de partes. ${ }^{3}$ Leibniz se centró con especial atención en el examen de la naturaleza corpórea desde finales de la década de 1660 y comienzos de la siguiente. Como veremos, con el correr de los años fue profundizando continuamente en sus exámenes relativos al cuerpo. En este capítulo desarrollaremos las argumentaciones que llevaron a Leibniz a la tesis del infinito actual en el contexto del examen de la materia que tuvieron lugar a finales de la década de 1660 y comienzos de la de 1670. En una primera instancia analizaremos sintéticamente los cuestionamientos de Leibniz a la tesis de Thomas White

\footnotetext{
${ }^{1}$ Véase la primera sección del capítulo 2.

${ }^{2}$ TMA, A VI 2, 264. "(1.) Dantur actu partes in continuo, contra quam sentit acutissimus Thomas Anglus, (2.) eaeque infinitae actu, indefinitum enim Cartesii non in re est, sed [in] cogitante". OFC, 8, 79.

${ }^{3}$ Esta interpretación de Richard Arthur, que seguiremos como hilo conductor, es presentada, por ejemplo, en la introducción de Leibniz, 2001, xxxii-xxxvii; Arthur, 2000: 6-7; Arthur, 2009. Leibniz mismo sugiere esto, por cierto, en el pasaje citado en la nota anterior.
} 
(1593-1676) según la cual las partes en el continuo nunca se dan actualmente. En segundo lugar, abordaremos la noción de materia de Leibniz y su crítica a la indeterminación de partes de la materia de Descartes.

\section{La actualidad de partes en el continuo}

Las reflexiones de Thomas White sobre el problema del continuo se encuentran en los dos prefacios que elaboró para la obra de Kenelm Digby (1603-1665) Demonstratio inmortalitate animae rationalis (1664) y que Leibniz conocía al menos desde el año 1668, cuando escribió una refutación de la hipótesis de White acerca del misterio de la eucaristía de acuerdo con lo que éste indicó particularmente en el artículo 12 del primer prefacio. ${ }^{4} \mathrm{Si}$ bien este escrito de Leibniz no trata especialmente sobre el laberinto del continuo, sí lo hace el prefacio que tiene en cuenta para su crítica. ${ }^{5}$ En efecto, White considera "si en el continuo existen o no partes en acto" como una cuestión previa para dilucidar los conceptos de lo denso y lo raro (o de lo sólido y lo líquido, como preferentemente dijeron varios pensadores de la temprana filosofía moderna) a los que el prefacio se dedica especialmente. ${ }^{6}$ La discusión acerca de lo denso y lo raro, así como también su vinculación con la actualidad de las partes del continuo, fueron cuestiones muy importantes en la física del siglo XVII, de lo cual son testimonio los desarrollos cartesianos que veremos más adelante en este capítulo. Como White está particularmente interesado en sintetizar elementos aristotélicos y corpuscularistas, una de sus preocupaciones es examinar si el concepto aristotélico de continuo es o no compatible con la constitución de la materia en términos corpusculares. ${ }^{7}$

El punto de partida de la posición de White está dado por una definición del concepto de continuo o de la magnitud en general que en gran medida limita el análisis posterior, a saber, que "el continuo o la magnitud es la única entidad que es divisible, no

\footnotetext{
${ }^{4}$ Demonstratio Possibilitatis Mysteriorum Eucharistiae, A VI 1, 501.

${ }^{5}$ Sintéticamente, la explicación que White ofrece del misterio de la Eucaristía es que la sustancia del pan y el vino serían aniquiladas mientras permanecen sus cualidades sensibles. Leibniz no admite dicha interpretación en la medida en que no podría ser aceptada por filósofos mecanicistas. La propuesta leibniziana está basada, por su parte, en la dilucidación del concepto de sustancia que subyace al problema de la transustanciación. Sobre esta cuestión, véase Mercer, 2004, capítulo 2.

${ }^{6}$ Digby, 1664, prefacio de White, s/n. "Praefatio Metaphysica. In quo consistant raritas et densitas. Quaestio previa ad resolutionem intentam. Utrum in Continuo sint partes actu".

${ }^{7}$ Beeley, 1996: 82-83.
} 
porque contenga muchas entidades en acto sino porque pueden producirse muchas a partir de ésta por cierto movimiento (que llamamos división) por fuerza de causas naturales". ${ }^{8}$ La existencia actual de partes en el continuo o en la magnitud, por consiguiente, conllevaría una inmediata contradicción respecto de dicha definición. El continuo es una cierta entidad unitaria, un todo cuyas partes son sólo potenciales, pero nunca en acto. Una pluralidad real de partes, independientemente de que se las piense en número finito o infinito, ${ }^{9}$ queda excluida de una composición del tipo de la que resulta algo continuo (como son líneas, superficies o cuerpos). ${ }^{10}$ La justificación última de esto se encuentra en una tesis típicamente escolástica según la cual la unidad es convertible con la entidad (ens et unum convertuntur). De esta manera, decir que algo es un ente es sencillamente lo mismo que decir que es algo uno, es decir, que está dotado de unidad. De este modo, el problema del continuo se traslada inmediatamente al problema de la unidad de las pretendidas partes.

De acuerdo con estas presuposiciones, White señala que, si se supusiera una pluralidad de partes (al margen de la cuestión sobre si son finitas o infinitas en número), se seguirían contradicciones. En efecto, si las partes existieran en acto, cada una de ellas debería ser tomada como una unidad, haciendo peligrar, de este modo, la unidad genuina del continuo y lo que tiene de específico. De allí que indique: “[p]or lo que, si la unidad de los compuesto consistiera en la entidad de lo compuesto, consistiría en el hecho de que es un ser que no es uno", 11 lo que iría en contra de la definición de continuo establecida por White. No obstante, para White las partes del continuo no son las mismas en el todo y en sí mismas, en el sentido de que en sí son entes completos, mientras que en el todo son

\footnotetext{
${ }^{8}$ Digby, 1664, prefacio de White, $\mathrm{s} / \mathrm{n}$. "Continuum seu magnitudinem unicam esse entitatem, quae sit divisibilis, non eo quod plures entitates actu claudat, sed quia plures ex ea per motum quendam (quem divisionem appelamus) vi causarum naturalium produci possint".

${ }^{9}$ White evalúa también las cuatro variantes que permite admitir el continuo actual, a saber: que existe [a] un número finito de partes divisibles, [b] un número finito de partes indivisibles, [c] un número infinito de partes divisibles y [d] un número infinito de partes indivisibles. Su conclusión, en última instancia, es que lo que hace problemático el análisis no es la determinación de la cantidad de partes que hay en el continuo, sino precisamente el hecho de que en él haya partes determinadas. White analiza esto particularmente en el artículo dos del prólogo (Quod specialiter in continuo non sint partes actu). Por lo demás, puede verse Beeley, 1996, capítulo 5, punto 5.2: "Die Potentialität der Teile im Kontinuum".

${ }_{10}$ Digby, 1664, prefacio de White, s/n. El autor señala que estas entidades son precisamente cosas continuas al comienzo del primer artículo del prólogo: "Quantum continuum, seu magnum, puta linea, superficies, vel corpus (...)". La aclaración de que las entidades que poseen dimensiones son precisamente continuas es muy importante desde el punto de vista de su intento de analizar aristotélicamente el pensamiento moderno, en el sentido de que la definición de continuo vale tanto para entidades geométricas como físicas. En este sentido, entendió que el concepto de magnitud se aplica unívocamente respecto de líneas y de cuerpos.

${ }^{11}$ Digby, 1664, prefacio de White, $\mathrm{s} / \mathrm{n}$. "Quare si unitas compositi consistat in entitate compositi, consistet in hoc quod est esse non unum".
} 
sustancialmente incompletas. ${ }^{12}$ De esta manera, la entidad de las partes está dada por su vinculación con el todo: "y las restantes partes tienen razón de ente en el todo, [pero] no la tienen fuera". ${ }^{13}$ La consecuencia que extrae White es inmediata: para salvar la unidad del continuo, debe negarse la actualidad de sus partes (lo que es lo mismo que decir que ellas no son entidades sustancialmente completas) y debe afirmarse que tienen un ser siempre relativo al todo: "y así, ninguna [de las partes] está en acto en el compuesto". ${ }^{14}$ De acuerdo con estos razonamientos, White cuestiona la posición cartesiana (que veremos en detalle a continuación) según la cual las partes existen indefinidamente, como premisa para justificar la diferencia entre lo sólido o denso y lo líquido o raro. El carácter indeterminado implica un serio problema epistemológico. Como señala $\mathrm{Ph}$. Beeley, para White el intento cartesiano de unir una posición corpuscular con el concepto de la divisibilidad infinita fracasa porque involucra la inadmisible transferencia de una determinación negativa de la mente, que es de carácter epistemológico, a la naturaleza, en tanto objeto de conocimiento. En este sentido, la naturaleza no admite una indeterminación, aunque para el entendimiento lo infinito solo sea dado como algo indefinido. ${ }^{15}$

Como veremos más adelante, Leibniz coincidió con este cuestionamiento de White al pensamiento cartesiano, y precisamente por eso para él lo indefinido de Descartes está 'en el pensante' pero no en la cosa. Sin embargo, tras analizar la concepción de White en 1668, también rechazó la definición de continuo que inspeccionamos anteriormente. En efecto, Leibniz sugiere que las partes que resultan de la división del todo están en acto incluso con anterioridad respecto de él, es decir, que preexisten al todo. ${ }^{16}$ Por eso, Leibniz no estaría dispuesto a aceptar la definición de continuo de White ni lo que se sigue de ella. No obstante, además de esto Leibniz entiende que la interpretación del pensador británico acarrea ciertos problemas teológicos que la llevarían a contradecir el dogma de la transustanciación. Es por esto que el filósofo de Leipzig concluye:

Pues Thomas White incurre en esta herejía que defiende abundantemente en todo este prefacio, que las partes de una cosa no están en ella en acto y por consecuencia que una cosa reunida con otra en un todo, hablando con precisión,

\footnotetext{
${ }^{12}$ Digby, 1664, prefacio de White, $\mathrm{s} / \mathrm{n}$.

${ }^{13}$ Digby, 1664, prefacio de White, s/n. "et caeterae partes rationem entis in toto habent, extra non habent".

${ }^{14}$ Digby, 1664, prefacio de White, s/n. "non sunt itaque ullae actu in composito".

${ }^{15}$ Beeley, 1996: 105.

${ }^{16}$ Demonstratio Possibilitatis Mysteriorum Eucharistiae, A VI 1, 501.
} 
desaparece, y se genera un todo; contrariamente, con la división desaparece el todo y se generan las partes. ${ }^{17}$

En consecuencia, Leibniz debe examinar cuál es la razón que justifica la preexistencia de las partes, esto es, el hecho de que ellas se den en acto en el continuo.

\section{Hacia la infinitud de partes en el continuo: el examen de la materia}

Como hemos dicho, en gran medida el examen de Leibniz que conduce hacia la tesis del infinito actual se enmarca en una consideración relativa a la naturaleza de la materia llevada a cabo entre finales de la década de 1660 y comienzos de la siguiente. Como señalamos en la introducción de este capítulo, Leibniz cuestionó los planteos de White y de Descartes al enunciar la tesis del infinito actual en la TMA. Ahora bien, en el período que aquí consideramos, el filósofo de Leipzig no conoció la obra de Descartes directamente. En 1675, Leibniz le confesó a Simon Foucher por correspondencia que no había leído con anterioridad la obra de Descartes con todo el cuidado que se merece debido al estilo geométrico de sus escritos. Recién cuando se 'convirtió en geómetra' fue capaz de introducirse en la lectura de los escritos de Descartes, así como también en la de los textos de Galileo. ${ }^{18}$ Por eso mismo, reconoce que, hasta ese momento, sus conocimientos de Descartes los había tomado de exposiciones populares: "[n]o obstante, lo que yo sé de las meditaciones metafísicas y físicas del Sr. Descartes casi no ha venido sino de la lectura de una cantidad de libros escritos [en un estilo] un poco más familiar, los cuales relatan sus opiniones". ${ }^{19}$ Entre el inverno de 1675 y la primavera del año siguiente, Leibniz leyó los Principia Philosophiae de Descartes. No obstante, el grado de conocimiento que tenía del pensamiento cartesiano con anterioridad es incierto. De acuerdo con esto, en lo que sigue

\footnotetext{
${ }^{17}$ Demonstratio Possibilitatis Mysteriorum Eucharistiae, A VI 1, 505. "Nam Thomas Anglus est in ea haeresi, quam tota illa praefatione fuse defendit, rei partes non esse in ea actu et per consequens rem aliquam cum alia in aliquod totum conflatam accurate loquendo interire, et generari totum, contra divisione interire totum et generari partes".

${ }^{18}$ Leibniz a S. Foucher, A II 1, 389. Véase también la introducción de Parkinson en PDSR, 1992: xi: "Cuando llegó a París, Leibniz tenía poco o ningún conocimiento de los desarrollos matemáticos recientes; en cuanto a la filosofía, él admite que, antes de 1675, su conocimiento de Descartes, el filósofo líder de la primera mitad del siglo diez y siete, fue en gran medida de segunda mano, basado en exposiciones populares". La traducción es nuestra.

${ }^{19}$ Leibniz a S. Foucher, A II 1, 389. "Cependant ce que je sçay des meditations metaphysiques et physiques de Mons. des Cartes n'est presque venu que de la lecture de quantité de livres ecrits un peu plus familierement, qui rapportent ses opinions".
} 
trazaremos un paralelismo entre lo que han dicho Descartes y Leibniz (en este caso, entre los últimos años de la década de 1660 y los primeros de la siguiente) sobre la realidad corpórea, a los fines de reconstruir los argumentos que, presumiblemente, habrían llevado al filósofo de Leipzig a cuestionar la concepción según la cual el número de partes en la materia es indeterminado y a asumir la infinitud de partes en la materia. Para cumplir con nuestro objetivo, nos detendremos en cuatro ejes, a saber: en primer lugar, analizaremos las notas esenciales que estos autores consideraron, cada uno por su parte, como definitorias de la materia; en segundo lugar, examinaremos sus respectivas interpretaciones sobre la relación entre la materia y el movimiento; en tercer lugar evaluaremos la vinculación entre el movimiento y la tesis del infinito actual; finalmente consideraremos el problema que supuso para Leibniz la indefinición de la materia de Descartes. En el caso de Leibniz, entre estos ejes también iremos señalando la evolución interna de su pensamiento a lo largo de los años.

\subsection{Las notas esenciales de la materia}

Como es sabido, Descartes se propuso el objetivo fundamental de hallar conocimientos por completo libres de duda. En este sentido, tanto en sus Meditationes de prima Philosophia (1641) como en sus Principia Philosophiae (1644) se preocupó inicialmente por introducir un procedimiento que disponga al ánimo para que se despoje de todos los prejuicios que haya asumido, de tal modo que permanezca únicamente aquello de lo que pueda estarse completamente seguro, esto es, de lo indubitable. ${ }^{20}$ "Para indagar la verdad -señala el autor- hay que dudar cuanto se pueda de todas las cosas, al menos una vez en la vida". ${ }^{21}$ Esto lo llevó, en primera instancia, a reconocer que hay solamente dos naturalezas distintas de cuya existencia se puede estar completamente seguro. ${ }^{22}$ Por un lado la mente o sustancia pensante, cuya esencia consistente en el mero pensamiento al que no le

\footnotetext{
${ }^{20}$ Por ejemplo: Principia Philosophiae, AT, VIII, $1, \S 1$.

${ }^{21}$ Principia Philosophiae, AT, VIII, 1, § 1. "Veritatem inquirenti, semel in vita de omnibus, quantum fieri potest, esse dubitandum". Traducción: Descartes y Leibniz, 1989: 29.

${ }^{22}$ Principia Philosophiae, AT, VIII, $1, \S 1$ y $\S 8$.
} 
pertenece nada que pueda ser denominado como magnitud, figura o movimiento. ${ }^{23}$ Por otro lado, el cuerpo o sustancia extensa. ${ }^{24}$

La propuesta de Descartes no apunta solamente a establecer esta distinción entre res cogitans y res extensa. En este sentido, mediante el mismo procedimiento buscó determinar, en segunda instancia, qué son clara y distintamente la cosa pensante y la extensa. ${ }^{25}$ En el caso del examen del cuerpo, el filósofo francés llevó a cabo un minucioso análisis para determinar cuáles son las notas que definen a la materia y cuáles no lo hacen. Como un primer paso por la vía de la negación, niega que las cualidades que la definan sean aquellas sensiblemente percibidas. ${ }^{26}$ Como conclusión, Descartes se opone a una tesis aristotélica común entre los escolásticos según la cual la veracidad de las imágenes sensibles recaería en el hecho de que ellas se asemejarían a los objetos percibidos. ${ }^{27}$ Los argumentos cartesianos apuntan fundamentalmente a marcar la diferencia entre la sensación o idea que tenemos de una cosa y lo que hay en el objeto que produce dicha sensación. ${ }^{28}$ Así, por ejemplo, si hubiera una tal semejanza, habría que decir que el sonido emitido cuando se pronuncia una palabra, al margen de la significación que lo acompaña, sería semejante al objeto que lo causa, ${ }^{29}$ o bien que hay una tal semejanza entre la sensación o

\footnotetext{
${ }^{23}$ Principia Philosophiae, AT, VIII, 1, § 8. En este sentido, la sustancia pensante se reduce a la conciencia, incluidas en ella tanto las actividades que realiza como las representaciones que posee.

${ }^{24}$ Principia Philosophiae, AT, VIII, $1, \S 9$.

${ }^{25}$ Más allá de esta breve indicación, dejamos de lado los exámenes metafísicos de Descartes. Como vimos en la cuarta sección del capítulo primero, Descartes señaló que su máximo aporte para la filosofía no fue tanto su metafísica sino su física.

${ }^{26}$ Esto puede encontrarse tanto en Le Monde como en Principia, aunque en este caso menos explícitamente y hasta derivadamente. En Le Monde ([a] AT, XI, 16-17; [b] AT, XI, 20-21) Descartes dice: [a] “(...) \& par mesme moyen, nous délivrer d'une erreur dont nous avons tous esté préoccupez dés nostre enfance, lors que nous avons crû qu'il n'y avoit point d'autres corps autour de nous, que ceux qui pouvoient estre sentis"; [b] "j'aurois peur que mon Discours ne devinst trop long, si j'entreprenois d'expliquer ce qui en est; \& les experiences dont j'ay parlé, ne sont point suffisantes pour le prouver, quoy qu'elles le soient assez, pour persuader que les espaces où nous ne Tentons rien, sont remplis de la mesme matiere, \& contiennent autant pour le moins de cette matiere, que ceux qui sont occupez par les corps que nous sentons". En Principia Philosophiae (AT, VIII, 2, § 11), por su parte, se observa al indicar: "si attendentes ad ideam quam habemus alicuius corporis, exempli causa, lapidis, rejiciamus ab illa id omne quod ad corporis naturam non requiri cognoscimus: nempe rejiciamus primo duritiem, quia si lapis liquefiat aut in pulvisculos quam minutissimos dividatur, illam amittet, neque tamen ideo definet esse corpus; rejiciamus etiam colorem, quia vidimus saepe lapides adeo pellucidos, ut nullus in iis esset colo; rejiciamus gravitatem, quia quamvis ignis sit levissimus, non ideo minus putatur esse corpus; ac denique rejiciamus frigus et calorem, aliasque omnes qualitates, quia vel non considerantur in lapide, vel iis mutatis, non ideo lapis corporis naturam amissise existimatur".

${ }^{27}$ La referencia a la tesis aristotélica la tomamos de la introducción de Gaukroger a Descartes, 2004: xiii. La crítica de Descartes, por su parte, puede observarse en la nota anterior.

${ }^{28}$ Le Monde, AT, XI, 3.

${ }^{29}$ Le Monde, AT, XI, 5.
} 
idea que se tiene de la luz y el objeto que produce la sensación. La negación de que haya notas sensibles que definan al cuerpo llevó a Descartes a indicar, por ejemplo, lo siguiente:

Pero como nos tomamos la libertad de imaginar esta materia como se nos antoje, atribuyámosle, si se nos permite, una naturaleza en la cual no haya nada que no pudieran conocer todos tan perfectamente como sea posible. Para este fin, supongamos expresamente que ella no tiene la forma de la Tierra, ni del Fuego, ni del Aire ni ninguna otra forma más particular, como la de la madera o de una piedra o de un metal; no [tiene esta forma] más que [lo que tiene] las cualidades de ser caliente o frío, seco o húmedo, ligero o pesado, o de tener algún sabor, u olor, o sonido, o color, o luz u otra [cualidad] semejante en la naturaleza de la cual se pueda decir que hay alguna cosa que no sea evidentemente conocida por todo el mundo. ${ }^{30}$

Que la determinación de la naturaleza corpórea no pueda darse mediante un examen empírico tiene consecuencias importantes para la ciencia que la considera, esto es, la física. Como mencionamos en el primer capítulo, Descartes pretende mostrar que los principios en lo que se apoya el conocimiento físico no pueden estar fundados en el conocimiento empírico sino que deben estarlo en la geometría. ${ }^{31}$ Por eso, se refiere a la materia en términos como estos:

Más bien concíbasela como un verdadero cuerpo, perfectamente sólido, que llena igualmente todas las longitudes, largos y profundidades de este gran espacio en medio del cual detuvimos nuestro pensamiento, de suerte que cada una de sus partes ocupa siempre una parte de este espacio de tal modo proporcional a su grandeza que no llena uno más grande ni se estrecha en uno menor, ni permite, mientras permanece, que otro encuentre un lugar allí. ${ }^{32}$

Cuando Leibniz aborda la definición cartesiana de cuerpo, reconoce que hay propiedades que el filósofo francés considera como inherentes a la materia pero que, sin

\footnotetext{
${ }^{30}$ Le Monde, AT XI, 33. "Or puisque nous prenons la liberté de feindre cette matiere à nostre fantaisie, attribuons luy, s'il vous plaist, une nature en laquelle il n'y ait rien du tout que chacun ne puisse connoistre aussi parfaitement qu'il est possible. Et pour cet effet, supposons expressément qu'elle n'a point la forme de la Terre, ny du Feu, ny de l'Air, ny aucune autre plus particuliere, comme du bois, d'une pierre, ou d'un metal, non plus que les qualitez d'estre chaude ou froide, séche ou humide, legere ou pesante, ou d'avoir quelque goût, ou odeur, ou son, ou couleur, ou lumiere, ou autre semblable, en la nature de laquelle on puisse dire qu'il y ait quelque chose qui ne soit pas evidemment connu de tout le monde". La traducción es nuestra.

${ }_{31}^{31}$ Gaukroger, 2002b: 70.

${ }^{32}$ Le Monde, AT, XI, 33. "Et ne pensons pas aussi d'autre costé qu'elle soit cette Matiere premiere des Philosophes, qu'on a si bien dépoüillée de toutes ses Formes \& Qualitez, qu'il n'y est rien demeuré de reste, qui puisse estre clairement entendu. Mais concevons-la comme un vray corps, parfaitement solide, qui remplit également toutes les longueurs, largeurs, \& profondeurs, de ce grand espace au milieu duquel nous avons arresté nostre pensée; en sorte que chacune de ses parties occupe toujours une partie de cet espace, tellement proportionnée à sa grandeur, qu'elle n'en sçauroit remplir une plus grande, ny se refferrer en une moindre, ny souffrir que, pendant qu'elle y demeure, quelqu'autre y trouve place". La traducción es nuestra.
} 
embargo, no pueden deducirse de la extensión tridimensional que la define. Recuérdese que, como se indicó sintéticamente en el primer capítulo, para Leibniz todo lo que pueda deducirse de una definición debe estar contenido en ella. Como se desprende de la cita anterior, Descartes sugiere que la misma noción de extensión tridimensional implica la imposibilidad de que un cuerpo encuentre lugar allí donde está otro. Por su parte, Leibniz es consciente de que la impenetrabilidad es efectivamente una nota definitoria de la materia. Sin embargo, ella no puede deducirse de la tridimensionalidad espacial, pues ésta, por sí misma, no incluye ninguna resistencia. ${ }^{33}$ A diferencia del examen cartesiano, en el planteo de Leibniz sobre la naturaleza corpórea se reconocen no una sino dos notas definitorias, a saber, la extensión y la impenetrabilidad. ${ }^{34}$

Como mencionamos al final del primer capítulo, Leibniz intentó reconstruir las nociones aristotélicas de materia, forma y mutación en términos que acaten la 'regla común' según la cual toda explicación relativa a la naturaleza corpórea debe darse en términos de magnitud, figura y movimiento. Incluso, reconoció que aprueba más cosas presentes en los libros físicos de Aristóteles (aunque los escolásticos hayan desvirtuado el significado de sus palabras) que en los de Descartes. ${ }^{35}$ En este sentido, si hay algo en lo que coincide con Descartes, es precisamente en aquella regla. ${ }^{36}$ Por eso, Leibniz intentó presentar las nociones aristotélicas de materia, forma y mutación en términos tales que pueda deducirse de ellas todo lo que está virtualmente contenido y que pueda explicarse todo lo relativo a la realidad corpórea según la magnitud, figura y movimiento. ${ }^{37} \mathrm{De}$ acuerdo con esto, la materia primera de Aristóteles es entendida por Leibniz como la masa que se define en virtud de aquellas dos notas antes indicadas, esto es, la extensión y la impenetrabilidad. ${ }^{38}$ Estas dos nociones son los requisitos de la materia que no pueden, a su vez, deducirse de otros. La extensión, por su parte, hace referencia al cuerpo matemático que se caracteriza por la tridimensionalidad y por ser el 'espacio universal' en el que están todas las cosas. De este modo, hace referencia al espacio que la materia llena u ocupa. ${ }^{39} \mathrm{En}$

\footnotetext{
${ }^{33} \mathrm{Zu}$ Descartes' Principia Philosophiae, A VI 3, 215.

${ }^{34}$ Leibniz a Thomasius, A II 1, 36.

${ }^{35}$ Leibniz a Thomasius, A II 1, 25 y 26.

${ }^{36}$ Leibniz a Thomasius, A II 1, 25.

${ }^{37}$ Leibniz, 2001: xxix-xxxi.

${ }^{38}$ Leibniz a Thomasius, A II 1, 26. Este tema es considerado en Fazio, 2012: 159-166. Como señala Garber, 2009: 8-9, en consecuencia, la materia primera es la 'sustancia extensa' de la filosofía mecánica.

${ }^{39}$ Leibniz a Thomasius, A II 1, 26.
} 
virtud de esto, el espacio es el ente primeramente extenso o extenso en primer grado, esto es, es el lugar universal de todas las cosas. ${ }^{40}$ Leibniz extrae de aquí dos consecuencias muy importantes: por un lado que, como dijimos, el espacio geométrico es una de las notas que definen a la interpretación moderna de la 'materia prima' como concepto explicativo de la física; por otro lado, que, precisamente por ser una de las notas definitorias, materia y espacio no son realidades idénticas. Es decir, la identificación leibniziana entre materia prima y masa no significa que la materia aristotélica sea precisamente el cuerpo geométrico, pues este último carece, por definición, de impenetrabilidad. La definición del cuerpo físico resulta de añadir a la noción de espacio la de materia. En este sentido, además de extensión o cuerpo matemático, la materia posee un cuerpo físico, esto es, precisamente, resistencia, antitipia o impenetrabilidad, es decir, la imposibilidad de que dos cuerpos estén simultáneamente en el mismo espacio. ${ }^{41}$

De acuerdo con los presupuestos metodológicos que antes mencionamos, toda otra propiedad que se diga del cuerpo debe poder deducirse de la extensión y de la impenetrabilidad como de su causa. ${ }^{42}$ El camino que Leibniz debe seguir para deducir de la noción de materia todo lo que pueda deducirse de ella es indicando, en primer lugar, aquello que puede deducirse de las notas que la definen, especialmente de la de extensión. El orden de la demostración le exige, consecuentemente, comenzar por las definiciones involucradas.

Def. 1. La extensión es una Cantidad supuesta con la posición de las partes (por lo que difiere del Número, que es una cantidad sin posición (es decir, [sin] suposición de existencia) de las partes; es decir, la extensión es una cantidad relacionada al sentido; el Número es una cantidad relacionada al intelecto).

Def. 2. El Espacio es Algo extenso por sí cuyas partes son simultáneas. (Es decir, un quantum asumido con la posición de las partes simultáneamente existentes).

Def. 3. El Tiempo es algo extenso por sí, cuyas partes son anteriores y posteriores.

Def. 4. Un Cuerpo es aquello que está en el espacio, una Cosa coextensa con el espacio (es decir, algo extenso por accidente cuyas partes son simultáneas).

\footnotetext{
${ }^{40}$ Leibniz a Thomasius, A II 1, 34. Como veremos luego, en los años siguientes Leibniz abandonará esta visión de un espacio o lugar universal. Arthur, 2015b: 152, señala que este abandono será fundamental para la consolidación de la concepción de la relatividad del movimiento (a la que nos referiremos en el noveno capítulo).

${ }^{41}$ Leibniz a Thomasius, A II 1, 34- 36.

${ }^{42}$ Leibniz a Thomasius, A II 1, 36.
} 
Def. 5. El Movimiento es una mutación de espacio (es decir, algo coextenso con el tiempo; es decir, algo extenso por accidente cuyas partes son anteriores y posteriores).

Def. 6. La Figura es la posición simultánea de las partes. ${ }^{43}$

Una vez obtenidas estas definiciones, en segundo lugar, Leibniz determina las propiedades que se contienen en la definición de espacio que está incluida en la de cuerpo:

Toda afección del espacio asumido por sí es la magnitud y figura y las cosas contenidas en ellas. Pues toda afección que está en algo por sí, debe deducirse de su definición. La definición del espacio es: un quantum asumido con la posición de las partes simultáneamente existentes. Por consiguiente, en la definición de espacio no se contiene ninguna otra cosa que la cantidad o magnitud, y la posición simultánea de las partes. La posición simultánea de las partes es la figura, por def. 6. Por consiguiente, en la definición de espacio no se contiene ninguna otra cosa que la magnitud y figura y las cosas contenidas en ellas. Por consiguiente, toda afección del espacio es la magnitud y figura y las cosas contenidas en ellas. Q. E. D. ${ }^{44}$

Finalmente, en tercer lugar, Leibniz determina las propiedades que se deducen de la definición de cuerpo, esto es, tras haber determinado las que se deducen de la noción de espacio, que es una de sus notas definitorias:

Pues Toda afección que está en algo debe deducirse de su definición. La definición de Cuerpo es: aquello que está en el espacio (es decir, lo que es coextenso con el espacio). Esta definición no contiene otra cosa que el espacio y la in-existencia en él. Por consiguiente, no hay ninguna otra afección por sí del cuerpo que todas las afecciones del espacio, y además la in-existencia en el espacio. Todas las afecciones del espacio por sí son la magnitud y figura, por teorema 1. La existencia en el espacio es la localidad. Pero la existencia en un espacio dado contiene la existenciabilidad [existentibilitatem] en otro espacio

\footnotetext{
${ }^{43}$ De rationibus motus, A VI 2, 167. "Def. 1. Extensio est Quantitas sumta cum positione partium (quo differt a Numero, qui est quantitas sine positione (seu suppositione existentiae) partium, seu extensio est quantitas relata ad sensum; Numerus est quantitas relata ad intelectum). / Def. 2. Spatium est Aliquid per se extensum cuius partes sunt simul. (Seu quantum sumtum cum positione partium simul existentium.) / Def. 3. Tempus est aliquid per se extensum, cuius partes sunt priores et posteriores. / Def. 4. Corpus est id quod est in spatio[,] Res spatio coextensa (seu aliquid per accidens extensum cuius partes sunt simul). / Def. 5. Motus est mutatio spatii (seu aliquid tempori coextensum; seu aliquid per accidens extensum cuius partes sunt priores et posteiores). / Def. 6. Figura est positio partium simul".

${ }^{44}$ De rationibus motus, A VI 2, 167. "Theor. 1. Omnis affectio spatii per se sumti est magnitudo et figura, et quae in his continentur. Nam omnis affectio quae alicui per se inest, est deducenda ex eius definitione. Definitio spatii est: Quantum sumtum cum positione partium simul existentium. Ergo definitione spatii nihil aliud continetur, quam quantitas seu magnitudo, et positio partium simul. Positio partium simul est figura per def. 6. Ergo definitione spatii nihil aliud continetur, quam magnitudo et figura, et aquae in his continentur. Ergo, omnis affectio spatii est magnitudo et figura, et quae in his continentur. Q. E. D.”.
} 
igual y similar (puesto que aquí no hay ninguna razón de la diversidad). Por consiguiente, la mutabilidad de un espacio dado, o lo que es lo mismo, la movilidad. Por consiguiente, toda afección del cuerpo es la magnitud, figura y localidad y las cosas contenidas en ellas, como en la localidad está contenida la movilidad. Por consiguiente, toda afección del cuerpo es la magnitud, figura y localidad y las cosas contenidas en ellas, como en la localidad está contenida la movilidad. Q. E. D. ${ }^{45}$

En síntesis, para Leibniz la materia se define por la extensión y la impenetrabilidad, así como también por las notas que se siguen de la extensión, esto es, magnitud, figura, localidad y, en consecuencia, mutabilidad.

\subsection{Materia y movimiento}

En última instancia, el examen cartesiano arribó a la determinación de una única nota definitoria de la sustancia corpórea, a saber, "la extensión en longitud, anchura y profundidad". ${ }^{46}$ Por eso, como dijimos a la pasada en el primer capítulo, para Descartes no hay una distinción real entre géneros de cuerpos, en el sentido de que el pensamiento claro y distinto de lo que es una cosa extensa es siempre uno y, por lo tanto, vale igualmente para referirse al cuerpo geométrico como al cuerpo físico. ${ }^{47}$ Que el concepto de cuerpo sea unívoco, esto es, que valga igualmente para el cuerpo geométrico y el físico, no implica que

\footnotetext{
${ }^{45}$ De rationibus motus, A VI 2, 167-168. "Nam omnis affectio quae alicui per se inest, est deducenda ex eius definitione. Definitio Corporis est: id quod est in spatio (seu quod spatio coextensum est). Haec definitio nihil aliud continet, quam spatium et inexistentiam in eo. Ergo nullae aliae per se sunt affectiones corporis, quam omnes affectiones spatii, et praeterea inexistentia in spatio. Affectiones omnes spatii per se, sunt magnitudo et figura per theorema $I$. Existentia in spatio est localitas. Existentia autem in spatio dato, continet existibilitatem in alio aequali et simili (quia nulla est hic ratio diversitatis). Ergo spatii dati mutabilitatem, seu quod idem est mobilitatem. Ergo omnis affectio corporis est magnitudo, figura et localitas, et quae in his continentur, quemadmodum in localitate continetur mobilitas. Q. E. D. hujus unius theorematis ictu corrunt omnes Qualitates reales philosophorum verbalium seu Scholasticorum, in primis si sequens adiungatur". (Introducimos el guión en la palabra 'in-existencia' para evitar que se confunda con el sentido negativo del término). Del mismo modo en la carta a Thomasius indica: "Por consiguiente, no debe afirmarse nada en los cuerpos que no fluya de la definición de Extensión y Antitypia". "Ex his patet, naturam Corporis constitui per Extensionem et Antitypiam (...)". Como ejemplos posteriores, puede verse la necesidad que reconoce, en el contexto de $D M M$, de incluir al movimiento en la definición de cuerpo (A VI 3, 99-100), o bien la imposibilidad de incluir a la acción en la definición de movimiento en el contexto del Pacidius Philalethi (A VI 3, 566 y ss.; OFC, 8, 151 y ss.).

${ }^{46}$ Principia Philosophiae, AT, VIII, 1, § 53. "Et quidem ex quolibet attributo substantia cognoscitur; sed una tamen est cuiusque substantiae praecipua proprietas, quae ipsius naturam essentiamque constituit, et ad quam aliae omnes referuntur. Nempe extensio in longum, latum et profundum, substantiae corporeae naturam constituit; et cogitatio constituit naturam substantiae cogitantis". Traducción: Descartes y Leibniz, 1989: 55.

${ }^{47}$ Gaukroger, 2002b: 92.
} 
no haya ninguna diferencia entre todos aquellos objetos que caen bajo esta misma denominación. Para Descartes hay al menos una diferencia entre ellos dada por la resistencia que los cuerpos ofrecen a separarse o dividirse. En este sentido, algunos pueden ser más fácilmente particionados y otros más difícilmente. No es la misma la cantidad de fuerza que se requiere para separar un cuerpo líquido, por ejemplo, que la que se requiere para uno sólido. Teniendo esto en vistas, Descartes presenta un espectro de posibles estados de los cuerpos en relación con su dureza o falta de ella.

El espectro tiene dos polos bien delimitados, a saber, el de los cuerpos duros (corps durs) y el de los líquidos (liquides). Un cuerpo duro es aquel respecto del cual se requiere de una cantidad de fuerza considerable para separar sus partes. ${ }^{48}$ Similarmente, un cuerpo líquido es aquel respecto del cual se requiere de una cantidad de fuerza mucho menor (tal vez incluso ínfima). ${ }^{49}$ El problema que Descartes debe solucionar es por qué en unos casos se requiere más fuerza y en otro menos. En cuanto a esto, reconoce que la dificultad o facilidad para llevar a cabo esta partición depende del estado en el que estén sus respectivas partes en relación con el movimiento. Es decir: en un cuerpo duro, las partes, que se tocan entre sí, no poseen cada una un movimiento que las haga recíprocamente alejarse. De este modo, están en reposo. Precisamente por eso, para separarlas se requiere de una cantidad de fuerza considerable. Inversamente, en un cuerpo líquido, las partes se tocan pero no por estar en reposo sino 'solamente a la pasada' (seulement en passant), en la medida en que cada una está dirigida por su movimiento en diversas direcciones. Por eso mismo, para separarlas se requiere de menos fuerza que en el caso de un cuerpo duro. El planteo cartesiano es aquí muy similar al empleado por Galileo para explicar la razón por la cual un cuerpo más pesado que el agua se hunde, a saber, debido a que en el agua las partes no ofrecen resistencia a dividirse. ${ }^{50}$ Para Descartes, por lo tanto, lo duro y lo líquido se establecen como extremos de un espectro que abarca todos los cuerpos, según el grado en que sus partes posean un movimiento de alejamiento entre sí. ${ }^{51}$

Ahora bien, dado que ésta es la única diferencia entre los cuerpos duros y los líquidos y que estos son los extremos de todo el espectro de cuerpos, entonces no hay otra

\footnotetext{
${ }^{48}$ Le Monde, AT, XI, 12.

${ }^{49}$ Le Monde, AT, XI, 13.

${ }^{50}$ Solis Santos, 2007: 216.

${ }^{51}$ Le Monde, AT, XI, 14.
} 
diferencia en los cuerpos que no sea la facilidad o dificultad para separar sus partes: "[p]ero no encuentro otra diferencia entre los cuerpos duros y los cuerpos líquidos excepto que las partes de uno pueden ser separadas del agregado más fácilmente que aquellas de los otros". ${ }^{52}$ Que no haya otra diferencia significa, como dijimos, una misma noción homogénea de materia para lo sólido y para lo líquido. ${ }^{53}$ Sin embargo, en este espectro, desde los cuerpos más duros hasta los más líquidos, hay dos supuestos: por un lado, la partición o división de la materia (de la que hablaremos más adelante); por otro lado, el movimiento, en virtud del cual las partes se separan con mayor o menor dificultad. El análisis del filósofo francés se enfrenta aquí a un inconveniente serio suscitado por la necesidad de tener que responder a la pregunta por qué es el movimiento. El problema es que, dada la definición del cuerpo como extensión, el movimiento no entra en su definición. Por eso, como dijimos en la cuarta sección del primer capítulo, la materia cartesiana es esencialmente inactiva.

No obstante esto, para Descartes el movimiento es un elemento muy importante de las explicaciones físicas. Más aún, todas las explicaciones relativas a los cuerpos deben ser ofrecidas en términos de movimiento, figura y tamaño de las partes de la materia. ${ }^{54}$ Este presupuesto genera un impacto en la filosofía natural cartesiana: aunque la materia se defina exclusivamente por la extensión tridimensional, de modo que el movimiento no entra en su definición, en la naturaleza "no hay nada en ninguna parte que no cambie". 55 Pero entonces, dado que la materia es inerte, ¿cómo debe explicarse la causa y el origen del movimiento? El tratamiento cartesiano no deja de ser ambiguo en este aspecto: por una parte, el filósofo francés indica que no considerará en su análisis la causa del movimiento, pero por otra parte afirma que la causa es la acción divina infundida en los cuerpos desde el comienzo del mundo. ${ }^{56}$ Presumiblemente, la intención de no considerar la causa se debe a

\footnotetext{
${ }^{52}$ Le Monde, AT, XI, 13. "Or je ne trouve point d'autre différence entre les corps durs \& les corps liquides, sinon que les parties des uns peuvent estre separées d'ensemble beaucoup plus aisément que celles des autres". La traducción es nuestra. Taliaferro, 1964: 17.

${ }^{53}$ Le Monde, AT, XI, 17.

${ }^{54}$ Le Monde, AT, XI, 26.

${ }^{55}$ Le Monde, AT, XI, 11. “(...) qu'il n'y a rien, en aucun lieu, qui ne se change”. La traducción es nuestra.

${ }^{56}$ Le Monde, AT, XI, 11.
} 
que, como queda manifiesto, su explicación no apela a principios geométricos sino teológico-metafísicos. ${ }^{57}$

La naturaleza del movimiento y su relación con la definición de cuerpo no corre una suerte muy distinta en los primerísimos planteos de Leibniz vistos en el apartado anterior (cuya evolución en este punto se verá en el apartado siguiente de este capítulo). Si para el filósofo de Leipzig en el concepto de cuerpo se incluyen dos notas definitorias, extensión e impenetrabilidad, y otras susceptibles de ser deducidas particularmente de la extensión, a saber, magnitud, figura, localidad y movilidad, se sigue que el movimiento no es una nota definitoria del cuerpo ni es susceptible de ser deducida de su definición. "El movimiento mismo - dice Leibniz- no fluye de ellos [esto es, de la extensión e impenetrabilidad]. De donde, propiamente hablando, no se da un movimiento en los cuerpos, como [tratándose de] un ente real en ellos". ${ }^{58}$ Como veremos, esta tesis tuvo consecuencias sumamente relevantes para la teoría leibniziana del cuerpo. Por lo pronto, aunque pueda aparentar que contradice lo anterior, fue el punto de partida para una distinción en el modo de concebir la materia en cuanto ella esté afectada por el movimiento o no lo esté. Es decir que, aunque no sea una nota definitoria suya, hay una gran diferencia en la materia si ella está en movimiento o en reposo. ${ }^{59}$

La distinción establecida por Descartes entre cuerpos duros y líquidos en virtud del movimiento de sus partes presupone una cuestión fundamental en relación con la tesis del infinito actual. Ante todo, la variación de acuerdo con el grado de movimiento mediante el

\footnotetext{
${ }^{57}$ Dutton, 1999, y Clarke, 1979, señalan atinadamente que este punto del examen cartesiano es una muestra de que la física y la metafísica cartesiana conforman una unidad.

${ }^{58}$ Leibniz a Thomasius, A II 1, 36. "Unde proprie loquendo non datur motus in corporibus, tamquam ens in iis reale". De acuerdo con Garber, 2009: 31 y 191, esta visión de Leibniz de 1669 es una variante del ocasionalismo. Esta tesis de Leibniz, cuya idea general retomará por el 1675 (véase el noveno capítulo), es que los cuerpos son continuamente creados (continuo creari), de manera tal que el movimiento se explica por una creación continua o, como lo denomina en el Pacidius Philalethi, por una transcreación (A VI 3, 559 y ss.). Así, aunque el movimiento no sea continuo, sí lo es la causalidad que lo produce. Véase Arthur, 2009, especialmente: "Phase 1 (1669): Unassignable gaps in the continuum". Como veremos más adelante, a comienzos de la década de 1670, Leibniz se vio fuertemente influenciado por el concepto de conato de Hobbes (aunque lo haya reformulado), de modo que no necesita apelar a Dios para explicar directamente el movimiento. Esto se ve, por ejemplo, en TMA, A VI 2, 264 y ss.

${ }_{59}$ De acuerdo con Racionero, 1980: 41, "la localización exige movilidad y ésta el movimiento". Esta interpretación suya no se ajusta a los textos. Ahora bien, como Racionero subraya, en un momento de su pensamiento Leibniz destacó que el movimiento es esencial al cuerpo. No obstante, esto lo ha dicho posteriormente al período al que ahora nos referimos. En este sentido, parecería que Racionero extrapola una conclusión que Leibniz extrajo en 1671-1672 a un período aún anterior. En rigor hay una evolución en el pensamiento del filósofo de Leipzig, pues primero rechazó que el movimiento sea una nota definitoria del cuerpo, aunque luego, como veremos, afirmó esto mismo.
} 
cual las partes se alejan supone que los cuerpos pueden dividirse efectivamente en partes. Pero más aún, supone que pueden hacerlo en partes extremadamente pequeñas. ${ }^{60}$ No por nada para Descartes es esencial al cuerpo también la divisibilidad. ${ }^{61}$ Sin embargo, la divisibilidad, esto es, la posibilidad de dividir la materia, no basta por sí misma, pues no alcanza para explicar las propiedades de la materia reductibles a ella ni sus modificaciones, a no ser en virtud del movimiento de dichas partes. La distinción entre cuerpos duros y líquidos supone que la división no sea una mera operación y posibilidad mental: "[p]ues la partición -señala Descartes-, que se hace sólo con el pensamiento, no cambia nada, sino que toda variación o diversidad en las formas de la materia depende del movimiento". ${ }^{62} \mathrm{De}$ aquí se desprende que el movimiento no solamente permite establecer el grado de dureza o fluidez de un cuerpo sino también (e incluso anteriormente) la posesión efectiva de partes, podríamos decir, en acto, que permite dicha diferenciación.

En buena medida, el planteo de Leibniz es similar al cartesiano, esto es, dado que pueden distinguirse partes en la materia solamente en virtud del movimiento y, por consiguiente, que la diversidad y la variedad en ella se generan precisamente por el movimiento. Contrariamente, mientras la materia repose, no es sino una masa continua y homogénea que llena el mundo. El movimiento rompe con la homogeneidad y con la continuidad dando lugar a sus opuestos, esto es, la variedad y la discontinuidad. ${ }^{63}$ Por esta misma razón, el movimiento es lo que permite determinar el estado de las partes de la materia en términos de actualidad y potencialidad. Es decir: la materia continua, en reposo, no posee consecuentemente partes actuales; ${ }^{64}$ por el contrario, en la materia discontinua hay partes en acto dado que la existencia de partes actuales es debida precisamente al movimiento.

\footnotetext{
${ }^{60}$ Le Monde, AT, XI, 11.

${ }^{61}$ Principia Philosophiae, AT, VIII, $1, \S 23$.

${ }^{62}$ Principia Philosophiae, AT, VIII, $2, \S 23$. "Partitio enim, quae fit sola cogitatione, nihil mutat; sed omnis materiae variatio, sive omnium eius formarum diversitas, pendet a motu". Traducción: Descartes y Leibniz, 1989: 87. En esta traducción, en vez de "partición" se traduce "división". Además de esto, es importante algo que Descartes señaló antes en el mismo parágrafo: "Omnesque proprietates, quas in ea clare percipimus, ad hoc unum reducuntur, quod sit partibilis, et mobilis secundum partes, et proinde capax illarum omnium affectionum, quas ex eius partium motu sequi posse percipimus".

${ }^{63}$ Leibniz a Thomasius, A II 1, 26. Los editores de la academia remiten a A VI 2, 435 (prefacio a la edición de Nizolio) donde Leibniz repite casi literalmente las mismas palabras, pero con un breve añadido: “(..) est enim ea in se spectata nulla diversitas, mera homogeneitas, nisi per motus". Esta oposiciónes analizada también por Levey, 1999: 82-85.

${ }^{64}$ Leibniz a Thomasius, A II 1, 26.
} 
Para Leibniz esto no significa, por cierto, que una materia en reposo carezca de magnitud, sino que su cantidad es indeterminada o indefinida. ${ }^{65}$ En estos años, Leibniz entendió que la magnitud es 'el número de las partes', lo cual significa en lo esencial que todo aquello respecto de lo cual puedan afirmarse partes es una magnitud. ${ }^{66}$ Sin embargo, la materia en movimiento es discontinua precisamente en virtud de la actualidad de las partes, en la medida en que cada parte posee extremos, esto es, términos que la delimitan y distinguen de las otras. ${ }^{67}$ A los extremos o términos de lo extenso, Leibniz los llamó 'figuras'. ${ }^{68}$ En este sentido, los cuerpos poseen figuras en virtud del movimiento. De allí que la variedad se deba al movimiento y que, si careciera de él, la materia sería homogénea. En sintonía con el intento de conciliar la filosofía aristotélica con la moderna, Leibniz asume que lo que en la física aristotélica se llama 'forma' es aquello que, en este contexto, es entendido como 'figura'. 69

De este modo, Leibniz extrae dos conclusiones solidarias entre sí. Por un lado, que la forma de un cuerpo, en la medida en que supone partes en acto, no puede darse en la materia a no ser por el movimiento: “[p] ues ya que la figura es el término del cuerpo, para introducir figuras de la materia, se necesitará de un término. Por consiguiente, para que varios términos surjan en la materia, se necesita de la discontinuidad de las partes". ${ }^{70}$ En segundo lugar, concluye que la materia, en la medida en que puede no estar afectada por el movimiento y dado que la forma es debida al movimiento, debe existir con anterioridad a la forma. En este sentido la materia posee un acto entitativo independientemente de toda forma, de modo que ella existe antes de ser informada. ${ }^{71}$

\footnotetext{
${ }^{65}$ Leibniz a Thomasius, A II 1, 26.

${ }^{66}$ Leibniz a Thomasius, A II 1, 34.

${ }^{67}$ Leibniz a Thomasius, A II 1, 27.

${ }^{68}$ Leibniz a Thomasius, A II 1, 34.

${ }^{69}$ Leibniz a Thomasius, A II 1, 27. En este sentido, Leibniz posee una interpretación similar a la de Erhard Weigel (con quien pasó un semestre en el año 1663). Weigel intentó elaborar un sistema único y coherente que concilie la filosofía de los antiguos (fundamentalmente de Aristóteles y Platón) con la de los filósofos mecánicos de su propia época. Para esto, ensayó dos vías de análisis compatibles. Por una parte, una vía 'ontológica', que corresponde al estudio de los principios de los que se constituyen las cosas en términos netamente aristotélicos, a saber: la materia y la forma. Sin embargo, en su descripción de la materia se pone de manifiesto que hay una cierta identificación con la materia cartesiana, lo cual él justifica porque las ideas de algunos nuevos filósofos, entre ellos Descartes, son meras extensiones de ideas aristotélicas (Mercer, 1999: 33-35).

${ }^{70}$ Leibniz a Thomasius, A II 1, 27. "Nam cum figura sit terminus corporis; ad figuras materiae inducendas, opus erit termino. Ut igitur varii in materia termini oriantur, opus est discontinuitate partium".

${ }^{71}$ Leibniz a Thomasius, A II 1, 26.
} 


\subsection{Movimiento e infinitas partes actuales}

Leibniz reexaminó su teoría de la materia en los primeros años de la década de 1670. Inmediatamente, arribó a la conclusión de que se seguirían contradicciones si no se admitiera que el movimiento es esencial al cuerpo. En este sentido, el filósofo de Leipzig reconoció que sería inconsistente admitir una materia en reposo. Leibniz llevó a cabo un nuevo análisis, cuyo punto de partida fue un cuestionamiento de la conclusión mencionada al final de la sección anterior sobre el acto entitativo de la materia. Inicialmente, y en relativa sintonía con el planteo previo, identificó la materia prima aristotélica con la materia líquida o sutil cartesiana, en la medida en que "[a]mbas son divisibles al infinito. Ambas carecen por sí de forma y movimiento, ambas reciben las formas por el movimiento". ${ }^{72}$ Más aún, Leibniz siguió reconociendo que el cuerpo no sólo debe ser entendido como algo coextenso con el espacio sino también como algo impenetrable. ${ }^{73}$ Sin embargo, se dio cuenta de que, si no se le añadiera movimiento, esto es, si reposara, la materia prima no sería nada, es decir, no podría decirse que existe. ${ }^{74}$ Como veremos, la conclusión a la que este examen arribó, cuya importancia a lo largo de los años fue aumentando, fue que " $[n] o$ hay espacio sin cuerpo y no [hay] cuerpo sin movimiento", 75 de modo que, por lo tanto, el movimiento debe ser incluido como una de las notas definitorias del cuerpo.

Ahora bien, Leibniz arribó a esta conclusión a partir de un examen de lo que define la existencia en general y, en particular, la existencia de la materia. En primer lugar, el filósofo de Leipzig parece haberse dado cuenta de que las nociones de existencia y de sensación están muy conectadas. En este sentido, defendió la peculiar tesis según la cual “"Existir' no es otra cosa que 'ser Sentido",. ${ }^{76}$ Lo fundamental de esta tesis es que, para que algo sea sentido, debe realizar una acción susceptible de ser justamente sentida por otra entidad. Por eso, una consecuencia inmediata de este planteo es la afirmación de existencia

\footnotetext{
${ }^{72}$ De materia prima, A VI 2, 279. "Materia prima Aristotelis, cum Materia subtili Cartesii idem est. Utraque est divisibilis in infinitum. Utraque forma motuque per se caret, utraque formas recipit per motum".

${ }^{73}$ Propositiones quaedam physicae, A VI 3, 56.

${ }_{75}^{74}$ De materia prima, A VI 2, 280.

${ }^{75}$ DMM, A VI 3, 97. "Nullum est spatium sine corpore, et nullum corpus sine motu", a lo que agrega inmediatamente: "Mira et a nemine observata haec demonstrandi ratio mihi patuit, ex interiore indivisibilium cognitione".

${ }^{76}$ Propositiones quaedam physicae, A VI 3, 56. “(...) nihil aliud esse Existere quam Sentiri (...)”. Asimismo, De minimo et maximo, A VI 3, 100. "Quid ergo tandem revera corpus motusque, ut circulus evitetur. Quid nisi ab alia $<$ mente $>$ sentiri".
} 
de entidades cuya acción es diversa de la de los cuerpos en tanto capaces de sentir precisamente las acciones de estos. ${ }^{77}$ Estas entidades o, como también las denomina, mentes incorpóreas son de dos tipos: por un lado, mentes como las de los hombres, que no confieren nada a la existencia de las cosas sentidas, que no pueden sentir todas las cosas simultáneamente y que no las hacen menos sentidas si una de estas mentes no las está sintiendo en un momento determinado $;^{78}$ por otro lado, la mente capaz de reunir en una sola consideración el agregado de todas las cosas, esto es, la mente divina. ${ }^{79}$ Leibniz aclara, en este caso, que 'ser sentido' por el autor de las cosas "no es otra cosa que agradarle, esto es, ser Armónico". ${ }^{80}$

Esta concepción lo llevó a examinar qué tipo de acciones son las de los cuerpos que producen las sensaciones que tenemos de ellos. Ante todo, esto significa que, dado que son sentidos, los cuerpos deben producir sensaciones y, por tanto, deben ser cosas activas. Ahora bien, si dijéramos que una sustancia se define como algo activo, los cuerpos serían sustancias. ${ }^{81}$ La acción que define a la sustancia corpórea no puede ser entendida sino en relación con el movimiento: "[a]hora bien, supuesto que 'existir es ser sentido', es necesario que 'el hecho de que un Cuerpo exista', sea 'producir una sensación', moverse o, al menos, tender [al movimiento], puesto que si todas las cosas reposaran, sin duda ni Dios las distinguiría de las que no son nada". ${ }^{82}$ Por lo tanto, Leibniz arribó a la conclusión de que

${ }^{77}$ DMM, A VI 3, 100. "Si nullae essent mentes, omnia corpora essent nihil"; "Ad Corporum existentiam, requiri certum est mentem quandam a corpore immunem, aliam ab illis omnibus quam sentimus"; Demonstratio substantiarum incorporearum, A VI 3, 74. "Substantia incorporea est cuius alia est actio praeter loci sui mutationem"; también Propositiones quaedam physicae, A VI 3, 67. "Ergo necessarium est Materiae addi mentem, seu supponi substantias incorporeas".

${ }_{78}^{78} D M$, A VI 3, 100-101.

${ }^{79} D M M$, A VI 3, 101. Que Leibniz se refiera al 'agregado' de todas las cosas y no a la 'totalidad' no es casual. Se encuentra implícita allí la negación de la posibilidad de que el conjunto infinito de todas las cosas sea un todo, es decir, algo incapaz de ser parte de otra cosa. Para esto, véase el sexto capítulo.

${ }^{80}$ Propositiones quaedam physicae, A VI 3, 56. “(...) sentiri autem si non a nobis saltem ab Autore rerum, a quo sentiri, nihil aliud est, quam ei placere, seu Harmonicum esse".

${ }^{81}$ Demonstratio substantiarum incorporearum, A VI 3, 74. Mercer, 2004, capítulo 10, punto 1, apartado "Physical papers of 1672", analiza este y otros aspectos metafísicos que se encuentran en los escritos físicos que aquí se analizan.

${ }^{82}$ Propositiones quaedam physicae, A VI 3, 56. "Posito iam existere esse sentiri, necesse est, Corpus existere, esse: sensum efficere, moveri vel saltem conari, quia si omnia quiescant, ne Deus quidem ea distinguet a nullis". Asimismo, Demonstratio substantiarum incorporearum, A VI 3, 74. "Corpus est substantia cuius actio unica est moveri vel locum suum mutare (vel saltem conari, seu incipere motum)". Un tratamiento que arriba a conclusiones similares se encuentra en Garber, 1995, punto 1: "Aristotelianism, mechanism, and Leibniz's early physics", Fazio, 2012, y Lawrenz, 2010, primera parte, capítulo 1: "The Young Leibniz and the Problem of Kinesis". Diferimos, sin embargo, en que en estos escritos se considera que la identidad entre materia y movimiento se da ya desde la TMA. Es cierto, como suelen indicar, que hay textos de 1671 en donde Leibniz insinúa dicha identidad. Por ejemplo, en una carta a Arnauld de noviembre de 1671 (A II 1, 
'ser cuerpo' no es otra cosa que 'estar en movimiento', esto es, que materia y movimiento son lo mismo, de tal modo que las diferencias que se piensen entre estas cosas no sean reales sino ficticias. ${ }^{83}$

Esta idea llevó a Leibniz a replantearse inevitablemente la concepción de que la materia tiene un acto entitativo independiente de o anterior al movimiento. Más aún, Leibniz dio marcha atrás en la idea de que la forma se sigue del movimiento y de que el movimiento no es una nota definitoria del cuerpo, y se ubicó tras las huellas de una tesis común entre los escolásticos: "[y] esto es lo que sin duda los Escolásticos dijeron oscuramente, que la Materia prima tiene incluso su existencia de la forma" ${ }^{84}$ Como no puede decirse que exista algo que no sea sentido y dado que la sensación exige variedad, una materia homogénea y continua, carente de variedad, no puede ser algo existente. De este modo, no existe una materia en reposo. ${ }^{85}$

Este análisis revela la importancia que tiene el movimiento en las explicaciones relativas a los cuerpos. Si una materia en reposo implicase una contradicción, entonces debería también negarse que haya una magnitud indeterminada. En este sentido, una magnitud de este tipo no se da efectivamente, pues las partes en la materia existen actualmente. En consecuencia, la indefinición no es algo que esté en la realidad, donde se encuentran partes actuales e infinitas, sino a lo sumo en la mente de quien piensa. Precisamente este es el cuestionamiento que Leibniz le hizo a Descartes. ${ }^{86}$ Los cuerpos, en virtud del movimiento, están divididos en acto en infinitas partes, ${ }^{87}$ de tal manera que ninguna se caracteriza por poseer partes que no se separen, o al decir de Leibniz, átomos. ${ }^{88}$ Como veremos en el capítulo siguiente, especialmente en la sección 3.2., el filósofo de

172). Sin embargo, no debe olvidarse que la datación de la $T M A$ se estima entre 1670 y 1671 . Es sumamente posible, consecuentemente, que Leibniz haya notado la necesidad de establecer la identidad entre materia y movimiento muy poco después de redactar la TMA. Esta interpretación es, a su vez, consistente con las críticas que realiza en $D M M$, en la medida en que la crítica al concepto de indivisible de la TMA se hace comprensible si allí aún no se suponía la identidad antes descrita. Es decir que, como se ha mostrado aquí, Leibniz llega a dicha identidad a partir precisamente de una revaluación de sus ideas de TMA.

${ }^{83}$ Propositiones quaedam physicae, A VI 3, 56.

${ }^{84}$ De materia prima, A VI 2, 280. "Idque esse quod quidan Scholastici obscure dixere, Materiam primam etiam existentiam a forma habere".

${ }^{85}$ De materia prima, A VI 2, 280.

${ }^{86}$ Véase la introducción de este capítulo.

${ }^{87}$ De materia prima, A VI 2, 280. Asimismo esto se señala y se considera con mayor profundidad en los primeros dos fundamentos predemostrables de TMA, A VI 2, 264.

${ }^{88}$ De materia prima, A VI 2, 280. 
Leipzig encontró en las observaciones microscópicas un gran aporte empírico para la tesis del infinito actual. ${ }^{89}$

\subsection{El problema de la indefinición cartesiana}

Como dijimos, la divisibilidad de la materia es fundamental en el examen de Descartes. Por lo pronto, la distinción entre cuerpos duros y líquidos supone una partición real, esto es, producida por el movimiento, y no un mero reconocimiento mental de las partes potenciales de un cuerpo. Ahora bien la división actual de la materia tiene, a su vez, una importancia aún más radical en la explicación del movimiento en el mundo. En este apartado consideraremos este aspecto del análisis cartesiano, que culminó en la afirmación de una división 'al infinito, o indefinida' de la materia que Leibniz cuestionó severamente.

Descartes se esforzó por evitar que su física sea entendida en términos atomistas. Para él, dada su definición de materia, el atomismo tiene inconsistencias radicales en las dos tesis capitales, esto es, en la de la existencia de corpúsculos atómicos y en la del vacío. Por una parte, los átomos, como cuerpos indivisibles, no pueden ser admitidos dado que la divisibilidad es esencial a la materia. En este sentido, basta con que la división pueda ser pensada para que la indivisión del átomo sea contradictoria. De esta manera, podríamos pensar en la mitad o en un número cualquiera de partes de una partícula de materia dada, sin importar cuán pequeña nos la imaginemos. Más aún, Descartes señaló que no habría partículas indivisibles ni siquiera en el caso de que Dios hubiese querido crear cosas respecto de las cuales no habría otras menores, a saber, puesto que debería haberse reservado al menos para Él el poder de dividirlas (si es que es omnipotente). ${ }^{90}$ Leibniz está de acuerdo con esta argumentación de Descartes. Más aún, la emplea como un contundente argumento contra el atomismo de Gassendi. ${ }^{91}$ En este sentido, para Leibniz también es evidente que un cuerpo extremadamente duro, como los átomos del sacerdote francés, no pueden tener lugar en la naturaleza. En efecto, reconoce que la dureza no puede por definición ser una nota esencial:

\footnotetext{
${ }^{89}$ Beeley, 1996: 197-198 y Leibniz, 2001: xxxii.

${ }^{90}$ Le Monde, AT, VIII, 2, § 20.

${ }^{91} \mathrm{Zu}$ Descartes' Principia Philosophiae, A VI 3, 215.
} 
(...) la dureza y la suavidad no son diferencias reales en los cuerpos (como son magnitud, figura y movimiento) sino solamente sensitivas, como son todas las cualidades sensibles. Pero aquella dureza que es percibida por los sentidos no es otra cosa que resistencia, y toda resistencia es movimiento (...). Esta proposición está en contra de los seguidores de Demócrito y Epicuro, y entre ellos el egregio Gassendi, quienes suponen que existen ciertos corpúsculos (ellos los llaman átomos) de tal modo sólidos que, cuando reposan, no se disuelven por el impacto de cualquier otro cuerpo. ${ }^{92}$

A diferencia de la argumentación en contra de los átomos, el razonamiento mediante el cual Descartes buscó mostrar que no existe un vacío en el mundo es un poco más complicado. Suele reconocerse que la negación del vacío es un problema que Descartes consideró particularmente a propósito de los cuerpos líquidos. ${ }^{93}$ Sin embargo, la clave de la justificación cartesiana de la imposibilidad del vacío parecería encontrarse en la definición misma de materia (esto es, la idea clara y distinta que vale igualmente para todo cuerpo, sea duro o líquido). La introducción del vacío fue un recurso empleado por algunos filósofos para explicar tanto el movimiento de los cuerpos (como traslación hacia un espacio en el que actualmente no está posicionado otro cuerpo) como la desigualdad en las velocidades de los movimientos. Por ejemplo, como veremos en el quinto capítulo, Rodrigo de Arriaga responde al problema de la desigualdad en las velocidades de los movimientos introduciendo en el trayecto del móvil más lento vacíos que explican el fenómeno de la lentificación, es decir, interponiendo en los trayectos de los móviles que se desplazan con mayor lentitud un número creciente de porciones de espacio vacías. ${ }^{94}$ La dificultad que Descartes reconoció a la hora de abordar la cuestión sobre la existencia o no del vacío consiste en que el término 'espacio vacío' se emplea usualmente de un modo muy poco técnico. En el lenguaje cotidiano, los hombres no utilizan el término 'cuerpo' para referirse a un espacio donde haya únicamente tridimensionalidad. Al contrario: en el uso cotidiano,

\footnotetext{
${ }^{92}$ De rationibus motus, A VI 2, 161. "Seu durities et mollities non sunt differentiae in corporibus reales (quales sunt magnitudo, figura et motus) sed tantum sensuales, quales sunt omnes qualitates sensibiles. Durities autem illa quae sensu percipitur, nihil ailud quam resistentia est, resistentia omnis est motus, ea igitur tantum dura sunt, quorum partes superficiales ita forti motu moventur, ut extrinseci impellentis impetum retundant. Haec propositio est contra sectatores Democriti et Epicuri, et inter eos egregium Gassendum, a quibus supponitur esse quaedam corpuscula (ipsi atomos vocant) ita solida ut etiam aun quiescent, impactu cujuscunque alterius corporis, non dissolvantur". Leibniz reitera la imposibilidad de los átomos de Gassendi en los años siguientes. Por ejemplo, Pacidius Philalethi, A VI 3, 554-555. OFC, 8, 142.

${ }_{93}$ Así por ejemplo indica Gaukroger en Descartes, 2004: xv-xvi.

${ }^{94}$ Beeley, 1996: 298-299. Aunque sin referirse explícitamente al nombre de Rodrigo de Arriaga, el argumento es referido en Froidmont, 1631: 60 y ss.
} 
un espacio de este tipo es considerado como desprovisto de un cuerpo. Para referirnos a un espacio en el que no haya un cuerpo, utilizamos sin más el término 'espacio' o incluso 'espacio vacío'. 95 Para negar el vacío en el mundo, Descartes considera que bastaría con recordar el concepto técnico de cuerpo, es decir, su idea clara y distinta, que no reconoce una distinción real entre 'cuerpo' y 'espacio' tridimensional. Por eso mismo, no tiene ningún significado real la distinción utilizada cotidianamente entre el 'espacio interno' ocupado por una sustancia corpórea y el 'espacio externo', esto es, aquel en el que se piensa la interrelación de un cuerpo con otros. ${ }^{96}$ En lo técnico, la diferencia entre espacio y cuerpo es conceptual, ${ }^{97}$ esto es, es la misma que la que constituye la diferencia entre género o especie del individuo, en tanto que en el cuerpo individual la extensión es considerada singularmente, mientras que en el espacio es considerada genéricamente. ${ }^{98}$ Por lo tanto, el 'espacio vacío' al que los hombres se refieren en el habla cotidiana, en la medida en que implica tridimensionalidad, es formalmente una porción de extensión. ${ }^{99}$

El reconocimiento de la ausencia de vacío en el mundo le exige a Descartes explicar el movimiento en el pleno. Dado el pleno, el movimiento de un cuerpo conlleva, a su vez, el desplazamiento de los cuerpos colindantes, que ‘ceden' su lugar y que 'toman' el lugar del cuerpo que se mueve. En este sentido, formalmente la traslación es recíproca. ${ }^{100} \mathrm{El}$ movimiento debe ser tal que, cuando un cuerpo se mueva, se desplaza también una totalidad que, en su movimiento, compensa los lugares en apariencia abandonados por el móvil -en el sentido de que no queda un lugar vacío. De este modo, Descartes necesitó un modelo teórico que le permita expresar este fenómeno según el cual un cuerpo se mueve “expulsando algún otro cuerpo del lugar al que llega, el cual a su vez expulsa a otro, y éste a otro, etc., hasta el último, el cual ocupa el lugar abandonado por el primero en el mismo momento en que lo dejó". ${ }^{101}$ El modelo teórico que permite explicar esto es el de

\footnotetext{
${ }^{95}$ Principia Philosophiae, AT, VIII, 2, § 5.

${ }^{96}$ Principia Philosophiae, AT, VIII, 2, § 13.

${ }^{97}$ Principia Philosophiae, AT, VIII, 2, § 12.

98 Principia Philosophiae, AT, VIII, 2, § 11. La distinción real entre cuerpos individuales ha sido un tema problemático en el pensamiento de Descartes. No obstante, de acuerdo con Slowik, 2001, esto no significa que para Descartes solamente la extensión como totalidad (y no los cuerpos 'individuales') puede ser entendida como sustancia.

${ }^{99}$ Principia Philosophiae, AT, VIII, 2, § 16.

${ }^{100}$ Principia Philosophiae, AT, VIII, 2, § 29.

${ }^{101}$ Principia Philosophiae, AT, VIII, 2, § 33. “(...) ita scilicet ut aliud aliquod corpus ex loco quem ingreditur expellat, hocque rursus aliud, et aliud, usque ad ultimum, quod in locum a primo derelictum, eodem temporis momento quo derelictus efs, ingrediatur”. Traducción: Descartes y Leibniz, 1989: 94-96.
} 
movimientos circulares, de modo que "[c]uando se produce un movimiento, se mueve al mismo tiempo un círculo completo de cuerpos". ${ }^{102} \mathrm{Y}$ no uno, sino todos los movimientos del mundo son de este tipo: ${ }^{103}$

Pero no nos damos usualmente cuenta de estos movimientos circulares cuando los cuerpos se desplazan en el aire, porque estamos acostumbrados a no concebir al aire más que como un espacio vacío. Pero mira a los peces nadar en la cuenca de una fuente; si no se aproximan demasiado a la superficie del agua no la van a sacudir, aunque pasen por debajo a una alta velocidad. De donde se sigue manifiestamente que el agua que empujan delante de ellos no empuja indiferentemente toda el agua de la cuenca, sino solamente aquella que puede servir mejor para perfeccionar el círculo de su movimiento y ocupar los lugares que son abandonados. Y estas experiencias alcanzan para mostrar cómo estos movimientos circulares son fáciles y familiares a la Naturaleza. ${ }^{104}$

El modelo circular para la explicación de los movimientos no carece de aspectos que deban ser analizados en detalle. El ejemplo que Descartes menciona en la cita anterior de peces que nadan en la cuenca de una fuente, puede interpretarse como el de un cuerpo sólido (el pez) que, cuando se mueve, genera la compensación por parte del cuerpo líquido que lo rodea (el agua). En un caso como éste (y lo mismo para cualquier otro), pueden distinguirse dos tipos de círculos que, en este ejemplo, dependen de la disposición del cuerpo duro en relación con la fuente, a saber, uno 'perfecto' y otro 'imperfecto'. La diferencia entre ellos debe ser tal que, no obstante, no contradiga la explicación del movimiento antes descrita. Considérese, por ejemplo, la siguiente imagen, en el que un cuerpo duro se ubica en el medio exacto del cuerpo líquido $\mathrm{ABCD}$ :

\footnotetext{
${ }^{102}$ Principia Philosophiae, AT, VIII, 2, § 33. "Quomodo in omni motu integer circulus corporum simul moveatur”. Traducción: Descartes y Leibniz, 1989: 94-96.

${ }^{103}$ Le Monde, AT, XI, 19.

${ }^{104}$ Le Monde, AT, XI, 19-20. "Or nous ne remarquons pas communément ces mouvemens circulaires, quand les corps se remuent en l'air, parce que nous sommes accoutumez de ne concevoir l'air que comme un espace vuide. Mais voyez nager des poissons dans le bassin d'une fontaine: s'ils ne s'approchent point trop prés de la surface de l'eau, ils ne la seront point du tout branler, encore qu'ils passent dessous avec une tres-grande vîtesse. D'où il paroist manifestement que l'eau qu'ils poussent devant eux, ne pousse pas indifferemment toute l'eau du bassin; mais seulement celle qui peut mieux servir à parfaire le cercle de leur mouvement, \& rentrer en la place qu'ils abandonnent. Et cette expérience suffit pour montrer, combien ces mouvemens circulaires sont aisez \& familiers à la Nature". La traducción es nuestra.
} 


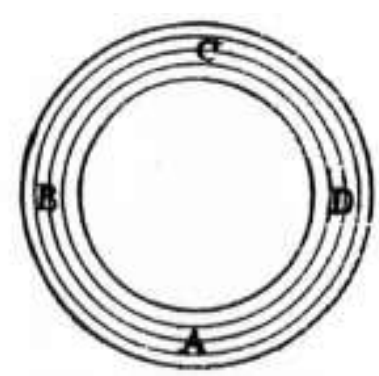

En este caso, el círculo es 'perfecto', en la medida en que la distancia desde el cuerpo duro hasta A es la misma que hasta B, C o D. De este modo, supuesto este caso de un círculo perfecto, cuando un cuerpo, como A, se mueve hacia B, B se mueve, a su vez, hacia C, y éste hacia $\mathrm{D}$, de manera que, finalmente, D ocupa el lugar dejado por A. ${ }^{105}$ Así, la compensación se manifiesta comprensible y viable. Ahora bien, ella debe serlo también en el caso de un círculo como el siguiente:

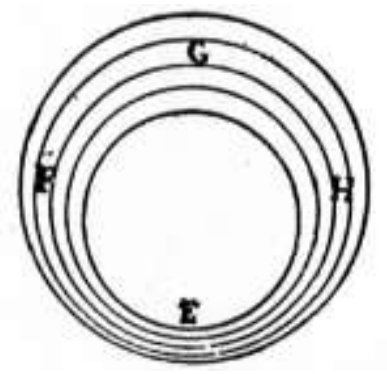

Aquí la distancia respecto del cuerpo duro varía en cada uno de los puntos del cuerpo líquido. Si, como dijimos, esta irregularidad no es impedimento para que lo mismo que se dijo anteriormente sea aplicado aquí, entonces, dado un movimiento, la materia en $\mathrm{E}$ se movería hacia F, del mismo modo que ella hacia $\mathrm{G}$, la cual se trasladaría hacia $\mathrm{H}$ que, finalmente, ocuparía el lugar de E. En esta traslación, sin embargo, la materia en H debería acomodar su figura al espacio en E justamente para poder llenarlo. La partición de la materia, entonces, debe ser tal que pueda acomodarse a cualquier estrechez de espacio y, por eso, debe poder ser tan pequeña como se requiera. Lo que compensaría la reducción del espacio es, eventualmente, la velocidad del movimiento: “y en los demás casos la velocidad del movimiento compensará también la reducción del espacio. De este modo, la cantidad de materia que pase por una parte de este círculo, en un tiempo determinado, será la misma que pasa por cualquiera otra". ${ }^{106}$

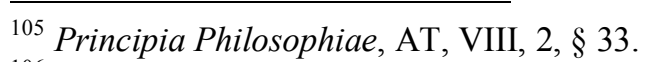

${ }^{106}$ Principia Philosophiae, AT, VIII, $2, \S 33$. "atque ita reliquis omnibus in locis motus celeritas angustiam loci compenset. Hoc enim pacto, in quovis determinato tempore, tantundem materiae per unam istius circuli 
La acomodación en virtud del movimiento a la estrechez del lugar conlleva, como requisito, que la materia esté dividida de tal manera que la compensación sea posible en cualquier caso. En la medida en que la estrechez puede ser de lo más variada, la división de la materia debe ser tal que sea susceptible de acomodarse a todas y cada una. De allí que Descartes mencione que la división es "al infinito, o indefinida", esto es, "en tantas partes que no podamos pensar en ninguna que no sea tan diminuta, que entendamos que no está dividida realmente en otras todavía más pequeñas". ${ }^{107}$ Esta tesis, que produjo una gran admiración por parte de Leibniz, ${ }^{108}$ le exigió a Descartes dilucidar dos cuestiones íntimamente relacionadas, a saber, la de la naturaleza del infinito y lo indefinido, así como la del conocimiento humano de ellas.

El hecho de que Descartes se haya referido a la división como 'al infinito o indefinida' es problemático, en la medida en que para él hay una diferencia conceptual entre estas nociones. Por un lado, aquello que se llame 'infinito' debe cumplir con dos condiciones. Negativamente, hay una condición cognitiva, a saber, debemos darnos cuenta de que carece por completo de límites. Positivamente, hay una condición ontológica, esto es, debemos entender que de hecho no tiene límites. Inversamente, se llama 'indefinido' aquello respecto de lo cual no podemos encontrar sus límites, si es que de hecho los tiene. ${ }^{109}$ Solamente Dios es, en el pensamiento cartesiano, aquello de lo que se puede estar

partem, quam per alteram transibit". La explicación, tal como la hemos expuesto, se presenta inmediatamente antes en el mismo parágrafo: "Sic tota materia contenta in spatio EFGH circulariter moveri potest absque ulla condensatione vel vacuo, et eodem tempore eius pars quae est versus E, transire versus $\mathrm{G}$, ac ea quae est versus $\mathrm{G}$, transire versus $\mathrm{E}$ : modo tantum, ut $<\mathrm{si}>$ spatium in $\mathrm{G}$ supponitur esse quadruplo latius quam in $\mathrm{E}$, ac duplo quam in $\mathrm{F} \& \mathrm{H}$, ita etiam quadruplo celerius moveatur in $\mathrm{E}$ quam in $\mathrm{G}$, ac duplo celerius quam in $\mathrm{F}$ vel H”. Traducción: Descartes y Leibniz, 1989: 94-96.

107 Principia Philosophiae, AT, VIII, 2, § 33. "nempe divisionem quarundam particularum materiae in infinitum, sive indefinitam, atque in tot partes, ut nullam cogitatione determinare possimus tam exiguam, quin intelligamus ipsam in alias adhuc minores reipsa esse divisam”. Traducción: Descartes y Leibniz, 1989: 9496.

${ }^{108}$ Cuando Leibniz, en 1692, escribe sus Animadversiones in partem generalem Principiorum Cartesianorum, indica, a propósito de los parágrafos que aquí se están considerando: "Sobre los artes. 33, 34 y 35. Muy apreciable y digno de su ingenio es lo que dice aquí Descartes, a saber, que todo movimiento en un lugar lleno supone un movimiento circular, y que es necesario que en alguna parte la materia esté dividida efectivamente en partes más pequeñas que cualquiera otra dada. Sin embargo, él mismo no parece haber visto todo el alcance de esta última conclusión" (utilizamos la traducción que se encuentra en Descartes y Leibniz, 1989: 153). Si bien es cierto que Leibniz escribe esto décadas después del contexto en el que se enmarca nuestro estudio, este comentario podría valer igualmente aquí. En cuanto a la denuncia final de la limitación en el tratamiento cartesiano, en el contexto que aquí se considera, en el próximo capítulo analizaremos el modo como Leibniz entiende el modelo de división de la materia fundado en los desarrollos sobre series infinitas que podría ser un aspecto de aquel alcance que le faltaría a la exposición de Descartes.

${ }^{109}$ Principia Philosophiae, AT, VIII, 1, § 27. 
seguro que carece por completo de límites. Por eso Descartes mismo aconseja utilizar el nombre de 'infinito' solamente para referirse a Él, mientras que para otras cuestiones, tales como la división de la materia o el problema de si se da una extensión sin límites, es preferible utilizar el de 'indefinido'. ${ }^{110}$ Sin embargo, esto no soluciona el uso ambiguo que Descartes hizo de los términos al referirse a la división de la materia: "[n]o quiero determinar si su número [de partes] es infinito o no; pero al menos es cierto que con respecto a nuestro conocimiento es indefinido, y que podemos suponer que hay varios millones en el más pequeño grano de arena que puede ser visto por nuestros ojos". ${ }^{111}$ De aquí se desprende la crítica de White y de Leibniz mencionada en el apartado precedente de este capítulo: si la indefinición se dice en relación con la limitación que el entendimiento humano tiene de conocer los límites, sería incorrecto decir que la división de la materia es indefinida. En este sentido, se confunde una limitación del pensamiento con una característica de la sustancia corpórea.

Debido a su condición específica, para Descartes la naturaleza misma de lo infinito es inaprehensible para el entendimiento finito humano. ${ }^{112} \mathrm{Si}$ se intentara determinar algo acerca del infinito, debería necesariamente limitarse; ${ }^{113}$ sin embargo, cualquier limitación es una imperfección, de manera tal que iría en contra de la perfección infinita que supone Dios (esto es, aquello único que propiamente puede y debe ser llamado infinito). ${ }^{114} \mathrm{La}$ naturaleza corpórea (cuya divisibilidad indefinida es lo que aquí se está considerando) no puede de ningún modo ser llamada infinita, en la medida en que para Descartes "ser divisible es una imperfección". ${ }^{115}$ Por eso, deberíamos decir que la división de los cuerpos es indefinida no sólo en virtud de su (posible) carencia de límites, sino de su condición de imperfección. Sin embargo, Descartes entiende que hay una limitación en la aplicación del concepto de lo indefinido a la división de la materia. El problema no es menor, pues se trata de la posible afirmación de la verdad de dicha división: por un lado, ella debe ser

\footnotetext{
${ }^{110}$ Principia Philosophiae, AT, VIII, 1, § 26.

${ }^{111}$ Le Monde, AT XI, 12. "Je ne veux point déterminer si leur nombre est infiny ou non; mais du moins il est certain, qu'à l'égard de nostre connoissance il est indéfiny, \& que nous pouvons supposer, qu'il y en a plusieurs millions dans le moindre petit grain de sable qui puisse estre apperceu de nos yeux". La traducción es nuestra.

112 Principia Philosophiae, AT, VIII, 1, § 19.

${ }_{113}$ Principia Philosophiae, AT, VIII, 1, § 26.

${ }^{114}$ Principia Philosophiae, AT, VIII, 1, § 22.

115 Principia Philosophiae, AT, VIII, 1, § 23. “(...) estque imperfectio esse divisibilem (...)”. Traducción: Descartes y Leibniz, 1989: 40.
} 
verdadera, pero por otro, el hombre no comprende cómo ocurre. ${ }^{116}$ Hay una tensión, entonces, entre la necesidad de afirmar la indefinición de la materia y la imposibilidad de comprender su división. La vía de escape cartesiana a esta tensión consiste en indicar que, aunque no comprendamos la división, se sigue de la naturaleza de la materia:

$\mathrm{Y}$ aunque no podamos comprender o abarcar con el pensamiento el modo en que ocurre esta división indefinida, no debemos dudar que ocurra, porque percibimos con claridad que tal división se sigue necesariamente de la naturaleza de la materia tal como evidentísimamente la conocemos, así como que se trata de una de las cosas que nuestra mente, por ser finita, no puede captar. $^{117}$

Como mencionamos anteriormente, recién en 1675 Leibniz leyó los Principia Philosophiae de Descartes. En las notas que dejó, ${ }^{118}$ se hace evidente que una de las grandes preocupaciones de Leibniz corresponde a los parágrafos de la segunda parte de este texto, en los que Descartes consideró el concepto de materia y el pleno que se basa en ella. Uno de los temas más atendidos por Leibniz es precisamente la infinitud o indefinición de la materia. Como hemos visto, Descartes se refirió a ella como 'al infinito o indefinida', dado que la división no pueda ser comprendida por la limitación que define a la mente humana. Sin embargo, como observa Leibniz, de ser así habría una ambigüedad irresoluble en el concepto de infinito, pues no se utilizaría exclusivamente para referirse a Dios, como inicialmente propuso Descartes. Una de las cosas que Leibniz enfatizó en las notas que se conservaron de su lectura de la obra cartesiana atiende precisamente al uso ambiguo del concepto de infinito que hace Descartes. En las notas sobre los Principia Philosophiae, Leibniz señala:

n. 26 y 27. En lugar de 'infinito', [Descartes] aconseja usar 'indefinido', es decir, [aquello] cuyos límites no pueden ser hallados por nosotros; también que el nombre de 'verdadero infinito' debe conservarse solamente para Dios. Pero contrariamente, [en] n. 36. part. 2., confiesa que la materia está realmente

\footnotetext{
${ }^{116}$ Principia Philosophiae, AT, VIII, 2, § 34.

117 Principia Philosophiae, AT, VIII, 2, § 35. "Et quamvis, quomodo fiat indefinita illa divisio, cogitatione comprehendere nequeamus, non ideo tamen debemus dubitare quin fiat: quia clare percipimus illam necessario sequi ex natura materiae nobis evidentissime cognita, percipimusque etiam eam esse de genere eorum quae a mente nostra, utpote finita, capi non possunt”. Traducción: Descartes y Leibniz, 1989: 97.

${ }^{118}$ Las notas pueden encontrarse en A VI $3, \mathrm{~N}^{\circ} 15$.
} 
dividida por un movimiento en partes menores que cualquiera asignable, y por lo tanto infinitas en acto. ${ }^{119}$

Leibniz detecta, por lo tanto, dos inconvenientes: por un lado, que la indefinición que Descartes le atribuye a la materia en realidad no tiene nada que ver con ella, sino con la imposibilidad que la inteligencia finita humana tiene de captar el límite de la división, si es que hay uno; ${ }^{120}$ por otro lado, que la justificación de la división debió llevarlo a afirmar no que la materia se divide en un número indefinido sino en uno infinito de partes. Esta segunda nota crítica, sin embargo, presupone un concepto de infinito que no es exactamente el mismo que Descartes tiene en cuenta cuando menciona que solamente es posible aplicar el nombre de 'infinito' a Dios. Analizar cómo entendió Leibniz el concepto de infinito en la tesis de la infinitud actual de partes no es sencillo. Por esta razón, dedicaremos el próximo capítulo a dilucidar esta cuestión.

Para finalizar este capítulo, recopilaremos las conclusiones parciales que hemos ido obteniendo a lo largo de las distintas secciones. En términos generales, hemos examinado el camino que condujo a Leibniz a la tesis del infinito actual en la materia en dos momentos. En primer lugar, hemos visto que Leibniz cuestionó la concepción de Thomas White según la cual en el continuo no hay partes actuales. En segundo lugar, hemos trazado un paralelismo entre los abordajes de Descartes y Leibniz sobre la naturaleza del cuerpo a los fines de reconstruir los argumentos que el filósofo de Leipzig podría haber empleado para concluir que lo indefinido de Descartes está en la mente. Para esto, dividimos el examen en tres partes. Por un lado, vimos que, mientras Descartes definió a la materia por la pura extensión, en sus primeras reflexiones Leibniz consideró que la impenetrabilidad también es una nota esencial de la materia. En siguiente lugar, hemos visto que Descartes estableció

\footnotetext{
${ }^{119}$ Zu Descartes' Principia Philosophiae, A VI 3, 214. “ $n$. 26. et 27. pro infinito indefinitum adhibere suadet, id est cuius limites a nobis inveniri non possunt, atque veri infiniti nomen servandum Deo solo. At contra $n$. 36. pars 2. fatetur materiam reapse dividi motu in partes qualibet assignabili minores, ac proinde actu infinitas".

${ }^{120}$ Concordamos con lo que ha dicho Bassler, 1998a: 2-3: “(...) Leibniz se aparta de lo que podríamos llamar (al menos desde la perspectiva de Leibniz) el finitismo epistemológico de Descartes: mientras que Descartes declara 'cum simus finiti, absurdum esset nos aliquid de ipso [infinito] determinare', y así descarta cualquier argumento que dependa de razonar sobre el infinito, Leibniz de hecho va a fundar toda su posición en la TMA (y luego) sobre la orientación provista por sus argumentos sobre la naturaleza del infinito".
} 
un espectro de cuerpos cuyos extremos son los cuerpos 'duros' y los 'líquidos', sobre la base del grado de movimiento de alejamiento que las partes posean. No obstante, el planteo cartesiano tiene el inconveniente de que el movimiento, fundamental para determinar dicho espectro de cuerpos, no es una nota esencial del cuerpo. Si bien en sus primeras reflexiones también consideró que el movimiento no es una nota esencial del cuerpo, más tarde Leibniz arribó a la conclusión contraria, esto es, que 'ser cuerpo' no es otra cosa que 'estar en movimiento'. Como consecuencia, a continuación vimos que para Leibniz una materia en reposo, homogénea y continua, no existe. De este modo, la variedad de la materia, esto es, la pluralidad de partes, se explica en virtud del movimiento. Finalmente, hemos visto que Descartes consideró que el número de partes es indeterminado, es decir, que no es posible saber si hay o no un número límite. No obstante, Leibniz consideró que este argumento cartesiano es deficiente, en la medida en que atribuye a la materia una limitación del pensamiento. Para el filósofo de Leipzig, por lo tanto, la división de materia no es indefinida sino al infinito. 


\section{CAPÍTULO 4: EL INFINITO Y LOS EXTREMOS DEL CONTINUO}

Como vimos en el capítulo precedente, una de las primeras conclusiones a las que Leibniz arribó en sus exámenes sobre la naturaleza corpórea es la existencia de infinitas partes actuales. Esta tesis es uno de los pilares sobre los cuales Leibniz desarrolló sus exámenes relativos a la composición del continuo. La primera manifestación de estas indagaciones leibnizianas se encuentra en un escrito que presentó a la Ilustre Academia Real de Francia en el año 1671, esto es, la TMA. Este fue el primer trabajo en el que Leibniz abordó ordenadamente el problema del movimiento, por lo que es un antecedente de lo que, tras muchos años de análisis, será su dinámica. Su preocupación por la teoría del movimiento surgió a raíz de un trabajo del científico holandés C. Huygens publicado en Philosophical Transactions ${ }^{1}$ (trabajo que Leibniz conocía gracias a Erich Mauritius) sobre las reglas de choque que ha escrito animado por la Real Academia de Londres. Por eso mismo, la TMA inicialmente formaba parte de un trabajo único junto con la Hypothesis physica nova de 1671 que finalmente fue enviada a la Real Academia de Londres. Como Leibniz había establecido relaciones con uno de los miembros de la Academia de París, Pierre de Carcavy, ${ }^{2}$ finalmente decidió separar los escritos y enviar uno a cada una de las dos academias. ${ }^{3}$ Aunque los exámenes de Leibniz de la TMA hayan ido profundizándose y muchas veces evolucionando en los años posteriores, se trata de una obra de gran importancia en el pensamiento de juventud del autor. Esto se debe, por una parte, a que es su primer intento histórico por abordar las razones universales de los movimientos al margen de las sensaciones y los fenómenos. ${ }^{4}$ En la segunda sección del primer capítulo explicamos la razón del proceder abstracto por parte de Leibniz en cuestiones relativas al movimiento. Asimismo, por otra parte, allí Leibniz presentó por primera vez un examen más o menos sistemático sobre el problema de la composición del continuo. Este aspecto del examen de Leibniz ha sido recientemente considerado, entre otros, por R. Arthur (por ejemplo, 1986, 1998, 2000, 2004, 2009, 2014, así como también en la introducción de

\footnotetext{
${ }^{1}$ La Philosophical Transactions of the Royal Society fue una de las primeras revistas científicas de la historia junto con Journal des Sçavans.

${ }_{2}^{2}$ Además de miembro de la Ilustre Academia Real de Francia, Pierre de Carcavy (ca. 1600-1684) fue el encargado de la biblioteca real.

${ }^{3}$ OFC 8, 73 y A VI 2, XXXI-XXXIII.

${ }^{4}$ Precisamente el título completo del escrito es "Theoria motus abstracti seu Rationes Motuum universales, a sensu et Phaenomenis independentes" (A VI 2, 259; OFC 8, 74).
} 
Leibniz, 2001), Ph. Beeley (por ejemplo, 1996, 1999), O. B. Bassler (1998a), J. Lawrenz (2010), etc. En una carta que Leibniz le envió a Pierre de Carcavy muy poco después de haber finalizado la redacción de la TMA, encontramos un resumen de los principales temas considerados, así como la ubicación de los respectivos tratamientos dentro de este escrito:

En la Teoría del movimiento abstracto se ha desarrollado: el laberinto de la composición del continuo, fund. predemost. 1-5, fund. 18; una demostración de la verdad de la Geometría de los indivisibles de Cavalieri, fund. 5, que hasta ahora solo había sido admitida con el valor de una hipótesis, porque de ella, si se la utiliza correctamente, pueden deducirse muchas verdades y ningún absurdo; ${ }^{5}$ la verdadera naturaleza del conato, fund. $6-16 ;{ }^{6}$ la primera e íntima razón de la cohesión o firmeza elaborada con certeza geométrica, fund. 15, 16, teor. $17 ;^{7}$ la verdadera distinción hasta ahora no considerada de la mente respecto del cuerpo, fund. 17; un examen de la discutida igualdad entre el ángulo de incidencia y el de reflexión, th. $7 ;^{8}$ una construcción física, esto es, exacta y al mismo tiempo real de las cosas geométricas, en los problem. ${ }^{9}$ producir una curva a partir de meros movimientos rectos y viceversa, probl. 6 , 7; producir un cilindro, un cono, una esfera a partir de meros cuerpos rectilíneos, probl. 17, 18, 19; producir cuerpos de secciones cónicas, probl. 20; acelerar y retardar continuamente un movimiento dado, probl. $24,25 .^{10}$

Como se ve, este repaso trasluce la centralidad del problema del continuo en la $T M A$. En este capítulo examinaremos la comprensión leibniziana de la estructura del continuo de la $T M A$, así como las variaciones que ella ha sufrido en el año siguiente a la

${ }^{5}$ Como veremos luego, Leibniz está refiriéndose a la Geometria indivisibilibus continuorum quadam nova ratione promota de Cavalieri a la que nos referimos en el segundo capítulo.

${ }^{6}$ Como veremos más adelante en este capítulo y especialmente en el quinto, el conato ha sido especialmente trabajado en el De corpore por Thomas Hobbes.

${ }^{7}$ El problema de la cohesión ha sido abordado por numerosos autores, entre los que se destacan en la época de Leibniz, a modo de ejemplo, las respuestas de tipo atomista de Galileo y Gassendi. Abordaremos este problema en el próximo capítulo.

${ }^{8}$ En esta cuestión Leibniz tiene especialmente en cuenta el trabajo de Hobbes de 1660 Examinatio et Emendatio Mathematicae hodiernae. Qualis explicatur in libris Johannis Wallisii geometriae professoris Saviliani in academia Oxoniensi. Distributa in sex dialogos, diálogo V (Hobbes, 1845b, vol. IV).

${ }^{9}$ Véase por ejemplo Hobbes, De corpore, IV.

${ }^{10}$ Leibniz a Pierre de Carcavy, A II 1, 236-237. "In THEORIA MOTUS ABSTRACTI, evolutum compositionis continui labyrinthum, fund. praedemonst. 1.-5. fund. 18.; demonstrationem veritatis Geometricae indivisibilium Cavalerii, fund. 5., quae hactenus ideo tantum probata est ad Hypotheseos cujusdam instar, quod multa vera, nihil absurdi, ex ea recte usurpata, deduci possit; veram naturam conatus, fund. 6.-15.; primam et intimam rationem cohaesionis seu firmitatis geometrica certitudine confectam, fund. 15. 16. theor. 17.; verum discrimen mentis a corpore hactenus intactum, fund. 17.; examen aequalitatis jactatae inter angulum incidentiae et reflexionis, th. 7.; constructionem physicam id est exactam simul et realem rerum geometricarum, in problem.; ex meris motibus rectis efficere curvum et contra, probl. 6. 7.; ex meris corporibus rectilineis efficere cylindrum, conum, sphaeram, probl. 17. 18 . 19.; corpora sectionum conicarum efficere, probl. 20.; datum motum continue accelerare ac retardare, probl. 24. 25". Para una presentación sucinta de los planteos de la TMA, véase, por ejemplo, Robinet, 1986: 144-151. 
publicación de dicha obra. Dado que, como vimos, para Leibniz en el continuo hay infinitas partes actuales, el examen que aquí emprenderemos exige analizar las maneras como el filósofo de Leipzig se habría representado una infinitud actual de partes en la TMA. Ahora bien, hay al menos tres dificultades que se presentan a la hora de llevar a cabo una reconstrucción como la que aquí pretendemos:

Por una parte, que hay una evolución de su posición que es interna al período delimitado, dado que en 1672 Leibniz discutió sus planteos previos. Por esta razón, en este examen se verán tanto los aspectos comunes de los planteos de la TMA y de 1672 como las diferencias entre ellos. Para mostrar esto, se procederá analíticamente, es decir, descomponiendo las soluciones leibnizianas del problema del continuo en distintos exámenes parciales que, reunidos, ofrecerán un panorama completo.

De lo anterior se sigue una segunda dificultad, a saber, que las soluciones de Leibniz se presentan como una conjunción de varios aspectos íntimamente conectados, es decir, como un bloque. De acuerdo con esto, el capítulo se estructurará de esta manera. En primer lugar analizaremos la manera como Leibniz habría entendido una infinitud actual de partes en la TMA. Sostendremos que para aclarar esto debemos remitirnos a sus indagaciones aritméticas del año siguiente. Así, buscaremos mostrar, mediante un examen de los primeros escritos aritméticos de Leibniz, que las reflexiones matemáticas de 1672 nos sirven para ver cómo habría entendido la división infinita actual en la TMA del año anterior. En segundo lugar, consideraremos el problema de los extremos de las partes que se dan en el continuo. Veremos inicialmente que Leibniz sostuvo que se dan extremos 'indivisibles' del espacio, el cuerpo, el tiempo y el movimiento que difieren de las partes extensas del continuo. Tras analizar este concepto, discutiremos la interpretación según la cual el continuo leibniziano de la TMA se compone de indivisibles. En tercer lugar, evaluaremos los problemas que Leibniz ha hallado en sus planteamientos de la TMA y que lo llevaron a introducir modificaciones en su manera de entender la composición del continuo en la etapa inmediatamente posterior. En ese respecto tiene un papel crucial la teoría leibniziana de los ángulos, entendida como la doctrina que trata sobre las cantidades de los inextensos, dado que de ella se seguiría una composición de indivisibles. Veremos, a su vez, que en 1672 Leibniz reconoció que sus exámenes de TMA no tomaron en consideración la interdependencia del espacio, el cuerpo y el movimiento. De acuerdo con 
esto, veremos que Leibniz argumentó que, como no hay espacios sin cuerpos ni cuerpos sin movimiento, se sigue que las porciones puntuales del continuo deben interpretarse como líneas infinitamente pequeñas que componen el continuo en su integridad.

Finalmente, la tercera dificultad se da por el hecho de que aquí aspiramos a comprender la estructura del continuo de los años antes mencionados, aunque el examen leibniziano comprenda aún más cosas. Por ejemplo, la estructura que analizaremos da lugar a soluciones de distintos problemas físicos, tanto relativos al movimiento como al cuerpo, que trascienden la intención de este capítulo. Estos problemas serán analizados en el capítulo quinto. En este sentido, una visión aún más integral de la comprensión leibniziana se obtendrá considerando este capítulo conjuntamente al menos con el tercero, el quinto y el sexto.

\section{Modelos de comprensión del infinito y la infinitud actual de partes del continuo}

El concepto de infinito fue empleado por Leibniz en ámbitos del pensamiento distintos, aunque sin embargo, como veremos, no por eso inconexos. En este sentido, por ejemplo, Leibniz lo ha empleado en la física al señalar, como vimos en el capítulo anterior, que en cualquier cuerpo dado hay infinitas criaturas. Sin embargo, el concepto de infinito encuentra también un lugar muy especial en la teoría de los números, esto es, en la aritmética. Especialmente, en aquella parte de esta disciplina denominada 'aritmética de los infinitos'. En lo que sigue veremos que la manera como Leibniz entendió una infinitud actual de partes en la TMA podría aclararse a partir de su trabajo posterior en aritmética de los infinitos, en particular, sobre series infinitas. ${ }^{11}$ Así, Leibniz habría comprendido que el infinito actual obedece a un orden determinado, por lo que las partes, que en las series infinitas están representadas en las fracciones, no pueden ser escogidas o asignadas arbitrariamente.

\footnotetext{
${ }^{11}$ No obstante, esto no quita que Leibniz haya propuesto distintos enfoques en los abordajes de TMA y en los escritos de aritmética en los que nos basaremos. Por ejemplo, como señala Beeley, 2009, mientras que en $T M A$ adoptó una aproximación ontológica del continuo (cuestión que veremos en este capítulo), en el escrito Accessio ad arithmeticam infinitorum (al que nos referiremos en breve) apela a la fuerza argumentativa provista por las pruebas matemáticas, tales como las relativas a una progresión infinita dentro de límites o términos finitos.
} 
Como es sabido, Leibniz no tuvo grandes conocimientos técnicos de matemática hasta su llegada a París en 1672, a pesar de haberse interesado por algunas cuestiones más bien epistemológicas, como por el método deductivo de la matemática y por el aspecto formal de la computación (por ejemplo, en su Dissertatio de arte combinatoria de 1666 ). ${ }^{12}$ En sus años escolares había tenido apenas contacto con el primer libro de los Elementos de Euclides (incluso, posiblemente con una versión abreviada) y con algunos trabajos aritméticos como el de Ch. Clavius (1537-1612) publicado en 1585, Epitome arithmetica practica, o el de Jo. Lanz (1564-1638) editado en 1616, Institutiones arithmeticae. Una vez graduado amplió un poco sus conocimientos - por ejemplo, tuvo en sus manos la Geometria indivisibilibus continuorum quadam nova ratione promota de B. Cavalieri-, pero sin lograr gran profundidad. ${ }^{13}$ Poco después de haber llegado a la capital francesa en 1672, Leibniz conoció a Christiaan Huygens (1629-1695), bajo cuya tutela comenzó a trabajar en los aspectos más bien técnicos de la matemática, especialmente de la aritmética. Incluso, fue Huygens quien le advirtió a Leibniz de la Arithmetica infinitorum de John Wallis y del Opus geometricum de Grégoire de Saint-Vincent. ${ }^{14}$ En efecto, uno de los primeros desafíos que el científico holandés le propuso a Leibniz fue que llevara a cabo la suma de la serie de los recíprocos de los números triangulares (esto es, $\frac{1}{1}, \frac{1}{3}, \frac{1}{6}, \frac{1}{10}$,etc.), o sea, de una serie infinita. ${ }^{15}$ No obstante, los resultados del trabajo de Leibniz fueron mucho más allá, pues además de cumplir con las expectativas de Huygens propuso una regla universal para la suma de series infinitas (que, por una cuestión de orden, será considerada en el sexto capítulo). ${ }^{16}$ A raíz de esto, Leibniz redactó un trabajo en el que sintetizó los resultados de sus primeras investigaciones matemáticas y se lo envió al entonces director del Journal des Sçavans, Jean Gallois, para ser publicado (aunque finalmente no lo haya sido por motivos ajenos a Leibniz). En este escrito, titulado Accessio ad arithmeticam infinitorum, es decir, Introducción a la aritmética de los infinitos, Leibniz llevó a cabo un examen sobre series infinitas que nos permite representarnos la manera como habría entendido anteriormente, en

\footnotetext{
${ }^{12}$ Como señalamos en la introducción general, algunos años más tarde Leibniz le confesó a Johann Friedrich que la verdadera razón por la que permaneció tanto tiempo en París fue la búsqueda de conocimiento matemático: A II 1, 753-754. Beeley, 2009.

${ }^{13}$ Véase Hofmann, 1974: 1-11 para los conocimientos matemáticos de Leibniz antes de su estadía en París.

${ }^{14}$ Breger, 1990: 59. Montesinos Sirera, 2009: 81-82.

${ }^{15}$ Leibniz mismo narra la historia en Leibniz a J. Gallois, A II 1, 344.

${ }^{16}$ Leibniz a J. Gallois, A II 1, 345.
} 
la $T M A$, una infinitud actual de partes. En efecto, como veremos, en estas series hay [a] infinitos términos (en el sentido de que no hay un último término asignable) [b] generados según un orden (esto es, según la ley de la serie) [c] que, sumados -excepto en algunos casos que serán examinados en el sexto capítulo-, dan lugar a un todo finito. En consonancia, las infinitas partes actuales del continuo de la TMA pueden representarse como los términos de la serie que no pueden ser escogidos arbitrariamente y que, agregados, dan lugar a una cierta totalidad finita.

Decir que Leibniz analiza el infinito en sus exámenes aritméticos no significa ni que haya sido especialmente novedoso en este terreno más allá de la regla para la suma de series a la que hemos aludido anteriormente, ni mucho menos que haya sido el primero en considerar estos asuntos. Más aún, Leibniz reconoce que la aritmética de los infinitos fue revitalizada en su tiempo por el matemático británico John Wallis (1616-1703). La historia del tratamiento matemático del infinito remite incluso hasta el pensamiento de la antigua Grecia. En algún sentido, el punto de partida de esta historia puede hallarse en el método de exhaución de Arquímedes (que fue el resultado de un perfeccionamiento del de Eudoxo). ${ }^{17}$ En los siglos XVI y XVII han sido fundamentales los trabajos de L. Valerio, J. Kepler, B. Cavalieri, G. Galilei, Grégoire de Saint-Vincent, Gilles Personne de Roberval, entre muchos otros. ${ }^{18}$ A su vez, el infinito ha sido objeto de un tratamiento no matemático sino filosófico fundamentalmente desde Aristóteles y el pensamiento escolástico del siglo XIII en adelante, destacándose por ejemplo la discusión sobre el problema del continuo, el

${ }^{17}$ Por una cuestión de orden, examinaremos algunos lineamientos centrales de este método en el séptimo capítulo.

${ }^{18}$ Para esto, véase Boyer, 1949, especialmente capítulo 2 y 4. Luca Valerio (1553-1618) toma el método de exhaución de Arquímedes e intenta mantener el rigor de la demostración omitiendo el procedimiento de reducción al absurdo. Con esto, logra anticiparse el concepto de límite en una forma geométrica, diciendo que la diferencia entre áreas puede ser menor que cualquier área especificada. Examinando el problema de la cuadratura del círculo, J. Kepler (1571-1630) toma al círculo como un polígono infinitángulo y considera que su área debe ser pensada como compuesta de triángulos infinitesimales. En este sentido, se refiere a "elementos infinitesimales" a los que ocasionalmente llama "indivisibles". Los lineamientos centrales del "método de los indivisibles" de B. Cavalieri (1598-1647), así como también las ideas de Galileo (1564-1642), fueron examinados en el segundo capítulo. Con Grégoire de Saint-Vincent (1584-1667) el método de exhaución deja de 'aproximarse' a la figura que está siendo examinada para verdaderamente 'agotarla'. En este sentido, el procedimiento continúa al infinito. De acuerdo con Boyer, Grégoire de Saint-Vincent fue posiblemente el primero en referirse explícitamente al límite de una serie infinita, aunque sin considerar la suma de dicha serie. Más aún, consideró que las paradojas de Zenón se explican en términos del límite de una serie infinita. Roberval (1602-1675), por su lado, ha defendido una composición homogénea de las figuras geométricas, considerando a los elementos de los que se componen como infinitamente pequeños, aunque por una cuestión de época los denominó 'indivisibles'. En este sentido, por ejemplo, una línea se compone de infinitas líneas infinitamente pequeñas. 
infinito y los indivisibles y sobre la actualidad o potencialidad del infinito en autores como T. Bradwardine, G. de Ockham, o posteriormente N. de Cusa. ${ }^{19}$ En el siglo de Leibniz, además de la revitalización de la aritmética de los infinitos por parte de Wallis, merecen una mención especial los exámenes de Pascal en relación con su Traité du triangle arithmétique de 1665. Como hemos dicho, aquí nos interesa mostrar que el examen leibniziano sobre series infinitas de 1672 permite que nos representemos la manera como Leibniz habría entendido la infinitud actual de partes del continuo en la TMA. Ahora bien, Leibniz tiene en cuenta dos tipos de series, según los procedimientos que determinan su generación. Por este motivo, a continuación consideraremos por separado estas dos variantes, refiriéndonos a ellas como 'dos modelos', para mostrar posteriormente que los escritos sobre el problema del continuo, tanto del año en que redactó la Accessio como del año anterior, se valen especialmente de uno de ellos.

El primer modelo mediante el cual podemos representarnos que Leibniz habría entendido una infinitud de partes actuales es el de series "decrecientes con una progresión Geométrica al infinito". ${ }^{20}$ En las series de este tipo, las partes son proporcionales, esto es, están divididas según una ratio que permanece constante. ${ }^{21}$ En este sentido, en estas series

\footnotetext{
${ }^{19}$ En cuando al examen de los escolásticos, Boyer, 1949, capítulo 3. Thomas Bradwardine (1290-1349) sostuvo que, aunque las magnitudes continuas incluyen un número infinito de indivisibles, no se componen de ellos sino de un número infinito de continua del mismo tipo. Ockham (ca. 1280-ca. 1349), por su lado, no admite que las partes sean indivisibles, aunque mantiene que una línea recta consiste de puntos no en potencia sino en acto. No obstante, señala también que los puntos, las líneas y las superficies son puras negaciones que no tienen realidad. Pedro Hispano reconoce dos tipos de infinito, en uno de los cuales todos los términos son actuales (empleando una denominación posterior, Boyer se refiere como "infinito categoremático"), y otro que implica cierta potencialidad de los términos ("sincategoremático"). De acuerdo con Bradwardine el primero sería una cantidad sin fin, mientras que el segundo sería una cantidad que siempre puede hacerse más grande. Nicolás de Cusa (1401-1464), en línea con el platonismo, asocia las entidades matemáticas con la realidad desde un punto de vista ontológico. De esta manera, la matemática no es concebida como una ciencia de la cantidad sino que es a priori o independiente de los sentidos. Este marco deja lugar a la posibilidad de admitir una referencia a lo indivisible y lo infinito, mientras tanto no haya inconsistencias en el pensamiento. Así, se produce un notable avance epistemológico, pues lo infinito y lo infinitamente pequeño pasan a ser reconocidos como parte del objeto de la matemática, cosa que no era admitida por Aristóteles. El uso que Nicolás de Cusa ha hecho del infinito y de lo infinitesimal no ha sido meramente como potencialidades, sino como actualidades que, en el caso de la aritmética, son los límites 'mayor' y 'menor' de la serie de los números naturales. Desde el punto de vista de la geometría, entendió que el círculo es un polígono infinitángulo, de manera que es posible hallar su área de la misma manera en que es posible obtenerlo para cualquier polígono, a saber, dividiéndolo en un número (infinito en este caso) de triángulos.

${ }^{20}$ Leibniz a Jean Gallois, A II 1, 343. "Veteres dedere nobis Regulam ineundi summam Fractionum sive Rationum Geometrica progressione in infinitum decrescentium". Leibniz, 2014: 52.

${ }^{21}$ Para denominarlas de esta manera tenemos en cuenta la noción de 'proporción' que Leibniz ha presentado algunos años más tarde: "Proportio est rationum aequalitas". De magnitudine, A VI 3, 483.
} 
una subsección es a una sección lo que ella es al todo. ${ }^{22}$ A modo de ejemplo, Leibniz expone en una línea una serie de fracciones tales que cada una sea una tercera parte de la anterior (de manera que la proporción sea la de un tercio):

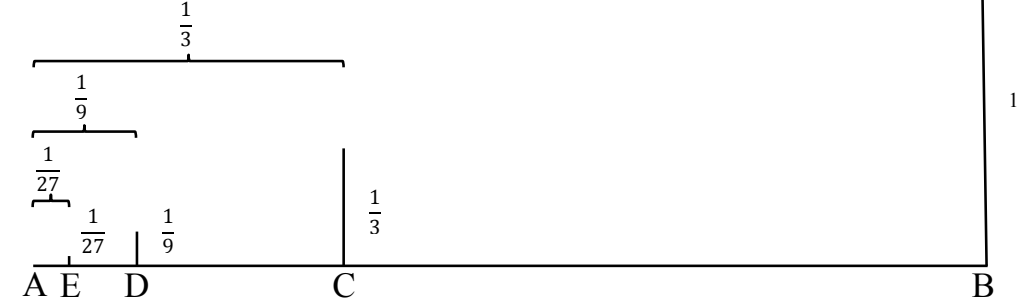

El hecho de que Leibniz exponga estas series en líneas es muy significativo para el problema del continuo. Por una cuestión de orden, examinaremos esto un poco más adelante, luego de presentar los dos modelos de series. En este ejemplo de Leibniz se observa la propiedad mencionada anteriormente, es decir, que entre una sección y el todo se mantiene la misma ratio que entre una subsección y una sección, de tal modo que el todo $\mathrm{AB}$ es a $\mathrm{AC}$ proporcionalmente lo mismo que $\mathrm{AC}$ a $\mathrm{AD}$, y así sucesivamente, esto es: $\frac{A B}{A C}=\frac{A C}{A D}=\frac{A D}{A E}=$ etc. En este ejemplo particular, cada subsección representa una tercera parte de la sección en la cual se incluye. De esta manera, $\mathrm{AC}$ es $\frac{1}{3} A B$, así como $\mathrm{AD}$ es $\frac{1}{3} A C$ y por eso mismo $\frac{1}{9} A B$, del mismo modo que $\mathrm{AE}$ es $\frac{1}{3} A D$ y $\frac{1}{27} A B$, y así sucesivamente.

Ahora bien, en la Accessio Leibniz abordó también otro tipo de series que en cuanto tales expresan otro modelo con el cual habría entendido una infinitud actual de partes. En este caso, no se trata de series que decrecen según una progresión geométrica al infinito sino de series que decrecen, utilizando una expresión de Leibniz, según los recíprocos de "alguna progresión aritmética replicada". ${ }^{23}$ Un ejemplo de series de este tipo es el que Huygens le planteó a Leibniz para que busque su suma, a saber, la serie de los recíprocos de los números triangulares. A decir de Leibniz, las 'progresiones aritméticas replicadas' son las mismas series que Pascal ha expuesto en su Traité du triangle arithmétique, es

\footnotetext{
${ }^{22}$ Leibniz a Jean Gallois, A II 1, 343. Allí Leibniz explica esta propiedad y menciona el ejemplo que daremos a continuación.

${ }^{23}$ Leibniz a Jean Gallois, A II 1, 345-346. "Et hi sunt Numeri, quorum series, alii vocant Ordines Numericos, alii Combinatorios, alii Numeros Progressionis Symmetricae, Pascalius eorum usus sane multos exposuit in Triangulo Arithmetico, seu tractatu quem de iis dedita opera scripsit. Ego Numeros appellare soleo, Progressionis Arithmeticae Replicatae". Traducción: Leibniz, 2014: 55.
} 
decir, son las series del triángulo de Pascal: ${ }^{24}$

$\begin{array}{lrrrrrrrrrr}{[\mathrm{A}]} & 1 & 1 & 1 & 1 & 1 & 1 & 1 & 1 & 1 & 1 \\ {[\mathrm{~B}]} & 1 & 2 & 3 & 4 & 5 & 6 & 7 & 8 & 9 & \\ {[\mathrm{C}]} & 1 & 3 & 6 & 10 & 15 & 21 & 28 & 36 & & \\ {[\mathrm{D}]} & 1 & 4 & 10 & 20 & 35 & 56 & 84 & & \\ {[\mathrm{E}]} & 1 & 5 & 15 & 35 & 70 & 126 & & & \\ {[\mathrm{~F}]} & 1 & 6 & 21 & 56 & 126 & & & & \\ {[\mathrm{G}]} & 1 & 7 & 28 & 84 & & & & & \\ {[\ldots]} & 1 & 8 & 36 & & & & & & & \\ & 1 & 9 & & & & & & & \end{array}$

Como puede observarse en la tabla, el triángulo expone números de distintos órdenes que se determinan según un procedimiento estipulado. En cualquiera de los órdenes, de acuerdo con Pascal, los términos de una serie son a su vez las diferencias de los términos de la serie del orden inmediatamente anterior. ${ }^{25}$ De esta manera, las unidades, que se observan en el primer nivel de la tabla, constituyen el primer orden (serie [A]), al mismo tiempo que son las diferencias de los términos del segundo orden. Dicho de otra manera, los números de segundo orden (serie [B]) son aquellos que se forman por la adición de los números del primer orden, esto es, de unidades. De esta manera, los números de segundo orden son los naturales, esto es, 1, 2, 3, 4, etc. Este mismo procedimiento puede replicarse al infinito, dando lugar a series de distinto orden. Así, luego de la de los números naturales se halla la serie de los triangulares (serie [C]), esto es, de los números que se forman por sumar los naturales $(1,3,6,10,15$, etc.), en siguiente lugar se encuentra la serie de los piramidales (serie [D]), los cuales números se forman por la adición de los triangulares (1, 4, 10, 20, etc.), y así sucesivamente al infinito. Pascal sintetiza el resultado de este procedimiento en la siguiente tabla: ${ }^{26}$

\begin{tabular}{cc|cccccc} 
& 1 & 2 & 3 & 4 & 5 & Etc. \\
\cline { 2 - 7 } Unidades & Orden 1 & 1 & 1 & 1 & 1 & 1 & Etc. \\
Naturales & Orden 2 & 1 & 2 & 3 & 4 & 5 & Etc. \\
Triangulares & Orden 3 & 1 & 3 & 6 & 10 & 15 & Etc. \\
Piramidales & Orden 4 & 1 & 4 & 10 & 20 & 35 & Etc. \\
& Etc. & & & & & &
\end{tabular}

Ahora bien, como hemos dicho, las series para las cuales Leibniz propuso una regla

\footnotetext{
${ }^{24}$ Leibniz se refiere a estas series en Leibniz a J. Gallois, A II 1, 345-346.

${ }^{25}$ Pascal, 1665: 2.

${ }^{26}$ El cuadro se encuentra en Pascal, 1665: 3. La traducción es nuestra.
} 
de suma en la Accessio no son formalmente las expuestas por Pascal en su triángulo aritmético sino las de los recíprocos de dichas series. Utilizando una expresión que en rigor empleó unos años más adelante, a partir del 'triángulo aritmético' de Pascal Leibniz construye el de los recíprocos correspondientes y que llamó 'triángulo armónico', esto es: ${ }^{27}$

Recíprocos de TRIÁNGULO ARMÓNICO

$\begin{array}{cccccccc}\text { Naturales } & \frac{1}{1} & \frac{1}{2} & \frac{1}{3} & \frac{1}{4} & \frac{1}{5} & \frac{1}{6} & \text { Etc. } \\ \text { Triangulares } & \frac{1}{1} & \frac{1}{3} & \frac{1}{6} & \frac{1}{10} & \frac{1}{15} & \text { Etc. } & \\ \text { Piramidales } & \frac{1}{1} & \frac{1}{4} & \frac{1}{10} & \frac{1}{20} & \text { Etc. } & \\ \text { Triángulo- } & \frac{1}{1} & \frac{1}{5} & \frac{1}{15} & \text { Etc. } & & \\ \text { Triangulares } & \frac{1}{1} & \frac{1}{6} & \text { Etc. } & & & \\ \text { Triángulo- } & \frac{1}{1} & \frac{1}{1} & \text { Etc. } & & & & \\ \text { Piramidales } & & & & & \\ \text { Piramido- } & \frac{1}{\text { Piramidales }} & & & & \end{array}$

Leibniz se refiere a este tipo de series como 'replicadas' porque, si se sustituyera la unidad como generador de la serie por otro número, se replicaría proporcionalmente toda la serie. Por ejemplo, si en vez de 1 el generador fuese 2, la serie que se obtendría en el caso de las fracciones triangulares sería $\frac{2}{2}, \frac{2}{6}, \frac{2}{12}$ etc. Ahora bien, precisamente por decrecer según los recíprocos de alguna progresión aritmética replicada, estas series no decrecen con una progresión geométrica, es decir, sus términos no son proporcionales. En esto difieren precisamente los dos modelos con los cuales podemos representarnos que Leibniz ha entendido una infinitud actual de partes. Sin embargo, entre estos dos modelos hay, como se ha dicho, una estructura común, pues en ambos la partición del todo debe responder a una cierta ley de sucesión tal que cada término sea menor que el anterior. Por eso mismo, en ambos modelos las fracciones no pueden ser escogidas o asignadas arbitrariamente.

Como hemos dicho al comienzo, los exámenes aritméticos de Leibniz son aquí importantes para observar el infinito presente en las series infinitas y en consecuencia para comprender, a partir de allí, la tesis de la infinitud actual de partes en el continuo. En lo siguiente mostraremos que, en la primera mitad de la década de 1670, Leibniz se ha

\footnotetext{
${ }^{27} D Q A, \mathrm{XL}, 230$. En la misma página puede hallarse la tabla sobre la que basamos el gráfico presentado a continuación.
} 
representado una infinitud actual de partes en el continuo según el modelo de las series infinitas. Aunque quizás sea en última instancia irrelevante qué tipo de series haya tenido en mente al considerar la infinitud de partes del continuo, Leibniz inicialmente ha tenido en cuenta el primer modelo, esto es, el de las series que decrecen según una progresión geométrica. Aunque será examinado detalladamente en el sexto capítulo, es significativo en relación con el problema del continuo el hecho de que la suma de muchas de las series, sea del primer o del segundo tipo, den por resultado cantidades finitas. Es significativo, decíamos, porque esto le ha permitido a Leibniz justificar sin absurdos que infinitas partes actuales no constituyen una cantidad infinita en magnitud. ${ }^{28}$ De esta manera, por ejemplo, la suma de la serie que decrece geométricamente en mitades es $\frac{1}{2}+\frac{1}{4}+\frac{1}{8}$ etc. $=\frac{1}{1}$; similarmente, la suma de la serie de los recíprocos de los números triangulares es $\frac{1}{1}+\frac{1}{3}+$ $\frac{1}{6}+\frac{1}{10}+\frac{1}{15}+\frac{1}{21}+\frac{1}{28}+$ etc. $=2 .^{29}$ Así, aunque sean series de distinto tipo, lo importante es que para que una suma infinita dé como resultado un todo finito, las fracciones componentes deben responder a un orden de sucesión dado. ${ }^{30}$

Veamos a continuación de qué manera los desarrollos de Leibniz de 1672 sobre series infinitas nos permiten representarnos la manera como habría entendido la infinitud actual de partes del continuo en la TMA. Anteriormente hemos señalado a la pasada que, para explicar las series en las cuales los términos son proporcionales, Leibniz se vale del recurso de exponerlas en líneas. ${ }^{31}$ Ahora bien, en los escritos en los que examina la tesis de la infinitud actual de partes en el continuo, sigue el mismo procedimiento, esto es, expone mediante una línea geométrica el continuo que está examinando. Así, por ejemplo, en el cuarto fundamento predemostrable de la TMA puede verse que, en el intento de justificar que se dan indivisibles en el continuo, Leibniz lleva a cabo una división de una magnitud, representada en la línea $a b$, en partes proporcionales:

\footnotetext{
${ }^{28}$ Si se pensara en términos geométricos, podría decirse "una cantidad infinita en extensión".

${ }^{29}$ Ambos ejemplos pueden encontrarse en Leibniz a Jean Gallois, A II 1, 344. Leibniz, 2014: 53.

${ }^{30} \mathrm{Sin}$ embargo, como veremos en el sexto capítulo, no todas las series infinitas dan por resultado cantidades finitas.

${ }^{31}$ Grosholz, 2015: 82, señala interesantemente, a propósito del examen leibniziano del tiempo, que el recurso a la exposición en una línea debe entenderse tanto en una clave aritmética como en una clave geométrica. Aritméticamente, expresa que el tiempo es asimétrico y que se mide en unidades, como segundos o años; geométricamente, expresa que el tiempo es continuo y que las unidades de medida no son atómicas. Asimismo, desde esta perspectiva se puede llegar analíticamente a puntos que, no obstante, no componen a las líneas (como por otra parte las unidades componen a los números) sino que son sus límites.
} 
Se dan los indivisibles o inextensos, de otro modo no puede entenderse ni el inicio ni el fin del movimiento o del cuerpo. La demostración es esta: se da el inicio y el fin del algún espacio, cuerpo, movimiento, tiempo; sea aquello cuyo inicio se busca expuesto en la línea $a b$, cuyo punto medio es $c$, y sea $d$ el medio entre $a$ y $c$ y $e$ entre $a$ y $d$, y así sucesivamente. Búsquese el inicio por la izquierda, en el lado $a$. Digo que $a c$ no es el inicio, puesto que puede quitársele $d c$ conservado el inicio; ni ad [es el inicio] puesto que puede quitarse ed [conservado el inicio], y así sucesivamente. Por consiguiente, no es un inicio algo a lo cual puede quitarse [una parte] a la derecha. [Algo] a lo cual no puede quitarse extensión es inextenso. Por consiguiente, el inicio del cuerpo, del espacio, del movimiento, del tiempo (el punto, el conato, el instante) o no es nada, lo que es absurdo, o es inextenso, que era lo que debía demostrarse. ${ }^{32}$

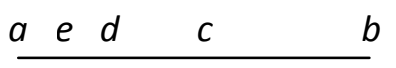

El análisis de los indivisibles será considerado en el tercer apartado de este capítulo, de modo que la justificación de su existencia no será examinada en este momento. Aquí nos interesa ver que, mediante su exposición en una línea, Leibniz divide al continuo en partes que son cada una de ellas la mitad de la anterior, esto es, según la serie conocida como 'serie de Zenón'. ${ }^{33}$ De esta manera, procede dividiendo primero la línea $a b$ en su mitad $a c$, para luego dividir esta sección nuevamente al medio, resultando de esta división $a d$, y así sucesivamente. De esta manera, $\frac{a b}{a c}=\frac{a c}{a d}=\frac{a d}{a e}=$ etc., esto es, se respeta aquí la propiedad de las series mencionada anteriormente según la cual entre una subsección y una sección se mantiene la misma razón que entre dicha sección y el todo. Como en este caso cada subsección representa la mitad de la sección en la cual se incluye, $a c$ es $\frac{1}{2} a b$, así como $a d$ es $\frac{1}{2} a c$ y por eso mismo $\frac{1}{4} a b$, del mismo modo que ae es $\frac{1}{2} a d$ y $\frac{1}{8} a b$, y así sucesivamente. En este sentido, este abordaje de Leibniz es notablemente similar al de Froidmont que

\footnotetext{
${ }^{32}$ TMA, A VI 2, 264. “(4.) Dantur indivisibilia seu inextensa, alioquin nec initium nec finis motus corporisve intelligi potest. Demonstratio haec est: datur initium finisque spatii, corporis, motus, temporis alicuius: esto illud cuius initium quaeritur, expositum linea $a b$, cuius punctum medium $c$, et medium inter $a$ et $c$ sit $d$, et inter $a$ et $d$ sit $e$, et ita porro: quaeratur initium sinistrorsum, in latere $a$. Aio ac non esse initium quia ei adimi potest $d c$ salvo initio; nec $a d$, quia $e d$ adimi potest, et ita porro; nihil ergo initium est, cui aliquid dextrorsum adimi potest. Cui nihil extensionis adimi potest, inextensum est; initium ergo corporis, spatii, motus, temporis (punctum nimirum, conatus, instans) aut nullum, quod absurdum, aut inextensum est, quod erat demonstrandum". OFC, 8, 79-80.

${ }^{33}$ Véase Arthur, 2014: 79 y ss.
} 
hemos explorado en el capítulo segundo. ${ }^{34}$

De esta manera, el hecho de exponer en líneas es una suerte de nexo epistemológico entre la aritmética y la física mediante la geometría, pues Leibniz expone en líneas (que son entidades geométricas) tanto series infinitas de números (entidades aritméticas) como un espacio, un cuerpo, un movimiento o un tiempo (entidades físicas). Dicho de otro modo, la manera de entender la división actual infinita del continuo fue para Leibniz idéntica a la partición de una línea geométrica que representa una serie infinita. Por eso, como atinadamente ha señalado $\mathrm{Ph}$. Beeley, la física leibniziana de estos años tiene un 'núcleo matemático'. ${ }^{35}$ Veamos el siguiente pasaje de un escrito de 1672 en el que también se considera la relación proporcional que se da entre el espacio, el tiempo y el movimiento:

Sea el espacio $a b$. Entiéndase que en él marcha el cuerpo $C$, con un movimiento uniforme, y atraviesa, en el espacio de una hora, de $a$ hasta $b$. Es necesario que, en el espacio de media hora, atraviese hasta $d$, y en el espacio de un cuarto [de hora] hasta $e$, y en un octavo [de hora] hasta $\mathrm{f}$, y así dividiendo continuamente el espacio y el tiempo en la misma razón. ${ }^{36}$

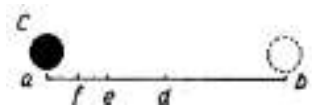

De acuerdo con Leibniz, dado un movimiento uniforme (es decir, uno que se mantenga constante, sin aumentar ni disminuir su velocidad a lo largo del trayecto recorrido), el espacio y el tiempo se dividirán en la misma razón. Por eso, la porción de espacio recorrido será proporcional a la de tiempo transcurrido. En este sentido, hay una isomorfía entre el espacio y el tiempo que tiene como una de sus consecuencias que la geometrización del espacio llevada a cabo por Leibniz acarrea necesariamente la del tiempo y, en fin, de los restantes continuos. ${ }^{37}$ Como se observa, la manera con la que Leibniz se representa dicha proporcionalidad no es otra que dividiendo el espacio y el tiempo en partes que decrecen al infinito con una progresión geométrica.

Hasta aquí hemos visto que los desarrollos de Leibniz sobre series infinitas podrían esclarecer el modo como ha comprendido infinitas partes actuales en el continuo de TMA,

\footnotetext{
${ }^{34}$ Recordemos que, como hemos mencionado también en el segundo capítulo, Leibniz ya conocía la obra de Froidmont en 1671.

${ }^{35}$ Véase Beeley, 1999. Incluso, en este trabajo considera particularmente el hecho de que la tesis del infinito actual leibniziano tiene sus orígenes en el continuo geométrico.

${ }^{36}$ Demonstratio substantiarum incorporearum, A VI 3, 81: "Esto spatium $a b$, in eo ferri intelligatur corpus $C$ motu uniformi et horae spatio pervenire ex $a$ in $b$, necesse est semihorae spatio pervenire in $d$ et spatio quadrantis in $e$ et semiquadrantis in $f$ et sic perpetuo subdividendo in eadem ratione locum et tempus".

${ }^{37}$ Retomaremos la relación que hay para Leibniz entre el tiempo y el espacio en el sexto capítulo.
} 
todo lo cual se funda epistemológicamente en la posibilidad de representarse geométricamente tanto una serie infinita como un continuo físico. No obstante, según la exposición que Leibniz ha ofrecido en la TMA quedaría aún un problema por resolver, a saber, el de los extremos indivisibles del continuo.

\section{Los extremos del continuo}

Tampoco un punto puede suceder a un punto, o un «ahora» a un «ahora», de tal manera que lo que resulte de ello sea una longitud o un tiempo; pues dos cosas están en sucesión si no hay entre ellas ninguna otra cosa del mismo género, pero entre dos puntos hay siempre una línea y entre dos ahoras hay siempre un tiempo.

ARISTÓTELES, Physica, 231b6-10.

En el cuarto fundamento predemostrable de la $T M A$ citado en el apartado anterior, Leibniz manifiesta que no pueden entenderse ni el 'inicio' ni el 'fin' de algún espacio, cuerpo, movimiento o tiempo (es decir, de magnitudes físicas), sino como indivisibles o inextensos. ${ }^{38}$ Como aclaró en 1672, por ‘inicio' no entiende otra cosa que 'la primera parte'. ${ }^{39}$ Por contraposición, el 'fin' hace referencia a la última parte. Leibniz también suele aludir a las nociones de 'inicio' y 'fin' como 'extremos', 'extremidades' e incluso 'términos' de aquellas magnitudes físicas. ${ }^{40}$ Para simplificar, nos referiremos a los extremos de los continuos. Como se observa en el mismo fundamento predemostrable recién mencionado, Leibniz denomina de distinta manera los extremos de cada una de aquellas magnitudes, esto es: a las del tiempo las llama 'instantes', a las del movimiento 'conato' y a las del espacio y el cuerpo 'puntos'. Los extremos cumplen una muy importante función en los análisis leibnizianos relativos al problema del continuo. En particular, Leibniz analiza varios interrogantes relativos a la naturaleza del movimiento y a la constitución de los cuerpos cuya solución se funda en los respectivos extremos (esto es,

\footnotetext{
${ }^{38}$ La cita se encuentra en la nota 32.

${ }^{39} D M M$, A VI 3, 100.

${ }^{40}$ En los capítulos siguientes se analizarán numerosos pasajes en los que Leibniz se refiere a los extremos, extremidades o términos. Algunos que se considerarán allí son: TMA, A VI 2, 266 (Leibniz se refiere como 'extremos'); Propositiones quaedam physicae, A VI 3, 8-9 (se refiere a las 'extremidades'); DMM, A VI 3, 97 (se refiere a los 'términos').
} 
en los conatos, tratándose del movimiento, y de los puntos, en el caso de los cuerpos). El examen de estos problemas y sus correspondientes soluciones (que posiblemente fueron para Leibniz lo más importante de su TMA) serán analizados respectivamente en el capítulo quinto. Sintéticamente, en lo que respecta al movimiento, Leibniz explicó que la desigualdad de las velocidades de los movimientos se funda en la diferencia en las magnitudes de los respectivos conatos, así como también, en lo que respecta al cuerpo, sostuvo que ellos están cohesionados puesto que sus partes tienen puntos extremos en común. Lo que consideraremos en lo que sigue de este capítulo es el examen de la ontología general de los extremos.

Es claro que en la TMA de 1671 Leibniz entendió a los extremos como 'indivisibles e inextensos'. Además, en dicha obra se ha esforzado por distinguirlos de lo que llamará 'mínimo', cuya existencia es para él contradictoria. ${ }^{41}$ El examen del concepto de lo mínimo, así como los argumentos empleados por Leibniz para negar su existencia, serán considerados en el capítulo sexto. Sea como fuere, es claro que, si Leibniz afirmó que existen indivisibles pero negó que existan mínimos, pensó alguna diferencia conceptual entre dichas nociones. No obstante, en un texto escrito apenas un año después de la $T M A$, Leibniz identificó los indivisibles con los mínimos y negó la existencia de unos y de otros en el continuo en general, es decir, tanto en lo que respecta al espacio y al cuerpo ("“ $n]$ o se da lo Mínimo o indivisible en el espacio y el cuerpo" ${ }^{42}$ como al tiempo y al movimiento (“[n]o se da lo mínimo o indivisible en el tiempo y el movimiento"). ${ }^{43}$ En este escrito de 1672, Leibniz tiene en cuenta los indivisibles que Galileo ha afirmado en los Discorsi, obra que leyó en el mismo año. Esta breve descripción basta para indicar que el filósofo de Leipzig fue cambiando la manera de entender la naturaleza de los extremos de los continuos. En este sentido, la consideración de su ontología ha ido evolucionando con el paso de los años y, junto con ella, también la manera de entender la estructura del continuo en general. Dada esta evolución de los planteos de Leibniz, a continuación consideraremos por separado los análisis de la TMA de 1671 y los de 1672. A su vez, dividiremos el examen del pensamiento leibniziano de la $T M A$ en dos partes: en la primera, analizaremos los argumentos empleados por Leibniz para justificar la existencia de los indivisibles y nos

\footnotetext{
${ }^{41}$ TMA, A VI 2, 264. OFC, 8, 79.

${ }^{42}$ DMM, A VI 3, 97. "Nullum datur Minimum, sive indivisibile in spatio et corpore".

${ }^{43}$ DMM, A VI 3, 98. "Nullum datur minimum seu indivisibile in tempore et motu".
} 
detendremos a analizar su naturaleza. En la segunda, discutiremos la interpretación según la cual el continuo leibniziano de la TMA se compone en su totalidad de indivisibles.

\section{Los extremos indivisibles de 1671}

\subsection{Existencia y naturaleza de los extremos indivisibles}

Como se ha mostrado en la primera sección de este capítulo, el modelo con el cual Leibniz entendería infinitas partes en el continuo en la $T M A$ es el de series que decrecen según una progresión geométrica al infinito. Es muy importante notar, en este sentido, que en el cuarto fundamento predemostrable de dicho escrito, en el que se esfuerza por justificar la necesidad de sostener inicios y finales, Leibniz no divide el continuo hasta alcanzar los indivisibles. Su argumento muestra, más bien, que dividiendo no se llega jamás a una primera parte: "no es un inicio algo a lo cual puede quitarse [una parte] a la derecha. [Algo] a lo cual no puede quitarse extensión es inextenso". ${ }^{44}$ Leibniz asume la noción tradicional de extensión, como partes extra partes, pues una parte extensa es aquella que dista de otra. $^{45}$ Por eso, en un escrito en el que intentó probar los fundamentos predemostrables de la TMA tras los cuestionamientos que John Wallis expresó en contra de ellos (que Leibniz conoció gracias a Oldenburg), Leibniz señaló que lo continuo es un todo entre cuyas partes se interponen otras del mismo tipo. ${ }^{46}$ Como analizaremos en detalle en breve, los extremos son 'indivisibles' precisamente porque sus partes no distan entre sí. Ya que las partes extensas pueden dividirse ininterrumpidamente al infinito, los extremos no podrían ser nunca alcanzados por una división en partes proporcionales. Y justamente, dado que los inicios y finales no pueden alcanzarse mediante la división de las partes extensas y divisibles, ellos son para Leibniz indivisibles e inextensos. ${ }^{47}$

Esto se puede entender mejor si pensamos los indivisibles desde el examen del

\footnotetext{
${ }^{44}$ La cita se encuentra en la nota 32.

${ }^{45}$ TMA, A VI 2, 267. OFC, 8, 83.

46 Specimen demonstrationum de natura rerum corporearum ex phaenomenis, A VI 2, 307. Véase Breger, 1990: 59.

47 Un análisis del concepto de "punto" como "extremo" se encuentra en Lawrenz, 2010, capítulo 8, punto 1: "The Labyrinth of the Continuum", salvado el hecho de que la descripción que allí se ofrece es posterior, pudiéndose encontrar recién en el contexto de De summa rerum. Más allá de esta aclaración, la descripción general del concepto de 'extremo' es acertada.
} 
movimiento. Richard Arthur ha ofrecido una interesante interpretación de este argumento leibniziano, presentándolo como una ‘inversión’ del argumento utilizado por Zenón de Elea para negar la existencia del movimiento. ${ }^{48}$ Uno de los argumentos con los cuales Zenón pretendió defender el carácter inmóvil y unitario del Ser parmenídeo fue reconstruido por Aristóteles de esta manera: “[s]egún el primero [de los argumentos] el movimiento es imposible, porque lo que se moviese tendría que llegar a la mitad antes de llegar al término final". ${ }^{49}$ De acuerdo con la reconstrucción del neoplatónico Simplicio, que es un poco más detallada que la de Aristóteles, el argumento apunta a mostrar la imposibilidad de recorrer un espacio infinito en un tiempo finito. ${ }^{50}$ Antes de alcanzar aquella mitad del trayecto señalada en la reconstrucción aristotélica, el móvil debería arribar a la cuarta parte, y previamente a la octava y así sucesivamente. En este sentido, como se puede seguir razonando de esta manera al infinito, no puede afirmarse ni siquiera que el móvil haya comenzado a moverse, es decir, que haya recorrido la primera parte, pues previamente debió recorrer la mitad de esta parte y así sucesivamente. El movimiento, concluye el filósofo de Elea, es imposible. A esto último apunta la 'inversión' del argumento llevada a cabo por Leibniz, de acuerdo con la interpretación de Arthur, pues para el filósofo de Leipzig no se trata de justificar si el movimiento existe o no, sino que su punto de partida es que hay movimiento y, por lo tanto, que debe tener un comienzo. ${ }^{51}$ Lo mismo vale, por cierto, para las otras magnitudes físicas. Como hemos visto en la segunda sección del

${ }^{48}$ Arthur, 2000. Es importante señalar que el objetivo del trabajo de Arthur no es afirmar que Leibniz explícitamente respondió a los argumentos de Zenón, sino que es posible reconstruir el argumento de aquél como una inversión de los de éste. En este sentido, señala: "No quiero decir que Leibniz formuló sus visiones como respuestas explícitas al famoso argumento de Zenón de Elea en contra del movimiento y la pluralidad (...). Sin embargo, creo que una comparación directa entre los dos es informativa. Pues creo que en su tratamiento del problema del movimiento continuo y de la pluralidad, Leibniz emplea un estilo característico de argumentación - un argumento-esquema- que puede útilmente considerarse como una inversión del modo de razonar típico de Zenón". La traducción es nuestra.

${ }^{49}$ Aristóteles, Physika, 239b10.

${ }^{50}$ Simplicio, Phys. 1013, 4ff, citado por Arthur, 2000: 4.

51 Arthur, 2000: 5. "Pues Leibniz también afirma que todo movimiento debe tener un comienzo. Pero él asume que hay movimiento, y de esta manera invierte la dicotomía para establecer algo ligeramente diferente". Asimismo, en la página 6: "Zenón ha argumentado en su Dicotomía que, dado que no es posible moverse a lo largo de un intervalo sin primero cruzar su primera mitad, y antes de esto [cruzar] la primera mitad de esa [mitad], ad infinitum, no puede haber un principio del movimiento; por lo tanto, el movimiento es imposible. Leibniz invierte este razonamiento, argumentando que, dado que el movimiento es real, y por lo tanto debe tener un comienzo, y dado que (por la Dicotomía) este comienzo no puede encontrarse en ningún sub-intervalo extenso del continuo, todos y cada uno de los sub-intervalos del continuo debe tener un comienzo inextenso. (Asumiendo que son reales, el mismo argumento se aplicará al cuerpo, tiempo y movimiento)". 
capítulo primero, para Leibniz el análisis sensible y el racional deben complementarse, en el sentido de que las explicaciones abstractas no deben contradecir a las experiencias sensibles sino justificarlas. Esto se observa en el punto de partida del cuarto fundamento predemostrable de la TMA, cuando Leibniz señala que se dan indivisibles pues "de otro modo no puede entenderse ni el inicio ni el fin del movimiento o del cuerpo"; no obstante, “[s]e da el inicio y el fin del algún espacio, cuerpo, movimiento, tiempo" porque efectivamente hay cuerpos que con un movimiento recorren cierto espacio en un determinado tiempo. ${ }^{52}$ El problema para Leibniz no es justificar ni el movimiento, ni el espacio, el cuerpo o el tiempo; incluso, tampoco lo es sostener que en ellos hay una primera parte. La cuestión central está en cómo son los inicios.

El hecho de que se refiera a los inicios y finales como 'indivisibles' no debe llevar a identificarlos con los indivisibles de Galileo. ${ }^{53}$ Ante todo, esto es evidente porque Leibniz accede a la obra de Galileo recién en el año 1672, esto es, luego de escribir la $T M A .{ }^{54}$ Pero además de esta razón histórica, hay una notable diferencia conceptual entre los indivisibles de Galileo y los de Leibniz. Mientras que para el científico italiano, como hemos visto, los indivisibles son non quanti, para Leibniz tienen magnitud o cantidad, aunque de una manera muy específica, es decir, diferente del modo como se dice que las partes extensas poseen magnitud. Recuérdese que, como se ha mencionado en el capítulo anterior, Leibniz entendió, en el contexto general en que escribió la $T M A$, que la magnitud de una cosa es el número de sus partes. En este sentido, tanto el cuerpo como el espacio, el tiempo y el movimiento son magnitudes. ${ }^{55}$ El hecho de que para Leibniz los indivisibles tengan magnitud se observa en el quinto fundamento predemostable de la $T M A$, en el cual define el concepto de punto (recuérdese que, como se vio en el cuarto fundamento predemostrable, el punto es el indivisible del cuerpo y el espacio, así como el conato lo es del movimiento y el instante del tiempo):

Un punto no es aquello que no tiene ninguna parte, ni aquello cuya parte no se

\footnotetext{
${ }^{52}$ Véase la nota 32.

${ }^{53}$ Coincidimos en general en este punto con Knobloch, 1999: 88, cuando indica: "Para Leibniz, en efecto, un indivisible fue una cantidad infinitamente pequeña de tamaño indefinido. Él definió exactamente lo que esto significa. Leibniz elaboró su concepción del infinito basado en la noción de cantidad en una divergencia consciente del concepto de infinito de Galileo basado en la noción de no-cantidades".

${ }^{54}$ Se conservan las anotaciones de Leibniz de su lectura de los Discorsi de Galileo llevada a cabo en 1672 : Aus und zu Galileis Discorsi, A VI 3, 163-168.

${ }^{55}$ Leibniz a Thomasius, A II 1, 34.
} 
considera, sino aquello que no tiene extensión, esto es, cuyas partes son indistantes, cuya magnitud es inconsiderable, inasignable, menor que la que pueda exponerse mediante una razón con otra [magnitud] sensible, a no ser que [la razón] sea infinita, menor que la que pueda darse. Y este es el fundamento del Método Cavaleriano con el que se demuestra evidentemente su verdad, de manera que se piensen ciertos rudimentos, por así decirlo, o inicios de las líneas y de las figuras menores que cualquiera que pueda darse. ${ }^{56}$

Un punto indivisible posee magnitud, esto es, partes, aunque ella, debido a su pequeñez, no sólo sea imperceptible o inasignable desde un punto de vista sensible sino que también, desde un punto de vista racional, no pueda ser expresada con ninguna ratio. ${ }^{57}$ Leibniz indica que los puntos no deben ser entendidos como mínimos o puntos euclidianos, esto es, como lo que no tiene una parte. Lo que indica la expresión es su condición de ser "minores quam dari possunt". En este sentido, los indivisibles pueden ser entendidos, por el momento y con cautela, como magnitudes infinitamente pequeñas. ${ }^{58}$ Las partes que posee, sin embargo, no pueden ser separadas unas de otras, y precisamente por ello son 'indistantes'. Una manera de comprender cómo han de entenderse las partes indistantes de los indivisibles es observando un ejemplo de Leibniz: como veremos en detalle en la cuarta sección de este capítulo, para el filósofo de Leipzig los ángulos son las partes de un punto. Es justamente debido a su infinita pequeñez y a la indistancia de partes distintas que los puntos no son extensos. Como un indivisible es una magnitud infinitamente pequeña, de su exposición en relación con una magnitud finita cualquiera no resultaría sino una razón

\footnotetext{
${ }^{56}$ TMA, A VI 2, 265. "Punctum non est, cuius pars nulla est, nec cuius pars non consideratur; sed cuius extensio nulla est, seu cuius partes sunt indistantes, cuius magnitudo est inconsiderabilis, inassignabilis, minor quam quae ratione, nisi infinita ad aliam sensibilem exponi possit, minor quam dari potest: atque hoc est fundamentum Methodi Cavalerianae, quo eius veritas evidenter demonstratur, ut cogitentur quaedam ut si dicam rudimenta seu initia linearum figurarumque qualibet dabili minora". OFC, 8,80 .

${ }^{57}$ Racionero, 1980: 40-41, señala que los cuerpos (que sin ser la extensión per se (es decir, el espacio) son sin embargo extensos) poseen una cantidad relativa a la extensión, lo que a su entender significa que "tienen no extensión sino magnitud". De esta manera, para Racionero la noción de magnitud se define en relación con la de extensión: "la magnitud es una constricción mecánica del concepto absoluto de espacio, que nos permite explicar geométricamente los cuerpos". Ahora bien, el hecho de que Leibniz se refiera a los puntos indivisibles como cosas que no tienen extensión pero sí magnitud, muestra que la noción de magnitud no se define en función de la de extensión sino de otra cosa, a saber, como dijimos antes, de la posesión de partes (al margen de que sean o no 'partes extra partes').

${ }^{58} \mathrm{La}$ 'cautela' surge del hecho de que, como se verá, Leibniz posteriormente negará los indivisibles pero sostendrá una composición de partes infinitesimales (infinite parva). Sin embargo, hay diferencias conceptuales muy importantes entre los indivisibles y los infinitesimales, aunque los primeros hayan sido también entendidos como cantidades infinitamente pequeñas.
} 
infinita, de modo que $\frac{\text { magnitud indivisible }}{\text { magnitud finita }}=\frac{1}{\infty} \cdot{ }^{59}$ Esta expresión, sin embargo, no aspira a indicar que un indivisible sea igual a cero, pues en dicho caso el punto no sería nada, esto es, no tendría magnitud. Más bien lo que significa es que la razón entre un punto, como indivisible del espacio, y un espacio sensible cualquiera es infinita.

Leibniz describe, como se observa, un concepto de punto sumamente específico. Es claro que la definición leibniziana de 'punto' dada en el quinto fundamento predemostrable de la TMA tiene como uno de sus objetivos diferenciarse de otras definiciones de esta noción. Es manifiesto, en este sentido, que Leibniz quiere dejar en claro que su concepto de punto no es el de "aquello que no tiene ninguna parte", ni tampoco el de "aquello cuya parte no se considera". ${ }^{60}$ Estas dos definiciones de punto son respectivamente la de Euclides y la de Hobbes. La valoración leibniziana del punto euclidiano, entendido como aquello que no tiene partes, será considerada en el capítulo sexto. ${ }^{61}$ Hobbes, por su parte, ha sido un pensador sumamente influyente en el pensamiento leibniziano de juventud. Ya hemos mencionados algunos aspectos de los análisis de Hobbes que han sido importantes para Leibniz en la tercera sección del primer capítulo. No obstante, el ámbito en el que el filósofo británico ha generado mayor impacto en el pensamiento de juventud de Leibniz fue el de la física. Esto se verá en el capítulo quinto. Leibniz conocía la obra de Hobbes y la tenía en gran estima. Por esta razón, a continuación analizaremos el concepto hobbesiano de punto y la crítica que Leibniz hace de él.

El punto de partida de Hobbes en este aspecto de su análisis es un rechazo explícito de la noción euclidiana de punto. Para el filósofo británico, algo que no posea cantidad no puede ser concebido en la naturaleza. ${ }^{62}$ Leibniz, como se vio, coincide en el reconocimiento de la incorrección de la definición euclidiana. La razón por la cual para Hobbes un punto entendido euclidianamente no puede darse depende de su ontología de las entidades geométricas elementales, a saber, puntos, líneas y superficies. En términos aristotélicos, como Hobbes reconoce, las superficies son definidas causalmente como producidas por el

\footnotetext{
${ }^{59} T M A$, A VI 2, 265. OFC, 8, 80.

${ }^{60}$ Véase la nota 56.

${ }^{61}$ En efecto, la primera de las definiciones del libro primero de los Elementa de Euclides es: "Un punto es lo que no tiene partes" (1991: 189). Breger, 1990: 59.

${ }^{62}$ Hobbes, De corpore, III, 15, 2. "Para la explicación de esto, debe recordarse la definición, [a saber,] que por un punto no debe entenderse lo que no tiene cantidad, o aquello que no puede ser dividido de ninguna manera; pues no hay una tal cosa en la naturaleza". La traducción es nuestra.
} 
movimiento de una línea, así como la línea por el movimiento de un punto. ${ }^{63}$ De aquí se desprende que su geometría está fundada, en última instancia, en los conceptos de punto y de movimiento. Por eso, una primera tarea que debe afrontar es definir los conceptos en cuestión. El concepto de punto de Hobbes se reduce a otro de los conceptos pilares de su filosofía primera, a saber, el de cuerpo. Describiendo precisamente la generación de una línea, dice el filósofo británico:

Aunque no haya un cuerpo que no tenga alguna magnitud, sin embargo, si, cuando algún cuerpo se mueve, su magnitud no es considerada en absoluto, el camino que él hace es llamado una línea, o una sola dimensión; y el espacio a través del cual pasa es llamado longitud; y el cuerpo mismo, un punto. ${ }^{64}$

De aquí precisamente que para Hobbes no exista aquello que no posea magnitud o cantidad, justamente porque eso no sería un cuerpo. El objeto de la matemática, en última instancia, descansa en los conceptos físicos de 'cuerpo' y de 'movimiento'. ${ }^{65}$ De este modo, para él, un punto no puede ser concebido como un indivisible sino como aquél cuerpo cuya cantidad no es considerada, es decir, "del cual ni la cantidad ni ninguna parte es computada en la demostración". ${ }^{66}$ Como el filósofo británico ejemplifica, la tierra misma es llamada 'punto' si no se considera su magnitud, así como la revolución anual producida por el movimiento de la tierra es la línea elíptica que recorre. ${ }^{67}$ Se desprende, entonces, una notable diferencia respecto del concepto leibniziano de punto: mientras que el punto hobbesiano requiere un acto de abstracción del sujeto, esto es, aquel por la cual se desprecia la cantidad del cuerpo, para Leibniz la infinita pequeñez del punto es la razón por la cual su magnitud escapa a toda consideración posible. No es una razón subjetiva sino inherente a la naturaleza misma del punto. La diferencia, sin embargo, es aún más radical si se atiende al

\footnotetext{
${ }^{63}$ Hobbes, De corpore, I, 6, 6. “(...) se forma una línea por el movimiento de un punto, una superficie por el movimiento de una línea". La traducción es nuestra. Esto remarca, asimismo, la importancia que tienen las definiciones para Hobbes, fundamentalmente en el ámbito geométrico. Una de las cosas en las que Hobbes creyó avanzar respecto de la geometría clásica ha sido precisamente redefiniendo varios de sus elementos. Al respecto, véase la tercera sección del primer capítulo.

${ }^{64}$ Hobbes, De corpore, II, 8, 12. "Though there be no body which has not some magnitude, yet if, when any body is moved, the magnitude of it be not at all considered, the way it makes is called a line, or one single dimension; and the space, through which it passeth, is called length; and the body itself, a point". La traducción es nuestra.

${ }^{65}$ Véase el trabajo de Jesseph, 1999, fundamentalmente el capítulo 3: "De Corpore and the Mathematics of Materialism".

${ }^{66}$ Hobbes, De corpore, III, 15, 2. “(...) [a point is] that, whose quantity is not at all considered, that is, whereof neither quantity nor any part is computed in demonstration; so that a point is not to be taken for an indivisible, but for an undivided thing". La traducción es nuestra.

${ }^{67}$ Hobbes, De corpore, II, 8, 12.
} 
hecho de que para Leibniz los puntos se dan en la naturaleza, es decir, en el continuo, mientras que para Hobbes lo realmente existente es el cuerpo, de cuya cantidad se hace abstracción y por eso no es considerada. Sin embargo, el concepto leibniziano de punto, como algo "minor quam dari potest", comporta una similitud respecto de otro concepto hobbesiano fundamental, a saber, el de conato:

Primero, defino al conato [endeavour, en latín conatus] como un movimiento hecho en menos espacio y tiempo que el que puede darse; esto es, menor que el que pueda ser determinado o asignado por exposición o número; esto es, movimiento hecho a través de la longitud de un punto, y en un instante o punto del tiempo. ${ }^{68}$

Esta definición, no obstante, genera inconsistencias si se la relaciona con la noción hobbesiana de punto que hemos mencionado anteriormente. En efecto, entender que el conato es un movimiento 'hecho a través de la longitud de un punto' iría en contra de la definición de punto como la de aquello cuya magnitud no es computada. ${ }^{69}$ En este sentido, en la definición de 'conato' el punto es pensado como algo que se da efectivamente y no como el resultado de una abstracción.

En síntesis, hemos visto que para Leibniz hay extremos indivisibles del continuo que no son obtenidos mediante una división de las partes extensas y que no deben entenderse ni como mínimos o puntos euclidianos ni como puntos hobbesianos. Ahora bien, una consecuencia que se sigue de aquí es que, en su condición de extremos, los indivisibles no compondrían íntegramente el continuo. ${ }^{70} \mathrm{~A}$ continuación examinaremos la

\footnotetext{
${ }^{68}$ Hobbes, De corpore, III, 15, 2. "First, I define endeavour to be motion made in less space and time than can be given; that is, less than can be determined or assigned by exposition or number; that is, motion made through the length of a point, and in a instant or point of time". La traducción es nuestra. La recepción leibniziana del conato de Hobbes ha sido analizada, entre otros, por Bernstein, 1980, McDonald Ross, 2007 y Lawrenz 2010, capítulo 1, punto "Hobbesian conatus".

${ }^{69}$ De aquí que para Howard Bernstein tanto Hobbes como Leibniz entendieron al punto como minor quam dari potest: "Tanto Hobbes como Leibniz repudiaron la definición de punto de Euclides como lo de aquello que no tiene partes. Sin embargo, ellos están de acuerdo en que un punto debe ser más pequeño que cualquier magnitud asignable (es decir, inasignablemente pequeña), lo que es simplemente decir que emplean la misma convención lingüística [es decir, 'minor quam quod dari potest']. Para Hobbes, aprendemos que 'menor que cualquiera asignable' significa, en efecto, que la dimensionalidad de un punto o la pequeñez de sus partes es tal que en la geometría puede prescindirse de ella. Como Hobbes dice, las partes existen, pero no son consideradas (...)". Bernstein, 1980: 27. La traducción es nuestra. Por otra parte, para Jesseph, aunque el concepto leibniziano de punto tiene sus raíces en el de conato de Hobbes, los puntos hobbesianos han de ser entendidos como cuerpos 'suficientemente pequeños'. Jesseph, 2008, particularmente en el punto 1, "Hobbes, Conatus, and the Mathematics of Motion".

${ }^{70}$ Similarmente, en la sintética reconstrucción de los lineamientos fundamentales de la TMA, Breger, 1990: 58-59, parece sugerir que el continuo no se compone de indivisibles, pues en el continuo no hay parte que no tenga parte, aunque haya indivisibles sin los que no podría pensarse el inicio del movimiento.
} 
interpretación de quienes entienden que el continuo leibniziano de la TMA se compone en su totalidad de indivisibles.

\subsection{Discusión de otras interpretaciones sobre el continuo leibniziano de 1671}

Hasta aquí hemos visto que en la TMA Leibniz habría comprendido que en el espacio, el tiempo, el cuerpo y el movimiento hay infinitas partes actuales entendidas como decrecientes según una progresión geométrica que, a su vez, poseen extremos indivisibles. Ahora bien, como todas las infinitas partes representadas en fracciones son por eso mismo asignables, ellas poseen, a su vez, una infinitud actual de partes. La consideración de la estructura interna de cada una de dichas partes debe replicar el mismo modelo de comprensión de un infinito actual en partes proporcionales antes mencionado. Como mencionamos en el tercer capítulo, Leibniz encontró en las observaciones microscópicas, especialmente de Hooke y Kircher, un gran aporte empírico para la tesis del infinito actual. En efecto, en la Theoria motus concreti, el filósofo de Leipzig ha dicho:

Porque se ha de saber que, como observaron los famosos Micrógrafos, Kircher y Hooke, una persona de vista muy aguda debería observar la mayoría de las cosas que percibimos en las cosas más grandes con proporción en las menores; si éstas continuaran al infinito - lo cual es ciertamente posible, puesto que el continuo es divisible al infinito- cualquier átomo sería como un mundo de infinitas especie y habría mundos en otros mundos al infinito. ${ }^{71}$

Llevado al problema del continuo, esto significa que en una parte de un espacio, un cuerpo, un tiempo o un movimiento cualquiera se da proporcionalmente la misma estructura que se halla en dicho espacio, cuerpo, tiempo o movimiento. En este sentido, cada una de las partes debe ser tomada como dividida según una misma razón. La manera como representarse un infinito actual en el continuo se replica al infinito, esto es, en cada una de las infinitas partes. ${ }^{72}$ Dicho en términos de series infinitas, a modo de ejemplo, la

\footnotetext{
71 Theoria motus concreti, A VI 2, 241. "Sciendum est enim, ut praeclari illi Micrographi, Kircherus et Hookius observare, pleraque quae nos sentimus in maioribus, lynceum aliquem deprehensurum proportione in minoribus, quae si in infinitum progrediantur, quod certe possibile est, cum continuum sit divisibile in infinitum, quaelibet atomus erit infinitarum specierum quidam velut mundus, et dabuntur mundi in mundis in infinitum". Traducción: OFC 8, 43. Sobre la importancia del corpuscularismo de Hooke (y otros) para el pensamiento de Leibniz, véase Escribano Cabeza, 2016: 89-98.

72 Por eso, como señala atinadamente Beeley, 1996: 202-204 y 2015: 32-33, no hay una relación causal entre los mundos, es decir, lo que acontece en un mundo no se explica por medio de lo que sucede en los mundos que están dentro de él.
} 
primera de las fracciones de la serie de Zenón $\left(\frac{1}{2}, \frac{1}{4}, \frac{1}{8}\right.$, etc.) es asimismo la suma de una serie infinita de fracciones (esto es, de $\frac{1}{3}, \frac{1}{9}, \frac{1}{27}$, etc.). En este sentido, hay 'series dentro de series al infinito'. Podemos referirnos a esta comprensión del continuo utilizando una denominación que, aunque sea muy posterior a Leibniz, representa a la perfección la intención del autor: la estructura del continuo leibniziano es fractal. Con esto nos referimos no a la teoría fractal sino específicamente al aspecto que adquieren las figuras fractales, esto es, a la estructura geométrica fractal en la que siempre se repite el mismo patrón (por ejemplo, como en un copo de nieve). Esto significa que el espacio, el cuerpo, el movimiento y el tiempo poseen una configuración particionada según una progresión geométrica decreciente al infinito que se repite en diversas escalas de grandeza o pequeñez. Antes que nosotros, Samuel Levey ha reconocido que los exámenes de Leibniz, particularmente los relativos al movimiento, incluyen la comprensión de una estructura fractal. No obstante, sus análisis recaen sobre los desarrollo leibnizianos de 1676 y que, por eso mismo, serán examinados en la tercera parte de nuestra tesis. ${ }^{73}$ Lo que aquí proponemos, entonces, es que la comprensión fractal de la estructura del continuo leibniziano es anterior a los pensamientos de 1676, pudiéndose así retrotraer hasta 1671.

Ahora bien, la interpretación que hemos ofrecido es notablemente distinta de otra que ya se ha vuelto clásica entre los intérpretes del pensamiento de juventud de Leibniz sobre el problema del continuo. Sintéticamente, de acuerdo con esta interpretación para Leibniz el continuo en 1671 estaría compuesto de indivisibles. O. B. Bassler, E. Lison y $\mathrm{Ph}$. Beeley son algunos de los defensores de esta comprensión del continuo leibniziano, que será analizada en detalle a continuación. ${ }^{74}$ En algunos de sus escritos, R. T. W. Arthur también sostiene esta interpretación, aunque en otros la cuestiona. ${ }^{75}$ En aquellos casos en los que no reconoce una composición de indivisibles, Arthur sostiene que el continuo leibniziano de 1671 se compone de partes o intervalos no puntuales que tienen extremos

\footnotetext{
73 Levey, 2003. El autor también considera, por cierto, la limitación que tiene la aplicación de una denominación contemporánea a la comprensión del continuo leibniziano (apartado sexto de su trabajo). En este sentido, la imagen fractal se considera a título ilustrativo.

${ }^{74}$ Bassler, 1998a, Lison, 2006 y Beeley, 2015. Estos trabajos se examinarán a continuación.

${ }^{75}$ Arthur defiende la interpretación clásica, por ejemplo, en Arthur, 1986: 108-109, 1998: 113, Leibniz, 2001, xxxii-xxxvii y Arthur, 2009, punto "Phase 2: Indivisible, unextended points". La cuestiona, por su parte, en Arthur, 2000: 7, y 2004, punto 2 “Leibniz's Atoms: Some Interpretations”. Como puede observarse, Arthur oscila entre aceptar una composición de indivisibles y rechazarla.
} 
indivisibles. En este aspecto su interpretación es similar a la nuestra. Hay, no obstante, una diferencia, fundada en que Arthur no parece haber percibido que el infinito actual puede entenderse según el modelo de una división en partes proporcionales. A nuestro juicio, este aspecto de nuestra tesis es crucial, pues justifica por qué para Leibniz de infinitas partes actuales no se sigue un continuo infinito en extensión. En este apartado presentaremos y discutiremos la interpretación clásica antes mencionada.

La interpretación clásica surge de tomar como complementarios los fundamentos predemostrables de la TMA en los que Leibniz afirma infinitas partes en acto en el continuo (es decir, los dos primeros) y el cuarto, en el que justifica que se dan indivisibles. De acuerdo con esta interpretación, entonces, Leibniz identificaría los indivisibles con las infinitas partes actuales que se dan en el continuo. La tesis del infinito actual, por lo tanto, se complementaría con la definición del concepto de indivisible. Uno de los defensores de esta interpretación, E. Lison, entiende que Leibniz explícitamente afirmó que el continuo se compone de puntos indivisibles y que, entonces, es absolutamente claro que las infinitas partes actuales deben tomarse como indivisibles. ${ }^{76}$ Para apoyar esta interpretación, Lison se remite a un muy interesante pasaje de una carta de Leibniz a Oldenburg de abril de 1671 en el que el filósofo de Leipzig sintetiza los elementos más destacados de su TMA:

La teoría del movimiento Abstracto explica las casi invencibles dificultades de la Composición del continuo, confirma la Geometría de los indivisibles y la Aritmética de los infinitos, muestra que no hay nada sin partes en la naturaleza de las cosas, que existen infinitas partes en acto en cualquier continuo, que la teoría de los ángulos trata sobre las cantidades de los inextensos, que un Movimiento es más fuerte que otro y por lo tanto que también un conato [es más fuerte] que otro: pero un Conato es un movimiento a través de un punto en un instante; por lo tanto, un punto es mayor que otro. ${ }^{77}$

No obstante, podemos observar que la referencia textual a la que refiere Lison no justifica en absoluto su interpretación. El pasaje al que él mismo hace referencia para ofrecer sustento textual a su tesis de que Leibniz explícitamente identificó las infinitas partes con los indivisibles, de hecho no confirma su aserción. Más aún, otros defensores de

\footnotetext{
${ }^{76}$ Lison, 2006.

77 Leibniz a H. Oldenburg, A II 1, 166. "Theoria motus Abstracti, invictas propemodum Compositionis continui difficultates explicat, Geometriam indivisibilium, et Arithmeticam infinitorum confirmat; ostendit nihil esse sine partibus in rerum natura; infinitas actu cujuscunque continui partes esse; doctrinam de angulis esse de quantitatibus inextensorum; Motum esse Motu fortiorem, ergo et conatum conatu: Conatum autem esse motum per punctum in instanti; punctum ergo puncto majus esse".
} 
esta interpretación, como Bassler y Arthur (en los escritos en los que precisamente sostiene esta lectura) reconocen que Leibniz nunca identificó explícitamente las infinitas partes con los indivisibles ni mencionó que el continuo se compone de ellos. ${ }^{78}$ Bassler, no obstante, sostiene que, a pesar de esto, realizar esta identificación es la única alternativa viable:

Sin embargo, creo que ambas afirmaciones se siguen directamente de la posición de Leibniz. En relación con lo primero, Leibniz declara que hay una infinitud actual de partes en el continuo, y a menos que tomemos la extremadamente implausible posición de que él se está refiriendo a las partes de los indivisibles, parece claro que son los indivisibles lo que tiene en mente. En segundo lugar, es claro que el continuo no puede fundamentalmente estar compuesto de partes extensas dado que estas partes extensas son siempre nuevamente (e infinitamente) divisibles. Entonces, el continuo debe estar compuesto de indivisibles. $^{79}$

El reconocimiento por parte de Arthur y Bassler de que Leibniz nunca ha identificado explícitamente los indivisibles y las infinitas partes da lugar a la posibilidad de que ésta no sea la única interpretación posible. La necesidad de afirmar la identificación entre las infinitas partes y los indivisibles sostenida por Bassler en la última cita, pierde su fuerza desde el momento en que se reconoce que Leibniz habría sostenido una estructura fractal del continuo. La tesis del infinito actual no conlleva, como sugiere Bassler, que las partes extensas sean siempre nuevamente divisibles, sino más bien que están de hecho divididas en partes proporcionales que mantienen la misma estructura que aquellas partes en las que se incluyen. Hay, a su vez, un argumento más contundente para mostrar lo incorrecto de esta interpretación: como veremos a continuación, mientras Leibniz nunca identificó los indivisibles con las infinitas partes del continuo, en cambio ha dicho que es

\footnotetext{
${ }^{78}$ Arthur, 2009, sección "Phase 2: Indivisible, Unextended Points", reconoce que la identidad es una asunción de su parte cuando dice: "Parece claro que Leibniz tiene la intención de identificar los indivisibles o 'comienzos' de un cuerpo o movimiento que aparecieron en el ([fundamento] 4) con los inasignables de (5), dado que ambos son descritos como cosas inextensas infinitamente pequeñas. Una característica extraña de esta presentación, sin embargo, es que estos indivisibles o inasignables no son explícitamente identificados con las 'infinitas partes actuales' referidas en (1) y (2), es decir, no se dice que ellas compongan el continuo". Bassler, 1998a: 8, nuevamente aclara: "La imagen del continuo leibniziano que presenté, como compuesto de indivisibles, ciertamente se extiende más allá de lo que Leibniz dijo en un punto importante, que quisiera defender ahora. A saber, aunque Leibniz dice que hay infinitas partes en el continuo, nunca llega a decir explícitamente que hay infinitos indivisibles o que el continuo se compone de indivisibles".

${ }^{79}$ Bassler, 1998a: 8-9. "However, I think that both of these assertions follow directly from Leibniz's position. Concerning the former, Leibniz declares that there are an actual infinity of parts in the continuum, and unless we are to take the extremely implausible position that he is referring here to the parts of indivisibles, it seems clear that it is the indivisibles which he has in mind. Secondly, it is clear that the continuum cannot be fundamentally composed out of extended parts since these extended parts are always further (and indefinitely) divisible. Hence the continuum must be composed out of indivisibles".
} 
imposible una división hasta los indivisibles.

El contexto en el que afirmó la imposibilidad de una división hasta los indivisibles es, a su vez, muy importante. Desde 1669, Leibniz estuvo trabajando los temas que dieron lugar a la versión definitiva de la TMA que presentó a la Ilustre Academia Real de Francia. Los editores de la edición crítica de las obras de Leibniz dividen los escritos preparatorios para la TMA en dos textos: al primero de ellos, del cual se conservan cuatro borradores, lo han titulado, siguiendo una expresión utilizada por Leibniz, De rationibus motus, es decir, Sobre las razones del movimiento. El segundo de ellos es una primera versión de la TMA. ${ }^{80}$ Tanto los borradores de De rationibus motus como la primera versión de TMA difieren en varios aspectos de la versión definitiva, lo cual revela que Leibniz estuvo trabajando en estas cuestiones con cierta constancia. La afirmación a la que hemos hecho mención anteriormente se encuentra en el segundo borrador de De rationibus motus. Uno de los temas considerados por Leibniz en este breve documento es el de la existencia del reposo, es decir, la ausencia de movimiento. Como se ha visto en el tercer capítulo, Leibniz reconoce tempranamente que ningún cuerpo que sea sentido está en estado de reposo y que, desde este punto de vista, el reposo absoluto es imposible. Leibniz sintetiza aquí la argumentación: "[t]odo cuerpo que es sentido, actúa en el que siente. Toda acción de un cuerpo es un movimiento. Por consiguiente, todo cuerpo que es sentido se mueve". ${ }^{81}$ Como consecuencia de este planteo, Leibniz considera a continuación qué sucede cuando dos cuerpos que se mueven chocan entre sí, esto es, si al chocar los cuerpos se unen o no y, en el caso de que se unan, si lo hacen en un punto, una línea o una cara (hedra). Leibniz reconoce que, si se supone que los cuerpos que chocan se unen en un punto o una línea, entonces ellos inevitablemente se dividirían hasta los puntos o líneas. Es en este contexto que Leibniz menciona que:

(...) si las cosas que concurren en un punto se unen, es necesario que la división suceda ininterrumpidamente hasta los puntos. Y si concurren en una línea, es necesario que la división de las partes suceda ininterrumpidamente hasta las líneas; pero tal división ininterrumpidamente hasta los indivisibles es, en

\footnotetext{
${ }^{80}$ Estos trabajos pueden encontrarse en A VI 2, 157-186.

${ }^{81}$ De rationibus motus, A VI 2, 165. "Omne corpus quod sentitur, agit in sentiens. Omnis actio corporis est motus. Ergo omne corpus quod sentitur movetur".
} 
realidad, imposible. ${ }^{82}$

Como veremos en el capítulo quinto, desde la TMA y al menos durante unos años más, Leibniz entendió que, al moverse y chocar, los cuerpos se unen en puntos. No obstante, para que, de acuerdo con lo mencionado en este borrador de De rationibus motus, no se siga de ello una división hasta indivisibles, Leibniz debió concebir la estructura del continuo de una manera distinta a la de una composición de indivisibles. Y esto implica al menos dos cosas que ya han sido mencionadas, a saber, que el modelo con el que se habría representado infinitas partes actuales no es el de una división hasta indivisibles sino en partes proporcionales y que a los indivisibles, como extremos de las partes, no se llega por división. De esta manera, Leibniz, siendo consciente de la imposibilidad de una división hasta los indivisibles, debió ensayar otra manera de entender la composición del continuo que, como una de sus consecuencias, justifique la unión de los cuerpos en puntos. De esto resulta el modelo de división según una razón constante y la afirmación de indivisibles como extremos de las partes en los que, en el caso de los cuerpos, se unen al chocar. Los indivisibles, así, se interpretan no como componiendo el continuo (al menos no íntegramente) sino como extremos de las partes y en todo caso como fundamento de su conexión.

La interpretación clásica del continuo leibniziano de 1671 sostiene, a su vez, que el filósofo de Leipzig habría tomado la idea de una 'composición de indivisibles' del método de Cavalieri que hemos examinado sintéticamente en el segundo capítulo. Bassler, por ejemplo, ha sostenido esta dependencia del pensamiento leibniziano sobre el continuo respecto del método de Cavalieri. En efecto, señala que:

En cambio, él [Leibniz] se vale de la autoridad del método de los indivisibles de Cavalieri para afirmar que el continuo está de hecho compuesto y de un número infinito de partes indivisibles, aunque no mínimas. En el caso del continuo espacial, Leibniz identifica estos indivisibles como partes (no, digamos, solamente límites [o extremos]), y entonces es acertado decir que Leibniz ve el continuo como compuesto, lo que significa construido, de puntos. ${ }^{83}$

\footnotetext{
${ }^{82}$ De rationibus motus, A VI 2, 165. "Ratio est, quia si ea uniuntur, quae in puncto concurrunt, necesse est divisionem fieri usque ad punta. Et si in linea concurrunt, necesse est divisionem partium fieri usque ad lineas, talis autem divisio ad indivisibilia usque est realiter impossibilis".

${ }^{83}$ Bassler, 1998a: 8. "Instead he [Leibniz] enlists the authority of Cavalieri's method of indivisibles to assert that the continuum in fact is composed, and out of an infinite number of indivisible parts, though not minima. In the case of the spatial continuum Leibniz identifies these indivisibles as parts (not, say, merely boundaries),
} 
En el quinto fundamento predemostrable de la TMA citado anteriormente, Leibniz ciertamente consideró que la definición de punto que allí ha desarrollado es “(...) el fundamento del Método Cavaleriano (...)" ${ }^{84}$ Esta no es, no obstante, la única mención. Leibniz indica reiteradamente que el problema del continuo, cuya dilucidación es uno de los objetivos de la $T M A$, es también importante (entre otras cosas) en vistas a ubicar en bases sólidas tanto la geometría de los indivisibles (haciendo referencia al pensamiento de Cavalieri) como la aritmética de los infinitos (refiriéndose, presumiblemente, a la de John Wallis). ${ }^{85}$ Esto se ha observado también en el resumen de los principales lineamientos de la $T M A$ que Leibniz le ha enviado en una carta a Carcavy y que mencionamos al comienzo de este capítulo. Sin embargo, a continuación mostraremos que hay al menos dos razones que sugieren que es incorrecto sostener que Leibniz ha tomado la idea de una composición de indivisibles de la obra de Cavalieri.

La primera razón es histórica. En efecto, Leibniz no tuvo un conocimiento profundo de la obra de Cavalieri, así como tampoco de la de Wallis, antes del comienzo de su estadía en París en $1672 .{ }^{86} \mathrm{Ph}$. Beeley señala, incluso, que el conocimiento que Leibniz ha tenido de las obras de aquellos ha sido indirecto, mediante los escritos de Thomas Hobbes donde de hecho se discuten los métodos de Cavalieri y especialmente de Wallis. ${ }^{87}$ En relación con el matemático británico, por cierto, Leibniz ha reconocido en la TMA que apenas conoce de oídas (gracias a Oldenburg y Hesentaler) sus obras editadas. ${ }^{88}$

La segunda razón no es histórica sino teórica. Si observamos los pasajes antes mencionados en los que Leibniz se refiere al método de Cavalieri, veremos que el filósofo de Leipzig nunca dice que ha tomado la idea de una composición de indivisibles de aquel método sino que cree haber ofrecido un fundamento para él. En este sentido, la relación entre el método de Cavalieri y la teoría leibniziana del continuo es exactamente inversa a la

and so it is accurate to say that Leibniz views the continuum as composed, which is to say built up, out of points". De un modo similar, Breger, 1990: 59 señala que Leibniz fue un 'seguidor incondicional' de Cavalieri. Arthur, en Leibniz, 2001: xxxv, tiene una interpretación distinta de la relación entre Leibniz y Cavalieri con la que coincidimos.

${ }^{84}$ Véase la nota 56.

${ }^{85} T M A$, A VI 2, 262. "nam labyrinthus in primis continui et motus compositionibus ingenia implicantem evolvisse, plurimim refert ad constituenda scientiarum fundamenta, confundendos Scepticorum triumphos; Geometriam Indivisibilium et Arithmeticam Infinitorum, tot egregiorum theorematum parentes, in solido locandas (...)". OFC 8, 75-76.

${ }^{86}$ Beeley, 2008: 44-45.

${ }^{87}$ Beeley, 2008: 44-45.

${ }^{88}$ TMA, A VI 2, 275. OFC 8, 94-95. 
sostenida por Bassler. En efecto, como hemos visto en el segundo capítulo, Cavalieri tiene la intención de ofrecer un procedimiento geométrico, de manera que en su examen quedan sin resolución algunos interrogantes ontológicos que subyacen al método, como si los indivisibles de una figura se obtienen por división o si una figura se compone o no de ellos. En lo que respecta a la primera cuestión, hemos visto que para Cavalieri los indivisibles no se obtienen por división sino que han de ser concebidos como los 'cortes posibles' en una figura plana que resultan del desplazamiento de una línea de un extremo al otro de dicha figura. En lo que respecta por su parte a la segunda cuestión, hemos señalado que, como su intención no fue resolver cuestiones ontológicas sino ofrecer un método geométrico, Cavalieri no se ha inclinado ni por afirmar ni por negar que una figura se compone de indivisibles. En consecuencia, la idea de que Leibniz sigue al matemático italiano en la afirmación de una composición de indivisibles es absurda. Más bien, como se ha dicho, Leibniz no ha tomado el método para aplicarlo a su interpretación del continuo, sino que ha elaborado una teoría del continuo que además tenía que justificar el método. Presumiblemente el filósofo de Leipzig entendió que su concepto de punto o en general su teoría del continuo puede servir como sustento especulativo del procedimiento cavaleriano.

La razón por la cual Beeley concibió una composición de indivisibles es distinta de la de Bassler y Arthur. De acuerdo con Beeley, Leibniz habría notado que las paradojas que se siguen de componer el continuo de verdaderos indivisibles, al modo del atomismo, podrían evitarse tan pronto como se elimine la 'distinción categórica' entre 'punto' y 'extensión'. En este sentido, Beeley entiende que los puntos y las líneas no son heterogéneos sino homogéneos (y lo mismo vale respecto de los conatos y los movimientos):

Así como el punto es ontológicamente el límite de una línea, así también el conato es ontológicamente el límite de un movimiento. Pero los puntos ya cumplían esta función en la tradición aristotélica, en la que fueron concebidos como verdaderos indivisibles. El desarrollo teórico decisivo que Leibniz propone en sus primeros escritos es que, mediante una replicación infinita, los puntos pueden verse como componiendo las líneas, así como, mediante una replicación infinita hacia adelante, los conatos pueden verse como componiendo al movimiento. ${ }^{89}$

\footnotetext{
${ }^{89}$ Beeley, 2015: 29. "Just as point is ontologically the limit of a line, so conatus is ontologically the limit of a motion. But points fulfilled this function already within the Aristotelian tradition, where they are conceived as
} 
Como se observa, por un lado, Beeley reconoce el valor de la noción aristotélica de continuo y de la función de los puntos como extremos que dicha noción les confiere. El mismo intérprete reconoce en otra parte que, de esta manera, Leibniz se estaría apartando de la relación homogénea entre punto (límite) y línea (limitado), al mismo tiempo que se aproximaría, sobre la base del concepto de continuo aristotélico, a la concepción de una relación heterogénea. ${ }^{90}$ Ahora bien, por otro lado, Beeley entiende que, simultáneamente, Leibniz estaría defendiendo una homogeneidad entre puntos y las líneas. ${ }^{91}$ Es cierto que Leibniz mantuvo una 'replicación infinita', lo que significa, en los términos abordados en este capítulo, que se apoyó en el modelo de las series infinitas. No obstante, esto no permite inferir una homogeneidad entre una línea y un punto, sino entre una línea y una porción suya, que como tal es algo extenso, es decir, no es un punto sino una línea. En otras palabras, para que sea posible afirmar consistentemente la homogeneidad entre puntos y líneas en la $T M A$, debería ser posible llegar a los puntos mediante la división de una línea. No obstante, como vimos, para Leibniz esto no es posible: “(...) no es un inicio algo a lo cual puede quitarse [una parte] a la derecha. [Algo] a lo cual no puede quitarse extensión es inextenso". ${ }^{92}$ En consecuencia, es cierto que Leibniz concibe a los puntos como límites, en concordancia con la tradición aristotélica, y por lo tanto (en contraposición con la interpretación de Beeley) no hay una homogeneidad entre puntos y líneas sino una heterogeneidad.

\section{De los indivisibles a las partes infinitamente pequeñas}

Poco después de publicada la TMA, Leibniz revisó su manera de resolver el problema del continuo e introdujo algunas modificaciones significativas. Esta evolución en

\footnotetext{
being true indivisibles. The decisive theoretical development which Leibniz proposes in his early philosophy is that through infinite replication points can be seen to compose lines, just as through infinite forward replication conatus can be seen to compose motion". La traducción es nuestra. Como veremos más adelante, Beeley identificó los indivisibles de TMA con los infinitesimales que Leibniz defendió en 1672. Véase la nota 105.

${ }^{90}$ Beeley, 1996: 256.

${ }^{91}$ Beeley, 2015: 30. "Implícitamente, los conceptos de punto, instante y conato son entendidos en la Theoria motus abstracti como infinitamente pequeños en relación con sus correspondientes conceptos cuantitativamente extensos de espacios, tiempo y movimiento". Como dijimos anteriormente, puede entenderse, con cierta cautela, que los indivisibles son magnitudes infinitamente pequeñas. No obstante, esto no significa que compongan el continuo.

${ }^{92} T M A$, A VI 3, 264. Citado en la nota 32.
} 
el pensamiento de Leibniz se manifiesta en un importante trabajo que ha escrito en 1672 y que ha titulado De minimo et maximo. De corporibus et mentibus, es decir, Sobre lo mínimo y lo máximo. Sobre los cuerpos y las mentes. ${ }^{93}$ El contexto en el que lo redactó es muy significativo. En primer lugar, su redacción data del mismo tiempo que la Accessio a la que nos hemos referido antes. ${ }^{94}$ En relación con esto, en segundo lugar, es contextualmente relevante el hecho de que Leibniz leyó los Discorsi de Galileo poco tiempo antes de redactar estos escritos. Como vimos en el capítulo segundo, en la primera jornada de este texto Galileo presenta, entre otras cosas, una interpretación de la composición del continuo. En efecto, sintéticamente, para Galileo el continuo se compone de un número infinito de indivisibles, bajo las siguientes condiciones: primero, que dicho número infinito de partes no se equipara con ningún número finito; segundo, que los indivisibles han de ser concebidos como carentes de cantidad (non quanti); tercero, finalmente, que los atributos de 'mayor', 'menor' e 'igual', que valen en lo finito, son incorrectamente aplicados tratándose de lo infinito.

Ahora bien, las tres condiciones recién mencionadas han sido problematizadas por Leibniz en 1672. Como veremos en el capítulo sexto, en los escritos de este año, Leibniz discutió la afirmación de Galileo de que existe el número infinito de todas las unidades, así como también se opuso a la limitación del alcance del axioma del todo y la parte a lo finito. Es más, ambas cuestiones fueron disputadas en los dos escritos mencionados de este año, es decir, la Accessio y DMM, aunque con diferente intensidad y detalle. ${ }^{95}$ Como veremos a continuación, aquí es especialmente relevante que en $D M M$, Leibniz discutió también la interpretación de la composición del continuo de indivisibles mantenida por Galileo. Más aún, Leibniz debió haber notado que el concepto de 'indivisible' que él presentó en la TMA es distinto del galileano, pues mientras los indivisibles de TMA poseen una cantidad, aunque inasignable, los de Galileo son non quanti. Así, Leibniz se dio cuenta de que hay una ambigüedad en el concepto de indivisible e intentó resolverla. En este sentido, no es de extrañar que haya identificado la noción galileana de 'indivisible' con el punto euclidiano,

\footnotetext{
${ }^{93}$ Este escrito puede encontrarse en A VI 3, 97-101.

${ }^{94}$ De acuerdo con la edición crítica, la marca de agua aparece recurrentemente entre noviembre y diciembre de 1672. A VI 3, 97.

${ }^{95}$ Leibniz a J. Gallois, A II 1, 348-356; DMM, A VI 3, 98.
} 
es decir, con aquello que no tiene partes, ${ }^{96}$ así como tampoco es de extrañar que haya dejado de utilizar la noción de 'indivisible' en el sentido de TMA. En cuanto a lo primero, como hemos mencionado a la pasada en la segunda sección de este capítulo, en $D M M$ Leibniz se esforzó por mostrar que no se da 'lo mínimo o indivisible' en el continuo (a diferencia de la TMA, donde negó la existencia de mínimos pero afirmó la de indivisibles, entendiéndolos en el sentido descrito anteriormente en este capítulo); en cuanto a lo segundo, a partir de un cuestionamiento de la teoría galileana, Leibniz repensó la manera de concebir la composición del continuo. De este replanteo del filósofo de Leipzig surgió una concepción según la cual el continuo se compone de partes 'infinitamente pequeñas'. De acuerdo con esto, ordenaremos esta sección de esta manera: en primer lugar, reconstruiremos la manera como Leibniz concibió una composición de indivisibles en $D M M$, esto es, al modo de Galileo. No examinaremos aquí los argumentos por los cuales en dicha obra negó esta manera de entender la composición del continuo. Esto será tratado en el capítulo sexto. Sin embargo, esta reconstrucción es la base a partir de la cual Leibniz hizo un replanteamiento de la composición del continuo. Por esta razón, en segundo lugar veremos cuál es la interpretación de la composición del continuo que presentó en $D M M$.

En el capítulo segundo hemos mencionado que el planteo de Galileo tiene su punto de partida en un cuestionamiento de la tesis típicamente aristotélica del carácter potencial del infinito. En efecto, de acuerdo con Galileo, si el continuo se dividiera simultáneamente en todas las partes en las que puede dividirse, entonces el número de partes sería infinito. Ahora bien, esta manera de dividir el continuo en infinitas partes es muy diferente de la manera como Leibniz entendió la infinitud actual de partes del continuo en la TMA, pues en una división hasta los indivisibles las partes no son proporcionales. Esta diferencia es esencial en la reconstrucción de la argumentación según la cual el continuo se compone de indivisibles de DMM. Para dicha reconstrucción, Leibniz parte de reconocer en primer lugar que los indivisibles pueden ser tomados como extremos o términos de los continuos. Dado que, como se ha visto en el cuarto fundamento predemostrable de la $T M A$, en una línea puede exponerse un espacio, un cuerpo, un tiempo o un movimiento, tomemos el caso de una línea $a b$ con puntos extremos indivisibles. ${ }^{97}$ Ahora bien, piénsese, en segundo lugar,

\footnotetext{
${ }^{96}$ Véase la sección 3.1. de este capítulo, especialmente la nota 56. Asimismo, para un examen minucioso véase la primera sección del capítulo sexto.

${ }^{97} D M M$, A VI 3, 97.
} 
que hay líneas perpendiculares a la línea $a b$ que la interceptan en un punto. Este sería el caso, por ejemplo, de la línea 1-2 en la imagen siguiente, por cuya intercepción se forma el ángulo de contacto $z$ :

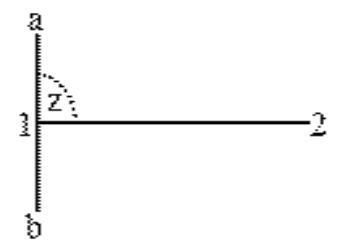

Así como se puede establecer la línea 1-2 perpendicular a $a b$, también pueden trazarse otras infinitas líneas que forman un ángulo recto al interceptar a $a b .{ }^{98}$ Ahora bien, lo que sigue en la argumentación de Leibniz depende de cómo ha entendido el concepto de ‘ángulo' en estos años. Esta noción, en efecto, ya había sido objeto de análisis en la TMA. Como hemos visto anteriormente, los indivisibles de la TMA no admiten una división de sus partes. No obstante, el hecho mismo de que Leibniz se refiera a las partes de los indivisibles sugiere que, aunque no sean ontológicamente separables, pueden ser consideradas como tales mentalmente. Podría decirse, siguiendo una expresión utilizada por Descartes a la que nos hemos referido en el capítulo tercero, que la partición que se hace sólo con el pensamiento no cambia nada. En este sentido, que para Leibniz sea posible hablar de las partes de los indivisibles no altera el hecho de que sean ontológicamente inseparables. Recién en el fundamento 18 de la TMA Leibniz se refiere a esta cuestión, cuando intenta explicar cómo deben entenderse las partes de los instantes, esto es, de los indivisibles del tiempo. Para esto, apela a una analogía: las partes de los instantes son “como los Ángulos en un punto". 99 Esto lo lleva a examinar la naturaleza de los ángulos, lo que, como dijimos, es importante para la reconstrucción de $D M M$ y, en consecuencia, para el devenir de la interpretación leibniziana del continuo. La definición de ángulo que ofrece en este escrito es:

Un ángulo es la cantidad de un punto de choque, es decir, una porción de un círculo menor que el que puede asignarse, esto es, del Centro; toda la doctrina acerca de los Ángulos trata sobre las cantidades de los inextensos. ${ }^{100}$

\footnotetext{
${ }^{98} D M M$, A VI 3, 97. Véase en la misma página la imagen que se adjunta para explicar el pasaje en cuestión. ${ }^{99} T M A$, A VI 2, 266. "ut Anguli in puncto". OFC, 8, 82.

${ }^{100} T M A$, A VI 2, 267. "Angulus est quantitas puncti concursus, seu portio circuli minoris quam qui assignari potest, id es Centri: tota de Angulis doctrina est de quantitatibus inextensorum”. OFC, 8, 83.
} 
Leibniz reconoce que el centro de un círculo cualquiera debe ser entendido no como una línea infinitamente pequeña sino como un círculo de características análogas. Como todo indivisible, el punto central del círculo posee una magnitud inasignable. Si se quisiera representar en una imagen, salvada, ciertamente, la distancia, el ángulo $x$, en tanto porción de un círculo menor que cualquiera dado $z$, sería:

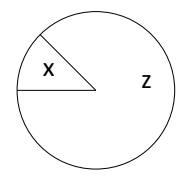

Esto sugiere, como se ha dicho, que aunque los indivisibles sean tales desde un punto de vista ontológico, existe al menos la posibilidad de considerar una parte suya, como $x$, que, en tanto parte, es menor que el punto dado. Leibniz intenta aclarar la cuestión indicando que los ángulos en tanto partes de puntos (al igual que las partes de los instantes en relación con los instantes mismos) son, de acuerdo con la denominación escolástica, signos, esto es: aunque el ángulo y el punto del cual es parte se dan simultáneamente en el tiempo, el primero depende causalmente del segundo. Es decir que para que se dé un ángulo, ha de darse un punto. ${ }^{101}$

Retomemos la argumentación de $D M M$. Como habíamos dicho, Leibniz subraya que pueden trazarse infinitas líneas perpendiculares a una línea cualquiera $a b$. Ahora bien, de aquí se sigue que los ángulos en la línea $a b$, es decir, los puntos de contacto, serán también infinitos. ${ }^{102}$ En la imagen anterior se observa asimismo que uno de los extremos de la línea 1-2 está sobre $a b$. Pero entonces los indivisibles no serán solamente los extremos de la línea $a b$. La conclusión que se sigue inevitablemente de lo anterior es que "[s]i se diera [lo indivisible] en la línea $a b$, se daría en ella en todas partes". ${ }^{103}$ Leibniz parece reconocer, entonces, que de la consideración conjunta de la tesis de que los indivisibles son extremos y

${ }^{101}$ TMA, A VI 2, 266, estableciendo una analogía precisamente entre las partes de un instante y los ángulos en tanto partes de un punto: “(...) quanquam non desint instanti partes suae, sed indistantes (ut Anguli in puncto) quas Scholastici, nescio an Euclidis exemplo, vocant signa, ut in iis apparet, quae sunt simul tempore, sed non simul natural, quia alterum alterius causa est". OFC, 8,82 .

${ }^{102}$ DMM, A VI 3, 99. "Nam angulus contactus punctum est". Previamente en la misma página indica: "Et Angulus quantitas puncti est, scilicet centri". Para nuestra reconstrucción del procedimiento, es esencial notar que Leibniz retoma en $D M M$ la misma noción de ángulo que presentó en $T M A$, es decir, como una porción de un círculo menor que cualquiera dado. DMM, A VI 3, 99. "(...) Centrum Circuli intelligi debet Circulus minor quovis dato, cuius portiones sunt anguli". Ahora bien, de acuerdo con Breger, 1990: 59-60, la crítica a la teoría de los indivisibles es al mismo tiempo una crítica a la teoría del infinito actual. Como veremos en el capítulo sexto, en cualquier caso es una crítica a la concepción de Galileo según la cual existe un número máximo, que es un todo y una unidad, pero no del infinito actual.

${ }^{103} D M M$, A VI 3, 97. "Si [indivisibile] datur in linea $a b$ dabitur in ea ubique". 
de la noción de ángulo, se sigue que el continuo estaría íntegramente compuesto de indivisibles.

Como mencionamos anteriormente, en DMM Leibniz muestra que una composición de indivisibles tal como la que resulta del argumento anterior no es posible. El hecho de que el sentido de indivisible que Leibniz tenga en cuenta pueda ser el de Galileo, es decir, algo non quanti, hace comprensible que el filósofo de Leipzig los identifique con los mínimos y señale en consecuencia que no se da 'lo mínimo o indivisible' en el espacio, el cuerpo, el tiempo y en movimiento. ${ }^{104}$ Ahora bien, la propuesta de Leibniz en DMM no retoma el concepto de indivisible de TMA. Más bien, a partir de esta reconstrucción y de la demostración de que una composición de indivisibles es imposible, Leibniz modificó no sólo la noción de punto como mero extremo indivisible del espacio o del cuerpo, sino que también reemplazó el concepto mismo de 'indivisible' por otro que le permitió evadir los problemas a los que esta noción lo llevó. Como veremos a continuación, de esto resulta la visión del continuo como compuesto íntegramente de (y no sólo delimitado por) cosas infinitamente pequeñas (infinite parva).

En el apartado 3.1. de este capítulo hemos indicado que los indivisibles pueden entenderse, con cierta cautela, como magnitudes infinitamente pequeñas. Esta reserva está fundada en el hecho de que Leibniz utiliza el nombre de 'cosa infinitamente pequeña' para referirse a otro tipo de entidades distintas de los indivisibles, que desde un punto de vista histórico los reemplazaron. Hay no obstante una similitud desde el punto de vista conceptual, en la medida en que Leibniz describe a los indivisibles, independientemente de su denominación, como magnitudes infinitamente pequeñas. Esta puede ser una de las razones que ha llevado a $\mathrm{Ph}$. Beeley, por ejemplo, a entender los indivisibles de Leibniz como infinitesimales. ${ }^{105}$ Sin embargo, veremos a continuación que la diferencia de nombre esconde además una diferencia conceptual muy importante para Leibniz.

La introducción que Leibniz hace de lo infinitamente pequeño en el continuo tiene lugar con un argumento muy similar al utilizado en la $T M A$ para los indivisibles, esto es,

\footnotetext{
${ }^{104}$ Pueden verse las citas en las notas 42 y 43.

105 De acuerdo con él, cuando en la TMA Leibniz define al punto como una magnitud "minor quam dari potest" lo describe apelando a la expresión que posteriormente utilizará para referirse a los infinitesimales. De allí que Beeley comprenda al punto de la $T M A$ "como una línea que, hablando figuradamente, tiene una distancia infinitamente grande respecto de una línea dada cualquiera”. Beeley, 1996: 256. Esta interpretación fue fuertemente cuestionada por Bassler, 1998a: 18 y ss.
} 
comenzando con la partición de una línea dada $a b$ e indagando por su inicio. ${ }^{106}$ No obstante, hay ciertas diferencias entre el trasfondo del planteamiento leibniziano en 1672 en relación con el de TMA que condicionaron sus conclusiones. Estas diferencias están vinculadas con los pensamientos de Leibniz relativos a la naturaleza del cuerpo que hemos mencionado en el tercer capítulo. Allí hemos visto que, mediante una reexaminación de la naturaleza corpórea, Leibniz arribó a la conclusión de que no hay espacio sin cuerpo y no hay cuerpo sin movimiento. ${ }^{107}$ La evolución del pensamiento de Leibniz respecto de la naturaleza corpórea está sorprendentemente vinculada con el abandono de los indivisibles y la aceptación de cosas infinitamente pequeñas pues, como él mismo reconoce, la razón que ha conducido a estas conclusiones fue un examen de los indivisibles. ${ }^{108}$

La inclusión del movimiento como una de las notas definitorias del cuerpo, o mejor dicho, la identidad entre espacio, cuerpo y movimiento fundada en el hecho de que las diferencias entre ellos son puramente ficticias, plantea nuevas exigencias en relación con el análisis del continuo en general y con el examen de los inicios y finales en particular. Dada esta identidad, los extremos de una línea cualquiera que represente un espacio deberían ser entendidos no como puntos indivisibles sino como puntos en movimiento, esto es, como líneas que no son, por eso mismo, indivisibles. En cambio, si no se diera la identidad, entonces el extremo de un espacio no se entendería en movimiento y, por lo tanto, debería concluirse que es indivisible. Ahora bien, en el capítulo tercero hemos visto que Leibniz admitió que ser cuerpo es estar en movimiento al menos desde 1670. Sin embargo, como veremos en la siguiente cita de $D M M$, reconoció que omitió esta tesis en la $T M A$ de 1671. En gran medida, el filósofo de Leipzig superó su pensamiento de la $T M A$ en los escritos de 1672 tras haber retomado la identidad entre espacio, cuerpo y movimiento:

Supóngase que un punto se concibe como una línea infinitamente pequeña, que una es mayor que otra y que se la piensa como designada en un espacio o cuerpo. [Supóngase] también que nos preguntamos por el inicio de un cierto cuerpo o espacio, esto es, por la primera parte, y que no se tiene por 'inicio' a lo que se le puede seccionar algo [mientras] el inicio [permanece] intacto.

\footnotetext{
${ }^{106}$ DMM, A VI 3, 98-99. El argumento, por ejemplo, comienza así: "Sunt aliqua in continuo infinite parva, seu infinities minora, quovis sensibili dato. Id de spatio primo ita ostendo. Esto linea ab, percurrenda aliquo motu. Cum possit aliquod intelligi initium motus in illa linea, initium etiam lineae hoc initio motus percurri intelligetur, esto illud initium $a c$ ". Breger, 1990: 60.

${ }^{107} D M M$, A VI 3, 97.

${ }^{108}$ Véase Leibniz, 2001: xxxv.
} 
Supuesto esto, llegaríamos necesariamente a indivisibles en el espacio y el cuerpo. Pues esta línea, por más pequeña que sea, no sería el verdadero inicio del cuerpo, pues aún podría seccionarse algo de ella, a saber, la diferencia entre ella y otra línea infinitamente pequeña todavía menor; y no descansaríamos hasta que llegáramos a una cosa carente de una parte, es decir, menor que la que no pueda imaginarse nada, lo que mostré que es imposible. Pero si un cuerpo fuera concebido como algo que se mueve, entonces su inicio se definiría como una línea infinitamente pequeña, aunque existiera, en efecto, otra línea menor que ella. Sin embargo, de este movimiento no puede asumirse ningún otro Inicio que el que fuera mayor que el Inicio de un movimiento más lento. Pero definimos al inicio de un cuerpo por el inicio mismo del movimiento, es decir, por el conato, pues de otra manera el inicio del cuerpo debería ser un indivisible. De aquí se sigue que en el cuerpo no hay una materia distinta del movimiento. En efecto, necesariamente contendría indivisibles. Por lo que muchos menos el espacio es distinto de la materia. Finalmente, de aquí se entiende que ser cuerpo no es otra cosa que moverse. ${ }^{109}$

Como se observa, a diferencia de la $T M A$, en donde la perspectiva era más bien estática o cinemática, en los escritos de 1672 Leibniz adoptó una perspectiva más bien dinámica. ${ }^{110}$ Así, aunque la línea infinitamente pequeña que un movimiento recorre en su inicio sea, en cuanto línea, nuevamente divisible, dado que aquello que se busca es precisamente el inicio de un movimiento particular, debería concluirse que éste es una línea infinitamente pequeña determinada y no otra. Esto significa que, aunque pueda proseguirse infinitamente la división de la línea infinitamente pequeña, ella es el inicio del movimiento determinado (es decir, de este movimiento y no de otro). Como no hay espacios sin cuerpos ni cuerpos sin movimiento, el inicio de una línea es proporcional a un conato. ${ }^{111}$ De este modo, no es necesaria una ulterior división hasta lo indivisible: "Y como el continuo es

\footnotetext{
${ }^{109} D M M$, A VI 3, 100. "Pone punctum intelligi lineam infinite parvam, aliamque alia esse maiorem, eamque in spatio aut corpore designatam cogitari; et de aliquo corporis aut spatii cuiusdam initio, id est prima parte, quaeri, et illud pro initio non haberi, cui aliquid salvo initio abscindi potest; hoc posito in spatio corporeque ad indivisibilia necessario deveniemus. Nam nec linea ista utcunque infinite pa[rva] erit verum corporis initium, cum adhuc aliquid ab ea abscindi possit, differentia scilicet inter ipsam, et aliam lineam infinite parvam, adhuc minorem: nec quiescetur, donec ad rem parte carentem, seu qua minor fingi nulla possit, deveniatur, qualem ostendi impossibilem. At si corpus intelligatur, id quod movetur, tunc initium eius linea infinite parva definietur, etsi enim ea linea alia minor extet; huius tamen motus, nullum aliud Initium assumi potest, quam quod alterius motus tardioris Initio sit maius. Corporis autem initium ipso motus initio seu conatu definimus, cum alioquin initium corporis indivisibile sit futurum. Hinc sequitur nullam esse in corpore materiam a motu distinctam, ea enim necessario indivisibilia contineret. Quare multo minus spatium a materia distinctum est. Hinc intelligitur denique nihil aliud esse, esse corpus quam moveri”. La cursiva es nuestra.

${ }^{110}$ Breger, 1990: 60.

111 Tomamos la expresión de Arthur, 2009, apartado "Phase 3: Infinitely small lines proportional to endeavours".
} 
capaz de ser seccionado al infinito -en efecto, como otros demostraron, es divisible al infinito-, se sigue que el inicio de la línea, es decir, lo que se recorrería con el inicio del movimiento, es infinitamente pequeño". ${ }^{112}$ De este modo, aunque la línea recorrida por un movimiento en el inicio pueda ser mayor o menor que la recorrida por otro, ${ }^{113}$ no por eso debería proseguirse la división de la línea del primer movimiento, puesto que aquello que se buscaba era $s u$ inicio. En consecuencia, Leibniz entendió a las cosas infinitamente pequeñas, en este caso, como puntos que pueden poseer diferentes magnitudes, en la medida en que un punto puede ser infinitamente más pequeño que otro punto. ${ }^{114}$

Todos estas reflexiones leibnizianas de 1672 tienen importantes consecuencias en relación con la composición del continuo. Ante todo, ahora Leibniz sí estaría dispuesto a asumir que el continuo se compone de partes infinitamente pequeñas en tanto que efectivamente pueden establecerse infinitos puntos de contacto entre una línea y las infinitas perpendiculares a ella. En este sentido, en relación, por ejemplo, con un movimiento, los conatos no serán solamente su inicio y su final, sino también los medios. ${ }^{115}$ Similarmente, también el espacio y el tiempo se componen de partes de espacio y de tiempo infinitamente pequeñas. ${ }^{116}$ Leibniz explica, por ejemplo, la composición de un espacio continuo de partes menores que cualquiera sensible dada en un pasaje del que hemos citado una pequeña parte en la primera sección de este capítulo. A continuación de aquel pasaje, Leibniz agrega:

Es necesario, por consiguiente, que en un momento dado o 'ahora' [el cuerpo $C$ ] atraviese alguna parte, pues si ahora no cambia el lugar o no atraviesa alguna parte, por consiguiente reposa. Y supongamos que ahora se mueve, esto es, que en un momento dado comienza un movimiento o tiende [a moverse]. Por consiguiente, 'ahora' o en un momento dado avanzará, pero a través de un

${ }^{112}$ DMM, A VI 3, 99. “(...) cumque in infinitum queat abscindi, continuum enim, ut alii demonstravere in infinitum divisibile est, sequitur initium lineae, seu quod initio motus percurritur esse infinite parvum". Lo que antecede a esta expresión en el argumento es: "Id de spatio primum ita ostendo. Esto linea $a b$, percurrenda aliquo motu. Cum possit aliquod intelligi initium motus in illa linea, initium etiam lineae hoc initio motus percurri intelligetur, esto illud initium $a c$. Sed manifestum est posse ab eo resecari $d c$ salvo initio, et si initium credatur $a d$ ab eo rursus $e d$ resecabitur initio salvo, idque in infinitum. Etsi enim nec manus mea, possit, nec animus velit prosequi divisionem in infinitum; potest tamen semel in universum intelligi, id omne ad initium non pertinere, quod salvo initio abscindi potest (...)".

${ }^{113}$ De consistentia corporum, A VI 3, 96.

${ }^{114}$ DMM, A VI 3, 99. Breger, 1990: 60.

115 Demonstratio substantiarum incorporearum, A VI 3, 80.

${ }^{116}$ Demonstratio substantiarum incorporearum, A VI 3, 80. En efecto, tras mencionar que "Conatus est pars actionis qualibet data minor, seu initium medium finisve actionis", Leibniz señala: "Ut instans temporis, punctum lineae". 
espacio menor que cualquiera determinable por nosotros. Por consiguiente, el espacio se compone de partes menores que cualquiera determinable por nosotros. O bien muy brevemente: el tiempo se compone de momentos o partes menores que cualquiera determinable por nosotros; en efecto, no existe nada [en el tiempo] sino el momento. El movimiento divide a la línea en partes proporcionales a las partes del tiempo. Por consiguiente, hay, en una línea, partes proporcionales a los momentos, es decir, menores que cualquiera determinable por nosotros. ${ }^{117}$

Puede observarse, consecuentemente, que la negación de la existencia de los indivisibles por parte de Leibniz no anula todo tratamiento de magnitudes o cantidades que, sin ser iguales a cero, son de hecho muy pequeñas. Para Leibniz, los infinitesimales o cosas infinitamente pequeñas no son partes mínimas dado que poseen partes y, por eso mismo, no admiten la propiedad de la indivisión. Poseen, así, una magnitud determinada que, aunque sea infinitamente pequeña, no es igual a cero. ${ }^{118}$

Por consiguiente, el concepto de lo infinitamente pequeño comporta ciertas similitudes respecto de lo indivisible de la $T M A$, aunque también exhibe notables diferencias. Hay una coincidencia en el hecho de que Leibniz los describa a ambos como menores que cualquier magnitud sensible dada, pues efectivamente las cosas infinitamente pequeñas son "infinitamente menores que cualquier cosa sensible dada". ${ }^{119}$ Difieren, sin embargo, en dos aspectos cruciales. Por un lado, dada la identidad entre espacio, cuerpo y movimiento, la búsqueda del inicio de una línea dada no pretende alcanzar lo indivisible sino la línea infinitamente pequeña que se recorre en el primer instante, aunque ésta, como línea, sea nuevamente divisible ad infinitum. En este sentido, las cosas infinitamente

\footnotetext{
${ }^{117}$ Demonstratio substantiarum incorporearum, A VI 3, 81. "Esto spatium $a b$, in eo ferri intelligatur corpus $C$ motu uniformi et horae spatio pervenire ex $a$ in $b$, necesse est semihorae spatio pervenire in $d$ et spatio quadrantis in $e$ et semiquadrantis in $f$ et sic perpetuo subdividendo in eadem ratione locum et tempus; necesse est ergo momento dato seu nunc pervenire aliquousque, nam si nunc non mutat locum seu non pervenit aliquousque quiescit ergo, at supponimus nunc moveri, id est momento dato incipere motum seu conari. Nunc ergo seu momento dato progredior, sed per spatium minus quolibet a nobis determinabili. Componitur ergo spatium ex partibus qualibet a nobis determinabili minoribus. Vel brevius: tempus componitur ex momentis seu partibus qualibet a nobis determinabili minoribus nunquam enim existit nisi momentum; motus lineam dividit in partes partibus temporis proportionales, sunt ergo partes in linea momentis proportionales, seu qualibet a nobis determinabili minores". La imagen que acompaña este pasaje ha sido presentada en la primera sección de este capítulo.

${ }^{118}$ Los infinitesimales leibnizianos, por cierto, no deben interpretarse solamente como líneas infinitamente pequeñas. Leibniz también dice, por ejemplo, que el centro de un círculo cualquiera debe entenderse como un círculo infinitamente pequeño (A VI 3, 99). En este sentido, el concepto de lo infinitesimal es un concepto a base de propiedades estructurales que vale para distintas figuras.

${ }^{119}$ DMM, A VI 3, 98. "Sunt aliqua in continuo infinite parva, seu infinities minora, quovis sensibili dato".
} 
pequeñas difieren de los indivisibles en tanto que no admiten precisamente la característica de la indivisión. Por eso, no son unidades mínimas, esto es, cosas menores que las que no puede imaginarse nada. ${ }^{120}$

En segundo lugar, difieren también en otra característica absolutamente definitoria del concepto de indivisible tal como aparece en la $T M A$. En efecto, Leibniz creía que, en razón de su pequeñez, los indivisibles, por un lado, son menores que cualquier magnitud sensible dada y, por otro lado, no pueden ser expuestos en una fracción o ratio. Las cosas infinitamente pequeñas que Leibniz describe desde 1672, aunque son menores que cualquier magnitud sensible dada, son divisibles y pueden exponerse en una ratio. En consecuencia, las cosas infinitamente pequeñas pueden ser concebidas como fracciones infinitamente pequeñas.

Nuevamente, en este punto los exámenes matemáticos de Leibniz complementan a los del continuo. Mientras que de las consideraciones sobre este laberinto Leibniz extrae las razones para justificar la existencia de cosas infinitamente pequeñas, de las matemáticas extrae una de sus características más importantes. En este sentido, una caracterización completa de las cosas infinitamente pequeñas afirmadas por Leibniz en 1672 se obtiene examinando los tratamientos relativos al problema del continuo y a su vez los matemáticos, relativos a las series infinitas. Que las cosas infinitamente pequeñas sean magnitudes menores que cualquiera sensiblemente dada significa, ante todo, que, si siguiéramos la guía de los sentidos, no podríamos persuadirnos de la existencia de una línea tan breve dividida a su vez en otras infinitas líneas infinitamente pequeñas. ${ }^{121}$ Ahora bien, esto no significa para Leibniz que estas líneas no mantengan una razón finita en relación con otra línea dada. Dicho afirmativamente, para Leibniz puede demostrarse que las cosas infinitamente pequeñas poseen una razón finita en relación con otra línea dada. ${ }^{122}$ No significa esto que la distancia entre una parte infinitamente pequeña y otra sensiblemente perceptible sea finita. Como se dijo, las cosas infinitamente pequeñas son infinitamente menores que cualquier magnitud sensible. Lo que Leibniz quiere expresar es que, en una serie decreciente al infinito ya sea geométrica o aritméticamente, se encontrarían términos infinitamente

\footnotetext{
${ }^{120} D M M$, A VI 3, 100. En este sentido, como señala Robinet, 1986: 146, el hecho de que en la TMA un punto indivisible sea al espacio como el uno al infinito, significa que es algo 'uno', es decir, una cierta unidad que no se reduce a sus componentes.

${ }^{121}$ Leibniz a Jean Gallois, A II 1, 342.

${ }^{122}$ Leibniz a Jean Gallois, A II 1, 342.
} 
pequeños que, no obstante, responden a la misma ley de sucesión que guía toda la serie. Para explicar esto, consideremos la serie que decrece según una progresión geométrica al infinito siguiendo la razón de $\frac{1}{2}$, es decir, $\frac{1}{2}, \frac{1}{4}, \frac{1}{8}, \frac{1}{16}, \frac{1}{32}$, etc. Como el 'etc.' significa 'al infinito', prosiguiendo la serie se alcanzarían términos infinitamente pequeños que, no obstante, serían la mitad respecto del término dado con anterioridad. En términos actuales, la expresión algebraica general de esta serie es $\frac{1}{2^{n}}$, donde $n$ son los números naturales. De esta manera, el infinitesimal correspondiente se expresaría $\frac{1}{2^{\infty}}$. De acuerdo con esto, un infinitesimal es visto por Leibniz como una fracción o razón infinitamente pequeña de una magnitud dada. Más aún, y por lo mismo, dicha cosa infinitamente pequeña admitiría la consideración de una parte suya que, siendo una cosa infinitamente pequeña menor, responde a la misma razón.

Para finalizar este capítulo, sintetizaremos las conclusiones parciales que se han ido extrayendo. En primer lugar, hemos visto que las infinitas partes actuales del continuo que Leibniz afirmó en la TMA, pueden entenderse a la luz de los desarrollos posteriores sobre series infinitas. De esta manera, pueden entenderse como las fracciones de una serie infinita de términos. Hemos visto también que esta interpretación es consistente con la afirmación, también mencionada por Leibniz en la $T M A$, de que hay indivisibles en el continuo. En efecto, Leibniz interpretó los indivisibles como extremos del continuo, de manera que el continuo no se compone de ellos en su integridad. No obstante, luego de publicar la TMA Leibniz leyó los Discorsi de Galileo y notó que hay una ambigüedad entre su noción de indivisible y la del científico italiano: mientras que en la TMA los indivisibles fueron concebidos como teniendo partes, es decir, como magnitudes inasignables, para Galileo no tienen cantidad en absoluto (son non quanti). Esta ambigüedad, junto con algunas contradicciones que Leibniz detectó que se siguen del modo como Galileo comprendió la composición del continuo, llevaron al filósofo de Leipzig a replantearse el modo de concebir el continuo. Como hemos visto, en 1672 Leibniz ha llegado a la conclusión de que el continuo se compone de partes infinitamente pequeñas que, siendo infinitamente 
menores que cualquier magnitud sensible dada, no obstante no son indivisibles. 



\section{CAPÍTUlO 5: ASPECTOS FÍSICOS DEL TRATAMIENTO DEL CONTINUO}

El hecho de que el problema del continuo haya sido concebido por Leibniz como un auténtico laberinto se apoya, al menos parcialmente, en que el filósofo de Leipzig ha mantenido distintas acepciones de la locución 'continuo' relacionadas con diferentes cuestiones. En efecto, pueden reconocerse tres sentidos distintos. En primer lugar, hay una acepción genérica de la noción de 'continuo' con la cual Leibniz se refiere a entidades tales como el espacio, el tiempo, el cuerpo y el movimiento. Este es claramente el sentido que Leibniz tiene en cuenta cuando señala, por ejemplo, que hay infinitas partes actuales en el continuo. Este ha sido el sentido de la noción de 'continuo' que ha primado en nuestro examen hasta este momento. No obstante, hay al menos otros dos significados muy relevantes para el examen leibniziano del continuo que aparecen en el seno de ciertas reflexiones físicas del filósofo de Leipzig. Por una parte, encontramos la acepción de 'continuo' con la cual Leibniz se refiere a la carencia de detenciones en el trayecto de un móvil. En este sentido, Leibniz ha señalado que "[e]l movimiento es continuo, es decir, no [está] interrumpido por reposos". ${ }^{1}$ Ahora bien, además de esta acepción evidentemente vinculada con la teoría del movimiento y de aquella otra genérica, hay un tercer sentido de la noción de 'continuo' que tiene una gran importancia fundamentalmente en el marco de las reflexiones leibnizianas sobre el cuerpo. En efecto, el filósofo de Leipzig asume también la noción aristotélica de 'continuo' como una subespecie de lo 'contiguo', tal como la hemos visto en el segundo capítulo. Como veremos, para Leibniz esta acepción, según la cual son continuas cosas que tengan un extremo en común, es esencial para explicar por qué los cuerpos se mantienen unidos o están cohesionados. ${ }^{2}$

En este capítulo buscaremos examinar los problemas relativos al movimiento y al cuerpo en los cuales tienen lugar las dos acepciones surgidas en el seno de sus reflexiones físicas. Según esto, analizaremos tanto los problemas que Leibniz tuvo en cuenta como las respectivas soluciones fundadas en las acepciones antes mencionadas. En gran medida, los

\footnotetext{
${ }^{1}$ TMA, A VI 2, 265. "Motus est continuus seu nullis quietulis interruptus". OFC 8, 80.

${ }^{2}$ Levey, 1999: 103-104, señala que Leibniz habría distinguido dos sentidos de continuo, a saber, por un lado la acepción que aquí vinculamos con la teoría del cuerpo y por otro lado un sentido metafísico en el que la continuidad debe se entiende como potencialidad. Este último caso sería, por ejemplo, el de la materia homogénea que Leibniz consideró en algunos escritos anteriores a la $T M A$, tal como vimos en el tercer capítulo. No obstante, como veremos, este caso no es relevante para el problema del continuo, una vez que Leibniz afirmó infinitas partes en acto.
} 
temas analizados en este capítulo se complementan con los considerados en los dos previos, pues mientras en ellos nos hemos centrado en el concepto de 'infinito', en este nos detendremos en el de 'continuo'. Más aún, algunos elementos de la teoría leibniziana presentados en el capítulo anterior, tal como la doctrina de los extremos, son sumamente importantes para los desarrollos que explicaremos a continuación. Obtendremos, así, un panorama que, junto con los desarrollos que presentaremos en el capítulo siguiente, corresponde a la primera manera como Leibniz ha afrontado el problema del continuo. De acuerdo con las diferenciaciones hechas anteriormente, abordaremos en primer lugar algunos problemas relativos al movimiento en los que la segunda acepción de 'continuo' antes mencionada tiene un papel preponderante. Para ello, presentaremos inicialmente un panorama del siglo XVII. Posteriormente, examinaremos las dificultades relativas a la teoría del cuerpo en los que cobra importancia la tercera acepción.

\section{La explicación de la diferencia de velocidades en el siglo XVII}

La interpretación asumida por Leibniz según la cual el movimiento no está interrumpido por reposos tiene lugar en el marco de uno de los problemas físicos que más interés ha despertado entre los pensadores de la temprana filosofía moderna, a saber, ¿cómo debe explicarse la diferencia de las velocidades de los movimientos? Este problema recibió una gran atención por parte de pensadores de distintas escuelas, aunque especialmente entre los atomistas. De acuerdo con Froidmont, los atomistas confiaban en la superioridad de sus explicaciones en el dominio físico frente a los planteos de Aristóteles, aunque no podían decir lo mismo en el ámbito geométrico, es decir, en lo que respecta a la explicación de la composición de las figuras geométricas. ${ }^{3}$ No obstante, como veremos, una interpretación 'ingenua' del atomismo sería incapaz de explicar el fenómeno de la diferencia en las velocidades. En efecto, si el movimiento implicara una sucesión de puntos atómicos densamente dispuestos en el espacio uno después de otro, entonces no habría manera de explicar por qué un cuerpo puede moverse, en un mismo tiempo, a una velocidad mayor que otro. Ciertamente ambos recorrerían, en un instante (esto es, en una porción atómica de tiempo), un punto del espacio. De esta manera, de acuerdo con una interpretación 'ingenua'

\footnotetext{
${ }^{3}$ Froidmont, 1631: 56 .
} 
del atomismo, debería concluirse que los cuerpos se mueven todos siempre a la misma velocidad. Siguiendo un argumento similar, Froidmont concluyó que el atomismo (en la versión que aquí llamamos 'ingenua') no podría evitar la paradoja de Zenón según la cual Aquiles, esto es, un móvil más veloz, nunca podría superar a la tortuga, o bien un móvil más lento. ${ }^{4}$ En efecto, Froidmont entiende que si el circuito en el que se desarrollaría la eventual carrera estuviera compuesto de puntos, deberían existir, correspondientemente, 'puntos del tiempo' o momentos (interpretados en términos de porciones temporales atómicas). ${ }^{5}$ En este sentido, el teólogo de Lovaina supone que hay una correspondencia entre el espacio, el tiempo y el movimiento, de manera tal que o bien todos ellos se consideran como divisibles al infinito o bien como compuestos de puntos. ${ }^{6}$ Teniendo en cuenta esta correspondencia, Froidmont nota que, para mostrar que ninguno de los continuos se compone de puntos, bastaría con dejar en evidencia que hay al menos uno de ellos -es decir, el espacio, el tiempo o el movimiento- que no admite este tipo de composición:

Por consiguiente, para un tránsito indivisible se requiere de una indivisibilidad por ambas partes, tanto del móvil mismo como del espacio. De allí que, si en el móvil y en el espacio no existen indivisibles entrelazados, tampoco podrán existir en el movimiento кıvท́ $\mu \alpha \tau \alpha$ [esto es, ‘átomos del movimiento'], ni instantes positivos en el tiempo. ${ }^{7}$

Esta situación llevó a los atomistas (y, como veremos, también a otros fuera de ellos) a buscar respuestas alternativas. Una de ellas, que es un poco más sofisticada que la anterior, propone que las partículas atómicas de movimiento no están ordenadas densamente, es decir, que entre ellas se interponen porciones en las que no hay movimiento. En este sentido, según esta alternativa, los átomos no se disponen sucesivamente de manera inmediata, sino que entre ellos se interponen ciertas porciones carentes de movimiento. ${ }^{8}$ Un ejemplo de esta interpretación, al menos en términos

\footnotetext{
${ }^{4}$ Froidmont, 1631: 57. Véase la sección 3.1. del segundo capítulo.

${ }^{5}$ Froidmont, 1631: 56.

${ }^{6}$ Froidmont, 1631: 22.

${ }^{7}$ Froidmont, 1631: 138. "Igitur ad indivisibilem transitum requiritur indivisibilitas utrimque, tam ipsius

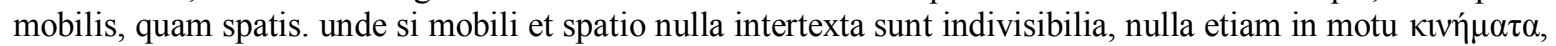
nulla in tempore positiva instantia poterunt esse". A esto se le suma el que, de acuerdo a Aristóteles, un punto añadido a otro no hace algo extenso. Froidmont, 1631: 77. "Si vero punctum unum alterum tanit; igitur ei illabitur, et penetrat, neque extensius aliquid cum eo, quam sine eodem facit. Hoc est, quod Aristoteles toties iterat: indivisibile proxime additum indivisibili divisibile extensius facere nequit".

${ }^{8}$ Froidmont, 1631: 76.
} 
generales, es la explicación dada por Galileo de la paradoja de los círculos concéntricos que examinamos anteriormente en la cuarta sección del segundo capítulo. De esta manera, los defensores de esta alternativa explican la diferencia en las velocidades de los movimientos de dos cuerpos interponiendo pequeñas pausas en el trayecto del móvil que se desplaza a una velocidad menor. En otras palabras, concibieron al movimiento como algo discontinuo, en la medida en que hay una 'mezcla' de movimiento y de reposo.

A pesar de que esta interpretación encontró una fuerte oposición en el siglo XVII, por ejemplo en Froidmont y, como veremos, también en Leibniz, no obstante también gozó de cierta popularidad, especialmente en España. El caso más destacado es, quizás, el de Rodrigo de Arriaga (1592-1667). ${ }^{9}$ Si bien de Arriaga mantiene en general una concepción aristotélica del continuo, explica la diferencia de velocidades sobre la base de una interpretación discontinuista tal como la que recién presentamos. ${ }^{10}$ Ahora bien, de acuerdo con este filósofo, en el continuo hay infinitas partes no en potencia sino en acto. Uno de los argumentos mediante los cuales justifica esto parte de señalar a priori que la 'distinción' y la 'identidad' son predicados esenciales de una cosa, de manera que no pueden provenir de otra cosa extrínseca. A modo de ejemplo, señala que una madera que permaneciera indivisa en acto, careciendo por lo tanto de partes distintas, no podría dividirse en muchas partes. En efecto, si sus partes se distinguieran solamente en potencia pero no en acto, entonces arribaríamos a una contradicción, pues la madera podría dividirse en partes que, no obstante, no existen en ella. ${ }^{11}$ En consecuencia de Arriaga dice, utilizando una expresión ejemplar, que "(...) en acto en este papel se dan infinitas partes determinadas, aunque unidas entre sí en acto". ${ }^{12}$

La explicación que da Rodrigo de Arriaga de la diferencia en las velocidades parte del reconocimiento explícito de que "en un único instante no puede recorrerse más o menos que un punto del espacio". ${ }^{13}$ No obstante, esto no significa para el español que los puntos

\footnotetext{
${ }^{9}$ Beeley, 1996: 298-299 y también Froidmont, 1631: 62.

${ }^{10}$ Evitaremos introducirnos en la disputa sobre si Arriaga ofrece o no una interpretación 'atomista' del movimiento puesto que, en última instancia, es irrelevante para nuestro examen.

${ }^{11}$ De Arriaga, Cursus philosophicus, Lib. VI Physic. Disp. XVI, sect. 2. Puede encontrarse una síntesis de los restantes argumentos en Luna Alcoba, 1994: 139-140.

${ }^{12}$ De Arriaga, Cursus philosophicus, Lib. VI Physic. Disp. XVI, sect. 3. “(...) ergo actu in hae charta dantur partes determinatae infinitae, licet actu unitae inter se". Tomamos la traducción de Luna Alcoba, 1994: 141, aunque con una ligera modificación.

${ }^{13}$ De Arriaga, Cursus philosophicus, Lib. VI Physic. Disp. XVI, sect. 11. “(...) in unico instante non potest magis minusve percurri quam unum punctum spatii".
} 
del espacio se ordenen densamente uno detrás del otro. En efecto, si así fuera, no podría evitarse la paradoja de Zenón. ${ }^{14}$ Ahora bien, aunque de Arriaga reconozca que la diferencia de velocidades no puede darse por el hecho de que un cuerpo recorra más o menos puntos del espacio en un instante, entiende que sí es posible que deje de recorrerlos intercaladamente. Esto significa que el móvil más lento permanece en una parte del espacio por dos partes del tiempo (si es que se mueve la mitad de rápido que el otro cuerpo), interrumpiendo el movimiento por ciertas demoras o retardaciones (morulas). ${ }^{15}$ De esta manera, de Arriaga muestra que la lentitud de un movimiento solamente puede consistir en pequeñas detenciones (in eis morulis), puesto que siempre que un cuerpo se mueva, solamente puede recorrer un punto del espacio, esto es, ni más ni menos.

Ahora bien, los defensores de la continuidad del movimiento suelen presentar argumentos en contra de la interpretación anteriormente descrita. Froidmont ha dedicado buena parte de su libro a cuestionar esta interpretación, que se había vuelto común en Lovaina. ${ }^{16}$ En efecto, reconoce que, de acuerdo con esta interpretación, supuesto un espacio de mil puntos que recorrieran un móvil más veloz, como $A$, y otro más lento, como $B, \mathrm{y}$ supuesto que $A$ se desplazara dos veces más rápido que $B$, entonces cada dos puntos que $A$ avance, $B$ avanzaría uno y reposaría otro. En consecuencia, cuando el más veloz llegara a la meta, el más lento habría alcanzado la mitad del recorrido. De esta manera, el móvil más veloz $A$ se movería continuamente en todos los momentos, mientras que el móvil más lento $B$ sólo alternativamente. ${ }^{17}$ Ahora bien, de acuerdo con el teólogo flamenco, surgen inconvenientes, por un lado, cuando se consideran otras diferencias de velocidades entre los mismos cuerpos, esto es, por ejemplo, cuando uno se mueve no dos veces más rápido que el otro sino mil veces. Esta situación implicaría que el móvil más lento, en vez de interponer un reposo por cada punto que avanza (lo que sucedería si el más veloz se moviera dos veces más rápido), interpone mil reposos. Sin embargo, para Froidmont esto no explicaría la causa que enseña al móvil más lento a conservar en un caso la proporción de la mitad y, en

\footnotetext{
${ }^{14}$ En este sentido, si se supone una carrera entre una tortuga y otro cuerpo más veloz, dada la correspondencia anteriormente indicada, debería decirse que recorren el mismo trayecto espacial. De Arriaga, Cursus philosophicus, Lib. VI Physic. Disp. XVI, sect. 11.

${ }^{15}$ De Arriaga, Cursus philosophicus, Lib. VI Physic. Disp. XVI, sect. 2.

${ }^{16}$ Froidmont, 1631: 58.

${ }^{17}$ Froidmont, 1631: 63.
} 
otro, la de una milésima. ${ }^{18}$ En consecuencia, esta explicación encuentra una falla en el análisis de la relación entre dos móviles. Sin embargo, por otro lado, falla también si se consideran otros móviles tanto más veloces como más lentos que los ya considerados. En este sentido, si se supone un cuerpo, como $C$, que se mueve con una velocidad incluso mayor que $A$, entonces el trayecto de este último debe también poseer demoras intercaladas. ${ }^{19}$ No obstante, como dijimos antes, no se explica cuál es la causa que le enseña a $A$ la proporción que, por una parte, debe conservar respecto de $C$ (o cualquier móvil más veloz) y al mismo tiempo la proporción que debe conservar, por otra parte, respecto del móvil $B$ (o cualquier otro más lento).

Ahora bien, esta no ha sido la única manera de explicar la desigualdad en las velocidades. De acuerdo con Froidmont, ha habido otra interpretación que pretende explicar este fenómeno, pero sin atender especialmente al hecho de que un cuerpo se mueva más lento que otro, sino al hecho de que el otro se mueva a una velocidad mayor. Según esta interpretación, el móvil más veloz recorrería en un instante más que un punto espacial, de tal modo que, si se moviera dos veces más rápido que otro cuerpo, en cada instante recorrería dos puntos espaciales, mientras que el más lento atravesaría solamente uno. De acuerdo con Froidmont, esta alternativa entiende que el móvil se 'replica' a través de una serie de puntos espaciales en un mismo instante. Así, si un cuerpo, como $B$ en la siguiente imagen, se moviera el doble de rápido que otro, como $A$, entonces recorrería dos puntos espaciales en cada instante. De este modo, el cuerpo $A$ adelantaría en un instante hasta el punto $\beta$ del espacio, mientras que el cuerpo $B$ haría lo propio hasta el punto 3 . Sin embargo, dado que el cuerpo $B$ no puede transitar hacia 3 sin pasar por 2, en un instante estaría replicado en esos puntos. ${ }^{20}$

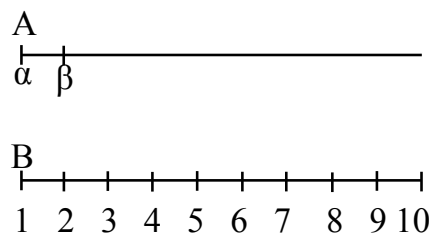

\footnotetext{
${ }^{18}$ Froidmont, 1631: 63.

${ }^{19}$ Froidmont, 1631: 63.

${ }^{20}$ Froidmont, 1631: 58-59. A los fines de obtener mayor claridad, hemos modificado los valores del gráfico introducido por Froidmont.
} 
No parecería haber problemas con esta situación hipotética si se la considerara solamente con el grado de complejidad que se propone en este ejemplo. Sin embargo, Froidmont lleva inmediatamente el asunto al extremo para poner de manifiesto lo absurdo de la replicación de los cuerpos. De esta manera, a modo de ejemplo, considera que el móvil $B$ se mueve no dos sino mil veces más rápido que $A$. Esto implicaría que en un instante estaría replicado en mil puntos, de tal manera que en el tiempo en que el cuerpo $A$ alcanza $\beta$, el cuerpo $B$ se replica hasta 10 (que en este caso representa el milésimo punto). Según Froidmont, al ojo "no se le escapa ningún momento del tiempo en el cual no contemplamos aquella cosa", ${ }^{21}$ de modo tal que no le pasaría desapercibido el fenómeno de la replicación a lo largo de mil puntos. En síntesis, Froidmont considera la imposibilidad de esta vía atendiendo, en principio, a un argumento empírico: “[y] así, el juicio de los ojos manifiestamente ha desmentido esta replicación de los puntos del cuerpo en un curso acelerado". 22

\section{Conatos, movimientos y diferencia de velocidades en Leibniz}

Leibniz era consciente de que el examen del movimiento había recibido mucha atención, por ejemplo, por parte de Galileo, Hobbes, Descartes, Huygens, entre otros. ${ }^{23}$ Sin embargo, es posible que, a finales de la década de 1660 y comienzos de la siguiente, no haya conocido directamente el pensamiento de algunos de estos autores, especialmente de Galileo y Descartes. ${ }^{24}$ No obstante, tenía conocimientos de las reglas del movimiento de C. Huygens, así como también algunas doctrinas de Hobbes. ${ }^{25}$ En lo que respecta al problema de la continuidad o no del movimiento, en la TMA y otros textos del mismo período, Leibniz discutió las interpretaciones discontinuistas que mencionamos en el apartado anterior. En este sentido, por ejemplo, no aceptó la explicación de la desigualdad de las

\footnotetext{
${ }^{21}$ Froidmont, 1631: 59: "nullum temporis momentum elabitur, quo rem illam, (...), non intueamur".

${ }^{22}$ Froidmont, 1631: 59: "Itaque hanc in celeri cursu punctorum corporis replicationem iudicium oculorum manifesto refellit".

${ }^{23}$ De rationibus motus, A VI 2, 159.

${ }^{24}$ Como señalamos en los capítulos anteriores, Leibniz leyó los Discorsi de Galileo en 1672 y los Principia Philosophiae de Descartes en 1675.

${ }^{25}$ El conocimiento de las reglas de Huygens queda en evidencia en De rationibus motus, A VI 2, 157-159, en donde Leibniz las enuncia. Incluso, más adelante en dicho escrito discute algunas de ellas. Similarmente, Leibniz se refiere a un ejemplo presente en el De motu de Huygens en TMA, A VI 3, 271. Con respecto al pensamiento de Hobbes, véanse las siguientes secciones de este capítulo.
} 
velocidades de los movimientos que supone demoras interpuestas en el trayecto del cuerpo que se desplaza lentamente, como defendió Rodrigo de Arriaga. Como hemos mencionado en la segunda sección del primer capítulo, desde comienzos de la década de 1670 Leibniz consideró que el reposo absoluto es imposible. De esta manera, el filósofo de Leipzig debió diseñar una estrategia totalmente distinta para explicar por qué los cuerpos se pueden mover a diferentes velocidades. ${ }^{26}$ Esto puede encontrarse en la TMA. Ahora bien, no debe olvidarse que en el mismo escrito Leibniz afirmó que hay infinitas partes en acto en el continuo, cada una de las cuales posee extremos indivisibles. Esto significa que el movimiento no fue concebido como una sucesión densa de conatos, esto es, de indivisibles del movimiento. ${ }^{27}$ En este sentido, la estrategia para explicar las diferencias de velocidades de los movimientos debió ser compatible con la afirmación de infinitas partes en acto en el continuo.

Ante todo, recordemos que, como hemos visto en la primera sección del capítulo precedente, en la explicación de los continuos (en el sentido genérico del término), Leibniz apela a su exposición en una línea. En este sentido, en una línea puede representarse tanto un espacio, un tiempo, un cuerpo o un movimiento, de manera que las conclusiones que se extraigan en este respecto valen análogamente para todos ellos. Por eso, en el caso que aquí nos interesa, los conatos, como indivisibles del movimiento, son proporcionales a los puntos, como comienzos indivisibles de una línea. ${ }^{28}$ En consecuencia, dado que hay un isomorfismo entre los continuos (como mencionamos en la primera sección del capítulo previo y como retomaremos en el capítulo siguiente), un movimiento es proporcional a una línea. De esta manera, si consideráramos el modo como Leibniz concibió la producción de las líneas, obtendríamos un buen indicio de cómo entendió los movimientos. Como hemos sugerido en el capítulo anterior y como veremos detalladamente en el próximo, para Leibniz una composición del continuo en términos de puntos acarrea contradicciones, de manera tal que no concibió a las líneas como sucesiones de puntos. Más bien encontramos

\footnotetext{
${ }^{26}$ Como atinadamente ha señalado Richard Arthur, sin embargo, con anterioridad Leibniz ha mantenido una interpretación discontinuista del movimiento. Por ejemplo, Arthur, 2009, parte "Phase 1 (1669): Unassignable gaps in the continuum".

${ }^{27}$ Evidentemente, quienes han mantenido que el continuo de $T M A$ se compone de indivisibles, como hemos visto en la sección 3.2. del capítulo anterior, no coincidirían con la interpretación que presentaremos a continuación.

${ }^{28}$ Como hemos indicado en los capítulos precedentes, la idea de una 'proporcionalidad' entre un conato y un punto es utilizada reiteradamente por Richard Arthur en sus trabajos.
} 
en el contexto inmediatamente anterior a la $T M A$ que Leibniz retomó la interpretación aristotélica de las explicaciones genéticas en la geometría, esto es, por ejemplo, que una línea (y algo similar vale para las restantes figuras geométricas) es el resultado del desplazamiento de un punto:

En efecto, ¿qué [hay] con más frecuencia en todos los libros de los Analíticos que ejemplos de Geometría? Parece que quiere que las demostraciones Geométricas sean como medida de las restantes. (...). Pero si pensamos el asunto con mayor precisión, parecería que ella [a saber, la geometría] demuestra a partir de las causas.

En efecto, demuestra las figuras a partir del movimiento: una línea surge del movimiento de un punto, una superficie del movimiento de una línea, un cuerpo del movimiento de una superficie. (...). Por lo tanto, las construcciones de las figuras son movimientos. Ahora bien, a partir de las construcciones se demuestran las afecciones de las figuras. Por lo tanto, a partir del movimiento, y en consecuencia a priori, a partir de la causa. ${ }^{29}$

Como hemos visto en el capítulo anterior, también Hobbes, quien, como veremos en lo siguiente, ha sido uno de los pensadores más influyentes en el pensamiento temprano de Leibniz, ha entendido que las figuras geométricas se explican genéticamente. ${ }^{30}$ Como justificaremos a continuación, la concepción leibniziana del movimiento en la TMA está estrechamente relacionada con las explicaciones geométricas. En efecto, así como para Leibniz en la generación de una línea es esencial el punto, así también el conato (esto es, el indivisible del movimiento) es fundamental para que se dé un movimiento. Leibniz mismo reconoce esta relación analógica entre el espacio, el movimiento y los indivisibles respectivos cuando señala que "[e]l conato es al movimiento como el punto al espacio, esto es, como el uno al infinito; en efecto, es el inicio y el fin del movimiento". ${ }^{31}$ Esta relación se contrapone a la del reposo que, dado que no existe en el mundo, es respecto del

\footnotetext{
${ }^{29}$ Leibniz a Thomasius, A II 1, 30-31. "Quid enim omnibus Analyticorum libris Geometrarum exemplis frequentius, ut videatur demonstrationes Geometricas velut mensuram caeterarum esse voluisse. (...). Sed si rem cogitemus accuratius, apparebit demonstrare eam ex causis. / Demonstrat enim figuras ex motu: ex motu puncti fit linea, ex motu lineae superficies, ex motu superficiei corpus. (...) Constructiones igitur figurarum sunt motus; jam ex constructionibus affectiones de figuris demonstrantur. Ergo ex motu, et per consequens a priori, et ex causa. Geometria igitur vera scientia est". Tenemos en cuenta la traducción de Loemker, 1989: 110. Ha de notarse que en la TMA Leibniz también concibe a la línea de esta manera, como implícitamente puede observarse en el pasaje que citaremos en la nota 42.

${ }^{30}$ Véase el punto 3 del capítulo anterior.

${ }^{31} T M A$, A VI 2, 265. "Conatus est ad motum, ut punctum ad spatium, seu ut unum ad infinitum, est enim initium finisque motus". OFC 8, 80. En la sección 3.1. del cuarto capítulo nos hemos referido a la relación del uno al infinito que es esencial en este fundamento predemostrable.
} 
movimiento como el cero al uno. ${ }^{32}$ En este sentido, si un cuerpo reposara, permanecería siempre en reposo, "a no ser que sobrevenga una nueva causa del movimiento". ${ }^{33}$ De este modo, así como de la propagación de un punto deviene una línea, de la de un conato deviene un movimiento. De esta manera se hace comprensible una tesis de gran importancia en la explicación leibniziana del movimiento, esto es, que “(...) el movimiento, como comienza, así continúa, a no ser que haya una causa extrínseca que lo cambie (...)”.34 En este sentido, en un examen cinemático o, como se lo llamaba en la época, foronómico, la propagación de un conato explica el surgimiento de un movimiento inercial. De este modo, Leibniz consideró que, una vez que una cosa se mueva, lo seguirá haciendo siempre con la misma velocidad y en la misma dirección -excepto que, como se ha dicho, algo externo lo perturbe.

Ahora bien, la importancia del conato en la teoría leibniziana del movimiento se evidencia aún más si se considera el problema que supone explicar la diferencia en las velocidades de los movimientos. Como dijimos antes, la explicación leibniziana presupone, por un lado, que no se dan reposos o demoras que retarden el movimiento (es decir, no es una interpretación discontinuista) y, por otro lado, que un movimiento -supuesto que es inercial- conserva la misma velocidad con la que comienza, esto es, la de su inicio. De allí se sigue que la razón por la cual un cuerpo se mueve con una velocidad mayor que la de otro cuerpo se halla en los conatos respectivos. Una primera consecuencia que se sigue de aquí es que los conatos, en la medida en que causan movimientos de diferentes velocidades, no pueden ser todos ellos iguales entre sí. ${ }^{35}$ Dicho afirmativamente, para Leibniz hay conatos mayores que otros por cuya diferencia se explica la de los movimientos a los que corresponden. $^{36}$

\footnotetext{
${ }^{32}$ TMA, A VI 2, 265. OFC 8, 80.

${ }^{33} T M A$, A VI 2, 265. "Nam (8.) ubi semel res quieverit, nisi nova motus causa accedat, semper quiescet". OFC $8,80$.

${ }^{34} T M A$, A VI 2, 265. “(...) quia motus ut incipit, ita pergit, nisi sit causa extrinseca mutans (...)”. OFC 8, 82. En un escrito posterior Leibniz confirma indirectamente que esta expresión debe comprenderse como aquí se interpreta, cuando señala, hablando de su manera de pensar en el pasado, que: "(...) semper enim in ipso motus inchoandi initio haesi, nam quod toto reliquo tempore evenire debebat, jam momento primo fieri quodammodo debere animadvertebam. Circa momenta autem atque puncta ratiocinari, id quidem supra meum captum esse fatebar". Pacidius Philalethi, A VI 3, 532. OFC, 8, 119.

${ }^{35}$ Retomaremos aquí un aspecto del examen de los indivisibles que ha sido sugerido en la sección 3.2. del capítulo cuarto pero cuya importancia en la cuestión actual nos obligó a considerarla recién en este momento de nuestro examen.

${ }^{36} T M A$, A VI 2, 266. OFC 8, 82.
} 
Ahora bien, esta tesis fundamental de Leibniz presupone que efectivamente los conatos, que -no debemos olvidarlo- son indivisibles, se diferencian en algo cuantitativamente. Como hemos visto en la sección 3.1. del capítulo precedente, para Leibniz los puntos son magnitudes, esto es, poseen partes, aunque no sean extensos. Si así fuera, no serían precisamente indivisibles. En analogía, podría decirse lo mismo de los conatos. Más aún, la magnitud en este caso puede ser entendida como intensiva, esto es, tal que, propagada, da lugar a un movimiento. ${ }^{37}$ En consecuencia, la diferencia en las velocidades estaría justificada en una diferencia de intensión, esto es, en las partes no extensas que definen al concepto leibniziano de indivisibles. De allí precisamente que Leibniz haya señalado que un conato es mayor que otro y haya justificado que, en consecuencia, también los puntos son unos mayores que otros:

Nadie negará con facilidad la desigualdad de los conatos; pero de allí se sigue la desigualdad de los puntos. Es evidente que un conato es mayor que [otro] conato, es decir, que un cuerpo que se mueve más rápido que otro ya recorre, desde el inicio, más espacio, pues si [el cuerpo que se mueve más rápido] recorre en el inicio exactamente lo mismo [que el más lento], siempre recorrerá exactamente lo mismo, pues el movimiento, como comienza, así continúa, a no ser que haya una causa extrínseca que lo cambie, por el fundamento 9; pero también, si los inicios son iguales, también son iguales los fines; por consiguiente en el momento de concurso tanto actúa el veloz sobre el lento como el lento sobre el veloz, lo que es absurdo: por tanto, serán desiguales. Por consiguiente, en un instante dado el [conato] más fuerte recorre más espacio que el más lento. Pero cualquier conato no puede recorrer en un instante más que un punto, es decir, una parte menor de espacio que la que puede exponerse; de otro modo recorrería, en el tiempo, una línea infinita. Por consiguiente un punto es mayor que [otro] punto. ${ }^{38}$

Esta compleja explicación de Leibniz puede separarse en una serie de partes. En primer lugar, para Leibniz la desigualdad de los conatos está de alguna manera justificada $a$ posteriori. En efecto, si un movimiento continúa como comienza y si es posible detectar

\footnotetext{
${ }^{37}$ En el caso del punto, la diferencia de intensión daría lugar a líneas de diferente largo.

${ }^{38}$ TMA, A VI 2, 266-267. "Conatu[u]m inaequalitatem nemo facile negaverit, sed inde sequitur inaequalitas punctorum. Conatum conatu maiorem esse, seu corpus, quod celerius alio movetur, iam ab initio plus spatii absolvere, patet: nam si initio tantundem absolvit, semper tantundem absolvet, quia motus it incipit, ita pergit, nisi sit causa extrinseca mutans per fund. 9., sed et, si initia aequalia sunt, etiam fines aequales sunt, ergo momento concursus tantum aget velox in tardum, quantum tardum in velox, quod est absurdum: sunto ergo inaequales. Ergo instanti dato fortior plus spatii absolvet, quam tardior, sed quilibet conatus non potest percurrere uno instanti plus quam punctum, seu partem spatii minorem, quam quae exponi potest; alioquin in tempore percurreret lineam infinitam: est ergo punctum puncto maius". OFC 8, 82.
} 
movimientos desiguales, se sigue en consecuencia que hay también una desigualdad en sus respectivos inicios. En segundo lugar, hay una evidente correspondencia entre un movimiento y un espacio, en tanto que un movimiento más veloz que otro no es sino aquel que recorre más espacio en el mismo tiempo. En analogía, por lo tanto, los puntos del espacio son también unos mayores que otros. De aquí se sigue, en tercer lugar, que hay una correspondencia entre el movimiento, el espacio y el tiempo que, no obstante, presenta una peculiaridad. En efecto, mientras que hay puntos y conatos mayores que otros, sin embargo no se dan instantes (esto es, indivisibles del tiempo) con estas características. Dicho de otra manera, los instantes son, para Leibniz, iguales entre sí. ${ }^{39}$ El fenómeno mismo de la diferencia en las velocidades requiere ciertamente de la igualdad del tiempo. ${ }^{40}$ En efecto, consiste en el hecho de que los cuerpos se mueven a distintas velocidades, esto es, recorren un espacio mayor o menor, en el mismo tiempo. En cuarto lugar, ha de notarse que Leibniz sostiene también la correspondencia entre puntos e instantes, en el sentido de que para el filósofo de Leipzig también en un instante solamente puede recorrerse un punto del espacio. Esto conlleva que todo espacio se recorre en un cierto tiempo cuando se considera más allá de los indivisibles, esto es, en la propagación que da lugar al movimiento. ${ }^{41} \mathrm{De}$ esta manera, en síntesis, para Leibniz un cuerpo tiende a moverse (conato, indivisible del movimiento), en un instante (inicio indivisible del tiempo siempre igual), un punto (extremo indivisible del espacio), de tal manera que una vez que se mueve (esto es, que se propaga el conato), recorre un espacio determinado en un cierto tiempo. La clave de la explicación de la desigualdad en las velocidades de los movimientos está, como se observa, en la desigualdad de los conatos. Ahora bien, cuando Leibniz examina el hecho de que puede haber una diferencia entre los puntos, presenta una indicación que, si no se la considera a la luz de lo anterior, puede llevar a confusiones:

Un punto de un cuerpo movido en el tiempo de un conato, es decir, menor que el que puede darse, está en varios lugares o puntos del espacio, esto es, llenará una parte del espacio mayor que sí [mismo], o mayor que la que llena [a] cuando reposa, [b] o [mayor que la que llena cuando es] movido más

\footnotetext{
${ }^{39} T M A$, A VI 2, 266. OFC 8, 82.

${ }^{40}$ Como sostiene, Beeley, 2015: 30, Leibniz justifica que hay puntos más grandes que otros, lo mismo que conatos, bajo la presuposición de que hay un tertium comparationis, a saber, la igualdad de los instantes.

${ }^{41}$ La indicación de Leibniz según la cual, si en un instante no se recorriera un punto sino una porción sensible de espacio entonces en un tiempo se recorrería una línea infinita, tiene un importante papel en la negación leibniziana de los mínimos en el continuo. Véase la primera sección del próximo capítulo.
} 
lentamente, [c] o [mayor que la que llena cuando] tiende [conans] solamente en una dirección. Sin embargo, esta [parte de espacio] también [es] inasignable, es decir, consiste en un punto, aunque la razón de un punto de un cuerpo (o de un punto del espacio que llena cuando reposa) a un punto del espacio que llena cuando [es] movido sea aquella del ángulo de contacto al rectilíneo, es decir, del punto a la línea. ${ }^{42}$

Algunos estudiosos recientes del pensamiento de Leibniz, como O. B. Bassler, se han basado en este pasaje para indicar que Leibniz habría entendido que el espacio se compone de puntos. ${ }^{43}$ Dada la correspondencia entre los continuos, esta interpretación conllevaría considerar que el movimiento estaría compuesto de conatos, de modo que la diferencia en las velocidades estaría dada en que el movimiento más veloz se compondría de conatos mayores. ${ }^{44}$ Sin embargo, como hemos mostrado en el capítulo anterior, el filósofo de Leipzig no ha concebido al espacio -ni al continuo en general- como compuesto de indivisibles. En este pasaje Leibniz ciertamente parece hablar con cierta indiferencia de 'puntos' y de 'partes'. No obstante, la clave que permite evitar la presunta ambigüedad se encuentra en el mismo pasaje. Reconstruyamos el argumento de Leibniz. El objetivo de este fundamento predemostrable es indicar que se dan puntos mayores que otros, de acuerdo con lo que hemos explicado anteriormente. Para esto, Leibniz examina distintas alternativas que se pueden dar si se considera un punto de un cuerpo en el inicio de su movimiento (esto es, 'en el tiempo de un conato'): en tanto que el cuerpo que se toma en cuenta está en el inicio del movimiento, el punto correspondiente sería mayor que en otras circunstancias, a saber, aquellas que hemos marcado en la cita con las letras [a] (mayor que cuando reposa), [b] (mayor que cuando se mueve más lentamente; como hemos explicado anteriormente, el conato de un movimiento más veloz es mayor que el de otro más lento) y [c] (mayor que cuando se mueve en una sola dirección). El problema es que Leibniz ha dicho que el punto del cuerpo movido está 'en varios lugares o puntos del espacio', o bien que llena 'una parte de espacio mayor'. Allí parecería identificarse 'puntos' con 'parte'.

\footnotetext{
${ }^{42}$ TMA, A VI 2, 265. "Unum corporis moti punctum tempore conatus seu minore quam quod dari potest est in pluribus locis seu punctis spatii, id est implebit partem spatii se maiorem, vel maiorem quam implet quiescens, aut tardius motum, aut conans in unam tantum plagam; attamen et ipsam inasignabilem seu in puncto consistentem quamquam puncti corporis (vel puncti spatii quod implet quiescens) ea sit ratio ad punctum spatii quod implet motu, quae est anguli contactus ad rectilineum, seu puncti ad lineam". OFC 8, 81 .

${ }^{43}$ Bassler, 1998a: 8. Este pasaje ha sido en general importante para todos los que sostienen que Leibniz ha concebido el continuo en la TMA como compuesto de indivisibles. Véase la sección 3.2. del capítulo precedente.

${ }^{44}$ Lison, 2006: 8-9, entre otros.
} 
Ahora bien, posteriormente Leibniz aclara que aquellos 'varios lugares' o aquella 'parte del espacio' debe ser concebida como un punto, esto es, como un indivisible (algo inasignable). Por eso, Leibniz expresa la diferencia como la de un punto 'en reposo' con la de un punto 'en movimiento', esto es, como la de un punto a una línea. Evidentemente Leibniz encuentra limitaciones en la manera de expresar esto, pues según lo que el mismo pasaje sugiere tampoco sería una línea sino un punto mayor que otro. Visto como aquí se propone, Leibniz se estaría valiendo de expresiones que impropiamente apuntan a señalar la posibilidad de una desigualdad en los indivisibles según como ha sido explicado.

Ahora bien, algunos aspectos de esta teoría leibniziana de 1671 se vieron modificados posteriormente. Estos cambios son paralelos a aquellos que hemos examinado en los dos capítulos precedentes. Notemos que, en el último análisis, Leibniz expresa que un punto de un cuerpo movido es mayor que uno que reposa. Ahora bien, ¿bajo qué razón decir esto, si es que el reposo se ha considerado como imposible y si el movimiento es una nota esencial del cuerpo $?^{45}$ Como hemos visto en la cuarta sección del capítulo anterior, un año después de publicar la TMA Leibniz ha notado que en su examen omitió considerar al movimiento como una nota definitoria del cuerpo, de manera tal que un punto en movimiento no sería propiamente un punto indivisible sino más bien una línea, aunque de muy pequeñas dimensiones. ${ }^{46}$ Esta omisión denunciada por Leibniz mismo se hace evidente en nuestro examen del último pasaje. Sin embargo, esta inadvertencia de Leibniz tiene importantes consecuencias: en primer lugar que, considerados al margen del movimiento, los puntos indivisibles, 'en reposo', serían todos iguales entre sí (pues, como no hay movimiento, no hay ninguna razón que explique una diferencia). Ahora bien, como veremos en la primera sección del capítulo siguiente, Leibniz considera que, de ser esto así, debería necesariamente concluirse que el continuo se compone íntegramente de indivisibles; no obstante, esto conlleva contradicciones. Precisamente por esto (como también hemos visto en el capítulo anterior), Leibniz modifica su interpretación del

\footnotetext{
${ }^{45}$ Este argumento supone la importancia del movimiento en la teoría leibniziana del cuerpo que hemos presentado en el tercer capítulo.

${ }^{46} D M M$, A VI 3, 100.
} 
continuo y pasa a considerar que el movimiento se compone, ahora sí, de partes infinitamente pequeñas, aunque no mínimas. ${ }^{47}$

Anteriormente hemos mencionado a la pasada la importancia que han tenido las reflexiones de Thomas Hobbes para el filósofo de Leipzig. Algunos aspectos de la influencia del filósofo británico en Leibniz han sido mencionados anteriormente. Sucintamente, los ámbitos de influencia ya considerados han sido los siguientes. Por una parte, como hemos visto en el primer capítulo, Hobbes ha influido en Leibniz en lo que respecta al pensamiento lógico. El uso práctico de esta influencia se verá en la sección 2.1. del próximo capítulo. Ahora bien, por otra parte, y como hemos visto en el capítulo anterior, Leibniz ha seguido el cuestionamiento de Hobbes a la noción euclidiana de punto, aunque no obstante luego haya optado por definirlo de una manera distinta. En tercer lugar, y como se ha sugerido en la sección 3.1. del capítulo previo y anteriormente en el presente, para Leibniz ha sido muy importante la noción hobbesiana de 'conato', aunque no lo haya interpretado exactamente de la misma manera. Con esto, Leibniz encuentra en Hobbes una fuente de inspiración no solamente en la lógica o en las definiciones geométricas, sino también en la física. Como se ha mencionado en el capítulo anterior, el concepto hobbesiano de conato es el de un movimiento en un espacio y un tiempo menor que el que pueda darse, esto es, un movimiento 'puntual'. Leibniz, que retoma la definición hobbesiana, ${ }^{48}$ lo entiende además como el comienzo de un movimiento, esto es, como la tendencia inicial que, propagada, da lugar a un movimiento. Todas estas cosas han sido sin duda importantes para que Leibniz se haya decidido a escribirle a Hobbes en $1670 .{ }^{49}$ Ahora bien, en el ámbito de la física la influencia de Hobbes ha sido incluso mayor. En efecto, en la carta recién mencionada, Leibniz destaca positivamente también algunos principios generales del movimiento expuestos por el filósofo británico (que, de acuerdo al

\footnotetext{
${ }^{47}$ Demonstratio substantiarum incorporearum, A VI 3, 81. Los cambios de la teoría leibniziana posteriores a la TMA son, en algún sentido, menos drásticos de lo que parecen a primera vista. En efecto, no hay que olvidar que, en virtud de la tesis del infinito actual, la explicación de los conatos indivisibles como extremos cuya propagación produce el movimiento es una estructura que se replica al infinito en distintas escalas de grandeza o pequeñez. En este sentido, hay en un movimiento infinitos conatos, o lo que es lo mismo, infinitos extremos de las infinitas partes, sin que esto signifique que el continuo se compone de ellos. Justamente por esto, el razonamiento es un argumento a base de propiedades invariantes. Ahora bien, quitada la noción de indivisible, no obstante persiste la infinita composición, aunque ahora de infinitas partes actualmente divididas al infinito (es decir, ninguna indivisible).

${ }^{48}$ Por ejemplo, en De rationibus motus, A VI 2, 171, dice Leibniz: "Motus autem in tempore minori quolibet dato, intra spatium minus quolibet dato est conatus".

${ }^{49}$ Leibniz a Hobbes, A II 1, 90-94.
} 
pensamiento lógico que hemos examinado, no son otra cosa que definiciones), e incluso hace propios algunos de ellos. ${ }^{50}$ A continuación haremos una comparación ilustrativa entre algunos razonamientos de Leibniz y de Hobbes sobre los principios del movimiento.

Para Leibniz, el choque entre cuerpos no es un impedimento para la propagación de los conatos, aunque evidentemente los conatos pueden verse alterados por un choque. Como veremos en la siguiente sección de este capítulo, una gran cantidad de fenómenos requiere precisamente de una suerte de transmisión de los conatos a lo largo de diversos cuerpos que se chocan. Es por eso que el filósofo de Leipzig ha presentado lo que podríamos denominar el principio de la propagación de los conatos: " $[d]$ e donde todo lo que se mueve, sin importar cuán débilmente [se mueva] ni cuán grande sea el obstáculo, propagará el conato a través de todo lo que lo obstaculice en el pleno al infinito y por lo tanto imprimirá su conato en todas las demás cosas". ${ }^{51}$ Este principio, sin embargo, ya había sido enunciado en términos muy similares por Hobbes cuando en el De corpore señaló que "[t]odo conato, sea fuerte o débil, es propagado a una distancia infinita por su movimiento". 52 Hay al menos dos cosas que se siguen de la propagación de los conatos al infinito en el pensamiento de Leibniz. Por una parte, que lo único que puede alterar el movimiento de un cuerpo es el choque con otro $\mathrm{y}$, en este sentido, como hemos visto anteriormente, que "lo que se mueve una vez, en cuanto depende de sí mismo, se moverá siempre con la misma velocidad y en el mismo espacio". ${ }^{33}$ Del mismo modo, Hobbes había indicado: "todo lo que se mueve se moverá siempre, excepto que haya otro cuerpo aparte de él que le cause el reposo".54 Por otra parte, se sigue que el tamaño de los cuerpos no afecta la propagación de los conatos, en tanto que un cuerpo agente de dimensiones arbitrariamente pequeñas produciría siempre un efecto en un cuerpo paciente de dimensiones arbitrariamente grandes. En este sentido, todo cuerpo actúa sobre los

\footnotetext{
${ }^{50}$ Leibniz a Hobbes, A II 1, 91.

51 TMA, A VI 2, 265. "Unde quicquid movetur, quantumcunque debiliter, quantumcunque etiam sit obstaculum, conatum per omnia obstantia in pleno propagabit in infinitum, ac proinde omnibus aliis imprimet conatum suum". OFC 8, 80.

${ }^{52}$ Hobbes, De corpore, II, 15, 7. "All endeavour, whether strong or weak, is propagated to infinite distance; for its motion". La traducción es nuestra.

${ }^{53}$ TMA, A VI 2, 265. “(...) quod semel movetur, quantum in ipso est, semper movetur eadem velocitate et plaga"; similarmente en De rationibus motus, A VI 2, 161. "Quicquid movetur semper movebitur eadem celeritate in eandem plagam, nisi ab alio corpore contiguo impediatur".

${ }^{54}$ Hobbes, De corpore, II, 8, 19. "In like manner, whatsoever is moved, will always be moved, except there be some other body besides it, which causeth it to rest". La traducción es nuestra.
} 
colindantes sin importar cuán pequeños o grandes sean. Nuevamente, Leibniz retoma este principio de Hobbes. Así, dice el filósofo de Leipzig: “(...) lo que reposa, por grande que sea, es empujado por algo que se mueve, por pequeño que sea, también con un movimiento por pequeño que sea"; también: "un cuerpo que reposa, por grande que sea, puede ser empujado por otro, por pequeño que sea, con un movimiento levísimo". 55 El filósofo británico, por su parte, había dicho: “(...) si un punto movido llega a tocar otro punto que reposa, por pequeño que sea el ímpetu o rapidez de su movimiento, moverá al otro punto". ${ }^{56}$ Finalmente, Leibniz entiende que el movimiento es un cambio de lugar que se da continuamente. $^{57}$ En virtud de esto, cuando un cuerpo se mueve, se encuentra constantemente en un lugar nuevo y, en consecuencia, nunca está en un solo lugar: “(...) nada de lo que se mueve está nunca en un lugar mientras se mueve ni siquiera por un instante o tiempo mínimo". ${ }^{58}$ Nuevamente, Hobbes había indicado: "aquello que se mueve, no está nunca en un lugar durante un tiempo, sin importar cuán pequeño sea ese tiempo".59

En síntesis, el modo como Leibniz explicó la diferencia de velocidades de los cuerpos se apoya, por una parte, en la concepción de que los continuos son isomórficos y, por otra, en la tradición aristotélica de concebir a las figuras geométricas genéticamente. De este modo, así como una línea se explica a partir de la difusión de un punto, así también un movimiento de la de un conato. En este sentido, un cuerpo se mueve más rápido que otro si el conato correspondiente es mayor. Como consecuencia, para Leibniz se siguen una serie de principios del movimiento que, a su vez, son una muestra más de la importancia que tuvo Hobbes en el pensamiento leibniziano de juventud.

\footnotetext{
55 De rationibus motus, A VI 2, 159. “(...) nimirum quiescens quantumcunque impelli a moto quantulocunque, etiam motu quantulocunque”. También Leibniz a Hobbes, A II 1, 91. “(...) corpus quiescens quantumcunque a quantulocunque, levissimo motu impelli posse (...)". Evidentemente el reposo ha de ser entendido aquí como relativo.

${ }^{56}$ Hobbes, De corpore, III, 15, 3. “(...) if a point moved come to touch another point which is at rest, how little soever the impetus or quickness of its motion be, it shall move that other point". La traducción es nuestra.

${ }^{57} T M A$, A VI 3, 265. Véase la nota 1 de este capítulo.

58 TMA, A VI 2, 265. "Sed et omnino quicquid movetur non est unquam in uno loco dum movetur, ne instanti quidem seu tempore minimo". OFC $8,81$.

${ }_{59}$ Hobbes, De corpore, II, 8, 11. "(...) whatsoever is moved, is not in one place during any time, how little soever that time be". La traducción es nuestra.
} 


\section{Presupuestos y justificación de la cohesión de los cuerpos}

Los problemas físicos que han preocupado a Leibniz en su juventud van más allá de aquellos relativos al movimiento que hemos examinado en el apartado anterior. En efecto, como vimos en el tercer capítulo, Leibniz se preocupó también por hallar una definición precisa de la noción de 'cuerpo'. No obstante, este no ha sido el único ni, quizás, el más destacado de los desarrollos de Leibniz en lo que respecta a la comprensión de la realidad corpórea. La tesis del infinito actual que hemos examinado en los capítulos precedentes se relaciona con un problema que Leibniz consideró con atención, a saber, ¿cuál es la razón por la que los cuerpos se mantienen unidos o están cohesionados?, esto es, ¿por qué ellos no se desintegran -como dijo en el final de sus días en París- 'hasta ser polvo'? ${ }^{60}$ El problema de la cohesión de los cuerpos ha sido tratado con mucha atención por los pensadores del siglo XVII, de modo que se han dado soluciones muy variadas. Entre los atomistas, por ejemplo, algunos como Gassendi entendieron que la unión se justifica por la posesión de ciertos 'ganchos' por parte de los átomos, mientras que otros como Galileo explicaron la cohesión en parte por el horror vacui y en parte por otras causas. ${ }^{61}$ Como Leibniz negó la existencia de los átomos y del vacío, su respuesta ha sido muy distinta. Por una parte, como trasfondo del planteo leibniziano, desde finales de la década de 1660, el filósofo de Leipzig mantuvo que los principios mecánicos no alcanzan para explicar la cohesión de los cuerpos. ${ }^{62}$ Por ejemplo, en la Confessio naturae contra atheistas, Leibniz indicó que, en última instancia, solamente es posible explicar los fenómenos naturales bajo la presuposición de que existe un ente incorporal, es decir, Dios. ${ }^{63}$ Ahora bien, por otra parte, al margen de esta presuposición, que en rigor es de carácter metafísico -de modo que está sólo indirectamente relacionada con el problema físico de la cohesión-, entre los años 1670 y 1672 Leibniz propuso una explicación de la cohesión de los cuerpos que, en el marco de sus reflexiones físicas, parecería ser mecánica. Asimismo, como veremos, para

\footnotetext{
${ }^{60}$ Pacidius Philalethi, A VI 3, 554. OFC, 8, 141. Entre 1670 y 1672, Leibniz se refiere a este problema, por ejemplo, en: Leibniz a Thomas Hobbes, A II 1, 90-94 (Loemker, 1989: 105-108); De materia prima, A VI 2, 280 (Leibniz, 2001: 343-344); TMA, A VI 2, 258-276 (OFC 8, 73-95); Theoria motus concreti, A VI 2, 237 238 (OFC 8, 35-36); Propositiones quaedam physicae, A VI 3, 28; Demonstratio substantiarum incorporearum, A VI 3, 79-80 (Leibniz, 2001: 1-5); De consistentia corporum, A VI 3, 94-96 (Leibniz, 2001: $18-23)$.

${ }^{61}$ Véase Arthur en Leibniz, 2001, xxxvii-xliii, así como también Arthur, 1998.

${ }^{62}$ Confessio naturae contra atheistas, A VI 1, 491.

${ }^{63}$ Racionero, 1980: 73.
} 
esta explicación, Leibniz se valió también de la noción de 'continuo' de Aristóteles y de la de 'conato' que retomó de Hobbes. A continuación analizaremos la justificación de la cohesión de los cuerpos que Leibniz presentó en los primeros años de la década de 1670, así como también sus presupuestos.

Ante todo, debe observarse que el examen de Leibniz tiene algunos presupuestos que han sido explorados en los capítulos previos y que cumplen un papel particularmente importante en esta cuestión. En primer lugar hay un supuesto metodológico que está relacionado con la manera en que Leibniz entendió que deben ser las explicaciones físicas. Como hemos visto en el primer capítulo, la delimitación aristotélica entre los tipos de ciencia ha sido cuestionada en la modernidad filosófica al menos parcialmente por postular como inadmisible que la física se valga de principios geométricos. Leibniz reconoció tempranamente que las explicaciones mecánicas sobre el cuerpo fundadas en la magnitud, la figura y el movimiento, que estaban muy difundidas en su tiempo, son más adecuadas al objeto de estudio de la física, esto es, el ente móvil. Todo esto significa, en el caso del problema que nos atañe, que la explicación leibniziana del problema de la cohesión de los cuerpos se funda en la magnitud, figura y movimiento de las partes del cuerpo dado.

Ahora bien, el filósofo de Leipzig también valoró algunas conclusiones que Aristóteles ha presentado en su Física. Un segundo género de presupuestos, que son de carácter más bien conceptual, está vinculado con esta consideración. En efecto, la explicación que Leibniz ofrece de la cohesión de los cuerpos presupone una concepción determinada y muy particular del concepto de 'cohesión'. Cuando Leibniz considera este problema, remite explícitamente a la noción de continuo de Aristóteles. Como hemos visto en la primera sección del segundo capítulo, para Aristóteles dos cosas son continuas si poseen un mismo extremo, esto es, un extremo en común. Leibniz retomó la noción aristotélica, de modo que para él las cosas que tengan un extremo en común son continuas o están cohesionadas. ${ }^{64}$ Es algo digno de ser destacado el hecho de que, como se verá más adelante, Leibniz no solamente cita la definición aristotélica de continuo, sino que incluso lo hace en el griego original. De este modo, la explicación que Leibniz dio de la cohesión de los cuerpos al comienzo de la década de 1670 no fue otra cosa que la aplicación del concepto de continuidad, según la tercera acepción de 'continuo' que hemos mencionado

\footnotetext{
${ }^{64} T M A$, A VI 2, 266. OFC 8, 81.
} 
en la introducción de este capítulo. Asimismo, en coincidencia con la noción aristotélica, que los cuerpos estén cohesionados significa, para Leibniz, que sus partes no son contiguas. De este modo, las cosas cohesionadas "no son ya solamente contiguas, sino continuas, y son en verdad un cuerpo". ${ }^{65}$ Más aún, Leibniz entendió que la consistencia o cohesión de los cuerpos no es otra cosa que el paso de la contigüidad a la continuidad: "[l] a consistencia de los cuerpos es la cantidad de fuerzas necesarias para la disolución de la contigüidad. Son continuas las cosas contiguas con cierta consistencia". ${ }^{66}$ De este modo, como conclusión, la explicación de la cohesión de los cuerpos en el pensamiento de juventud de Leibniz no significa otra cosa que la exposición de la razón de por qué cuerpos previamente contiguos pasan a tener un extremo en común. Dada la regla metodológica indicada anteriormente, Leibniz debió ofrecer una explicación de este fenómeno en términos de la magnitud, la figura y el movimiento.

Ahora bien, no puede pasar inadvertido que en la definición aristotélica de continuo que Leibniz hace propia, como la de aquello cuyos extremos son uno, aparece una noción con un significado muy peculiar en el pensamiento leibniziano sobre el problema del continuo, a saber, la de extremo. Como hemos visto en el capítulo previo y anteriormente en este mismo capítulo, en el contexto de la TMA Leibniz interpretó a los extremos como indivisibles aunque posteriormente haya modificado esta concepción. Recordemos, asimismo, que así como los extremos de un espacio o de un cuerpo son 'puntos', los de un tiempo son 'instantes' y los de un movimiento 'conatos'. De este modo, en lo que respecta al problema que aquí nos atañe, Leibniz sostuvo que los cuerpos que están cohesionados son aquellos cuyos puntos extremos están en un mismo lugar. ${ }^{67}$ Ahora bien, dado que la explicación de la cohesión debe darse de acuerdo con la regla metodológica antes mencionada, el extremo del movimiento, esto es, el conato, cumplió un papel importante. Es interesante que Hobbes haya sido también relevante para Leibniz en lo que respecta al problema de la cohesión de los cuerpos, aunque quizás de un modo diferente. En efecto, en la carta que el filósofo de Leipzig le escribió a Hobbes en 1670 mencionada en la sección

\footnotetext{
${ }^{65}$ Leibniz a Thomas Hobbes, A II 1, 92. “(...) non jam contigua tantum, sed continua sunt, et vere unum corpus (...)". Loemker, 1989: 107.

66 De consistentia corporum, A VI 3, 94. "Consistentia corporum est quantitas virium necessariarum ad solutionem contiguitatis. Continua sunt contigua cum aliqua consistentia”. Leibniz, 2001: 19.

${ }^{67} T M A$, A VI 2, 266. OFC 8, 81.
} 
precedente de este capítulo, Leibniz le propuso al filósofo británico su explicación de la cohesión.

Estos tres presupuestos (la regla metodológica, la noción aristotélica de 'continuo' que Leibniz hace propia y el concepto leibniziano de 'extremo') constituyen la base a partir de la cual Leibniz piensa novedosamente una respuesta al problema de la cohesión de los cuerpos. De acuerdo con ellos, en síntesis, Leibniz debe explicar la cohesión de los cuerpos, esto es, la disolución de la contigüidad de las partes, por el movimiento. Según Leibniz, la cohesión se da cuando una parte de un cuerpo se mueve y aprieta a otra. ${ }^{68} \mathrm{Al}$ moverse, golpea al cuerpo que le es contiguo y, como consecuencia, ejerce una presión sobre él, esto es, tiende a entrar en el lugar ocupado por aquel otro cuerpo. Como para Leibniz la 'tendencia' que da lugar al movimiento es el conato, esto es, el extremo del movimiento, cuando un cuerpo comienza a moverse y aprieta a otro, simultáneamente comienza a estar en su lugar, esto es, a penetrarlo. Consecuentemente, el inicio del movimiento y el inicio de la penetración o unión entre cuerpos previamente contiguos es la misma cosa. Los cuerpos que se aprieten comenzarán a unirse, de modo que sus extremos dejarán de ser distintos (como cuando eran contiguos) y pasarán a ser uno y el mismo, es decir, continuos. Esta explicación es propuesta reiteradamente por Leibniz en estos años, lo que muestra que ha sido una de las conclusiones físicas más importantes de su juventud. Veamos, a continuación, un par de citas en las que propone esta cuestión.

Yo he creído que, para que se produzca la cohesión de los cuerpos, basta una tendencia recíproca de las partes [partium conatum ad se invicem], es decir, un movimiento por el que una aprieta a otra. Puesto que las cosas que se aprietan tienden a penetrarse [sunt in conatu penetrationis]. El conato es un inicio, la penetración, una unión. Por consiguiente, están en el inicio de la unión. Pero son uno los inicios o términos de aquellas cosas que están en el inicio de la unión. $^{69}$

Por el contrario, en el tiempo del impulso, del impacto, del concurso, dos extremos de los cuerpos, es decir, puntos, se penetran, es decir, están en el mismo punto del espacio. En efecto, cuando uno de los que concurren tiende

\footnotetext{
${ }^{68}$ Leibniz reitera numerosamente la tesis que aquí se expone. A modo de ejemplo, pueden verse Leibniz a Hobbes, A II 1, 92-93 (Loemker, 1989: 106-107) y TMA, A VI 2, 266 (OFC 8, 81). Ambos textos se citarán a continuación. Véase también Arthur, 1998: 113-119.

${ }^{69}$ Leibniz a Hobbes, A II 1, 92. "Ego crediderim ad cohaesionem corporum efficiendam sufficere partium conatum ad se invicem, seu motum quo una aliam premit. Quia quae se premunt sunt in conatu penetrationis. Conatus est initium, penetratio unio. Sunt ergo in initio unionis. Quae autem sunt in initio unionis, eorum initia vel termini sunt unum". Loemker, 1989: 107.
} 
[conetur] hacia el lugar del otro, comienza a estar en él, esto es, comienza a penetrar o a unirse. En efecto, el conato es un inicio, la penetración, una unión. Por consiguiente, están en el inicio de la unión, es decir, sus términos son uno. Por consiguiente, los cuerpos que se aprietan o empujan están cohesionados, pues sus términos son uno, y entonces, también por la definición de Aristóteles, $\tilde{\omega} v \tau \grave{\alpha}$ Ě $\sigma \chi \alpha \tau \alpha \tilde{\varepsilon} v$, estas cosas son continuas o están cohesionadas, puesto que si dos [términos] están en un lugar, uno no puede ser empujado sin el otro. ${ }^{70}$

En consecuencia, puede observarse que al comienzo de la década de 1670 Leibniz ha justificado que la cohesión de los cuerpos existe por el conato o el movimiento. De este modo, ha ofrecido una solución al problema siguiendo, por un lado, la 'regla común' antes mencionada y, por otro, la noción aristotélica de continuo. Como señala S. Levey, el extremo compartido por los cuerpos cohesionados no debe ser entendido como un 'cemento' que, por decirlo así, sea la fuente de la cohesión, sino que es su resultado. ${ }^{71}$ Ahora bien, Richard Arthur ha señalado atinadamente que, como la cohesión dura solamente durante el tiempo de un conato, entonces es momentánea, pues para Leibniz "[n]ingún conato sin movimiento dura más que un momento excepto en las mentes". De esta manera, para que la cohesión dure, se requiere de un movimiento continuo, "pues lo que en un momento es un conato, en el tiempo [es] un movimiento del cuerpo". ${ }^{72}$ El hecho de que Leibniz mencione que el conato dura en las mentes no significa que estas entidades incorpóreas cumplan un rol directo en la explicación de la cohesión de los cuerpos. De acuerdo con Leibniz, las mentes son un principio de movimiento no corporal que, por una parte, explica por qué los cuerpos no alcanzan un estado de reposo absoluto (a saber, puesto que, como vimos en el tercer capítulo, afirmar que la materia reposa implicaría contradicciones) y en consecuencia, por otra parte, da razón de la diversidad de los cuerpos

\footnotetext{
${ }^{70}$ TMA, A VI 2, 266. “(15.) Contra, tempore impulsus, impactus, concursus, duo corporum extrema, seu puncta se penetrant, seu sunt in eodem spatii puncto: cum enim concurrentium alterum in alterius locum conetur, incipiet in eo esse, id est incipiet penetrare, vel uniri. Conatus enim est initium, penetratio unio; sunt igitur in initio unionis, seu eorum termini sunt unum, (16.) ergo corpora quae se premunt vel impellunt,

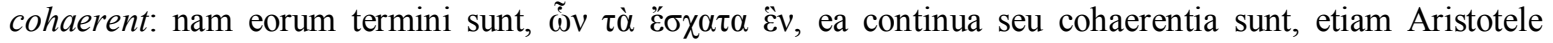
definiente, quia si duo in uno loco sunt, alterum sine altero impelli non potest”. OFC 8, 81. La traducción de OFC introduce 'cuerpos' allí donde nosotros introducimos 'términos' entre corchetes. En efecto, lo que está en un mismo lugar son los extremos, no los cuerpos.

${ }^{71}$ Levey, 1999: 100-101.

${ }^{72}$ Arthur, 1998: 115-116. TMA, A VI 2, 266. "Nullum conatus sine motu durat ultra momentum praeterquam in mentibus. Nam quod in momento est conatus, id in tempore motus corporis". OFC 8, 82. Un análisis de la noción de mente y de su desarrollo del pensamiento leibniziano -en vinculación con el concepto maduro de 'forma sustancial'- se encuentra en Escribano Cabezas, 2016: 123-167.
} 
en términos de lo sólido o denso y lo líquido o raro. ${ }^{73}$ Para Leibniz, la mente compara los conatos que retiene. ${ }^{74}$ En consecuencia, como dijimos anteriormente, aunque las mentes no cumplan una función directa en la explicación de la cohesión de los cuerpos (y en este sentido decimos que Leibniz explica la cohesión de los cuerpos en términos mecánicos), son indirectamente relevantes, en la medida en que forman parte de la explicación del movimiento continuo. ${ }^{75}$ Como veremos en el noveno capítulo, en los últimos años de sus días en París Leibniz cambió su concepción y admitió que las mentes directamente explican la cohesión.

\section{Algunas consecuencias de la explicación leibniziana de la cohesión de los cuerpos}

La teoría de la cohesión de los cuerpos que hemos expuesto en la sección anterior acarrea varias consecuencias que muestran el alcance completo de la concepción leibniziana. En primer lugar, se sigue inmediatamente de la explicación leibniziana de la unión o consistencia que los cuerpos que estén cohesionados por compartir un extremo en común no se mueven cada uno con su propio movimiento sino conjuntamente con el mismo. ${ }^{76}$ En este sentido, si los puntos extremos de dos cuerpos o partes están en el mismo lugar, no puede empujarse o moverse uno sin que simultáneamente se mueva el otro. ${ }^{77} \mathrm{De}$ allí que Leibniz señale que "[e]stán cohesionadas las partes de las cuales movida una se moverán las restantes". ${ }^{78}$ De este modo, los cuerpos que están cohesionados, señala Leibniz, padecen conjuntamente (sympathica sunt) el influjo de un cuerpo que los mueve y precisamente por ello se co-mueven $($ sunt $\sigma v \gamma \kappa i ́ v \eta \tau \alpha){ }^{79}$ De acuerdo con S. Levey, la cohesión de los cuerpos se explica por el movimiento conjunto. No obstante, como vimos,

\footnotetext{
${ }^{73}$ Propositiones quaedam physicae, A VI 3, 57. Asimismo, A VI 3, 66-67. Véase las secciones 2.2. y 2.3. del tercer capítulo.

${ }^{74}$ Esta cuestión es analizada por Blank, 2009, especialmente en la segunda sección: "Substance Monism and Substance Pluralism, 1668-1672". Véase también Garber, 2009: 29-37, quien vincula el pensamiento de Leibniz sobre esta cuestión con el de Hobbes.

${ }^{75}$ Levey, 2011: 295-296, acentúa el cambio que esta tesis significa en relación con el planteo que Leibniz mantuvo en 1668-1671 (es decir, que el movimiento no se sigue de las notas que definen al cuerpo y, en consecuencia, que el movimiento tendría un fundamento externo en Dios), pues con las mentes, el filósofo de Leipzig habría considerado un principio interno de movimiento.

${ }^{76}$ Propositiones quaedam physicae, A VI 3, 28.

${ }^{77}$ Levey, 1999: 85-86 señala algunas expresiones utilizadas por Leibniz a lo largo de los años para referirse al hecho de que haya un movimiento común, a saber, motus generalis, motus communis o motus conspirans.

${ }_{78}^{78}$ TMA, A VI 2, 264. "Cohaerent partes quarum una mota movebuntur caeterae". OFC 8, 78.

79 Demonstratio substantiarum incorporearum, A VI 3, 80. Leibniz, 2001: 3-5.
} 
el movimiento conjunto no parece ser la razón de la cohesión sino más bien una consecuencia de ella. ${ }^{80}$

La característica recién descrita de los cuerpos que están cohesionados, esto es, el co-movimiento, muestra, a su vez, el alcance que tiene la propuesta leibniziana. En este sentido, la justificación de Leibniz permite explicar no solamente la unión interna de las partes de un cuerpo dado sino también la de todo caso en que dos o más cuerpos se muevan conjuntamente. Dicho de otra manera, en cualquier caso en que el movimiento de un cuerpo acarree como consecuencia el de otro, debería decirse que dichos cuerpos están unidos en un extremo, es decir, que de alguna manera son continuos o están cohesionados mientras se muevan juntos. Leibniz considera el siguiente ejemplo:

Sea un cuerpo $a b$ que presiona al cuerpo $c$; imaginémonos que $a b$ sea un bastón presionado con la mano sobre el cuerpo $c$ colocado sobre un plano firme ce y que el hombre, sin embargo, avanza hacia $d$. Digo que tratará de arrastrar consigo el cuerpo $c$ hacia $e$. Es decir, lo arrastrará eficazmente si no hay resistencia suficiente en el cuerpo $c$. La razón es que un cuerpo que presiona sobre otro intenta entrar dentro de otro o de penetrarlo, e incluso comienza a penetrarlo. (...). Se sigue, por lo tanto, que la extremidad $b$ del cuerpo que presiona $a b$ (que es empujado hacia $d$ ), es igualmente empujada junto con todo $a b$; pero la extremidad $b$ ha ingresado en la extremidad del cuerpo $c$, es decir, estas dos extremidades se han convertido en una, o están precisamente en un mismo lugar; por lo tanto, una no puede ser empujada sin la otra. ${ }^{81}$

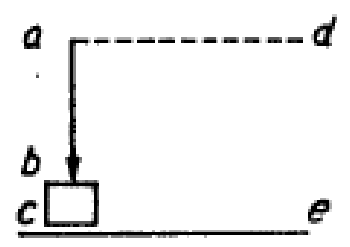

De esta manera, la explicación de la cohesión de los cuerpos de Leibniz es un argumento que justifica la unión entre ellos independientemente de la 'grandeza' o

\footnotetext{
${ }^{80}$ Levey, 1999: 93-95 y 99-101.

${ }^{81}$ Propositiones quaedam physicae, A VI 3, 8-9. "Soit un corps $a b$ pressant le corps $c$, imaginons nous, qu' $a b$ soit un baton pressé avec la main sur le corps $c$ posé sur un plan ferme $c e$ et que l'homme cependant avance vers $d$. Je dis, qu'il tachera d'emporter avec soy le corps $c$ vers $e$. C'est à dire, qu'il l'emportera effectivement, s'il n'y a point de resistence suffisante dans le corps $c$. La raison est, par ce qu'un corps pressant sur un autre, tache d'entrer dedans ou de le penetrer, et même commence à le penetrer. (...) Il s'ensuit donc, que le corps qui presse, comme $a b$ estant poussé à part, vers $d$, son extremité $b$ soit poussée de même avec le tout $a b$ mais l'extremité $b$ est entrée dans l'extremité du corps $c$, même ces deux extremitez sont devenus un, ou sont precisement dans un même lieu, donc l'une ne peut pas estre poussée sans l'autre". Modificamos ligeramente la redacción de Leibniz a los fines de ofrecer una traducción más comprensible.
} 
'pequeñez' del caso analizado. En este sentido, siempre que hayan cuerpos que se mueven juntos sucede que ellos están cohesionados mientras se co-muevan, sea tratándose de cuerpos diminutos o sea entre cuerpos sensiblemente perceptibles. En última instancia, se trata proporcionalmente del mismo fenómeno. Ahora bien, precisamente por esto es que la explicación de la cohesión de las partes de un cuerpo determinado no remite causalmente a la de la cohesión de las infinitas partes que hay en cada una de las partes de dicho cuerpo. Esto conllevaría explicar lo que acontece en un cuerpo por medio de lo que sucede en las infinitas criaturas que están dentro de él. Si se diera esta dependencia causal, en virtud de la tesis del infinito actual, no habría manera de evitar una regresión al infinito. ${ }^{82}$ Por eso la explicación de Leibniz es única y vale proporcionalmente en lo grande y en lo pequeño.

Hay, por último, otra consecuencia del examen de Leibniz que se sigue de un interrogante que se plantea en el año 1672, a saber, si es posible que un cuerpo actúe inmediatamente sobre otro distante, es decir, si puede mover a otro que no esté a su lado. ${ }^{83}$ Cuando se plantea esto, Leibniz tiene la intención de explicar fenómenos en los que aparentemente hay una acción a distancia, como por ejemplo el de la iluminación del sol sobre los cuerpos terrestres. ${ }^{84} \mathrm{Si}$ toda acción de un cuerpo debe ser entendida y explicada por medio del movimiento, entonces el fenómeno de la propagación de la luz desde un cuerpo brillante también debe serlo. No obstante, el movimiento de un cuerpo solamente puede tener consecuencias en los cuerpos que están a su lado, es decir, en los contiguos, de manera tal que no existe realmente una acción inmediata a distancia. ${ }^{85}$ En este sentido, toda acción es inmediata en lo contiguo y sólo mediata en lo discontiguo. Leibniz debe, entonces, diseñar una estrategia para explicar este tipo de fenómenos.

Dado que el movimiento de un cuerpo repercute solamente en el que lo sucede y con el que está en contacto, Leibniz reduce toda aparente acción inmediata a distancia a una serie de acciones inmediatas entre cuerpos contiguos. Dice Leibniz que "[e]s 'mediata' cuando el cuerpo $A$ actúa en el cuerpo $B$ y el cuerpo $B$ en el cuerpo $C$ y el cuerpo $C$ en el

\footnotetext{
${ }^{82}$ Esto es explicado por Beeley, 1996: 202-204.

${ }^{83}$ Demonstratio substantiarum incorporearum, A VI 3, 74.

${ }^{84}$ El argumento puede encontrarse en Propositiones quaedam physicae, A VI 3, 15 y 16, como explicación de la proposición "In omni spatio illuminato, qatenus illuminatum est, corpus seu materia est".

${ }^{85}$ Demonstratio substantiarum incorporearum, A VI 3, 76.
} 
cuerpo $D$ etc., y se dice que el cuerpo $A$ actúa en $C$ o $D$ " ${ }^{86}$ Entonces, una acción a distancia sucede a través de la serie de los cuerpos contiguos. ${ }^{87}$ En este sentido, la luz se propaga desde el cuerpo brillante a través de toda la serie de cuerpos transparentes que median entre aquel y el opaco hasta finalmente alcanzar a este último. De allí que, entonces, pueda deducirse que hay entre el astro brillante y el cuerpo opaco una cadena de cuerpos sensibles. Leibniz nota que, para que pueda darse una acción mediata, en la cadena de cuerpos contiguos debe darse una presión de unos sobre otros. Es decir que, siguiendo el caso anterior, para que el cuerpo $A$ llegue a actuar sobre $D$, debe chocar y presionar a $B$, así como éste debe hacerlo sobre $C$ y éste finalmente sobre $D$. De este modo, se presenta una imagen en la que se da una serie continuada de cuerpos contiguos, y por lo tanto, una cohesión de toda la cadena de los cuerpos entre sí: “[p]or consiguiente, también está cohesionada toda la serie de las cosas que chocan mediatamente, puesto que se compone de cosas que se chocan inmediatamente, y por lo tanto cohesionadas". 88

La explicación del fenómeno de la iluminación, así como la de cualquier otro acontecimiento que suponga una acción a distancia, supone que hay de hecho una multiplicidad de cuerpos que median entre aquellos dos distantes. Más aún, es esencial en la explicación leibniziana que sea imposible una ausencia total de cuerpos. En efecto, si faltaran cuerpos en la cadena, de tal manera que medie un vacío entre uno y otro, la explicación de la acción a distancia perdería toda su fuerza. Asimismo, como hemos visto en la sección 2.3. del capítulo tercero, no debemos olvidar que Leibniz afirmó que no hay espacio sin cuerpos. En este sentido, en el marco de la teoría del cuerpo, hay una suerte de correlato de lo que se ha dicho a propósito del reposo en lo que respecta al movimiento, esto es: no hay reposos en un movimiento, del mismo modo que "[ $n]$ o hay Espacio Vacio sensible en el mundo visible". ${ }^{89}$ La consecuencia para Leibniz es evidente: omnia esse plena. En este sentido, como consecuencia de su explicación de la cohesión de los cuerpos,

\footnotetext{
${ }^{86}$ Demonstratio substantiarum incorporearum, A VI 3, 76: "Mediata es, cum corpus $A$ agit in corpus $B$ et corpus $B$ in corpus $C$ et corpus $C$ in corpus $D$ etc. et corpus $A$ agere dicitur in corpus $C$ vel $D$ etc.".

${ }^{87}$ Demonstratio substantiarum incorporearum, A VI 3, 76.

${ }^{88}$ Demonstratio substantiarum incorporearum, A VI 3, 80. "Tota ergo series etiam mediate impellentium cohaeret, quia ex immediate impellentibus, ac proinde cohaerentibus componitur". Leibniz, $2001: 3$. Asimismo, en una nota marginal en la página 74 indica: "Continuatum est series contiguorum, seu cuius partes mediate immediateve contigua sunt. Ita mare Balticum et mediterraneum unius maris generalis continuati partes sunt".

${ }^{89}$ Demonstratio substantiarum incorporearum, A VI 3, 86. "Nullum est Spatium Vacuum sensibile in mundo aspectabili".
} 
Leibniz presenta un argumento con el que justificar la plenitud del mundo. Este no es el único argumento dado por Leibniz con esta finalidad. Como vimos en el tercer capítulo, Leibniz demostró a priori que el mundo es pleno a partir de la definición de cuerpo. No obstante, en este caso la explicación es a posteriori, es decir, a partir de la sensación y de las experiencias vinculadas con la proyección de la luz y la coloración de los cuerpos. ${ }^{90} \mathrm{El}$ filósofo de Leipzig reconoce que los rayos de los astros pueden llegar a la tierra desde cualquier punto sensible del cielo, de manera tal que entre el astro y el planeta se interpone un gran número de cuerpos:

Ahora bien, dentro de la esfera de la actividad de los astros, hay todo un intervalo entre ellos y nosotros (en efecto, ciertamente, son vistos por nosotros); por consiguiente, no hay un punto sensible del espacio en todo el intervalo entre los astros que vemos y nosotros en el que no caiga un rayo de luz, a no ser que algún cuerpo que obstruya esté en ese punto del espacio. Ahora bien, todo rayo de luz es o un cuerpo o un movimiento o presión de un cuerpo. Por consiguiente, no existe ningún punto sensible vacío en todo el intervalo entre los astros y nosotros y, por lo tanto, [no lo hay] en todo el mundo visible. ${ }^{91}$

Leibniz presenta la siguiente disposición gráfica como complemento de su argumento: ${ }^{92}$

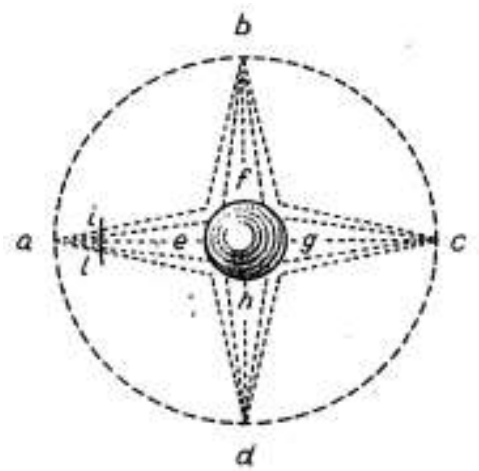

En esta figura $a b c d$ los astros son señalados con las letras $a, b, c$ y $d$, mientras que los puntos de la tierra iluminados por los rayos son representados por $e, f, g$ y $h$. Según lo que ha sido explicado anteriormente, para que efectivamente la tierra sea iluminada, los espacios afh, beg, cfh y deg deben necesariamente estar llenos de cuerpos. Esto es

\footnotetext{
${ }^{90}$ Demonstratio substantiarum incorporearum, A VI 3, 86.

${ }^{91}$ Demonstratio substantiarum incorporearum, A VI 3, 86. "Iam intra sphaeram activitatis siderum est totum intervallum inter ipsa et nos (videntur enim utique a nobis), ergo nullum est punctum spatii sensibile in toto intervallo inter sidera quae videntur, et nos, [in] quod non cadat radius lucis nisi aliquod corpus obstans ei puncto spatii insit. Iam omnis radius lucis est aut corpus aut corporis motus pressiove. Nullum ergo est punctum sensibile vacuum in toto intervallo inter sidera et nos, ac proinde in toto mundo aspectabili".

${ }_{92}$ Este ejemplo se encuentra en Demonstratio substantiarum incorporearum, A VI 3, 86-87.
} 
requerido, como hemos visto, de acuerdo con la explicación leibniziana de la acción a distancia. De esta manera, “(...) se sigue que en todo el espacio comprehendido entre abcd y efgh no hay un punto sensible vacío de rayos y, por lo tanto, de cuerpos". 93 Así, como consecuencia de la explicación de la cohesión, Leibniz presenta un argumento a posteriori que justifica el pleno.

En última instancia, en síntesis, todo esto muestra que la explicación de la cohesión de los cuerpos tiene importantes consecuencias en la física leibniziana. En efecto, casi todas las consecuencias exploradas anteriormente están completamente por fuera de la mera cuestión de explicar la unidad de las partes de un cuerpo determinado. Quizás por eso, como dijimos antes, Leibniz se refirió en numerosas oportunidades a esta cuestión, es decir, por considerarla como una suerte de principio de importancia para distintas cuestiones físicas.

Para finalizar este capítulo, sintetizaremos las conclusiones parciales que hemos presentado en las distintas secciones. En lo que respecta al examen del movimiento, luego de mostrar algunas de las alternativas atomistas que surgieron en el siglo XVII para explicar la diferencia de velocidades de los movimientos, vimos que el planteo leibniziano descansa, en última instancia, en su concepción de los extremos del movimiento. En efecto, dado que sostuvo un isomorfismo entre los continuos, para Leibniz los movimientos son análogos a las líneas. En consecuencia, así como una línea es el resultado de la propagación de un punto, así también un movimiento es el resultado de la propagación de un conato. De esta manera, la razón por la cual un cuerpo recorre, en un mismo tiempo, un espacio mayor que otro, se encuentra en que el conato de dicho cuerpo es mayor que el del otro. Por otro lado, en lo que respecta al problema de la cohesión de los cuerpos, hemos visto, en primer lugar, que el examen leibniziano posee presupuestos tanto metodológicos como conceptuales. Desde el punto de vista metodológico, Leibniz presentó una explicación de la cohesión que se funda en la magnitud, figura y movimiento de las partes del cuerpo dado.

\footnotetext{
${ }^{93}$ Demonstratio substantiarum incorporearum, A VI 3, 87. “(...) sequitur in toto spatio inter abcd et efgh comprehenso nullum esse punctum sensibile radiis vacuum ac proinde corporibus".
} 
Desde un punto de vista conceptual, la explicación de Leibniz se apoya en la noción de 'continuo' de Aristóteles, así como también en la noción de ‘conato’ de Hobbes. Sobre la base de estos presupuestos, hemos visto que Leibniz sostuvo que, al moverse y apretarse, los cuerpos comienzan a unirse, es decir, a tener un extremo en común. Finalmente, examinamos algunas consecuencias del planteo leibniziano, a saber, que los cuerpos cohesionados se mueven conjuntamente; que, en consecuencia, siempre que haya cuerpos que se muevan juntos sucede que están cohesionados, al menos mientras se muevan juntos; por lo tanto, que toda acción a distancia se reduce a una cadena de acciones inmediatas; por último, y como corolario de lo anterior, que puede probarse a posteriori la plenitud del mundo. 



\section{CAPÍTULO 6: LO MÍNIMO Y LO MÁXIMO EN EL CONTINUO}

En este capítulo examinaremos algunas consecuencias de la manera como Leibniz entendió el infinito tanto 'hacia lo pequeño' (lo mínimo) como 'hacia lo grande' (lo máximo). En la primera sección, veremos que la afirmación de una infinitud actual de partes llevó a Leibniz a argumentar que en el continuo no se dan partículas más pequeñas que las cuales no habrían otras. Según esto, analizaremos la manera como Leibniz definió lo 'mínimo', así como también los argumentos que empleó, a lo largo de todo el período estudiado, para negar una composición del continuo de tales partículas últimas. En este sentido, el tema abordado en este capítulo es una constante en el pensamiento juvenil de Leibniz. Por eso, conectaremos, al menos parcialmente, la segunda y la tercera parte de esta tesis. Ahora bien, en uno de los argumentos presentados en DMM (conocido como 'argumento de la diagonal'), Leibniz parecería suponer algunos presupuestos del pensamiento de Galileo, como por ejemplo que el axioma según el cual 'el todo es mayor que una parte' no vale para cantidades infinitas. A pesar de esto, Leibniz extrajo conclusiones muy diferentes a las de Galileo. Esto se observa, especialmente, en los estudios que Leibniz llevó a cabo sobre la otra cara del concepto de infinito, esto es, sobre lo máximo. De acuerdo con esto, en la segunda sección del capítulo analizaremos el problema del número máximo o número infinito de todas las unidades y mostraremos que Leibniz realizó dos abordajes paralelos sobre esta cuestión que, incluso, fueron relativamente independientes entre sí, a saber, uno filosófico y otro aritmético. Desde un punto de vista filosófico, veremos que, a los fines de demostrar que el número infinito es contradictorio, Leibniz intentó justificar la universalidad del axioma, es decir, su validez tanto para cantidades finitas como infinitas. Como consecuencia, en este enfoque se consideran algunos presupuestos epistemológicos de relevancia, como por ejemplo que todos los 'axiomas' son demostrables. Desde un punto de vista aritmético, en los que los razonamientos filosóficos no revisten importancia, el filósofo de Leipzig analizó el problema del número infinito mediante un examen de reglas para sumar series infinitas tanto geométrica como aritméticamente decrecientes al infinito. 


\section{El infinito actual y los mínimos en el continuo}

En los capítulos anteriores vimos que para Leibniz el continuo está actualmente dividido en infinitas partes proporcionales. En este sentido, las explicaciones atomistas, sean geométricas como la de Galileo o físicas como la de Gassendi, resultaron insatisfactorias para el filósofo de Leipzig. Como veremos, Leibniz consideró que una composición de puntos o átomos no puede evitar manifiestas contradicciones. Ahora bien, de los capítulos anteriores también se desprende que, para el filósofo de Leipzig, el problema del continuo no se circunscribe ni al dominio geométrico ni al físico, sino que los abarca a los dos. En este sentido, Leibniz se encuentra con un problema terminológico a la hora de demostrar las inconsistencias de una composición que no resuelva el continuo en partes proporcionales, a saber: ¿cómo deben denominarse las partículas últimas? El problema se hace evidente si se tiene en cuenta, como hemos visto en el cuarto capítulo, que Leibniz reinterpreta el concepto de 'punto' en términos que lo harían compatible con su manera de entender la composición del continuo. Así, los extremos indivisibles del espacio y el cuerpo de la TMA son llamados 'puntos', como también los infinitesimales actuales que afirmó luego de dicho escrito de 1671. Como está interesado en negar una composición de partes últimas tanto en el dominio geométrico como en el físico, Leibniz requiere de una denominación genérica que abarque ambas regiones. Por eso, el concepto de ‘átomo’, que en general Leibniz asocia a la interpretación física de Gassendi, tampoco resulta satisfactorio. ${ }^{1}$ El término preferido por Leibniz para referirse a estas partes últimas es el de 'mínimo'.

Ahora bien, por las mismas razones antes mencionadas, es claro que el concepto de mínimo tiene unas notas muy específicas, de modo que se distingue tanto del concepto de 'indivisible' de 1671 como del de lo 'infinitamente pequeño' que Leibniz afirmó posteriormente. De acuerdo con lo que vimos en el cuarto capítulo, Leibniz reconoció que la división actual imposibilita por definición afirmar la existencia de partes que no tengan a

\footnotetext{
${ }^{1}$ Como explica Arthur, 2004, quizás la manera como Leibniz entendió el concepto de átomo haya sido más amplia que lo que aquí sugerimos. En este sentido, Leibniz habría tenido en cuenta también el 'atomismo químico' por ejemplo de Daniel Sennert que sintéticamente explicamos en la quinta sección del capítulo 2. Blank, 2011, ha argumentado que, además de las analogías que podrían trazarse entre el pensamiento de Sennert y de Leibniz, hay algunas diferencias. Por lo demás, en la sección 2.2. del noveno capítulo examinaremos con más detalle la noción leibniziana de átomo de 1675/1676.
} 
su vez partes. De esta manera, lo mínimo fue definido por Leibniz, al menos parcialmente, como aquello que no tiene magnitud o partes. $^{2}$ La carencia de partes parecería ser la nota más importante que Leibniz le atribuyó a lo mínimo, aunque, como veremos, en los años siguientes señaló también otras. En la sección 3.1. del cuarto capítulo, vimos que, con esta definición, Leibniz se refirió explícitamente al concepto de punto euclidiano (coincidiendo con Hobbes en la necesidad de redefinir dicho concepto). ${ }^{3}$ A su vez, como mencionamos en la sección 3.2. del segundo capítulo, Leibniz entendió por 'mínimo' lo mismo que lo que Froidmont por 'punto’. Más aún, como veremos en lo siguiente, hay notables coincidencias en la manera de abordar su negación, aunque también hay algunas diferencias. Ahora bien, la disyunción que se encuentra en la definición leibniziana de lo mínimo indica una identidad entre 'carecer de magnitud' y 'carecer de partes'. Esta identidad se apoya en el concepto de magnitud que Leibniz sostuvo al menos desde finales de la década de 1660 y durante buena parte de la siguiente, como el número de partes en lo extenso, a la que nos hemos referido reiteradamente con anterioridad. ${ }^{4}$ En consecuencia, en un primer momento, Leibniz reemplazó el concepto de punto de Euclides por el de 'punto indivisible' de TMA, esto es, aquello que tiene magnitud, puesto que tiene partes, aunque no obstante ellas sean indistantes entre sí. ${ }^{5}$

A lo largo de los años, Leibniz planteó distintos argumentos que mostrarían que una composición de mínimos sería contradictoria. Los primeros de ellos se encuentran en el tercer fundamento predemostrable de la $T M A$ :

No hay nada mínimo en el espacio o cuerpo, esto es, aquello que no tenga magnitud o parte. En efecto, no hay ninguna posición [situs] de una cosa tal, ya que todo lo que está posicionado en alguna parte puede ser tocado simultáneamente por muchas cosas que no se tocan entre sí, y por lo tanto tiene muchas caras. Pero tampoco puede afirmarse lo Mínimo sin que se siga que habría tantos mínimos de un todo como de una parte, lo que implicaría [una contradicción]. ${ }^{6}$

\footnotetext{
${ }^{2}$ Véase la nota 6 a continuación.

3 Es recurrente encontrar la identificación de los mínimos leibnizianos con los puntos euclidianos en la bibliografía sobre el tratamiento leibniziano del continuo. Por ejemplo, Beeley, 1996: 243 y Arthur, 2000: 6, y 2009: 5-6.

${ }^{4}$ Bassler, 1998a: 7. Anteriormente nos hemos referido a la noción leibniziana de "magnitud" en el contexto del comienzo de la década de 1670 en la sección 2.2. del tercer capítulo y en la sección 3.1. del cuarto.

${ }^{5}$ Véase la tercera sección del cuarto capítulo.

${ }^{6}$ TMA, A VI 2, 264. "Nullum est minimum in spatio aut corpore, seu cujus magnitudo vel pars sit nulla: talis enim rei nec situs ullus est, cum quicquid alicubi situm est, simul a pluribus se non tangentibus tangi possit,
} 
De acuerdo con el primero de los argumentos, no existe lo mínimo en el espacio o el cuerpo, dado que un cuerpo sin magnitud o sin partes no podría estar espacialmente posicionado, de modo que, en consecuencia, no sería susceptible de ser tocado por varias cosas que mientras tanto no se tocan entre sí. Como hemos visto en la sección 2.1. del tercer capítulo, una de las afecciones que se siguen necesariamente de la noción de cuerpo es la localidad o existencia en el espacio. De esta manera, aquello que no esté posicionado no cumpliría con los requisitos que se siguen de la definición de cuerpo. ${ }^{7}$ Este argumento de Leibniz es una reconstrucción de un razonamiento que Platón formuló en el Parménides. ${ }^{8}$ Ahora bien, Leibniz reconoció que negar los mínimos en el espacio y el cuerpo conllevaría necesariamente negarlos también en el tiempo. En este sentido, hay una correspondencia entre las distintas magnitudes continuas tal que, si no se dieran los mínimos en una de ellas, tampoco se darían en las otras. Como vimos en los capítulos previos, podemos decir que los continuos poseen una estructura isomórfica. ${ }^{9}$ Como veremos, Leibniz sugirió esto tanto en la TMA como en escritos posteriores. En el fundamento predemostrable 14 de la $T M A$, Leibniz señaló que, si se diera un mínimo del tiempo, debería darse también en el espacio, “[p] ues lo que en un tiempo recorre una línea, en un tiempo menor que el que puede darse recorrería una línea menor que la pueda darse,

ac proinde plures habeat facies; sed nec poni Minimum potest, quin sequatur tot esse totius, quot partis minima, quod implicat". OFC, $8,79$.

${ }^{7}$ Coincidimos, en este sentido, con la conclusion de Bassler, 1998a: 4-5, quien menciona que, "[d]ado que es absurdo hablar de una parte de un cuerpo que no tiene posición, Leibniz concluye que los mínimos espaciales y corporales no pueden existir". La traducción es nuestra.

${ }^{8}$ Platón, Parménides, 138a. "Y si es tal [a saber, algo sin partes], no podría estar en ningún lugar, dado que no puede estar ni en otro ni en sí mismo". Tomamos la traducción de Platón, 1988. Seguimos la indicación de la remisión del argumento de Leibniz a esta obra de Platón de Arthur, 2009: 12 y Arthur, 2000: 7.

${ }^{9}$ Tomamos la expresión utilizada por Palmerino, 2011, aunque, por cierto, su análisis no trate específicamente sobre Leibniz. En este trabajo puede encontrarse un muy interesante análisis de la isomorfía entre el espacio, el tiempo y la materia en la obra de Froidmont y de otros pensadores de la época. Incluso, en cuanto a Leibniz, ella menciona: "un rechazo explícito del isomorfismo del espacio, el tiempo y la materia se encuentra, en cambio, en los escritos de Leibniz. Tanto en su correspondencia como en sus trabajos publicados, Leibniz observa repetidamente que la incapacidad para distinguir entre la estructura de las magnitudes abstractas y la de las cosas sustanciales ha causado que muchos se pierdan en el laberinto del continuo". La traducción es nuestra. Sin embargo, en su trabajo se observan referencias al pensamiento maduro de Leibniz, por ejemplo, a su Nuevo sistema.... Según lo que aquí proponemos, es manifiesto que el 'anti-isomorfismo' de Leibniz es quizás una tesis adquirida con los años, pero que en cualquier caso no se encuentra en sus escritos de juventud. El punto de partida del cambio en la relación isomórfica, como veremos en la tercera parte de la tesis, tuvo lugar desde años 1675-1676 a partir de una modificación en la comprensión de la ontología del espacio y el tiempo que Leibniz asume, y que debe ser correctamente circunscrita. 
es decir, un punto. $\mathrm{Y}$ en un tiempo absolutamente mínimo [recorrería] una parte absolutamente mínima del espacio, la cual no existe" por la razón aludida anteriormente. ${ }^{10}$

El segundo argumento que Leibniz menciona en la TMA para negar la existencia de lo mínimo, esto es, que de afirmarlos serían tantos en un todo como en una parte suya, no recibe mayor atención en este escrito de 1671 que a lo que se alude en la cita a la que nos referimos anteriormente. Evidentemente, en este caso para Leibniz se contradiría el axioma del todo y la parte. Como veremos un poco más adelante, algunos exégetas del pensamiento de Leibniz entendieron que este argumento está estrechamente vinculado con otro que utilizó reiteradamente para negar los mínimos en el continuo. Ahora bien, los desarrollos posteriores de Leibniz en esta cuestión, específicamente en $D M M$ de 1672, se entrecruzan con otro problema: como hemos sugerido en el capítulo cuarto, en este año Leibniz ofreció argumentos para negar una composición de mínimos o indivisibles en el continuo. ${ }^{11}$ De esta manera, parece haber reconocido que una composición del continuo de indivisibles, interpretados en el sentido de Galileo, acarrearía los mismos problemas que los de una composición de mínimos. Una buena razón por la que Leibniz podría haber considerado esto así es que, en última instancia, lo mínimo y lo indivisible comparten una característica común: aunque por razones aparentemente diferentes, ambos admiten la propiedad de la indivisión, esto es, los mínimos por carecer de partes y los indivisibles de Galileo dado que, como vimos en el segundo capítulo, no tienen cantidad. En consecuencia, los indivisibles de Galileo, dicho en términos leibnizianos, son algo mínimo. ${ }^{12}$ Como vimos en el cuarto capítulo, los infinitesimales que Leibniz sostuvo en 1672 carecen justamente de la propiedad de la indivisión. En consecuencia, los mínimos o indivisibles serían unidades últimas, esto es, respecto de las que no sería posible hallar otra menor que ellas. ${ }^{13}$ Por esta razón, los mínimos no admitirían ni un más ni un menos. ${ }^{14}$ Esta nota es fundamental, pues, como hemos visto en los capítulos precedentes, toda parte del continuo, representada en

${ }^{10}$ TMA, A VI 2, 265-266. "Nam quod tempore absolvit lineam, tempore minore quam quod dari potest, absolvet lineam minorem quam quae dari potest seu punctum; et tempore absolute minimo partem spatii absolute minimam, qualis nulla est per fund. 3". OFC, $8,81$.

${ }^{11}$ Véanse los puntos 2 y 4 del cuarto capítulo.

${ }^{12}$ Esta interpretación es aún más consistente si se la vincula con lo que veremos en la segunda sección de este capítulo. Coincidimos con Robinet, 1986: 186, quien señala que, en esta ocasión, Leibniz habría entendido lo indivisible como lo 'mínimo absoluto'.

${ }^{13} D M M$, A VI 3, 98.

${ }^{14}$ Como se ha dicho, Leibniz asigna esta característica en 1672 también a los indivisibles, aunque los extremos indivisibles de la TMA, como se ha visto en el capítulo quinto, admitían un más y un menos. 
una fracción, admite una menor que respete la misma ley de sucesión que genera la serie. En síntesis, en 1672, Leibniz argumentó que una composición de unidades últimas (mínimas o indivisibles) acarrearía contradicciones.

Al igual que en la TMA, las contradicciones que conllevaría suponer una composición del continuo de mínimos que Leibniz reconoció en $D M M$, valen no solamente para el espacio y el cuerpo sino para el continuo en general. En este sentido, Leibniz siguió pensando que hay una estructura isomórfica entre los continuos. Así, por ejemplo, en un pasaje de dicho escrito, Leibniz indicó que "[s]i no se dieran mínimos en el tiempo y el espacio, tampoco se darían en el movimiento y el cuerpo; y por consecuencia, [no se daría] ninguno en el universo". 15 Aunque finalmente haya decidido descartar este pasaje posiblemente en vistas a alcanzar mayor claridad y ser más consistente en su negación de los mínimos respecto de cualquier magnitud- y haya distinguido entre los argumentos que muestran la contradicción de suponer los mínimos en el espacio y cuerpo y aquellos otros que muestran esto mismo respecto del tiempo y el movimiento, permanece presente la idea subyacente de que el tiempo y el espacio se dividen proporcionalmente. ${ }^{16}$

La isomorfía estructural entre los continuos está fundada tanto en el hecho de que todos se dividen proporcionalmente como en las contradicciones que se seguirían si esto se negara. Uno de los argumentos que Leibniz ofreció en $D M M$ para mostrar la contradicción que supone la afirmación de mínimos, parte justamente de suponer que no se da una isomorfía estructural entre el espacio y el tiempo y, en consecuencia, de asumir que en un tiempo mínimo (supuesto que existiera) un cuerpo puede recorrer un espacio que es mayor que un mínimo. Ahora bien, para Leibniz la razón de lo indivisible o mínimo (como $m$ ) a cualquier cosa que sea mayor que un mínimo ( $\operatorname{como} n$ ) es como la de lo finito a lo infinito, esto es, que $\frac{m}{n}=\frac{\text { finito }}{\text { infinito }}$. Como consecuencia de esto, si en un tiempo mínimo se recorriera un espacio no mínimo sino mayor, cuando el tiempo que se considere sea sensible, el espacio que habría recorrido debería ser necesariamente infinito, lo que es manifiestamente imposible. ${ }^{17}$ Recordemos que, como señalamos en el primer capítulo, para Leibniz toda

\footnotetext{
${ }^{15}$ DMM, A VI 3, 97. "Si nulla dantur minima in tempore et spatio, nec dabuntur in motu et corpore; ac per consequens nulla in universum". Esta correspondencia entre el espacio y el tiempo se explorará con más detalle en lo sucesivo.

${ }^{16}$ Para esto, véase el cuarto capítulo.

${ }^{17}$ DMM, A VI 3, 98.
} 
explicación abstracta del movimiento debe ser compatible con una sensible; sin embargo, recorrer un espacio infinito es sensiblemente un absurdo.

Además del argumento anterior, en $D M M$ Leibniz presentó otro que se volvió paradigmático, en la medida en que lo empleó reiteradamente en los años siguientes. ${ }^{18}$ Este razonamiento es muy similar a los argumentos geométricos que Froidmont presentó en su Labyrinthus explicados en la sección 3.2. del segundo capítulo. No obstante, el planteo de Leibniz difiere del de Froidmont en un aspecto crucial: mientras que el teólogo de Lovaina lo utilizó para mostrar que una composición de puntos finitos en número acarrearía contradicciones, el filósofo de Leipzig infinitizó el argumento. ${ }^{19}$ En este sentido, su planteo es menos ingenuo que el de Froidmont, pues aspira a mostrar no sólo que un continuo no puede componerse de un número finito de puntos sino que tampoco puede de un número infinito de ellos. Este argumento, conocido como 'de la diagonal', parte de trazar primero dos líneas rectas paralelas entre sí, $a b$ y $c d$, y luego otras infinitas líneas que, siendo perpendiculares a las anteriores, sean paralelas entre sí: ${ }^{20}$

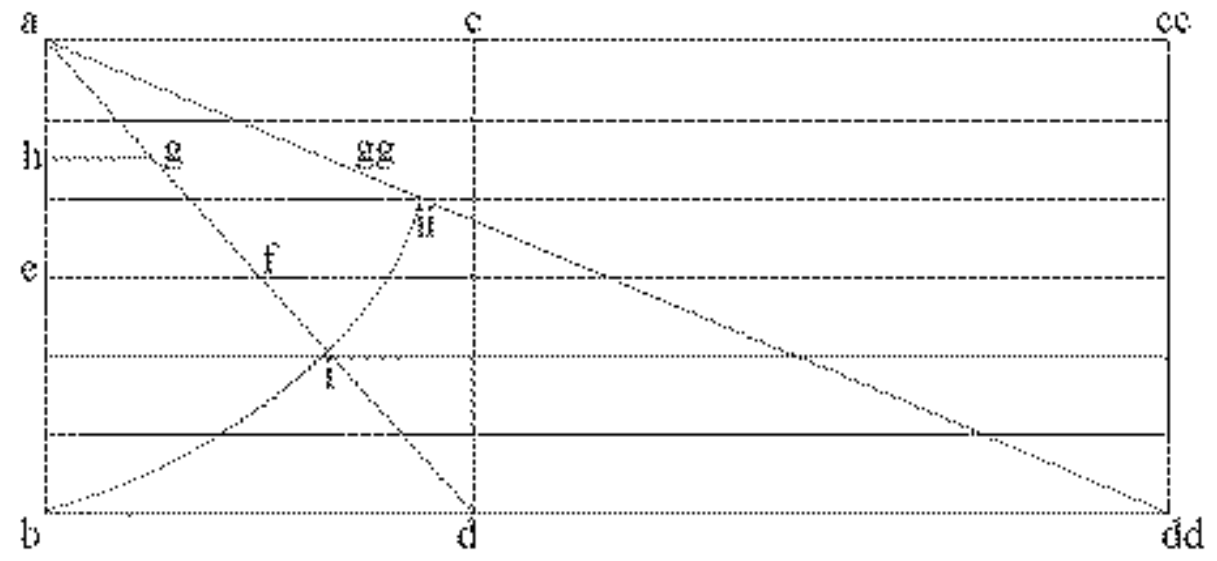

Como consecuencia, se obtiene un paralelogramo cuya área está íntegramente atravesada por las líneas perpendiculares, como $a-c, b-d$, etc. Ahora bien, dado esto, si se trazara una diagonal $a d$, no sería posible asignar ningún punto en el que dicha línea transversal no esté

\footnotetext{
${ }^{18}$ Este argumento, que desarrollaremos en breve, puede encontrarse, por ejemplo, en DMM, A VI 3, 97-98 de 1672 y en Pacidius Philalethi, A VI 3, 549-550 de 1676. OFC, 8, 137-138.

${ }^{19}$ Beeley, 1996: 295.

${ }^{20}$ Reconstruiremos el argumento basándonos fundamentalmente en la versión de 1672, de acuerdo con la referencia indicada en la nota 18. En lo siguiente señalaremos alguna diferencia que esta formulación tiene respecto de la versión de 1676, que tendremos en cuenta, aunque no la desarrollaremos, para hacer más clara la presentación del argumento. Pueden hallarse reconstrucciones similares en Leibniz, 2001:xxxiv, Arthur, 2000: 7-9, Lison 2006: 2-3, entre otros.
} 
atravesada por una de las líneas perpendiculares. Recuérdese que, como vimos en el capítulo cuarto, entre dos líneas que concurren se produce un ángulo que incide en un punto. Así, por ejemplo, una de las líneas perpendiculares atraviesa a ad en $g$. Como consecuencia de lo anterior, se sigue que las líneas que atraviesen a la diagonal ad serían numéricamente tantas como las que atraviesan los lados $a b$ y $c d$. "Por lo tanto -señala Leibniz-, habría tantos puntos indivisibles de la línea ad como líneas paralelas se tracen desde $a b$, esto es, como puntos indivisibles haya en la línea $a b "{ }^{21} \mathrm{Si}$ bien Leibniz no lo dice, es claro que esta situación iría en contra del célebre teorema trigonométrico de Pitágoras, pues si $a b$ es igual a $a d$, también lo serían sus respectivos cuadrados (de manera que la cantidad de puntos del otro cateto debería ser nula, y por lo tanto no sería un triángulo). Sin embargo, lo que Leibniz hace es determinar una porción de la diagonal que sea extensionalmente igual a la de uno de sus lados, como $a b$. De este procedimiento resulta la sección $a i$ de la diagonal. De esta manera, se obtiene que $a b$ tiene la misma cantidad de puntos que $a d$, así como también tiene la misma cantidad de puntos que ai. En consecuencia, si ad tiene la misma cantidad de puntos que ai, entonces en lo restante de la diagonal, esto es, $i d$, no debe haber puntos en absoluto, lo que contradice las suposiciones anteriores. $^{22}$

Hay al menos dos aclaraciones que deben hacerse respecto de este argumento de Leibniz. En primer lugar, algunos exégetas entendieron que Leibniz extrajo de este argumento la conclusión de que una composición de puntos contradiría el axioma del todo y la parte. De acuerdo con H. Breger, S. Levey, E. Lison o R. Arthur (en algunas ocasiones), ${ }^{23}$ la posibilidad de establecer una correspondencia biunívoca entre los puntos de la diagonal ad y del lado ab implicaría que el lado sería igual a la diagonal, aunque no obstante es evidente que la línea transversal es mayor que el lado. Sin embargo, como vimos, la conclusión a la que Leibniz llegó es que habría una sección de la diagonal, a

\footnotetext{
${ }^{21} D M M$, A VI 3, 97. “(...) tot ergo erunt puncta indivisibilia lineae $a d$, quot lineae parallelae exeunt ex $a b$, id est quot sunt puncta indivisibilia in linea ab (...)".

${ }^{22}$ Richard Arthur ha señalado atinadamente la limitación de esta última conclusión desde un punto de vista contemporáneo en Arthur, 2009: 16: "[d]esde una perspectiva contemporánea, este argumento es propenso a parecer falaz: pareciera que Leibniz ha mezclado la medida del conjunto de puntos en una línea con el número de puntos contenidos en ella. Del hecho de que haya el mismo número de indivisibles en $a i$ y en $a d$, no se sigue que la diferencia $i d$ entre ellas tenga una magnitud cero".

${ }^{23}$ Breger, 1990: 59-60; Levey, 1998: 61-62; Lison, 2006: 3. Por su parte, Arthur mantiene lo mismo en la introducción que ha hecho a las traducciones, en Leibniz, 2001:xxxiv, aunque anteriormente, en Arthur, 2000: 8-9, había interpretado correctamente, según nuestro parecer.
} 
saber, $i d$, en la que no habría puntos, lo que contradiría la suposición de que el continuo se compone de ellos. Si bien es cierto que en 1672 Leibniz examinó intensamente el alcance del axioma del todo y la parte, inclusive en $D M M$, en el argumento de la diagonal no se presupone el axioma. En este sentido, parecería que, en este argumento, Leibniz estaría operando con los presupuestos de Galileo. Por eso, estaría mostrando la imposibilidad de una composición de mínimos al margen del axioma del todo y la parte. Así, en el argumento, las infinitas partes no son consideradas como proporcionales. Como consecuencia, Leibniz buscó también justificar la imposibilidad de entender el infinito como una sumatoria de unidades. Como veremos en la segunda sección de este capítulo, para hacer esto (es decir, no antes), Leibniz tuvo que justificar la universalidad del axioma del todo y la parte. De esta manera, en síntesis, hay dos problemas íntimamente conectados: no puede darse lo mínimo (una unidad última respecto de la cual no pueda haber otra menor), pero tampoco lo máximo (esto es, una sumatoria infinita de unidades mínimas).

Como dijimos, el argumento de la diagonal presentado por Leibniz supera al de Froidmont, en la medida en que pretende demostrar que no puede darse una composición no sólo de un número finito de puntos sino tampoco de un número infinito de ellos. Hacia el final de su estadía en París, por el año 1676, Leibniz retomó el examen de la imposibilidad de lo mínimo en el continuo e introdujo importantes aclaraciones. Por lo pronto, esforzándose por aclarar que en el continuo no puede haber puntos ni finitos en número ni infinitos, ${ }^{24}$ Leibniz ofreció argumentos para ambas variantes. ${ }^{25}$ En este sentido, además del argumento de la diagonal, presentó otro que muestra que el continuo no puede componerse, en este caso, de un número finito de puntos. Para mostrar esto, basta con recordar el principio geométrico según el cual toda línea puede dividirse en un número finito de partes iguales entre sí. Si se supusiera una composición finita de puntos, se contradiría dicho principio. Tómense, por ejemplo, un triángulo $E C D$ y trácese una línea $A B$ que, aunque paralela a la base $C D$, sea menor que ella:

\footnotetext{
${ }^{24}$ Pacidius Philalethi, A VI 3, 548. OFC, 8, 136.

${ }^{25}$ Un examen detallado de estos dos argumentos puede encontrarse en Levey, 1998: 58-62.
} 


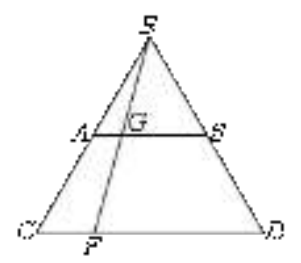

Ambas líneas, $A B$ y $C D$, pueden dividirse en el mismo número de partes iguales. Por poner un caso, trácese una línea desde $E$ hacia un punto cualquiera de la línea $C D$, como $F$, que atraviese a la línea $A B$ por $G$. Las líneas $A B$ y $C D$ fueron divididas ambas en dos partes (por un lado $A G$ y $G B$, por otro lado $C F$ y $F D$ ) de tal modo que mantienen la misma proporción, es decir, que $\frac{A G}{A B}=\frac{C F}{C D}$. Dado que se intenta mostrar que las líneas no pueden componerse de un número finito de puntos, supóngase que $A B$ y $C D$ se componen respectivamente de 99 puntos, que $A G$ es $\frac{1}{99}$ de $A B$ y que $C F$ es $\frac{1}{99}$ de $C D$. Como cualquier línea puede dividirse en un número finito cualquiera de partes iguales y supuesto que las líneas $A B$ y $C D$ se componen de 99 puntos, ¿qué sucedería si se quisieran dividir en 100 partes? La centésima debería conocerse como una fracción de un punto. No obstante, esto contradice el presupuesto. Por consiguiente, dado que las líneas pueden dividirse en un número finito cualquiera de partes iguales entre sí, no pueden componerse de puntos. ${ }^{26}$

No obstante, el examen de los mínimos en los últimos años de Leibniz en París se orientó también en otras direcciones. En 1675-1676, Leibniz consideró al menos dos cuestiones vinculadas con la negación de una composición de mínimos, a saber, la tensión entre la tesis del infinito actual y la posibilidad de partículas mínimas, y la imposibilidad de explicar la cohesión de los cuerpos supuesta una composición de mínimos. ${ }^{27}$ Leibniz retomó el examen de los mínimos en estas dos direcciones tras analizar algunas conclusiones que se desprenden de la filosofía de Descartes. En efecto, como mencionamos en el tercer capítulo, Leibniz leyó los Principia Philosophiae en este año y discutió varios aspectos de las dos primeras partes de esta obra. Por un lado, reconoció que hay una ambigüedad en la manera como Descartes entendió el concepto de infinito; por otro, como consecuencia, reconoció que la visión de Descartes conllevaría una interpretación de la composición del continuo de partes mínimas. En efecto, Leibniz entendió que, si la materia se moviera únicamente para llenar el espacio dejado al moverse y si asimismo ella debe

${ }^{26}$ Pacidius Philalethi, A VI 3, 548-549. OFC, 8, 136-137.

${ }^{27}$ De la misma manera lo ha entendido previamente R. Arthur en, por ejemplo, Leibniz, 2001:lii-liii. 
acomodar su figura incluso a la estrechez más pequeña, entonces no sólo no sería divisible indefinidamente sino que estaría actualmente dividida en infinitas partes mínimas: "[p]ero si comenzaras un movimiento en un líquido homogéneo, se dividiría absolutamente en [partes] mínimas, puesto que no habría ninguna razón de por qué no [se dividiera] en las [partes] menores". 28

El reconocimiento por parte de Leibniz de que el examen cartesiano de la materia conlleva una división infinita en partes mínimas le exigió reevaluar la posibilidad de sostener la tesis del infinito actual sin afirmar simultáneamente que las partes deben ser mínimas. La tensión entre el infinito actual y los mínimos fue, sin dudas, uno de las grandes preocupaciones de Leibniz en estos años, si se atiende a la cantidad de veces que se refiere a este problema. Esto se observa, por ejemplo, cuando se pregunta: "si supusiéramos que algún cuerpo está resuelto en acto en cosas menores, es decir, si se suponen unos Mundos en otros, ¿acaso por esto está dividido en partes Mínimas?”. ${ }^{29}$ Es claro, entonces, que Leibniz observó que parecería haber una conexión necesaria entre la tesis del infinito actual y la existencia de mínimos en el continuo. Uno de sus grandes desafíos fue desarticular este vínculo incorrecto y mostrar que el infinito actual puede comprenderse de una manera que evada por completo los mínimos. Por eso, para Leibniz fue claro que no es lo mismo una división en mínimos que una división decreciente al infinito en la que no hay una última parte. $^{30}$

Leibniz notó también que hay un serio problema físico que se desprende del examen cartesiano, a saber, que no podría explicarse la cohesión a partir de partes mínimas. Para mostrar esto, justificó primero que, si se afirmara que hay mínimos en el continuo, entonces lo compondrían íntegramente, esto es, no restaría una parte que no sea mínima. En efecto, supongamos que hay mínimos en el continuo y además una parte que no es mínima. Dicha parte restante debería ser mayor que un mínimo, "puesto que no es menor ni igual". 31 Ahora bien, si la parte restante es mayor que un mínimo, deberíamos decir que se compone

${ }^{28}$ De veritatibus, de mente, de Deo, de universo, A VI 3, 513. "At si inciperet motus in liquido homogeneo, absolute in minimas divideretur, quia ratio nulla foret cur non in menores".

${ }_{29}$ De veritatibus, de mente, de Deo, de universo, A VI 3, 513. "Si poneremus quodlibet corpus rursus in minora actu resolutum esse; seu si ponantur semper alii in aliis Mundi, an ideo divisum sit in Minimas partes".

${ }^{30}$ De veritatibus, de mente, de Deo, de universo, A VI 3, 513. Véase, asimismo, Leibniz, 2001: 1viii-lix. No obstante, retomaremos el examen de Leibniz sobre esta cuestión en el séptimo capítulo.

${ }^{31}$ De materia, de motu, de minimis, de continuo, A VI 3, 470. "ergo ea pars est maior minimo, cum nec minor sit nec aequalis, ergo et in ipsa sint minima". 
de mínimos: "si hay en el continuo partes mínimas, se sigue que el continuo se compone de ellas". ${ }^{32}$ Lo relevante aquí es por qué la parte restante no podría ser menor o igual a un mínimo. Leibniz no desarrolla una justificación para esta afirmación, presumiblemente debido a que le parece evidente. Podríamos reconstruir el argumento, sin embargo, de este modo: no puede ser menor porque, en ese caso, o bien sería una parte de un mínimo (contra esto está el que los mínimos no tienen partes) o bien esto menor sería el verdadero mínimo (y entonces no sería ‘menor que un mínimo' sino lo mínimo mismo); no puede ser igual, por su parte, debido a que, si lo fuera, sería precisamente un mínimo. ${ }^{33}$ El examen cartesiano, que para Leibniz arriba a esta conclusión, no podría explicar por qué las partes de un cuerpo no se desintegran como si fueran granos de arena. ${ }^{34}$ Leibniz expone una magnífica síntesis de su cuestionamiento al planteo cartesiano en uno de sus más importantes escritos de 1676, el diálogo Pacidius Philalethi:

PACIDIO: De aquí [a saber, de lo señalado por Descartes] parece seguirse que la materia está dividida en puntos: en efecto, está dividida en todas las partes posibles, y por tanto en partes] mínimas. Por consiguiente, el cuerpo y el espacio se compondrán de puntos.

CARINO: ¿Qué [dice] Descartes de esto?

PACIDIO: Contentándose con decir que la materia está dividida en acto en partes menores que todas las que puedan ser entendidas por nosotros, advierte que no deben negarse las cosas que afirma demostradas, aunque nuestra mente finita no capte de qué modo suceden. Pero una cosa es explicar de qué modo algo sucede, y otra satisfacer la objeción y evitar la absurdidad.

CARINO: Ciertamente, ha debido explicar de qué modo la materia no se resuelve así hasta ser polvo que, por decirlo así, conste de puntos, ya que es evidente que [en el polvo] no queda ningún punto coherente con ningún [otro]; en efecto, cada [punto] singular se moverá por sí mismo con un movimiento diferente del movimiento de algún otro.

\footnotetext{
${ }^{32}$ De materia, de motu, de minimis, de continuo, A VI 3, 470. "Si sunt in continuo partes minimae, sequitur continuum ex ipsis componi”.

${ }^{33}$ Un argumento complementario es señalado en Esquisabel, 1992-1993: 76. A propósito de los átomos, señala: "Esta solución [a saber, el atomismo] tampoco satisface a Leibniz. En primer lugar, si existieran átomos, cada uno sería exactamente igual a cualquier otro (dado que ninguno de ellos poseería un principio de distinción intrínseco) y en consecuencia serán indiscernibles, con lo cual no se podría hallar fundamento alguno para la variedad que realmente se da en el mundo". En la medida en que los átomos corresponderían a los mínimos en cuanto relativos al análisis de la materia, puede inferirse que dicha característica corresponde a los mínimos en general.

${ }^{34}$ La imagen de los granos de arena para graficar la división en mínimos está en correlación con la distinción entre 'división en mínimos' y 'división sin fin' a la que hemos aludido en la nota 30. Como allí se ha dicho, retomaremos el examen de esta distinción en el séptimo capítulo.
} 
PACIDIO: Si hubiera prolongado su razonamiento hasta aquí, quizá hubiera reconocido que su opinión está cubierta con aquellas dificultades que padece la composición del continuo de puntos y ciertamente hubiera estado obligado a responder a la dificultad. ${ }^{35}$

Como hemos mostrado en el capítulo anterior, en la TMA y otros escritos del mismo período, Leibniz explicó que la cohesión de los cuerpos se da porque las partes poseen un extremo en común. Como vimos, esta explicación solamente tiene sentido si las partes no son mínimas, pues si lo fueran, no podría distinguirse el extremo del resto de la parte. No obstante, en el final de su estadía en París, Leibniz notó que esta interpretación de la cohesión acarrea contradicciones. De esta manera, se vio obligado a reelaborar su teoría de la cohesión de los cuerpos y, en general, del continuo. Aunque examinar esta evolución del examen de Leibniz excede el objetivo de este capítulo, es importante tenerlo en cuenta como uno de los elementos en los que progresa el examen leibniziano que hemos presentado en la segunda parte de la tesis.

\section{El número infinito de todas las unidades}

Como mencionamos anteriormente, Leibniz se preocupó por dilucidar cuál es el alcance del axioma del todo y la parte. Como veremos, esta cuestión es especialmente relevante para el tratamiento del problema del número infinito. El examen de la imposibilidad de existencia del número infinito de todas las unidades o, como también suele decir, del número máximo, fue una de las cuestiones más atendidas por Leibniz en el año $1672 .^{36}$ En efecto, como sugerimos antes, la inexistencia de unidades últimas y la imposibilidad del número infinito de todas las unidades son dos cuestiones íntimamente ligadas que Leibniz se esfuerza notablemente por justificar. El filósofo de Leipzig sintetizó

\footnotetext{
${ }^{35}$ Pacidius Philalethi, A VI 3, 554. "Pa.: Hinc videtur sequi materiam divisam esse in puncta: divisa est enim in omnes partes possibiles, ac proinde in minimas. Ergo corpus et spatium ex punctis componentur. - Ch.: Quid hic Cartesius? - $P a$.: Contentus dixisse materiam actu dividi in partes minores omnibus quae a nobis intelligi possunt, monet non esse neganda quae demonstrata putat, tametsi finita mens nostra non capiat quomodo fiant. Sed aliud est explicare quomodo quid fiat, aliud satisfacere objectioni et evitare absurditatem. - Ch.: Debuisset utique explicare quomodo sic materia non resolvatur in pulverem ut ita dicam ex punctis constantem: cum nullum punctum nulli cohaerens relinqui pateat, singula enim per se movebuntur motu differente a motu alterius cuiuscunque. $P a$.: Si huc usque produxisset ratiocinationem, fortasse recognovisset sententiam suam difficultatibus illis premi quibus laborat compositio continui ex punctis coactusque fuisset utique respondere difficultati". OFC, 8, 141.

${ }^{36} D M M$, A VI 3, 98. Otros escritos de 1672 en donde Leibniz considera este problema son Aus und zu Galileis Discorsi, A VI 3, 168 y Leibniz a J. Gallois, A II 1, 342-356.
} 
la conclusión a la que pretende arribar de esta manera: "[t]enemos, por consiguiente, dos cosas excluidas de las cosas inteligibles: lo Mínimo y lo Máximo: lo indivisible, o [algo] absolutamente uno, y el todo; lo que carece de partes, y lo que no puede ser parte de otra cosa". ${ }^{37}$

La negación de la existencia del número infinito de todas las unidades es una consecuencia del examen que Leibniz llevó a cabo de una de las tesis más destacadas de los Discorsi de Galileo. Como hemos indicado en la cuarta sección del segundo capítulo, Leibniz leyó esta obra de Galileo en 1672 y discutió varias de sus conclusiones relativas al continuo y al infinito. Como hemos visto en aquel capítulo, Galileo sostuvo que el número infinito de todos los números naturales existe dado que no contradice el axioma del todo y la parte. En efecto, defendió que este axioma tiene un alcance limitado, pues está circunscrito a la esfera de lo finito. Como las propiedades de 'ser mayor que' y 'ser menor que' son propias de lo finito, para el científico italiano no es correcto asignarlas a lo infinito, que escapa al entendimiento finito humano. Como una consecuencia, Galileo equipara el número infinito con la unidad, precisamente porque este número cumple con el único requisito del número infinito, a saber, que el todo sea igual a la parte (pues cualquier potencia del número 1 es igual a sí). No obstante, el científico italiano no fue el único que limitó el alcance del axioma. En efecto, Grégoire de Saint-Vincent (1584-1667) también sugirió que el axioma falla en el ángulo de contacto. ${ }^{38}$ Para mostrar esto, este autor traza dos semicírculos concéntricos $B C D H$ y $B E F G$ que tengan un punto $B$ en común: ${ }^{39}$

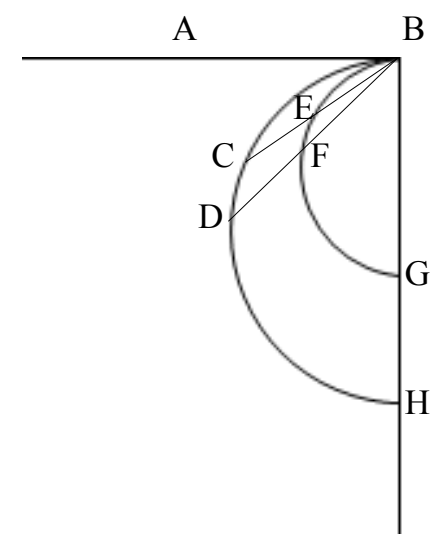

\footnotetext{
${ }^{37}$ DMM, A VI 3, 98. "Scholion. Habemus ergo exclusa rebus intelligibilibus, duo: Minimum et Maximum: indivisibile, vel omnino unum, et omne; quod partibus careat, et quod pars alterius esse non possit".

${ }^{38}$ Leibniz a J. Gallois, A II 1, 349.

${ }^{39}$ Grégoire de Saint-Vincent, 1647: 871.
} 
Luego de esto, divide la circunferencia del semicírculo mayor en D y traza una línea desde dicho punto hacia $\mathrm{B}$ atravesando consecuentemente el semicírculo menor. Así, en el semicírculo menor se generan partes proporcionales a las del semicírculo mayor, esto es, $\mathrm{BF}$ (proporcional a $\mathrm{BD}$ en el semicírculo mayor) y FG (proporcional a $\mathrm{DH}$ ). Como consecuencia, Grégoire de Saint-Vincent señala que los ángulos formados, esto es, DBH y FBG, son iguales. El mismo procedimiento puede realizarse ahora sobre las secciones de los semicírculos $\mathrm{BCD}$ y $\mathrm{BEF}$ : divídase $\mathrm{BCD}$ en el punto $\mathrm{C}$ y trácese una línea hacia $\mathrm{B}$ que atraviese el arco menor. Como consecuencia, los ángulos BCD y BEF son iguales. ${ }^{40}$ Ya que puede seguirse el mismo procedimiento al infinito, “en consecuencia, la cantidad del ángulo HBCD del semiperímetro con el diámetro es igual a la cantidad del ángulo GBEF del semiperímetro BFG con el diámetro BG" ${ }^{41}$ Ahora bien, el ángulo GBEF es una parte del ángulo $\mathrm{HBCD}$. En consecuencia, de aquí se sigue que en casos como el presente se destruye uno de los principios de la geometría, pues el todo es igual a una parte. ${ }^{42}$

Las conclusiones de Leibniz relativas al axioma del todo y la parte, no obstante, son radicalmente opuestas a las de Galileo y de Grégoire de Saint-Vincent:

Pero yo, ya que tengo por sabido que todo 'todo' [omne totum] es mayor que una parte suya, audazmente concluyo que este Número infinito o número máximo, es decir, la suma de todas las Unidades posibles, que también puedes llamar 'infinitísimo', o el número de todos los números, es 0 , es decir, Nada. ${ }^{43}$

El objetivo de Leibniz en lo que respecta al número infinito es al menos doble: por una parte, el filósofo de Leipzig pretende mostrar que este número no se compara con la unidad, como pretendía Galileo, sino con el cero. En este sentido, Leibniz aspira a mostrar que el número con el que se equipara el número infinito es aquel que no representa ninguna cantidad (o sea, nihil). ${ }^{44}$ No obstante, por otra parte, Leibniz intentó demostrar que la existencia de dicho número es contradictoria. Como sugiere la última cita, para justificar esto, Leibniz debió mostrar que efectivamente todo 'todo' es mayor que una parte suya,

\footnotetext{
${ }^{40}$ Grégoire de Saint-Vincent, 1647: 871.

${ }^{41}$ Grégoire de Saint-Vincent, 1647: 871. "igitur quantitas anguli HBCD semiperimetri cum diametro aequalis est quantitate anguli GBEF semiperimetri BFG, cum diametro BG".

${ }^{42}$ Grégoire de Saint-Vincent, 1647: 871.

${ }^{43}$ Leibniz a J. Gallois, A II 1, 352. "Ego vero cum habeam pro comperto, omne totum sua parte majus esse, audacter concludo, Numerum istum infinitum sive Numerum maximum seu omnium Unitatum possibilium summam, quam et infinitissimum appellare possis, sive numerum omnium numerorum esse 0 seu Nihil". Leibniz, 2014: 63.

${ }^{44}$ Breger, 1990: 60 .
} 
esto es, que el axioma del todo y la parte no se circunscribe a la esfera de lo finito sino que su alcance es universal.

Podría considerarse que la diferencia entre los planteos de Galileo y de Leibniz se funda en última instancia en que sostienen premisas diferentes. En efecto, hay dos premisas que entran en conflicto, a saber, (a) que en el infinito el todo es mayor que una parte y (b) que un conjunto infinito, como el de los números naturales, es un todo. Mientras que el científico italiano reconoce la tesis (b) y rechaza (a), el filósofo de Leipzig hace lo contrario. ${ }^{45}$ No obstante, como señala E. Lison, ${ }^{46}$ si así fuera Leibniz no podría desaprobar, mediante su argumento, las afirmaciones basadas en las premisas de Galileo. En este sentido, no podría decir que el número infinito es contradictorio, pues la asunción de otras premisas lo haría posible. No obstante, mostraremos a continuación que para Leibniz no se trató de una cuestión de premisas supuestas. En efecto, Leibniz abordó el problema del número infinito desde dos frentes, uno filosófico y el otro aritmético, que considerados conjuntamente ofrecen un panorama completo de la interpretación leibniziana. No obstante, estos dos frentes en gran medida son paralelos, esto es, tales que lo que se concluye desde uno de ellos no reviste importancia para el otro. En este sentido, parecería que la convergencia de argumentos distintos fue para Leibniz lo suficientemente persuasiva como para convencerlo de la inexistencia del número infinito de todas las unidades y de su igualación con el cero. En lo siguiente consideraremos primero el abordaje filosófico de Leibniz y luego el aritmético, señalando las peculiaridades de cada uno de ellos y también las diferencias.

\subsection{El abordaje filosófico: la demostración del axioma}

Desde el punto de vista filosófico, la preocupación de Leibniz consiste en demostrar que el número infinito es imposible. No obstante, el camino que conduce a esta conclusión está cubierto de notables reflexiones epistemológicas por parte del filósofo de Leipzig que

\footnotetext{
${ }^{45}$ Esta es la manera como sintéticamente piensa Arthur la diferencia en los planteos de Leibniz y de Cantor en Arthur, 2001. Arthur no se refiere, ciertamente, al pensamiento de Galileo. No obstante, quizás podría decirse lo mismo en este caso, y precisamente por eso lo mencionamos como una interpretación posible. Por lo demás, en Fazio, 2014: 71-80, puede encontrarse una síntesis del modo como los intérpretes han abordado el planteo de Leibniz sobre el número infinito, por ejemplo, analizando qué entendió Leibniz por la 'igualdad' que se daría entre una parte y el todo.

${ }^{46}$ En Lison, 2006.
} 
hacen del abordaje filosófico un trabajo verdaderamente sorprendente. Como mencionamos antes, Leibniz nota que la clave para probar que el número infinito es imposible es reconocer que el axioma tiene un alcance universal, esto es, que no puede circunscribirse solamente a la esfera de lo finito, como sostenía Galileo. Ahora bien, ¿cómo justificar la universalidad del axioma? La respuesta de Leibniz no se hace esperar: demostrándolo. ${ }^{47}$ En este sentido, Leibniz nota que, si pudiera demostrar el axioma analíticamente, entonces no podría limitarse arbitrariamente el alcance de su aplicación a lo finito, es decir, quedaría en evidencia su alcance universal. ${ }^{48}$ Como consecuencia, se probaría que la conclusión de Galileo es errónea, o mejor dicho, contradictoria. ${ }^{49}$ Como veremos, detrás de la intención leibniziana de demostrar el axioma del todo y la parte, se encuentra una reflexión sobre cuáles son las proposiciones que deberían aceptarse en la filosofía para que pueda darse un verdadero avance en ella.

La intención leibniziana de 'demostrar el axioma' podría parecer paradójica. En alguna medida, podría decirse que aún hoy se entiende la noción de axioma o principio en los términos presentados por Aristóteles en los Analíticos segundos, esto es, como verdades primeras conocidas por sí mismas que, precisamente por eso, escapan a toda posible demostración. ${ }^{50}$ No obstante, en la presente discusión Leibniz se encuentra con que una de estas presuntas verdades primeras no es reconocida como tal por Galileo y Grégoire de Saint-Vincent:

En efecto, como esta proposición: el todo es mayor que la parte, que ha sido objeto de dudas por parte de muy grandes Geómetras como son Galileo y

\footnotetext{
${ }^{47}$ El título completo de la Accessio que Leibniz le remitió a J. Gallois y en que basaremos buena parte de la presentación siguiente, ya sugiere cuál será la perspectiva que Leibniz adopte en su abordaje: "Accessio ad Arithmeticam Infinitorum ubi et ostenditur Numerum maximum seu numerum omnium numerorum impossibilem esse sive nullum; item quae pro axiomatis habentur, demonstrabilia esse evincitur exemplis" (A II 1, 342; Leibniz, 2014: 51).

${ }^{48}$ Lison, 2006: 12, señala que “(...) al arribar a París, Leibniz llegó a la conclusión de que el axioma euclidiano de que el todo es mayor que una parte puede ser probado utilizando el Principio de Contradicción. Esto significa que, desde este momento, Leibniz comienza a relacionar el [axioma de que] el todo es mayor que una parte como un principio cuya verdad es eterna, independiente del contexto y que no está sujeta a dudas". La traducción es nuestra.

${ }^{49}$ Por esto, entendemos que, para Leibniz, no se trató de una cuestión de cuáles premisas se asumen. En efecto, si Leibniz creyó que puede demostrarse la universalidad del axioma, sostener lo contrario no habría sido una opción viable.

${ }^{50}$ Aristóteles, Analíticos segundos, 76a30. "Llamo principios, en cada género, a aquellos que no cabe demostrar que son. Se da, pues, por supuesto qué significan las cosas primeras y derivadas de ellas; en cuanto al $<$ hecho de $>$ que son, los principios es necesario darlos por verdaderos, y las demás cosas, demostrarlas". Tomamos la traducción de Aristóteles, $1995 \mathrm{~b}$.
} 
Grégoire de Saint-Vincent. ¿Acaso podremos seguir reclamando de ahora en adelante que hay otras [proposiciones] conocidas por sí mismas? ${ }^{51}$

El hecho de que pueda dudarse tan fácilmente de una 'verdad primera' conlleva, para Leibniz, que no debe aceptarse en la filosofía ninguna proposición, con excepción de aquellas que o consten por observación inmediata de los sentidos, o se basen en una idea clara y distinta, o estén demostradas a partir de definiciones. ${ }^{52}$ Para la presente discusión es particularmente importante el segundo tipo de proposiciones, esto es, las demostradas. De este modo, para Leibniz si se acepta una proposición que no consta por los sentidos, es porque fue demostrada. Como consecuencia, ninguna proposición debe tomarse como evidente por sí. Leibniz menciona un claro ejemplo de presuntas proposiciones evidentes por sí que no obstante deben demostrarse:

De lo anterior se hace evidente también que estas proposiciones: [1] cosas iguales a una misma cosa son también iguales entre sí; [2] si a cosas iguales se le añaden o quitan cosas iguales, se obtienen cosas iguales; [3] el todo es mayor que una parte; [4] los equimúltiplos son como los simples, [5] si a cosas proporcionales se les añaden o quitan cosas proporcionales, los productos serán proporcionales, etc., requieren una demostración, puesto que se puede dudar de ellas, y si son verdaderas, serían demostrables, a saber, a partir de términos, es decir, de definiciones. ${ }^{53}$

En esta cita pueden reconocerse algunos de los célebres axiomas de Euclides, entre los que se destaca el que está involucrado en la discusión con Galileo. ${ }^{54}$ Además del hecho fáctico de que pueda dudarse de los axiomas, como efectivamente dudó el científico

\footnotetext{
${ }^{51}$ Leibniz a J. Gallois, A II 1, 351. "Cum enim ista propositio: totum esse majus parte, dubitationem receperit apud maximos Geometras, quales certe Galilaeus et P. Gregorius a S. Vincentio fuere, ullasne alias imposterum per se notas clamitare pergemus?". Traducción: Leibniz, 2014: 62.

${ }^{52}$ Leibniz a J. Gallois, A II 1, 351.

${ }^{53}$ Leibniz a J. Gallois, A II 1, 352. "Hinc apparet etiam propositiones istas: eidem aequalia etiam inter se esse, aequalia aequalibus addita vel demta facere aequalia, totum esse majus parte, aequimultiplicia esse ut simpla, si proportionalibus addantur demanturve proportionalia, producta esse proportionalia etc., cum dubitationis capaces sint, demonstratione indigere, et si sunt verae, demonstrabiles esse, ex terminis scilicet, seu definitionibus.”. Traducción: Leibniz, 2014: 63.

${ }^{54}$ Se trata, por cierto, de algunas de las conocidas como "nociones comunes" presentes en Euclides, Elementa, Lib. I, noc. com. (1991: 199-201). "1. Las cosas iguales a una misma son también iguales entre sí. 2. Y si se añaden cosas iguales a cosas iguales, los totales son iguales. 3. Y si de cosas iguales se quitan cosas iguales, los restos son iguales. 7. Y las cosas que coinciden entre sí son iguales entre sí. 8. Y el todo es mayor que la parte". Algunos años más tarde Leibniz señala que el enunciado 'el todo es mayor que una parte' es un teorema y no un axioma, precisamente porque ser demostrable, y añade: "Ut vel hinc discamus omnem propositionem quae non est accidentalis (ut experimentum) neque arbitraria (ut definitio) neque identica (ut nihil potest simul esse et non esse, quodlibet sibi ipsi aequale est etc.) esse demonstrabilem". De magnitudine, A VI 3, 483.
} 
italiano, Leibniz reconoce otra importante razón por la cual ellos no pueden ser tomados como verdades evidentes por sí. Se trata, en este caso, de una razón epistemológica: no puede establecerse ninguna facultad o potencia intelectual del hombre que establezca las mismas verdades para todos y con el mismo criterio. Esto, reconoce el autor, llevaría inevitablemente al más profundo de los escepticismos. En este punto, Leibniz se muestra fuertemente crítico de la concepción cartesiana según la cual es posible conocer proposiciones con evidencia: $:^{55}$

[E]sto [es decir, que todas las proposiciones deben demostrarse, lo digo] contra aquellos que piensan que [las verdades] son conocidas por sí mismas mediante no sé qué luz natural, puesto que es sabido que algunos consideran ciertas [proposiciones] como conocidas por sí mismas, mientras que otros las rechazan y las diferencian, y no proporcionan un criterio de lo que es conocido por sí mismo, a no ser quizá la opinión común que, si no fuera que está sujeta a dudas, pondría fundamentos probables de las demostraciones, lo que es darle la mano a Pirrón. ${ }^{56}$

La demostración de los axiomas -así como de toda proposición que deba tomarse en la filosofía y que no conste por los sentidos- debe realizarse para Leibniz a partir de definiciones. El filósofo de Leipzig se reconoce deudor del pensamiento escolástico en la tesis de que las verdades se hacen manifiestas mediante la inspección de los términos. ${ }^{57} \mathrm{El}$ paso obligado en el examen de Leibniz consiste en analizar por una parte las definiciones como tales y, por otra, su papel en las demostraciones. Ante todo, el hecho de que pueda demostrarse a partir de definiciones tiene en su base la comprensión de que una definición es "la significación de una idea" 58 Podría entenderse esto diciendo que una definición expresa el significado de una idea. ${ }^{59}$ No obstante, esto no significa en absoluto que las definiciones sean iguales para todos. De hecho, Leibniz reconoce que las definiciones en

\footnotetext{
${ }^{55}$ Principia Philosophiae, AT, VIII, $1, \S 30$.

${ }^{56}$ Leibniz a J. Gallois, A II 1, 352. "contra quam illi qui nescio quo lumine naturali per se notas putant. Cum constet quaedam ab aliquibus inter per se nota poni, quae ab aliis rejiciantur aut distinguantur, nec criterion afferri per se noti nisi forte opinionem communem, quae praeterquam quod dubitationibus obnoxia est, probabilia poneret fundamenta demonstrationum, quod est Pyrrhoniis manus dare". Traducción: Leibniz, 2014: 63-64.

${ }^{57}$ Leibniz a J. Gallois, A II 1, 352.

${ }^{58}$ Leibniz a J. Gallois, A II 1, 351. “(...) quae ideae significatio est, definitione (...)”.

${ }^{59}$ A propósito de esto, Esquisabel, 2012b: 12, señala: "La significatio es la explicación o desarrollo del contenido de la idea" y agrega: "Pero en la medida en que la definición es una expresión lingüística, debe entenderse también en el sentido de una designación en el sentido de un 'señalamiento' o 'indicación'. La definición significa, señala, la idea, pero no es la idea misma, por lo cual constituye un signo de la idea, algo que la representa y está en lugar de ella”.
} 
cuanto tales son arbitrarias. ${ }^{60}$ Por eso, no porque una definición sea la significación de una idea debe ser aceptada sin más. Lo que debe aceptarse son las proposiciones demostradas a partir de definiciones, pero no las definiciones mismas. Son las proposiciones demostradas las que pueden ser, como tales, verdaderas o falsas. Sobre las definiciones a partir de las cuales se llevan a cabo las demostraciones, dice Leibniz, coincidiendo en este punto con el examen de Galileo, "no debe argüirse falsedad sino ineptitud u oscuridad". 61

La afirmación de que toda proposición que se admita como verdadera debe estar demostrada a partir de definiciones acarrea inevitablemente un gran problema: si las definiciones en cuanto tales son arbitrarias, entonces ¿son también arbitrarias las verdades? Es decir, ¿esto significa también que todas las verdades dependen del arbitrio humano? No han faltado quienes sostuvieron esta interpretación. Uno de ellos fue Thomas Hobbes, un pensador que, como hemos mostrado reiteradamente en los capítulos anteriores, fue decisivo en el pensamiento de juventud de Leibniz. El planteo hobbesiano, sintéticamente, es que las verdades son arbitrarias precisamente porque dependen de definiciones arbitrarias. ${ }^{62}$ No obstante, Leibniz está en desacuerdo con esta interpretación. Según el filósofo de Leipzig, es claro que hay una cierta dependencia entre las proposiciones y las definiciones, en la medida en que las primeras son enunciadas precisamente mediante palabras u otros signos. ${ }^{63}$ Sin embargo, las conexiones de las ideas mismas, que son expresadas por las definiciones, son como tales asimbólicas (asymbolas), esto es, independientes de los términos del lenguaje. Dichas conexiones de las ideas dependen, como se ha dicho, de la sensación o de una idea, pero no de las definiciones. ${ }^{64}$ Como los pensamientos son asimbólicos, no son arbitrarios como las definiciones, pues la arbitrariedad de éstas depende de los términos utilizados. "Por consiguiente -señala

\footnotetext{
${ }^{60}$ Leibniz a J. Gallois, A II 1, 351. En efecto, tras haber indicado que todas las proposiciones que se tomen en la filosofía deben o constar por los sentidos o estar demostradas, Leibniz aclara: "exceptis scilicet ipsis definitionibus, quae ut toties in suis scriptis inculcat restaurator philosophiae Galilaeus, arbitrariae sunt, nec falsitatis, sed ineptiae obscuritatisque tantum arguendae".

${ }^{61}$ Leibniz a J. Gallois, A II 1, 351. Para la cita, véase la nota anterior. Traducción: Leibniz, 2014: 62. Véase Esquisabel, 2012b: 11.

${ }^{62}$ Hobbes, De corpore, I, 3, 8. Leibniz ha desarrollado dos versiones de la Accessio. Nosotros consideramos la definitiva. No obstante, en la primera de ellas mantuvo una concepción convencionalista de la definición que lo llevó a la tesis de que los axiomas son verdaderos por convención. Sobre esta cuestión, véase Esquisabel, 2012b: 9-14.

${ }^{63}$ Leibniz a J. Gallois, A II 1, 353.

${ }^{64}$ Leibniz a J. Gallois, A II 1, 353.
} 
Leibniz-, las notaciones y los símbolos son arbitrarios, o son palabras o caracteres, [pero] se presentan las mismas ideas para todos". ${ }^{65}$

No obstante, el empleo de símbolos o caracteres admite una particularidad. En efecto, Leibniz reconoce que, en un gran número de ocasiones, procedemos por mera manipulación simbólica, sin tener en consideración directa las ideas mismas a las cuales los caracteres se refieren. ${ }^{66}$ Para Leibniz este no es por sí mismo o necesariamente un uso indebido de los símbolos. Más aún, en gran medida proceder por medio de caracteres adquiere su importancia justamente por prescindir de la consideración de las ideas. Leibniz presenta un ejemplo claro en este sentido: “(...) como cuando decimos 100.000, nadie se imagina en su mente todas las unidades de este número, pues sabe que puede abstenerse de este trabajo gracias a los símbolos". ${ }^{67}$ En consecuencia, denomina ciegos a los pensamientos que proceden por medio de meros símbolos absteniéndose de la consideración de las ideas, precisamente por conducirse de este modo. De acuerdo con Leibniz, en los pensamientos ciegos se procede de manera análoga a como se procede en aquellos casos en los que se consideran unas pocas ideas comprendidas clara y distintamente. Esto significa, siguiendo el ejemplo anterior, que la comprensión del número 100.000, representado en esos mismos caracteres, es inteligible mediante el recurso a una comprensión análoga de la progresión decádica. ${ }^{68}$ Sin esta progresión que sirva como base para un procedimiento analógico, dice Leibniz, “(...) sería imposible para los mortales calcular, a causa del tedio, números muy grandes" ${ }^{69}$ El carácter analógico del empleo de los símbolos, fundamentalmente en casos en los que se consideran simbólicamente cosas que son muy complejas, como el número 100.000, es donde descansa en última instancia la utilidad del uso de símbolos:

Y el arte de forjar símbolos consiste en esto: [ellos] abrevian aún más que las Ideas mismas, y sin embargo están desprovistos de confusión y son aptos para descubrir en ellos mismos proporciones de todo género con no menor facilidad,

\footnotetext{
${ }^{65}$ Leibniz a J. Gallois, A II 1, 353. "Notae ergo symbolaque arbitraria sunt, sive sint verba, sive characteres, ideae ipsae omnibus gentibus eaedem obversantur". Traducción: Leibniz, 2014: 65.

${ }^{66}$ Leibniz a J. Gallois, A II 1, 353-354.

${ }^{67}$ Leibniz a J. Gallois, A II 1, 354. "ut cum 100000 dicimus, nemo omnes hujus numeri unitates sibi mente fingit, scit enim eo labore sibi post symbola supersedere licere". Traducción: Leibniz, 2014: 65.

${ }^{68}$ Leibniz a J. Gallois, A II 1, 354.

${ }^{69}$ Leibniz a J. Gallois, A II 1, 354. "Sine progressione enim ejusmodi impossibile fuisset mortalibus ingentes numerous supputare, ob taedium". Traducción: Leibniz, 2014: 66.
} 
en la medida en que eso puede hacerse, que si fuesen resueltos en últimos elementos, es decir, [si fuesen] entendidos clara y distintamente. ${ }^{70}$

Como vimos, para Leibniz la ventaja del uso de símbolos es muy clara. No obstante, reconoce que hasta el momento no contamos con un sistema de símbolos ni simples, ni completos ni ordenados, ni siquiera en las ciencias matemáticas puras. A partir de este hecho, Leibniz diseña un proyecto: "de ello se hace manifiesto que, acerca de todo razonamiento humano, nadie podría tener mayor mérito que quien diseñase ya sea un Lenguaje o, lo que sería suficiente, una Escritura Filosófica". ${ }^{71}$

Una vez justificado el proceder por medio de símbolos, Leibniz pasa a demostrar, "con los hechos mismos más que con palabras", 72 aquellos axiomas a los que se les ha negado el carácter de 'verdades evidentes por sí'. Nos centraremos a continuación en la breve pero importante demostración del axioma del todo y la parte. De acuerdo con el procedimiento estipulado, la demostración debe partir de definiciones. En primer lugar, entonces, define los dos pares de conceptos esenciales en este axioma, a saber, todo-parte y mayor-menor. Las cuatro definiciones involucradas son presentadas por Leibniz de este modo: “[p]ues si (definición 1) las partes son a, b, el todo (definición 2) será $a+b$. A su vez, si $a$ es menor (definición 3), $c=a+b$ será mayor (definición 4)". ${ }^{73}$ Ahora bien, el hecho de que haya entendido que toda proposición que sea aceptada debe demostrarse a partir de definiciones supone implícitamente una concepción determinada de lo que es una demostración. El planteo de Leibniz en este punto es al menos similar al de Hobbes que

\footnotetext{
${ }^{70}$ Leibniz a J. Gallois, A II 1, 354. "Et in eo consistit ars symbola excogitandi, ut sint compendiosiora ipsis Ideis, et tamen confusionis expertia, aptaque ad omnis generis proportiones in ipsis non minus facile, quoad ejus fieri potest detegendas ac si in ultima, fuissent resoluta, seu clare distincteque intellecta". Traducción: Leibniz, 2014: 65-66.

${ }^{71}$ Leibniz a J. Gallois, A II 1, 354. “(...) hinc apparet de tota ratiocinatione humana neminem mereri posse melius, quam qui excogitet sive Linguam, sive quod sufficit, Scripturam Philosophicam". Traducción: Leibniz, 2014: 66. Puede encontrarse un examen detallado de la manera como Leibniz entiende el empleo de símbolos en la Accessio y su proyecto de una lengua universal en Esquisabel, 2012b: 14-26.

${ }^{72}$ Leibniz a J. Gallois, A II 1, 354. "Sed age demonstrabilitatem axiomatum in exemplum propositorum opere ipso potius quam verbis ostendamus". Traducción: Leibniz, 2014: 67.

${ }^{73}$ Leibniz a J. Gallois, A II 1, 355. "Nam si (defin. 1) partes sint a, b, totum (defin. 2) erit $a+b$. Item si minus (defin. 3) sit idem $a$, majus (defin. 4) erit $c=a+b$ ". Traducción: Leibniz, 2014: 67-68. Es interesante notar que en las presentes definiciones, Leibniz emplea signos tales como " $="$. Como ha explicado Esquisabel, 2012b: 7, “(...) Leibniz encuentra los nexos entre los lenguajes matemáticos y los naturales en las analogías existentes entre las ecuaciones matemáticas y las definiciones, puesto que, estas últimas afirman una equivalencia conceptual, en forma análoga a las ecuaciones, que expresan igualdades". Esta analogía comporta, a su vez, una notable importancia en relación el proyecto previamente sugerido por Leibniz de una 'Escritura Filosófica': "De manera que si se diseña un sistema de simbolización apropiado para las definiciones y una serie de procedimientos formales para su tratamiento, tendremos puestas las bases para crear una escritura conceptual analítica similar a la algebraica" (ibídem).
} 
hemos explorado en la tercera sección del primer capítulo. Como hemos visto, para el filósofo británico una demostración es una cadena de silogismos que parten de definiciones, motivo por el cual las conclusiones deben estar ya contenidas en dichas definiciones. De acuerdo con Leibniz, este es el procedimiento de las ciencias puras, esto es, de las no empíricas. ${ }^{74}$ En efecto, en ellas lo que se hace es enunciar una definición o una parte de una definición sobre lo definido. ${ }^{75}$ Como hemos sugerido también en el primer capítulo, Leibniz retoma este modo de entender las demostraciones. En el presente caso, esto significa que la demostración del axioma del todo y la parte debe poder deducirse de las definiciones de todo, parte, mayor y menor. Precisamente por esto, tras establecer dichas definiciones, Leibniz agrega: “[s]i se juntan las definiciones, se compone la demostración: el Todo $=a+b$ (definición 2) $a+b=c$ (definición 4) $c=$ mayor (dicha definición 4), parte $=a$ (definición 1), $a=$ menor (definición 3)". ${ }^{76}$

Leibniz cuenta así, por lo tanto, con una demostración analítica (esto es, a partir de definiciones) del axioma del todo y la parte. De esta manera, queda garantizado el alcance universal del axioma, es decir, su validez para toda cantidad, sea finita o infinita. Por lo tanto, decir que el axioma 'falla' en lo infinito es incorrecto, así como también lo es afirmar que el número infinito de todas las unidades (que para Galileo no contradice el axioma puesto que está fuera de su ámbito) no implica ninguna contradicción. Esto lleva consecuentemente a concluir que el número infinito de todas las unidades es imposible, precisamente porque entra en contradicción con dicho axioma. Si es imposible, finalmente, no existe.

\subsection{El abordaje aritmético: la equiparación con el cero}

Como dijimos, Leibniz aborda el problema del número infinito desde dos frentes: uno filosófico y otro aritmético. Ahora bien, mientras que desde el punto de vista filosófico apunta a mostrar que el número infinito contradice el axioma del todo y la parte y, por lo

\footnotetext{
${ }^{74}$ Incluso, Leibniz recuerda unos años más tarde: "Definitionum connexio facit demonstrationem". De mente, de Deo, de universo, A VI 3, 462.

${ }_{76}^{75}$ Leibniz a Jean Gallois, A II 1, 354.

${ }^{76}$ Leibniz a J. Gallois, A II 1, 355. "Conjunctis definitionibus connectetur demonstratio: Totum $=a+b$ (defin.2) $a+b=c$ (defin. 4) $c=$ majus (dict. defin. 4), pars = $a$ (def. 1), $a=$ minus (defin. 3)". Traducción: Leibniz, 2014: 68 .
} 
tanto, que no existe, desde el punto de vista aritmético el examen de Leibniz toma otro rumbo, pues no aspira a mostrar que el número infinito es imposible sino que no se equipara con el 1, como sostenía Galileo, sino con el 0. Esto significa para Leibniz que el número infinito no representa una cantidad o, lo que es lo mismo, que no es nada. ${ }^{77}$ Como veremos, el examen aritmético de Leibniz sobre el problema del número infinito permanece al margen de la discusión sobre la universalidad o no del axioma. A su vez, veremos que el abordaje filosófico y el aritmético, aunque distintos, son complementarios.

El desarrollo de Leibniz desde el punto de vista aritmético se lleva a cabo en dos momentos. En el primero de ellos, Leibniz retoma la conclusión de Galileo según la cual el requisito del número infinito es que en él el todo sea igual a una parte y señala que el científico italiano concluyó erróneamente la igualación del número infinito con el 1 a partir de dicho requisito. Leibniz entiende que, si en el número infinito el todo es igual a una parte, entonces en dicho número debe haber no sólo tantas potencias como raíces (es decir, por ejemplo, no sólo tantos números naturales como cuadrados) sino también tantos números pares e impares (es decir, los números simpliciter) como números pares, y como números triangulares, piramidales o de cualquier progresión de este tipo dada, y como dobles, triples, etc. de los números simpliciter (esto es, sumados por sí dos veces, tres, etc.), y así sucesivamente. ${ }^{78}$ Dicho de otra manera, el conjunto de los números naturales debe ser igual a cualquier subconjunto suyo, no sólo a las potencias. Sin embargo, estos requisitos no se cumplen todos en la unidad. El doble de $1(1+1)$ o el triple $(1+1+1)$ no es igual a 1 . De allí que, cuando Leibniz se pregunte con qué número se equipararía el número infinito, observa que el número que cumple verdaderamente con este requisito no es el 1 sino el 0. Solamente en el 0 hay tantos números pares e impares como pares, triangulares, piramidales, etc., así como también solo el doble o el triple de este número es igual a sí, y demás. Que el número infinito se equipare con el 0 significa para Leibniz que no es nada o, mejor dicho, que no representa un todo. ${ }^{79}$

Ahora bien, el segundo momento del examen aritmético de Leibniz aspira a justificar la equiparación con el cero. El procedimiento de Leibniz en este punto está

\footnotetext{
${ }^{77}$ Véase la nota 47.

${ }^{78}$ Leibniz a J. Gallois, A II 1, 349.

${ }^{79}$ Leibniz a J. Gallois, A II 1, 349-350. Véase, asimismo, Aus und zu Galileis Discorsi, A VI 3, 168, y DMM, A VI 3, 98. Levey, 2015: 178-181, vincula esta cuestión con la negación del axioma del todo y la parte: como no es un todo, en el infinito no puede fallar el axioma del todo y la parte.
} 
estrechamente vinculado con una de sus más importantes iniciativas matemáticas del período parisino, a saber, la suma de series infinitas. Como mencionamos en el cuarto capítulo, Leibniz comenzó a trabajar en esta cuestión bajo la tutela de Huygens y, como resultado, presentó una regla universal para la suma de series infinitas. ${ }^{80}$ La regla de Leibniz, que presentó en la Accessio, tiene una gran importancia para la presente discusión puesto que, como veremos, su aplicación a la serie del número infinito muestra que su suma es igual a cero.

En el capítulo cuarto nos hemos referido a los modelos de comprensión del infinito actual que Leibniz mantuvo en estos años de su juventud, a saber, el de series que decrecen al infinito geométricamente y el de series que decrecen aritméticamente. Los desarrollos de Leibniz sobre sumas de series infinitas deben tomarse como la otra cara de sus exámenes sobre el infinito, especialmente si pensamos el infinito en relación con el problema del continuo. En efecto, desde este punto de vista, Leibniz justifica por qué infinitas partes pueden dar por resultado una cantidad finita. Ahora bien, la regla universal que Leibniz cree haber hallado vale para sumar las series que decrecen al infinito aritméticamente. No significa esto que no se puedan sumar las series del otro tipo, sino que la regla de Leibniz no alcanza este tipo de series. No obstante, para Leibniz puede extraerse una regla para sumar las series que decrecen al infinito geométricamente como consecuencia de un examen que 'los antiguos' han hecho de dichas series. ${ }^{81}$ De esta manera, Leibniz cuenta con dos reglas: una que no ha sido inventada por él y que sirve para sumar las series que decrecen geométricamente, y otra que es fruto de su invención y que sirve para sumar los recíprocos de cualquier progresión aritmética replicada. Ambas reglas le permiten justificar que la suma de la serie del número infinito da por resultado cero. En lo siguiente presentaremos las dos reglas y luego mostraremos cómo es que de su aplicación se puede concluir la equiparación del número infinito con el cero.

La regla que Leibniz extrajo para la suma de series que decrecen geométricamente al infinito es relativamente simple. Ella solamente presupone una sencilla ordenación entre las series de este tipo. Dicho orden se establece de acuerdo con la ratio según la cual las series se generan. En este sentido, la serie que decrece según la ratio de $\frac{1}{3}$ está, en el orden

\footnotetext{
${ }^{80}$ Leibniz a J. Gallois, A II 1, 345. Puede verse la primera del cuarto capítulo.

${ }^{81}$ Puede observarse dicho procedimiento en Leibniz a J. Gallois, A II 1, 343-344. Asimismo, lo hemos utilizado para reconstruir el concepto de infinito de Leibniz en el punto 1 del cuarto capítulo.
} 
de las series, antes de aquella que decrece según la ratio de $\frac{1}{4}$ pero luego de la que decrece según la ratio de $\frac{1}{2}$. Con esta simple presuposición, la regla que Leibniz extrae como una consecuencia es:

Supuestas las Fracciones continuamente decrecientes cuyo numerador sea la unidad, pero cuyos Denominadores sean los términos de alguna progresión geométrica, la suma de todas las Fracciones de una progresión dada será la primera Fracción de la progresión Geométrica precedente. ${ }^{82}$

De acuerdo con esta regla, la suma de una serie que decrece geométricamente al infinito, por ejemplo, según la razón de $\frac{1}{4}$, da por resultado la primera fracción de la serie precedente, esto es, $\frac{1}{3}$. En síntesis, se obtiene que:
a) $\frac{1}{2}+\frac{1}{4}+\frac{1}{8}+$ etc. $=\frac{1}{1}$.
b) $\frac{1}{3}+\frac{1}{9}+\frac{1}{27}+$ etc. $=\frac{1}{2}$.
c) $\frac{1}{4}+\frac{1}{16}+\frac{1}{64}+$ etc. $=\frac{1}{3}$.
Y así sucesivamente.

Ahora bien, la regla para sumar series que decrecen aritméticamente al infinito inventada por Leibniz es un poco más compleja que la anterior. Sin embargo, comparte con ella el hecho de que se presupone una cierta ordenación entre las series. Recordemos que, como se ha mencionado en la primera sección del capítulo cuarto, Leibniz denomina a las series que decrecen de esta manera como las de los recíprocos de 'alguna progresión aritmética replicada'. Asimismo, vimos que Leibniz llama 'progresiones aritméticas replicadas' a las series del triángulo aritmético de Pascal, de manera que las series de sus recíprocos constituyen el triángulo armónico. Recordemos la siguiente tabla:

\footnotetext{
${ }^{82}$ Leibniz a J. Gallois, A II 1, 344. "Sumtis Fractionibus continue decrescentibus, quarum numerator sit unitas, Nominatores vero termini progressionis cujusdam geometricae, summa Fractionum omnium progressionis datae, erit Fractio prima progressionis Geometricae praecedentis". Traducción: Leibniz, 2014: 53.
} 
Recíprocos de

TRIÁNGULO ARMÓNICO

$\begin{array}{cccccccc}\text { Naturales } & \frac{1}{1} & \frac{1}{2} & \frac{1}{3} & \frac{1}{4} & \frac{1}{5} & \frac{1}{6} & \text { Etc. } \\ \text { Triangulares } & \frac{1}{1} & \frac{1}{3} & \frac{1}{6} & \frac{1}{10} & \frac{1}{15} & \text { Etc. } & \\ \text { Piramidales } & \frac{1}{1} & \frac{1}{4} & \frac{1}{10} & \frac{1}{20} & \text { Etc. } & \\ \text { Triángulo- } & \frac{1}{1} & \frac{1}{5} & \frac{1}{15} & \text { Etc. } & & \\ \text { Triangulares } & \frac{1}{6} & \frac{1}{6} & \text { Etc. } & & & \\ \text { Triángulo- } & \frac{1}{1} & \frac{1}{1} & \text { Etc. } & & & & \\ \text { Piramidales } & & & & & \end{array}$

Como señalamos, los términos de alguna de las series del triángulo de Pascal son, a su vez, las diferencias de los términos de la serie inmediatamente anterior. En este sentido, hay un orden de las series, de tal modo que algunas son anteriores y otras posteriores. El hecho de que haya una ordenación es fundamental para la regla leibniziana. No obstante, como se ha dicho, el método presentado por el filósofo de Leipzig no sirve para sumar los números de los distintos órdenes del triángulo de Pascal sino las series de los respectivos recíprocos, esto es, aquellas cuyos términos son fracciones en las que los denominadores son los términos de alguna progresión aritmética replicada pero cuyo numerador es siempre la unidad. En este sentido, el orden de las series del triángulo aritmético se conserva en el caso de que se tomen en consideración los recíprocos. A los fines de explicar la regla, denominaremos las series de los recíprocos en orden, comenzando por la letra A, tal como se muestra a continuación:
[A] recíprocos de las unidades: $\frac{1}{1}, \frac{1}{1}, \frac{1}{1}, \frac{1}{1}, \frac{1}{1}, \frac{1}{1}, \frac{1}{1}$, etc.
[B] recíprocos de los naturales: $\frac{1}{1}, \frac{1}{2}, \frac{1}{3}, \frac{1}{4}, \frac{1}{5}, \frac{1}{6}, \frac{1}{7}$, etc.
[C] recíprocos de los triangulares: $\frac{1}{1}, \frac{1}{3}, \frac{1}{6}, \frac{1}{10}, \frac{1}{15}, \frac{1}{21}, \frac{1}{28}$, etc.
[D] recíprocos de los piramidales: $\frac{1}{1}, \frac{1}{4}, \frac{1}{10}, \frac{1}{20}, \frac{1}{35}, \frac{1}{56}, \frac{1}{84}$, etc.

Y así sucesivamente.

Ahora bien, aunque los recíprocos de la serie [A] sean iguales a los términos de dicha serie, no sucede lo mismo cuando se consideran las restantes. De acuerdo con esto, la 
regla de Leibniz para la suma de las series de los recíprocos de alguna progresión aritmética replicada, que presupone la ordenación entre las series recién explicada, es:

La Suma de una serie de fracciones de las cuales el numerador es el generador y los denominadores son los términos de alguna progresión Aritmética Replicada, es decir, lo que es lo mismo, la suma de las razones en las que el antecedente es la Unidad y el consecuente es un término de una progresión Aritmética Replicada que tiene a la Unidad como generatriz; esta suma, digo, es una fracción o razón cuyo numerador o antecedente es el exponente de la serie precedente inmediata, es decir, de la penúltima (supuesta, a saber, una última dada), pero el denominador o consecuente es el exponente de la serie precedente inmediata a la precedente, esto es, de la antepenúltima. ${ }^{83}$

Aunque la formulación de la regla sea más bien críptica, su aplicación es sencilla. Hay tres cuestiones que, aclaradas, la hacen fácilmente comprensible. En primer lugar, debe tenerse en cuenta que, como se menciona en la cita, el resultado de la suma de cualquiera de las series tiene la forma de una fracción. En este sentido, la suma de una serie de recíprocos es $\frac{x}{y}$. En segundo lugar, el hecho de que la regla se refiera a la serie 'precedente inmediata' o a la 'precedente inmediata a la precedente', presupone la ordenación de las series explicada anteriormente. De esta manera, $x$ es el 'número exponente' de la serie anterior a aquella cuya suma se busca, así como $y$ es el 'número exponente' de la serie anterior a la serie referida para obtener $x$. Lo que resta aclarar en tercer lugar es, consecuentemente, qué entiende Leibniz por el 'número exponente' de una serie. Este número no es otro que aquel que expresa el orden de una serie en la ordenación general de las mismas. Como queda en evidencia en la tabla expuesta anteriormente, la serie de las unidades, [A], es la primera, de manera tal que el exponente de esa serie es 1. Por la misma razón, el exponente de la serie [B] es 2, así como de [C] 3, de [D] 4 y así sucesivamente. Como consecuencia, el número exponente coincide con el segundo número de la progresión aritmética considerada, o bien con el denominador del segundo término de la serie de los

\footnotetext{
${ }^{83}$ Leibniz a J. Gallois, A II 1, 346. "Regula Universalis haec est: Summa seriei fractionum, quarum numerator est generator, nominatores sunt termini cujusdam progressionis Arithmeticae Replicatae, seu, quod idem est, summa rationum in quibus antecedens Unitas, consequens est terminus progressionis Arithmeticae Replicatae Unitatem habentis generatricem, haec summa, inquam, est fractio seu ratio cujus numerator seu antecedens est exponens seriei proximae praecedentis seu penultimae (data scilicet supposita ultima) nominator vero seu consequens est exponens seriei proxime praecedentis praecedentem, seu antepenultimae". Traducción: Leibniz, 2014: 55.
} 
recíprocos respectivos. ${ }^{84}$ De esta manera, de la aplicación de la regla de Leibniz resulta que, por ejemplo,

la suma de los recíprocos de la serie $[\mathrm{D}], \frac{1}{1}+\frac{1}{4}+\frac{1}{10}+\frac{1}{20}+\frac{1}{35}+\frac{1}{56}+\frac{1}{84}+$ etc.,

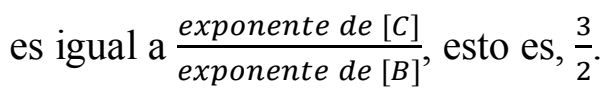

la suma de los recíprocos de la serie $[\mathrm{C}], \frac{1}{1}+\frac{1}{3}+\frac{1}{6}+\frac{1}{10}+\frac{1}{15}+\frac{1}{21}+\frac{1}{28}+$ etc.,

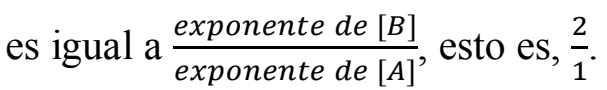

Y así sucesivamente.

Leibniz presenta la siguiente tabla que sintetiza todo el procedimiento (y que anticipa el resultado de la aplicación de la regla a la serie del número infinito) ${ }^{85}$

SERIES DE FRACCIONES DE UNA PROGRESIÓN ARITMÉTICA REPLICADA

\begin{tabular}{|c|c|c|c|c|c|c|c|}
\hline Exponentes & 1 & 2 & 3 & 4 & 5 & 6 & 7 \\
\hline & 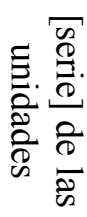 & 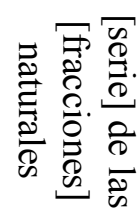 & 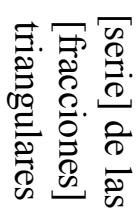 & 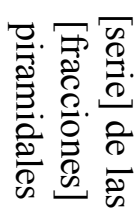 & 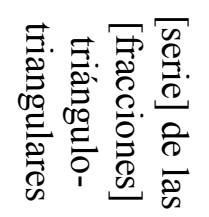 & 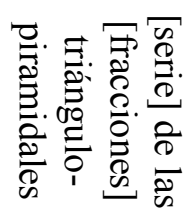 & 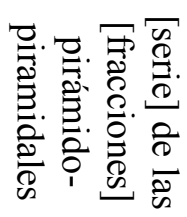 \\
\hline & 1 & 1 & 1 & 1 & 1 & 1 & 1 \\
\hline & $\overline{1}$ & $\overline{1}$ & $\overline{1}$ & $\overline{1}$ & $\overline{1}$ & $\overline{1}$ & $\overline{1}$ \\
\hline & 1 & 1 & 1 & 1 & 1 & 1 & 1 \\
\hline & $\overline{1}$ & $\overline{2}$ & $\overline{3}$ & $\overline{4}$ & $\overline{5}$ & $\overline{6}$ & $\overline{7}$ \\
\hline & 1 & 1 & 1 & 1 & 1 & 1 & 1 \\
\hline & $\overline{1}$ & $\overline{3}$ & $\overline{6}$ & $\overline{10}$ & $\overline{15}$ & $\overline{21}$ & $\overline{28}$ \\
\hline & 1 & 1 & 1 & 1 & 1 & 1 & 1 \\
\hline & $\overline{1}$ & $\overline{4}$ & $\overline{10}$ & $\overline{20}$ & $\overline{35}$ & $\overline{56}$ & $\overline{84}$ \\
\hline & 1 & 1 & 1 & 1 & 1 & 1 & 1 \\
\hline & $\overline{1}$ & $\overline{5}$ & $\overline{15}$ & $\overline{35}$ & $\overline{70}$ & $\overline{126}$ & $\overline{210}$ \\
\hline & 1 & 1 & 1 & 1 & 1 & 1 & 1 \\
\hline & $\overline{1}$ & $\overline{6}$ & $\overline{21}$ & $\overline{56}$ & $\overline{126}$ & 252 & 462 \\
\hline & 1 & 1 & 1 & 1 & 1 & 1 & 1 \\
\hline & $\overline{1}$ & $\overline{7}$ & $\overline{28}$ & $\overline{84}$ & $\overline{210}$ & $\overline{462}$ & $\overline{924}$ \\
\hline Sumas & $\underline{0}$ & $\underline{1}$ & $\frac{2}{2}$ & 3 & 4 & 5 & 6 \\
\hline Sumas & $\overline{0}$ & $\overline{0}$ & $\overline{1}$ & $\overline{2}$ & $\overline{3}$ & $\overline{4}$ & $\overline{5}$ \\
\hline
\end{tabular}

${ }^{84}$ Leibniz a J. Gallois, A II 1, 346.

${ }^{85}$ La tabla se encuentra en Leibniz a J. Gallois, A II 1, 347. 
Como hemos dicho anteriormente, tanto la regla para sumar los términos de una progresión geométricamente decreciente al infinito como aquella para sumar los de una progresión aritméticamente decreciente al infinito le permiten a Leibniz justificar que la suma de la serie del número infinito da por resultado cero. ${ }^{86}$ Como hemos visto, dicha serie es la de las unidades. De esta manera, lo que Leibniz quiere argumentar es que $\frac{1}{1}+\frac{1}{1}+\frac{1}{1}+$ $\frac{1}{1}+\frac{1}{1}+\frac{1}{1}+\frac{1}{1}+$ etc. $=0$. De acuerdo con la regla para sumar series que decrecen geométricamente, la suma de una serie da por resultado la primera fracción de la precedente. De esta manera, como hemos visto, la suma de $\frac{1}{3}+\frac{1}{9}+\frac{1}{27}+$ etc. da por resultado $\frac{1}{2}$, de la misma manera que la suma de $\frac{1}{2}+\frac{1}{4}+\frac{1}{8}+$ etc. da por resultado $\frac{1}{1}$, esto es, la primera fracción de la serie precedente. Ahora bien, dicha serie precedente, cuya primera fracción es $\frac{1}{1}$, es la serie del número infinito, esto es, $\frac{1}{1}, \frac{1}{1}, \frac{1}{1}, \frac{1}{1}, \frac{1}{1}$, etc. Si se intentaran sumar los términos de esta serie de acuerdo con la regla para las series que decrecen geométricamente al infinito, deberíamos concluir que $\frac{1}{1}+\frac{1}{1}+\frac{1}{1}+\frac{1}{1}+\frac{1}{1}+$ etc. es igual a la primera fracción de la serie anterior. Ahora bien, de acuerdo con Leibniz la serie anterior no puede ser otra que la de los nullae, esto es, la de cero. De esta manera, la suma de la serie de las unidades es $\frac{0}{0}$. Del mismo modo, de acuerdo con la regla para sumar series que decrecen aritméticamente al infinito, la suma de una serie es una fracción en la que el numerador es el exponente de la serie anterior y el denominador es el exponente de la serie anterior a aquella. Ahora bien, si aplicáramos esta regla a la serie [B] de las fracciones naturales y a la serie $[\mathrm{A}]$ de las unidades, obtendríamos el mismo resultado:

$$
\begin{aligned}
& \frac{1}{1}+\frac{1}{2}+\frac{1}{3}+\frac{1}{4}+\frac{1}{5}+\frac{1}{6}+\frac{1}{7}+\text { etc. }=\frac{\text { exponente de la serie precedente }}{\text { exponente de la serie precedente a la precedente }}=\frac{1}{0} . \\
& \frac{1}{1}+\frac{1}{1}+\frac{1}{1}+\frac{1}{1}+\frac{1}{1}+\frac{1}{1}+\frac{1}{1} \text { etc. }=\frac{\text { exponente de la serie precedente }}{\text { exponente de la serie precedente a la precedente }}=\frac{0}{-} .
\end{aligned}
$$

El hecho de que Leibniz llegue en matemáticas a la igualación del número infinito con el cero, tanto mediante la aplicación de la regla para sumar series que decrecen geométricamente al infinito como de aquella para las que decrecen aritméticamente, debió haberle parecido un buen indicio de la corrección de su propuesta. No obstante, debe notarse que el proceder de Leibniz en este punto es incorrecto a los ojos de un examinador

${ }^{86}$ Leibniz a J. Gallois, A II 1, 349-350. 
contemporáneo. En efecto, Leibniz aplica la última regla presentada indistintamente tanto a la serie de las unidades o de la fracciones naturales como a la de las fracciones triangulares o a cualquiera otra serie de recíprocos que le siguen en la ordenación que queda plasmada en el triángulo de Pascal, aunque no obstante estas últimas series son convergentes mientras que no lo son las primeras dos. De este modo, la regla permite extraer resultados correctos cuando es aplicada a series como la de las fracciones triangulares, esto es, las que son convergentes, aunque no en otros casos. Leibniz no pudo haber notado la 'limitación' de la universalidad de la regla dado que en su tiempo no se disponían de criterios de convergencia. Con esto queremos decir que la incorrección en el proceder de Leibniz es algo que quizá no hubiese sido posible de detectar en su contexto dadas las herramientas teóricas con las que contaba. El modo de proceder de Leibniz presupone que todas las series (sean convergentes o divergentes, dicho en términos actuales) son totalizables. ${ }^{87}$ Es precisamente por esto que Leibniz busca la suma de las unidades. Sin embargo, es posible que Leibniz haya notado algo extraño en su manera de proceder. En efecto, cuando unos años más tarde consideró la fundamentación de esta regla, introdujo la siguiente tabla: ${ }^{88}$

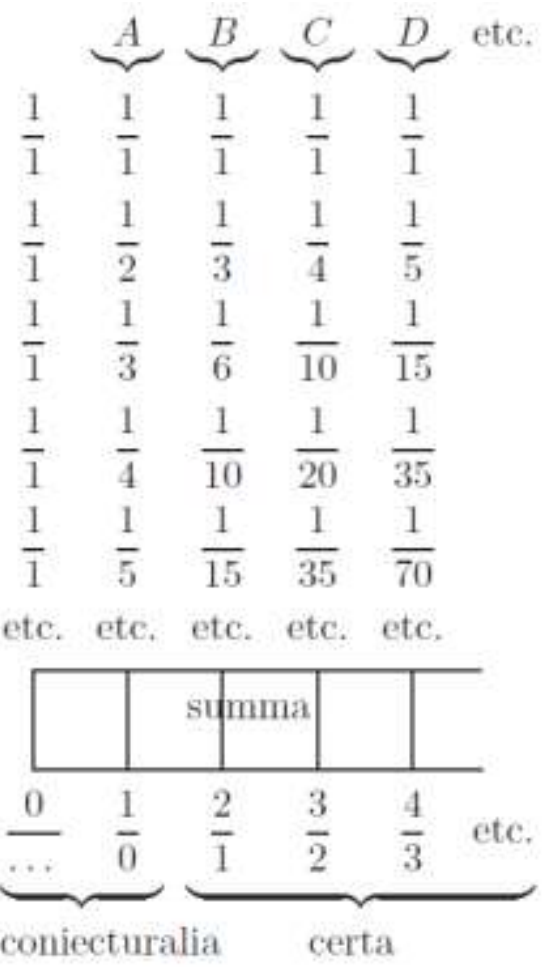

\footnotetext{
${ }^{87}$ Arthur, 2008b:6.

${ }^{88}$ La tabla, así como el razonamiento anterior, puede encontrarse en Scheda Exigua, A VII 3, 714.
} 
Nótese que, mientras las sumas de cualquiera de las series que siguen a la de las fracciones naturales son ciertas, según el resultado ofrecido por la aplicación de la regla, las sumas de las primeras dos revisten un carácter conjetural. ¿Cuál fue la razón de Leibniz para decir esto? Responder a este interrogante exige que se considere el razonamiento mediante el cual Leibniz justificó la regla antes trabajada en el escrito en que precisamente presentó este cuadro. En efecto, Leibniz presentó un argumento para el cual es necesaria la siguiente disposición gráfica:

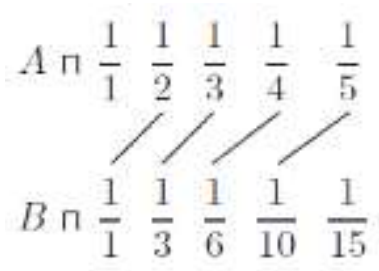

En esta imagen se observan dos series sucesivas, las de A y B (el signo $\Pi$ representa la igualdad), ${ }^{89}$ dispuestas la anterior A encima de la posterior $\mathrm{B}$, de las cuales los términos de la anterior A están conectados por una barra con los términos de B. Como se observa, dispuestos los términos ordenadamente, la barra conecta los términos de A no con aquellos que están inmediatamente debajo sino con los anteriores. Nótese, por cierto, que las series A y B en este gráfico no son las mismas que las asignadas previamente con esas letras. Dispuestas las cosas de este modo, Leibniz nota que si a un término de A se le sumara la mitad del término de $\mathrm{B}$ conectado a él por la barra, el resultado sería el término de A anterior al que ha sido tomado, es decir, el que está por encima del de B del cual se ha considerado la mitad. ${ }^{90}$ Por ejemplo, tómese el segundo término de A, esto es, $\frac{1}{2}$, y súmesele la mitad del término de B conectado por una barra, esto es, la mitad de $\frac{1}{1}$, a saber, $\frac{1}{2}$. El resultado de esta suma es efectivamente el primer término de la serie A, es decir, $\frac{1}{1}$. Leibniz reconoce que lo mismo sucede con cualquiera de los restantes términos de las series, es decir, que en cualquier caso si se suma la mitad del término de B al de A conectado por una barra, el resultado es la fracción anterior de la serie A. El filósofo de Leipzig reconoce que pueden probarse las sumas de las fracciones triangulares y las que le siguen en la ordenación de las series, tal como hemos visto, una vez reconocida la propiedad que

\footnotetext{
${ }^{89}$ Esto se ve, por ejemplo, en De la méthode de l'universalité de 1674, texto que se encuentra en la versión preliminar del volumen A VII 7 del 28/10/2015. En particular, ver la tabla de signos que está en A VII 7, 22.

${ }_{90}$ Scheda Exigua, A VII 3, 712.
} 
relaciona las series recién analizada. Para justificar, por ejemplo, que la suma de la serie B, esto es, de las fracciones triangulares, es igual a 2, Leibniz parte de tomar la serie A de las fracciones naturales y restarle el primer término, esto es, la unidad:

(1) $A-1 \sqcap \frac{1}{2}+\frac{1}{3}+\frac{1}{4}+\frac{1}{5}$ etc.

En siguiente lugar, toma la suma de las mitades de cada uno de los términos de la serie B de las fracciones triangulares, sobre la base de la propiedad que antes hemos analizado:

(2) $\frac{1}{2} B \sqcap \frac{1}{2}+\frac{1}{6}+\frac{1}{12}+\frac{1}{20}$ etc.

Finalmente, Leibniz procede a sumar lo anterior, es decir, los pasos (1) y (2). El filósofo de Leipzig reconoce que sumarle $\frac{1}{2} B$ a $A-1$ da por resultado la restitución de la serie completa A de las fracciones naturales:

(3) $A-1+\frac{1}{2} B \sqcap 1+\frac{1}{2}+\frac{1}{3}+\frac{1}{4}$ etc.

Dicho de otra manera, lo que Leibniz nota es que $A-1+\frac{1}{2} B=A$. Lo que sigue en el examen leibniziano es una consecuencia necesaria: $\frac{1}{2} B=1$, y por lo tanto $B=\frac{2}{1} \cdot{ }^{91} \mathrm{El}$ mismo procedimiento que aquí hemos realizado para justificar la suma de B puede realizarse a propósito de otra serie cualquiera. En este sentido, se pueden disponer otras series sucesivas una sobre la otra, como por ejemplo B y C, vincular los términos correspondientes mediante una barra de manera análoga a como ha hecho anteriormente con los términos de A y de B, y finalmente examinar qué fracción de los términos de la segunda serie deberían sumársele a los de la primera conectados por una barra para obtener como resultado el término anterior de la primera que se está considerando. Expresado en una imagen:

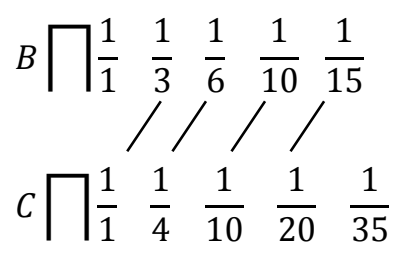

La conclusión que se extrae es que se requiere sumar $\frac{2}{3}$ de los términos de $\mathrm{C}$ a los de $\mathrm{B}$ conectados por una barra, de manera análoga a como vimos previamente que debían sumarse $\frac{1}{2}$ de los de B a los de A conectados por la barra. Del mismo modo, y siguiendo un

${ }^{91}$ Scheda Exigua, A VII 3, 713-714. 
procedimiento análogo, para saber cuánto suma $\mathrm{C}$, debe procederse restándole la unidad a $\mathrm{B}$ (es decir, $B-1)$ y debe examinarse qué fracción de los términos de la serie siguiente $\mathrm{C}$ deberían sumársele para restituir la serie B completa. Sintéticamente, la conclusión será que $B-1+\frac{2}{3} C=B$, y por lo tanto $C=\frac{3}{2}$.

El mismo procedimiento puede emplearse, como se ha dicho, en cualquiera de los otros casos. Un corolario del examen de Leibniz, que es particularmente importante en vistas al problema de la serie del número infinito, es el reconocimiento de que hay una secuencia en los coeficientes para las series. Es decir: así como para obtener A debe sumársele $\frac{1}{2} B$ a A-1, así también para obtener B debe sumársele a B-1 unos $\frac{2}{3}$ de C, de la misma manera en que para obtener $\mathrm{C}$ debe sumársele a C-1 unos $\frac{3}{4}$ de $\mathrm{D}$, para obtener D debe sumársele a D-1 unos $\frac{4}{5}$ de E, y así sucesivamente. De la misma manera, Leibniz reconoce que la suma de las series correspondientes es el recíproco del coeficiente que debe sumársele a la serie precedente habiéndole restado la unidad para restituir dicha serie, esto es: la suma de B es $\frac{2}{1}$, la de $\mathrm{C} \frac{3}{2}$, la de $\mathrm{D} \frac{4}{3}$, y así sucesivamente.

Presumiblemente en vistas a esta secuencia entre las sumas de las series sucesivas, y pensando la secuencia hacia atrás, Leibniz concluyó que la suma de A es $\frac{0}{1}$, así como la de la serie anterior (es decir, la de las unidades) es $\underset{-}{\frac{0}{2}}$. No obstante, debe notarse que el procedimiento que anteriormente explicamos para justificar las sumas de las distintas series no puede aplicarse a la de los recíprocos de los números naturales y a la de las unidades. Para mostrar esto, supongamos que nos preguntáramos por la suma de A, esto es, de los recíprocos de los números naturales. Para comenzar, deberíamos disponer los términos de esta serie por debajo de aquellos de la serie anterior, que llamaremos Z (a saber, la de las unidades), y conectar los términos de estas series con una barra según los presupuestos anteriormente señalados:

$$
\begin{aligned}
& Z \prod \frac{1}{1} \frac{1}{1} \frac{1}{1} \quad \frac{1}{1} \frac{1}{1} \\
& A \prod \frac{1}{1} \quad \frac{1}{2} \quad \frac{1}{3} \quad \frac{1}{4} \quad \frac{1}{5}
\end{aligned}
$$


En siguiente lugar, debemos determinar qué fracción de los términos de A deben sumarse a los de $\mathrm{Z}$ conectados por una barra para obtener como resultado el término anterior de $\mathrm{Z}$. Ahora bien, mientras que en cualquiera de las series antes consideradas, esto es, B, C, D, etc., debía sumarse una fracción determinada del término de la segunda serie al de la primera conectado por una barra (de manera que, hay que sumar $\frac{1}{2}$ de cualquier término de $\mathrm{B}$ al de A conectado por una barra para obtener el término anterior de $\mathrm{A}$, y análogamente a propósito de las restantes series), no sucede lo mismo en este caso: como los términos de Z son todas unidades, para obtener el término anterior debe sumársele 0 del término de $\mathrm{A}$ conectado por una barra, es decir, no debe sumársele ninguna fracción, o sea, nada. Aquí hay, en consecuencia, una notable diferencia respecto de los otros casos, pues mientras en ellos puede saberse que la suma de una serie da por resultado el recíproco del coeficiente que debe sumársele de ella a la serie precedente restada la unidad para restituirla, en el caso de la serie de las unidades y de las fracciones naturales no puede decirse lo mismo por el hecho de que no hay nada que sumar. Es posible que la razón por la cual Leibniz señaló que las sumas de las series de las unidades y de las fracciones naturales revisten un carácter conjetural se funde precisamente en el hecho de que el procedimiento que justifica la aplicación de la regla análogamente para cualquiera de las series posteriores a la de las fracciones naturales no se sigue igualmente para esta última serie ni para la anterior a ella. En este sentido, por ser conjetural, el examen aritmético de Leibniz a propósito de estas dos series, la de las unidades y la de las fracciones naturales, no es concluyente.

Para finalizar este capítulo, haremos una breve recopilación de las conclusiones parciales que hemos ido extrayendo a lo largo de las distintas secciones. En primer lugar, hemos visto que para Leibniz sería contradictorio afirmar que existen partes mínimas, esto es, partes que no tengan partes y, en consecuencia, respecto de las que no puede haber otra menor. El filósofo de Leipzig ha encontrado múltiples razones para negar la existencia de mínimos, por ejemplo: que un cuerpo mínimo no podría ser tocado por varios lados por cosas que a su vez no se tocan entre sí; que, supuesto que se dieran mínimos pero que no hubiera una isomorfía entre los continuos, en un tiempo mínimo se recorrería un espacio 
infinito; entre otras. Para mostrar las contradicciones que se siguen supuesto este último caso, Leibniz presentó el célebre 'argumento de la diagonal'. Ahora bien, mientras que algunos intérpretes han mantenido que Leibniz habría mostrado que este argumento deja en evidencia que una composición de mínimos contradice el axioma del todo y la parte, por nuestro lado hemos defendido que Leibniz concluyó más bien que en una parte de la diagonal no podrían haber mínimos o indivisibles, lo que contradice el presupuesto del que se partía, a saber, que el continuo se compone de ellos. No obstante, esto no significa que el axioma del todo y la parte no fue importante para los exámenes de Leibniz sobre el infinito, en especial sobre el número infinito de todos los números. En este sentido, en segundo lugar hemos visto que Leibniz llevó a cabo un doble abordaje sobre el número infinito, uno filosófico y otro aritmético, que arriban a conclusiones solidarias entre sí: el primero a la imposibilidad de existencia del número infinito, el segundo a su igualación con el cero. Desde el punto de vista filosófico, hemos visto que, para demostrar la imposibilidad del número infinito, Leibniz prueba el alcance universal del axioma analíticamente, es decir, a partir de definiciones. De esta manera, para Leibniz el número infinito no está fuera del alcance del axioma, como consideró Galileo. En consecuencia, la afirmación de existencia de dicho número acarrea contradicciones. Ahora bien, desde un punto de vista aritmético, la discusión sobre el axioma y la existencia o no del número infinito de todas las unidades no tiene ninguna importancia. En efecto, el axioma no tiene importancia a la hora de señalar que los requisitos del número infinito solamente se cumplen en el cero, así como tampoco reviste importancia en relación con la regla para sumar las series infinitas del triángulo armónico propuesta por Leibniz. De todo esto se sigue que el abordaje filosófico y el aritmético son independientes o paralelos, de manera que el modo de proceder de Leibniz en cuestiones aritméticas no necesariamente tiene en cuenta las conclusiones filosóficas ni viceversa. 


\section{TERCERA PARTE:}

CONTINUO E INFINITO EN DE SUMMA RERUM 



\section{CAPÍTULO 7: EL INFINITO ENTRE LA MATEMÁTICA Y LA METAFÍSICA}

\section{Los diversos grados de infinito}

En sus últimos años en París, Leibniz reformuló y repensó muchas de sus tesis anteriores sobre el continuo y el infinito. Para esto, como veremos, fueron capitales tanto sus estudios matemáticos como también su avance en cuestiones metafísicas. En relación especialmente con esto último, ha sido muy importante para Leibniz la figura de Ehrenfried Walther von Tschirnhaus (1651-1708), a quien Leibniz conoció hacia el final de sus días en París y con quien contrajo una amistad. Tschirnhaus había arribado a París en 1675 donde, siguiendo un consejo de B. Spinoza (1632-1677), se relacionó con C. Huygens y gracias a él con Leibniz. ${ }^{1}$ Anteriormente, Tschirnhaus había conocido a Spinoza, con quien mantenía una correspondencia relativamente fluida. Incluso, le pidió permiso a Spinoza para comunicarle sus escritos a Leibniz, aunque su pedido no fue aceptado bajo pretexto de que sería una imprudencia dárselos a conocer a Leibniz tan prematuramente. ${ }^{2}$ Gracias a las anotaciones de Leibniz sabemos que, no obstante, Tschirnhaus le comentó muchas de las cosas que se encuentran en el libro de Spinoza. ${ }^{3}$ Precisamente por esto, Tschirnhaus es un personaje relevante para el pensamiento leibniziano de 1675-1676. ${ }^{4}$ Como veremos a lo largo de este y de los siguientes capítulos, Spinoza fue muy influyente en Leibniz, aunque como sugiere M. Kulstad, en algún sentido la metafísica de Leibniz de este período es una metafísica 'a tres manos', esto es, forjada bajo la influencia de Spinoza por medio de Tschirnhaus. ${ }^{5}$ Así, como atinadamente señala M. Laerke, el conocimiento que Leibniz tenía no era tanto del 'spinozismo de Spinoza' como del 'spinozismo de Tschirnhaus'. 6

\footnotetext{
${ }^{1}$ Los datos sobre la llegada de Tschirnhaus a París fueron descritos por Georg Hermann Schuller a Spinoza en una carta de Noviembre de 1675. EP LXX (IV, 301-303. véase Spinoza, 2007: 265-266).

${ }^{2}$ EP LXX (IV, 302-303), para el pedido de Tschirnhaus a Spinoza por medio de Schuller, así como EP LXXII (IV, 305), para la respuesta de Spinoza.

${ }^{3}$ Über Spinozas Ethik, A VI 3, 384. Las fuentes de la influencia de Spinoza en Leibniz en este período fueron analizadas por Laerke, 2009, especialmente en el segundo apartado, "Leibniz's knowledge of Spinoza's metaphysics in 1675-1676".

${ }^{4}$ El papel de Tschirnhaus ha sido destacado, por Laerke, 2008 (a lo largo de toda la parte III, "La curiosité métaphysique"), Goldenbaum, 2014, Kulstad, 1999a, 1999b y 2014, Pasini, 2014, Piro, 2014, entre otros.

${ }^{5}$ Kulstad, 2014.

${ }^{6}$ Laerke, 2008: 443.
} 
Ahora bien, además de sus conversaciones con Tschirnhaus sobre la ética de Spinoza, Leibniz dispuso también de algunas cosas que le fueron comunicadas por G. H. Schuller por correspondencia en febrero de $1676 .{ }^{7}$ Entre ellas, se encuentra la célebre carta XII, conocida como 'carta sobre el infinito', ${ }^{8}$ enviada por Spinoza a L. Meyer el 20 de abril de $1663 .{ }^{9}$ En las anotaciones de Leibniz tanto de sus conversaciones con Tschirnhaus como también de su lectura de la carta XII, hay una constante, a saber: en ambos casos, el filósofo de Leipzig sistematiza lo que él entiende por infinito. Por ejemplo:

(+ Yo suelo decir que hay tres grados de infinito, [1] el ínfimo, v.g., como la asíntota de una hipérbola. Yo suelo llamar 'infinito' solamente a esto. Esto es mayor que cualquier cosa asignable, lo que también puede decirse de los demás [grados]. [2] Otro es lo máximo, a saber, en su género, como lo máximo de todas las cosas extensas es el espacio todo, lo máximo de todas las cosas sucesivas es la eternidad. [3] El tercer [grado] de infinito, y este mismo es el grado sumo, [es] todas las cosas, como lo infinito está en Dios; en efecto, él es todas las cosas en una. En él, en efecto, están contenidos los requisitos de la existencia de todas las demás cosas. Anoto estas cosas de pasada +$).{ }^{10}$

Leibniz distingue, entonces, tres grados de infinito: el infinito en el grado ínfimo, lo máximo en su género y Dios. Aunque son diferentes, los tres comparten el hecho de ser mayores que cualquier cosa asignable. En alguna medida, todos los capítulos que componen la tercera parte de nuestra tesis están orientados hacia la dilucidación de estos sentidos de infinito y de las consecuencias que tienen en el problema del continuo. Lo que buscaremos mostrar, a su vez, es que hay una coherencia entre ellos. Por ejemplo: la posibilidad de pensar en el espacio infinito comprendido entre la asíntota y la hipérbola está supeditada a la consideración de la extensión por sí misma. Como veremos en el próximo capítulo, para Leibniz se trata de una forma simple, también denominada 'inmensidad', que además concibe como un atributo de Dios. Por esto, en Dios se halla la razón por la cual las cosas extensas se dicen tales.

\footnotetext{
${ }^{7}$ Communicata ex literis domini Schulleri, A VI 3, 275-282.

${ }^{8}$ Así la denomina por ejemplo Tschirnhaus en correspondencia con Spinoza. EP LXXX (IV, 331).

${ }^{9}$ EP XII (IV, 52-62). La versión con las anotaciones de Leibniz se encuentra en A VI 3, 276-282.

${ }^{10}$ Über Spinozas Ethik, A VI 3, 384. "(+ Ego soleo dicere: tres esse infiniti gradus, infimum v. g. ut exempli causa asymptoti hyperbolae; et hoc ego soleo tantum vocare infinitum. Id est majus quolibet assignabili; quod et de caeteris omnibus dici potest; alterum est maximum in suo scilicet genere, ut maximum omnium extensorum est totum spatium, maximum omnium successivorum est aeternitas. Tertius infiniti, isque summus gradus est ipsum, omnia, quale infinitum est in Deo, is enim est unus omnia; in eo enim caeterorum omnium ad existendum requisita continentur. Haec obiter annoto. + )".
} 
En las siguientes secciones de este capítulo nos centraremos en el primer grado de infinito. Como para examinar los restantes grados es necesario considerar también algunos aspectos muy especiales de la metafísica de Leibniz del período de $D S R$, postergamos su tratamiento para el próximo capítulo. Así, en la siguiente sección examinaremos la descripción del infinito como 'la asíntota de una hipérbola', tras lo cual veremos también su vinculación con algunas de las más importantes tesis de Leibniz sobre el problema del continuo, a saber, la distinción entre una división del continuo 'en mínimos' y una división 'sin fin', y el carácter ficcional de las cantidades infinitamente pequeñas.

\section{El infinito 'como la asíntota de una hipérbola'}

Cuando Leibniz describe el primer grado de infinito, es decir, aquello mayor que cualquier cosa asignable, apela a una expresión geométrica, a saber, es 'como la asíntota de una hipérbola'. En los últimos años de su estadía en París, Leibniz estuvo trabajando con mucha atención en el problema de la cuadratura de las secciones cónicas. El gran resultado de este esfuerzo fue De quadratura arithmetica circuli, ellipseos et hyperbolae, cujus corollarium est trigonometria sine tabulis de 1675/1676. Como veremos, en el escolio de la undécima proposición de esta obra, así como en otros escritos del mismo período, se detectan algunas reflexiones muy sutiles de Leibniz sobre el infinito que son decisivas para la comprensión de su pensamiento del período de $D S R$. La expresión geométrica de la que se vale el filósofo de Leipzig implica que una línea recta (la asíntota) que se aproxima a otra curva (la sección cónica llamada hipérbola) sin nunca llegar a coincidir con ella, es infinita. Leibniz, que se vale de esta caracterización relativamente intuitiva que fue dada entre los antiguos por Apolonio de Pérgamo ( $c a$. siglo III a. C.), parece ser consciente de que la expresión que emplea representa de un modo geométrico el infinito que hemos examinado aritméticamente en los capítulos anteriores, por ejemplo, el de la serie infinita de las fracciones naturales:

Finalmente, las cosas infinitas de grado ínfimo son aquellas cuya magnitud es mayor que la que pueda ser explicada por nosotros con una razón asignable en relación con una cosa sensible. Aunque se diera algo mayor que estas cosas. Como el espacio infinito entre la asíntota y la hipérbola comprendido por 
Apolonio, que es uno de los más moderados infinitos a los que en cierto modo corresponde en números la suma de todos los espacios: $\frac{1}{1} \frac{1}{2} \frac{1}{3} \frac{1}{4}$ etc. que es $\frac{1}{0} .^{11}$

Como hemos visto en los capítulos precedentes, el ejemplo que Leibniz menciona fue objeto de un minucioso examen por su parte. Una de las conclusiones que extrajo sobre la serie de los recíprocos de los números naturales es que no puede tener una suma total puesto que -dicho en términos más actuales- es una serie divergente, a pesar de que pueda tener una suma parcial. Si se representara la serie mencionada por el autor en el espacio comprendido por una hipérbola y una línea recta, se obtendría como resultado:

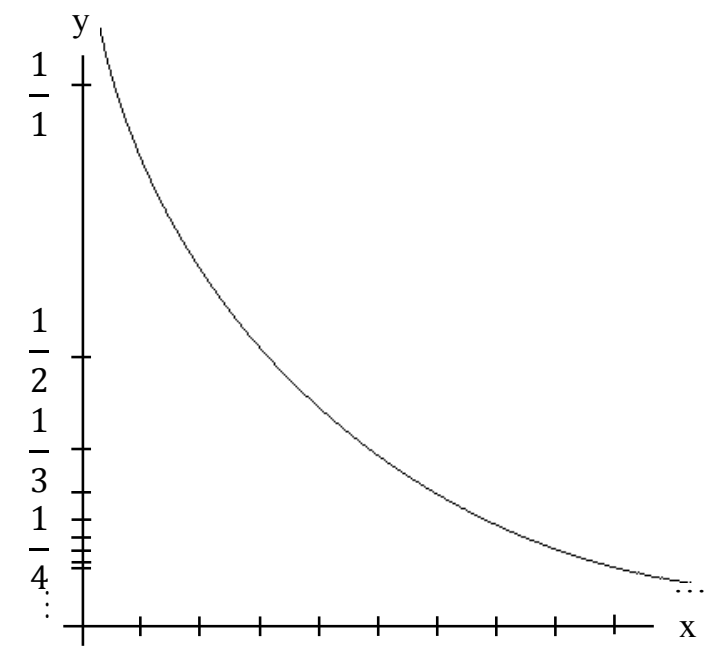

En este gráfico, que representa la serie decreciente de las fracciones naturales, se observa que la hipérbola se aproxima a la línea recta $x$ sin llegar jamás a tocarla. ${ }^{12}$ Ahora bien, desde un punto de vista geométrico, Leibniz introdujo una serie de precisiones que son fundamentales para su examen y que se desprenden de reconocer que sería admirable que alguien pudiera reducir el espacio absolutamente sin término que se interpone entre la

${ }^{11}$ Communicata ex literis domini Schulleri, A VI 3, 282. "Infinita denique infimi gradus sunt quorum magnitudo major est, quam ut a nobis ratione assignabili ad sensibilia, possit explicari. Quanquam aliquid detur ipsis majus. Quemadmodum spatium infinitum inter asymptoton et Hyperbolam Apollonii comprehensum quod ex moderatissimis infinitis unum est, cui respondet quodammodo in numeris summa huius spatii; $\frac{1}{1} \frac{1}{2} \frac{1}{3} \frac{1}{4}$ etc. quae est $\frac{1}{0}$. Modo scilicet, intelligamus ipsum 0 , seu Nullitatem, aut potius hoc loco quantitatem infinite seu inassignabiliter parvam, majorem esse minoremve, prout ultimum seriei huius fractionum, infinitae, Nominatorem, qui infinitus et ipse est, minorem majoremve assumserimus. Maximus enim in numeros non cadit". Nachtomy, 2014: 163-165. En el sexto capítulo hemos explorando la regla para sumar series infinitas que desarrolló en 1672 y que explica buena parte de este pasaje, así como también algunas consecuencias de ella relativas especialmente a la serie de las fracciones naturales.

${ }^{12}$ Arthur, 2015a: 140-141, aborda la manera Leibniz se representó la serie de los recíprocos de los números naturales en términos geométricos, esto es, en el espacio entre la asíntota y la hipérbola que recién consideramos. 
curva y una asíntota perfecta a un espacio finito, o al menos a un espacio con término. ${ }^{13}$ Como veremos, el problema que aborda Leibniz es el de la medición del área comprendida por las líneas. Por una cuestión de orden, relegamos un poco la aclaración de la noción de 'asíntota perfecta' que es esencial para el problema que se ha planteado. En última instancia, el interrogante que Leibniz se propone es sobre el área que yace entre la asíntota y la hipérbola (es decir, el espacio asintótico). El filósofo de Leipzig reconoce que no está familiarizado con ninguna reducción a un espacio finito del espacio absolutamente interminado entre una hipérbola y una asíntota perfecta. No obstante, esto no anula todo tratamiento por parte de Leibniz. Su abordaje supone la introducción de una locución que podría parecer paradójica, pero que es esencial para su planteo, a saber, la de líneas que, aunque sean infinitas, sin embargo no carecen de un término (es decir, no son interminatae). ${ }^{14}$

Este planteo de Leibniz presupone, en consecuencia, una distinción entre dos tipos de infinito, a saber, sin término (interminatum) y con término (terminatum). Es importante notar que para Leibniz no sería imposible pensar un infinito que sin embargo tenga un término. En este sentido, dice: "[p]ero [llamo] infinito a una cantidad, sea con término o sin término, a condición de que la entendamos mayor que cualquiera asignable por nosotros o designable por números". ${ }^{15}$ En consecuencia, para Leibniz una cantidad no es menos infinita por el hecho de ser terminada. Así, mientras una línea infinita sin término es aquella en la cual no puede asumirse ningún último punto, por lo menos de una parte, ${ }^{16}$ por contraposición una línea infinita con término es aquella mayor que cualquiera asignable pero con un último punto. ${ }^{17} \mathrm{~A}$ los fines de aclarar estas nociones y de mostrar su importancia para la geometría, Leibniz entiende que la diferencia entre lo que no tiene un término y lo infinito es como la diferencia entre lo infinitamente pequeño y lo indivisible:

De allí que deba recordarse que la diferencia entre lo infinito y lo que no tiene un término es como la que hay entre lo indivisible y lo infinitamente pequeño. La Geometría de los indivisibles es falaz, a no ser que se explique algo sobre

\footnotetext{
${ }^{13} D Q A$, XI, esc., 98. En lo que sigue tendremos muy en cuenta los exámenes de Knobloch, 1990 y 1994.

${ }^{14} D Q A, \mathrm{XI}$, esc., 98.

${ }^{15} D Q A$, XI, esc., 98. "Infinitum vero, quantitatem sive terminatam, sive interminatam, modo qualibet a nobis assignabili, numerisve designabili, majorem intelligamus".

${ }^{16}$ Linea interminata, A VI 3, 485. Similarmente, DQA, XI, esc., 98.

${ }^{17}$ Linea infinita est inmobilis, A VI 3, 471; Linea interminata, A VI 3, 485. Breger, 1990: 64-65. Más adelante introduciremos alguna precisión sobre la noción de infinito terminado y del proceso de terminación de una línea de este tipo.
} 
los infinitamente pequeños, y [a no ser que] no se empleen con seguridad puntos verdaderamente indivisibles, sino que deben utilizarse líneas sin duda infinitamente pequeñas, [que son] sin embargo líneas y por lo tanto divisibles. Ciertamente, del mismo modo una cantidad sin término difiere de una infinita. ${ }^{18}$

La noción de lo infinitamente pequeño y los problemas que conlleva serán examinados más adelante en este capítulo. Lo que aquí es importante remarcar del pasaje es que, así como en una línea infinitamente pequeña puede seccionarse una parte más pequeña que cualquiera dada, en la medida en que efectivamente es una línea y por lo tanto divisible, así también en una línea sin término puede hallarse un punto más lejano que cualquiera que se haya considerado. No obstante, la analogía implica otra coincidencia entre dichas nociones: así como la magnitud de un punto no está sujeta a las consideraciones de los geómetras, así tampoco la de una línea sin término. Esta afirmación de Leibniz tiene consecuencias cruciales para el problema que guía su examen, esto es, el de la medición del área que se interpone entre la asíntota y la hipérbola. En efecto, el filósofo de Leipzig reconoce, como consecuencia de la falta de consideración geométrica de las magnitudes del punto y de una línea sin término, que los puntos, aunque fueran infinitos en número, se añaden o sustraen en vano de una línea terminada, de la misma manera que una línea sin término no puede ser 'agotada' (exhaurire non potest) por un número cuanto se quiera grande de líneas terminadas. Sin embargo, para Leibniz es seguro que una línea terminada, aunque sea infinita, está constituida por una multitud de líneas finitas, aunque dicha multitud exceda todo número. Ahora bien, así como una línea infinita terminada se compone de líneas finitas, así también una línea finita se compone de líneas infinitamente pequeñas (que, en tanto que son líneas, son divisibles). ${ }^{19}$ De esta manera, Leibniz nota que, aunque una línea terminada no pueda ser una media proporcional entre un punto y una línea sin término, sin embargo puede decirse que "una línea finita es una media proporcional, no de cualquier manera sino verdadera y exactamente, entre alguna [línea] infinitamente pequeña y alguna [línea] infinita", con tal que se la entienda terminada, es decir:

\footnotetext{
${ }^{18} \mathrm{DQA}$, XI, esc., 98. "Ideo admonendum est, quemadmodum plurimum interest inter indivisibile et infinite parvum ita longam esse differentiam, inter infinitum et interminatum. Fallax est indivisibilium Geometria, nisi de infinite parvis explicetur; neque enim puncta vere indivisibilia tuto adhibentur, sed lineis utendum est, infinite quidem parvis, lineis tamen ac proinde divisibilibus. Eodem plane modo quantitas interminata differt ab infinita".

${ }^{19} D Q A$, XI, esc., 98.
} 
$\frac{\text { línea infinita }}{\text { línea finita }}=\frac{\text { línea finita }}{\text { línea infinitamente pequeña }} \cdot{ }^{20}$ Como se ha dicho antes, esta conclusión de Leibniz es esencial para poder calcular el área que media entre la asíntota y la hipérbola. A modo de ejemplo, consideremos una hipérbola cónica del tipo $\mathrm{x}^{\mathrm{n}} \mathrm{y}^{\mathrm{m}}=\mathrm{a}:^{21}$

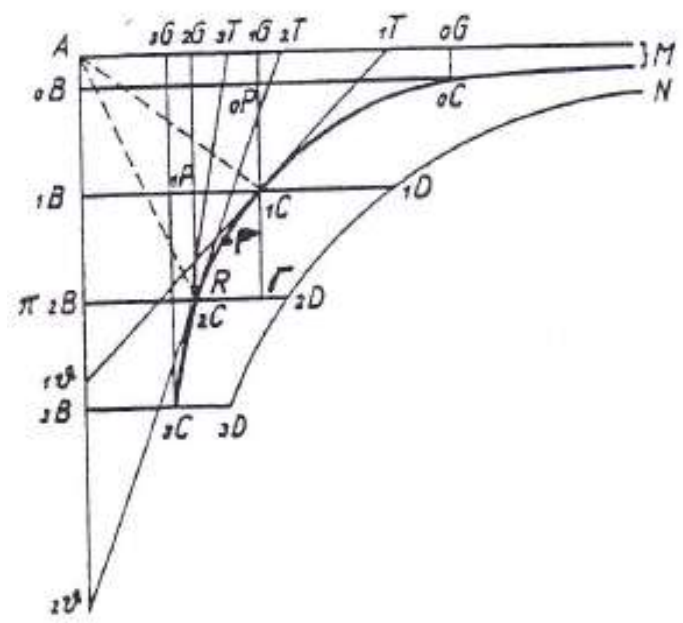

Supongamos en esta imagen un rectángulo cuyos lados sean $\mathrm{A}_{0} \mathrm{~B}$ y ${ }_{0} \mathrm{~B}_{0} \mathrm{C}$, que la ordenada $\mathrm{A}_{0} \mathrm{~B}$ es infinitamente pequeña $\mathrm{y}$ que la abscisa ${ }_{0} \mathrm{~B}_{0} \mathrm{C}$ es por contraposición infinitamente grande. Si la curva se aproximara constantemente a la recta pero nunca llegara a tocarla, es decir, si la aproximación fuera interminata, la asíntota sería perfecta. ${ }^{22}$ No obstante, si se le añadiera un término al infinito interminatum (de modo que la aproximación sea infinita pero terminata), habría un punto infinitamente lejano donde la curva y la recta se encontrarían. La utilidad de este último caso es evidente a la luz de lo dicho anteriormente: como una línea finita es una media proporcional entre una línea infinita y una línea infinitamente pequeña, entonces el rectángulo cuyos lados sean la línea infinitamente pequeña y la línea infinitamente grande sería igual a un cierto rectángulo finito. ${ }^{23}$ Esto significa, de acuerdo con el ejemplo anterior, que, si $\mathrm{n}=\mathrm{m}$, el rectángulo ${ }_{0} \mathrm{C}_{0} \mathrm{G}_{0} \mathrm{~A}_{0} \mathrm{~B}$ es igual al cuadrado finito $\mathrm{A}_{2} \mathrm{BR}_{2} \mathrm{G}$. Por eso, para Leibniz no hay esencialmente

\footnotetext{
${ }^{20} D Q A$, XI, esc., 98. "Hinc dici non potest Lineam terminatam esse proportionem mediam inter punctum seu lineam minimam, et interminatam seu lineam maximam. At dici potest lineam finitam esse mediam proportione, non quodammodo, sed vere exacteque inter quondam infinite parvam et quondam infinitam". Véase también Knobloch, 1990: 40-41.

${ }^{21}$ Tomamos la imagen de $D Q A$, XIV (aunque en la proposición XXI también se refiere a ella), y la explicación del ejemplo de Knobloch, 1990: 41 y 1993: 83-84.

${ }^{22}$ Sobre la noción de asíntota en la distinción que aquí mencionamos, seguimos a Knobloch, 1990: 47-48.

${ }^{23}$ Como atinadamente Knobloch, 1990: 41, del hecho de que una línea finita sea una media proporcional entre una línea infinita y una infinitamente pequeña se deduce la ecuación: línea infinita $x$ línea infinitamente pequeña $=$ línea finita ${ }^{2}$.
} 
nada de extraordinario en la acción llevada a cabo por la mente cuando mide espacios infinitos, como por otra parte consideró el jesuita francés Ignace-Gaston Pardies (16361674), para quien las meditaciones de este tipo son un argumento eficaz para reivindicar la inmaterialidad del alma. El motivo por el cual para Leibniz no hay nada de extraordinario en la acción de la mente es que ella se apoya en una ficción, a saber, en el añadido de un término, de modo que, supuesta una línea terminada, aunque no obstante infinita, la medición no es más problemática que la de un espacio finito en longitud. ${ }^{24}$

\section{In minima divisum esse y sine fine divisum esse}

Esta manera de entender el infinito y lo que no tiene un término acarrea importantes consecuencias en la manera como Leibniz aborda el problema del continuo. En el capítulo sexto hemos mencionado a la pasada que, en el contexto de $D S R$, Leibniz introdujo nuevos argumentos para demostrar que es imposible una composición de mínimos. Hemos dicho a su vez que su lectura de los Principia Philosophiae de Descartes en estos años fue un factor importante para retomar el problema de los mínimos, puesto que para Leibniz el examen cartesiano de la materia conlleva una división infinita en partes mínimas. No obstante, como veremos, Leibniz sigue defendiendo la tesis de que en una criatura pueden encontrarse otras infinitas en cantidad. En este sentido, se plantea el interrogante de si en última instancia la segunda de estas tesis no acarrea necesariamente la primera: "[s]i es verdad que cualquier parte de materia, sin importar cuán exigua, contiene infinitas criaturas, esto es, es un Mundo, se sigue también que la materia está realmente dividida en infinitos puntos". 25

No obstante, Leibniz rápidamente encuentra el camino para evitar que dichas tesis sean tomadas como idénticas, a saber: notar que la subdivisión puede ser 'mayor' o 'menor'. En efecto, en De arcanis sublimium vel de summa rerum de febrero de 1676, Leibniz nota que, si pudiera demostrarse que la materia puede dividirse más o menos, entonces sería imposible que se resuelva en indivisibles o puntos matemáticos, esto es, idénticos unos con

\footnotetext{
${ }^{24} D Q A, \mathrm{XI}$, esc., 96.

${ }^{25}$ De arcanis sublimium vel de summa rerum, A VI 3, 474. "Si verum est quamlibet partem materiae, utcunque exiguam continere infinitas creaturas, sive esse Mundum, sequitur etiam materiam esse reapse in infinita puncta divisam". Esta cuestión fue abordada, entre otros, por Levey, 1998, Arthur, 1998 y en la introducción a Leibniz, 2001.
} 
otros, pues siempre sería admisible una división ulterior. ${ }^{26}$ En este sentido, el problema se resolvería si se pudiera demostrar que, aunque no haya algo indivisible, hay algo infinitamente pequeño. ${ }^{27}$ Como veremos en la siguiente sección de este capítulo, el concepto de lo infinitamente pequeño es objeto de un examen minucioso por parte de Leibniz en los escritos de este período. Aquí alcanza con entender que la diferencia entre lo indivisible y lo infinitamente pequeño es que lo infinitesimal siempre admite cosas menores. Recordemos que en la cuarta sección del cuarto capítulo hemos visto que, cuando Leibniz afirmó infinitesimales actuales en 1672, mencionó no solamente que pueden haber algunos más pequeños que otros sino incluso infinitamente más pequeños. ${ }^{28}$ Más aún, esta característica es mencionada en el período de $D S R$, pues como hemos visto en el pasaje citado en la nota 18 de la sección anterior, Leibniz entiende que, a diferencia de un indivisible, una línea infinitamente pequeña es no obstante una línea, y precisamente por eso es divisible. Esta idea de que la subdivisión puede ser menor o mayor parece entusiasmar a Leibniz. En este sentido, hay una propiedad que Leibniz sostiene y que podemos describir, siguiendo una expresión que utiliza en el Pacidius Philalethi de Octubre de 1676, diciendo que 'la magnitud o pequeñez no vienen al caso' (magnitudo aut parvitas nihil ad rem faciat). ${ }^{29}$ Dicho de otra manera, hay una proporcionalidad entre lo grande y lo pequeño tal que la grandeza y la pequeñez del caso examinado son irrelevantes en una explicación. De este modo, la división de la materia en partes menores no se detiene en una primera partición, sino que cada una de las partes en las que se divide está también seccionada. Consecuentemente, lo mismo puede decirse al infinito. ${ }^{30}$ Como 'no viene al caso' cuán pequeña sea la parte considerada, la división no alcanza nunca porciones que no

\footnotetext{
${ }^{26}$ De arcanis sublimium vel de summa rerum, A VI 3, 474. Levey, 2007.

${ }^{27}$ De arcanis sublimium vel de summa rerum, A VI 3, 475.

${ }^{28}$ DMM, A VI 3, 99.

${ }^{29}$ Pacidius Philalethi, A VI 3, 560. OFC, 8, 145. Esta propiedad (que es la versión filosófica del axioma de Arquímedes, al que nos referiremos en la siguiente sección de este capítulo) es mencionada por Leibniz cuando intenta explicar cuál es el absurdo de introducir saltos en el movimiento no de los cuerpos sensibles sino de las pequeñas partículas que lo componen. De allí que, si nos resulta absurdo pensar que nosotros saltamos hasta Roma sin atravesar los puntos intermedios, "cum enim magnitudo aut parvitas nihil ad rem faciat", los saltos serían igualmente absurdos en las pequeñas partículas. Abordaremos un poco más este argumento en lo siguiente y el problema del movimiento en el noveno capítulo.

${ }^{30}$ Como sugerimos en los capítulos anteriores, esta hipótesis de que las estructuras materiales se replican al infinito es, a decir de Beeley, 2015: 27, uno de los conceptos metafísicos que deja en evidencia la interrelación entre la matemática y las explicaciones de la naturaleza.
} 
puedan ser nuevamente divididas, y en consecuencia en el continuo encontramos una división en la que no hay un último punto, esto es, una división sin fin:

Hay que tener en cuenta lo siguiente: si supusiéramos que algún cuerpo está resuelto en acto en cosas menores, es decir, si se suponen unos Mundos en otros, ¿acaso por esto está dividido en partes Mínimas? Y así, una cosa es estar dividido sin fin y otra estar dividido en mínimos. A saber, [en una división sin fin] no habría una parte última. Del mismo modo, en una línea sin término no hay un punto último. ${ }^{31}$

Como se observa, el plexo de conceptos relacionado con el de infinito que hemos visto en la sección anterior tiene un papel muy importante en la explicación del continuo. Ante todo, Leibniz aclara que el modo como debe comprenderse la 'infinitud' de partes del continuo es en el sentido de lo que no tiene un término (interminatum). En el Pacidius Philalethi Leibniz introduce una imagen muy elocuente para referirse a la división sin fin del continuo: no debe ser pensada como la división 'de la arena en granos', que representa la división en mínimos, sino como la división 'de un papel o una túnica en pliegues':

Por tanto, la división del continuo no debe ser considerada como la [división] de la arena en granos, sino como la [división] de un papel o una túnica en pliegues; y así, aunque sucedan algunos pliegues infinitos en número menores que otros, no por ello ningún cuerpo se disolverá en puntos o mínimos. ${ }^{32}$

La célebre imagen de los pliegues de un papel o una túnica le permite a Leibniz mostrar que no se da un pliegue que no esté a su vez subdividido en otro nuevo pliegue. En este sentido, la magnitud o pequeñez del pliegue no viene al caso: siempre hay otro menor. Por esta razón, no podría decirse que un papel se resuelve en puntos, puesto que, aunque algunos pliegues sean menores que otros al infinito, los pliegues son siempre extensos (son, en efecto, partes de un papel, que es extenso). ${ }^{33}$ Si bien H. Breger ha sostenido que en el Pacidius Philalethi Leibniz habría concebido al continuo como infinito en potencia, ${ }^{34} \mathrm{a}$ nuestro modo de ver, no debe pasarse por alto que, ante todo, el filósofo de Leipzig acentúa

\footnotetext{
${ }^{31}$ De veritatibus, de mente, de Deo, de universo, A VI 3, 513. "Valde considerandum; si poneremus quodlibet corpus rursus in minora actu resolutum esse; seu si ponantur semper alii in aliis Mundi, an ideo divisum sit in Minimas partes. Itaque aliud est sine fine divisum et in minima divisum esse. Scilicet pars ultima erit nulla. Quemadmodum in linea interminata punctum ultimum est nullum". En la primera sección del capítulo anterior, nos referimos a este pasaje a la pasada.

${ }^{32}$ Pacidius Philalethi, A VI 3, 555. "ac proinde divisio continui non consideranda ut arenae in grana, sed ut chartae vel tunicae in plicas; itaque licet plicae numero infinitae aliae aliis minores fiant, non ideo corpus unquam in puncta seu minima dissolvetur". OFC, 8, 142.

${ }^{33}$ Pacidius Philalethi, A VI 3, 555. OFC, 8, 142.

${ }^{34}$ Breger, 1990: 61.
} 
una connotación actual, en el sentido de que siempre hay (es decir, existe) un pliegue más pequeño que cualquiera que se considere. En este sentido, Breger parece considerar que el hecho de que Leibniz haya negado la existencia de un número infinito significa al mismo tiempo la negación del infinito actual. Como vimos en el capítulo anterior, es cierto que para Leibniz no hay un número infinito. No obstante, esto no significa que las partes en el continuo no sean infinitas en acto, sino que el infinito no se equipara con ningún número, es decir, no es un todo. ${ }^{35}$

Posiblemente, esta explicación de Leibniz pueda también entenderse en términos de series infinitas tal como hemos visto en el cuarto capítulo. En efecto, allí hemos visto que los términos de dichas series se establecen de acuerdo a la ley de sucesión que guía la serie, de manera que cada término es menor que el anterior al infinito. En este sentido, por ejemplo, si se considera la serie de Zenón (esto es, $\frac{1}{2}, \frac{1}{4}, \frac{1}{8}, \frac{1}{16}, \frac{1}{32}$,etc.), cada término es la mitad del que lo precede y el doble del que lo sigue, sin importar cuán grande o pequeña sea la fracción considerada. Como vimos en el cuarto capítulo, Samuel Levey ha reconocido también que Leibniz habría encontrado en el curso de sus estudios matemáticos sobre series infinitas un modelo para entender la división de la materia en una infinitud actual de partes sin que ello signifique una división hasta los puntos. ${ }^{36}$ Esta remisión a los trabajos sobre series infinitas de Leibniz también permite explicar que, en última instancia, el modo como entiende la división sin fin no implica que el continuo esté dividido en todas partes, pues si así fuera no se respetaría la ley de la serie. De hecho, al examinar el modo como Descartes entiende la división de la materia (cuestión que hemos tratado en el tercer capítulo), Leibniz concluye: “[d]e aquí parece seguirse que la materia está dividida en puntos: en efecto, está dividida en todas las partes posibles, y por tanto en [partes] mínimas". ${ }^{37}$ Por contraposición, entendiendo que la división sin fin de Leibniz puede concebirse de acuerdo con el modelo de las series, se explicaría también que, aunque la división de la materia no tenga un fin, sin embargo no es arbitraria.

\footnotetext{
${ }^{35}$ Incluso, más adelante en su trabajo (Breger, 1990: 63), el autor señala llamativamente que el infinito actual de la metafísica leibniziana no tiene términos y no es algo uno, en el sentido de que es solamente una multiplicidad actualmente existente de más cosas que las que se pueden asignar con cualquier número. En este sentido, entiende al infinito actual como lo que no cumple con los requisitos del número infinito, o sea, lo describe como infinitum interminatum.

${ }^{36}$ Levey, 1998: 68-69.

${ }^{37}$ Pacidius Philalethi, A VI 3, 554. "Hinc videtur sequi materiam divisam esse in puncta: divisa est enim in omnes partes possibiles, ac proinde in minimas". OFC, 8, 141.
} 
De acuerdo con lo que hemos visto, para la explicación leibniziana de la división sin fin es fundamental la propiedad que hemos mencionado anteriormente según la cual la grandeza o pequeñez no vienen al caso. Ahora bien, resta aún por examinar de qué modo Leibniz justifica esto. Para el filósofo de Leipzig, el incumplimiento de esta propiedad significaría una falta de simetría o incongruencia (inconcinnitas). ${ }^{38}$ Ténganse en cuenta que lo que Leibniz estaría explicando por medio de esta expresión es lo que sucedería si no hubiera una proporcionalidad entre lo grande y lo pequeño. Para referirse a la incongruencia, Leibniz se vale también de expresiones tales como 'violencia' (presuntamente, porque iría en contra de la simetría que hay entre lo grande y lo pequeño, dado que la grandeza o pequeñez no alteran el caso) o 'milagro ordinario' (quizás debido a que, si la simetría no se cumpliera en un grado de grandeza o pequeñez, entonces sucedería un milagro pero tratándose de cosas comunes). ${ }^{39}$ La explicación de Leibniz de acuerdo con la cual ha de ser resistida la incongruencia se encuentra en el diálogo Pacidius Philalethi, en un momento en que se está examinando la posibilidad de admitir 'saltos' en el movimiento (cuestión que será examinada en el noveno capítulo). En el curso del diálogo, los interlocutores examinan la alternativa de negar saltos en lo sensible (precisamente porque no los podemos observar sensiblemente) pero admitirlos en los cuerpos menores. No obstante, Leibniz reconoce que, si así fuera, se produciría una incongruencia que iría en contra de la belleza de las cosas y de la sabiduría de Dios:

Haces bien resistiéndote a esta opinión [a saber, la que afirma saltos en cuerpos más pequeños], Carino, que está en contradicción con la belleza de las cosas y la sabiduría de Dios. De lo contrario, sería del mismo modo como si Dios quisiera ocultar solamente a nosotros o disimular ciertas incongruencias que, a saber, no podría evitar en la naturaleza, a saber, transfiriéndolas a cosas muy menores entre las cosas, donde no pudieran ser advertidas. Pero [tú] mismo ves, si lo considero en cosas aún más estrechas, que, dondequiera que se suponga que este salto sucede, allí éste podría ser esquivado del mismo modo. Pues por

\footnotetext{
${ }^{38}$ Pacidius Philalethi, A VI 3, 560. OFC, 8, 145. En sintonía con lo que hemos mencionado en la nota 29 y como veremos a continuación, esta explicación de Leibniz se enmarca en el intento de justificar el absurdo que implica introducir saltos en el movimiento. Siguiendo la breve explicación mencionada dicha nota, Leibniz agrega: "Pone enim illi corpusculo rationem ac sensum dari, eam profecto inconcinnitatem deprehenderet in saltu suo qui nobis exiguus, at ipsi satis magnus est, quam nos in nostro".

${ }^{39}$ Pacidius Philalethi, A VI 3, 560. OFC, 8, 145. Nuevamente, recuérdese el contexto en el que Leibniz examina este problema, mencionado en la nota 29 y en la 38. Coincidimos con Breger, 2016: 15, quien señala que la relación de simetría implica para Leibniz que cosas diferentes deben entenderse mediante los mismos principios básicos: "Leibniz ve la belleza y perfección del universo en esta interacción de la abundancia de cosas y la identidad de las estructuras". La traducción es nuestra.
} 
la razón por la que nosotros sostuvimos que este salto concierne no a nosotros sino a ciertos cuerpos muy menores, por la misma razón estos cuerpos muy menores, si los imagináramos razonando acerca de estas cosas, relegarían [esta] misma falta de simetría a otras cosas aún menores. Esto también está de acuerdo con la razón, pues cuando existe la potestad de elegir, ciertamente el sabio elegirá más bien una falta de simetría menor; Y así, estos animalitos dirán con razón que este salto debiera ocurrir más en cosas menores que entre ellos. Pero ya que otras cosas menores cuanto se quiera pudieran [argumentar] con el mismo argumento, es evidente que estos saltos siempre [podrían] llevarse hacia cosas cada vez menores y no podrían colocarse en ningún lugar en la naturaleza de las cosas. ${ }^{40}$

Ahora bien, la justificación última de Leibniz, que concluye el asunto definitivamente, se apoya en uno de sus más importantes principios, a saber, que "el sapientísimo autor de todas las cosas no hace nada sin razón". ${ }^{41}$ En efecto, Leibniz señala que no habría ninguna razón para que se dé una incongruencia (es decir, en el ejemplo que está examinando, para que se den los saltos) en un orden de grandeza o pequeñez cualquiera y no en otro. Incluso, es relevante que Leibniz mencione, a propósito de los saltos en la explicación del movimiento, que estos 'milagros ordinarios' solamente serían posibles si se admitieran átomos, es decir, "cuerpos tan firmes que no permiten ninguna subdivisión o flexión". ${ }^{42}$ Ahora bien, de acuerdo con lo que hemos explicado antes, para Leibniz un cuerpo que no pueda subdividirse implicaría también una incongruencia, precisamente porque la división de la materia no tiene un fin. En consecuencia, si se afirmaran saltos en el movimiento de los átomos, se estaría justificando un 'milagro ordinario', a saber, el de los saltos, en otro 'milagro ordinario', esto es, el de la suma

\footnotetext{
${ }^{40}$ Pacidius Philalethi, A VI 3, 560-561. "Recte facis Charine, quod huic sententiae resistis, quae pugnat cum pulchritudine rerum, et sapientia Dei. Alioqui perinde esset ac si Deus incongruitates quasdam, quas in natura scilicet evitare non poterat, tegere tantum nobis ac dissimulare voluisset, transferendo scilicet illas in minutiora rerum, ubi animadverti non possint. Sed vides ipse, ut fortius adhuc stringam, ubicunque ponamus hunc saltum fieri, ibi eodem modo eum potuisse declinari; nam eo jure quo nos contendimus, saltum illum contingere non apud nos, sed apud minutiora quaedam corpora, eodem jure eadem minutiora corpora, si ratiocinari de his rebus fingerentur, eandem inconcinnitatem ad minora adhuc alia relegarent. Quod rationi etiam consentaneum est, nam cum eligendi potestas est, utique sapiens minorem potius inconcinnitatem eliget; itaque jure dicent animalcula illa, in minoribus potius hunc saltum debuisse evenire quam apud se. Sed cum minora alia quaecunque eodem argumento uti possint, patet saltus istos semper ad minora ac minora propelli et nusquam consistere posse in natura rerum". OFC, 8, 145-146.

${ }^{41}$ Pacidius Philalethi, A VI 3, 561. "Denique, quod rem omnem conficit, nihil sine ratione facit sapientissimus rerum autor". OFC, 8, 146.

${ }^{42}$ Pacidius Philalethi, A VI 3, 561. "nulla autem ratio est, cur huic potius quam illi corpusculorum gradui saltus illi miraculosi ascribantur, nisi atomos scilicet admittainus, corpora ita firma ut nullam subdivisionem nullumve flexum patiantur (...)”.OFC, 8, 146.
} 
solidez de los átomos. No obstante, para Leibniz los átomos no solamente han de ser tan negados como los saltos, sino que también deben serlo por la misma razón, esto es, porque implicarían una falta de simetría: "[p] ero yo no afirmo que tales cuerpos [es decir, los átomos] existen en la naturaleza de las cosas, ciertamente con el mismo argumento con el que excluyo estos saltos". 43 En síntesis, Leibniz reduce la explicación de la proporcionalidad entre lo grande y lo pequeño, o lo que es lo mismo, de la propiedad según la cual la grandeza o pequeñez no vienen al caso, al hecho de que conllevaría contradecir que Dios tiene una razón para todo lo que hace.

De este modo, queda clara la conexión entre los exámenes metafísicos y matemáticos de Leibniz, a saber, pues la infinitud actual de partes del continuo se entiende a la luz de la noción de un infinito sin término. Esto no significa que la razón que haya tenido Leibniz para sostener la tesis del infinito actual sea matemática. Como vimos, en última instancia, el razonamiento de Leibniz se apoya en el principio de razón suficiente. En cualquier caso, vemos que, desde un punto de vista epistemológico, el infinito se ubica, de alguna manera, entre la matemática y la metafísica.

\section{Cantidades ficticias infinitas e infinitamente pequeñas}

En sus numerosos trabajos sobre el problema del continuo, Richard Arthur suele mencionar que, en el período parisino, Leibniz pasó de concebir los infinitesimales como entidades actuales (tal como vimos en el cuarto capítulo) a tomarlos como 'fícciones'. Esto puede encontrarse, por ejemplo, en Arthur, 2000, 2008, 2009, 2013, 2015a, así como también en la introducción de Leibniz, 2001, especialmente xxxiii-xxxiv y lvi-lvii. Las distintas perspectivas adoptadas en los trabajos de Arthur muestran la complejidad del cambio de concepción operado por Leibniz. En efecto, en algunos de sus trabajos, Arthur aborda este cambio de concepción a partir de cuestiones físicas, en otros examina también la labor matemática de Leibniz y finalmente en algunos lo considera desde un examen general del problema del continuo. Como veremos, Leibniz ciertamente se refirió a las cantidades infinitamente pequeñas como ficciones. Pero, ¿qué significó esto para él?

\footnotetext{
${ }^{43}$ Pacidius Philalethi, A VI 3, 561. "Sed talia ego corpora in natura rerum esse non puto; eo ipso plane argumento, quo hos saltus excludo". OFC, 8, 146.
} 
Nuestro objetivo aquí es reconstruir el contexto que ha llevado a Leibniz a referirse a las cantidades infinitamente pequeñas como ficciones, examinar las razones que tuvo para ello y considerar la repercusión que generó en el examen del continuo.

En los capítulos anteriores, especialmente en el cuarto y el sexto, hemos examinado la importancia de los primeros exámenes aritméticos de Leibniz que tuvieron lugar apenas arribó a la capital francesa a finales de 1672. Asimismo, anteriormente en este capítulo hemos visto cómo Leibniz introdujo aclaraciones relativas al concepto de infinito en un importante trabajo suyo de geometría de 1675/1676, esto es, $D Q A$. En este sentido, entonces, el paso de Leibniz por la capital francesa entre 1672 y 1676 potenció su labor como matemático. No obstante, como también mencionamos anteriormente, esto no significó un abandono de los tratamientos metafísicos o filosóficos en general. La cuestión sobre el carácter ficticio de los infinitesimales es una muestra de ello, pues es una cuestión trabajada tanto en algunos escritos eminentemente matemáticos, como el mencionado tratado $D Q A$ o también Numeri infiniti del productivo mes de abril de 1676, como en otros esencialmente filosóficos, como en el importantísimo diálogo que ha escrito entre finales de octubre y principios de noviembre de 1676, Pacidius Philalethi. Ahora bien, a pesar de las consecuencias metafísicas que conlleva, el problema que parecería llevar a Leibniz a referirse finalmente a cantidades ficticias infinitamente pequeñas es eminentemente geométrico, a saber, el de la cuadratura del círculo y de las secciones cónicas en general. Nos hemos referido anteriormente a este problema en dos momentos de nuestro trabajo. En primer lugar, en el segundo capítulo, cuando examinamos sintéticamente algunos de los elementos del método de Cavalieri para cuadrar figuras e indicamos que su finalidad fue presentar un procedimiento para hallar la razón que hay entre dos figuras dadas. En este sentido, su planteo es diferente del de la mayoría de los matemáticos modernos, que se habrían propuesto determinar la razón entre las áreas de las dos figuras expresadas numéricamente. ${ }^{44}$ En segundo lugar, en la primera sección del cuarto capítulo, cuando mencionamos a la pasada que los primeros exámenes históricos sobre el infinito se remontan al método de exhaución de Eudoxo y a su posterior perfeccionamiento por parte de Arquímedes. Como veremos, Leibniz tuvo muy en cuenta el método de exhaución de los antiguos griegos. De esta manera, antes de presentar el tratamiento de Leibniz del problema

\footnotetext{
${ }^{44}$ Andersen, 1986: 18.
} 
de la cuadratura, haremos una síntesis de los lineamientos centrales del método de exhaución.

\subsection{La cuadratura del círculo y el método de exhaución}

El problema al que respondería el método de exhaución podría ser presentado, en términos actuales, mediante la pregunta acerca de cuál es el área de un círculo determinado. $^{45}$ Por cuestiones históricas, la manera como los griegos se plantearon esta pregunta y el modo en que abordaron una respuesta a ella presenta muchas diferencias en relación con la manera de hacerlo hoy en día. Por lo pronto, hoy diríamos que el área de un círculo resulta de multiplicar $\pi \cdot$ radio $^{2}$. No obstante, los griegos no tenían una expresión general para $\pi$. Incluso, Leibniz ha sido quien demostró que, si el cuadrado del diámetro de un círculo es 1 , entonces dicho círculo es igual a $\frac{1}{1}-\frac{1}{3}+\frac{1}{5}-\frac{1}{7}+\frac{1}{9}-\frac{1}{11}+$ etc. ${ }^{46}$ Pero por otra parte, los griegos no pensaron cuestiones como éstas en términos algebraicos, es decir, no dieron definiciones numéricas de cantidades como área, volumen, etc., como sucede hoy en día. De esta manera, la pregunta por el área de un círculo no hubiese tenido sentido para un griego, aunque sí lo hubiese tenido, en el marco de la teoría de las proporciones, la pregunta por cuál es la razón entre un círculo y otra figura, por ejemplo, una figura cuadrangular. Como vimos en el segundo capítulo, en el trasfondo del planteo de Cavalieri se encuentran algunos de estos presupuestos de la matemática griega. En el prefacio al tratado $D Q A$, Leibniz sintetizó los lineamientos centrales de lo que constituye el problema de la cuadratura, así como también algunos hitos de la historia del tratamiento de este problema:

Cuando Pitágoras y sus discípulos expusieron los elementos de la Geometría rectilínea, después redactados en un cuerpo por Euclides, ya se demostró que, para cualquier figura rectilínea plana dada, puede exhibirse un cuadrado igual; éste [es decir, el cuadrado] es la más simple de todas las figuras rectilíneas y, en cierto modo, es la medida de las restantes [figuras]. Empezó entonces a pensarse si no podría exhibirse una figura rectilínea igual al círculo y, por tanto,

\footnotetext{
${ }^{45}$ En esta sintética presentación del método de exhaución seguimos en general a Boyer, 1949, capítulo 2.

${ }^{46}$ GM V, 96. Como señala Beeley, 2009, Leibniz llama a la cuadratura de las secciones cónicas 'aritmética' dado que la magnitud del círculo, la elipse, la hipérbola y la parábola son descubiertas por medio de series infinitas que hoy en día llamaríamos 'convergentes'. De acuerdo con Knobloch, 2002: 67, lo que constituye la aritmética de infinitos es la utilización de una docena de reglas con las que Leibniz opera.
} 
también un cuadrado igual [al círculo]. Y esto es lo que vulgarmente se llama la cuadratura del círculo, pues si pudiera describirse cierto Triángulo u otro Polígono cualquiera, igual al círculo, en todo caso sería en potencia igual al cuadrado. Y puesto que Arquímedes señaló que un Triángulo rectángulo cuya altura sea de un radio y la base como la circunferencia extendida en [línea] recta, sería el doble del círculo, si alguien encontrase alguna recta igual a la circunferencia del círculo, daría con nuestra cuadratura. ${ }^{47}$

Cuando Eudoxo abordó este problema, ofreció un procedimiento basado en un principio que puede hallarse en la primera proposición del décimo libro de los Elementos de Euclides y que posteriormente fue conocido como el axioma de Arquímedes, a saber: supuestas dos magnitudes que no sean iguales, si a la mayor de ellas se le quitara una parte que sea mayor que su mitad, nuevamente a la parte restante se le quitara una parte que sea mayor que su mitad, y se replicara sucesivamente el mismo procedimiento, entonces se obtendría finalmente una magnitud menor que la magnitud más pequeña de las dos consideradas inicialmente. ${ }^{48}$ A modo de ejemplo, tómense dos líneas desiguales $A B$ y $Z$, en donde la primera de ellas es más grande que la segunda. Luego, quítesele a $A B$ una sección que sea mayor que su mitad, esto es, mayor que $A C$, como es la sección $D B$. Si este proceso se repite continuamente, se obtendría como resultado una magnitud que sería menor que $Z$.

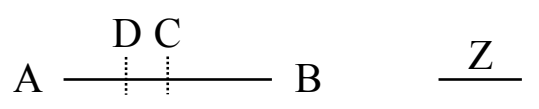

Dicho en sentido contrario, dadas dos cantidades geométricas $x$ e $y$ tales que $x<\mathrm{y}$, es posible hallar un número natural $n$ de modo que $n x>y .{ }^{49} \mathrm{El}$ hecho de que se proponga que el procedimiento se repita continua o sucesivamente es lo que llevó a que muchos siglos más tarde se hayan referido al método de 'exhaución'. No obstante, para los griegos este procedimiento de recorte no consistía en un número infinito de pasos. Las dos primeras

\footnotetext{
${ }^{47}$ GM V, 93. "Cum Pythagoras eiusque discipuli Geometriae rectilinea Elementa absolvissent, quae postea ab Euclide in unum corpus redacta sunt, iamque id effectum esset, ut cuilibet figurae rectilineae planae datae exhiberi posset, quadratum aequale, quod scilicet omnium figurarum rectilinearum simplicissimum et quodammodo caeterorum mensura est; cogitari coepit an non posset circulo exhiberi aequalis figura rectilinea, adeoque et aequale quadratum. Et hoc est illud, quod Circuli quadratura vulgo vocatur; nam si Triangulo quoddam aut aliud Polygonum quodcunque Circulo aequale describi posset, utique et quadratum ei aequale esset in potestate. Et quoniam Archimedes ostendit, Triangulum rectangulum, cuius altitudo sit radius, basis autem sit circumferentia in rectam extensa, fore circuli duplum, ideo si quis inveniet rectam quandam circumferentiae circuli aequalem, daret nobis quadraturam". Seguimos la traducción de Manuel Luna Alcoba -aunque introducimos modificaciones- que se encuentra en su compilación En el laberinto. Escritos sobre el continuo, p. 35.

${ }^{48}$ Euclides, Elementa, X, 1.

${ }^{49}$ Levey, 2008: 113; Arthur, 2013: 559-561.
} 
proposiciones del doceavo libro de los Elementos de Euclides nos permiten ilustrar la importancia de este principio $\mathrm{y}$, en consecuencia, del método de exhaución. La primera proposición de dicho libro establece que "[1]os polígonos semejantes inscriptos en círculos son uno a otro como los cuadrados de los diámetros" y la segunda que "[1]os círculos son uno a otro como los cuadrados de sus diámetros". ${ }^{50}$ En consecuencia, la razón que hay entre dos círculos es la misma que entre los dos polígonos inscriptos. La justificación de estas proposiciones excede la intención de esta breve presentación. Lo relevante, entonces, es que para responder a la pregunta por la razón que hay entre dos círculos, Eudoxo propuso un procedimiento que apela al trazado de polígonos inscriptos que pueden volverse sucesivamente más y más complejos. Dicho procedimiento ha sido posteriormente perfeccionado por Arquímedes, quien introdujo además polígonos circunscriptos. En este sentido, en el procedimiento de Arquímedes se procede construyendo secuencias de aproximaciones (polígonos inscriptos y circunscriptos) que convergen de un modo sistemático en el resultado buscado. ${ }^{51}$ En consecuencia, el método de Arquímedes apunta a mostrar por una doble reducción al absurdo que un círculo no puede ser menor que el polígono circunscripto ni mayor que el polígono inscripto. ${ }^{52}$

Ahora bien, algunos pensadores del siglo XVII consideraron que el método de exhaución tiene el defecto de que en muchos casos sirve solamente para confirmar resultados alcanzados por medio de otros métodos. En efecto, Arquímedes utilizaba, por un lado, como procedimiento heurístico, un método de los indivisibles, ${ }^{53} \mathrm{y}$, por otro, como procedimiento de demostración, el método que apela a una doble reducción al absurdo. En consecuencia, en el siglo XVII el método de exhación fue considerado como poco adecuado para cumplir con la tarea de descubrir nuevos resultados (además de haber sido concebido como engorroso e incapaz de proveer de generalidades). ${ }^{54}$ Como vimos en el primer capítulo, los pensadores del siglo XVII demandaron un método que no solamente permita demostrar sino también descubrir. No obstante, hacia finales de 1674, Leibniz comenzó a pensar que el método que emplea figuras inscriptas y circunscriptas puede servir no solamente para la demostración sino también para el descubrimiento, puesto que, como

\footnotetext{
${ }^{50}$ Traducciones de Euclides, 1996: 267-268.

51 Jesseph, 2015: 190-191.

${ }^{52}$ Arthur, 2013: 559-560.

${ }^{53}$ Katz y Sherry, 2013: 574-575. Sobre este procedimiento de Arquímedes, véase Julien, 2015d: 451-457.

54 Jesseph, 2015: 191-192.
} 
permite demostrar las cosas que se descubren por medio de otros métodos, también las abarca (y en este sentido, lo concibió como un 'método general'). ${ }^{55}$ Cuando Leibniz abordó el problema de la cuadratura en $D Q A$, confesó dos cosas. En primer lugar, reconoció que no conocía un método con el que demostrar perfectamente la cuadratura sin apelar a una deducción al absurdo, lo que ya proponía Arquímedes. ${ }^{56} \mathrm{~A}$ pesar de ello, mostró preferencias por un tipo de deducción al absurdo por ser más simple y semejante a una demostración directa, a saber, la que no utiliza figuras inscriptas y circunscriptas sino solamente 'algo intermedio' para mostrar que entre dos cantidades no hay ninguna diferencia, y por lo tanto que son iguales. ${ }^{57}$ Ahora bien, en segundo lugar, esto no significa para Leibniz que no sea posible demostrar de un modo perfecto la cuadratura. Sin embargo, confiesa que esto no puede lograrse por la naturaleza misma de las cosas. Dicho de otra manera, es posible demostrarla utilizando en el procedimiento algo que no pertenece a la naturaleza misma de las cosas. En este sentido, Leibniz reconoce que una demostración directa, sin apelar a una reducción al absurdo, no es posible "sin asumir cantidades ficticias, a saber, infinitas o infinitamente pequeñas". ${ }^{58}$ Dicho de un modo afirmativo: es posible hacer esto si asumimos dichas cantidades ficticias, que, como justificaremos en breve, no pertenecen a la naturaleza misma de las figuras curvas. Ahora bien, antes de abordar el problema de las cantidades ficticias, es necesario considerar algunas cuestiones sobre el método infinitesimal que Leibniz presentó en $D Q A$.

\subsection{Los fundamentos del método infinitesimal de Leibniz}

Por lo que Leibniz señala desde el comienzo del tratado, es claro que el sexto teorema tiene un papel muy importante. ${ }^{59}$ De acuerdo con el autor, en esta 'espinosísima'

\footnotetext{
${ }^{55}$ De inscriptorum et circumscriptorum usus, A VII 5, 113.

${ }^{56} D Q A$, VII, esc., 68.

${ }^{57} D Q A$, VII, esc., 68-71. Arthur, 2008: 8. En la próxima subsección aclararemos cómo debe entenderse lo 'intermedio'.

${ }^{58} D Q A$, VII, esc., 68. "imo rationes habeo, cur verear ut id fieri possit per naturam rerum sine quantitatibus fictitiis, infinitis scilicet vel infinite parvis assumtis". En este sentido, como señala Beeley, 2015: 43-44 y como veremos más adelante, Leibniz concluye que el error que se obtiene si se emplean cantidades infinitamente pequeñas es menor que cualquiera asignable $\mathrm{y}$, en consecuencia, es nulo.

${ }^{59}$ Como explica Rabouin, 2015: 350-353 y 358-359, las cinco proposiciones anteriores son lemas necesarios para la prueba presentada en esta proposición, así como el séptimo teorema, en el que se muestra la cuadratura de una curva cualquiera, es una consecuencia de ella.
} 
proposición se muestra con dificultad algo que muchos suelen asumir, a saber, que algunos polígonos y espacios escalonados pueden hacerse progresivamente más complejos, de modo tal que la diferencia entre ellos mismos o respecto de líneas curvas llegue a ser una cantidad 'menor que cualquiera dada'. Ahora bien, aunque confiesa que inicialmente puede omitirse la lectura de esta proposición, "sin embargo, sirve para establecer firmísimamente los fundamentos de todo el Método de los indivisibles". ${ }^{60}$ La razón de esta afirmación de Leibniz es que en esta proposición se justifica que dos figuras, de las cuales una se transformaría en la otra si se inscribiera al infinito, se aproximan a una diferencia menor que cualquiera asignada con un número finito de inscripciones. ${ }^{61}$ No es nuestra intención reconstruir por completo esta compleja proposición. A continuación haremos una breve presentación de la sexta proposición y luego nos detendremos en su demostración, para lo cual seguiremos las reconstrucciones realizadas por Knobloch y Arthur. ${ }^{62}$ Como veremos, tras la demostración de la sexta proposición, cobra una enorme importancia la introducción de cantidades ficticias infinitas e infinitamente pequeñas.

La siguiente figura introducida por Leibniz de una curva cuadratriz, que es muy compleja, acompaña a la sexta proposición: ${ }^{63}$

${ }^{60} D Q A$, Index Notabiliorum, 34. "Praeteriri initio eius lectio potest, servit tamen ad fundamenta totius Methodi indivisibilium firmissime iacienda". No significa esto que Leibniz apruebe el método de los indivisibles tal como lo presentó Cavalieri. Como vimos en la segunda sección de este capítulo, para Leibniz el método de los indivisibles es falaz a no ser que se utilicen líneas infinitamente pequeñas en lugar de indivisibles. En este sentido, la referencia al 'método de los indivisibles' es puramente nominal, en el sentido de que Leibniz se está refiriendo a su versión de dicho procedimiento. Esto queda más claro si se tiene en cuenta que el procedimiento de Cavalieri evita deliberadamente utilizar aproximaciones arbitrariamente pequeñas. Jullien, $2015 \mathrm{~b}: 9$.

${ }^{61} D Q A$, VI, 46. Véase Knobloch, 2002: 61-62, la nota 3 de M. Parmentier DQA, VI, 47 y Arthur, 2008: 24.

${ }^{62}$ Knobloch, 2002: 61-67. Arthur, 2008: 20-24. Otra reconstrucción puede hallarse en Rabouin, 2015: 353358.

${ }^{63}$ Esta figura se encuentra en $D Q A$, VI, 48. En nuestro caso, la tomamos de Arthur, 2008: 21, por ser más nítida. La indicación de que se trata de una curva cuadratriz la tomamos de Rabouin, 2015: 354. 


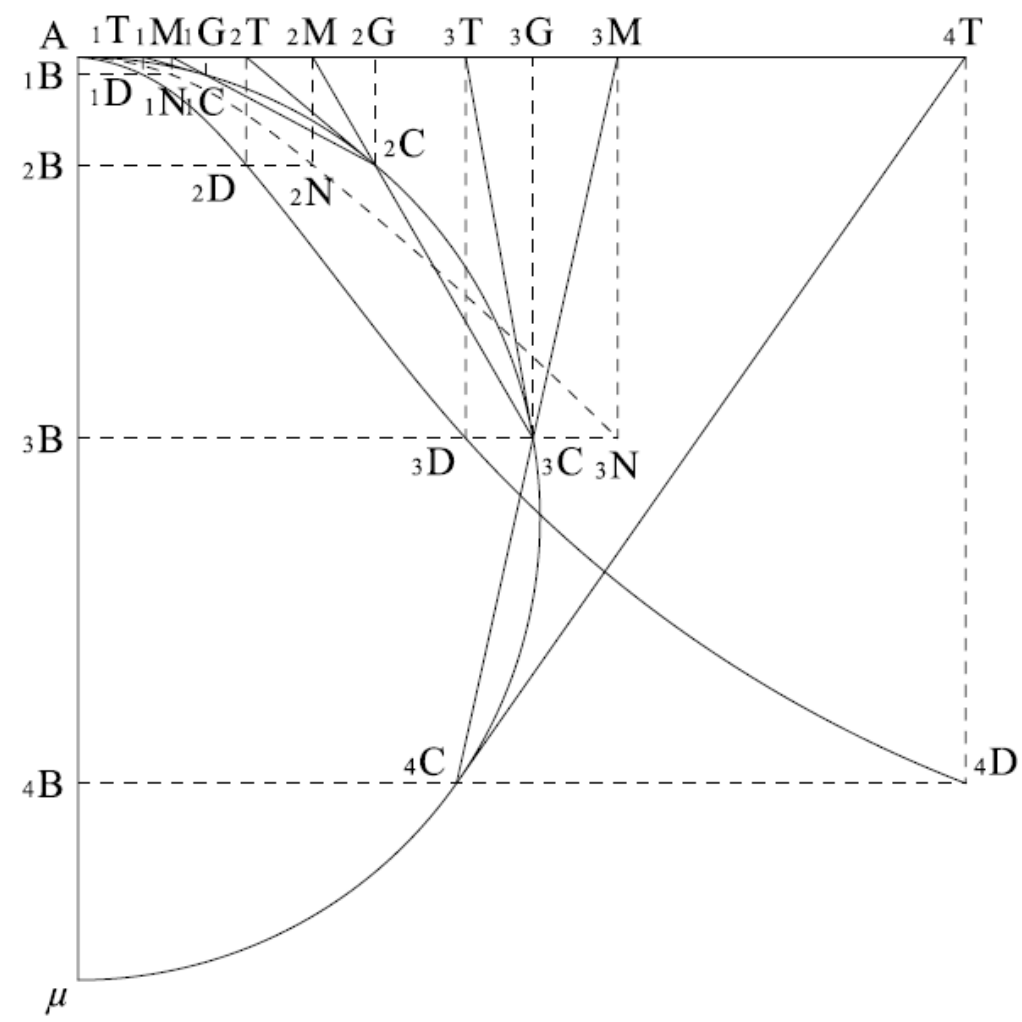

El eje vertical es el eje $x$ y el horizontal es el eje $y$. A través de los puntos $\mathrm{C}\left({ }_{1} \mathrm{C},{ }_{2} \mathrm{C}\right.$, ${ }_{3} \mathrm{C},{ }_{4} \mathrm{C}$, etc.), Leibniz traza el arco circular C. En siguiente lugar, se construye otra curva a través de los puntos de D. Dichos puntos $\left({ }_{1} \mathrm{D},{ }_{2} \mathrm{D},{ }_{3} \mathrm{D},{ }_{4} \mathrm{D}\right.$, etc.) se obtienen de esta manera: primero, las tangentes en $\mathrm{C}$ cortan al eje $y$ en $\mathrm{T}$ (es decir, la tangente en ${ }_{1} \mathrm{C}$ corta al eje $y$ en ${ }_{1} \mathrm{~T}$, y así sucesivamente); luego, se establecen los puntos de intersección entre las perpendiculares al eje $y$ a través de los puntos $\mathrm{T}$ y las ordenadas que pasan a través de los puntos C de la primera curva (es decir, las que se trazan desde los puntos B en el eje $x$ ). Tales puntos de intersección son los puntos D. Como señala Knobloch, una vez que se construyó la curva D, el arco circular C puede ser omitido. Esto se debe a que la cuadratura corresponde a la curva D. En este sentido, la demostración se centra en el área que está debajo de la curva auxiliar $\mathrm{D}$ delimitada por las ordenadas ${ }_{1} \mathrm{~B}$ y ${ }_{3} \mathrm{~B}$, como puede verse en la siguiente figura (introducida por Knobloch), que es una ampliación del segmento en cuestión: 


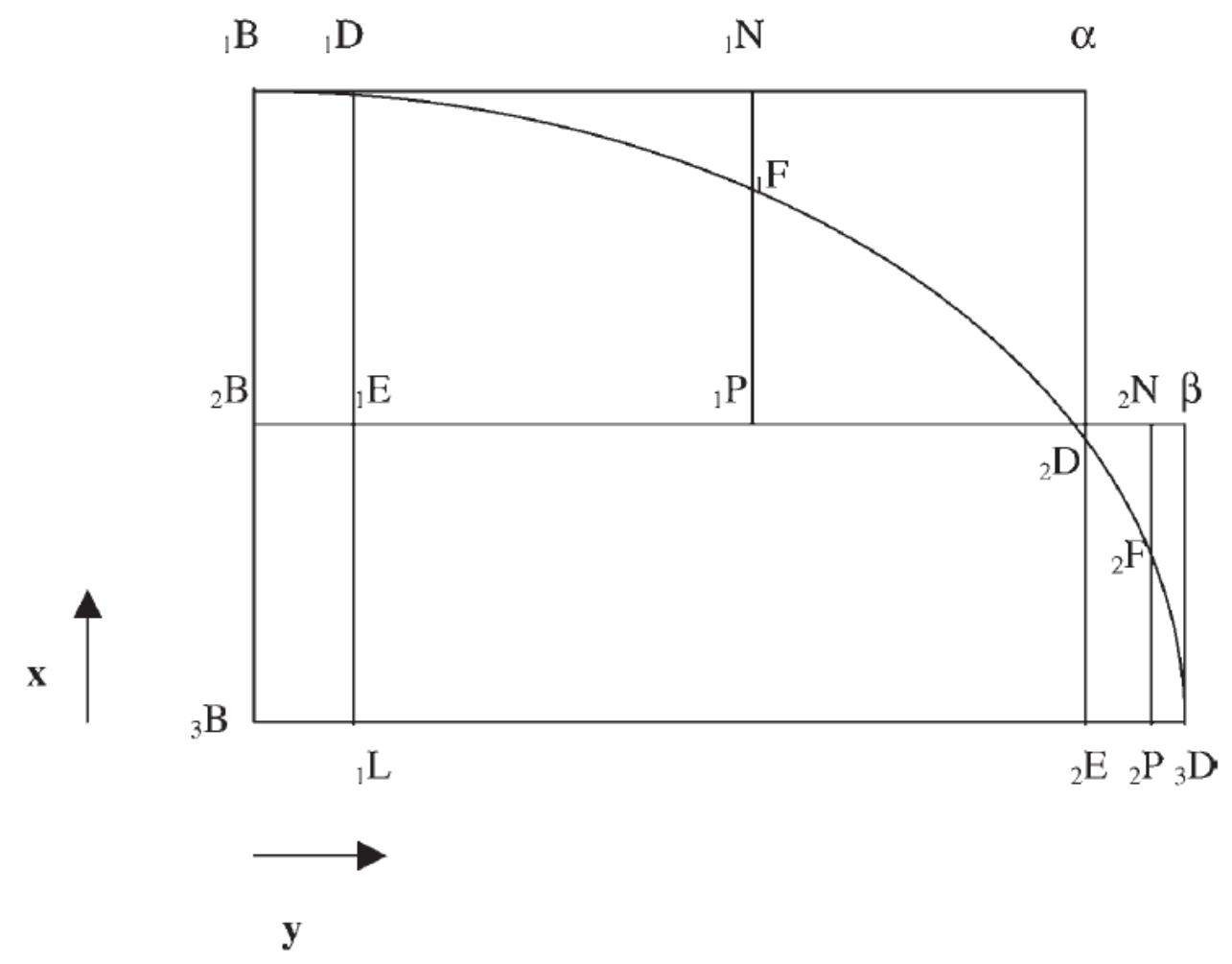

La sexta proposición sostiene que la diferencia entre las áreas de la figura mixtilínea ${ }_{1} \mathrm{~B}_{1} \mathrm{D}_{2} \mathrm{D}_{3} \mathrm{D}_{3} \mathrm{~B}_{1} \mathrm{~B}$ y de la figura escalonada ${ }_{1} \mathrm{~B}_{1} \mathrm{~N}_{1} \mathrm{P}_{2} \mathrm{~N}_{2} \mathrm{P}_{3} \mathrm{~B}_{1} \mathrm{~B}$ puede hacerse más pequeña que cualquier cantidad dada. ${ }^{64}$ Como señaló Knobloch, mientras que el 'método común de los indivisibles' consideró figuras inscriptas y circunscriptas, la figura escalonada no es de ninguno de estos dos tipos, sino más bien algo intermedio (pues, como puede verse, en parte está por debajo de la figura mixtilínea y en parte por encima de ella). En términos modernos, Leibniz demostró la integrabilidad de una gran clase de funciones por medio de sumas riemannianas. ${ }^{65} \mathrm{La}$ demostración de esta proposición consta de ocho pasos:

1. Seccionamos el área ${ }_{1} \mathrm{~B}_{3} \mathrm{~B}$ de la imagen anterior en un número finito de intervalos desiguales entre sí, por ejemplo, ${ }_{1} \mathrm{~B}_{2} \mathrm{~B}$ y ${ }_{2} \mathrm{~B}_{3} \mathrm{~B}$. A partir de esto, se construye, en cada sección, por un lado, un 'rectángulo elemental', cuyo límite por la izquierda es el eje $x$ y por la derecha una vertical a través de $\mathrm{N}$ y, por otro lado, un 'rectángulo complementario', delimitado por dos verticales que atraviesan dos puntos consecutivos de D. De esta manera, para la sección ${ }_{1} \mathrm{~B}_{2} \mathrm{~B}$ el rectángulo elemental es ${ }_{1} \mathrm{~B}_{1} \mathrm{~N}_{1} \mathrm{P}_{2} \mathrm{~B}$ y el rectángulo complementario ${ }_{1} \mathrm{D} \alpha_{2} \mathrm{D}_{1} \mathrm{E}$, mientras que para la sección ${ }_{2} \mathrm{~B}_{3} \mathrm{~B}$ el rectángulo elemental es ${ }_{2} \mathrm{~B}_{2} \mathrm{~N}_{2} \mathrm{P}_{3} \mathrm{~B}$ y el

\footnotetext{
${ }^{64}$ Knobloch, 2002: 63. Véase la bibliografía indicada en la nota 61.

${ }^{65}$ Knobloch, 2002: 63.
} 
rectángulo complementario ${ }_{2} \mathrm{D} \beta_{3} \mathrm{D}_{2} \mathrm{E}$. Como puede observarse, para cada caso los rectángulos se solapan.

2. Leibniz estima o computa el valor absoluto de la diferencia entre el área de un rectángulo elemental, por ejemplo ${ }_{1} \mathrm{~B}_{1} \mathrm{~N}_{1} \mathrm{P}_{2} \mathrm{~B}$, y una figura mixtilínea que corresponda al mismo intervalo que el rectángulo elemental, por ejemplo, ${ }_{1} \mathrm{~B}_{1} \mathrm{D}_{2} \mathrm{D}_{2} \mathrm{~B}$, y establece que dicha diferencia es menor que el rectángulo complementario ${ }_{1} \mathrm{D}_{2} \mathrm{D}_{1} \mathrm{E}$ (es decir, ${ }_{1} \mathrm{~B}_{1} \mathrm{~N}_{1} \mathrm{P}_{2} \mathrm{~B}-$ $\left.{ }_{1} \mathrm{~B}_{1} \mathrm{D}_{2} \mathrm{D}_{2} \mathrm{~B}<{ }_{1} \mathrm{D} \alpha_{2} \mathrm{D}_{1} \mathrm{E}\right)$.

3. Se demuestra el paso anterior substrayendo de la figura mixtilínea ${ }_{1} B_{1} D_{2} D_{2} B$ y del rectángulo elemental ${ }_{1} \mathrm{~B}_{1} \mathrm{~N}_{1} \mathrm{P}_{2} \mathrm{~B}$ la parte que tienen en común, es decir, ${ }_{1} \mathrm{~B}_{1} \mathrm{D}_{1} \mathrm{~F}_{1} \mathrm{P}_{2} \mathrm{~B}$. Como resultado, restan dos áreas de tres líneas, ${ }_{1} \mathrm{D}_{1} \mathrm{~N}_{1} \mathrm{~F}$ y ${ }_{1} \mathrm{~F}_{2} \mathrm{D}_{1} \mathrm{P}$. Estas áreas de tres líneas, que no se solapan, están dentro del rectángulo complementario. Por lo tanto, la suma de estas dos áreas de tres líneas es menor que el rectángulo complementario. En consecuencia, la diferencia entre la figura mixtilínea y el rectángulo elemental correspondiente también es menor que el rectángulo complementario.

4. Se generaliza la demostración anterior, de modo que vale para todos los rectángulos y espacios mixtilíneos. En consecuencia, la diferencia entre la suma de las áreas de todas las figuras mixtilíneas (M) y la suma de las áreas de todos los rectángulos elementales (E) es más pequeña que la suma de las áreas de todos los rectángulos complementarios (C). Es decir: $\mathrm{M}-\mathrm{E}<\mathrm{C}$.

5. Se determina la manera en que se calcula la suma de las áreas de todos los rectángulos complementarios (es decir, C). Dicha suma es más pequeña que la suma de las bases de los rectángulos complementarios multiplicada por la altura máxima. Naturalmente, si la altura fuera siempre la misma, es decir, una altura común (lo que no sucede en este caso, por el paso 1), la suma $\mathrm{C}$ sería igual a la base por la altura. La suma de las bases es la diferencia entre la ordenada más grande y la más pequeña, es decir, entre ${ }_{1} \mathrm{~B}_{1} \mathrm{D}$ y ${ }_{3} \mathrm{~B}_{3} \mathrm{D}$. En consecuencia, es ${ }_{1} \mathrm{~L}_{3} \mathrm{D}$. Si denomináramos $h_{m}$ a la altura máxima, entonces tendríamos que $\mathrm{C}<{ }_{1} \mathrm{~L}_{3} \mathrm{D} \cdot h_{m}$. (Del mismo modo, si $h_{m}$ fuera una altura común, entonces $\mathrm{C}={ }_{1} \mathrm{~L}_{3} \mathrm{D} \cdot h_{m}$ ).

6. De los pasos 4 y 5 se sigue que $\mathrm{M}-\mathrm{E}<{ }_{1} \mathrm{~L}_{3} \mathrm{D} \cdot h_{m}$.

7. Se reduce la cantidad ${ }_{1} \mathrm{~L}_{3} \mathrm{D} \cdot h_{m}$. En virtud de que la curva $\mathrm{D}$ es continua (es decir, que pueden escogerse en ella dos puntos próximos cuanto se quiera), podría concebirse una 
altura máxima más pequeña. Esto podría hacerse incluso al infinito, es decir, de modo tal que se pueda tomar como menor que una cantidad dada.

Por lo tanto, supuesto que la recta $\psi_{4} \mathrm{D}$ [es decir, la altura máxima] pueda suponerse menor que una línea asignada (...), se sigue que también el rectángulo [complementario] $\psi_{4} \mathrm{D}_{1} \mathrm{~L}$ [es decir, en nuestro caso, ${ }_{1} \mathrm{D} \alpha_{2} \mathrm{D}_{1} \mathrm{E}$ ], que tiene una altura que podría suponerse menor que una recta dada, también puede hacerse menor que cualquier superficie dada. ${ }^{66}$

8. A partir del paso 7, se reduce la diferencia $\mathrm{M}-\mathrm{E}$ :

Supuestas ahora estas cosas, la demostración se concluye así: la diferencia entre el total Cuadrilíneo [es decir, M] y el espacio escalonado [es decir, E] es menor que el rectángulo $\psi_{4} \mathrm{D}_{1} \mathrm{~L}$ [es decir, $\mathrm{C}$ ], por el artículo 6 . Y pueden suponerse puntos en la curva con tan exiguo intervalo [entre ellos] y en tan gran número, de modo que el rectángulo $\psi_{4} \mathrm{D}_{1} \mathrm{~L}$ sea menor que un espacio dado, por el artículo 7. Por lo tanto, con el mismo trabajo también la Diferencia entre este Cuadrilíneo [esto es, M] (sobre el que también se habla en la proposición) y el espacio escalonado [esto es, E] puede hacerse menor que una cantidad dada. Q. E. D. ${ }^{67}$

De acuerdo con Arthur, en el octavo paso del procedimiento, Leibniz arriba a la conclusión de que la diferencia entre $\mathrm{M}$ y E es menor que cualquiera asignable $\mathrm{y}$, por lo tanto, es nula. ${ }^{68}$ Según este exégeta, Leibniz ya estaría recurriendo a infinitesimales en la sexta proposición. Por eso, Arthur sostiene que " $[\mathrm{u}] \mathrm{n}$ infinitesimal es, por lo tanto, una abreviatura de una cantidad que puede ser tomada tan pequeña como se quiera". ${ }^{9}$ David Rabouin entiende los infinitesimales de Leibniz de la misma manera que Arthur: "[1]a idea principal detrás de la caracterización de Leibniz de una cantidad infinitesimal (...) es transferir la noción de una cantidad fija a una propiedad relacional vinculada con la arbitrariedad del 'tamaño' de la 'diferencia",. ${ }^{70}$ La visión de Samuel Levey coincide con la

\footnotetext{
${ }^{66} D Q A$, VI, dem., 58. "Posito ergo rectam $\psi_{4} \mathrm{D}$ assignata linea minorem sumi posse, (...) sequetur et rectangulum $\psi_{4} \mathrm{D}_{1} \mathrm{~L}$, altitudinem habens quae data recta minor sumi possit, etiam data aliqua superficie reddi posse minus".

${ }^{67} D Q A$, VI, dem., 58. "His iam positis demonstratio ita absolvetur: differentia Quadrilinei totalis et spatii gradiformis minor est rectangulo $\psi_{4} \mathrm{D}_{1} \mathrm{~L}$, per artic. 6 . Et puncta in curva tam exiguo intervallo tantoque numero assumi possunt, ut rectangulum $\psi_{4} \mathrm{D}_{1} \mathrm{~L}$ sit dato spatio minus per artic. 7. Ergo eadem opera etiam Differentia huius Quadrilinei, (de quo et propositio loquitur) et spatii gradiformis data quantitate minor reddi potest. Q. E. D.".

${ }^{68}$ Arthur, 2008: 24.

${ }^{69}$ Arthur, 2008: 27. "An infinitesimal, therefore, is simply a shorthand for a quantity that may be taken as small as desired". La traducción es nuestra.

${ }^{70}$ Rabouin, 2015: 361. "The main idea behind Leibniz's characterization of infinitesimal quantity (...) is to transfer the notion from a fixed object to a relational property linked to the arbitrariness of the 'size' of the
} 
de estos intérpretes. ${ }^{71}$ Tanto Arthur como Rabouin y Levey entienden que esta interpretación de los infinitesimales leibnizianos de 1675/1676 es acorde con la visión madura de los infinitesimales que dio $\mathrm{H}$. Ishiguro. De acuerdo con Ishiguro, los infinitesimales tienen un significado 'sincategoremático', en el sentido escolástico del término, es decir, en tanto que no designan entidades. "'Leibniz negó -dice Ishiguro- que los infinitesimales fueran cantidades fijas, y afirmó que [con ellos] estaríamos afirmando la existencia de magnitudes finitas variables que podemos elegir tan pequeñas como queramos". ${ }^{73}$ No es nuestra intención discutir la interpretación de Ishiguro a propósito del pensamiento maduro de Leibniz. ${ }^{74}$ No obstante, el hecho de que en 1675/1676 Leibniz se haya referido a 'cantidades ficticias infinitas o infinitamente pequeñas' podría tomarse como un indicio de que estas palabras significan cantidades, es decir, que tienen un claro significado categoremático. En este sentido, en la siguiente sección discutiremos la interpretación de que los infinitesimales de 1675/1676 deben concebirse sincategoremáticamente.

\subsection{La introducción de cantidades ficticias}

Una de las razones que podrían haber tenido Levey, Arthur y Rabouin para considerar a los infinitesimales sincategoremáticamente es que con ellos podría justificarse que el procedimiento de Leibniz consta de un número finito de pasos. Esto es: mientras que el método de Arquímedes demuestra por una doble reducción al absurdo, Leibniz, como dijimos antes, prefiere una reducción directa con la que se muestra en un número finito de pasos que la diferencia entre dos cantidades es nula, aunque dicha reducción no sea posible por medios naturales, es decir, sin apelar a cantidades ficticias infinitas e infinitamente pequeñas. ${ }^{75}$ Es cierto que el método de Leibniz consta de un número finito de pasos; no

\footnotetext{
'difference'”. La traducción es nuestra. Un poco más adelante (362), señala que esta concepción se sigue del axioma de Arquímedes. No obstante, a diferencia de Arthur, Rabouin no considera que Leibniz esté introduciendo ficciones en el sexto teorema. Como veremos, en esto su planteo es acertado.

${ }^{71}$ Levey, 2008: 107-111.

${ }^{72}$ Ishiguro, 1990: 82; Arthur, 2008: 27; Rabouin, 2015: 362.

${ }^{73}$ Ishiguro, 1990: 92.

${ }^{74}$ Al respecto, véase Jesseph, 1998. Como es sabido, en su madurez Leibniz discutió con Jean Bernoulli sobre la naturaleza de los infinitesimales. Al respecto, véase Montesinos Sirera, 2009: 89-97.

${ }^{75}$ Arthur, 2008: 24. Según Arthur, la interpretación de Knlobloch, 2002: 65, está de acuerdo con la visión de que los infinitesimales pueden tomarse sincategoremáticamente.
} 
obstante, este procedimiento tiene presupuestos que exceden lo que se presentó en los ocho pasos de la demostración de la sexta proposición. En última instancia, como vimos antes, en este teorema Leibniz se propuso mostrar que dos figuras se aproximan a una diferencia menor que cualquiera asignada con un número finito de inscripciones, aunque no ha dicho demasiado sobre la instancia en la que la diferencia sería precisamente menor que cualquier diferencia asignable. Incluso, el filósofo de Leipzig señaló que esta aproximación fue generalmente asumida por otros, haciendo referencia a Arquímedes. ${ }^{76}$ En última instancia, esto muestra que Leibniz empleó el axioma de Arquímedes al que nos referimos en la sección 4.1. de este capítulo. Por la aplicación de este axioma, la aproximación no requiere de una justificación en cada caso, sino que basta con mostrar que puede hacerse en un caso general. ${ }^{77}$ Para hacer esto, es esencial la suposición de que la curva D es continua, pues en caso contrario no sería lícito suponer que puede tomarse al infinito una altura máxima más pequeña (lo que, como vimos, se requiere para la suma de C). Para Leibniz este importante supuesto no está presente en el 'método común de los indivisibles', a saber, dado que no habría una altura menor que la altura común entre dos indivisibles. ${ }^{78}$ Lo que hasta aquí hemos dicho sobre la proposición sexta constituye uno de los pasos del método de Leibniz, pero no el único: como un segundo paso, deben introducirse cantidades ficticias infinitas e infinitamente pequeñas. ${ }^{79}$

Hay dos grandes interrogantes que podrían tener lugar en este momento de nuestra presentación. Por un lado, ¿por qué Leibniz considera necesario introducir cantidades ficticias? Por otro lado, ¿cómo se introducen estas cantidades en el método de Leibniz? En lo que sigue buscaremos responder a cada una de estas preguntas. En lo que respecta a la primera de ellas, como dijimos antes, Leibniz considera necesario asumir cantidades ficticias infinitas o infinitamente pequeñas para demostrar directamente la cuadratura. El provecho que conllevaría introducir estas cantidades ficticias puede ser comprendido por los demás hombres “(...) tan pronto como perciban correctamente solo esto: toda figura curvilínea no es otra cosa que un polígono con un número infinito de lados de magnitud

\footnotetext{
${ }^{76} D Q A$, VI, 46. Knobloch, 2002: 61.

${ }^{77}$ Arthur, 2013: 559-561.

${ }^{78} D Q A$, VI, 58-60.

79 Tomamos la idea de una secuencia de 'dos pasos' de un trabajo inédito de Oscar Esquisabel titulado "El tratado De Quadratura Arithmetica Circuli y su importancia para la fundamentación de la matemática infinitaria leibniziana. Nuevas interpretaciones" del año 2015.
} 
infinitamente pequeña". ${ }^{80}$ Con esta indicación, el filósofo de Lepzig introdujo en sus exámenes una relación operativa fundamental para su método, a saber, la de equipolencia entre una curva y un polígono infinitángulo. En efecto, gracias a esta relación se justifica la posibilidad de transformar un círculo o cualquiera otra figura curva en una figura racional equipolente, así como también, en consecuencia, permite que las figuras curvas sean expresadas por medio de sumas infinitas racionales. ${ }^{81}$ De esta manera, la relación de equipolencia entre una curva y un polígono es el presupuesto teórico que subyace a la posibilidad de cuadrar el círculo. Ahora bien, para que las figuras curvas puedan ser puestas en correspondencia con los polígonos, se requiere de la introducción de cantidad ficticias infinitas (un número infinito de lados) e infinitamente pequeñas (lados de magnitud infinitamente pequeña). En este sentido, Leibniz introdujo cantidades ficticias, infinitas e infinitamente pequeñas, para explicar las figuras curvas, como son las secciones cónicas en general. En este sentido, por ejemplo, un círculo, que es concebido como "un Polígono mayor que cualquier asignable, como si éste fuera posible", es un ente ficticio. ${ }^{82}$ En el escrito Numeri infiniti, Leibniz explica en detalle cuál es el significado de esto. Supongamos un círculo y un polígono inscripto cualquiera, por ejemplo:

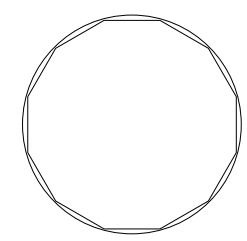

Hay ciertamente una ley por la cual los polígonos crecen, es decir, se hacen más y más complejos, a pesar de que haya propiedades que valen para todos ellos independientemente de cuán complejos sean. En este sentido, los polígonos no tienen por sí mismos un límite posible de lados asignables. De este modo, así como en la imagen adjunta el polígono inscripto es un dodecágono, podría tener un número progresivamente mayor de lados. En consecuencia, la diferencia $a$ que hay entre el dodecágono de la imagen y el

\footnotetext{
${ }^{80} D Q A$, XXIII, esc., 184. "Sed malim id lectores suo potius experimento discere quam meis verbis, sentient autem quantus inveniendi campus pateat, ubi hoc unum recte perceperint, figuam curvilineam omnem nihil aliud quam polygonum laterum numero infinitorum, magnitudine infinite parvorum esse". Esta concepción de los círculos como polígonos infinitángulos tiene una larga historia, que Leibniz podría haber hallado en Galileo (como vimos en el segundo capítulo) o en Kepler, pero que tiene su origen en Nicolás de Cusa. Katz y Sherry, 2013: 578.

${ }^{81}$ Knobloch, 1993: 74 y, especialmente, 2015: 96-100.

${ }^{82}$ Numeri infiniti, A VI 3, 498. "Circulus aliaque id genus, Entia ficta sunt; ut Polygonum, quolibet assignabili maius, quasi hoc esset possibile”.
} 
círculo, es mayor que la diferencia $b$ que habría si el polígono fuera un quiliógono, y así sucesivamente. De acuerdo con lo que hemos explicado en la sección previa de este capítulo, podría decirse que la progresión de los polígonos es interminata. En consecuencia, no hay un polígono en el cual el error sea menor que todos los asignables, aunque podamos decir que de alguna manera los polígonos se acercan de un modo ordenado a una tal cosa. ${ }^{83}$ No obstante esto, supongamos que nuestra mente se imagina un último polígono (mens nostra quiddam ultimum fingit). De acuerdo con lo dicho anteriormente, no sería otra cosa que un círculo. ${ }^{84}$ No debemos olvidar que, como se trata de un producto de la imaginación, no ha de ser concebido como un ente existente sino, como se ha dicho antes, como si éste fuera posible, aunque incluso no sea posible que exista en la naturaleza un tal polígono con un número infinito de lados infinitamente pequeños. Lo que sucede es que nos imaginamos círculos, esto es, polígonos cuyos lados no aparecen distintamente. Ahora bien, de acuerdo con Leibniz, para imaginarse este supuesto último polígono, como si se tratase de un ente que no tiene ningún lado, la mente parecería aplicar la uniformidad a la figura poligonal, de modo que omitiría las desigualdades producidas por la multiplicidad de lados. Sin embargo, para Leibniz no se trata de una aplicación efectiva de un pensamiento de uniformidad en sentido estricto sino que, formalmente, se trata del olvido de la carencia de uniformidad. Dicho olvido se debe a una limitación de las potencias cognitivas humanas:

Pero debe decirse que en la mente existe un pensamiento de la uniformidad, pero no una imagen del círculo perfecto. Pero olvidamos que hemos aplicado después la uniformidad a esta imagen porque [olvidamos] haber sentido desigualdades. ¿Acaso hemos sido alguna vez conscientes de haberlas sentido? Para olvidar, en efecto, es necesario esto [es decir, haber sido conscientes]. Pero este no es [el caso]. Por consiguiente, debe decirse más bien que cuando sentimos un círculo o un polígono, nosotros nunca sentimos uniformidad en él, pero no sentimos tampoco la no-uniformidad [difformitatem], es decir, nosotros no recordamos haber sentido nada no-uniforme en él, puesto que la desigualdad

\footnotetext{
${ }^{83}$ Numeri infiniti, A VI 3, 498. Beeley, 2015: 31-32.

${ }^{84}$ Breger, 1990: 62-63, introduce una sugerencia muy interesante, a saber, que Leibniz ya podría estar sosteniendo que decir [a] que una aproximación en desarrollo (es decir, por ejemplo, una serie o un polígono) y un resultado (esto es, el de la serie o el círculo) son iguales, es lo mismo que decir [b] que entre ellos hay una diferencia infinitesimal, sobre la base de la suposición de que el principio de continuidad ('igualdad' como 'desigualdad infinitesimal') es válido. Del mismo modo, Rabouin, 2015: 360, señala que Leibniz, inspirándose en Arquímedes, introdujo un nuevo concepto de igualdad: dos cantidades son iguales cuando la diferencia entre ellas es nula, y una diferencia es nula cuando puede demostrarse que es más pequeña que cualquier cantidad.
} 
no conmovía los ojos [percellabat oculos] de inmediato. Y por este recuerdo ahora le atribuimos el nombre de uniformidad. ${ }^{85}$

Ahora bien, esta última explicación no reviste importancia en los escritos geométricos de Leibniz. En cualquier caso, para el filósofo de Leipzig "corresponde al Metafísico investigar si la naturaleza de las cosas acepta cantidades de este tipo; al Geómetra le basta demostrar qué se sigue de su suposición". ${ }^{86}$ Así, siguiendo el ejemplo anterior, el polígono inscripto sería aquel ente en el que la diferencia con el círculo sería menor que todas las asignables, aunque sea solamente como si pudiera darse. En este sentido, basta con que pueda darse una expresión para él. ${ }^{87}$

En consecuencia, que los infinitesimales sean ficciones significa para Leibniz dos cosas al mismo tiempo. Por un lado, como acentuaremos en la siguiente subsección, significa que en la realidad no existen ni es posible que existan cantidades ni infinitas ni infinitamente pequeñas. Es importante notar que, en los pasajes citados o referidos anteriormente, cada vez que Leibniz se refiere a cantidades ficticias infinitamente pequeñas, se refiere al mismo tiempo a cantidades ficticias infinitas. En este sentido, componen un binomio. ${ }^{88}$ Por otro lado, a consecuencia de lo anterior, significa que, para operar con ellos, se requiere que el geómetra los introduzca en sus demostraciones. ${ }^{89}$ De esta manera, como hemos visto, se introduce una ficción al pensar en un último polígono, esto es, aquel que tendría el mayor número de lados (es decir, una cantidad infinita de lados), cada uno de los cuales sería el más pequeño de todos (o sea, infinitamente pequeño). Como la progresión de los polígonos no tiene un término, es decir, como no hay un límite posible de lados asignables, un polígono que no admita un número mayor de lados es una ficción. En este

\footnotetext{
${ }^{85}$ Numeri infiniti, A VI 3, 499. "Sed dicendum est in mente esse cogitationem uniformitatis, nullam autem circuli perfecti imaginem, sed a nobis applicari uniformitatem postea ad hanc imaginem, quod nos sensisse inaequalitates, obliviscimur; consciine aliquando fuimus nos sensisse? hoc enim necesse ad oblivionem. Sed hoc non est. Dicendum ergo potius, cum circulum sentimus, vel polygonum, nunquam nos in eo sentire uniformitatem, sed saltem non sentire difformitatem, seu meminisse nos nihil in eo difforme sensisse; quoniam inaequalitas non statim percellebat oculos. Et ob hanc memoriam ipsi iam uniformitatis nomen tribuimus".

${ }^{86} D Q A$, XI, esc., 98. "An autem hujusmodi quantitates ferat natura rerum Metaphysici est disquirere; Geometrae sufficit, quid ex ipsis positis sequatur, demonstrare".

${ }^{87}$ Numeri infiniti, A VI 3, 498.

${ }^{88}$ Arthur, 2013: 558-559.

${ }^{89} \mathrm{Si}$ bien el carácter ficticio de los infinitesimales recibió mucha atención por los intérpretes del pensamiento de Leibniz, el caso del infinito no fue muy explorado. Quizás Arthur, 2015a: 141, 146, haya sido uno de los pocos que lo ha examinado. En efecto, Arthur señala atinadamente que el hecho de que el infinito pueda ser considerado como una ficción significa que puede ser tratado 'como si' fuera una entidad, a condición de que la afirmación en la que esto se dice pueda interpretarse sin suponer una tal cosa.
} 
sentido, dado que el número infinito es contradictorio, como vimos en el capítulo anterior, un polígono con un número infinito de lados no es algo posible. Correlativamente, si el polígono infinitángulo es pensado como aquel respecto del cual no hay otro con un número mayor de lados, entonces no habría tampoco lados más pequeños que los de dicho polígono, y en consecuencia la pequeñez de sus lados es también una ficción. La ficción es, por lo tanto, imaginar un último polígono, fingir un límite respecto de la posibilidad de pensar siempre un polígono con un número de lados mayor que cualquiera dado.

En este momento estamos en condiciones de responder al segundo interrogante mencionado anteriormente, a saber, cómo se introducen estas cantidades ficticias en el procedimiento desarrollado por Leibniz. En primer lugar, notemos que la descripción que Leibniz dio de la posibilidad de que los polígonos se hagan cada vez más complejos coincide con lo que vimos anteriormente sobre la sexta proposición del $D Q A$, aunque parcialmente: si bien no hay un polígono inscripto en el cual el error sea menor que todos los asignables, los polígonos se acercan de un modo ordenado a una tal cosa. Recordemos que en dicha proposición, Leibniz justificó que podemos saber, en un número finito de pasos, que dos figuras se aproximan a una diferencia menor que cualquiera asignada, supuesto que coincidirían si una de ellas se inscribiera al infinito. En ambos casos, Leibniz subraya un acercamiento o una aproximación. Ahora bien, en la explicación de la progresión de los polígonos de Numeri infiniti, Leibniz dice algo más: si nuestra mente se imaginara un último polígono, tendríamos un círculo. Esta indicación excede lo que vimos de la sexta proposición, en la medida en que, en ese caso, Leibniz se refirió solamente a la posibilidad de saberse que dos figuras se aproximan a una diferencia menor que cualquiera asignada, aunque no ha dicho nada sobre la última instancia en la que la diferencia sería nula. La introducción de las cantidades ficticias en el procedimiento de Leibniz tiene lugar sobre la base de esta imaginación. Aquí se entiende la indicación de Leibniz mencionada anteriormente de que el provecho de introducir estas cantidades puede ser comprendido cuando se reconoce que “(...) toda figura curvilínea no es otra cosa que un polígono con un número infinito de lados de magnitud infinitamente pequeña". ${ }^{90}$ Como veremos, una vez introducidas las ficciones, es decir, un número infinito (de lados del polígono infinitángulo) y líneas mínimas (es decir, lados de magnitud infinitamente pequeña), es posible determinar,

${ }^{90} D Q A$, XXIII, esc., 184. 
en un número finito de pasos, que hay una instancia en que la diferencia -ahora sí- sería menor que cualquiera dable.

Una muestra de la introducción de cantidades ficticias en el procedimiento de Leibniz se encuentra en la séptima proposición. Para la explicación de esta proposición, téngase en cuenta la siguiente imagen, que es muy similar a la que presentamos anteriormente, aunque con más indicaciones. En la séptima proposición, que es una consecuencia de la anterior, Leibniz muestra la cuadratura de una curva cualquiera. ${ }^{91}$ En concreto, prueba que el espacio cuadrilíneo ${ }_{1} \mathrm{D}_{1} \mathrm{~B}_{3} \mathrm{~B}_{3} \mathrm{D}_{2} \mathrm{D}_{1} \mathrm{D}$ (al que se refiere como ' $\mathrm{Q}$ ') es igual al doble del espacio de tres líneas ${ }_{1} \mathrm{CA}_{3} \mathrm{C}_{2} \mathrm{C}_{1} \mathrm{C}$ ('T'), es decir: $\mathrm{Q}=2 \mathrm{~T}$. No es nuestra intención detenernos en los cinco pasos de la demostración. Para cumplir con nuestro objetivo, nos detendremos en el primero de ellos y resumiremos los siguientes cuatro: ${ }^{92}$

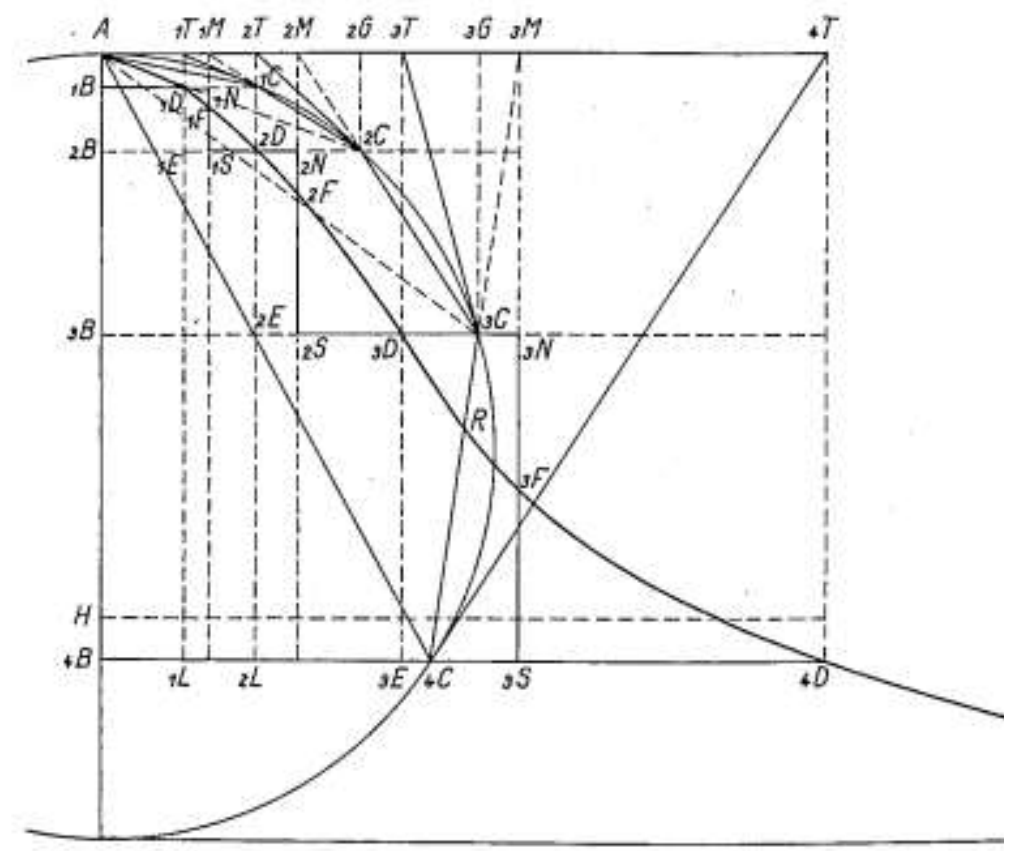

1. Leibniz recurre a una reducción al absurdo, de modo que supone que el espacio cuadrilíneo no es igual al doble del espacio de tres líneas. En consecuencia, habría una diferencia, que llama ' $Z$ ' (es decir, $Q-2 \mathrm{~T}=\mathrm{Z}$ ). Luego, requiere que en la curva ${ }_{1} \mathrm{C}_{2} \mathrm{C}_{3} \mathrm{C}$ se inscriban polígonos finitos en número, todos los que sean necesarios, de modo que "(...) el último de los Polígonos de este tipo sea la figura rectilínea $\mathrm{A}_{1} \mathrm{C}_{2} \mathrm{C}_{3} \mathrm{CA}(\ldots)$ ". ${ }^{93}$ Llamemos 'P' a este último polígono, que es la suma de todos los polígonos inscriptos. Luego, traza

\footnotetext{
${ }^{91}$ Rabouin, 2015: 358-359.

${ }^{92} D Q A$, VII, 64-68.

${ }^{93} D Q A$, VII, 66. “(...) ultimum ex ejusmodi Polygonis sit figura rectilinea $\mathrm{A}_{1} \mathrm{C}_{2} \mathrm{C}_{3} \mathrm{CA}(\ldots)$ ”.
} 
los puntos de intersección entre las perpendiculares al eje $x$ a través de los puntos ${ }_{1} \mathrm{M},{ }_{2} \mathrm{M}$, etc. y las perpendiculares al eje y a través de los puntos B. Dichos puntos de intersección son ${ }_{1} \mathrm{~S},{ }_{2} \mathrm{~S}$, etc. Como veremos, estos puntos servirán para determinar un espacio escalonado ${ }_{1} \mathrm{~B}_{1} \mathrm{~N}_{1} \mathrm{~S}_{2} \mathrm{~N}_{2} \mathrm{~S}_{3} \mathrm{~B}{ }_{1} \mathrm{~B}$, al que se refiere como ' $\mathrm{G}$ '.

Sintéticamente, en los siguientes cuatro artículos, Leibniz muestra que:

2. Supóngase que $\mathrm{T}-\mathrm{P}<\frac{1}{4} \mathrm{Z}$ y que $\mathrm{Q}-\mathrm{G}<\frac{1}{4} \mathrm{Z}$. Para Leibniz no hay inconvenientes en suponer que la diferencia pueda hacerse menor que la cuarta parte de Z: "[e]n efecto, puede producirse hasta que se haga menor que cualquier cantidad dada". ${ }^{94}$

3. $\mathrm{G}=2 \mathrm{P}$, por la primera proposición. ${ }^{95}$

4. Entonces, $\mathrm{Q}-2 \mathrm{P}<\frac{1}{4} \mathrm{Z}$. Del artículo 2 , se sigue que $2 \mathrm{~T}-2 \mathrm{P}<\frac{2}{4} \mathrm{Z}$.

5. Por lo tanto, $Q-2 \mathrm{~T}<\frac{3}{4} \mathrm{Z}$. Es decir, la diferencia sería menor que Z. Ahora bien, en el artículo 1 se supuso que, $Q-2 T=Z$. En consecuencia, la conclusión es absurda: “[p]or lo tanto, no puede asumirse ninguna diferencia, ya que $\mathrm{Z}$ puede concebirse como indefinida respecto de cualquier [diferencia], y por eso son iguales el doble del [espacio de] tres líneas y el [espacio] cuadrilíneo". 96

Como dijimos antes, el primer paso es fundamental desde el punto de vista de la introducción de cantidades ficticias. Ante todo, notemos que Leibniz supone un último polígono que, a saber, es una figura recta, $\mathrm{A}_{1} \mathrm{C}_{2} \mathrm{C}_{3} \mathrm{CA}$. Ahora bien, el espacio de tres líneas (T), del cual el doble es igual al espacio cuadrilíneo Q, fue presentado por Leibniz como una figura que posee una sección curva, ${ }_{1} \mathrm{CA}_{3} \mathrm{C}_{2} \mathrm{C}_{1} \mathrm{C}$. En última instancia, como vimos, toda la demostración se apoya en esta presuposición, pues, a saber, si se supone -como en el artículo 2- que la diferencia entre el polígono $\mathrm{P}$ y el espacio de tres líneas $\mathrm{T}$ es menor que una cuarta parte de Z, se siguen absurdos. Esto habilita a que en el quinto paso señale que $\mathrm{Z}=0$, o mejor, que sería absurdo que haya una diferencia $\mathrm{Z}$ cualquiera (y en consecuencia, $\mathrm{Q}=2 \mathrm{~T}){ }^{97} \mathrm{Si}$ se tiene en cuenta la relación de equipolencia, es claro que no

\footnotetext{
${ }^{94} D Q A$, VII, 66. "Potest enim eousque produci donec fiat minori quantitate quavis data".

${ }^{95} D Q A, \mathrm{I}, 36$.

${ }^{96} D Q A$, VII, 68. "Nulla ergo differentia assumi potest, cum $\mathrm{Z}$ indefinita intelligi possit de qualibet, adeoque trilineum duplum et quadrilineum simplum aequalia sunt".

${ }^{97}$ Véase De infinite parvis, A VI 3, 434. "Videndum exacte an demonstrari possit in quadraturis, quod differentia non tamen sit infinite parva, sed quod omnino nulla, quod ostendetur, si constet eousque inflecti semper posse polygonum, ut differentia assumta etiam infinite parva minor fiat error. Quo posito sequitur non tantum errorem non esse infinite parvum, sed omnino esse nullum. Quippe cum nullus assumi possit”.
} 
hay diferencia alguna entre la figura recta poligonal $\mathrm{A}_{1} \mathrm{C}_{2} \mathrm{C}_{3} \mathrm{CA}$ y la figura de tres líneas ${ }_{1} \mathrm{CA}_{3} \mathrm{C}_{2} \mathrm{C}_{1} \mathrm{C}$, que posee un segmento de curva. En consecuencia, con la introducción de cantidades ficticias - dicho en términos más actuales- ya no nos referimos solamente a la aproximación a un límite, sino a que el límite mismo formaría parte de la serie. ${ }^{98}$

Como hemos mencionado antes y como desarrollaremos un poco más adelante, el geómetra introduce estas cantidades en sus demostraciones, aunque no obstante Leibniz haya afirmado que, desde un punto de vista metafísico, dichas cantidades sean contradictorias: "[n]o hay un número máximo y no hay una línea mínima". 99 Por esto mismo, es claro que las cantidades ficticias de 1675/1676 no deben interpretarse en un sentido sincategoremático, sino categoremáticamente, a saber, como cantidad que tienen propiedades bien determinadas: el número infinito tiene la propiedad de ser una cantidad máxima, mayor que la cual no hay otra (cantidad ficticia infinita), mientras que una línea mínima tiene la propiedad de ser última, es decir, menor que la cual no hay otra (cantidad ficticia infinitamente pequeña). ${ }^{100}$

Notemos que, con la introducción de las ficciones, Leibniz efectivamente propondría un procedimiento que constaría de un número finito de pasos. En efecto, en un número determinado de instancias, permitiría saber que las dos figuras son iguales. En este sentido, para Leibniz estos entes ficticios son abreviaciones de enunciados que sirven tanto para hablar, pensar, descubrir o demostrar. ${ }^{101} \mathrm{Su}$ utilidad está precisamente en que la Geometría muestra verdades que podría enunciar sin estas ficciones. ${ }^{102}$ Esto significa que el procedimiento propuesto por Leibniz, que se vale de entes ficticios, puede ser reemplazado

\footnotetext{
${ }^{98}$ Esto mostraría que el desarrollo de estas ideas lo llevó, muchos años más tarde, a la formulación del principio de continuidad. Por ejemplo, en Historia et Origo Calculi Differentialis (Leibniz, 1846: 40), Leibniz dijo: "Propositu quocunque transitu continuo in aliquem terminum desinente, liceat ratiocinationem communem instituaere, qua ultimus terminus comprehendatur". Asimismo, véase Esquisabel, 2012c: 73-76.

${ }^{99}$ Numeri infiniti, A VI 3, 502. "Nullus est numerus maximus, et nulla est linea minima". Similarmente, Pacidius Philalethi, A VI 3, 569 (reconstruido). "Quemadmodum circulus polygonum regulare infinitorum laterum pro circulo metaphysice haberi non potest, tametsi in Geometria pro circulo habeatur, ob errorem minorem quam ut numero ullo a nobis exprimi possit".

${ }^{100}$ Por otro lado, Arthur, 2013: 558-559, señala que la justificación del carácter ficticio del infinito está conectada con la de lo infinitamente pequeño, en la medida en que, respecto de una serie infinita, justificar que ellas puedan tratarse como un todo es al mismo tiempo justificar que tendrían un último término infinitamente pequeño. A nuestro modo de ver, esta explicación conlleva concebir el infinito y lo infinitamente pequeño en términos categoremáticos, es decir: concebir a las series infinitas como totalizables implica suponer que tienen un número infinito de términos y, en consecuencia, que hay un último término que tiene la propiedad de ser infinitamente pequeño.

${ }^{101} D Q A$, XXIII, esc., 182. Véase la cita completa en la nota 106.

${ }^{102}$ Por esto, no es correcta la indicación de Breger, 1990: 64-65, según quien, en el período parisino, Leibniz parece haber tenido dudas sobre la utilidad matemática de un infinitum terminatum.
} 
por una prueba conforme al método de exhaución de Arquímedes, en la que no es necesario que se utilicen tales entes ficticios. ${ }^{103}$ Incluso, con esto se entiende por qué para Leibniz puede demostrarse la cuadratura de un modo perfecto introduciendo cantidades ficticias, aunque no por la naturaleza misma de las cosas. En efecto, el axioma de Arquímedes no se les aplica a estas cantidades. Es decir, el axioma según el cual puede encontrarse siempre una cantidad geométrica más pequeña que otra dada, no recae sobre una última instancia en la que la diferencia sería menor que cualquiera asignable, es decir, nula. No es que Leibniz esté comprometido con dos métodos distintos (es decir, el de Arquímedes y el que utiliza ficciones), ${ }^{104}$ sino que, como vimos, hay una conexión y una continuidad entre el procedimiento del matemático griego y el de Leibniz. No obstante, por lo que dijimos antes, el procedimiento de Arquímedes no es el más simple ni, por lo tanto, el preferido por Leibniz. Precisamente por eso, es innegable la utilidad de operar con estas abreviaciones. ${ }^{105}$ En el escolio de la proposición 23 del $D Q A$, Leibniz sintetiza los puntos salientes de lo que hemos expuesto hasta aquí de esta manera:

A algunos les parecerán oscuras las cosas que hasta aquí hemos dicho sobre los infinitos y los infinitamente pequeños, como [parecen oscuras] todas las cosas nuevas. Pero con un poco de meditación, cada uno las percibirá fácilmente; quien en verdad las haya percibido, reconocerá el fruto. No importa si acaso tales cantidades existen en la naturaleza de las cosas; en efecto, alcanza con introducir una ficción, porque ofrecen abreviaciones del hablar y del pensar, y por lo tanto del descubrir, del mismo modo que del demostrar, de modo que no sea siempre necesario hacer uso de [figuras] inscriptas o circunscriptas, llevar a cabo [deducciones] al absurdo ni mostrar que el error [es] menor que cualquiera asignable. (...) En efecto, [ante la cuestión de] si en verdad es posible que se exhiban demostraciones directas sobre estas cosas, me atrevería a afirmar que no pueden darse, a no ser que se admitan cantidad ficticias, infinitamente pequeñas o infinitas (...). Por lo tanto, si en el futuro alguien se quejara del uso de estas cantidades, éste se mostraría o ignorante o ingrato. Ignorante, a saber, si no entiende cuánta luz se enciende en todo el método de los indivisibles y en materia de las cuadraturas; pero ingrato, si disimula la utilidad que percibe. ${ }^{106}$

\footnotetext{
103 Jesseph, 2015: 198.

${ }^{104}$ Katz y Sherry, 2013: 576-577. Véase Arthur, 2013: 560-561.

${ }^{105}$ Numeri infiniti, A VI 3, 499.

${ }^{106} D Q A$, XXIII, esc., 182-184. "Quae de infinitis atque infinite parvis huc usque diximus, obscura quibusdam videbuntur, ut omnia nova; sed mediocri meditatione ab unoquoque facile percipientur: qui vero perceperit, fructum agnoscet. Nec refert an tales quantitates sint in rerum natura, sufficit enim fictione introduci, cum loquendi cogitandique ac proinde inveniendi pariter ac demonstrandi compendia praebeant, ne semper
} 
Como puede observarse, la introducción de ficciones trasluce la idea leibniziana de buscar un método general que sirva no solamente para demostrar sino también para descubrir. ${ }^{107}$ Asimismo, dicha introducción muestra que de alguna manera había comenzado a generarse un cambio en la concepción general de la matemática. Esto no significa que Leibniz haya dejado de concebirla como la ciencia de las cantidades. Más aún, aunque las cantidades infinitas e infinitamente pequeñas sean ficticias, son no obstante cantidades. ${ }^{108}$ Sin embargo, las cantidades con las que se trata en la matemática no necesariamente tienen que ser metafísicamente posibles. Dicho de otra manera, esta ciencia no opera con supuestos de existencia. Leibniz ya reconoció en la Accessio que es posible obtener resultados correctos “(...$)$ aun admitiendo cosas imposibles, como son dimensiones que sobrepasan la tercera [dimensión], los números sordos y los menores que cero". ${ }^{109}$ Como señalamos antes, en $D Q A$ Leibniz señaló que al geómetra le basta demostrar qué se sigue de suponer las cantidades infinitas terminadas, aunque no le corresponde indagar sobre la existencia de dichas cantidades en la naturaleza de las cosas. Esta idea, que también se repite muchos años más tarde, ${ }^{110}$ parece signo de un cambio en la concepción de la matemática. Al margen de estas especulaciones, y como síntesis para concluir esta subsección, las ficciones, que son introducidas por el geómetra en sus demostraciones y que facilitan su labor, son cantidades. En este sentido, las voces 'infinito' e 'infinitamente

inscriptis vel circumcriptis uti, et ad absurdum ducere, et errorem assignabili quovis minorem ostendere necesse sit. (...) Imo si quidem possibile est directas de his rebus exhiberi demonstrationes, ausim asserere, non posse eas dari, nisi his quantitatibus fictitiis, infinite parvis, aut infinitis, admissis (...). Si quid ergo imposterum queretur de usu harum quantitatum, is aut ignarum se ostendet aut ingratum. Ignarum quidem, si non intelligit, quanta hic lux accendatur in tota methodo indivisibilium, et materia quadraturarum; ingratum vero, si utilitatem quam percibir, disimulat".

${ }^{107}$ Jesseph, 2015: 192.

${ }^{108}$ Knobloch, 2002: 61.

${ }^{109}$ Leibniz a J. Gallois, A II 1, 354. "Idem in Geometria praestat Algebra, adeo ut impossibilibus etiam assumtis, ut sunt dimensiones ultra tertiam transgressae, numerique surdi et nihilo minores, suum tamen consequatur". Traducción: Leibniz, 2014: 66. La utilización de cantidades imposibles se remonta al Ars Magna (1545) de Cardano, quien empleó raíces imaginarias para solucionar problemas imposibles. Posteriormente, Bombelli también operó con cosas imaginarias en su Algebra (1572), obra que Leibniz conocía. Véase Katz y Sherry, 2012:168-169.

${ }^{110}$ Por ejemplo: Leibniz a Des Bosses, GP II, 305. "Ego philosophice loquendo non magis statuo magnitudines infinite parvas quam infinite magnas, seu non magis infinitesimas quam infinituplas. Utrasque enim per modum loquendi compendiosum pro mentis fictionibus habeo, ad calculum aptis, quales etiam sunt radices imaginariae in Algebra. Interim demonstravi, magnum has expressiones usum habere ad compendium cogitandi adeoque ad inventionem, et in errorem ducere non posse, cum pro infinite parvo substituere sufficiat tam parvum quam quis volet, ut error sit minor dato, unde consequitur errorem dari non posse". Similarmente, Leibniz a Joh. Bernoulli, GM III, 524. "Inter nos autem haec addo, quod et iam olim in dicto Tractatu inedito adscripsi, dubitari posse an lineae rectae infinitae longitudine et tamen terminatae revera dentur. Interim sufficere pro Calculo, ut fingantur, uti imaginariae radices in Algebra”. 
pequeño' que se refieren a estas ficciones, no son sincategoremáticas sino, por el contrario categoremáticas, a saber, puesto que designan respectivamente un número infinito (de lados del polígono infinitángulo) y una línea mínima (los lados de tal polígono).

\subsection{Las cantidades infinitamente pequeñas desde el punto de vista metafísico}

Hasta aquí hemos explicado por qué razón Leibniz concibe cantidades ficticias infinitas e infinitamente pequeñas, así como también el procedimiento por el cual ellas se introducen. No obstante, resta que examinemos por qué para Leibniz no pueden darse realmente. En este sentido, pasaremos de examinar la utilidad que tienen para la geometría a evaluar las conclusiones metafísicas que Leibniz ha extraído sobre ellas. En última instancia, de acuerdo con lo que vimos en el capítulo anterior y en la sección previa de este capítulo, un polígono con un número infinito de lados es imposible puesto que para Leibniz el número infinito es contradictorio, de modo que no hay un límite posible de pliegues en el continuo. En este momento nos centraremos en los argumentos para las cantidades infinitamente pequeñas.

Leibniz examina la cuestión de la existencia de los infinitesimales a través de la noción de ángulo. En el cuarto capítulo hemos mencionado que, en el contexto de la TMA, concibió a los ángulos como porciones de un círculo menor que cualquiera dado, de modo tal que un ángulo es un signo de un punto. No obstante, en el contexto de DSR, Leibniz cuestiona sus planteos previos sobre la naturaleza del ángulo. En especial, a la luz de las reflexiones sobre el infinito que presentamos anteriormente, parece que el filósofo de Leipzig encuentra que es problemático concebir al ángulo como signo de un punto. En efecto, si así fuera, debería decirse que un ángulo está en un punto. Detrás de esta idea se encuentra la concepción de que, supuestas dos líneas que convergen, el ángulo que se forma no depende en absoluto de la longitud de dichas líneas. ${ }^{111}$ En consecuencia, bajo estos supuestos, un ángulo sería lo que está entre líneas que sean más pequeñas que cualquiera asignable, es decir, líneas respecto de las cuales no haya otras menores:

Si se lo toma por una cosa que existe en un punto en cuanto tal, a saber, si suponemos que un Ángulo está en un punto, es decir, que subsiste mientras se recorta una línea asignable cualquiera, se da la cantidad del ángulo. Es el

${ }^{111}$ Numeri infiniti, A VI 3, 498. 
mismo ángulo que cuando están producidos los lados. Supuestas estas cosas, un ángulo sería aquello que está en líneas más pequeñas que cualquiera interceptada, es decir, [sería] el espacio comprendido por dos líneas concurrentes menores que cualquiera asignable. $\mathrm{Y}$ tal Ente es ficticio, puesto que las líneas de este tipo [son] ficticias. ${ }^{12}$

De lo dicho anteriormente, es claro por qué para Leibniz estas líneas menores que cualquiera asignable son ficticias. Por eso, en el contexto de $D S R$, Leibniz concibió que un ángulo no 'está en' un punto, sino que, para que haya uno, debe darse la concurrencia de líneas. ${ }^{113}$ Ahora bien, en este punto de su examen, Leibniz introduce una aclaración que es muy significativa y que, como intentaremos justificar, es decisiva para la comprensión del carácter ficticio de los infinitesimales. Un poco antes del último pasaje citado, Leibniz señaló:

Debe responderse, en primer lugar, que no hay un ángulo en un punto a no ser que se añadan líneas. Ahora bien: si estas líneas son infinitamente pequeñas, [son] sin embargo líneas [y entonces] la dificultad permanecería. En efecto, las [podría] recortar nuevamente del mismo modo. ${ }^{114}$

No obstante, debe notarse que hay una notable diferencia entre la pequeñez de las líneas mencionadas en este pasaje en relación con el anterior: mientras que en el último pasaje Leibniz se refiere a líneas infinitamente pequeñas que no obstante son líneas, y por eso nuevamente divisibles, en el pasaje anterior, se refirió a las líneas más pequeñas que cualquiera, que como tales son ficticias. Es claro que, en este segundo caso, Leibniz hace referencia a una cantidad infinitamente pequeña ficticia; pero, ¿puede decirse lo mismo de las líneas infinitamente pequeñas que sin embargo son líneas, y por lo tanto admiten otras nuevamente más pequeñas? ¿O acaso opera en Leibniz una distinción entre dos sentidos de la noción de lo infinitamente pequeño, a saber, aquel con el cual se refiere a cantidades ficticias que tienen la propiedad de ser menores que cualquiera asignable y aquel otro con el que se refiere a cosas infinitamente pequeñas en relación con otras, pero que no obstante

\footnotetext{
${ }^{112}$ Numeri infiniti, A VI 3, 498-499. "Si pro aliqua re in ipso puncto existente sumatur, scilicet si ponamus, Angulus est in puncto, seu linea quavis assignabili resecta subsistit, datur quantitas anguli. Idem est angulus, lateribus productis. His positis erit angulus, id quod est in lineis qualibet intersecta minoribus, seu spatium comprehensum duabus lineis concurrentibus, qualibet assignabili minoribus. At tale Ens fictitium est, quoniam lineae eiusmodi fictitiae".

${ }_{113}$ Numeri infiniti, A VI 3, 498.

${ }^{114}$ Numeri infiniti, A VI 3, 498. "Respondendum primum angulum in solo puncto nullum esse, nisi accedant lineae. Si jam eae lineae sint infinite parvae, lineae tamen, manebit difficultas, eodem enim modo ab illis resecabo".
} 
son mayores que otras? ${ }^{115}$ Creemos que se puede defender la última posición no solamente a partir de lo ya dicho sino especialmente a partir de la argumentación de Leibniz presente en el diálogo Pacidius Philalethi, en la que explica precisamente por qué razón no pueden admitirse en la realidad las cantidades infinitamente pequeñas ficticias:

Yo sin duda admitiría estos espacios y tiempos infinitamente pequeños en Geometría, por el bien de la invención, aunque fueran imaginarios. Pero me pregunto si acaso pueden ser admitidos en la naturaleza. (...) [Y]a que pueden asumirse al infinito otras cosas infinitamente pequeñas aún menores que otras, nuevamente no puede ofrecerse una razón de por qué se asumen unas más que otras; pero nada sucede sin razón. ${ }^{116}$

En este pasaje puede observarse que para Leibniz no pueden admitirse en la naturaleza de las cosas espacios o tiempos infinitamente pequeños, puesto que podemos asumir otras cosas que no solo sean más pequeñas que ellos, sino incluso infinitamente más pequeñas. A primera vista, la argumentación de Leibniz podría parecer paradójica, pues para negar la existencia de unas cantidades infinitamente pequeñas apela a la posibilidad de pensar en cosas infinitamente más pequeñas que ellas. No obstante, esta paradoja se disuelve si se tiene en cuenta la distinción entre dos sentidos de lo infinitamente pequeño que propusimos anteriormente. En síntesis, podríamos decir que para Leibniz (1) no existe en la naturaleza una cantidad infinitamente pequeña, esto es, mínima o última, que tenga la propiedad de ser menor que cualquiera asignable, por el argumento recién citado. Si se confronta este argumento con lo que hemos mencionado en la sección anterior, podríamos decir que una cantidad infinitamente pequeña no puede darse en la naturaleza de las cosas porque su existencia sería incongruente. No obstante, a pesar de no existir una cantidad infinitamente pequeña en el sentido recién expuesto, (2) Leibniz parece reconocer que existen cosas infinitamente pequeñas, esto es, no absolutamente (menores que cualquier cantidad asignable), sino en relación con otra cosa. Esto parece ser lo que Leibniz quiere decir en el pasaje anterior: un infinitesimal en el sentido de (1) no existe porque para

\footnotetext{
${ }^{115}$ Una idea similar a la que aquí proponemos, aunque en relación con el pensamiento maduro de Leibniz, fue presentada por Earman, 1975: 238, quien distingue entre dos tipos de infinitesimales, a saber, por un lado como cantidades intrínsecamente pequeñas, y por otro lado como cantidades que no son intrínsecamente pequeñas, pero que son incomparablemente pequeñas en relación con cantidades ordinarias. No obstante, no es claro que podamos hablar de una 'incomparabilidad' en los escritos juveniles de Leibniz.

${ }^{116}$ Pacidius Philalethi, A VI 3, 564-565. "Ego spatia haec et tempora infinite parva in Geometria quidem admitterem, inventionis causa, licet essent imaginaria. Sed an possint admitti in natura delibero. (...) Praeterea cum infinitae parvae quoque aliae aliis minores assumi possint in infinitum, rursus non potest ratio reddi, cur aliae prae aliis assumantur; nihil autem fit sine ratione". OFC, 8, 150.
} 
cualquier cosa puede pensarse otra que sea incluso infinitamente más pequeña que ella, es decir, (2), con tal que se entienda que esta otra cosa más pequeña puede ser pensada del mismo modo en una relación con otra incluso infinitamente más pequeña. De ese modo, se garantiza que no se dé una incongruencia. En muchos de los pasajes citados en esta y en las anteriores secciones de este capítulo, se puede observar cómo opera esta distinción, por ejemplo, en todas aquellas menciones en las que Leibniz se refiere a una línea infinitamente pequeña que no obstante, dado que es una línea, es divisible (y por lo tanto, es infinitamente pequeña en relación con otra cosa). ${ }^{117}$

Para concluir esta subsección, en síntesis, podemos reconocer que Leibniz distinguió entre dos sentidos de la noción de lo infinitamente pequeño: por una parte, algo último que posee la propiedad de ser infinitamente pequeño y que por eso mismo es una ficción; por otra parte, una cierta relación con otra cosa que en comparación sea infinitamente grande, aunque esta cosa infinitamente pequeña pueda estar en relación con otras cosas que sean infinitamente más pequeñas que ella. ${ }^{118}$ Esto no significa que el segundo sentido de lo infinitamente pequeño, es decir, como relación, haga referencia a una 'cosa real' en el sentido metafísicamente fuerte de la expresión. Para Leibniz, las relaciones no son entes verdaderos sino cuando son pensadas por nosotros. ${ }^{119}$ Así, aunque en este sentido lo infinitamente pequeño no sea algo contradictorio, sin embargo no existe en la realidad como una 'cosa'. Ahora bien, de alguna manera, el segundo sentido de lo infinitamente pequeño podría entenderse en términos sincategoremáticos. En efecto, en última instancia no importa cuán pequeña sea una cosa que es infinitamente pequeña en relación con otra, con tal haya otras cosas menores que ella. No obstante, en este caso no estamos tratando con cantidades ficticias. En consecuencia, de alguna manera la distinción entre lo infinitamente pequeño como propiedad y lo infinitamente pequeño como relación, muestra que Leibniz habría tenido en mente un sentido categoremático y otro sincategoremático de lo infinitamente pequeño. Cuando Ishiguro expuso su concepción de los infinitesimales, señaló lo siguiente: “[e]1 límite puede ser una fícción bien fundada, pero

\footnotetext{
${ }^{117}$ Véanse, por ejemplo, los pasajes que se encuentran en las notas 18, 112 y 114.

${ }^{118}$ Le debo a José Seoane la muy útil sugerencia (que me dio en el simposio "Diagramas, visualización y formalismo en la filosofía de la práctica matemática" que tuvo lugar en el marco del XVII Congreso Nacional de Filosofía organizado por AFRA y UNL los días 4-8 de Agosto del 2015 en la ciudad de Santa Fe) de utilizar los nombres de 'infinitamente pequeño como propiedad' e 'infinitamente pequeño como relación'.

${ }^{119}$ De motu et materia, A VI 3, 495; De mente, de Deo, de universo, A VI 3, 463.
} 
hablar de infinitesimales es, como él [es decir, Leibniz] dice, sincategoremático (...)". ${ }^{120}$ Como dijimos antes, no es nuestra intención discutir el pensamiento leibniziano de madurez sobre esta cuestión. No obstante, siguiendo este pasaje de Ishiguro para referirnos al pensamiento leibniziano de 1675/1676, podríamos decir que la distinción entre 'el límite' (como ficción) y 'el infinitesimal' (en su sentido sincategoremático), muestra que sería erróneo confundir los dos sentidos de lo infinitamente pequeño que describimos antes.

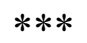

En síntesis, en este capítulo hemos arribado a las siguientes conclusiones parciales. Tras mencionar los tres grados de infinito, hemos visto, en primer lugar, que Leibniz distinguió entre el infinito sin término (no hay un último punto) y el infinito con término (hay un último punto). Esta distinción le permitió no sólo justificar algunas operaciones geométricas sino también explicar que el continuo no se divide en mínimos (esto es, una división en la que habría una última parte), de modo que su división se explica en analogía con una línea sin término, esto es, no tiene un fin. Detrás de esta afirmación se encuentra la convicción de Leibniz de que 'la magnitud o pequeñez no vienen al caso', de modo que una parte última implicaría una incongruencia. En este sentido, en virtud de la propiedad antes mencionada, para Leibniz no habría razón para detener la división en presuntas partes mínimas. Como Dios tiene una razón para todo lo que hace, aquellas presuntas partes últimas no pueden ser admitidas (es decir, dado que no tienen razón de ser). En siguiente lugar, tras una breve introducción al problema de la cuadratura del círculo, hemos visto que Leibniz propuso introducir cantidades ficticias infinitas e infinitamente pequeñas a los fines de simplificar el procedimiento de Arquímedes para cuadrar las figuras cónicas. En el trasfondo de la propuesta de Leibniz, está la concepción según la cual las figuras curvilíneas pueden concebirse como polígonos con un número infinito de lados, cada uno de los cuales es de una magnitud infinitamente pequeña. De acuerdo con Leibniz, los geómetras introducen estas cantidades ficticias en sus razonamientos, dado que son abreviaciones del hablar, pensar, demostrar y descubrir. En este sentido, las palabras

\footnotetext{
${ }^{120}$ Ishiguro, 1990: 90. "The limit may be a well-founded fiction, but talk of infinitesimals is, as he says, syncategorematic (...)".
} 
‘infinito' e 'infinitamente pequeño', que designan estas ficciones, tienen un sentido categoremático. No obstante, estas cantidades ficticias, infinitas e infinitamente pequeñas, no existen en la realidad. Ahora bien, esto no significa que para Leibniz no existan cosas infinitamente más pequeñas que otras. En este sentido, hemos visto que, por una parte, el filósofo de Leipzig negó que existan cantidades infinitamente pequeñas y, por otra parte, afirmó que algunas cosas pueden ser infinitamente más pequeñas que otras, aunque haya otras cosas aún más pequeñas que ellas. 



\section{CAPÍTULO 8: FORMAS, MODOS Y EL CONTINUO}

Lo absoluto es anterior a lo limitado.

Numeri infiniti, A VI 3, 502

Suele reconocerse que el pensamiento leibniziano que corresponde al final de su estadía en París y que comprende los escritos agrupados bajo el título de $D S R$ pertenece a lo que a lo largo de los siglos ha sido conocido en la literatura filosófica como 'metafísica'. Como veremos, esto es sin duda cierto. No obstante, muchos de los temas propios del pensamiento leibniziano que se encuentran en los escritos de $D S R$, algunos de los cuales fueron examinados en el capítulo anterior, a primera vista no serían considerados como metafísicos. Ahora bien, esto no significa que estas cuestiones no estén relacionadas con la metafísica leibniziana, sino que incluso sucede más bien todo lo contrario: en última instancia, como veremos, todo lo que ha sido tratado por Leibniz en estos escritos está orientado hacia una teoría metafísica novedosa dentro del pensamiento del filósofo de Leipzig. De esta manera, la profunda metafísica leibniziana de $D S R$ se vincula con las cuestiones anteriormente vistas y con las que veremos en el capítulo siguiente. Las indicaciones que haremos a continuación pueden servir como un sintético marco de referencia conceptual que anticipa los tratamientos que abordaremos en este capítulo.

La vinculación entre la metafísica de Leibniz y las cuestiones examinadas en los capítulos previos, fundamentalmente las que a priori parecerían forzadamente relacionadas con ella, se observa por ejemplo en lo siguiente. En la primera sección del capítulo anterior, hemos visto que el filósofo de Leipzig distinguió tres grados de infinito, a saber, lo que es mayor que cualquier cosa asignable, lo máximo en su género y Dios, en cuanto que en Él están contenidos los requisitos de existencia de todas las cosas, es decir, que es todas las cosas en una. El primero de estos sentidos fue examinado detalladamente en el capítulo anterior. No obstante, quedó pendiente abordar el segundo y el tercer sentido de infinito. Ahora bien, hablar de 'lo máximo' en el pensamiento leibniziano es problemático. Por

\footnotetext{
${ }^{1}$ Así señala Parkinson en la introducción de PDSR, 1992: xi-xiv. Algunos de los muchos trabajos en los que se considera el pensamiento metafísico de Leibniz de este período son: Adams, 1994, especialmente el capítulo 4, Blank, 2001; 2009; 2011, 2014, Brown, 1999c, Kulstad, 1999a; 1999b; 2000; 2014, Mercer, 2004, fundamentalmente el capítulo 10, Laerke, 2008; 2009, Wilson, 1999, etc.
} 
ejemplo, como vimos en el capítulo sexto, para Leibniz el 'número máximo', esto es, el número infinito de todas las unidades, es contradictorio $\mathrm{y}$, en consecuencia, no existe. Como veremos, cuando Leibniz se refirió a 'lo máximo' en el marco de sus reflexiones metafísicas de 1675/1676, expuso lo que en última instancia da razón de las cosas en sus respectivos géneros y de la unidad del género mismo. A modo de ejemplo, como detallaremos en este capítulo, Leibniz entendió que lo máximo en el género de las cosas extensas es la 'extensión' o 'inmensidad', concebido como un atributo de la sustancia divina. Como consecuencia de ello, la 'extensión' (y lo mismo vale, como veremos, para los demás atributos) es algo absoluto respecto de las cosas limitadas de su propio género. ${ }^{2}$ De allí el epígrafe elegido para este capítulo.

Si bien Leibniz mencionó distintos atributos divinos (la omnisciencia, la eternidad, la omnipotencia), el abordaje de la ‘extensión' fue objeto de un análisis más minucioso. En alguna medida, como veremos, Leibniz conectó los tratamientos de los demás atributos con el de la extensión. Por este motivo, tras examinar la concepción de Dios como la suma de todos los requisitos en la primera sección, en las dos secciones siguientes nos centraremos en la extensión y en su conexión con otras nociones relacionas. Esto nos servirá de referencia para que en la cuarta sección examinemos otros atributos vinculados con el problema del continuo, a saber, la eternidad respecto del tiempo y la omnisciencia respecto de las mentes individuales. En lo que respecta a este último caso, discutiremos la interpretación puramente 'monista' del pensamiento leibniziano de $D S R$ y justificaremos que el filósofo de Leipzig defendió un pluralismo de 'entes' tipo mentes. Finalmente, en la última sección introduciremos algunas precisiones que exceden la cuestión de la relación entre un atributo en particular y el género que le corresponde, y que están vinculadas con el conocimiento de las formas en general y su clasificación.

\section{El infinito como la suma de todos los requisitos}

En el período de $D S R$, puede observarse una centralidad del examen del tercer grado de infinito, a saber, aquel con el cual Leibniz se refirió a Dios como lo que contiene los requisitos de todas las cosas para existir. A primera vista, podría pensarse que este sentido

\footnotetext{
${ }^{2}$ De origine rerum ex formis, A VI 3, 519.
} 
no tiene mayores consecuencias en relación con el problema del continuo. No obstante, como veremos, hay una estrecha relación que se percibe al examinar la conexión con el segundo grado de infinito. El examen de aquello que es la suma de todos los requisitos no solamente tiene un papel central en $D S R$, sino que incluso es pensado por Leibniz como el punto de partida absoluto de la reflexión filosófica. Aunque el filósofo de Leipzig reconozca que en el orden del filosofar la proposición cartesiana 'yo pienso' es la primera de las verdades reales (dado que es más simple comenzar por el sujeto de la primera proposición experimental que por los predicados), no obstante señala a su vez que, en última instancia, Descartes no llevó a cabo un análisis hasta obtener las formas primeras, lo que en este caso vendría a ser 'pensamiento'.3 Para Leibniz esto significó que, en última instancia, Descartes no comenzó por Dios. ${ }^{4}$ El hecho de que Leibniz comience sus exámenes por medio de una consideración de Dios parece tener una clara connotación spinozista. De acuerdo con las anotaciones de sus conversaciones con Tschirnhaus sobre Spinoza, sabemos que Leibniz era consciente de que el pensador holandés consideraba que los filósofos escolásticos comenzaron a filosofar por las cosas creadas, Descartes por la mente y él mismo por Dios. ${ }^{5}$ La razón por la cual habría que empezar por Dios parece ser para Leibniz algo claro. En un escrito de diciembre de 1676, Leibniz sintetizó de esta manera la razón en cuestión:

Para la existencia es necesario que esté presente el agregado de todos los requisitos. Requisito es aquello sin lo cual la cosa no puede ser. El agregado de todos los requisitos es la causa plena de la cosa. Nada existe sin razón, porque nada existe sin el agregado de todos los requisitos. ${ }^{6}$

Para Leibniz el ente que contiene los requisitos de todas las cosas es Dios, es decir, el ‘ente perfectísimo' o ‘ente necesario'.7 Ahora bien, una de las características más destacas

\footnotetext{
${ }^{3}$ La referencia de Leibniz al pensamiento como forma es recurrente en los escritos de DSR. Véase, por ejemplo, De magnitudine, A VI 3, 483 o De formis seu attributis Dei, A VI 3, 513-514.

${ }^{4}$ De veritatibus, de mente, de Deo, de universo, A VI 3, 508.

${ }^{5}$ Über Spinozas Ethik, A VI 3, 385. Laerke, 2008: 445-447.

${ }^{6}$ De existentia, A VI 3, 587. "Ad existentiam necesse est aggregatum omnium adesse Requisitorum. Requisitum est id sine quo res esse non potest. Aggregatum omnium requisitorum est causa plena rei. Nihil est sine ratione. Quia nihil est sine aggregato omnium requisitorum". Tomamos la traducción de OFC 2, 105, aunque introducimos algunos modificaciones. Di Bella, 2014: 243-245, señala que el hecho de que Leibniz se haya referido a los 'requisitos', de manera que la suma o el agregado de ellos constituya la causa o condición suficiente, es una manifestación de la influencia de Hobbes en lo que respecta a las definiciones genéticas. Nos hemos referido a esto último en la tercera sección del primer capítulo.

${ }^{7}$ Hay una pluralidad de textos en los que Leibniz aborda la caracterización de Dios como el 'ser perfectísimo', como son Quod ens perfectissimum sit possibile, A VI 3, 571-574, Ens perfectissimum existit,
} 
del abordaje que Leibniz llevó a cabo en $D S R$ en lo que respecta al examen de Dios es que se dio cuenta de que las argumentaciones que se han dado con anterioridad para mostrar que existe son insuficientes. Leibniz pone su atención, por ejemplo, en el célebre argumento de Anselmo de Canterbury (1033-1109), según el cual "Dios es aquello mayor que lo cual nada puede pensarse". ${ }^{8}$ Ahora bien, de acuerdo con Leibniz este argumento recae en algo que fue aducido por otros como Descartes, a saber, que el ente perfectísimo existe porque la existencia necesaria está contenida en nuestro concepto de Dios. ${ }^{9}$ Como dijimos, Leibniz nota que, si se detuviera el examen aquí, el argumento sería insuficiente. No obstante, él no sigue los pasos de quienes buscaron refutar este argumento, como Tomás de Aquino (1224-1274). ${ }^{10}$ Por el contrario, para Leibniz este argumento no debe refutarse, aunque necesita un suplemento: “[e]n efecto, supone que el Ente que no puede no ser, lo mismo que el Ente máximo o perfectísimo, son posibles". ${ }^{11}$ Incluso, el filósofo de Leipzig se jacta de haber sido el primero en señalar que ante todo debe mostrarse que Dios es posible para luego poder deducirse que existe. ${ }^{12}$

A VI 3, 574-577, Quod ens perfectissimum existit, A VI 3, 578-579. En todos estos ensayos, como veremos, la clave está en mostrar primero que dicho ente es posible y luego que su existencia es necesaria. De existentia, A VI 3, 587. "Ens necessarium in se omnium rerum requisita continere".

${ }^{8}$ De veritatibus, de mente, de Deo, de universo, A VI 3, 510. "Deus est, quo nihil maius cogitari potest". Anselmo de Canterbury desarrolla este argumento en el capítulo segundo del Proslogion.

${ }^{9}$ Principia Philosophiae, AT, VIII, $1, \S 14$. Leibniz se refiere a Descartes explícitamente, por ejemplo, en Quod ens perfectissimum existit, A VI 3, 579.

${ }_{10}$ Por ejemplo, en Summa Contra Gentiles, I, 11. "Nec oportet ut statim, cognita huius nominis Deus significatione, Deum esse sit notum, ut prima ratio intendebat. Primo quidem, quia non omnibus notum est, etiam concedentibus Deum esse, quod Deus sit id quo maius cogitari non possit: cum multi antiquorum mundum istum dixerint Deum esse. Nec etiam ex interpretationibus huius nominis Deus, quas Damascenus ponit, aliquid huiusmodi intelligi datur. Deinde quia, dato quod ab omnibus per hoc nomen Deus intelligatur aliquid quo maius cogitari non possit, non necesse erit aliquid esse quo maius cogitari non potest in rerum natura. Eodem enim modo necesse est poni rem, et nominis rationem. Ex hoc autem quod mente concipitur quod profertur hoc nomine Deus, non sequitur Deum esse nisi in intellectu. Unde nec oportebit id quo maius cogitari non potest esse nisi in intellectu. Et ex hoc non sequitur quod sit aliquid in rerum natura quo maius cogitari non possit. Et sic nihil inconveniens accidit ponentibus Deum non esse: non enim inconveniens est quolibet dato vel in re vel in intellectu aliquid maius cogitari posse, nisi ei qui concedit esse aliquid quo maius cogitari non possit in rerum natura".

${ }^{11}$ De veritatibus, de mente, de Deo, de universo, A VI 3, 510-511. "In D. Thomae Summa contra Gentes capite: an Deum esse sit per se notum, elegans quorundam refertur argumentum pro probanda Dei existentia: Deus est, quo nihil maius cogitari potest. At vero quo nihi maius cogitari potest; id non potest non esse. Nam aliud quod non potest non esse, eo malus foret. Ergo Deus non potest non esse. Argumentum in idem recidit cum eo quod ab aliis saepe allatum est, Ens perfectissimum existere. D. Thomas hoc argumentum refutat, mihi videtur non esse refutandum, sed indigere supplemento, suppon[it] enim Ens quod non potest non esse, item Ens maximum seu perfectissimum esse possibilia".

${ }^{12}$ Notizen zur Wissenschaft und Metaphysik, A VI 3, 395. Como vemos, en estos escritos Leibniz aborda por primera vez su argumentación clásica del argumento ontológico. 
En última instancia, el gran interrogante aquí es por qué razón para Leibniz es necesario mostrar primero que Dios es posible para luego poder concluir que su existencia es necesaria. La respuesta a este interrogante no es simple, pues está estrechamente relacionada con algunas consideraciones epistemológicas que en parte son similares a las que hemos examinado en el sexto capítulo. En DSR, Leibniz aborda esta cuestión tempranamente en De mente, de universo, de Deo de diciembre de 1675, tras establecer una comparación entre lo que denomina el 'proceso por ideas' (processum per ideas) y el 'proceso por definiciones o caracteres' (processum per definitiones, vel characteres). La disyunción en este último caso no indica una oposición, pues para Leibniz "una definición es la explicitación de un carácter". ${ }^{13}$ El proceso por definiciones se caracteriza por añadir al proceso por ideas el hecho de hacer fijo el pensamiento mediante signos. Esto permite que el pensamiento se haga visible, tanto para nosotros como también para los otros, de modo que el proceso de pensar pueda ser percibido en una mirada. ${ }^{14}$ La ventaja que comporta, además, es que, cuando no procedemos por definiciones, corremos el peligro de que la memoria nos falle. ${ }^{15}$

Ahora bien, Leibniz señala que, cuando pensamos en Dios como 'aquello mayor que lo cual no puede pensarse', no estamos pensando una única idea. Es decir: tenemos ideas de cada una de estas cosas singulares por separado (la idea de 'algo', la de 'mayor', la de 'pensarse', la de 'no', la de 'poder'), aunque no obstante ellas no son luego conjugadas. ${ }^{16}$ Lo que se conjuga son los vocablos o caracteres, formando en consecuencia una definición. El gran inconveniente aquí es que imaginamos que tenemos una idea de 'aquello mayor que lo cual no puede pensarse' como si se tratara de una idea en la que se piensan todas estas cosas simultáneamente. Para Leibniz ésta es una fuente de errores: “[t]enemos ideas de las cosas simples, tenemos solamente caracteres de las cosas compuestas". ${ }^{17}$ En consecuencia,

\footnotetext{
${ }^{13}$ De mente, de universo, de Deo, A VI 3, 462. “(...) definitio enim characteris explicatio est”.

${ }^{14}$ Esquisabel, 2012a: 19 y ss., señala que una de las características del modo como Leibniz concibió el pensamiento simbólico (tema que se aborda exhaustivamente en dicho trabajo) es su capacidad de hacer perceptible o sensible los pensamientos.

${ }^{15}$ De mente, de universo, de Deo, A VI 3, 462. La idea de que los errores en el razonamiento humano deben ser explicados por una mala memoria o por una falta de atención, como señala Beeley, 2015: 37-38, se encuentra también en escritos muy posteriores de Leibniz.

${ }^{16}$ Di Bella, 2014: 239, explica esto diciendo que “(...) el hecho de que conozcamos el significado de las palabras individuales no garantiza que captemos el significado que corresponde a su conexión".

${ }^{17}$ De mente, de universo, de Deo, A VI 3, 462. "Cum cogito aliquid quo majus cogitari non potest, quid aliud cogito quam separatim, ideas singulorum quae sub his vocibus continentur, ut aliquid, majus, cogitari, non, posse. Separatim habeo ideam, eius quod voco aliquid; eius quod voco majus, eius quod voco cogitationem,
} 
del hecho de tener ideas de las cosas que entran en una definición no se sigue que tengamos una idea de lo definido, pues para ello deberíamos poder pensar simultáneamente todas las ideas cuyos caracteres entran en su definición, lo que no sucede. ${ }^{18}$ Recordemos que ésta es la virtud de las definiciones, esto es, fijar el pensamiento y hacer que el proceso de pensar sea perceptible en una mirada.

En síntesis, Leibniz subraya que, sin importar cómo lo definamos, no tenemos una idea de Dios. ${ }^{19}$ En efecto, como se ha dicho, no tenemos ideas de cosas compuestas. Ahora bien, esto no significa que las cosas compuestas sean imposibles y por lo tanto que no existan (al menos no necesariamente). De allí que Leibniz analice entonces cómo hacemos para juzgar sobre la posibilidad de una cosa compleja. Es claro que no podemos juzgar sobre la posibilidad de una cosa a partir de la cognoscibilidad de sus requisitos, si es que lo que conocemos son los requisitos singulares, esto es, sin conjugarlos, pues no es posible para nosotros conjugar las ideas en un único acto de intelección. En consecuencia, no podemos juzgar acerca de la posibilidad considerando puramente las ideas, pues no podemos pensarlas a todas simultáneamente. No obstante, como se ha dicho, para Leibniz es posible unir los caracteres que fijan el pensamiento. De esta manera, aunque no pueda juzgarse sobre la posibilidad considerando puramente las ideas, es posible mediante caracteres, porque estos últimos se pueden trazar o dibujar en la materia, siendo de esta manera posible, nuevamente, percibirlos todos simultáneamente. ${ }^{20}$ Así, podemos proceder ordenadamente, avanzando hacia las cosas posteriores estando seguros de que no nos olvidamos nada de lo anterior (es decir, podemos proceder asegurándonos de no cometer errores). Leibniz sintetiza varios de sus planteos de esta manera, a propósito de la idea compleja- de círculo:

Y así no hay en nosotros una idea de círculo como hay en Dios, quien piensa todas las cosas simultáneamente. Hay en nosotros cierta imagen del círculo, y está la definición de círculo, y están en nosotros las ideas de las cosas que son

\footnotetext{
itaque unum post alterum cogitans; non ideas horum inter se sed postea vocabula tantum seu characteres conjungo et fingo me ideam habere eius quo majus cogitari non potest; quasi scilicet omnia haec simul cogitem. In quo decipimus et decipimur, et hoc est origo erroris de ideis. Habemus ideas simplicium, habemus tantum characteres compositorum".

${ }^{18}$ De mente, de universo, de Deo, A VI 3, 462.

${ }^{19}$ De mente, de universo, de Deo, A VI 3, 462. Posteriormente, las cosas que aquí Leibniz dice fueron problemáticas, especialmente en relación con la creencia de que la idea de Dios es innata. Esto se puede observar, por ejemplo, en Quid sit idea, GP VII, 263-264.

${ }^{20}$ De mente, de universo, de Deo, A VI 3, 462-463.
} 
necesarias para pensar el círculo. Pensamos acerca del círculo, demostramos sobre el círculo, conocemos el círculo: tenemos su esencia pensada; pero por partes. Si pensáramos simultáneamente toda la esencia del círculo, tendríamos la idea del círculo. Solo de Dios es propio tener ideas de las cosas compuestas. Entretanto, conocemos la esencia del círculo mientras pensamos por partes sus requisitos. Reemplaza en nosotros el defecto de la idea cierta imagen sensible, o bien una definición, es decir, un agregado de caracteres en los cuales no es necesaria ninguna semejanza. Siempre reemplaza el lugar de la idea cierta imagen que es sentida toda simultáneamente. Las imágenes excitan los sentidos, los caracteres el pensamiento: aquellas [son] más apropiadas para obrar, éstos para razonar. ${ }^{21}$

Aquí, finalmente, se explica por qué para Leibniz es necesario primero mostrar que Dios es posible para posteriormente concluir que existe necesariamente, a saber, puesto que hay definiciones de algunas cosas máximas (esto es, 'de las que no puede pensarse nada mayor') de las que, sin embargo, puede demostrarse su imposibilidad. Dicho de otro modo, hay nociones que son incapaces de perfección, de absoluto o de lo máximo en su género. ${ }^{22}$ Leibniz considera dos casos, a saber, el número de todos los números ('el número máximo') y el movimiento más veloz (el 'movimiento máximo'). ${ }^{23}$ Dado que hay algunas cosas máximas que son imposibles, Leibniz parecería concluir que no porque Dios sea definido como 'aquello mayor que lo cual nada puede pensarse' se sigue necesariamente que existe. De acuerdo con lo dicho, primero hay que mostrar que es posible.

En el capítulo sexto hemos examinado en detalle la cuestión del número máximo. Por esta razón, no nos detendremos aquí en este asunto. Sobre este caso, solamente basta destacar que el hecho de que Leibniz haya notado que este número es contradictorio lo ha llevado a darse cuenta de que no todas las cosas que son inteligibles constituyen

\footnotetext{
${ }^{21}$ De mente, de universo, de Deo, A VI 3, 462-463. "Itaque nulla est in nobis idea circuli, ut in Deo est, qui omnia simul cogitat. Imago aliqua circuli est in nobis; est et definitio circuli, et ideae sunt in nobis eorum, quae ad circulum cogitandum necessaria sunt. Cogitamus de circulo, demonstramus de circulo, cognoscimus circulum: essentiam eius habemus cognitam; sed per partes. Si essentiam circuli totam simul cogitaremus, haberemus circuli ideam. Solius Dei est ideas habere rerum compositarum. Interea essentiam circuli cognoscimus, cogitando eius requisita per partes. Ideae defectum in nobis supplet imago aliqua sensibilis, aut definitio; sive aggregatum characterum, in quibus nulla opus est similitudine. Semper ideae locum supplet phantasma aliquod quod totum simul sentitur. Imagines sensus excitant, characteres cogitatione: illae ad operandum, [hi] ad ratiocinandum aptiores".

${ }^{22}$ Pacidius Philalethi, A VI 3, 551. OFC, 8, 138.

${ }^{23}$ De mente, de universo, de Deo, A VI 3, 463.
} 
necesariamente una totalidad: "[1]os números, modos, relaciones, no son Entes". ${ }^{24}$ Para completar el argumento de Leibniz, examinaremos la imposibilidad del movimiento máximo. Este caso es examinado por Leibniz de este modo: supongamos una rueda que es puesta a girar con el movimiento más veloz e imaginemos luego que uno de los radios de dicha rueda se prolonga por fuera de ella:

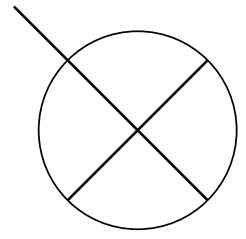

Supuesto esto, un punto del radio extendido por fuera de la rueda recorre, en el mismo tiempo, un espacio mayor que el de la circunferencia de la rueda. De esta manera, se mueve con un movimiento que es más rápido que el de la rueda, es decir, es más veloz que el movimiento más veloz. ${ }^{25}$ De aquí se sigue, en consecuencia, que el movimiento más rápido no es posible. ${ }^{26}$

Resta por ver, entonces, la demostración de que Dios es posible. Para el examen de esta cuestión, Leibniz entiende que "Dios es el sujeto de todas las formas absolutas simples, de las absolutas, esto es, afirmativas". ${ }^{27}$ Más aún, señala que la esencia de Dios consiste en "ser el sujeto de todos los atributos compatibles". ${ }^{28}$ Tengamos en cuenta dos cosas: en primer lugar, el hecho de que Leibniz se interese por mostrar que son compatibles, apunta precisamente a lo que hemos visto con anterioridad, es decir, a mostrar que no se genera una contradicción. ${ }^{29}$ En segundo lugar, para Leibniz las nociones de 'forma simple' y de

\footnotetext{
${ }^{24}$ De mente, de universo, de Deo, A VI 3, 463. "Numeri, modi, relationes non sunt Entia". Sobre la imposibilidad del número máximo también ha dicho en el Pacidius Philalethi, A VI 3, 551. "- Ch.: Quid si audeam dicere nullum omnino esse numerum omnium numerorum, talemque notionem implicare contradictionem? - Th.: Mirum aliquid et audax dixisti, Charine". OFC, 8, 138.

${ }^{25}$ Cabe aclarar que Leibniz está hablando técnicamente de la velocidad lineal, pero no de la angular.

${ }^{26}$ Pacidius Philalethi, A VI 3, 551-552. OFC, 8, 138-139. Similarmente, en De origine rerum ex formis, A VI 3,520 .

${ }^{27}$ De origine rerum ex formis, A VI 3, 519. "Deus est subjectum omnium formarum absolutarum simplicium, absolutarum id est affirmativarum". Piro, 2014: 119-123.

${ }^{28}$ De formis seu attributis Dei, A VI 3, 514. "Attributa Dei infinita, sed eorum nullum essentiam Dei involvit totam; nam essentia Dei in eo consistit, ut sit subjectum omnium attributorum compatibilium". Como señaló Di Bella, 2014: 241-242, para Leibniz el argumento de la posibilidad de Dios es un argumento sobre la compatibilidad de las formas.

${ }^{29}$ En Quod ens perfectissimum sit possibile, A VI 3, 572, Leibniz dice al respecto: "Demonstrationem reperisse videor, quod Ens perfectissimum, seu quod omnem Essentiam contineat, seu quod omnes habeat Qualitates, seu omnia attributa affirmativa, sit possibile, seu non implicet contradictionem. / Hoc patebit si ostendero omnia attributa (positiva) esse inter se compatibilia".
} 
'atributo de Dios' son sinónimas, pues un atributo de Dios es una forma simple. ${ }^{30}$ En las siguientes secciones llevaremos a cabo un examen de las formas simples, motivo por el cual en este lugar nos basta con señalar que se alcanzan si se procede resolviendo unas definiciones en otras hasta llegar a los términos indefinibles. ${ }^{31}$ No obstante, esto no significa una limitación para el conocimiento, sino más bien todo lo contrario, pues las formas simples son percepciones por sí, esto es, sin caracteres. ${ }^{32}$ En consecuencia, son irresolubles. De este tipo son, por ejemplo, 'pensamiento', 'duración', ‘existencia', etc. De esta manera, Leibniz aspira a mostrar que el sujeto de todas las formas simples no implica una contradicción. Dado que la existencia es una de dichas formas, de la posibilidad de Dios se sigue necesariamente su existencia.

La estrategia que sigue Leibniz para mostrar la compatibilidad de todas las formas simples, es decir, de los atributos afirmativos irresolubles, consiste en demostrar el absurdo que supondría su incompatibilidad. Para ello, Leibniz asume dos atributos cualquiera $A$ y $B$ y considera que, si fueran incompatibles, entonces la proposición 'las cualidades $A$ y $B$ no pueden existir en el mismo sujeto’ sería necesaria ya sea por ser idéntica o por ser demostrable. Si se tratara de una identidad, entonces en el enunciado 'donde sea $A$ no puede ser $B^{\prime}$ (que sería una identidad), uno de los atributos explicaría la exclusión del otro. No obstante, Leibniz reconoce que, si esto fuera así, entonces uno de ellos sería negativo del otro, lo cual contradice la hipótesis inicial de que todos los atributos son afirmativos. Si se tratara, por el contrario, de un enunciado demostrable, entonces en el enunciado anterior 'donde sea $A$ no puede ser $B$ ', o uno o los dos atributos deberían ser resolubles, lo que también es contrario a la hipótesis puesto que se los afirmó irresolubles. La conclusión de Leibniz se sigue con claridad: “[p]or lo tanto, no hay ninguna incompatibilidad, de modo que dos cualesquiera cualidades afirmativas son compatibles y, por consiguiente, todas son compatibles con todas; así pues, el Ente que tenga todos los atributos es posible". ${ }^{33}$ El paso de la posibilidad a la existencia del ser necesario es luego algo sencillo: si se ha establecido

\footnotetext{
${ }^{30}$ De formis seu attributis Dei, A VI 3, 514. Leibniz señala, incluso, que por "esencia" debe concebirse el agregado de todos los atributos. Quod ens perfectissimum sit possibile, A VI 3, 574.

${ }^{31}$ De veritatibus, de mente, de Deo, de universo, A VI 3, 509.

${ }^{32}$ De formis seu attributis Dei, A VI 3, 514. Cogitatio non est motus, A VI 3, 587.

${ }^{33}$ Quod ens perfectissimum sit possibile, A VI 3, 572. "Nulla, est ergo, adeoque duae quaelibet qualitates affirmativae sunt compatibiles, adeoque omnes omnibus; possibile est ergo Ens quod omnia habeat attributa". Traducción de OFC 2, 90. En el argumento de Leibniz está supuesto un paso, a saber, que lo que se ha dicho de dos atributos cualesquiera puede decirse de todos, en tanto que ninguno de ellos puede ser negativo o resoluble, pues sería contrario a la hipótesis. Véase Robinet, 1986: 178-179.
} 
que en Él se encuentran los requisitos de todas las cosas para existir, entonces sería contrario a la hipótesis decir o bien que tiene razón para existir en otro, o bien que no tiene ninguna razón para existir. En consecuencia, para Leibniz Dios existe necesariamente. ${ }^{34}$

\section{2. 'Cosas extensas' y 'extensión'}

Anteriormente en nuestro trabajo hemos mencionado que entre mediados de $1675 \mathrm{y}$ el comienzo del año siguiente, Leibniz leyó los Principia Philosophiae de Descartes y dejó múltiples anotaciones y comentarios. Muchos de ellos ponen de manifiesto un desacuerdo de Leibniz en relación con algunas ideas del filósofo francés. ${ }^{35}$ Por ejemplo, Leibniz cuestionó a Descartes por hacer un uso ambiguo del concepto de infinito y también por su teoría del cuerpo. Ahora bien, del cuestionamiento que Leibniz hizo de la teoría cartesiana del cuerpo se desprenden los lineamientos que lo condujeron a un examen metafísico. En efecto, Leibniz llevó a cabo una distinción entre 'cuerpos' o 'cosas extensas' y 'extensión' que se estructura en dos niveles. Como veremos, el sentido de 'extensión' en cada nivel es distinto, aunque ambas acepciones del término están conectadas.

En primer lugar, Leibniz reconoce que, aunque la extensión sea una nota definitoria del cuerpo, no por eso se identifica con él. Como hemos visto en el tercer capítulo, para Descartes la única nota que define esencialmente al cuerpo es la extensión, esto es, la misma nota que define al espacio. En efecto, el filósofo francés considera que, si se le quitara a un cuerpo cualquiera todo lo que no le es esencial, lo único que quedaría sería la extensión. ${ }^{36} \mathrm{Sin}$ embargo, hemos visto que en sus primerísimas reflexiones sobre la naturaleza del cuerpo, Leibniz señaló que es insuficiente considerar a la extensión como la única nota definitoria de la realidad corpórea, pues la impenetrabilidad no puede deducirse

\footnotetext{
${ }^{34}$ Quod ens perfectissimum sit possibile, A VI 3, 572. Di Bella, 2014: 242-243.

${ }^{35} \mathrm{Si}$ bien las referencias a los Principia Philosophiae de Descartes se dan a lo largo de muchos escritos de 1675-1676, una muestra clara de los comentarios de Leibniz puede hallarse en Zu Descartes' Principia Philosophiae, A VI 3, 213-217.

${ }^{36}$ Descartes lleva a cabo este examen mental por el cual le 'quita' a un cuerpo todo lo que no le es esencial fundamentalmente en AT, VIII, 2, § 4 y 11. Estos son precisamente dos parágrafos explícitamente señalados por Leibniz en su lectura de la obra cartesiana: Zu Descartes' Principia Philosophiae, A VI 3, 215. "Part.2. num. 4. et 11. naturam corporis in extensione ait consistere, caetera enim ex corpore tolli posse salva, ut sic dicam corporalitate. Mihi videtur esse qualitatem quandam praeter extensionem quae a corpore tolli nequeat nempe impenetrabilitatem, seu quae facit, ut corpus corpori cedat; nec video quomodo ea possit ab extensione derivari”.
} 
de la tridimensionalidad espacial. Esta idea de Leibniz está también presente en el final de su estadía en París, pues nota, como una consecuencia necesaria de lo anterior, que la extensión debe ser diferenciada de las cosas extensas, esto es, de los cuerpos:

La demostración óptima de que un cuerpo difiere del espacio o extensión, se toma de que de la sola extensión, es decir, de la noción de largo, ancho y profundidad, no puede demostrarse la impenetrabilidad, es decir, [no puede demostrarse] que dos cosas extensas no pueden estar en el mismo lugar, o que es imposible que dos cosas extensas sean sólidas congruentes entre sí, es decir, tales que ningún punto [de una de estas cosas extensas] sea un Punto que no carezca de distancia respecto de un punto de la otra. ${ }^{37}$

En este sentido, se diferencia entre 'cuerpo', que es extenso e impenetrable, y espacio, que es extenso pero no incluye la impenetrabilidad como una de sus notas definitorias. Como vemos, en este primer nivel la extesión se refiere a la espacialidad. Ahora bien, la diferencia entre los cuerpos y la extensión adquiere una dimensión más profunda en los escritos de $D S R$, que trasciende la mera cuestión de si la noción de espacio basta o no para definir al cuerpo. En este sentido, parecería que la distinción entre 'extensión' y 'cosas extensas' se estructura también en un nivel más bien metafísico:

Como en la duración, así también en la Extensión hay cierta forma simple inteligible por sí, cuya idea está presente en la mente, y que por ello es irresoluble. Por lo tanto, [esta forma simple es] aquello según lo cual las cosas se dicen extensas, aquello a lo cual solamente por sí compete la extensión (...). Mientras tanto, será suficiente notar que esta Inmensidad responde a la eternidad, y así como la eternidad no implica por sí una sucesión, así tampoco la inmensidad implica extensión o partes. De allí notaremos que tanto difiere el lugar del cuerpo como el tiempo de la cosa existente: Y con el argumento por el cual Descartes y sus seguidores prueban que el espacio mismo, puesto que [es] extenso, es divisible, y por ello móvil, por lo tanto es un cuerpo; con el mismo [argumento] se probará también que las partes del tiempo son separables, y que una hora puede removerse de otra más larga, lo que repugna a la misma idea de tiempo que tenemos. ${ }^{38}$

\footnotetext{
${ }^{37}$ Catena mirabilium demonstrationum de Summa rerum, A VI 3, 585. "Optima demonstratio, quod corpus a spatio seu extensione differat, ex eo sumitur, quod ex sola extensione seu longitudinis latitudinis et profunditatis notione demonstrari non potest impenetrabilitas, seu quod duo extensa non possint esse in eodem loco sive quod impossibile sit duo esse extensa, solida inter se congruentia, seu quorum nullum punctum sit Punctum, quod non distantia ab aliquo alterius puncto careat".

${ }^{38}$ De magnitudine, A VI 3, 484. "Ut in duratione, ita in Extensione est forma quaedam simplex per se intelligibilis, cuius idea est praesens menti, quaeque adeo est inexplicabilis. Id ergo secundum quod res dicuntur extensae, cui extensio sola per se competit (...). Illud interea notare suffecerit Immensitatem
} 
En consecuencia, la distinción que Leibniz tiene en mente en este punto es entre las cosas extensas, es decir, las que ocupan un cierto espacio, y aquello en virtud de lo cual se dicen precisamente 'extensas', esto es, lo que aquí es llamado 'extensión' y que como veremos es más usualmente llamado 'lo inmenso'. Ahora bien, la cita anterior concluye con una analogía entre el espacio y el tiempo (cuyo objetivo es reforzar la idea de que es absurdo entender cartesianamente que el espacio es un cuerpo) que es notablemente similar a una aclaración que Spinoza ha introducido en la célebre carta XII sobre el infinito a la que nos hemos referido anteriormente en el capítulo anterior. Allí, Spinoza menciona:

Para que usted vea esto con más claridad aún, tome el siguiente ejemplo: a saber, si alguien concibiera abstractamente la duración y confundiéndola con el tiempo, empezara a dividirla en partes, no podría entender jamás, verbigracia, de qué modo pasa una hora. Pues para que pase una hora será necesario que antes pase su mitad y después la mitad del resto y luego la mitad del resto que queda, y si se continúa así infinitamente quitando la mitad del resto, no se podría llegar jamás al final de la hora. Por lo cual muchos, que no están habituados a distinguir los entes de razón de los seres reales, han osado aseverar que la duración se compone de momentos, y así, queriendo evitar a Caribdis, han caído en Escila. ${ }^{39}$

Como dijimos en el capítulo anterior, Leibniz leyó esta carta de Spinoza en febrero de $1676 .{ }^{40}$ Sintéticamente, Spinoza cuestiona allí, entre muchas otras cosas, la idea cartesiana de que una sustancia extensa consta de partes o cuerpos. En efecto, para Spinoza quienes sostengan esto mantienen incorrectamente no solo que la sustancia extensa es finita sino también que está compuesta de partes. ${ }^{41}$ Para el filósofo holandés, la razón de que tendamos a dividir la sustancia extensa es que podemos concebir a la cantidad de dos

\footnotetext{
respondere aeternitati, utque aeternitas per se non dicit successionem, ita nec immensitatem dicere extensionem sive partes. Deinde notabimus, tam differe locum a corpore, quam tempus a re existente; Et quo argumento Cartesius eiusque sectatores probant, spatium ipsum, quia extensum, esse divisibile, adeoque mobile, et proinde esse corpus; eodem probabitur et temporis partes esse separabiles, horamque unani ab alia longius removeri posse, quod cum ipsa quam habemus temporis idea pugnat". Di Bella, 2014: 240, señala que Leibniz intenta mantener "algo parecido a la tradicional relación de «eminencia»".

${ }^{39}$ EP XII (IV, 58). "quod ut adhuc clarius videas, cape hoc exemplum: nempe ubi quis Durationem abstracte conceperit, eamque cum Tempore confundendo in partes dividere inceperit, nunquam poterit intelligere, qua ratione hora ex. grat. transire possit. Nam ut hora transeat, necesse erit, eius dimidium prius transire, et postea dimidium reliqui, et deinde dimidium, quod huius reliqui superset; et si sic porro infinite dimidium a reliquo substrahas, nunquam ad finem horae pervenire poteris. Quare multi, quia Entia rationis a realibus distinguere assueti non sunt, Durationem ex momentis componi, ausi sunt asseverare, et sic in Scyllam inciderunt cupientes vitare Charybdim. Idem enim est Durationem ex momentis componere, quam Numerum ex sola nullitatum additione”. Traducción de Spinoza, 2007: 57 (con algunas ligeras modificaciones nuestras).

${ }^{40}$ Communicata ex literis domini Schulleri, A VI 3, 276-282.

${ }^{41}$ EP XII (IV, 55-56). Communicata ex literis domini Schulleri, A VI 3, 278.
} 
maneras, a saber: por un lado abstracta o superficialmente, en la imaginación y con el auxilio de los sentidos, donde la hallamos finita, divisible, compuesta de partes y múltiple; por otro lado, en el intelecto, donde se percibe tal como es en sí misma, de modo que la hallamos infinita, indivisible y única. ${ }^{42}$ Es posible que Spinoza haya influido en Leibniz en esta cuestión indirectamente, a través de la carta XII y también de Tschirnhaus. En efecto, en las anotaciones sobre sus conversaciones con Tschirnhaus sobre la Ethica de Spinoza, Leibniz subraya que Descartes se ha equivocado al señalar que la extensión implica divisibilidad. ${ }^{43}$ No obstante, esto no significa que Leibniz se limite a repetir las ideas de Spinoza. De hecho, por ejemplo, Leibniz entiende que la afirmación spinozista de que la sustancia extensa no se compone de partes es lo mismo que Thomas White ha querido probar en el prefacio a la Demonstratio immortalitate animae rationalis de Kenelm Digby, tesis a la que nos hemos referido en el capítulo tercero. ${ }^{44}$ Como veremos en el próximo capítulo, para Leibniz un cuerpo es un agregado de partes. Sin embargo, como veremos a continuación, Leibniz parece aproximarse a la crítica de Spinoza a la noción cartesiana de extensión, así como también a otros planteos del filósofo holandés.

\section{3. 'La extensión' o 'lo inmenso'}

La distinción que hace Leibniz entre cuerpos y extensión, acarrea una gran cantidad de cuestiones, como por ejemplo: ¿qué entiende por 'extensión' o 'inmensidad’? ¿Por qué diferencia esto de las cosas extensas? ¿Cómo entiende su relación con ellas? Hallar una respuesta a estas cuestiones no es sencillo, pues el pensamiento de Leibniz en los escritos de 1675 y 1676 es fragmentario, disperso y poco o nada sistemático. En este sentido, en ningún texto de estos años se encuentra un desarrollo articulado de la noción de 'extensión'. No obstante, Leibniz recurrentemente marca algunas notas de esta noción, fundamentalmente cuando se esfuerza por distinguirla de la de espacio. En consecuencia, comenzaremos la reconstrucción de la noción leibniziana de 'extensión' mediante el examen de algunos conceptos de los que se diferencia, como son los de 'lugar' y 'espacio'.

\footnotetext{
${ }^{42}$ EP XII (IV, 56). Vésae también Eth. 1 esc15 (II, 57-60). Communicata ex literis domini Schulleri, A VI 3, 278.

${ }^{43}$ Über Spinozas Ethik, A VI 3, 385.

${ }^{44}$ Communicata ex literis domini Schulleri, A VI 3, 278.
} 
La primera de las nociones antes mencionadas, esto es, la de 'lugar', es entendida por Leibniz como aquella con la cual nos referimos a las cosas que contienen otras. En este sentido, es la noción empleada para referirse al espacio ocupado por un cuerpo en particular. Ahora bien, como veremos un poco más detalladamente en el capítulo siguiente, la noción de 'espacio' es empleada por Leibniz para referirse a la sumatoria de todos los lugares, esto es, de todas las porciones espaciales que son ocupadas por los cuerpos particulares. ${ }^{45}$ El espacio universal, entonces, es una unidad per accidens que resulta del agregado de los lugares de todos los cuerpos. De aquí se desprenden, como consecuencia, una serie de características del espacio.

En primer lugar se sigue que el espacio tiene partes, a saber, los lugares o porciones espaciales ocupadas por los cuerpos (también llamados por Leibniz 'intervalos' e incluso 'espacios', con tal que no se confundan con el 'espacio universal'). ${ }^{46}$ Como el espacio universal es un agregado, los lugares existen con anterioridad respecto de esta unidad per aggregationem. Ahora bien, en segundo lugar, se sigue que el espacio universal varía constantemente, esto es, cambia continuamente de forma. Esta característica depende de la manera como Leibniz ha concebido al movimiento. Sintéticamente, para el filósofo de Leipzig el movimiento de los cuerpos es un cambio o una mutación de lugar. ${ }^{47}$ En consecuencia, cuando un cuerpo cambia de lugar, varía simultáneamente el agregado de todos los lugares. En este sentido, el espacio universal se reconfigura constantemente, según los cuerpos se vayan moviendo. Leibniz se vale de una imagen muy elocuente para representarse al espacio universal: es “(...) como una red, la cual red recibe continuamente otra forma y por eso cambia". ${ }^{48}$ En tercer lugar, Leibniz reconoce que hay ciertas propiedades que se le confieren a los cuerpos y que se determinan necesariamente en relación con el espacio. Así, en la medida en que el lugar es la porción de espacio ocupado por un cuerpo, según el espacio concebimos a las cosas como posicionadas, esto es, teniendo tal o cual posición ('allí', 'aquí', 'en este o aquel lugar', etc.). Del mismo modo, según el espacio concebimos a las cosas como sensibles. Similarmente, la distancia entre

\footnotetext{
${ }^{45}$ De magnitudine, A VI 3, 484.

${ }^{46}$ Así por ejemplo en De origine rerum ex formis, A VI 3, 519.

${ }^{47}$ Véase, a modo de ejemplo, Pacidius Philalethi, A VI 3, 534. OFC, 8, 122. Profundizaremos en esta noción en el capítulo siguiente.

${ }^{48}$ De origine rerum ex formis, A VI 3, 519. "sed hoc spatium universum est Ens per aggregationem, continue variabile; compositum scilicet ex spatiis vacuis plenis, ut rete, quod rete continuo aliam accipit formam, adeoque mutatur".
} 
dos cuerpos es algo que puede concebirse en relación con el espacio. De la misma manera (y este caso será retomando más adelante), concebimos a las cosas como teniendo una figura determinada, pues toda figura presupone una cierta disposición en el espacio. ${ }^{49}$

Tenemos, en síntesis, que el espacio infinito está dividido en partes que cambian constantemente, en la medida en que se modifican los lugares respectivos de los cuerpos. Ahora bien, en este punto de su examen Leibniz parece reconocer que hace falta una cierta naturaleza que dé razón de la unidad en la multiplicidad. Dicho de otra manera, el mero examen del espacio no revela nada que por sí justifique la unidad requerida por la variedad de configuraciones que el espacio adopta sucesivamente, de la misma manera que no revela nada que dé razón de la homogeneidad de las partes que hace posible, en consecuencia, su agregación. Ante estas insuficiencias inherentes al concepto mismo de 'espacio', Leibniz reconoce que hay algo de otra índole que permanece en el continuo cambiar del espacio, algo indivisible en el espacio infinitamente dividido en acto, algo absoluto en el espacio infinito, a saber, la 'extensión' o 'lo inmenso':

Pero puesto que cada espacio está en continua mutación y, a saber, algo persiste en uno y otro, ¿acaso estas dos cosas que persisten [haec duo persistentia] difieren entre sí? ¿Acaso, en verdad, [persiste] en uno y otro la misma -por decirlo así- idea o naturaleza universal? Considero que sí. ${ }^{50}$

Como explicaremos en breve, aquella naturaleza que permanece es concebida por Leibniz como un atributo de Dios:

Supuesto que el espacio tiene partes, a saber, mientras está dividido por los cuerpos en partes vacías y plenas de diversas figuras, se sigue que el espacio mismo es un todo o Ente por accidente, que cambia continuamente y deviene una y otra cosa, a saber, mientras las partes cambian, se extinguen y reaparecen otras. Pero hay algo en el espacio que permanece entre los cambios. Esto es en verdad eterno y no es otra cosa que la misma inmensidad de Dios, a saber, un atributo uno e indivisible y simultáneamente inmenso. ${ }^{51}$

\footnotetext{
${ }^{49}$ De magnitudine, A VI 3, 484.

${ }^{50}$ De veritatibus, de mente, de Deo, de universo, A VI 3, 512-513. "Sed quoniam spatium in continua est mutatione unumquodque scilicet et in utroque aliquid persistit, an haec duo persistentia a se invicem differunt; an vero eadem in utroque velut idea seu natura universalis? Ita puto".

${ }^{51}$ Notizen zur Wissenschaft und Metaphysik, A VI 3, 391. "Posito spatium habere partes, dum scilicet in partes vacuas et plenas, variarum figurarum, a corporibus dividitur, sequitur spatium ipsum esse totum sive Ens per accidens: continuo mutari, et aliud atque aliud fieri: mutatis scilicet partibus, et extinctis, aliisque subnatis. Sed est aliquid in spatio, quod manet inter mutationes, id vero aeternum est, neque aliud est, quam ipsa immensitas Dei, attributum scilicet unum atque indivisibile simul et immensum". De la misma manera, a continuación del pasaje citado en la nota anterior Leibniz añadió: "Et haec natura facit ut Deus illi pariter ac
} 
Mientras algunos intérpretes, como M. Kulstad, han señalado que la afirmación de la extensión como atributo de Dios es una sugerencia de Leibniz acorde con un monismo panteísta, otros, como C. Mercer, han afirmado que, más que un panteísmo, en los escritos metafísicos del filósofo de Leipzig hay un platonismo. ${ }^{52}$ Como veremos en lo que sigue, en lo que respecta a la extensión, parecería haber soporte textual para ambas interpretaciones. En este sentido, es posible que haya algo de verdad en ambas. Sea como fuere, antes de explorar la noción de lo inmenso, debemos notar la importancia que tiene para el examen leibniziano del continuo y la novedad que supone en relación con lo que hemos presentado anteriormente. Para Leibniz los distintos grados de infinito están perfectamente articulados, pues la inmensidad es un atributo de Dios que en consecuencia presupone su infinitud, a la vez que justifica la infinitud del espacio en el sentido analizado en el capítulo anterior, a saber, como lo que no tiene un último punto asignable:

La razón de por qué es algo lo que no tiene término, es decir, algo mayor que cualquier cosa finita, pero no lo infinitamente pequeño, es esta: que lo Máximo en el continuo es algo pero no lo Mínimo; que lo perfectísimo es algo pero no lo Mínimo; que Dios es Algo, la nada no es algo. En el continuo el todo es anterior a las partes. Lo absoluto es anterior a lo limitado. Y así, lo que no tiene término [es anterior] a lo que tiene un término ya que el término es una especie de añadido [accessio quaedam.$^{53}$

La presentación que hemos hecho anteriormente de las características que para Leibniz definen al espacio nos servirá a continuación para detectar aquellas que, en

huic mundo sit praesens (...)" (De veritatibus, de mente, de Deo, de universo, A VI 3, 513). Asimismo, De origine rerum ex formis, A VI 3, 519. "Mens nostra differt a Deo, ut Extensum absolutum, quod maximum, et indivisibile est a spatio, seu loco; sive ut ipsum per se extensum, a loco".

${ }_{52}$ Mercer, 2000, especialmente pp. 92-93; Kulstad, 2000: 101-102. En sintonía con Mercer, Di Bella, 2014: 240-241. Por su parte, Orio de Miguel, 1994: 494-495, menciona que, al final de su vida, Leibniz confesó que desde joven se sintió atraído por la filosofía de Platón. La sugerencia de Mercer es particularmente interesante en contexto de $D S R$ si se tiene en cuenta que, por una parte, se conservan extractos del Fedón y del Teeteto de Platón seleccionados por Leibniz (A VI 3, 284-311) y, por otra parte, que en un pasaje con grandes connotaciones monistas, Leibniz se refirió explícitamente a la doctrina de Platón: A VI 3, 573: "Si ea tantum realiter differunt, quae possunt separari seu quorum alterum perfecte sine altero intelligi potest, sequitur nihil realiter ab altero differre, sed omnia esse unum, quemadmodum dissent et Plato in Parmenide". Refiriéndose al Parménides Leibniz parecería acentuar, en términos platónicos, al Uno como causa del ser (Orio de Miguel, 1994: 497). Por su parte, examinaremos la interpretación de Kulstad desde otro punto de vista en la sección 3.2.1. de este capítulo.

${ }^{53}$ Numeri infiniti, A VI 3, 502. "Ratio cur interminatum, seu quolibet finito maius sit aliquid, non vero infinite parvum, haec est, quod Maximum in continuo est aliquid, non vero Minimum; perfectissimum est quiddam[,] non vero Minimum, Deus est aliquid, nihilum non est aliquid. Totum in continuo est prius partibus. Absolutum prius limitato. Adeoque interminatum, habente terminum, cum terminus sit accessio quaedam". 
contraposición, definen a lo inmenso. ${ }^{54}$ En efecto, mientras que el espacio es concebido por el filósofo de Leipzig como dividido en partes, la inmensidad, como naturaleza o idea universal común a toda porción espacial, es indivisible por carecer de partes. El hecho de no tener en absoluto partes es un indicio de la manera como Leibniz concibió este atributo, pues en consecuencia lo inmenso o la extensión no es algo extenso. Dicho de otra manera, no es lo mismo la idea o naturaleza de la extensión que las cosas extensas. Más aún, es muy posible que en este punto Leibniz se haya visto influido por Spinoza (como siempre, indirectamente). No debemos olvidar que la distinción entre los tres sentidos de infinito de Leibniz se encuentra en unas anotaciones de sus conversaciones con Tschirnhaus sobre las ideas que se presentarían en la Ética del filósofo holandés. La idea leibniziana de que la extensión es lo absoluto de todas las cosas extensas, esto es, "aquello según lo cual las cosas se dicen extensas", ${ }^{55}$ es similar a la tesis de Spinoza de que los atributos de Dios expresan una esencia infinita en su género. ${ }^{56}$ Leibniz conocía esta doctrina de Spinoza gracias a lo que Schuller le había transmitido por correspondencia. En efecto, allí se menciona que Spinoza "[d]efine a Dios así: Aquello que es el Ente absolutamente infinito, esto es, la sustancia que consta de infinitos atributos, cada uno de los cuales expresa una esencia infinita y eterna, y así es inmenso". ${ }^{57}$ Como señala Richard Arthur, esta definición es idéntica con aquella presentada en la Ethica, exceptuando que aquí se introduce la expresión final "y así es inmenso". 58

De lo dicho anteriormente se sigue que lo inmenso tampoco varía o muta, pues todo cambio supone una multiplicidad de partes ('cambiar de lugar' implica un lugar que se abandona y otro que se adquiere). En efecto, la idea es lo que persiste en aquella multiplicidad: "pero la base del espacio es lo extenso mismo por sí, indivisible, y permanece mientras duran los cambios, y no cambia puesto que penetra todas las cosas". 59

\footnotetext{
${ }^{54}$ Laerke, 2009, especialmente en la sección "Absolute extension as an attribute of God", realiza un planteo similar al nuestro, oponiendo las características del espacio y de la extensión.

${ }^{55}$ De magnitudine, A VI 3, 484. Véase la cita en la nota 38.

${ }^{56}$ Eth. 1prop16 (II, 60). Coincidimos con Piro, 2014: 114-119, quien señala que la noción leibniziana de atributo tiene similitudes con la noción de Descartes (las perfecciones divinas son propiedad de la sustancia divina) y también con la de Spinoza (un atributo expresa un ámbito o género de ser determinado).

${ }^{57}$ Communicata ex literis domini Schulleri, A VI 3, 276. "Deum sic definit. Quod sit Ens absolute infinitum, hoc est substantia constans infinitis attributis, quorum unumquodque infinitam et aeternam essentiam exprimit adeoque immensum est".

${ }^{58}$ Leibniz, 2001: 399 (nota 6).

${ }^{59}$ De origine rerum ex formis, A VI 3, 519. "Spatii sunt partes, ipsius extensi per se nullae sunt partes; sed aliqui sunt eius modi. Spatium eo ipso quia in partes dissecatur, mutabile est, et varie dissecatur; imo continue
} 
Por la misma razón, lo inmenso no es infinito como lo es el espacio. En efecto, la posibilidad de que haya siempre un punto más lejano que cualquiera considerado presupone la posibilidad de asignar partes, cosa que no es posible en lo que carece de partes y es indiviso. No obstante, esto no significa para Leibniz que no sea infinito, sino que lo es de un modo absoluto, como naturaleza o idea que es un atributo de Dios. ${ }^{60}$ Una tesis similar se encuentra en la carta XII de Spinoza. En efecto, el filósofo holandés señala allí que hay algunas cosas que son infinitas por fuerza de la causa en la que están (inhaerent). Leibniz introduce en este punto una nota: "como la duración, la extensión". ${ }^{61}$ Se entiende que, en la medida en que son infinitas por ser atributos de la sustancia, la extensión es interpretada, en términos leibnizianos, de un modo absoluto. ${ }^{62}$

Ahora bien, la manera en que Leibniz justifica el hecho de que lo inmenso penetre todas las cosas, aunque no tenga partes, es una consecuencia de reconocer que hay ciertos modos o modificaciones suyas. El concepto de modo o modificación de los atributos también fue presentado por Leibniz de manera dispersa. Ahora bien, esta noción es muy importante en el pensamiento de Spinoza, para quien los modos son las afecciones de la sustancia, es decir, lo que es en otro, por medio del cual es también concebido. ${ }^{63}$ Para el filósofo holandés, los modos son lo que se sigue de la naturaleza de Dios, esto es, la natura naturata. ${ }^{64}$ Leibniz conocía la noción de modo de Spinoza, puesto que se encuentra en la carta XII. ${ }^{65}$ Una aproximación a la manera como Leibniz concibió los modos puede desprenderse de este pasaje en el cual explica la diferencia entre la inmensidad y los modos que le corresponden:

\footnotetext{
aliud atque aliud est, at basis spatii, ipsum per se extensum, indivisibile est, manetque durantibus mutationibus, neque immutatur, quia omnia penetrat. (...). Perplacet itaque, ut hoc ut a spatio distinguam, vocem ipsum Immensum. Immensum itaque est, quod in continua spatii mutatione perstat, hoc ergo terminos nec habet nec habere potest, estque unum et indivisibile. Posses et appellare ipsum Expansum".

${ }^{60}$ De origine rerum ex formis, A VI 3, 519.

${ }^{61}$ Communicata ex literis domini Schulleri, A VI 3, 281. "Ex omnibus jam dictis clare videre est, quaedam sua natura esse infinita, nec ullo modo finita concipi posse; quaedam vero vi causae cui inhaerent (...)". Leibniz introduce como nota: "ut duratio, extensio".

${ }^{62}$ En coincidencia con lo que hemos dicho y también con lo que veremos en lo que sigue, Laerke, 2009, ha señalado atinadamente que la noción de lo inmenso de Leibniz recuerda al atributo de la extensión de Spinoza en tres aspectos, a saber, en que lo inmenso (a) es infinito, eterno e indivisible, como la extensión es para Spinoza; (b) no tiene partes, aunque sí modificaciones, tal como la extensión para Spinoza; (c) es un atributo de Dios, tal como la extensión para Spinoza.

${ }^{63}$ Eth. 1def5 (II, 45).

${ }^{64}$ Eth. 1esc29 (II, 71).

${ }^{65}$ Communicata ex literis domini Schulleri, A VI 3, 277.
} 
De aquí es suficientemente evidente que lo inmenso mismo no es un intervalo ni es un lugar ni es cambiable, pero [también] que las modificaciones no se producen por un cambio suyo sino por el sobreañadido de otra cosa, a saber, de la Mole o Masa. De la adición de la mole y de la masa resultan los espacios, lugares, intervalos, el agregado de los cuales da el Espacio Universal (...). ${ }^{66}$

Es posible que, como explicaremos un poco más adelante, Leibniz haya entendido los modos como las cosas particulares que no son máximas sino limitadas, es decir, las cosas que pertenecen a un género. Por eso, los lugares, intervalos y demás son los modos de la extensión, esto es, las cosas que se dicen extensas. Una aproximación similar a la descrita se encuentra en relación no al examen leibniziano de la extensión sino del pensamiento. En efecto, para el filósofo de Leipzig los pensamientos difieren entre sí en razón de los objetos. ${ }^{67}$ Hay una modificación en el pensamiento en el sentido de que se trata de un pensamiento de una cosa determinada, es decir, es un modo particular de pensar aunque no es una 'parte' del pensamiento. Los conceptos de modificación y de parte no son idénticos, pues las modificaciones no componen los atributos o formas (es decir, no son partes suyas). Quizás haya influido en Leibniz el concepto cartesiano de 'modo' presente en los Principia Philosophiae, como manera de ser de un atributo cuando la sustancia es afectada o variada (es decir, por ejemplo, los modos de la extensión son las distintas maneras de ser extenso). ${ }^{68}$ En consecuencia, el objeto determina al pensamiento, esto es, le pone términos, lo limita. De esta manera, el pensamiento no se modifica a sí mismo, por su propia virtud, sino que para ello necesita del objeto. Las modificaciones de lo inmenso o de cualquier otro atributo suceden de manera análoga. Dado que la extensión es inmutable, para que se produzca una modificación en ella se requiere que se le añada otra cosa que le ponga términos, a saber, la 'mole o masa'. Si bien examinaremos este concepto en el siguiente capítulo, aquí alcanza con reconocer que es aquello que limita lo absoluto de las formas o atributos. En el caso de lo inmenso, las modificaciones producidas por la mole o masa son

\footnotetext{
${ }^{66}$ De origine rerum ex formis, A VI 3, 519. "Satis ex his patet ipsum hoc immensum non esse intervallum, nec esse locum, nec esse mutabile; modificationes autem fieri nulla eius mutatione, sed superadditione alterius, nempe Molis, sive Massae; ex additione molis et massae resultant spatia, loca, intervalla, quorum aggregata dant Spatium Universum, sed hoc spatium universum est Ens per aggregationem, continue variabile; compositum scilicet ex punctis vacuis plenis, ut rete, quod rete continuo aliam accipit formam, adeoque mutatur; sed quod in illa mutatione perstat, est ipsum immensum. Ipsum autem immensum est Deus quatenus cogitatur esse ubique, seu quatenus eam perfectionem, sive formam absolutam affirmativam quae tribuitur rebus, quando dicitur eas esse alicubi, continet".

${ }^{67}$ De origine rerum ex formis, A VI 3, 518.

${ }^{68}$ Principia Philosophiae, AT, VIII, 1, §56. Seguimos a Gaukroger, 2002b: 88.
} 
los lugares y las figuras de los cuerpos. ${ }^{69}$ Esto explicaría el pasaje citado anteriormente, en el que Leibniz menciona que "[1]o absoluto es anterior a lo limitado. Y así, lo que no tiene término [es anterior] a lo que tiene un término ya que el término es una especie de añadido", ${ }^{70}$ como en este caso la 'mole' o 'masa' es lo que introduce un término. De esta manera, se obtiene un panorama que articula de manera clara la extensión y el espacio, a saber: como modificaciones de la extensión devienen los lugares, el agregado de los cuales da lugar al espacio universal. En consecuencia, lo inmenso es la base y el principio del espacio aunque no se identifica con él. ${ }^{71}$

De lo anterior se sigue que, dado que toda modificación de una forma es una limitación, para Leibniz es imposible la existencia de modificaciones que sean máximas en su género. ${ }^{72}$ En este sentido, algunos casos reiteradamente mencionados por Leibniz son la imposibilidad de existencia de un movimiento más veloz que cualquier otro, así como de una figura máxima. En efecto, el filósofo de Leipzig argumenta que "[n]o puede existir el movimiento más veloz puesto que el movimiento es una modificación y es la traslación de cierta cosa en cierto tiempo. En una palabra, así como no puede darse la figura máxima". ${ }^{73}$

Ahora bien, hay un aspecto del examen de la extensión (y que vale asimismo para los restantes atributos) que es clave en el pensamiento leibniziano del final de la estadía en París, a saber, el que corresponde a la pregunta por lo que podríamos llamar la 'condición de existencia' de lo inmenso. En efecto, ¿es algo real? Como veremos en detalle más adelante, Leibniz entiende que en nuestra mente tenemos una idea de la extensión que se corresponde con el atributo de Dios. En este sentido, el atributo es, en cuanto tal, algo cuya existencia no depende de nuestra mente y a lo que le corresponde la idea que tenemos. Quizás podría decirse con Spinoza que "[u]na idea verdadera debe ser conforme a lo ideado por ella", esto es, que lo que se contiene objetivamente en el entendimiento debe darse

\footnotetext{
${ }^{69}$ De origine rerum ex formis, A VI 3, 518. De acuerdo con Laerke, Leibniz mantendría un paralelismo en términos, aunque no idénticos, al menos similares a los de Spinoza, pues como vimos, concibió que las sensaciones son modificaciones de la mente del mismo modo que las figuras son modificaciones de la extensión (Laerke, 2009, sección "Absolute extension as an attribute of God").

${ }^{70}$ Numeri infiniti, A VI 3, 502. Véase la cita en la nota 53.

${ }^{71}$ De origine rerum ex formis, A VI 3, 519. Notizen zur Wissenschaft und Metaphysik, A VI 3, 392.

${ }_{73}^{72}$ De formis seu atributis Dei, A VI 3, 514.

${ }^{73}$ De origine rerum ex formis, A VI 3, 520. "Motus celerrimus, esse non potest, quia motus est modificatio. Estque certae rei translatio; in certo tempore. Prorsus quemadmodum figura maxima dari non potest".
} 
necesariamente en la naturaleza. ${ }^{74}$ En consecuencia, el espacio imaginario, es decir, la idea de una extensión, no solamente es para Leibniz algo real sino que incluso “(...) es máximamente real; es, en efecto, Dios mismo en cuanto es considerado en todas partes, esto es, inmenso". ${ }^{75}$ Este es, quizás, uno de los aspectos más novedosos del pensamiento de Leibniz en este período: rigurosamente hablando, el espacio imaginario es real como atributo de Dios.

\section{Otros atributos relacionados con el problema del continuo}

Lo absoluto es anterior a lo limitado no solamente en el espacio sino en el continuo en general. En este sentido, para Leibniz hay una explicación análoga de lo que se ha dicho para el espacio a propósito del tiempo, del movimiento, de los cuerpos, y demás. De esta manera, así como el atributo de la extensión está en relación con el espacio, así también hay otros atributos que ofician de lo permanente en sus respectivos géneros:

En síntesis, así como en el espacio hay algo divino, la inmensidad misma de Dios, del mismo modo en la mente hay algo divino, lo que Aristóteles llamaba intelecto agente; y esto es lo mismo que la omnisciencia de Dios. Del mismo modo que aquello que es divino y eterno en el espacio es lo mismo que la inmensidad de Dios, también aquello que es divino y eterno en el cuerpo o ente móvil es lo mismo que la omnipotencia de Dios, y también aquello que es divino en el tiempo es lo mismo que la eternidad. ${ }^{76}$

De esta manera, Leibniz señala al menos cuatro formas absolutas que están en la base de sus respectivas modificaciones: para el espacio, la inmensidad; para la mente, la omnisciencia; para 'el cuerpo o ente móvil', la omnipotencia; para el tiempo, la eternidad. A continuación examinaremos en primer lugar el atributo de la eternidad y su carácter de base o principio del tiempo y luego haremos lo correspondiente con la omnisciencia y el

\footnotetext{
${ }^{74}$ Eth. 1ax6 (II, 47). "Idea vera debet suo ideato convenire". Traducción de Spinoza, 2011: 58. Véase Eth. 1prop30 (II, 71).

${ }^{75}$ De origine rerum ex formis, A VI 3, 519. "Eodem plane modo Mens divina est ad nostram, ut spatium quod vocant imaginarium (cum sit maxime reale, est enim ipse Deus, quatenus consideratur ubique seu immensus) est ad locum, et varias in ipso immenso natas figuras".

${ }^{76}$ Notizen zur Wissenchaft und Metaphysik, A VI 3, 391-392. “(...) prorsus ut in spatio est aliquid divinum, ipsa immensitas Dei, ita in mente est divinum quiddam, quod Aristoteles vocabat intellectum agentem, et hoc idem est cum omniscientia Dei; quemadmodum id quod in spatio divinum atque aeternum est, idem est cum Dei immensitate et id quod in corpore sive ente mobili divinum atque aeternum, idem est cum Dei omnipotentia; et id quod in tempore est divinum idem est cum aeternitate". Véase también De origine rerum ex formis, A VI 3, 519-520.
} 
pensamiento. Por una cuestión de orden, dado que implica profundas modificaciones de la teoría leibniziana del movimiento expuesta en la segunda parte de esta tesis, postergamos el examen del atributo de la omnipotencia y su condición de lo absoluto respecto del ente móvil para el próximo capítulo.

\subsection{Tiempo y eternidad}

Como se ha dicho, los atributos son análogos entre sí, en el sentido de que para Leibniz la inmensidad es al espacio lo que la eternidad al tiempo. Sin embargo, el examen del atributo de la eternidad es quizás más complejo que el de la extensión, puesto que es una noción para la que el filósofo de Leipzig reconoce múltiples significados. De acuerdo con Parkinson, esta variedad de los sentidos del término manifiesta cierta ambigüedad en el concepto leibniziano de eternidad. ${ }^{77}$ No obstante, a continuación mostraremos que, lejos de haber una ambigüedad, los tres sentidos son pensados como articulados y complementarios.

En primer lugar, hay un sentido según el cual Leibniz concibe a la eternidad como algo que es homogéneo con el tiempo. De esta manera, la eternidad es entendida como un tiempo que carece por completo de término. ${ }^{78}$ En este sentido, es tomada como un tiempo infinito de acuerdo al primero de los significados de este término que hemos visto en el capítulo anterior. Precisamente por eso, no obstante, esta primera acepción no es el correlato de lo inmenso en lo que respecta al examen del tiempo. En segundo lugar, Leibniz concibe a la eternidad "como un atributo de algo eterno", y de este modo "será la duración a través de un tiempo sin término". ${ }^{79}$ El concepto clave que tiene lugar en este sentido de eternidad, a saber, el de duración, no es sinónimo del de tiempo: mientras que el primero es concebido por el filósofo de Leipzig como la continuidad en el existir, el segundo de ellos es definido como "algo continuo según lo cual se entiende que algo dura". ${ }^{80}$ De esta manera, 'un día' no es una duración, puesto que no hace referencia a la existencia de algo sino a cierta medición de su duración $-\mathrm{y}$ en consecuencia es un tiempo. Algo distinto es

\footnotetext{
${ }^{77}$ En la introducción de PDSR, 1992: xxxvii-xxxviii.

${ }_{78}^{78}$ De magnitudine, A VI 3, 484.

${ }^{79}$ De magnitudine, A VI 3, 484. "sin ut atributum alicuius aeterni, erit duratio per tempus interminatum".

${ }^{80}$ De magnitudine, A VI 3, 484. "Duratio est existendi continuitas. Tempus non est duratio, non magis quam spatium collocatio. Et ineptum foret dicere, diem se durationem. Cum contra Hemerobia per diem durare dicamus. Tempus est continuum quoddam secundum quod aliquid intelligitur durare. Sed ut rem darius explicem, cogitandum est eam potissimum tempori naturam tribui, ut plura simul esse intelligantur".
} 
para Leibniz decir que 'hay cosas que duran un día', pues en dicho caso la referencia está puesta en la existencia, cuya duración es luego medida temporalmente en días. En este punto parecería haber una cierta similitud en relación con el planteo de Spinoza, pues en la carta XII el filósofo holandés distingue entre la duración, que es algo real, y el tiempo, que es un ente de razón mediante el cual medimos la duración. ${ }^{81}$ No obstante, para Spinoza la eternidad permite explicar la existencia de la sustancia, así como la duración permite explicar la de los modos, de manera tal que no tendría sentido para él hablar de la 'eternidad' como una 'duración a través de un tiempo sin término', esto es, de una duración eterna. $^{82}$

Finalmente, en tercer lugar, Leibniz reconoce un sentido de eternidad que no está relacionado ni con el tiempo ni con la duración, aunque está enlazado con los dos significados anteriores del término en cuestión: “[p]ero el verdadero origen y la naturaleza íntima de la eternidad es la misma necesidad del existir, que no dice por sí ninguna sucesión, aunque hace que coexista lo que es eterno con todas las cosas". ${ }^{83}$ De esta manera, la eternidad está referida no a la duración de la existencia sino a su necesidad. En este sentido para Leibniz hay una cierta necesidad en las cosas por el mero hecho de existir, sin que esto signifique que ellas son necesarias por sí, sino que hay causas necesarias suyas. ${ }^{84}$ Así, las razones de las cosas son eternas. Como un ejemplo de la necesidad de la existencia de las cosas, Leibniz considera la imposibilidad de deshacer un hecho que ha sucedido en el pasado. En efecto, en las cosas pasadas hay una cierta necesidad que implica la imposibilidad de no haber sucedido: “[e]s imposible que Pedro no haya sido. Por lo tanto es necesario que Pedro haya sido. Por lo tanto, la existencia pasada de Pedro es necesaria". ${ }^{85}$ De este modo, según este tercer sentido de eternidad se dice que hay algo eterno en las cosas, en la medida en que hay una cierta necesidad en ellas aunque no sean necesarias por sí mismas. En consecuencia, según este sentido la eternidad penetra o atraviesa todas las

\footnotetext{
${ }^{81}$ EP XII (IV, 56-57).

${ }^{82}$ EP XII (IV, 54-55).

${ }^{83}$ De magnitudine, A VI 3, 484. "Sed vera origo atque intima aeternitatis natura est ipsa existendi necessitas, quae nullam per se dicit successionem, etsi fiat ut omnibus coexistat, quod aeternum est".

${ }^{84}$ De arcanis sublimium vel de summa rerum, A VI 3, 472.

${ }^{85}$ De mente, de Deo, de universo, A VI 3, 434. "Propositio haec necessaria est: Quicquid futurum sit id futurum sit. Factum infectum reddi non potest. Impossibile est Petrum non fuisse. Ergo Petrum fuisse necessarium est. Ergo praeterita Petri existentia necessaria est”.
} 
cosas, análogamente a como se ha dicho que la inmensidad persiste en el espacio continuamente variable.

\subsection{Mentes individuales e intelecto agente universal}

Al comienzo de la cuarta sección de este capítulo, hemos citado un escrito en el que Leibniz señaló que, así como la inmensidad y la eternidad son lo divino y eterno a propósito respectivamente del espacio y el tiempo, así también hay algo absoluto en relación con las mentes, “(...) lo que Aristóteles llamaba intelecto agente; y esto es lo mismo que la omnisciencia de Dios". Este oscuro pasaje ha suscitado por lo menos dos intensas discusiones entre los intérpretes del pensamiento leibniziano. Por un lado, ha generado una discusión sobre si Leibniz mantuvo o no una concepción de tipo averroísta, esto es, si entendió que hay un único intelecto agente universal común a todas las mentes. Ahora bien, por otro lado, algunos intérpretes han utilizado este pasaje para justificar que Leibniz habría mantenido un monismo sustancial en los escritos de $D S R$, mientras que otros consideran que defiende además un pluralismo complementario. Para C. Wilson y E. De Tommaso, por ejemplo, la indicación de Leibniz de que el intelecto agente es lo divino en las mentes es una expresión con implicancias que la hacen directamente afín con una concepción panteísta. ${ }^{86}$ Más aún, en su argumentación, Wilson hace depender la primera de las cuestiones (el presunto averroísmo) de la segunda (el monismo o pluralismo). Sin embargo, creemos que no es correcto decir ni que Leibniz fue averroísta ni que defendió exclusivamente un monismo. Ahora bien, para justificar esto y tener un panorama claro de la manera en que Leibniz entendió que el 'intelecto agente' es lo divino en las mentes,

dividiremos nuestro análisis en dos partes: en primer lugar abordaremos el problema del monismo o pluralismo en los escritos de $D S R$ y en segundo lugar examinaremos cómo entendió la relación entre la omnisciencia divina y las mentes creadas.

${ }^{86}$ Wilson, 1999: 224-228; De Tommaso, 2014: 102. 


\subsubsection{Pluralismo de entes en $D S R$}

En un escrito de finales de 1676, Quod ens perfectissimum sit possibile, Leibniz reconoció que, si todas las cosas encuentran en Dios los requisitos para existir, entonces ellas "no se distinguen como sustancias, sino como modos". ${ }^{87}$ En este sentido, como dijimos antes, algunos estudiosos del pensamiento de Leibniz han entendido que habría defendido que hay una única sustancia de la cual todas las cosas son modos. Así, por ejemplo, M. Laerke, se refiere a un ‘unisustancialismo’ de Leibniz, mientras que, R. Adams o más recientemente M. Kulstad, a un 'monismo sustancial'. ${ }^{88}$ Por su parte, A. Blank ${ }^{89}$ considera que en el pensamiento leibniziano de estos años opera una distinción entre dos sentidos de la noción de 'sustancia', a saber, por una parte como lo que no requiere de otra cosa para existir y por otra parte como una cosa activa. En este segundo sentido, Leibniz podría haber entendido que, como el pensamiento es una acción, las mentes son cosas activas. ${ }^{90}$ En consecuencia, de acuerdo con Blank, para Leibniz hay un monismo sustancial (Dios como la sustancia que no requiere de otra cosa para existir) al mismo tiempo que un pluralismo de sustancias tipo mentes (como cosas activas). De acuerdo con este exégeta, los dos sentidos no son incompatibles, puesto que el segundo de ellos no requiere independencia en el ser como sí el primero de ellos: “(...) hay una sola sustancia (en el sentido de 'ser independiente') compatible con la afirmación de que hay muchas sustancias (en el sentido de 'cosas activas')". 91

Sin embargo, la afirmación de una pluralidad de sustancias se enfrenta a una gran dificultad, a saber, que en los escritos de DSR Leibniz utiliza pocas veces la noción de sustancia y lo hace para referirse a Dios como sujeto de todos los atributos afirmativos

\footnotetext{
${ }^{87}$ Quod ens perfectissimum sit possibile, A VI 3, 573. "Res omnes non ut substantias [nota de Leibniz: radicaliter] sed modos distingui, facile demonstrari potest, ex eo quod quae radicaliter distincta sunt, eorum unum sine altero perfecte intelligi potest, id est omnia requisita unius intelligi possunt, quin omnia requisita alterius intelligantur. At vero hoc ipsum non est in rebus, quia enim Ultima ratio rerum unica est, quae sola continet aggregatum omnium requisitorum, omnium rerum, manifestum est, omnium rerum requisita esse eadem; adeoque et essentiam, posito essentiam esse aggregatum omnium requisitorum primorum, omnium ergo rerum essentia eadem, ac res non differunt nisi modo, quemadmodum Urbs spectata ex summo loco differt a spectata ex campo".

${ }^{88}$ Laerke, 2008: 500-517; Adams, 1994: 123-124; Kulstad, 1999a: 245; Kulstad, 2000.

${ }^{89}$ Blank, 2001 y 2014. La conclusión sobre el pluralismo sustancial también es abordada en Blank, 2009.

${ }^{90}$ De origine rerum ex formis, A VI 3, 518.

${ }^{91}$ Blank, 2001: 223. "(...) there is only one substance (in the sense of 'independent being') compatible with the claim that there are many substances (in the sense of 'active things')". La traducción es nuestra.
} 
compatibles. ${ }^{92}$ En este sentido, no encontramos un texto en el que Leibniz diga explícitamente que hay un pluralismo de sustancias. Sin embargo, esto no anula por completo la interpretación de Blank, pues Leibniz reserva una denominación especial para referirse a las mentes, tanto la divina como las restantes, a saber: ellas son entes. El filósofo de Leipzig emplea el concepto de ente, por una parte, para diferenciar a Dios de las cosas: “(...) solemos decir que 'Dios es un Ente', pero no solemos decir que 'Dios es una cosa'". 93 Sin embargo, por otra parte, el concepto de ente no es exclusivo de Dios sino de las mentes en general, pues para Leibniz las mentes son "los verdaderos Entes" (omnia vera Entia seu Mentes). ${ }^{94}$ Esta tesis de Leibniz implica un cambio importante en relación con sus planteos previos. Por ejemplo, en la célebre carta que Leibniz le envió a J. Thomasius en abril de 1669 y que hemos examinado parcialmente en el tercer capítulo, afirmó que no se da en el mundo ningún ente exceptuando la mente, el espacio, la materia y el movimiento. ${ }^{95}$ No es nuestra intención aquí centrarnos en todas las consecuencias que podría tener este cambio en el pensamiento de Leibniz. Basta con señalar que en el contexto de DSR, Leibniz sostuvo un pluralismo de 'verdaderos entes' tipo mentes.

Ahora bien, el hecho de que pueda hablarse de una pluralidad de entes se funda, al menos parcialmente, en el hecho de que puede reconocerse que hay algo que permanece idéntico en cada mente. Para Leibniz se trata, en cada caso, de algo particular. Así, por ejemplo, señala en De veritatibus, de mente, de Deo, de universo:

En nuestra Mente hay una percepción o sensación de sí mismo, en tanto que una cierta cosa particular que está siempre en nosotros, puesto que siempre que aplicamos una palabra, entonces reconocemos al instante [que hemos hecho] esto. (...). Esto es lo que vulgarmente llamamos 'idéntico', esta facultad en nosotros independiente de las cosas externas. ${ }^{96}$

\footnotetext{
${ }^{92}$ Quod ens perfectissimum sit possibile, A VI 3, 573. Similarmente, De formis seu attributis Dei, A VI 3, 514.

${ }^{93}$ De origine rerum ex formis, A VI 3, 519. “(...) solemus dicere Deus est Ens, non solemus dicere Deus est res".

${ }^{94}$ De veritatibus, de mente, de Deo, de universo, A VI 3, 510.

${ }^{95}$ Leibniz a Thomasius, A II 1, 34.

${ }^{96}$ De veritatibus, de mente, de Deo, de universo, A VI 3, 509. "Mente nostra est perceptio seu sensus sui, ut certae cuiusdam rei particularis, haec semper in nobis, quia quoties vocabulum adhibemus, tunc id statim agnoscimus. (...) hoc est quod vulgo appellamus idem, haec in nobis facultas independens ab externis". Blank, 2009, lleva a cabo un análisis similar, en el que concluye que las nociones de actividad interna (especialmente la reflexión) y de persistencia a lo largo del tiempo dan lugar a una noción de 'sujeto' bien determinada y acorde con una visión pluralista.
} 
Leibniz se refiere también a "la identidad de la mente" (mentis identitas) o a la “memoria intelectual” (memoria intellectualis) para hablar de lo 'idéntico' en cada mente. 97 De alguna manera, pareciera que, para ser un 'ente', no es necesario ser 'sustancia', aunque sí poseer una identidad mental. Ahora bien, Leibniz nota que hay algo que permanece en una mente, “(...) como algo particular que posee ciertas modificaciones, lo que, a saber, percibe estas o aquellas cosas". ${ }^{98}$ El hecho de que una mente sea concebida por Leibniz como algo que posee modificaciones podría llevar a pensar que la considera como una sustancia. Como dijimos, Leibniz conocía la definición de ‘modo’ que Spinoza presentó en la célebre carta sobre el infinito enviada a L. Meyer en 1663, como afección de la sustancia. ${ }^{99}$ Más aún, cuando Leibniz lee esta carta de Spinoza, hace la siguiente anotación: “[a]sí pues, ¿la definición de un modo no puede ser de alguna manera la definición de una sustancia?". ${ }^{100}$ Si esta pregunta de Leibniz se considera conjuntamente con otra anotación que hizo en el mismo escrito de Spinoza, a saber, que aún no ha sido probado que la sustancia no puede concebirse sino como infinita, ${ }^{101}$ se obtiene un fuerte indicio de que concibió a las mentes como sustancias. En este sentido, quizás podría hablarse de un pluralismo de sustancias en los escritos de $D S R$, sin que esto signifique que las mentes sean independientes. A pesar de esto, preferimos referirnos a esta tesis leibniziana como la afirmación de un 'pluralismo de entes tipo mentes'. ${ }^{102}$

\subsubsection{Mentes y omnisciencia}

Como mencionamos anteriormente, quienes defienden que Leibniz habría afirmado exclusivamente un monismo sustancial en los escritos de DSR suelen interpretar en

\footnotetext{
${ }^{97}$ De veritatibus, de mente, de Deo, de universo, A VI 3, 509.

${ }^{98}$ De veritatibus, de mente, de Deo, de universo, A VI 3, 509. "Non video quomodo homo seu mens mori seu extingui possit durantibus illis reflexionibus. Manet aliquid in modificationibus non ut ipsi per se extensio in spatio, sed ut quiddam particulare, ceitis modificutionibus praeditum, quod scilicet haec vel illa percepit".

${ }^{99}$ Communicata ex literis domini Schulleri, A VI 3, 277.

${ }^{100}$ Communicata ex literis domini Schulleri, A VI 3, 277. "Ergone certa ratione definitio modi definitio substantiae esse potest?".

${ }^{101}$ Communicata ex literis domini Schulleri, A VI 3, 278.

${ }^{102}$ En una carta a Bourguet de 1714, Leibniz indicó que, si no hubiera mónadas, Spinoza tendría razón (GP III, 575). En este sentido, la afirmación de un pluralismo complementario a la sustancia divina, en oposición a la concepción de Spinoza, parece haber recorrido toda la obra de Leibniz, desde el período de DSR en adelante. Morfino, 2014: 97-112, analiza esta cuestión en el pensamiento tardío de Leibniz a propósito de la distinción entre la noción spinozista de 'modo' y la leibniziana de 'mónada'.
} 
términos averroístas el pasaje citado al comienzo de la cuarta sección según el cual el intelecto agente es a la mente lo que la inmensidad es al espacio. En este sentido, por ejemplo, Laerke subraya que en sus escritos de juventud (especialmente en De transubstantiatione de 1668), Leibniz se habría mostrado benévolo frente al averroísmo. ${ }^{103}$ Averroes (1126-1198) entendió que, como los inteligibles son únicos y eternos, el intelecto agente, esto es, el que los actualiza en el intelecto material, debe también serlo. ${ }^{104}$ En consecuencia, el intelecto agente es único y universal. ${ }^{105}$ Esta concepción averroista ha sido retomada recurrente por defensores de un monismo de la sustancia, como John Selden (1584-1654) en la temprana filosofía moderna, pues permite justificar que la acción de las mentes no está estrictamente en ellas sino en la única sustancia activa. ${ }^{106}$ No obstante, la afirmación del intelecto agente como algo divino y eterno en las mentes supone un desafío para la interpretación pluralista que defendimos en la sección anterior. En este sentido, A. Blank (2014) ha detectado y abordado el siguiente problema: si la acción que supone el intelecto agente no es propia de la mente particular sino algo común a todas ellas, entonces no se daría una pluralidad en sentido estricto. En efecto, como vimos antes, para Blank el pluralismo se funda en el hecho de comprender que una sustancia es 'algo activo'. En consecuencia, debe examinarse cómo ha de entenderse la afirmación de Leibniz de que el

${ }^{103}$ Laerke, 2008: 488-489.

${ }^{104}$ Averroes, Tafsir (2003: 20). El intelecto material es aquel que está en potencia de recibir las formas inteligibles materiales. De allí que, si se reconoce un intelecto material, en potencia, es en consecuencia necesario un intelecto en acto, esto es, el intelecto agente, "que hace pasar estas intenciones de la potencia al acto" (p. 31, véase también, entre otros, p. 35).

${ }^{105}$ Averroes, Tafsir (2003: 36-37). “Así pues, según el modo mediante el cual [los inteligibles] son únicos, necesariamente son eternos, al no separarse del sujeto recibido, es decir, del motor, que es la intención de las formas imaginativas, y no haber allí obstáculo por parte del receptor. Pues la generación y la corrupción no se produce en ellos sino por la multiplicidad que les afecta, y no por el modo mediante el cual son únicos. Y por esto, cuando respecto de un individuo se corrompe alguno de los primeros inteligibles por la corrupción del sujeto mediante el cual está unido con nosotros y es verdadero, ese inteligible necesariamente es incorruptible en sentido absoluto, pero corruptible respecto a cada uno de los individuos. Es de este modo como podemos afirmar que el intelecto especulativo es uno en todos [los hombres]". Véase también p. 57.

${ }^{106}$ En su trabajo On the Law of Nature and Nations according to the Teaching of the Hebrews de 1640, Selden señala: "El emperador y filósofo Marco Aurelio dice [...]: «Esas cosas que agradan al genio o demonio que Júpiter asignó a cada uno de nosotros como gobernante y guía, deberían ser del agrado del ser humano activo. En efecto, se trata de una partícula de la naturaleza divina, me refiero a la mente y razón en cada uno de nosotros». Similares términos no dejan de aparecer en los escritos de los paganos. Si bien Platón, Prisciano de Lidia y Alejandro de Afrodisia se muestran en esto más explícitos [...] Incluso el propio Aristóteles sigue en parte de su obra esa misma línea [...] En los árabes encontramos una opinión concordante, en Avicena, Averroes, Algazel y otros. Aun no estando de acuerdo entre ellos respecto a que en los humanos la inteligencia y su grado de realización se deba a un intelecto agente, sin embargo sí aceptan que esto se explique por el orden y prescripción de algún numen. Pero no sostienen que la forma humana sea ese numen o una parte de él, sino que es algo más divino". Tomamos la traducción de Blank, 2014: 233. 
intelecto agente es lo divino en las mentes en el contexto de un pluralismo sustancial (o como preferimos decir, de entes tipo mentes). En respuesta, Blank defiende que a lo largo de la historia se encuentran concepciones en las que se sostiene un único intelecto agente al mismo tiempo que se reconoce una pluralidad de sustancias. Tal es el caso de Alessandro Achillini (1463-1512), quien de acuerdo con Blank “(...) defiende que la teoría de un intelecto agente universal es compatible con la visión de que las mentes humanas son genuinas sustancias poseedoras de acciones cognitivas espontáneas". ${ }^{107}$ En pocas palabras, para Achillini hay un único intelecto agente universal que se identifica con el primer motor, un único intelecto paciente capaz de entender las formas abstraídas por el intelecto agente, así como también cada cuerpo humano está dotado de una forma sustancial propia que no es el intelecto agente sino aquello que le confiere a cada ser humano la capacidad racional, de modo que, aunque el intelecto agente sea uno, lo mismo que el paciente, hay una pluralidad de formas sustanciales y, con ello, una pluralidad de sustancias que lo poseen. ${ }^{108}$ No es la intención de Blank afirmar que Leibniz conoció el pensamiento de Achillini, sino simplemente mostrar que existieron históricamente interpretaciones no monistas del intelecto agente universal.

Ahora bien, las dos líneas interpretativas mencionadas anteriormente, esto es, la que sostiene un monismo sustancial y la que mantiene además un pluralismo de sustancias activas en $D S R$, han entendido que Leibniz afirma una concepción averroísta del intelecto agente. No obstante, Leibniz nunca afirma esto en los escritos de DSR. Consideramos que hay también otra manera de entender la afirmación simultánea del intelecto agente como lo divino en las mentes y de una pluralidad de entes tipo mentes individuales. Para exponerlo, debemos atender especialmente a dos cosas que se siguen una de otra. En primer lugar, recordemos que para Leibniz hay una pluralidad de entes tipo mentes y que en cada mente hay algo particular, a saber, 'lo mismo' o la identidad en cada mente. De acuerdo con el filósofo de Leipzig, la identidad de la mente no puede ser destruida por las modificaciones, de tal manera que ella no puede extinguirse o dejar de ser. Sin embargo, para Leibniz las concepciones que sostienen que una mente puede extinguirse y retornar a Dios, afirman en consecuencia un intelecto universal. De esta manera, para Leibniz la tesis de la persistencia

\footnotetext{
${ }^{107}$ Blank, 2014: 234.

${ }^{108}$ Blank, 2014: 235-241.
} 
de 'lo mismo' en la mente singular está estrictamente vinculada con la negación de un intelecto de esas características:

Si una Mente ha podido comenzar, podrá extinguirse. Y del mismo modo que ha sido hecha por Dios, también volverá a Dios. Esta será una opinión acorde con la Aristotélica y con aquellas que [hablan] de un intelecto universal. Por el contrario, a mí me parece que nunca un alma ha comenzado o puede cesar. No por esto, sin embargo, una Mente será menos creada por Dios, puesto que existirá y subsistirá por la voluntad de Dios, esto es, de un intelecto bueno. ${ }^{109}$

Como vemos, Leibniz sostiene que la opinión de aquellos que entienden que las mentes se extinguen, está relacionada con la afirmación de un intelecto universal. De esta manera, la negación por parte de Leibniz del hecho de que las mentes se extingan, conlleva oponerse a la afirmación de una inteligencia universal. Esto explica también que Leibniz se aleje de algunas opiniones de Spinoza que conocía gracias a Tschirnhaus, tales como que lo que constituye el ser actual del alma es la idea de una cosa singular ${ }^{110}$ o que el alma humana es una parte de Dios: ${ }^{111}$

Y así no apruebo la opinión de Spinoza, que la Mente singular se extingue con el cuerpo, que la mente de ningún modo habrá de recordar lo precedente, que reste solamente aquello que es eterno en la Mente, la Idea o esencia del cuerpo, a saber, de este [cuerpo]. ${ }^{112}$

En consecuencia, el modo como ha de entenderse que el intelecto agente es 'lo divino' en las mentes, no ha de ser pensado en términos de un intelecto universal. En última instancia, el argumento que recién presentamos no explica cómo debe entenderse el intelecto agente como 'lo divino en' las mentes. Para explicar esto debe tenerse en cuenta, de acuerdo con el texto citado al comienzo de la cuarta sección, que para Leibniz el intelecto agente es lo mismo que la omnisciencia de Dios. De acuerdo con M. Laerke, Leibniz se valdría de términos tradicionales para reformular algunas ideas de Spinoza, puesto que declararse abiertamente a favor de las tesis del filósofo holandés en el siglo

\footnotetext{
${ }^{109}$ De veritatibus, de mente, de Deo, de universo, A VI 3, 509. "Si Mens incipere potuit, potent extingui. Et quemadmodum facta est ex Deo, redibit in Deum. Haec foret sententia Aristotelicae consentiens, et iis qui de intellectu universali. Mihi contra videtur, nullam unquam animam cepisse, aut desinere posse. Non ideo tamen minus Mens creabitur a Deo, quia erit et, subsistet Dei voluntate, Id est intellectus boni”.

${ }^{110}$ En el caso de Leibniz véase A VI 3, 385; en Spinoza, Eth. 2prop11 (II, 94).

${ }^{111}$ Nuevamente, en el caso de Leibniz considérese A VI 3, 384, y para Spinoza Eth. 2cor11 (II, 94-95).

${ }^{112}$ De veritatibus, de mente, de Deo, de universo, A VI 3, 510. "Itaque Spinosae sententiam non probo, quod Mens singularis cum corpore extinguatur, quod Mens ullo modo meminerit praecedentium, quod supersit tantum id quod in Mente aeternum est, corporis Idea vel essentia, huius scilicet".
} 
XVII era problemático debido a sus resonancias materialistas y naturalistas. En este sentido, por ejemplo, Leibniz se habría referido a la extensión absoluta como 'inmensidad' e incluso 'omnipresencia'. ${ }^{113}$ Similarmente, Laerke podría decir que Leibniz se habría referido a la 'omnisciencia' de manera análoga. No obstante, las conclusiones extraídas en el apartado anterior nos permiten sugerir que, al menos en lo que respecta a la afirmación del intelecto agente, sucede más bien lo contrario, esto es, que Leibniz muchas veces expresa ideas tradicionales en términos de su época, presumiblemente para adaptarse a sus interlocutores (en este caso, por ejemplo, Tschirnhaus). Para aclarar lo que queremos decir con esto, recordemos el pasaje que introdujo la polémica que guía nuestro trabajo: "así como en el espacio hay algo divino, la inmensidad misma de Dios, del mismo modo en la mente hay algo divino, lo que Aristóteles llamaba intelecto agente; y esto es lo mismo que la omnisciencia de Dios". ${ }^{114}$ Aunque la mayoría de los especialistas en el pensamiento de Leibniz se centraron en la mención del 'intelecto agente', lo cierto es que en DSR Leibniz no utiliza esta expresión más que en esta cita. No obstante, la noción de 'omnisciencia' fue tratada con cierta profundidad. A continuación examinaremos la analogía entre inmensidad y omnisciencia.

Como se ha dicho, la omnisciencia de Dios es en las mentes lo que la extensión en el espacio, con la diferencia de que en las mentes, que como vimos son 'verdaderos entes', hay también algo singular que persiste. Recordemos que la extensión no es una parte del espacio sino su principio. Esto significa, en consecuencia, que lo mismo debe decirse respecto de las mentes, esto es, que el intelecto agente o la omnisciencia no es una parte sino principio de las mentes. En Notizen zur Wissenschaft und Metaphysik aclara precisamente lo que recién indicábamos: “(...) Dios no constituye parte de las cosas, sino que es un principio [de las cosas]. Una perfección es un atributo absoluto afirmativo; y [la perfección] contiene siempre todas las cosas de su género, pues no hay nada que lo limite". ${ }^{115}$ En consecuencia, en analogía, la omnisciencia, como atributo de Dios, podría entenderse como aquello perfecto en el género de las mentes, o más precisamente del

\footnotetext{
${ }^{113}$ Laerke, 2008: 475-476.

${ }^{114}$ Notizen zur Wissenchaft und Metaphysik, A VI 3, 391. La cita puede verse en la nota 76.

${ }^{115}$ Notizen zur Wissenschaft und Metaphysik, A VI 3, 392. "Est in materia, ut et in spatio quiddam aeternum; et indivisibile, quod illi intellexisse videntur, qui Deum ipsum esse credidere materiam rerum. Quod tamen non is dicitur proprie, quia Deus non facit partem rerum: sed principium. Perfectio est attributum affirmativum absolutum; continetque semper omnia sui generis, cum nihil sit, quod ipsum limitet: nam cui aliquid dandum est, et ratio non est cur certum quiddam des, ei omnia dedisti”.
} 
pensamiento o de la scientia; es lo absoluto en relación con lo limitado, con todo pensamiento que no sea omnisciente al modo divino. En este sentido, por ejemplo, Leibniz señala: "[s]i una mente no piensa algo en particular, pero sin embargo piensa, será Dios, es decir, pensará todas las cosas". ${ }^{116}$ El conocimiento de Dios abarca todo, pues Él es omnisciente; sin embargo, cualquier otro conocimiento, esto es, de las mentes particulares, que no conocen distintamente todo y por lo tanto no son perfectamente omniscientes, se dice tal en su relación con lo perfecto en su género, esto es, la omnisciencia divina. Dios conoce distintamente todas las cosas; sin embargo, las mentes particulares sólo confusamente: “[m]e parece que Toda mente es omnisciente confusamente, y que cualquier Mente simultáneamente percibe todo lo que sucede en todo el mundo". 117

En consecuencia, lo que Leibniz quiere decir al afirmar que hay algo divino en las mentes no es que la acción no les pertenece propia e individualmente sino que, en el ejercicio de su acción, esto es, pensando, las mentes no conocen todas las cosas distintamente, y que este conocimiento parcial y limitado se dice tal en relación con un conocimiento que no encuentra límites y que es, en consecuencia, absoluto, a saber, el conocimiento de aquello que es omnisciente de un modo perfecto. Para Leibniz, en efecto, "nada impide que haya un pensamiento perfecto, es decir, de todas las cosas". ${ }^{118}$ En este sentido, Leibniz explica que las mentes (esto es, excluyendo la divina) pueden tener un conocimiento claro y distinto solamente de cosas particulares, pero no de todas las cosas: “'[p]ues sin duda es verdadero que yo percibo 'alguna cosa' clara y distintamente y que esto es cierto para mí por ahora, pero no tengo ninguna certeza de que haya entendido 'todas las cosas' clara y distintamente". ${ }^{119}$ De esta manera, cuando Leibniz señala que "en la mente hay algo divino, lo que Aristóteles llamaba intelecto agente; y esto es lo mismo que la omnisciencia de Dios", parece estar entendiendo que la omnisciencia perfecta de Dios, esto es, el conocimiento distinto de todo, es lo mismo que el intelecto agente, esto es, interpretado aristotélicamente, aquel en que están en acto las formas inteligibles. Asimismo,

\footnotetext{
${ }^{116}$ De veritatibus, de mente, de Deo, de universo, A VI 3, 512. "Si Mens quaedam nihil cogitet particulare, sed cogitet tamen, est Deus: seu cogitabit omnia".

${ }^{117}$ De plenitudine mundi, A VI 3, 524. "Mihi videtur Omnem mentem esse omnisciam, confuse. Et quamlibet Mentem simul percipere quicquid fit in toto mundo".

${ }^{118}$ De formis seu attributis Dei, A VI 3, 514. "At cogitationem perfectam seu omnium esse nil impedit".

${ }^{119}$ De veritatibus, de mente, de Deo, de universo, A VI 3, 508. "Nam verum quidem est me quid clare distincteque percipere, et certum mihi impraesentiarum, sed nullam habeo certitudinem, quod omnia clare distincteque intellexerim".
} 
en síntesis, entender el atributo de la omnisciencia divina de esta manera es más acorde con la visión de Leibniz explorada anteriormente, de que Dios no ha de ser concebido como algo puramente imaginario e incapaz de pensamiento, de voluntad o en general de acción. En consecuencia, que el atributo divino de la omnisciencia sea lo eterno en las mentes acarrea una concepción de Dios como de “(...) cierta Sustancia, Persona, Mente”, es decir, una "sustancia inteligente". ${ }^{120}$

En síntesis, el hecho de que para Leibniz el intelecto agente sea lo divino en la mente no significa que haya un intelecto universal común a todas las mentes. Más bien, hemos visto que para Leibniz es imposible que haya un intelecto único. No obstante, nada impide que haya un intelecto supremo que conozca todas las cosas clara y distintamente, es decir, de un modo perfecto. En consecuencia, aunque Dios no sea la única inteligencia, es sin embargo la inteligencia primera:

Dios es la inteligencia primera en cuanto que es omnisciente, es decir, en cuanto que contiene esa forma absoluta afirmativa que se atribuye limitadamente a las otras cosas que se dicen percibir algo. De la misma manera Dios es lo Inmenso mismo en cuanto que se le atribuye una perfección, esto es, la forma afirmativa absoluta que se halla en las cosas cuando se atribuye a ellas estar en algún lado, estar presentes. ${ }^{121}$

De acuerdo con Laerke, Leibniz estaría diciendo que las mentes humanas son expresiones limitadas o finitas del intelecto agente de Dios. ${ }^{122}$ No obstante, Leibniz no parece estar refiriéndose a mentes que expresan limitadamente el intelecto divino, sino más bien a una forma que se atribuye (tribuitur) absolutamente a la mente divina y limitadamente a las restantes mentes. Esto deja nuevamente en evidencia que, como vimos

\footnotetext{
${ }^{120}$ De arcanis sublimium vel de summa rerum, A VI 3, 474-475. "Deus non est quiddam Metaphysicum, imaginarium, incapax cogitationis, voluntatis, actionis, qualem nonnulli faciunt, ut idem futurum sit ac si diceres Deum esse naturam, fatum, fortunam, necessitatem, Mundum, sed Deus est Substantia quaedam, Persona, Mens. Possent inscribi Meditationes istae, de arcanis sublimium, vel etiam de Summa Rerum. (...) Ostendendum est Deum esse personam seu substantiam intelligentem. Rigorose demonstrandum est, quod sentit se agere in se ipsum, nihil enim admirabilius quam idem sentire ac pati a se ipso". Por eso, como señala Goldenbaum, 2014: 31, este en uno de los puntos donde el pensamiento de Leibniz se aleja claramente del de Spinoza, quien cuestiona todo tipo de antropomorfización de Dios. Nadler, 2014: 251-265, examina detenidamente las distintas concepciones de Dios que se dieron en el siglo de Leibniz, entre las que se encuentran la de estos dos autores.

${ }^{121}$ De origine rerum ex formis, A VI 3, 520. "Deus est intelligentia prima, quatenus est omniscius, seu quatenus eam continet formam absolutam affirmativam, quae limitate tribuitur aliis quae aliquid percipere dicuntur. Quemadmodum Deus est ipsum Immensum, quatenus perfectio ei tribuitur id est forma affirmativa absoluta quae invenitur in rebus, cum tribuitur ipsis esse alicubi, esse praesentes".

${ }^{122}$ Laerke, 2009.
} 
en la sección previa y anteriormente en ésta, Leibniz concibió a las mentes como entes particulares que poseen modificaciones, de modo que poseen el atributo de la omnisciencia, aunque de manera limitada.

Hay dos aclaraciones con las que quisiéramos finalizar esta sección. En primer lugar, resta aún la pregunta por cómo explicaría Leibniz que las mentes, exceptuada la divina, conocen de un modo limitado. Sin profundizar demasiado en el asunto, Leibniz menciona que las mentes están añadidas a la materia, de manera que sin la materia no percibirían del modo en que lo hacen. En este sentido, para Leibniz es debida a la naturaleza de la materia y de la mente que se producen disposiciones en nuestra mente, tales como la de la luz, el enrojecimiento y otras semejantes. ${ }^{123}$ En este sentido, la 'omnisciencia confusa' puede ser explicada como percepción desde un punto de vista:

Además, no es admirable que una mente perciba las cosas que suceden en todo el mundo, puesto que no hay cuerpo tan exiguo que, supuesta la plenitud del Mundo, no sienta todas las demás cosas. Y así, de este modo, surge una admirable variedad: en efecto, las mentes son tantas como las diversas relaciones del universo, como si se contempla la misma ciudad desde diversos lugares. Y así, con la creación de muchas Mentes Dios quiso producir, respecto del universo, lo que, respecto de una gran ciudad, un pintor que quisiera exhibir varias imágenes o proyecciones pintadas de la misma; el pintor en la tabla como Dios en la mente. ${ }^{124}$

En segundo lugar, debemos reconocer que la analogía que Leibniz establece entre la inmensidad respecto del espacio y el intelecto agente respecto de la mente tiene dos limitaciones. Por un lado, hay una limitación en el hecho de que, mientras las mentes son entes, el espacio no lo es. Esta diferencia se observa cuando Leibniz compara el Espacio Universal, esto es, el agregado de todos los lugares, y la República Universal, esto es, la Sociedad de todas las Mentes, pues mientras los lugares o intervalos se destruyen o extinguen, las mentes no lo hacen. ${ }^{125}$ Por otro lado, y como consecuencia de lo anterior, hay

\footnotetext{
${ }^{123}$ De origine rerum ex formis, A VI 3, 518. El examen leibniziano de la material sera retomado en el próximo capítulo.

${ }^{124}$ De plenitudine mundi, A VI 3, 521. "Porro mirum non est quandam mentem percipere quae aguntur in toto mundo, quia nullum est corpus tam exiguum, quin posita Mundi plenitudine alia omnia sentiat. Itaque hoc modo mira oritur varietas, quot enim mentes, tot diversae universi relationes; quemadmodum si urbs eadem e diversis locis spectetur, itaque plurium Mentium creatione Deus efficere voluit de universo, quod pictor aliquis de magna urbe, qui varias eius species sive projectiones delineatas exhibere vellet, pictor in tabula, ut Deus in mente".

${ }^{125}$ De origine rerum ex formis, A VI 3, 521.
} 
una diferencia en la medida en que las mentes, los 'verdaderos entes', siempre crecen en perfección, ${ }^{126}$ aunque no suceda lo mismo con los cuerpos. A propósito de ellos, Leibniz menciona que el hecho de que no crezcan en perfección es una verdadera razón a priori de por qué las fuerzas siempre permanecen iguales (esto es, como veremos en el próximo capítulo, de la formulación leibniziana de la ley de conservación). ${ }^{127}$ En contraposición, el perfeccionamiento de las mentes no significa otra cosa que un crecimiento en el conocimiento: "[s]iempre la misma potencia, no siempre la misma ciencia nuestra". ${ }^{128}$

\section{Conocimiento y clasificación de las formas}

Hasta el momento nos hemos referido indistintamente a los conceptos de 'atributo' y 'forma' con los que Leibniz alude a la inmensidad, a la eternidad y a las demás cosas de este tipo. No obstante, esto no supone un problema en el marco del pensamiento leibniziano, puesto que, como dijimos en la primera sección, en algún sentido Leibniz los tomó como sinónimos: "[t]oda forma simple es un atributo de Dios". ${ }^{129}$ Dicho de otra manera, todo predicado necesario de Dios que no pueda resolverse en otras cosas, y que en consecuencia es concebido por sí, es por eso mismo una forma simple. ${ }^{130}$ Ahora bien, esta concepción de las formas simples como 'concebidas por sí' que Leibniz mantuvo, es similar a aquella presente en el pensamiento de Spinoza que el filósofo de Leipzig conoció gracias a lo que le había sido comunicado por Schuller. En efecto, Schuller le comentó por correspondencia a Leibniz que Spinoza "entiende por sustancia aquello que es en sí y se concibe por sí, esto es, aquello cuya idea o concepto no se origina a partir de la Idea o concepto de otra cosa”, a lo cual Leibniz añadió la siguiente anotación: “[p]arece que concebimos por sí [aquellas cosas] cuyos términos o Voces son indefinibles, es decir, cuyas ideas [son] irresolubles, como Existencia, Yo, percepción, lo mismo, el cambio, también las

\footnotetext{
${ }^{126}$ De veritatibus, de mente, de Deo, de universo, A VI 3, 510.

127 De origine rerum ex formis, A VI 3, 521-522.

${ }^{128}$ De origine rerum ex formis, A VI 3, 522. "Eadem semper potentia, non eadem semper scientia nostra". La cuestión de la perfección de los individuos y del mundo siguió siendo analizada por Leibniz en sus escritos posteriores. Véase, por ejemplo, Look, 2014: 131-146.

${ }^{129}$ De formis seu atributis Dei, A VI 3, 514. "Attributum Dei est, forma simplex quaelibet".

${ }^{130}$ Quod ens perfectissimum sit possibile, A VI 3, 574.
} 
cualidades sensibles como el calor, el frío la luz, etc." ${ }^{131}$ Debe sumársele al hecho de que Leibniz considere que las formas son concebidas por sí, el hecho de que dichas formas, como atributos de Dios, son perfecciones, esto es, cualidades absolutas positivas. ${ }^{132}$ Ahora bien, parecería que estos dos conceptos, esto es, el de 'forma simple' y el de 'atributo', se refieren a lo mismo pero desde aspectos distintos. En general, cuando Leibniz se refiere a la inmensidad, a la eternidad, etc. en relación con las cosas (y así, los toma como lo indivisible, inmutable, lo absoluto), habla de 'formas simples'. Es muy posible que las formas deban ser entendidas en proximidad al sentido propio del platonismo, esto es, como principios determinantes de las cosas, en contraposición con aquello otro que limita dichos principios y que, como hemos dicho, Leibniz denominó 'mole' o 'masa'. ${ }^{133}$ No obstante, difieren de la acepción platónica en la medida en que las formas penetran todas las cosas, en el sentido de que son aquello que tienen en común. Sin embargo, cuando Leibniz refiere las formas simples a un sujeto, esto es, en particular (aunque, como veremos, no siempre exclusivamente), a Dios, habla de ellas como de 'atributos' ${ }^{134}$ En consecuencia, la esencia de Dios (esto es, el agregado de todos los atributos) comprende por definición la totalidad de las formas simples. En este apartado examinaremos las formas o atributos atendiendo a los dos aspectos antes mencionados. Así, veremos en primer lugar el conocimiento que tenemos de las formas, para luego diferenciar distintos tipos, tras lo cual analizaremos la distinción establecida por Leibniz entre 'forma' y 'sujeto de una forma'.

El conocimiento de las formas -y, al mismo tiempo, su rol en el conocimiento en general- está enlazado con el examen del modo como Leibniz concibe las percepciones. En efecto, como veremos en el próximo capítulo, para Leibniz las percepciones sensibles son, estrictamente hablando, un agregado de infinitas percepciones. El alma percibe unas y otras cosas de manera confusa a lo largo de un trecho de tiempo y luego 'enlaza' las

\footnotetext{
${ }^{131}$ Communicata ex literis domini Schulleri, A VI 3, 275. "Per substantiam intelligit id quod in se est, et per se concipitur, hoc est id cuius idea vel conceptus ex Idea vel conceptu alterius rei non oritur / Videntur a nobis per se concipi, quorum termini sive Voces sunt indefinibiles, seu quorum ideae irresolubiles, ut Existentia, Ego, perceptio, idem, mutatio; tum qualitates sensibiles; ut calor, frigus, lumen, etc.”. Laerke, 2009, sección "Absolute extension as an attribute of God".

${ }^{132}$ Ens perfectissimum existit, A VI 3, 575. Asimismo, Quod ens perfectissimum existit, A VI 3, 578.

${ }^{133}$ Esta interpretación de la materia como principio de limitación ha generado controversias entre los estudiosos del pensamiento de Leibniz de este período. Por ejemplo, es rechazada por Laerke, 2008: 535-538, mientras que es sugerida por Kulstad, 1999b: 83-85. Retomaremos este problema en el próximo capítulo.

${ }^{134}$ Di Bella, 2014: 240, señala, en términos similares: "En líneas generales, [Leibniz] parece deseoso de evitar una continuidad demasiado estrecha (o lo que sería aún peor, una identificación) entre las formas asumidas como constituyentes de Dios y las formas vistas como integrantes de la realidad creada".
} 
percepciones dando lugar a una percepción coherente. De esta manera, la percepción de, por ejemplo, un color, es compleja, en el sentido de que no se resuelve en 'un' acto sino, como se ha dicho, en un agregado de muchos. Ahora bien, Leibniz nota que en esta explicación se requiere de ciertas percepciones que, no obstante, no sean un agregado sino que sean percibidas por 'un' acto:

Existen necesariamente formas simples, es decir, percepciones por sí, puesto que unas cosas se perciben a través de otras. Si otra vez éstas [se percibieran] siempre a través de otras, no se percibiría nada. La razón de por qué no percibimos distintamente aquellas cosas en las que [hay] una variedad, como el color, es que percibimos el color en un cierto tiempo. (...). Pero aquellas cosas que se perciben con un acto, como existir, percepción, extensión, esas se entienden perfectamente. ${ }^{135}$

En este sentido, siguiendo el ejemplo anterior, para percibir un color (que no es algo inteligible por sí sino que su percepción se da a lo largo de un tiempo) se requiere de una forma o naturaleza inteligible por sí que permanezca en la variedad de percepciones dada por la infinita divisibilidad del tiempo, a saber, como la corporeidad en este caso. ${ }^{136}$ De esta manera, en síntesis, se tiene un conocimiento inmediato de las formas que, asimismo, son una suerte de precondición del conocimiento de las restantes cosas. ${ }^{137}$ Así, de alguna manera Leibniz argumenta que tenemos un conocimiento de las formas puesto que de otra manera no podría evitarte una regresión al infinito. Si las cosas se percibieran siempre a través de otras al infinito, entonces no podríamos dar razón del conocimiento en absoluto. Es necesario, entonces, poner un término a la regresión, esto es, reconocer que hay algo que no es conocido a través de otra cosa. ${ }^{138}$ Así es, por ejemplo, el conocimiento que tenemos de lo que es 'extensión’ o ‘inmensidad', 'pensamiento', 'duración', ‘existencia', entre otras. En todos estos casos se trata de cosas que se conocen por un acto y no por un agregado. Precisamente por eso, se conciben por sí y no a causa de otra cosa: "[n]o puede entenderse

\footnotetext{
${ }^{135}$ De formis seu attributis Dei, A VI 3, 514. "Necessario sunt formae simplices seu perceptiones per se, quia quae per alia percipiuntur; si haec rursus semper per alia, perciperetur nihil. Ea in quibus varietas, ut color, cur a nobis non percipiantur distincte ratio est, quia tempore aliquo certo colorem percipimus; cum tamen id tempus in infinitas partes subdividi possit, et qualibet eius parte aliquid ad rem pertinens egerimus, sed non meminimus, ob organorum defectum. Sed ea quae uno actu percipiuntur, ut, esse, perceptio, extensio, ea perfecte intelliguntur".

${ }^{136}$ De magnitudine, A VI 3, 483.

${ }^{137}$ De magnitudine, A VI 3, 484.

${ }^{138}$ Cogitatio non est motus, A VI 3, 586-587.
} 
una causa de todo lo que se concibe por sí". ${ }^{139}$ A diferencia, se conoce por ejemplo que las cosas existen a través del conocimiento de la forma 'existir', así como también se conoce que las cosas duran a través del conocimiento de la forma 'duración', y demás. En gran medida, el hecho de que el conocimiento de las formas simples sea por medio de 'un' acto del intelecto, esto es, el hecho de que no sean conocidas a través de otras cosas, implica que en el conocimiento que tenemos de ellas no se ven involucrados caracteres: "[e]n toda intelección pura, esto es, liberada de caracteres, se percibe toda forma simple que una cosa implica". 140

Ahora bien, el hecho de que todas las formas sean concebidas por sí mismas no significa para Leibniz que no haya ninguna diferencia entre ellas. En este sentido, de acuerdo con un criterio que podríamos llamar 'de extensión' se distinguen algunas formas que son 'más comunes' de otras que son 'más especiales'. Según este criterio, hay algunas formas que competen a más cosas que otras. De esta manera, a modo de ejemplo, la existencia o la duración son formas 'más comunes' que la extensión o el pensamiento, pues corresponde existir o durar a lo extenso, aunque no obstante no todo lo que existe o dura es extenso (y lo mismo puede decirse respecto de lo pensante). En consecuencia, de acuerdo con Leibniz, 'duración' o 'existencia' son formas simples 'más comunes', esto es, que competen a más cosas que 'extensión' o 'pensamiento'. ${ }^{141}$ Ahora bien, hay al menos otros dos criterios empleados por Leibniz para establecer distinciones entre las formas. Además del anterior, el filósofo de Leipzig también distingue las formas de acuerdo a un criterio que podríamos denominar de 'referencialidad'. Según este criterio, se distingue entre las formas que se refieren a un número mayor de cosas que otras, no en un sentido extensional sino en virtud de la naturaleza misma de la forma en cuestión. En este sentido, mientras la extensión es algo absoluto, esto es, que tiene solamente sujeto, el pensamiento es algo que refiere no solamente al sujeto sino también al objeto. En consecuencia, en virtud de la

\footnotetext{
${ }^{139}$ De formis seu atributis Dei, A VI 3, 514. "Quicquid per se concipitur eius non potest intelligi causa".

${ }^{140}$ Cogitatio non est motus, A VI 3, 587. "In omni intellectione pura seu a characteribus purgata percipitur omnis forma simplex quam res involvit. Ergo si purgata a characteribus cogitatione aliqua forma simplex non deprehenditur in aliquo, ideo utique non inest". Por todo esto, coincimos con Piro, 2014: 114-115, en entender a las formas simples como predicados elementales. Di Bella, 2014: 239, señala atinadamente (como puede verse a partir de lo que examinamos a lo largo de este capítulo) que las formas simples son los elementos últimos tanto del conocimiento como de la realidad.

${ }^{141}$ De formis seu attributis Dei, A VI 3, 513. En este sentido, sostenemos que no es correcta la interpretación de Piro, 2014: 117, quien, traduciendo 'specialior forma' por 'forma derivada', concluye que la extensión no es un atributo de Dios sino, precisamente, una propiedad derivada.
} 
referencialidad del pensamiento, "[t]odo lo que piensa, siempre piensa algo". ${ }^{142} \mathrm{El}$ único caso especial admitido por Leibniz es el de la conciencia de sí mismo, en donde el sujeto y el objeto son lo mismo. Finalmente, se distinguen las formas según un tercer criterio que corresponde al hecho de tratarse de un 'estado' o de una 'acción'. Así, mientras que por ejemplo el pensamiento es una acción llevada a cabo por un sujeto, la extensión es un estado que, podría decirse, se posee. ${ }^{143}$

Hay una distinción adicional que es pensada por Leibniz pero que, en este caso, no implica una diferenciación entre tipos de formas, aunque sí entre las formas en general y aquello en lo que están las formas como atributos, esto es, el sujeto de las formas:

[Es] algo admirable que un sujeto sea otra cosa que las formas o atributos. Y esto es necesario, puesto que no puede decirse nada acerca de las formas a causa de su simplicidad; por consiguiente, no habría ninguna proposición verdadera a no ser que las formas se unieran a un sujeto. Pensamiento no es duración, pero el que piensa es uno que dura. Y esta es la diferencia de la sustancia respecto de las formas. ${ }^{144}$

Como hemos indicado anteriormente, si Leibniz concibió a todas las formas simples como atributos de Dios, entonces en la base de esta caracterización se encuentra la distinción entre 'formas' y 'sujeto de las formas'. Ahora bien, esta distinción muestra que los planteos de Leibniz difieren de los de Descartes y Spinoza en algo esencial. Para Descartes, un atributo es una propiedad principal que constituye la naturaleza y esencia de una sustancia. ${ }^{145}$ Spinoza, por su parte, entiende, en términos similares, que un atributo es aquello que el entendimiento percibe de una sustancia como constitutivo de su esencia. ${ }^{146}$ No obstante, como vemos, para el filósofo de Leipzig un atributo no es aquello gracias a lo cual reconocemos una sustancia sino una propiedad que inhiere en un sujeto. Como señalamos en la primera sección, Leibniz entiende que la esencia de Dios consiste en "ser el

\footnotetext{
${ }^{142}$ De origine rerum ex formis, A VI 3, 518. "Extensio est quiddam absolutum. Cogitatio relativum. Omne cogitans cogitat utique aliquid". Asimismo, De formis seu attributis Dei, A VI 3, 513-514. "Itaque formae in eo differunt, quod aliae relativae magis minusve; exempli causa, cogitatio habet et subjectum et objectum, extensio habet subjectum tantum. Videtur tamen ipsa per se conscientia sui esse quiddam quemadmodum extensio per se, scilicet status, tunc enim subjectum et objectum idem".

${ }^{143}$ De origine rerum ex formis, A VI 3, 518.

${ }^{144}$ De formis seu atributis Dei, A VI 3, 514. "Mira res, aliud esse subjectum quam formas seu attributa. Idque necesse est, quoniam de formis ob ipsarum simplicitatem nihil potest dici, ergo nulla propositio foret vera nisi unirentur formae subjecto. Cogitatio non est duratio, sed cogitans est durans. Et haec est differentia substantiae a formis".

${ }_{145}^{145}$ Principia Philosohpiae, AT, VIII, 1, § 52 y 53.

${ }^{146}$ Eth. 1 def4 (II, 1).
} 
sujeto de todos los atributos compatibles", ${ }^{147}$ y en este sentido es sustancia. Así, a diferencia de Descartes y Spinoza, para Leibniz un atributo no constituye la esencia de una sustancia. Al margen de esto, aquí se encuentra la justificación de que hayamos preferido referirnos a una pluralidad de 'entes tipo mentes' en lugar de 'sustancias'. Pues, como hemos visto, Leibniz parece reservar la noción de sustancia para referirse al sujeto de las formas, y en este sentido solamente Dios es sustancia, al menos en un sentido radical (radicaliter). Esto es lo que presumiblemente quiere decir Leibniz cuando se refiere al sujeto de las formas. En favor de la tesis de Blank, la introducción de Leibniz de la anotación 'radicaliter' para referirse a este sentido de sustancia, deja abierta la posibilidad de que pueda entenderse otro sentido de sustancia que no sea éste. Más aún, en algunos pasajes Leibniz parecería sugerir que deben admitirse otros sujetos además de Dios. Por ejemplo, en De formis simplicibus Leibniz dice:

El sujeto mismo, es decir, Dios, con su ubicuidad da lo inmenso; esto inmenso combinado con otros sujetos hace que se sigan todos los Modos posibles, es decir, las Cosas en él mismo. Las variadas cosas resultantes de las formas combinadas con un sujeto, hacen que resulten las cosas particulares. ${ }^{148}$

Ahora bien, de acuerdo con M. Laerke, los 'otros sujetos' que se mencionan en la cita no son distintos del 'sujeto mismo', es decir, de Dios, sino más bien solamente son distintos del sujeto mismo 'con su ubicuidad'. En este sentido, Laerke entiende que los otros sujetos son 'Dios en tanto que tal o tal otro atributo'. ${ }^{149}$ Así, por ejemplo, otro sujeto sería Dios 'en tanto pensamiento absoluto'. Aunque la explicación parece un poco forzada, sería la única explicación coherente en el caso de que Leibniz haya entendido solamente un sentido de 'sujeto', esto es, Dios como sujeto de las formas simples. No obstante, parece claro que estaría marcando una diferencia al referirse a 'otros sujetos'. Para ejemplificar esto, recordemos que, en un pasaje mencionado hace poco, Leibniz señala que "[p]ensamiento no es duración, pero el que piensa es uno que dura”. En este sentido, parecería que un sujeto es una combinatoria de formas. De esta manera, si cambiara la combinación, el sujeto sería distinto. Por esta razón, como veremos con más detalle en la sección 1.3. del

\footnotetext{
${ }^{147}$ De formis seu atributis Dei, A VI 3, 514. "nam essentia Dei in eo consistit, ut sit subjectum omnium attributorum compatibilium".

${ }^{148}$ De formis simplicibus, A VI 3, 523. "Subjectum ipsum seu Deus cum sua ubiquitate dat immensum, hoc immensum combinatum cum aliis subjectis, facit sequi Modos omnes possibiles, seu Res in ipso. Varia resultantia ex formis is combinata cum subjecto, faciunt resultare particularia".

${ }^{149}$ Laerke, 2008: 532-535.
} 
próximo capítulo, Leibniz concibe que la variedad de cosas se origina a partir de la variedad de formas, de modo que las diferentes combinaciones son como diferentes perspectivas de lo mismo. Esto permitiría explicar, por ejemplo, que la omnisciencia se atribuya tanto a Dios como a las mentes, con la diferencia de que en un caso la omnisciencia es perfecta y en el otro es limitada. En este sentido, en última instancia, el problema de los otros sujetos parecería ser, para Leibniz, la cuestión del origen de las cosas a partir de las formas. ${ }^{150}$

Para finalizar, recopilaremos las principales conclusiones que hemos ido extrayendo a lo largo del capítulo. En la primera sección hemos abordado el tercer grado de infinito reconocido por Leibniz, esto es, el que se refiere a Dios como aquél en quien están contenidos los requisitos de existencia de todas las demás cosas. Para el filósofo de Leipzig, debe mostrarse primero que Dios es posible para poder luego deducirse legítimamente su existencia efectiva. Detrás de este planteo, se encuentra la concepción leibniziana de que, aunque podamos definirlo, no tenemos una idea de Dios. En consecuencia, Leibniz procede a demostrar la posibilidad de Dios a partir de la definición de Él como sujeto de todas las formas simples absolutas afirmativas. Para Leibniz, el Ente que tenga todas las cualidades afirmativas compatibles es posible. Como la existencia se encuentra entre todas las cualidades afirmativas que Dios posee, no solamente es posible sino que existe efectivamente. Posteriormente hemos visto que, siguiendo los pasos de Spinoza, Leibniz ha notado algunas inconsistencias en la propuesta cartesiana de definir a los cuerpos solamente sobre la base de la noción de extensión. Por un lado, Leibniz destaca que la impenetrabilidad, que es una de las notas fundamentales de la noción de cuerpo, no puede deducirse de la mera noción de extensión. Por otro lado, reconoce que las cosas que ocupan un cierto lugar se diferencian de aquello según lo cual se dicen 'extensas' y que llama 'extensión' o ‘inmensidad'. Esto no debe ser confundido con el espacio universal, que está dividido en partes que cambian constantemente. Más aún, lo inmenso es algo que el espacio

\footnotetext{
${ }^{150}$ Kulstad, 1999b: 78-80 llama 'teoría de las relaciones puras' a la visión de que la variedad de cosas se origina a partir de las formas solas. Como sugerimos antes, nos detendremos con más detalle en algunos aspectos de esta cuestión del origen de las cosas en la sección 1.3. del próximo capítulo.
} 
universal supone como lo permanente en el continuo cambiar del espacio y que, como tal, es absolutamente infinito e indivisible. Por lo cual, esta naturaleza universal según la cual todas las cosas extensas se dicen tales es, al mismo tiempo, un atributo de Dios. Ahora bien, el examen de Leibniz no se circunscribe al dominio de la extensión sino que hay otros atributos divinos que también son lo absoluto en sus respectivos géneros, a saber, la eternidad, la omnipotencia y la omnisciencia. En lo que respecta al último atributo mencionado, hemos visto que el examen de Leibniz presenta cierta complejidad. En efecto, por un lado, el filósofo de Leipzig reconoce que hay un pluralismo de entes tipo mentes, en cada una de las cuales hay algo particular que permanece idéntico ante la variedad de modificaciones que puede tener. Ahora bien, por otro lado, como se dijo, hay algo divino y eterno a propósito de las mentes que es la omnisciencia divina. No obstante, esto no significa que haya un intelecto universal, sino que las cosas que perciben algo son omniscientes de un modo confuso, mientras que Dios conoce todo clara y distintamente, es decir, es omnisciente perfectamente. En este sentido, la omnisciencia se encuentra de manera limitada en las mentes, esto es, los verdaderos entes que se dicen 'percibir algo'. Finalmente, hemos visto que, desde el punto de vista del conocimiento, las formas simples son percepciones que se entienden perfectamente con un acto del intelecto. En este sentido, en su conocimiento no se ven involucrados caracteres. En consecuencia, son epistemológicamente irresolubles, en el sentido de que no requieren de otra cosa para ser entendidas, aunque no obstante a partir de ellas pueden conocerse otras cosas (a saber, las resolubles). Así, dijimos que el conocimiento de las formas simples es una precondición del conocimiento de las restantes cosas. Para terminar, hemos abordado algunas distinciones o clasificaciones hechas por Leibniz entre las formas, como por ejemplo la distinción entre ‘formas más comunes' y 'más simples', entre formas que se refieren solamente a un sujeto y las que se refieren a un sujeto y a un objeto, así como también la distinción entre 'formas' $\mathrm{y}$ 'sujeto de las formas', entre otras. 


\section{CAPÍTUlO 9: MATERIA, MOVIMIENTO Y ACCIÓN EN DSR}

Mientras que en el séptimo capítulo examinamos el aspecto más bien matemático del problema del continuo y en el octavo el predominantemente metafísico, en este capítulo abordaremos algunas cuestiones destacadas de la filosofía natural del final del período parisino de Leibniz. Como el título del capítulo sugiere, centraremos los exámenes en tres ejes conceptuales. En primer lugar, abordaremos los tratamientos de Leibniz sobre la materia, desde distintas facetas, tras lo cual consideraremos el importante giro en el abordaje de la cuestión de la cohesión de los cuerpos llevado a cabo por Leibniz en el período en cuestión. Luego, analizaremos la 'filosofía primera' del movimiento, deteniéndonos primero en la cuestión de la uniformidad -o no- del movimiento y luego en la de su relatividad o respectividad. Finalmente, abordaremos el cuestionamiento a la ley de conservación del movimiento de Descartes, la versión leibniziana de dicha ley y la concepción de la acción mantenida por Leibniz en el período de $D S R$. Como veremos, en todas estas cuestiones Leibniz revisó sus planteos previos. En buena medida, los cambios que tuvieron lugar están estrechamente conectados con los desarrollos matemáticos y metafísicos que hemos examinado anteriormente. En este sentido, este capítulo también servirá para poner de manifiesto el complejo entramado que constituye el problema del continuo y su importancia en el pensamiento leibniziano de juventud.

\section{La naturaleza de la materia}

En el tercer y el séptimo capítulo hemos mencionado que la lectura de los Principia Philosophiae de Descartes por parte de Leibniz trajo aparejada una serie de cuestionamientos de la teoría cartesiana. Uno de los planteos cartesianos más discutidos por Leibniz en sus escritos de 1675-1676 ha sido la ontología que distingue entre sólidos y líquidos. Como hemos visto en la sección 2.2. del tercer capítulo, Descartes sostuvo que, aunque la noción de cuerpo sea unívoca, puede distinguirse entre aquellos cuerpos que requieren de más fuerza para separase que otros, esto es, entre aquellos que se resisten más a dividirse y los que se resisten menos. Leibniz reconoció al menos dos problemas que conlleva esta tesis cartesiana. Por un lado, como hemos mencionado a la pasada en la 
tercera sección del séptimo capítulo y veremos en detalle más adelante, de acuerdo con el filósofo de Leipzig, la ontología cartesiana del cuerpo no puede evitar la conclusión de que la materia líquida se compone de infinitos puntos mínimos. ${ }^{1}$ Leibniz entiende que, si la materia líquida se caracterizara por la ausencia de resistencia a la división, como considera que propuso Descartes, entonces se dividiría en todas las partes en las que pueda dividirse, es decir, en puntos perfectos o mínimos. En consecuencia, la materia no sería algo continuo sino discreto, es decir, una multitud de puntos. ${ }^{2}$ Por otro lado, para Leibniz la ontología cartesiana de lo sólido y lo líquido tiene un segundo inconveniente, a saber, que un líquido perfecto no podría distinguirse de un espacio vacío. De acuerdo con Leibniz, un fluido perfecto que solamente se mueva para compensar el espacio dejado por un cuerpo sólido que se mueve en él (como el agua que rellena el lugar dejado por un pez al desplazarse) y que repose si no tuviera que compensar un espacio abandonado, en última instancia no se distinguiría de un espacio vacío. En este sentido, la tesis cartesiana conllevaría que "ser no es otra cosa que poder ser percibido", pues una materia líquida, que es la que compensa los espacios abandonados, es percibida como un espacio vacío. ${ }^{3}$ Lo mismo puede decirse si todas las cosas se movieran en una misma dirección, pues parecería que nada se mueve. Ahora bien, como hemos visto en la sección 2.3. del tercer capítulo, al comienzo de su estancia en París Leibniz defendió que “"Existir' no es otra cosa que 'ser Sentido",. ${ }^{4}$ De esta manera, al mismo tiempo que cuestiona a Descartes, Leibniz reconsidera algunos aspectos de su propia teoría del cuerpo. A continuación nos detendremos en tres aspectos destacados de la concepción leibniziana de la materia de 1675-1676, algunos de ellos superadores de sus planteos previos, a saber: su reevaluación de la tesis de que ser es ser sentido; su concepción de la flexibilidad de los cuerpos, como superación de la distinción cartesiana entre sólidos y líquidos; finalmente, su concepción de la 'materia', 'mole' o 'masa' como elemento metafísico que oficia de principio pasivo o limitador en relación con lo absoluto de las formas.

\footnotetext{
${ }^{1}$ De arcanis sublimium vel de summa rerum, A VI 3, 473.

${ }^{2}$ Pacidius Philalethi, A VI 3, 554. OFC, 8, 137. Asimismo, De arcanis sublimium vel de summa rerum, A VI $3,473$.

${ }^{3}$ De materia, de motu, de minimis, de continuo, A VI 3, 466. "Esse nihil aliud esse quam percipi posse, sequitur ex quibusdam ratiocinandi modis".

${ }^{4}$ Propositiones quaedam physicae, A VI 3, 56. “(...) nihil aliud esse Existere quam Sentiri (...)”.
} 


\subsection{La congruencia de las sensaciones}

La tesis de que existir es ser sentido ha sido objeto de una importante revisión en los escritos de DSR. Leibniz analizó esta cuestión tras haber leído en 1675 la Critique de la recherche de la verité de Simon Foucher. Esta breve obra, que, como su nombre deja en evidencia, es una crítica a la Recherche de la verité de Malebranche, fue publicada en diciembre de 1674, esto es, apenas siete meses después de que el trabajo de Malebranche se hiciera público. En este escrito, entre otras cosas, Foucher puso en tela de juicio la realidad de las cosas externas. Algunos meses más tarde, Leibniz le escribió a Foucher y discutió algunas de sus ideas. ${ }^{5}$ Desde finales de 1675 , el filósofo de Leipzig justificó que no es correcto afirmar que existir es ser sentido, siguiendo un argumento próximo al que empleó Descartes para poner metódicamente en duda la existencia de los cuerpos, ${ }^{6}$ a saber, que negamos que existan realmente cosas que soñamos. ${ }^{7}$ En este sentido, Leibniz reconoce que la sensación no es la existencia de las cosas, dado que reconocemos que existen cosas que sin embargo no son sentidas.

Es importante tener en cuenta que Leibniz está aquí explorando la noción de existencia que corresponde al cuerpo, aunque no a las mentes. ${ }^{8}$ Incluso, reconoce que 'existir' no se dice unívocamente respecto del cuerpo y de las mentes: "nosotros sentimos o percibimos el existir; cuando decimos que los cuerpos existen, queremos decir que hay ciertas sensaciones congruentes que tienen una causa particular constante". 9 En este sentido, Leibniz reconoce que, para decir que un cuerpo existe, no basta solamente con que sea sentido sino que se requieren dos cosas más. Por un lado, se requiere que las sensaciones que se tengan de las cosas sean verdaderas, es decir, que sean consistentes o se correspondan (consentientes) de tal manera que, gracias a la regularidad que encontramos en ellas, sea posible que nos anticipemos, en el sentido de que podemos hacer predicciones verdaderas sobre las cosas sentidas, como sucede con los eclipses. ${ }^{10}$ Leibniz suele referirse

\footnotetext{
${ }^{5}$ Sobre el texto de Foucher y las críticas de Leibniz, Garber, 2009: 268-279.

${ }^{6}$ Principia Philosophiae, AT, VIII, $1, \S 4$.

${ }^{7}$ De mente, de universo, de Deo, A VI 3, 464.

${ }^{8}$ Castañeda, 1978: 101-102.

${ }^{9}$ De veritatibus, de mente, de Deo, de universo, A VI 3, 512. "nos esse sentimus seu percipimus: corpora esse cum dicimus, id volumus sensiones quasdam ese congruentes, causam habentes constantem particularem".

${ }^{10}$ De mente, de universo, de Deo, A VI 3, 464. Asimismo, De veritatibus, de mente, de Deo, de universo, A VI 3, 511.
} 
a la 'conformidad', 'coherencia' o 'congruencia' de las sensaciones para referirse a esto. El filósofo de Leipzig no pone en tela de juicio el hecho de que tengamos sensaciones o apariciones sino que, de hecho, la variedad de percepciones es uno de los elementos del conocimiento, junto con el principio de identidad y las definiciones. ${ }^{11}$ Ahora bien, por otro lado, para que las sensaciones sean conformes, es necesario algo distinto de ellas que explique precisamente su coherencia. En este caso, se trata de leyes que justifican una cierta regularidad presente en las sensaciones, sin las cuales todas las cosas serían como en los sueños. ${ }^{12}$ Leibniz reconoce en esto lo esencial de la existencia de la materia:

Ya que lo que puede juzgarse sobre la existencia de las cosas materiales no es otra cosa que la congruencia de las sensaciones, bien puede juzgarse que no podemos atribuir a la materia otra cosa que [el hecho de] ser sentida según ciertas leyes de las que, sin embargo, confieso que me falta buscar la razón. ${ }^{13}$

En este sentido, la posibilidad de decir que algo existe supone tres cosas, a saber, una pluralidad de sensaciones conformes, alguien que las sienta y una causa de las sensaciones coherentes, ${ }^{14}$ de modo que, "es cierto solamente aquello de que nosotros sentimos y que sentimos congruentemente y que en el sentir observamos cierta regla". 15 Algunos intérpretes, como D. Garber y S. Levey, han señalado que en el pensamiento leibniziano de DSR habría un fenomenalismo, es decir, “(...) la visión de que los cuerpos son solamente phenomena o 'apariciones' y no sustancias que existen fuera de su ser percibido". ${ }^{16}$ Si bien parece claro que hay un cierto fenomenalismo, en la medida en que la 'coherencia de las sensaciones' hace referencia a una mente que tenga tales sensaciones, de alguna manera Leibniz parece suponer que la causa de las sensaciones coherentes debe ser necesariamente algo extramental, a saber, puesto que hay diversas mentes capaces de sentir las mismas

\footnotetext{
${ }^{11}$ De veritatibus, de mente, de Deo, de universo, A VI 3, 508.

${ }^{12}$ De veritatibus, de mente, de Deo, de universo, A VI 3, 511.

${ }^{13}$ De veritatibus, de mente, de Deo, de universo, A VI 3, 508. "Cum quod a nobis judicari potest de existentia rerum materialium, nihi aliud sit, quam sensuum congruentia satis judicari potest nihil aliud a nobis materiae tribui posse, quam sentiri secundum quasdam leges certas, quarum tamen fateor rationem quaerendam superesse".

${ }^{14}$ De mente, de universo, de Deo, A VI 3, 464.

${ }^{15}$ De veritatibus, de mente, de Deo, de universo, A VI 3, 511. "Re recte expensa, tantum illud certum est nos sentire, et sentire congruenter, et quandam in sentiendo observari a [no]bis regulam”.

${ }^{16}$ Levey, 2011: 298. La traducción es nuestra. Garber, 2009: 279, considera que este (supuesto) fenomenalismo de Leibniz 'no es del todo diferente' del inmaterialismo de Berkeley.
} 
cosas, sin que esto signifique que una mente actúe sobre otras. ${ }^{17}$ De esta manera, para justificar esto, la causa de las sensaciones en nosotros o en otros debe ser la misma. ${ }^{18}$

Como consecuencia de este cuestionamiento de la tesis según la cual 'existir' es 'ser sentido', Leibniz considera ahora, a diferencia de lo que dijo en 1672, que "la existencia es una cualidad del sujeto por la cual sucede que tenemos sensaciones coherentes". ${ }^{19}$ Dicho de otra manera, para Leibniz la existencia es una propiedad de una cosa. Ahora bien, si la existencia de un cuerpo es una cualidad por la cual tenemos sensaciones coherentes, de tal manera que puede distinguirse entre nuestras sensaciones y la causa de ellas, entonces es posible pensar que existen cosas que sin embargo no son sentidas por nosotros, no porque falte aquella cualidad en las cosas sino a causa de un defecto en nuestra capacidad de sentir. ${ }^{20}$ Leibniz reconoce que, en el caso de aquellas cosas que nosotros percibimos, llamamos 'cuerpos' a algo que es percibido congruentemente, y llamamos 'espacio' a lo que hace que muchas percepciones sean coherentes entre sí. ${ }^{21}$ En este sentido, de acuerdo a lo dicho anteriormente, el espacio es lo que nos permite separar nuestro mundo del 'mundo de los sueños'. ${ }^{22}$ Ahora bien, Leibniz extrae una consecuencia curiosa de esta manera de concebir el espacio: si existieran mentes capaces de percibir cosas que no son congruentes con las que podemos percibir nosotros (aunque entre ellas tengan percepciones de las mismas cosas), entonces se sigue que pueden existir otros infinitos espacios (es decir,

\footnotetext{
${ }^{17}$ En este sentido, nuestra interpretación es opuesta a la de Garber, 2009: 278. Leibniz continuó con el tratamiento de la cuestión de la coherencia de las sensaciones en sus escritos posteriores, por ejemplo, en De modo distinguendi phaenomena realia ab imaginaria (A VI 4, 1498-1504) (véase Esquisabel, 1999b). La diferencia fundamental entre el tratamiento de juventud y el de madurez se halla precisamente en este punto: en los escritos juveniles Leibniz supuso una relación causal, un influjo real, cosa que rechazó en los escritos de madurez en virtud de la hipótesis de la concomitancia.

${ }^{18}$ De veritatibus, de mente, de Deo, de universo, A VI 3, 511. Coincidimos con Robinet, 1986: 165, quien señala que "[1]a diversidad de nuestras apariciones remite a una existencia externa al sujeto que las recibe". La traducción es nuestra. Véase también pp. 171-174. Por otro lado, de acuerdo con Castañeda, 1978: 108111, la causa es única (que llama 'noúmeno') en el sentido de que es la misma para todo sistema de percepciones congruentes. En consecuencia, no debe ser identificada con un objeto físico, es decir, con un objeto material, sino con Dios. No obstante, Castañeda no explica por qué razón debe sostenerse esta fundamentación teológica. Incluso, en las páginas 119-120 encuentra algunas dificultades en su visión. El hecho de que Leibniz se esté refiriendo a la existencia de las cosas materiales es un indicio de que esta lectura es incorrecta.

${ }^{19}$ De mente, de Deo, de universo, A VI 3, 464. "Existentia ergo est qualitas subjecti, qua fit ut cohaerentes habeamus sensiones".

${ }^{20}$ De mente, de Deo, de universo, A VI 3, 464.

${ }^{21}$ De veritatibus, de mente, de Deo, de universo, A VI 3, 511. Por esta razón M. Laerke entiende que el atributo divino de la extensión cumple esta función, aunque no obstante no hay ningún pasaje de Leibniz que fundamente su aserción. Laerke, 2009, sección "Absolute extension as an attribute of God".

${ }^{22}$ De veritatibus, de mente, de Deo, de universo, A VI 3, 511.
} 
infinitas maneras diversas de que ciertas percepciones sean entre sí coherentes, aunque quizás no para nosotros) e infinitos mundos (esto es, no ya el de nuestra vigilia ni el del sueño, sino otros totalmente ajenos a nosotros). ${ }^{23}$ En consecuencia, Leibniz admite que pueden existir actualmente infinitos mundos, aunque para nosotros solamente haya uno, esto es, aquel en el que tenemos sensaciones coherentes. "[Si] alguien preguntara si acaso no puede existir otro mundo, otro espacio, éste solamente preguntaría si acaso hay otras mentes que no se comunican en nada con las nuestras". ${ }^{24}$

\subsection{La flexibilidad de todos los cuerpos}

Las reflexiones leibnizianas suscitadas por su lectura de la obra cartesiana no se detienen en la reconsideración de la concepción según la cual 'existir' es 'ser sentido' que mantuvo en los años previos al período de $D S R$ y que hemos explorado en la sección anterior. El examen de la ontología cartesiana que distingue entre sólidos y líquidos como extremos de un espectro que comprehende todos los cuerpos, ha llevado a Leibniz a considerar que todos los cuerpos son flexibles. Como veremos, esto significa, en términos generales, que para el filósofo de Leipzig no es posible que existan cuerpos ni perfectamente líquidos, ni perfectamente sólidos.

Como hemos mencionado anteriormente, Leibniz entiende que las propiedades con las que Descartes concibe la materia líquida lo conducen necesariamente a concluir que ella no es sino una multitud de partículas mínimas. Para justificar esto, toma como punto de partida el examen mediante el cual Descartes explicó los movimientos en el pleno, que hemos abordado en la sección 2.4. del tercer capítulo, y lo lleva hasta sus últimas consecuencias. El filósofo de Leipzig toma como modelo un vaso circular $A B C D$, como el de la imagen adjunta, en el que hay una materia líquida, como $f, e, g$, y en el que, además, se encuentra un cuerpo sólido $H$ que no está en el centro del vaso. En este sentido, Leibniz

\footnotetext{
${ }^{23}$ De veritatibus, de mente, de Deo, de universo, A VI 3, 511.

${ }^{24}$ De veritatibus, de mente, de Deo, de universo, A VI 3,512. "Quicunque quaerit an alius possit esse mundus, aliud spatium, is hoc tantum quaerit, an aliae sint mentes nihil nostris communicantes". Por su parte, Kulstad, 2014: 60-70 también entendió que Leibniz habría afirmado una multitud de mundos. No obstante, la manera como este intérprete entendió esto difiere de nuestra concepción, aunque no por eso consideremos que sea errónea. En efecto, Kulstad analiza la cuestión a partir del hecho de que Leibniz habría sostenido que los mundos son tantos como los atributos de Dios. Profundizaremos un poco más en esta cuestión en la sección 1.3 de este capítulo.
} 
toma el caso propuesto por Descartes de un 'círculo imperfecto' que abordamos en el tercer capítulo:

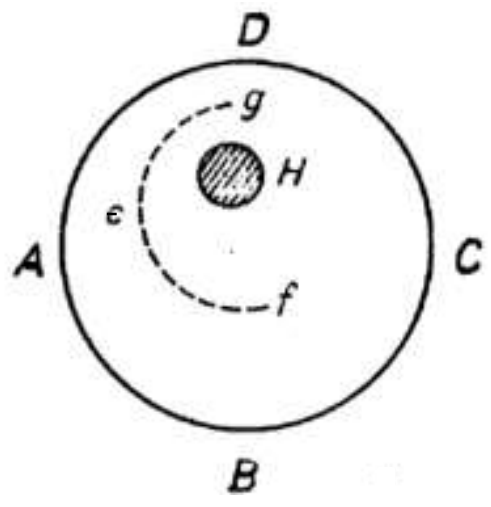

Dado que con este ejemplo Descartes intentó explicar el movimiento en el pleno, el cuerpo líquido no puede dejar ninguna sección espacial vacía a causa de su movimiento, motivo por el cual postula que, cuanto más pequeño sea el espacio que deba atravesar la materia líquida, más velozmente ella se desplaza. De esta manera, supuesto que la materia líquida esté en movimiento, se desplazaría más rápidamente en $g$ que en alguno de los otros puntos, como en $e$. Del mismo modo, en $e$ se movería más rápidamente que en $f$, y así sucesivamente. ${ }^{25}$ Ahora bien, dado que podemos tomar otros puntos que no sean los mencionados en cualquier parte y que la misma explicación debe valer también para ellos, se sigue que la materia líquida debe estar necesariamente dividida en acto en todas partes. En consecuencia Leibniz extrae la siguiente conclusión:

De aquí parece seguirse que la materia está dividida en puntos: en efecto, está dividida en todas las partes posibles, y por tanto en [partes] mínimas. Por consiguiente, el cuerpo y el espacio se compondrán de puntos. ${ }^{26}$

Como hemos mostrado en el sexto capítulo y en otras partes de nuestro trabajo, para Leibniz una composición de mínimos acarrea contradicciones. Por esta razón, en consecuencia, para él sería insostenible defender una materia perfectamente líquida. Ahora bien, como dijimos antes, para el filósofo de Leipzig es igualmente absurdo sostener una materia perfectamente sólida. En este caso, parecería que Leibniz conscientemente radicaliza la interpretación cartesiana, en el sentido de que se esfuerza por excluir de las explicaciones físicas no que haya cuerpos que poseen una gran resistencia a dividirse

${ }^{25}$ Pacidius Philalethi, A VI 3, 553. OFC, 8, 140-141.

${ }^{26}$ Pacidius Philalethi, A VI 3, 554. "Hinc videtur sequi materiam divisam esse in puncta: divisa est enim in omnes partes possibiles, ac proinde in minimas. Ergo corpus et spatium ex punctis componentur". OFC, 8, 141. 
(noción cartesiana de 'cuerpo sólido'), sino cuerpos que sean de hecho indivisibles. Dicho de otra manera, Leibniz rechaza que existan los átomos de Gassendi. Como vimos en la sexta sección del segundo capítulo, para el sacerdote francés los átomos son cuerpos pequeñísimos físicamente indivisibles. Como veremos en la sección 2.2. de este capítulo, en el período de $D S R$, Leibniz parece usar el concepto de átomo en dos sentidos, a saber, por una parte como cuerpos que resisten a la disipación (en un sentido próximo al de la 'materia sólida' de Descartes) y por otra parte para referirse a los cuerpos impartibles de Gassendi. ${ }^{27}$ En este sentido, como vimos en el tercer capítulo, Leibniz coincide con Descartes en que es imposible que existan partes de materia indivisibles por naturaleza puesto que al menos podrían ser divididas por Dios, cosa que, de acuerdo con el filósofo de Leipzig, ni siquiera fue negado por Gassendi. ${ }^{28}$ En consecuencia, Leibniz señala:

Yo no admito ni los átomos de Gassendi, es decir, un cuerpo perfectamente sólido, ni la materia sutil de Descartes, es decir, un cuerpo perfectamente fluido; sin embargo, no niego por ello un cuerpo flexible en todas partes, al punto de afirmar que todo cuerpo es tal. ${ }^{29}$

De acuerdo con Leibniz, que todo cuerpo sea 'flexible' significa, por un lado, que no hay ninguno tan firme que no permita una nueva subdivisión o flexión. ${ }^{30}$ En este sentido, la flexibilidad de todos los cuerpos explica por qué ninguno es indivisible, así como también explica por qué no puede haber un cuerpo que esté dividido 'en todas partes' (esto es, una materia líquida dividida en mínimos). De esta manera, por otro lado, un cuerpo flexible posee cierta resistencia a la disipación, de tal manera que tiene partes cohesionadas, aunque ellas sean distintas entre sí. En última instancia, la flexibilidad explica por qué el continuo no se divide como la arena en granos sino como los pliegues de una túnica, pues como vimos en la tercera sección del séptimo capítulo, a pesar de que un cuerpo no se disuelve en

\footnotetext{
${ }^{27}$ Arthur, 2004, subraya que la noción de 'átomo' estándar en el siglo XVII, vinculada con fuentes químicas, no acarrea necesariamente la nota de la indivisibilidad o perfecta solidez. Similarmente, Robinet, 1986: 189 señaló la presencia de una noción de átomo en el final del período parisino de Leibniz, que no tiene connotaciones físicas sino metafísicas.

${ }^{28}$ Principia Philosophiae, AT, VIII, 2, § 20. Por su parte, Leibniz ha indicado en sus anotaciones de los Principia Philosophiae de Descartes, A VI 3, 215: "num. 20. nullas atomos dari posse, quia a Deo saltem dividi possint, hoc nec Gassendus negaverit".

${ }^{29}$ Pacidius Philalethi, A VI 3, 554. "ego neque atomos Gassendi admitto seu corpus perfecte solidum, neque materiam subtilem Cartesii seu corpus perfecte fluidum, corpus tamen ubique flexile adeo non nego, ut putem omne corpus tale esse". OFC, 8, 142.

${ }^{30}$ Pacidius Philalethi, A VI 3, 561. OFC, 8, 146.
} 
puntos, hay pliegues infinitos en número unos menores que otros. ${ }^{31}$ Quizás por esto Leibniz también se refiere a la 'elasticidad' de los cuerpos. Esta noción tiene un papel central en uno de los exámenes más destacados que Leibniz llevó a cabo en estos años, a saber, su reformulación de la ley cartesiana de conservación del movimiento. En efecto, Leibniz considera que la conservación es causa de la elasticidad. ${ }^{32}$ Ahora bien, el examen de la ley de conservación será abordado en la cuarta sección de este capítulo, motivo por el cual postergamos para dicha instancia la consideración de la vinculación entre la elasticidad y dicha ley.

\subsection{La materia, mole o masa: sobre la variedad de cosas en lo inmenso}

En la segunda sección del capítulo anterior hemos mencionado a la pasada que, para explicar cómo se produce la multiplicidad de modificaciones del atributo de la inmensidad, Leibniz introdujo la noción de 'mole' o 'masa'. Recordemos este pasaje citado en el capítulo anterior:

De aquí es suficientemente evidente que lo inmenso mismo no es un intervalo ni es un lugar ni es cambiable, pero [también] que las modificaciones no se producen por un cambio suyo sino por el sobreañadido de otra cosa, a saber, de la Mole o Masa. De la adición de la mole y de la masa resultan los espacios, lugares, intervalos, el agregado de los cuales da el Espacio Universal (...). ${ }^{33}$

No obstante, quedó pendiente examinar qué entiende Leibniz por 'mole' o 'masa'. Ante todo, se trata de un elemento que tiene lugar a los fines de explicar lo que el filósofo de Leipzig llamó el 'origen de las cosas', esto es, de la multiplicidad de modificaciones de los atributos, en particular, en este caso, a propósito del atributo de la inmensidad. La cuestión sobre el origen de las cosas a partir de las formas comporta una gran complejidad, como por otra parte observaron atinadamente, entre otros, Laerke y Kulstad al detectar las

\footnotetext{
${ }^{31}$ Pacidius Philalethi, A VI 3, 555. OFC, 8, 142.

${ }^{32}$ De materia, de motu, de minimis, de continuo, A VI 3, 468.

${ }^{33}$ De origine rerum ex formis, A VI 3, 519. "Satis ex his patet ipsum hoc immensum non esse intervallum, nec esse locum, nec esse mutabile; modificationes autem fieri nulla eius mutatione, sed superadditione alterius, nempe Molis, sive Massae; ex additione molis et massae resultant spatia, loca, intervalla, quorum aggregata dant Spatium Universum, sed hoc spatium universum est Ens per aggregationem, continue variabile; compositum scilicet ex punctis vacuis plenis, ut rete, quod rete continuo aliam accipit formam, adeoque mutatur; sed quod in illa mutatione perstat, est ipsum immensum. Ipsum autem immensum est Deus quatenus cogitatur esse ubique, seu quatenus eam perfectionem, sive formam absolutam affirmativam quae tribuitur rebus, quando dicitur eas esse alicubi, continet".
} 
múltiples explicaciones dadas por Leibniz para explicar esta cuestión. ${ }^{34}$ No es nuestro interés plantear aquí toda la dimensión del problema, a pesar de que, como veremos, para examinar el origen de las cosas en relación con el atributo de la inmensidad nos referiremos por lo menos a dos de las propuestas explicativas sugeridas por estos intérpretes.

En alguna medida, parecería que, detrás de los planteos de Leibniz, hay una crítica implícita a la manera como Spinoza se refirió a las modificaciones. En efecto, las explicaciones sobre cómo se dan las modificaciones de los atributos que se encuentran en varios textos que Leibniz redactó en abril de 1676, parecen estar estrechamente vinculadas con uno de los planteos que Tschirnhaus le manifiesta a Spinoza en la relación epistolar que mantuvieron. Más aún, Tschirnhaus parecería manifestarle al filósofo holandés algunas opiniones de Leibniz, aunque de manera encubierta, en una carta que le envió el 23 de junio de $1676 .{ }^{35}$ En dicha carta, el joven amigo de Leibniz le solicita a Spinoza que le explique cómo se puede demostrar a priori la variedad de las cosas a partir del concepto de Extensión. ${ }^{36}$ Tschirnhaus le confiesa a Spinoza que hay una motivación fundada en la matemática que subyace a su planteo, pues observa que en esa disciplina es posible deducir a partir de la definición de una cosa solamente una propiedad, de manera tal que, para obtener muchas propiedades, es necesario conectar la cosa definida con otras. Tschirnhaus pone como ejemplo el caso de que se considere solamente la periferia del círculo. En este caso, es posible extraer la propiedad de la uniformidad de todas sus partes, pero no mucho más que eso. De esta manera, para saber alguna otra propiedad sería necesario poner en relación la periferia del círculo con alguna otra cosa, por ejemplo, con los radios que se tracen desde el centro. ${ }^{37} \mathrm{~A}$ partir de esto podría saberse, por ejemplo, la equidistancia. Como puede observarse, este planteo de Tschirnhaus es muy similar al planteo de Leibniz según el cual la variedad de las cosas puede explicarse tal como se explica la variedad de propiedades a partir de una esencia, esto es, relacionándola con otra cosa:

\footnotetext{
${ }^{34}$ Kulstad, 1999b: 78-84; Laerke, 2008: 517-541. En la cuarta sección del capítulo precedente nos hemos referido a algunas de las explicaciones presentadas por estos autores, como la denominada 'teoría del sujeto' y la 'teoría de las relaciones puras'. Además de ellas, Kulstad señala la teoría de la adición de la materia. Sobre esta cuestión, véase también Edamura, 2016.

${ }^{35}$ Kulstad, 1999b: 69-70, sugiere que algunos pensamientos de Leibniz del período de DSR pueden entenderse como una 'respuesta creativa' al intercambio epistolar entre Tschirnhaus y Spinoza sobre la cuestión de cómo se puede deducir la infinita variedad de figuras y movimientos de los cuerpos solamente del atributo de la extensión.

${ }^{36}$ EP LXXXII (IV, 333).

${ }^{37}$ EP LXXXII (IV, 333-334).
} 
Se da la misma variedad en cualquier género de mundo, y esto no es otra cosa que la misma esencia relacionada de diversas maneras, como si miraras una misma ciudad desde diversos lugares, o si relacionaras la esencia del seis al tres será $3 \times 2$ o $3+3$, pero si [la relacionaras] al cuatro será $\frac{6}{4}=\frac{3}{2}$, es decir, $6=4 \times$ $\frac{3}{2} \cdot 38$

Así, las distintas expresiones de lo mismo son como distintas propiedades de algo por cuya combinación obtenemos teoremas. Es posible que a partir de esto Leibniz haya considerado que las modificaciones son resultado de tomar simultáneamente todas las formas: "[e]sta variedad infinita no puede originarse a no ser de una causa infinita, esto es, de varias formas". ${ }^{39}$ En este sentido, aquel 'algo otro' con lo que se vincularía una forma para explicar las modificaciones en ella serían todas las restantes. Incluso, es llamativo que, en la carta antes mencionada de Tschirnhaus a Spinoza, el autor le haya planteado, como opción para resolver el problema de explicar la variedad de cosas a partir del mero concepto de extensión, tomar todos los atributos de manera conjunta. ${ }^{40}$ Quizás Leibniz haya inspirado a Tschirnhaus en dicha respuesta. ${ }^{41}$ Se trata, en este caso, de la explicación de la multiplicidad de cosas a partir de las formas que Kulstad y Laerke denominan 'teoría de las relaciones puras'. Es llamativo que, en su respuesta a la carta de Tschirnhaus, Spinoza evite introducirse en esta cuestión:

[Acerca de] [1]o que usted pregunta, si a partir del solo concepto de la Extensión se puede demostrar a priori la variedad de las cosas, creo que ya he mostrado, bastante claramente, que ello es imposible; y que, por tanto, la materia ha sido erróneamente definida por Descartes por medio de la extensión, pues debe ser explicada necesariamente por medio de un atributo que exprese una esencia eterna e infinita. Pero de esto hablaré quizás con usted más claramente alguna

\footnotetext{
${ }^{38}$ De formis simplicibus, A VI 3, 523. "Varietas eadem in quolibet genere mundi, nec est quicquam aliud, quam eadem essentia diversimode relata, ut si urbem eandem ex diversis locis aspicias, aut si essentiam senarii referas ad ternarium, erit $3 \times 2$ vel $3+2$, sin ad quaternarium erit $\frac{6}{4}=\frac{3}{2}$ seu $6=4 \times \frac{3}{2}$, . Como puede observarse, hemos corregido el texto allí donde dice " $3+2$ ". De acuerdo con Robinet, 1986: 184, este ejemplo es un caso de intervención del concepto matemático de serie en los escritos filosóficos.

${ }^{39}$ De formis simplicibus, A VI 3, 522. "Formae simplices: perceptio, situs. At Mutatio et Materia, sive ipsae Modificationes sunt resultantia ex omnibus allis Formis simul sumtis. (...) Quae varietas infinita, non nisi ex causa infinita, id est variis formis oriri potest". Kulstad, 2014: 57-60.

${ }^{40}$ EP LXXXII (IV, 334).

${ }^{41}$ Kulstad, 2014: 53-60.
} 
vez, si me queda vida; pues al respecto, hasta ahora, no me ha sido posible poner nada en orden. ${ }^{42}$

Como es sabido, Spinoza murió pocos meses después, de modo que no le quedó vida para hablar con Tschirnhaus más en detalle, pues incluso el pasaje anterior es el último fragmento de la relación epistolar entre estos autores. Sea como fuere, además de la 'teoría de las relaciones puras', en lo que respecta en particular a la inmensidad, Leibniz pensó que sus modificaciones pueden explicarse por la adición de lo que llamó un poco crípticamente 'mole' o 'masa' e incluso 'materia'. Ahora bien, entre los intérpretes no hay coincidencias en cuanto a la manera de concebir la naturaleza de la materia. En efecto, mientras que Kulstad la entiende como un principio de limitación de las formas, para Laerke la materia sería el principio de movimiento que no es otra cosa que la omnipotencia de Dios (de manera que reduce la 'teoría de la adición de la materia' a la 'teoría de las relaciones puras'). ${ }^{43}$ Por nuestra parte, como mostraremos a continuación, consideramos que, a diferencia de Laerke, es posible concebir a la materia como un principio de limitación.

Debe notarse, ante todo, que para Leibniz las nociones de 'mole', 'masa' y 'materia' son sinónimas. El pasaje con el que comenzamos esta sección deja en evidencia que para Leibniz las modificaciones en lo inmenso se explican por el sobreañadido de otra cosa, denominado 'mole' o 'masa', dado que los atributos no se modifican a sí mismos (y en esto último coincidiría con Spinoza). En el mismo texto, De origine rerum ex formis, Leibniz se refiere a lo sobreañadido bajo una tercera denominación, a saber, la de 'materia':

$[\mathrm{P}]$ ero la base del espacio es lo extenso mismo por sí, indivisible, y permanece mientras duran los cambios, y no cambia puesto que penetra todas las cosas. Por lo tanto, el lugar no es una parte suya sino una modificación suya por la materia añadida [ex accedente materia], es decir, es algo que resulta de la [base] misma [del espacio] y la materia. ${ }^{44}$

De esta manera, para Leibniz la 'materia' (lo mismo que la mole o masa) es aquello que se le añade a lo extenso y gracias a lo cual se dan las modificaciones. Ahora bien, en

\footnotetext{
${ }^{42}$ EP LXXXII (IV, 334). "Quod petis, an ex solo Extensionis conceptu rerum varietas a priori possit demonstrari, creo me iam satis clare ostendisse, id impossibile esse; ideoque materiam a Cartesio male definiri per Extensionem; sed eam necesario debere explicari per attributum, quod aeternam, et infinitam essentiam exprimat. Sed de his forsan aliquando, si vita suppetit, clarius tecum agam. Nam huc usque nihil de his ordine disponere mihi licuit”. Traducción de Spinoza, 2007: 292-293.

${ }^{43}$ Kulstad, 1999b: 83-84; Laerke, 2008: 536-538.

${ }^{44}$ De origine rerum ex formis, A VI 3, 519. “(...) at basis spatii, ipsum per se extensum, indivisibile est, manetque durantibus mutationibus, neque immutatur, quia omnia penetrat. Non ergo locus est eius pars, sed eius modificatio, ex accedente materia, seu aliquid ex ipsa et materia resultans".
} 
segundo lugar debe notarse que la materia, mole o masa fue concebida por Leibniz como un principio de limitación. El motivo por el cual Laerke se ha opuesto a esta interpretación es que Leibniz no se refirió explícitamente de esta manera al aludir a la materia en ningún texto de $D S R$, a pesar de que algunos pasajes permitirían entenderla como una suerte de principio de 'división'. ${ }^{45}$ Ahora bien, si bien es cierto que Leibniz no mencionó literalmente la expresión 'principio de limitación' al referirse a la materia, no obstante, como hemos visto en el capítulo anterior, es claro que para el filósofo de Leipzig en las cosas se encuentran limitadamente las formas que en Dios se atribuyen absolutamente. Recordemos el siguiente pasaje:

Dios es la inteligencia primera en cuanto es omnisciente, es decir, en cuanto ella contiene la forma absoluta afirmativa que se atribuye limitadamente a las otras cosas que se dicen percibir algo. De la misma manera Dios es lo Inmenso mismo en cuanto que se le atribuye una perfección, esto es, la forma afirmativa absoluta que se halla en las cosas cuando se atribuye a ellas estar en algún lado, estar presentes. ${ }^{46}$

Como puede observarse, para Leibniz la inmensidad se atribuye limitadamente a las cosas que están en algún lado, es decir, a las modificaciones de lo inmenso, de la misma manera que la omnisciencia se atribuye limitadamente a las mentes finitas. En consecuencia, las modificaciones son una cierta limitación, a pesar de que no son una parte del atributo correspondiente. En este sentido, en consecuencia, si las modificaciones son limitaciones y si la 'materia', 'mole' o 'masa' es aquello por cuyo sobreañadido resultan las modificaciones, entonces no parecería haber inconvenientes en decir que la materia es un cierto principio de limitación. En este sentido, mientras las modificaciones de lo inmenso son los lugares en los que pueden estar las cosas, Dios es omnipresente:

Dios no es una parte de nuestra Mente, como tampoco lo inmenso es una parte de un lugar o intervalo. Así como Dios es aquello que percibe perfectamente todo lo que puede percibirse, es decir, una inteligencia, así también Dios es

\footnotetext{
${ }^{45}$ Laerke, 2008: 536.

${ }^{46}$ De origine rerum ex formis, A VI 3, 520. "Deus est intelligentia prima, quatenus est omniscius, seu quatenus eam continet formam absolutam affirmativam, quae limitate tribuitur aliis quae aliquid percipere dicuntur. Quemadmodum Deus est ipsum Immensum, quatenus perfectio ei tribuitur id est forma affirmativa absoluta quae invenitur in rebus, cum tribuitur ipsis esse alicubi, esse praesentes". Un poco antes en el mismo texto (519) había señalado: "Ipsum autem immensum est Deus quatenus cogitatur esse ubique, seu quatenus eam perfectionem, sive formam absolutam affirmativam quae tribuitur rebus, quando dicitur eas esse alicubi, continet".
} 
aquello que está perfectamente en algún lugar dondequiera que algo pueda estar. $^{47}$

De aquí se sigue que lo que Leibniz llama 'materia', 'mole' o 'masa' es ese 'algo' que puede estar en algún lugar, esto es, lo que ocupa un lugar (locatus). En este sentido, si se quitara la materia, se suprimiría el lugar correspondiente, esto es, la modificación de lo inmenso que surgió por la adición de aquella mole o masa que ahora se suprime. ${ }^{48}$ Ahora bien, a pesar de que con esto puede explicar la función de la materia, en cuanto limita las formas, Leibniz no parece haber fundamentado nada sobre su existencia. En cuanto a esto, una de las características del planteo de Leibniz ha sido la tesis según la cual "ella [es decir, la materia] no existe sino en una relación", 49 a saber, con una mente. Ahora bien, como veremos en la siguiente sección, la cuestión de la vinculación de la materia con la mente conduce a Leibniz al planteo del problema de la individuación de los cuerpos y de la explicación de la cohesión.

\section{Individuación y cohesión de los cuerpos}

A lo largo de la tercera parte de nuestra tesis hemos visto de qué manera, hacia el final de sus días en París, Leibniz ha ido reformulando, corrigiendo o profundizando algunas de las conclusiones relativas al problema de la composición del continuo que extrajo en los años anteriores. No obstante, en el caso de la explicación de la cohesión de los cuerpos que mantuvo en la TMA y en los escritos inmediatamente posteriores sucedió algo más radical, a saber, como veremos, Leibniz la rechazó por inconsistente y la reemplazó por una nueva justificación. De acuerdo con esto, a continuación en primer lugar consideraremos los motivos por los que concibió como inconsistente su primer planteo y luego abordaremos el nuevo planteo que lo reemplazó.

\footnotetext{
${ }^{47}$ De origine rerum ex formis, A VI 3, 520-521. "Deus non est pars Mentis nostrae, quemadmodum nec immensum pars est loci cuiusdam sive intervalli. Ut Deus est id quod perfecte percipit, quicquid percipi potest, sive intelligentia, ita idem Deus est id quod perfecte alicubi est, ubicunque aliquid esse potest".

${ }^{48}$ De origine rerum ex formis, A VI 3, 521.

${ }^{49}$ Notizen zur Wissenschaft und Metaphysik, A VI 3, 392. "Quoniam ipsa non nisi in relatione existit, ut alibi vel ex individuationis principio omnium reum ostendi”.
} 


\subsection{El problema de la continuidad de los agregados}

En el quinto capítulo hemos mostrado que entre 1670 y 1672 Leibniz concibió que los cuerpos están cohesionados o permanecen unidos en virtud de que las partes poseen extremos en común, esto es, de acuerdo con la definición aristotélica, que son continuas. En este sentido, consideró que, cuando un cuerpo se mueve, presiona al cuerpo que le es contiguo, de tal manera que tiende a entrar en el lugar que ocupa aquel otro cuerpo. En consecuencia, arribó a la conclusión de que el inicio del movimiento (es decir, la tendencia, el conato) es al mismo tiempo el inicio de la unión entre cuerpos que previamente eran contiguos. De esta manera, la cohesión de los cuerpos, esto es, el hecho de que entre las partes haya un extremo en común, se funda en su movimiento. Como veremos, en los escritos de DSR el concepto aristotélico de 'continuo' ya no es útil para explicar la cohesión de los cuerpos, tal como propuso Leibniz en los años previos.

El trasfondo del rechazo de la explicación de la cohesión de los cuerpos fundada en la noción aristotélica de continuo, está constituido por una marcada distinción que Leibniz elaboró en estos años entre aquellas cosas que son un 'todo' y aquellas que, por el contrario, son 'un agregado'. Por un lado, la noción leibniziana de 'todo' está esencialmente ligada a la de 'magnitud'. En los capítulos correspondientes a la segunda parte de esta tesis, hemos visto que, entre finales de la década de 1660 y comienzos de la siguiente, Leibniz concibió la magnitud como el número de las partes. No obstante, hacia el final de su estadía en París reconoció que esta manera de concebirla no cumple con los requisitos de una buena definición, pues supone que las partes son iguales entre sí o mantienen una misma razón, y la noción de 'magnitud' está incluida en las de igualdad y de razón. En consecuencia, se estaría definiendo lo mismo por lo mismo, esto es, incurriendo en una petición de principio. ${ }^{50}$ En el intento de reformular la definición de magnitud, Leibniz ha señalado:

Después de muchos intentos, me parece que he hallado esta comodísima noción de Magnitud. La cantidad o magnitud es aquello según lo cual alguna cosa (que se dice tan grande) se dice que puede ser congruente (esto es, puede reducirse

\footnotetext{
${ }^{50}$ De magnitudine, A VI 3, 482.
} 
dentro de los mismos límites) con alguna otra. En efecto, digo que son congruentes las cosas que están entre los mismos términos. ${ }^{51}$

A modo de ejemplo, tómense dos líneas, una recta y otra curva, tales que, extendida la segunda, sean iguales en extensión. Así, digamos -siguiendo a Leibniz- que son de tres pies. Esto significaría, en términos del filósofo de Leipzig, que son congruentes, esto es, que están dentro de los mismos términos. Si la magnitud es aquello según lo cual se dice que dos cosas son congruentes, entonces 'tres pies' sería la magnitud del arco y de la recta. Allí se encuentra ejemplificada, por consiguiente, la noción de magnitud. ${ }^{52}$ Ahora bien, de aquí se sigue que el conocimiento de la magnitud del arco conlleva el conocimiento de dicha línea como una cierta totalidad. Es en este sentido que para Leibniz "[1]a magnitud es la constitución de la cosa por la que, conocida, puede ser tenida por un todo". ${ }^{53}$

Estas reflexiones de Leibniz sobre la noción de magnitud presuponen una novedosa comprensión de la relación entre un todo y sus partes. Veremos a continuación esta novedad siguiendo el curso de los argumentos que lo han llevado a ella. Nótese, ante todo, que en los ejemplos considerados anteriormente hay siempre una unidad de medida, como 'un pie' en el caso de las líneas comparadas. ${ }^{54}$ En este sentido, decir que las líneas son 'de tres pies' implica que tienen tres partes de esa unidad de medida. Ahora bien, si el sistema métrico escogido fuese otro, la unidad de medida sería distinta y, en consecuencia, también lo serían las partes. De esta manera, la determinación de las partes presupone siempre la totalidad de la que se está tratando. Precisamente por eso, Leibniz ha dicho que "[s]er en algo (esto es, entre límites) y [ser] algo que no puede entenderse sin otra cosa, es ser una parte". ${ }^{55}$ En este sentido, una parte siempre dice relación al todo sin el cual no puede entenderse. Para Leibniz, en efecto, un todo está siempre dado con anterioridad a las partes, las cuales se determinan posteriormente de manera arbitraria. De allí, que para Leibniz "[e]n lo continuo el todo es anterior a las partes". ${ }^{56}$ De esta manera, así como una parte es

\footnotetext{
${ }^{51}$ De magnitudine, A VI 3, 482. "Multa tentando hanc reperisse videor commodissimam Magnitudinis notionem. Quantitas sive Magnitudo est, secundum quam res aliqua (quae tanta dicitur) alteri cuidam, congruere posse (id est intra eosdem terminos redigi posse) dicitur. Congruere enim aio quae sunt intra eosdem terminos".

${ }^{52}$ De magnitudine, A VI 3, 482.

${ }^{53}$ Numeri infiniti, A VI 3, 503. "Magnitudo est rei constitutio, qua cognita, ipsa tota haberi potest".

${ }^{54}$ De magnitudine, A VI 3, 482.

${ }^{55}$ De materia, de motu, de minimis, de continuo, A VI 3, 470. "Esse in aliquo (id est intra terminos) et aliquid sine alio intelligi non posse, est esse partem".

${ }^{56}$ Numeri infiniti, A VI 3, 502. "Totum in continuo est prius partibus".
} 
algo que no puede entenderse sin otra cosa, así también "[u]n todo es aquello tal que puede entenderse que a su naturaleza le pertenecen muchas cosas homogéneas que se dicen partes". 57 Ahora bien, que puedan entenderse las partes significa para Leibniz que, al tratarse de un todo, ellas no se dan en acto con anterioridad:

Parece también que un Todo es lo que no tiene partes, sólo lo que puede tenerlas. Hay un todo cuando muchas cosas pueden llegar a ser a partir de algo uno. Pero ‘que lleguen a ser a partir de algo uno' es 'que permanezca algo'. ${ }^{58}$

Las consecuencias que se siguen de este examen de Leibniz son muy relevantes para el problema del continuo. Por lo pronto, está estrictamente relacionado con la negación de una composición de puntos mínimos que hemos examinado en la primera sección del capítulo sexto. Como vimos, uno de los argumentos capitales empleados por Leibniz en 1676 para negar una composición de mínimos se apoya en el principio geométrico según el cual una línea puede dividirse en un número cualquiera de partes iguales entre sí. Ahora bien, un presupuesto de este principio es el hecho de que solamente puedan producirse partes cuando haya algo que permanece, a saber, un todo. Leibniz extrae de aquí una notable conclusión en el Pacidius Philalethi:

Pero no hay puntos, líneas, superficies en cualquier parte y en general los extremos no son otra cosa que los que surgen al dividir: y las partes no existen en el Continuo también antes de que se produzcan por la división. Pero nunca se hacen todas las divisiones que pudieran hacerse. Pero el número de las divisiones posibles no es mayor que el de los Entes posibles, que coincide con el número de todos los números. ${ }^{59}$

En síntesis, para Leibniz en las líneas y en otras entidades geométricas se cumplen los requisitos que definen a un todo, de manera tal que las partes en ellas no existen en acto antes de ser asignadas. Es claro que, aunque Leibniz no utilice esta expresión abiertamente,

\footnotetext{
${ }^{57}$ De magnitudine, A VI 3, 483. "Totum est ad cuius naturam plura homogenea pertinere intelligi potest, quae dicuntur partes". Que sean homogéneas significa, sintéticamente, que las partes deben ser de un mismo género de cosas. En efecto, Leibniz define a la homogeneidad de esta manera: "Homogenea sunt quibus aliqua sive natura per se intelligibilis variis modis convenit". En el capítulo anterior hemos visto algunos elementos que ayudaron a esclarecer esta definición, como los de "forma" o "modo".

${ }^{58}$ Numeri infiniti, A VI 3, 503. "Videtur Totum esse etiam quod non habet partes modo habere possit. Totum est, cum ex uno fieri possunt plura. Ex uno autem fieri, est aliquid manere".

${ }^{59}$ Pacidius Philalethi, A VI 3, 552-553. "Sed alibi non esse et puncta, lineas, superficies, et in universum extrema non alia esse, quam quae fiunt dividendo: et partes quoque non esse in Continuo antequam divisione producantur. Nunquam autem fiunt omnes divisiones quae fieri possunt”. OFC, 8, 140. Levey, 1999: 89-91, señala que con esto Leibniz estaría negando que en el continuo haya partes en acto. Ahora bien, parece que este intérprete no notó que este pasaje se explica sobre la base de la distinción entre las nociones de 'todo' (anterior a las partes) y agregado (posterior a ellas).
} 
los textos sugieren fuertemente que las partes están en potencia respecto del todo. Ahora bien, para el filósofo de Leipzig es claro que hay una multiplicidad de cosas que no pueden ser concebidas como totalidades, precisamente porque no cumplen con el requisito fundamental que define a un todo, a saber, ser anterior a sus partes. Cuando se trata de cosas cuyas partes no son potenciales sino actuales, es decir, de cosas cuyo carácter unitario no está dado con anterioridad a la multiplicidad arbitrariamente asignada sino de alguna manera posteriormente, entonces ya no se está frente a un 'todo' sino a lo que Leibniz llama un 'agregado'.60

La relación entre el concepto de 'agregado' y la teoría leibniziana del cuerpo ha sido examinada por P. Lodge, quien mantiene que desde mediados de la década de 1680 Leibniz sostuvo que los cuerpos son agregados de sustancias, aunque inicialmente para referirse al cuerpo humano y recién más tarde para todo cuerpo en general. ${ }^{61}$ De acuerdo con Lodge, el concepto leibniziano de 'agregado' es más complejo que la mera idea de una colección de cosas diversas, pues supone una cierta unidad (el agregado) constituida por una variedad (las cosas agregadas). No obstante, no se trata de algo que posee una unidad per se sino per accidens. Precisamente por ello, Lodge entiende que los conceptos de 'ens per aggregationem' y de 'ens per accidens' son sinónimos en el pensamiento leibniziano. Ahora bien, como la unidad no es debida a relaciones internas de las cosas agregadas, de acuerdo con Lodge, para Leibniz la unidad de lo agregado es mental, esto es, es la unidad de nuestras ideas de ellos, y así su ser es dependiente de la mente. ${ }^{62}$ No significa esto que Leibniz haya identificado las ideas de los agregados con ellos, aunque sí que dichas ideas son componentes esenciales de ellos, de manera tal que la unidad de los agregados debe ser identificada con la de sus respectivas ideas. De allí que Lodge concluya que el ser de los agregados es mental o fenoménico, con tal que se reconozcan dos supuestos, a saber, por un lado que las relaciones entre las cosas agregadas no son características del mundo real y por otro que, como 'ser' y 'uno' son convertibles y como la unidad del agregado es mental, su

\footnotetext{
${ }^{60}$ Numeri infiniti, A VI 3, 503.

${ }^{61}$ Lodge, 2001.

${ }^{62}$ Lodge, 2001: 472. "Leibniz nota que, mientras que muestras ideas de agregados tienen una unidad que es 'muy genuina', los mismos agregados o colecciones están unidos simplemente por una relación fundada en 'lo que en el caso está dentro de' las cosas que son agregadas. Desde aquí, concluye que la única unidad verdadera y 'perfecta' que poseen los agregados, es la unidad fundada en nuestras ideas de ellas, y que su ser es también dependiente de una mente". La traducción es nuestra.
} 
ser es, en consecuencia, semi-mental. ${ }^{63}$ Ahora bien, observamos que el concepto de agregado puede encontrarse en el pensamiento de Leibniz ya entre los años 1675 y 1676. En este período el concepto en cuestión se encuentra en plena gestación, de manera que, si bien pueden hallarse aquí algunas de las notas que Lodge ha reconocido en textos posteriores, también se observan algunas diferencias. La más importante corresponde al hecho de que en nuestro contexto Leibniz no ha sostenido que los cuerpos sean agregados de sustancias. A pesar de esto, el concepto de agregado, independientemente de qué cosas sean las agregadas, ya estaba en gran medida conformado.

Leibniz aplica el concepto de agregado a diversas cosas. En primer lugar, una definición es "un agregado de caracteres en los cuales no es necesaria ninguna semejanza" en relación con aquello que es definido. ${ }^{64}$ En este sentido, para que haya una definición se requiere que estén dados con anterioridad los caracteres que auxilian al pensamiento. En segundo lugar, la percepción de una cosa sensible, en sentido estricto, no requiere para Leibniz de un acto del intelecto sino de un agregado de infinitos. ${ }^{65}$ En efecto, para sentir una cosa sensible o tener una sensación (por ejemplo, sensaciones de colores, gustos, etc.), se requiere de cierto trecho de tiempo. Ahora bien, “(...) el tiempo es divisible al infinito, y es cierto que en cualquier momento el alma percibe unas y otras cosas, pero de todas las infinitas percepciones confusas en algo uno se originan las percepciones de las cosas sensibles" ${ }^{66}$ De esta manera, lo que parece una percepción unitaria y coherente supone en rigor una multiplicidad dada previamente de la que se origina. En tercer lugar, también el espacio universal es concebido como un agregado de los múltiples lugares o porciones espaciales ocupados por la 'mole' o 'masa'. ${ }^{67}$ Este espacio, dado que supone las partes con anterioridad (esto es, los lugares o porciones espaciales), no posee consecuentemente una unidad por sí:

Supuesto que el espacio tiene partes, a saber, mientras está dividido por los cuerpos en partes vacías y plenas de diversas figuras, se sigue que el espacio mismo es un todo o Ente por accidente, que cambia continuamente y deviene

\footnotetext{
${ }^{63}$ Lodge se opone, de esta manera, a la interpretación de Adams, 1994: 246, según quien el ser y la unidad de los agregados es completamente mental.

${ }^{64}$ De mente, de Deo, de universo, A VI 3, 463.

${ }^{65}$ De formis seu attributis Dei, A VI 3, 515. También De plenitudine mundi, A VI 3, 524.

${ }^{66}$ De plenitudine mundi, A VI 3, 524. "Tempus autem in infinitum divisibile, et certum est quolibet momento percipere animam, alia atque alia, sed ex omnibus perceptionibus infinitis in unum confusis oriri rerum sensibilium perceptiones".

${ }^{67}$ De origine rerum ex fomis, A VI 3, 519.
} 
una y otra cosa, a saber, mientras las partes cambian, se extinguen y reaparecen otras. $^{68}$

Para Leibniz esto es lo mismo que decir que el espacio universal es un ente por agregación. ${ }^{69}$ En cuarto lugar, y en concordancia con el espacio, también los cuerpos pueden ser considerados como agregados en la medida en que para Leibniz ellos poseen infinitas partes en acto:

Así pues, opino que no hay ninguna porción de materia que no esté dividida en acto en muchas partes, y así, no hay ningún cuerpo tan exiguo en el cual no haya un mundo de infinitas criaturas. Del mismo modo, no hay ninguna parte del tiempo en la [cual] no suceda alguna mutación o movimiento en alguna parte o punto del cuerpo. Y así, ningún movimiento dura lo mismo a lo largo de un espacio o tiempo cuanto se quiera exiguo; y así como [lo está] el cuerpo, así también tanto el espacio como el tiempo estarán en acto subdivididos al infinito. $^{70}$

Finalmente, el movimiento de un cuerpo ha sido concebido por Leibniz como "(...) un agregado de dos existencias de la cosa (...) en dos puntos próximos (...), en dos momentos también próximos". ${ }^{71}$ Más aún, toda mutación o cambio en general ha sido entendido como un "contacto o agregado de dos estados opuestos". ${ }^{72}$ Es precisamente en el examen de la mutación en general que se encuentran varios rasgos esenciales de la noción de agregado que nos permitirán mostrar el rechazo de Leibniz a la antigua explicación de la cohesión de los cuerpos que se apoya en la noción aristotélica de continuo.

\footnotetext{
${ }^{68}$ Notizen zur Wissenschaft und Metaphysik, A VI 3, 391. "Posito spatium habere partes, dum scilicet in partes vacuas et plenas, variarum figurarum, a corporibus dividitur, sequitur spatium ipsum esse totum sive Ens per accidens: continuo mutari, et aliud atque aliud fieri: mutatis scilicet partibus, et extinctis, aliisque subnatis. Sed est aliquid in spatio, quod manet inter mutationes, id vero aeternum est, neque aliud est, quam ipsa immensitas Dei, attributum scilicet unum atque indivisibile simul et immensum". Ya nos referimos a este pasaje en la tercera sección del capítulo anterior.

${ }^{69}$ De origine rerum ex formis, A VI 3, 519. En el mismo texto pueden encontrarse otras apariciones de la expresión 'ente por agregación' para referirse al espacio.

${ }^{70}$ Pacidius Philalethi, A VI 3, 565-566. "Itaque sic sentio: nullam esse portionem materiae quae non in plures partes actu sit divisa, itaque nullum corpus esse tam exiguum in quo non sit infinitarum creaturarum mundus. Similiter nullam esse temporis partem in [qua] non cuilibet corporis parti vel puncto aliqua obtingat mutatio vel motus. Nullum itaque motum eundem durare, per spatium tempusve utcunque exiguum; itaque ut corpus ita et spatium et tempus actu in infinitum subdivisa erunt". OFC, 8, 151. Leibniz se refiere explícitamente a los cuerpos como agregados en De origine rerum ex formis, A VI 3, 521, en una comparación entre cuerpo y mente: "Quicquid agit, illud destrui non potest, saltem enim durat dum agit, ergo durabit semper. Quicquid patitur neque agit, id destrui potest, ut locus, figura. Corpus omne aggregatum destrui potest".

${ }^{71}$ Pacidius Philalethi, A VI 3, 546. "Motus ergo nunc est aggregatum duarum existentiarum rei (...) in duobus punctis (...) proximis, duobus momentis etiam proximis". OFC, 8, 134.

${ }^{72}$ Pacidius Philalethi, A VI 3, 541. “(...) contactum vel aggregatum duorum statuum oppositorum”. OFC, 8, 129.
} 
La consideración del movimiento como un 'agregado' es una consecuencia de un complejo examen de Leibniz mediante el cual considera cómo debe concebirse el estado de mutación, esto es, el estado en el que el cuerpo en cuestión muta o cambia de lugar. En efecto, Leibniz observa que, si se lo tomara como 'un estado (numéricamente hablando)' y no como 'un agregado de dos estados opuestos', se seguirían inevitablemente contradicciones, puesto que conllevaría que un cuerpo está en un lugar al mismo tiempo que no lo está. A modo de ejemplo, Leibniz considera la muerte como un tipo de mutación, es decir, el acto mismo de morir que es un cierto punto de inflexión (esto es, un cambio o una mutación) entre la vida (el 'estado en que se está vivo') y la muerte (esto es, el 'estado en que se está muerto'). La muerte, en síntesis, es una mutación en la que el que muere dejar de estar vivo para pasar a estar muerto. En este sentido, se tienen dos estados que son opuestos y se tiene a su vez el hecho de mutar o cambiar de uno a otro. ${ }^{73}$ Leibniz reconoce que si la muerte (es decir, la mutación misma) fuera un estado numéricamente distinto de los estados opuestos que de alguna manera vincula, entonces toda mutación se resolvería en tres estados: el que se abandona, el de mutación y el que se adquiere. No obstante, ese tercer estado de mutación sería por su propia naturaleza contradictorio, pues debería tener algo en común con los otros dos. De esta manera, el acto mismo de morir implicaría que el que se está muriendo está al mismo tiempo vivo (pues aún no está muerto) y muerto (pues está perdiendo la vida). En consecuencia, el filósofo de Leipzig se da cuenta de que considerar al estado de mutación como si fuese sui generis, esto es, un tercer estado distinto de los otros dos, contradice el principio de tercero excluido: ${ }^{74}$

PACIDIO: Resta que me respondas esta sola cosa: ¿No es lo mismo el último momento del vivir y el primer momento del no vivir?

CARINO: Si no debe afirmarse nada sino lo que comprendemos ciertamente, sin duda no me atrevería a afirmar esto.

PACIDIO: Te felicito Carino, pues aprendiste el arte de dudar, [el cual] en verdad no [es] pequeño. En efecto, aquí (te [lo] confesaré) he querido poner a prueba tu juicio. Pero dime, te [lo] pido: ¿qué te hizo [estar] tan cauto aquí?

\footnotetext{
${ }^{73}$ Pacidius Philalethi, A VI 3, 535. OFC, 8, 122-123.

${ }^{74}$ Pacidius Philalethi, A VI 3, 535. OFC, 8, 123.
} 
CARINO: Vi que tú querías inferir [de esto] que, en el momento común del vivir y del no vivir, alguien simultáneamente vive y no vive. Lo cual reconozco que es absurdo. ${ }^{75}$

En consecuencia, Leibniz reconoce que, aunque no pueda darse un estado distinto, sí pueden darse sucesiva e inmediatamente el último momento de un estado (en el ejemplo, de vivir) y el primero del otro (de estar muerto). ${ }^{76}$ Dicho de otra manera, el estado de mutación en rigor no es sino un agregado del último momento de un estado y del primero del siguiente. En el caso del movimiento, se agregan dos puntos próximos que corresponden justamente a los dos momentos. Precisamente por eso, dichos puntos son asimismo sucesivos, pero no comunes. La posibilidad de hallar dos puntos que se sigan próximamente sin que por ello sean uno y el mismo es justificada por Leibniz con el auxilio de un ejemplo: si se suponen una tabla plana $A B$ sobre la que se encuentra una esfera $C$ y se dice que el punto en que se contactan dichas figuras es uno y el mismo (esto es, $e$ para la tabla y $d$ para la esfera), entonces sería imposible mover una de esas figuras (como la esfera $C$ hacia uno de los extremos de la tabla) sin mover necesariamente la otra. En consecuencia, los puntos $d$ de la esfera y $e$ de la tabla se dan simultáneamente, aunque no sean uno y el mismo. ${ }^{77}$

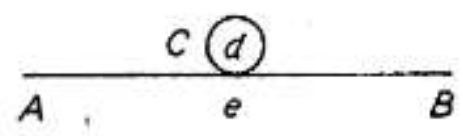

En este sentido, parecería que Leibniz notó que la función cohesiva que les había atribuido a los puntos extremos al comienzo de la década de 1670 no puede sostenerse,

\footnotetext{
${ }^{75}$ Pacidius Philalethi, A VI 3, 536-537. "Pa.: Superest hoc unum mihi respondeas, idemne sit ultimum momentum vivendi, et primum momentum non vivendi. - Ch.: Si nihil asserendum est quam quod certo comprehendimus, id quidem asseverare non ausim. - Pa.: Gratulor tibi Charine, quod artem dubitandi, sane non exiguam, didicisti. Hic enim (fatebor tibi) aliquod judicii tui experimentum capere volui. Sed dic mihi quaeso quid te hic tam cautum fecerit. - Ch.: Videbam inferre te vele, communi vivendi ac non vivendi momento eundem simul vivere ac non vivere. Quod absurdum esse agnosco". OFC, 8, 124. Similarmente, ha dicho anteriormente en la página 535: "Pa.: In quo non est hic status id vita carece dicimus. - Ch.: Esto. - Pa.: Nonne mortis momentum illud est, quo quis incipit vita carere. - Ch.: Quidni. - Pa. : Aut quo desinit vitam habere. - Ch.: Perinde est. - Pa.: Quaero an hoc momento absit an adsit vita. - Ch.: Video difficultatem, neque enim ratio est cur alterum prae altero dicam. - Pa.: Opus est ergo, ut neutrum dicas aut utrumque. - Ch. : Sed tute mihi exitum hunc interclusisti. Nam satis video, statum aliquem necessario adesse aut neque simul adesse et abesse, vel nec adesse nec abesse".

${ }^{76}$ Pacidius Philalethi, A VI 3, 537. OFC, 8, 124.

${ }^{77}$ Pacidius Philalethi, A VI 3, 537. OFC, 8, 124.
} 
precisamente porque un extremo en común contradice el principio de tercero excluido. ${ }^{78}$ En consecuencia, se sigue del hecho de que no haya un estado intermedio, es decir, un extremo en común, que los cuerpos o los agregados en general no cumplen con los requisitos para ser considerados como 'cosas continuas' de acuerdo con la definición aristotélica, sino solamente 'cosas contiguas':

TEÓFILO: Recuerdo que también Aristóteles discierne lo Contiguo de lo Continuo de tal modo que son Continuas [aquellas cosas] cuyos extremos son uno, [y] Contiguas [aquellas] cuyos extremos son simultáneos.

PACIDIO: Del mismo modo, por lo tanto, decimos con Carino que el estado de vivo y [el estado] de muerto son solamente contiguos, y que no tienen un extremo común. $^{79}$

De esta manera, de aquí parecería seguirse que no hay continuidad allí donde se trate de agregados. No obstante, sí la hay cuando se trate de un todo, pues en dicho caso las partes no se dan antes de ser asignadas. Esto tiene también consecuencias en uno de los recursos más utilizados por Leibniz para examinar el problema del continuo, esto es, la exposición del continuo que está considerando en una línea. ${ }^{80} \mathrm{El}$ empleo de este recurso en el período de $D S R$ se diferencia del uso que le dio en la $T M A$ y en otros escritos por tener que señalar con mucha precisión la distinción entre una línea geométrica (que, como es un todo, es continua y no está dividida en acto) y una línea que representa un movimiento o cualquier otro continuo (que, como no es un todo sino un agregado, está dividida en acto en partes y que, en consecuencia, no es una línea continua sino una serie de líneas contiguas agregadas):

Pero esta conversación nuestra no es acerca de 'alguna línea uniforme continua' en la cual no pudieran siquiera asumirse dos puntos del mismo tipo $B$ y $D$ inmediatos entre sí, sino acerca de 'la línea $A C$ que ya [está] por naturaleza cortada en acto en partes', puesto que asumimos una mutación sucedida de tal modo que en un momento el móvil existiría en el extremo $B$ de una de sus

\footnotetext{
${ }^{78} \mathrm{La}$ vinculación entre las ideas sobre el cambio en la concepción de la cohesión de los cuerpos y la imposibilidad de un estado de mutación fueron atinadamente señaladas por Levey, 1999: 102-103.

79 Pacidius Philalethi, A VI 3, 537. “Th.: Memini Aristotelem quoque Contiguum a Continuo ita discernere, ut Continua sint quorum extrema unum sunt, Contigua quorum extrema simul sunt. - Pa.: Eodem ergo modo dicemus cum Charino statum vivi mortuique tantum contigua esse, nec communia extrema habere". OFC, 8, 125. Quizás un anticipo de esta visión puede encontrarse en un escrito datado entre 1673 y 1675 , De vera methodo philosophiae et theologiae (A VI 3, 158), en el que Leibniz mantuvo que es difícil concebir cómo muchos cuerpos pueden estar en un mismo lugar. Véase Garber, 2009: 47.

${ }^{80}$ En la primera sección del cuarto capítulo hemos mostrado la importancia de este recurso en los exámenes de Leibniz del período que aquí es discutido.
} 
partes $A B$, y en otro [momento existiría] en el extremo $D$ de la otra parte $D C$. Y la diferencia entre estas dos líneas contiguas divididas por sí en acto y una [línea] indivisa o continua es manifiesta: que, como ya ha notado Aristóteles, los extremos $B$ [y] $D$ en las líneas contiguas difieren, [pero] en una [línea] continua coinciden, como también hemos notado antes. ${ }^{81}$

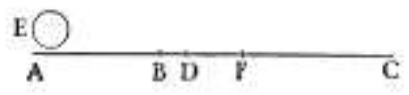

Este importante pasaje muestra que la distinción aristotélica entre lo contiguo y lo continuo es abordada de una nueva manera en el examen leibniziano de DSR. Mientras que en los escritos anteriores lo contiguo no tenía lugar en el examen del problema del continuo, en los escritos de 1675-1676 adquiere relevancia, en la medida en que algunas de las cosas que se llaman genéricamente 'continuas', como el cuerpo o el movimiento, no lo son rigurosamente hablando.

\subsection{Los cuerpos que se resisten a la disipación: la unidad de los agregados}

Hemos visto que mientras un todo es para Leibniz algo uno dado con anterioridad a la multiplicidad de partes asignables arbitrariamente, un agregado es algo que resulta posteriormente de muchas partes dadas en acto. Precisamente por esto, un todo es algo uno que permanece aun cuando se le asignen partes, mientras que un agregado eventualmente llega a ser algo uno. Ahora bien, Leibniz se encuentra con un inconveniente cuando quiere explicar si los agregados, rigurosamente hablando, pueden ser tomados como unidades. Como hemos visto, para Leibniz hay un todo cuando muchas cosas pueden llegar a ser a partir de algo uno. Ahora bien, el filósofo de Leipzig confiesa que "[n]o sé si puede ser llamado 'uno' lo que realmente está dividido, es decir, un Agregado". ${ }^{82}$ El problema, entonces, es si corresponde referirse a los agregados como si se trataran de unidades.

\footnotetext{
${ }^{81}$ Pacidius Philalethi, A VI 3, 563-564. "At nobis hic sermo est non de linea aliqua uniformi continua, in qua duo eiusmodi puncta sibi immediata $B$ et $D$ ne sumi quidem potuissent, sed de linea $A C$ iam actu in partes secta, a natura, quia ponimus mutationem ita factam, ut uno momento existeret mobile in unius eius partis $A B$ extremo $B$, et altero in alterius partis $D C$ extremo $D$. Estque discrimen inter has lineas duas actu a se divisas contiguas, et unam indivisam seu continuam manifestum, quod ut iam Aristoteles notavit, extrema $B, D$ in duobus contiguis lineis differunt, in una continua coincidunt, quemadmodum et supra notavimus". OFC, 8 , 149.

${ }^{82}$ Numeri infiniti, A VI 3, 503. "Quod reapse divisum est seu Aggregatum, nescio an dici possit unum".
} 
En buena medida, la resolución de este inconveniente implica examinar la naturaleza de la unidad numérica y en consecuencia de los números en general. De acuerdo con Leibniz, el número uno es aquel a partir del cual se definen todos los otros, esto es, tanto los números enteros y racionales, todos los cuales son sumatorias de unidades, como las fracciones y los números irracionales, todos los cuales son siempre entendidos en relación con una unidad:

Número, si entiendes solamente el entero racional, es un todo que consta de unidades. Si se toma [en un sentido] más general, y se comprende la fracción y el irracional, será una Cantidad homogénea con la unidad, [una Cantidad] inteligible en relación con la unidad. ${ }^{83}$

De esta manera, a modo de ejemplo, un número entero como ' 6 ' es algo que consta de unidades, esto es, de ' $1+1+1+1+1+1$ ', así como una fracción, como $\frac{1}{4}$, se entiende siempre vinculada a una unidad (esto es, aquí, a $\frac{4}{4}$, es decir, $\frac{1}{1}$ ). No obstante, esto no significa para Leibniz que todo número se relacione con la unidad. Como hemos visto en el sexto capítulo, el filósofo de Leipzig ha justificado que el número de todas las unidades, esto es, el número infinito, es contradictorio y, en consecuencia no es un todo y no se equipara con la unidad sino con el cero. Leibniz sospecha, en consecuencia, que no todas las cosas inteligibles pueden constituir un todo. ${ }^{84} \mathrm{Sin}$ embargo, considera que en general es posible tomar a los agregados, esto es, lo que está realmente dividido, como 'algo uno'. Incluso, una clara muestra de que pueden ser llamados algo uno se encuentra en el hecho de que nos valemos de nombres que se refieren de manera unitaria a los agregados de muchas cosas. ${ }^{85}$ Esto vale incluso para el número infinito de todos los números, puesto que, aunque dicho número no pueda constituir algo uno, hay un nombre que le corresponde. Este hecho deja en evidencia que para Leibniz las palabras tienen una función unitiva desde el punto de vista de nuestra comprensión de las cosas. Ahora bien, Leibniz ya había expuesto esta idea varios años antes en su Dissertatio de Arte Combinatoria. Al comienzo de este texto, el filósofo de Leipzig determinó el siguiente postulado:

\footnotetext{
${ }^{83}$ De magnitudine, A VI 3, 482. "Numerus si integrum rationalem tantum intelligas, est totum ex unitatibus constans. Si generalius sumatur, fractumque et irrationalem comprehendat, erit Quantitas homogenea unitati, intelligibilis relationem ad unitate".

${ }^{84}$ De mente, de Deo, de universo, A VI 3, 463.

${ }^{85}$ Numeri infiniti, A VI 3, 503.
} 
Pueden tomarse simultáneamente todas las cosas que se quiera y suponerlas como un Todo. Presento [esto por] si acaso algún obstinado lo niega. El concepto de partes implica que hayan muchos Entes sobre todos los cuales, si puede entenderse algo [en común], se inventa un nombre (puesto que es siempre incómodo o imposible nombrarlos a todos) que, aplicado en el razonamiento en lugar de todas las partes para abreviar el discurso, se llama 'Todo'. Y esto es verdadero para todo [número de] cosas, pues puede entenderse para todas las cosas que se quiera dadas, incluso infinitas. Puesto que enumerarlas parte por parte a todas es posible solamente en un tiempo infinito, en las consideraciones se podrá disponer de un nombre en lugar de todos; este mismo será el Todo. ${ }^{86}$

Este pasaje revela varios elementos importantes. Primero que, cuando se trate de muchas partes, e incluso de infinitas, nombrarlas una por una resultaría algo incómodo o quizás imposible. En efecto, para ello se requeriría de un tiempo infinito. De esta manera, en segundo lugar, asignar un nombre para considerar aquella pluralidad de manera conjunta simplifica y facilita el discurso. Precisamente por esto, en síntesis, para Leibniz hay en las palabras una función unitiva cuya utilidad es innegable. Como hemos visto, esta idea es la misma que está presente en los escritos de mediados de la década de 1670, en la medida en que los agregados pueden ser tomados como algo uno porque la mente es capaz de denominar un conjunto de cosas agregadas bajo un mismo nombre.

Ahora bien, en el caso particular del examen de los cuerpos, la unidad de los agregados implica algo más que la mera unidad de la palabra. Una suerte de presupuesto de esta cuestión es que la idea de unidad no se obtiene del cuerpo, como tampoco la de identidad e incluso la de existencia. ${ }^{87}$ En este sentido, la explicación de que los cuerpos sean ciertas cosas individuales está relacionada con algo que hemos mencionado al final de la sección 1.3. de este capítulo, a saber, que la materia existe en relación con una mente. Como hemos visto en el capítulo anterior, las mentes tienen una percepción de sí como de cierta cosa particular, lo que Leibniz llama también 'identidad de la mente'. En

\footnotetext{
${ }^{86}$ Dissertatio de Arte Combinatoria, A VI 1, 169. "Liceat quotcumque res simul sumere, et tanquam unum Totum supponere. Si quis praefractus hoc neget, ostendo. Conceptus partium est, ut sint Entia plura, de quibus omnibus si quid intelligi potest, quoniam semper omnes nominare vel incommodum vel impossibile est, excogitatur unum nomen, quod in ratiocinationem pro omnibus partium adhibitum compendii sermonis causa, apellatur Totum. Cumque datis quotcunque rebus, etiam infinitis, intelligi possit, quod de omnibus verum est; quia omnes particulatim enumerare infinito demum tempore possibile est, licebit unum nomen in rationes ponere loco omnium: quod ipsum erit Totum". En la inclusion de 'en común' entre corchetes seguimos la traducción de Loemker, 1989: 73.

${ }^{87}$ De origine rerum ex formis, A VI 3, 518.
} 
consecuencia, como Leibniz piensa que hay una relación entre materia y mente, la unidad o cohesión de las partes de un cuerpo se debe a que hay una mente implantada en la materia:

Por lo tanto, pienso que la solidez o unidad de los cuerpos es debida a una mente, que tantas son las mentes cuantos vórtices, que tantos los vórtices cuantos los cuerpos sólidos, que el cuerpo resiste, que esta resistencia es una sensación. Resiste, a saber, a lo que tiende a dividirlo. La sensación es cierta reacción. El cuerpo [es] incorruptible del mismo modo que la mente, pero varios órganos alrededor de él mutan variadamente. ${ }^{88}$

Este pasaje señala varios aspectos de la manera como Leibniz explicó en $D S R$ la cohesión o unidad de los cuerpos que iremos examinando en detalle en lo que sigue, como la mención de los 'vórtices'. Ahora bien, lo más relevante que se menciona allí es que los cuerpos mantienen su unidad porque resisten a dividirse y que esa resistencia está relacionada con una mente. En este sentido, hay un principio no corpóreo que forma parte de la explicación de la unidad de los cuerpos. ${ }^{89}$ Así como la materia es algo que está en relación con una mente, por conversión para Leibniz la mente también es algo que tiene una relación con una porción de materia. Esto no significa que tenga una relación con cualquier porción de materia, sino con una parte en particular. ${ }^{90}$ En el pasaje, Leibniz se refiere como 'sólidos' a los cuerpos que poseen la característica de mantenerse unidos. Ahora bien, hay al menos dos maneras de interpretar la mención de los cuerpos sólidos. Por una parte, de acuerdo con lo visto en la sección 1.2. de este capítulo, significa que no son líquidos (esto es, los que no tendrían ningún tipo de resistencia a la separación, de modo que estarían divididos en todas partes) y que no son como los átomos de Gassendi, esto es, tales que no es posible dividirlos. No obstante, lo que Leibniz llama ‘cuerpo sólido’ no sería el extremo contrario al líquido (que sería el átomo del sacerdote francés), sino el cuerpo que resiste a ser dividido pero que no es un indivisible, es decir, un cuerpo flexible. Esta manera de

\footnotetext{
${ }^{88}$ De veritatibus, de mente, de Deo, de universo, A VI 3, 509-510. "Ergo ita sentio, soliditatem seu unitatem corporis esse a mente, tot esse mentes, quot vortices, tot vortices, quot corpora solida, corpus resistere, hanc resistentiam esse sensum. Resistit scilicet dividere conanti. Sensus quaedam reactio est. Corpus incorruptibile pariter ac mens, varia circa ipsum organa varie mutantur". Leibniz emplea la expresión "mente implantada a la materia' en De arcanis sublimium vel de summa rerum, A VI 3, 476. "Mentem omnem etiam Materiae cuidam indissolubiliter implantatam".

${ }^{89}$ Levey, 2007: 41. Más aún, mientras los cuerpos son agregados, de alguna manera las mentes son totalidades. Esto último fue observado por Goldenbaum, 2014: 45. Podría decirse que, de alguna manera, estas reflexiones de Leibniz son un anticipo de la distinción entre sustancias (que son algo uno) y los seres por agregación, propia del pensamiento de madurez. Nachtomy, 2014: 157-161.

${ }^{90}$ Notizen zur Wissenchaft und Metaphysik, A VI 3, 392.
} 
interpretar la noción de 'cuerpo sólido' se desprende del último pasaje citado y también, entre otros, del siguiente:

Parece que -y digo esto a la pasada - todos los sólidos están informados por cierta mente. Hay que ver si acaso estos sólidos son al menos flexibles, aunque no puedan ser separados; por lo mismo, hay que ver si acaso los cuerpos no sean ni sólidos ni fluidos, sino intermedios por su propia naturaleza. ${ }^{91}$

No obstante, esta interpretación parecería encontrar algunas dificultades en otros pasajes en los que Leibniz se refiere a los cuerpos que poseen una mente implantada no como cuerpos que poseen una cierta resistencia a la división sino como cuerpos 'incortables':

Por consiguiente, ya que me consta de otra parte que existe una porción de materia sólida y no frágil (...) se sigue que el pensamiento entra a formarla [a la

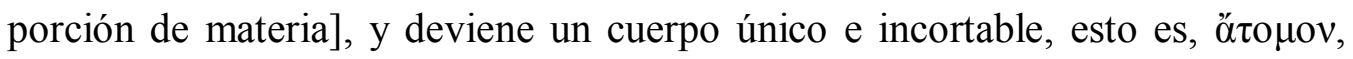
cualquiera que sea su magnitud, siempre que tenga una cierta mente. Además, los vórtices puestos necesariamente en movimiento por el solo movimiento de los cuerpos firmes, son tantos en la naturaleza como los cuerpos firmes. Y tantas son las Mentes, o Mundillos, o percepciones, cuantos son los vórtices en el Mundo. ${ }^{92}$

El hecho de que Leibniz se refiera a los cuerpos incortables como 'átomos' es problemático, pues parecería sugerir que no se trata de cuerpos que sean difíciles de separar, sino cuerpos imposibles de separar. Según esta manera de interpretarlo, serían como los átomos de Gassendi. ${ }^{93}$ No obstante, como veremos, el 'átomo' que Leibniz describe no es el mismo que el de sacerdote francés. Lo que proponemos es que Leibniz interpretó la noción de átomo en dos sentidos distintos: en un sentido, 'átomo' es el elemento propuesto por Gassendi que Leibniz constantemente critica, esto es, un cuerpo perfectamente sólido, pero en otros sentido, ‘átomo' es ‘cuerpo sólido' en el sentido que recién mencionamos y que exploraremos en detalle en lo que sigue.

\footnotetext{
${ }^{91}$ De arcanis sublimium vel de summa rerum, A VI 3, 473. "Videntur, ut id obiter dicam, omnia solida esse quadam mente informata. Videndum an solida illa saltem flexilia sint, etsi separari non possint, videndum item an non sint corpora, neque solida neque fluida, sed media ex ipsa natura sua".

${ }_{92}$ Notizen zur Wissenchaft und Metaphysik, A VI 3, 393. "Cum ergo aliunde mihi constet esse aliquam materiae portionem solidam, et infrangibilem, sequitur accedere cogitationem ad eam formandam, et unum fieri corpus atque insecabile, sive ö́o $\mu \mathrm{ov}$, cuiuscunque sit magnitudinis, quandocunque aliquam unam habet mentem. Porro quot sunt corpora firma in natura, tot necessario excitantur vortices, solo corporum firmorum motu. Et quot sunt vortices in Mundo, tot sunt Mentes, sive Munduli, sive perceptiones".

${ }^{93}$ Seguimos las indicaciones de Arthur, 2004. Además del sentido clásico de 'átomo', Arthur señala que en el contexto de $D S R$ opera otro sentido en el que se supone una mente que organiza la materia. Como se verá en lo que sigue, coincidimos plenamente con esta parte de su planteo.
} 
Una muestra del segundo sentido de 'átomo' se encuentra en algunos pasajes en los que Leibniz se refiere a los átomos como cuerpos sólidos que resisten a la disipación o disolución, de modo que precisamente por eso forman una especie de vórtice. ${ }^{94}$ En este sentido, Leibniz considera hipotéticamente que si se tomara a la materia aisladamente, esto es, sin considerar la relación que mantiene con una mente particular, de manera que cesaría aquello que la mantiene unida, entonces se reduciría al estado de liquidez, esto es, se compondría de puntos. ${ }^{95}$ Por esta razón, si ellos no existieran, todas las cosas se disolverían. ${ }^{96}$ Ahora bien, como vimos antes, para Leibniz es imposible una división en mínimos, como la que se daría supuesto un líquido perfecto. Así, un átomo sería un cuerpo que mantiene una unidad, de modo que no está dividido 'en todas partes'. En este sentido, de acuerdo con lo que dijimos antes, sería un cuerpo flexible. Recordemos que una de las características que implicaba la flexibilidad de los cuerpos era cierta cohesión de sus partes. Ahora bien, esto muestra que la característica a partir de la cual Leibniz piensa los átomos, esto es, la resistencia a la división, no tiene que ver con su dimensión. En este sentido, no podrían ser concebidos como cuerpos pequeñísimos tal como vimos en el segundo capítulo que mantiene Gassendi. Así, para Leibniz cualquier cuerpo que resista a la división sería un cierto átomo, "(...) cualquiera que sea su magnitud, siempre que tenga una cierta mente". 97 El filósofo de Leipzig examina esto cuando se esfuerza por explicar el pleno constituido por átomos. Como estos cuerpos incortables (Insecabilia corpora) deben ser simples, Leibniz los concibe de manera esférica. De este modo, un pleno constituido de átomos es concebido por el filósofo de Leipzig de acuerdo con la siguiente imagen: ${ }^{98}$

\footnotetext{
${ }^{94}$ De arcanis sublimium vel de summa rerum, A VI 3, 473.

${ }^{95}$ De arcanis sublimium vel de summa rerum, A VI 3, 473-474.

${ }^{96}$ De plenitudine mundi, A VI 3, 525.

${ }^{97}$ Notizen zur Wissenchaft und Metaphysik, A VI 3, 393. Para la cita véase la nota 92. Coincidimos en este punto con el examen de Wilson, 1999: 237, aunque a nuestro modo de ver el hecho de que la autora comprenda que hay un panteísmo en los escritos de $D S R$ en alguna medida limita su planteo. En efecto, para que pueda explicarse las unidades de los cuerpos gracias a las mentes, es necesario que las mentes mismas estén dotadas de una cierta unidad propia, cosa que, como vimos, se explica porque hay algo propio en ellas, es decir, porque son 'verdaderos entes'. Coincidimos también con el examen de Garber, 2009: 62-66.

98 Tomamos la imagen de De plenitudine mundi, A VI 3, 525.
} 


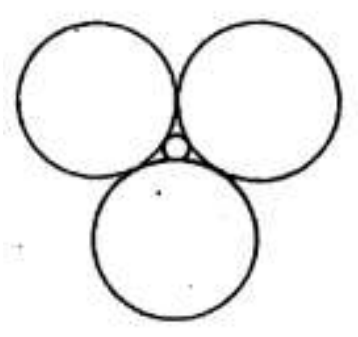

Como la imagen muestra, Leibniz pretende explicar el pleno conformado por átomos esféricos apoyándose en la posibilidad de pensar que no hay un lugar tan pequeño en el que no pueda existir una esfera menor. En consecuencia, “(...) supuesta la plenitud del Mundo, es necesario que los glóbulos sean unos menores que otros al infinito". ${ }^{99}$ Así, los átomos propuestos por Leibniz difieren de los de Gassendi al menos en dos cosas: por un lado, en que no son cuerpos pequeñísimos, o al menos no necesariamente. En efecto, lo que caracteriza por sobre todas las cosas al átomo de Leibniz es la unidad, esto es, la resistencia a la división. Por otro lado, a partir de lo dicho anteriormente, puede observarse que el átomo de Leibniz difiere del de Gassendi en el hecho de que no es puramente físico, pues se trata de una porción de materia que está relacionada con una cierta mente. ${ }^{100}$ En este sentido, la unidad se justifica por dicha relación y no como explicó Gassendi, como vimos en la tercera sección del quinto capítulo, por el hecho de que los átomos posean ciertos ganchos: "[a] partir de los solos glóbulos puede explicarse la conexión de los cuerpos sin ningún gancho ni garfio, los cuales son ineptos y ajenos a la simplicidad y belleza de las cosas". ${ }^{101}$

Anteriormente hemos visto que, cuando Leibniz se refiere a los cuerpos que se resisten a lo que tiende a dividirlos, menciona que las mentes son tantas como los 'vórtices'. En los escritos de $D S R$, Leibniz se refiere reiteradamente a la imagen de los vórtices para referirse a sus átomos con la idea de graficar el modo de pensar la manera en que las mentes mantienen la cohesión en la materia con la que están relacionadas. De alguna manera, como sugiere C. Wilson, parecería que el filósofo de Leipzig considera que la

\footnotetext{
${ }^{99}$ De plenitudine mundi, A VI 3, 525. "Nullus enim locus est tam parvus quin fingi possit esse in eo sphaeram ipso minorem. (...) Est tamen ubi demonstrari potest varietas, ut globorum, nam posita plenitudine Mundi, necesse est globulos esse alios allis minores in infinitum".

${ }^{100}$ Garber, 2009: 65-66, señaló atinadamente que en las notas del período parisino, Leibniz “(...) se da cuenta de que lo que necesita no es una unidad fisica -dureza- sino una unidad metafisica, esto es, una individualidad genuina". La traducción es nuestra.

${ }^{101}$ De plenitudine mundi, A VI 3, 525. "Ex globulis solis explicari potest connexio corporum, sine ullis hamis, uncisque, qui inepti et a rerum simplicitate et pulcritudine alieni".
} 
unión que los cuerpos poseen en virtud de la mente que está en ellos se explica por medio de un movimiento circular en torno a su propio centro. ${ }^{102}$ En este sentido, las mentes que están implantadas en una cierta porción de materia, tienen un vórtice alrededor de ella. ${ }^{103}$

Ahora bien, la explicación de la unidad o cohesión de los cuerpos fundada en la relación entre la materia y la mente está estrechamente vinculada con la manera como Leibniz aborda el problema del principio de individuación en los escritos de DSR. Para abordar este problema, Leibniz parte de un ejemplo en el que se suponen dos cuadrados perfectamente similares pero uno de ellos constituido por dos rectángulos y el otro por dos triángulos: ${ }^{104}$

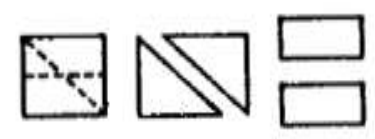

La dificultad que este ejemplo supone radica en que para uno u otro caso se muestra el mismo cuadrado, a pesar de que sus partes son distintas y de que, en consecuencia, deben poder distinguirse. Para explicar la individuación, Leibniz se vale del principio de equipolencia, según el cual “(...) un efecto envuelve a su causa, esto es, de modo que quien entienda perfectamente algún efecto, llega al conocimiento de su causa". ${ }^{105}$ En este sentido, hay una conexión necesaria entre un efecto y la causa correspondiente. Basándose en este principio, Leibniz propone distinguir los cuadrados no según lo que puede observarse en ellos, pues el cuadrado que se muestra es el mismo, sino según su causa, esto es, su modo de producción. "Y por esto -señala Leibniz- es imposible que dos cuadrados del mismo tipo sean perfectamente similares, puesto que constarían de materia, pero esta tendría una mente, y la mente retendría el efecto del estado anterior". ${ }^{106}$ En este sentido, lo que

\footnotetext{
102 Wilson, 1999: 251. "Es posible que Leibniz entienda simplemente que la presencia de un cuerpo indica la presencia de un conjunto de movimientos para preservar la unidad, análogos a aquellos que poseen la forma típica de "torbellino"”. La traducción es nuestra. Leibniz sugiere esto mismo en De plenitudine mundi, A VI 3, 525. "Quot sunt corpora insecabilia, tot sunt vortices, seu motus circumsectorum relatione ad unum quoddam variati".

${ }^{103}$ De arcanis sublimium vel de summa rerum, A VI 3, 476-477.

${ }^{104}$ La imagen es tomada de Meditatio de principio individui, A VI 3, 490.

${ }^{105}$ Meditatio de principio individui, A VI 3, 490. "effectum involvere causam suam; Id est ita ut qui perfecte intelligat effectum aliquem, etiam ad causae eius cognitionem perveniat”. Como señala Robinet, 1986: 185, la la ley de equipolencia no solamente tiene una aplicación en el dominio de la física. Desde un punto de vista metafísisco, fue fundamental para la reinserción del término 'sustancia' en el pensamiento maduro de Leibniz. ${ }^{106}$ Meditatio de principio individui, A VI 3, 490-491. "Quare si aliunde nobis certum sit, effectum involvere suam causam, necesse est in productis quadratis modum productionis semper discerni posse. Adeoque
} 
distingue a los cuadrados está 'fuera' de ellos, esto es, en su causa, a saber, en que hay una mente, que retiene un estado anterior, añadida a una porción de materia. En este sentido, la materia y la mente que corresponden a un cuadrado son distintas de las que corresponden a otros.

El abordaje leibniziano del principio de individuación parece mostrar que la afirmación de átomos, esto es, cuerpos constituidos por una porción de materia unida a una mente que se resisten a la separación de sus partes, no contradice la afirmación de que en la materia hay infinitas partes en acto, sino que de hecho la complementa. En este sentido, parecería que para Leibniz un cuerpo supone una cierta unidad en la infinitud de partes, no porque la materia no esté dividida, sino porque hay una mente en ella que explica la cohesión. Incluso, en el Pacidius Philalethi Leibniz le cuestiona a Descartes precisamente que en la materia líquida, que el filósofo de Leipzig interpreta como constituida de puntos, no habría ningún punto coherente con otro. En virtud precisamente de esto, propone concebir a los cuerpos como flexibles en todas partes, que poseen partes unidas, aunque la resistencia que posean a dividirse no sea siempre igual. ${ }^{107}$ En este sentido, el hecho de considerar que, dada la plenitud del mundo, algunos globos son infinitamente menores que otros, se complementa con la tesis hay mundos dentro de mundos. Así, en dicho diálogo, Teófilo le dice a Pacidio (quien expresa las ideas de Leibniz):

Parecen haber dicho algo grande quienes declaran infinitos globos de estrellas en este espacio Mundano y que en un cada globo hay un mundo; tú muestras que en algún grano de arena no [hay] solamente un mundo sino también infinitos mundos: no sé si puede decirse algo más espléndido y más conveniente con la grandeza divina que esto. ${ }^{108}$

En síntesis, para Leibniz los agregados constan de partes dispuestas de manera contigua, de modo que solamente en un todo, es decir, en lo que no posee partes actuales, hay verdadera continuidad. A pesar de esto, hay algo no corpóreo gracias a lo cual se da una cierta unidad en los cuerpos. En este sentido, los cuerpos son ciertos 'átomos', es decir, se resisten a la disipación o disolución dado que hay mentes implantadas en la materia.

impossibile esse, ut duo quadrata eiusmodi sint perfecte similia, quia ex materia constabunt, ea autem mentem habebit, et mens retinebit effectum status prioris".

${ }^{107}$ Pacidius Philalethi, A VI 3, 554-555. OFC, 8, 142.

${ }^{108}$ Pacidius Philalethi, A VI 3, 566. "Magnam rem dixisse visi sunt, qui infinitos in spatio hoc Mundano stellarum globos, et in unoquoque globo esse mundum asseruere, tu inqualibet arenula non mundum tantum, sed et infinitos ostendis mundos, quo nescio an dici possit aliquid splendidius, ac magnitudini divinae convenientius". OFC, $8,152$. 


\section{Naturaleza del movimiento}

Como vimos en las secciones anteriores, en los escritos de DSR Leibniz modificó varios aspectos de su teoría de la materia de los años previos. Con respecto a la teoría del movimiento sucede algo similar: en varios textos, especialmente el Pacidius Philalethi, Leibniz abordó un examen de la naturaleza del movimiento que lo llevó a algunas conclusiones novedosas. En la sección 2.1. de este capítulo hemos visto una de ellas, a saber, que el movimiento es considerado como un agregado de estados opuestos, de modo que es algo contiguo pero no 'continuo' en el sentido de poseer un extremo en común. A continuación consideraremos otras de ellas, como son la no-uniformidad del movimiento y su carácter respectivo o relativo.

La cuestión acerca de si el movimiento es o no uniforme se sigue como consecuencia de la tesis de acuerdo con la cual el movimiento es el agregado de dos existencias momentáneas en dos lugares próximos. En efecto, Leibniz reconoce que esta manera de entender el movimiento puede llevar a concebir al espacio como compuesto de puntos y al tiempo de momentos si no se dilucidan los supuestos en los que se apoya. Leibniz plantea la dificultad de esta manera:

Si el movimiento presente es un agregado de dos existencias, será un continuado de muchas [existencias]. Pues asumimos que es continuo y uniforme. Pero hay existencias diversas de momentos y puntos diversos. Y durando la totalidad del tiempo y del lugar, no hay sino unas y otras existencias que se siguen inmediatamente entre sí; por consiguiente, no habrá sino momentos y puntos que se siguen inmediatamente entre sí en el tiempo y el lugar. $^{109}$

Como puede observarse, y como ha señalado atinadamente S. Levey, ${ }^{110}$ Leibniz considera dos supuestos del movimiento, a saber, por un lado que es continuo, y por otro que es uniforme. De acuerdo con el filósofo de Leipzig, alguno de los dos supuestos debe ser incorrecto, puesto que de otra manera se seguiría una composición de puntos y

\footnotetext{
${ }^{109}$ Pacidius Philalethi, A VI 3, 546-547. "Si motus praesens est aggregatum duarum existentiarum, erit continuatus plurium. Nam continuum sumsimus atque uniformem. Existentiae autem diversae diversorum sunt momentorum atque punctorum. Et toto tempore atque loco durantibus non nisi aliae atque aliae existentiae sunt sese immediate sequentes, ergo non nisi momenta atque puncta se immediate sequentia in tempore ac loco erunt". OFC, 8, 134.

${ }^{110}$ Levey, 2003.
} 
momentos, cosa que Leibniz no puede aceptar por las contradicciones que supone y que hemos visto reiteradamente en nuestro trabajo, especialmente en el sexto capítulo. En efecto, si se supone un cuerpo móvil, como $G$ en la siguiente imagen, y se considera que se mueve, es decir, que cambia de lugar, entonces en el tiempo $N$ estaría en el lugar $A$, mientras que en el tiempo $O$ pasaría a estar en el lugar $C$ :

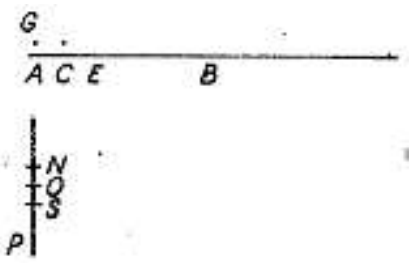

Ahora bien, si se conceden los dos supuestos antes mencionados, esto es, que el movimiento es continuo y uniforme, entonces no habría manera de evitar la conclusión de que en el momento inmediatamente próximo a $O$, como $S$ en la imagen, el cuerpo móvil debería estar en el punto inmediatamente próximo a $C$, como $E$ en la imagen. ${ }^{111}$ Como el mismo argumento podría replicarse al infinito, bajo estos supuestos el espacio y el tiempo se compondrían respectivamente de puntos y momentos:

Por lo tanto, puesto que el movimiento no es sino el agregado de diversas existencias a lo largo de momentos y puntos, y éste es continuo como [lo son] el espacio y el tiempo, también por esto se seguirán inmediatamente entre sí en todas partes puntos en el espacio y momentos en el tiempo, a saber, los mismos [puntos y momentos] en los cuales el movimiento incide en sucesión continua; por esto, el tiempo no será sino un agregado de momentos y el espacio de puntos. $^{112}$

Similarmente, un poco más adelante señala:

Supuesto un movimiento continuo uniforme y establecida la noción de mutación que has dicho, no puedo negar que el continuo se componga de puntos. Pues mientras dura el movimiento, así como asumimos, para un punto y un momento, otro próximo, así, no hay ninguna razón de por qué no asumir también, para este segundo, otro próximo tercero. Y ya que, continuando de

\footnotetext{
111 Tanto la imagen como el ejemplo pueden hallarse en Pacidius Philalethi, A VI 3, 547.

${ }^{112}$ Pacidius Philalethi, A VI 3, 547. "Quoniam ergo motus non nisi diversarum existentiarum per momenta punctaque aggregatum est et aeque continuus est ac spatium tempusque, ideo etiam ubique in spatio puncta, et in tempore momenta sese immediate sequentur, ea ipsa scilicet in qua motus continua successione incidit, ideo tempus non nisi momentorum et spatium non nisi punctorum aggregatum erit”. OFC, 8, 135.
} 
este modo, finalmente se completarán [todo] el espacio y el tiempo, [ellos] constarán, ciertamente, de puntos y momentos inmediatos entre sí. ${ }^{113}$

De esta manera, con el objetivo de evitar estas contradicciones, Leibniz se dedica a examinar con detalle cada uno de los supuestos para ver cuál ha sido erróneamente asumido. En el quinto capítulo hemos visto que Leibniz defendió que el movimiento es continuo desde la TMA. Al igual que en dicho escrito, Leibniz sigue considerando que un movimiento continuo es aquel que no está interrumpido por reposos, así como también que quienes han considerado los reposos lo han hecho con la finalidad de explicar la desigualdad en las velocidades de los movimientos. ${ }^{114}$ En cuanto a lo primero, de acuerdo con Leibniz la interposición de reposos en un movimiento significaría que el cuerpo móvil permanece en un mismo lugar por un trecho de tiempo. Ahora bien, entre dos reposos cualquiera que hubiera en un movimiento, se interpone un movimiento que puede o bien ser momentáneo, o bien durar un cierto tiempo. No obstante, de acuerdo con Leibniz no puede ser momentáneo, pues en dicho caso sería como si el móvil saltara por el espacio. ${ }^{115}$ Como vimos en la tercera sección del séptimo capítulo, Leibniz rechaza que se den saltos de acuerdo con el principio de que 'la magnitud o pequeñez no vienen al caso'. Es decir: los saltos no tienen lugar en la naturaleza dado que podría siempre pensarse que quienes realizan los saltos son criaturas más pequeñas. En consecuencia, supuesto que el movimiento no fuera continuo, entre dos reposos habría un movimiento que dura un cierto tiempo. No obstante, suponer esto conlleva un gran inconveniente, a saber, que este movimiento interpuesto entre dos reposos o es continuo o encuentra otros reposos interpuestos. Supuesta la segunda alternativa, en consecuencia, se replicaría el argumento y se retomaría la misma pregunta, a saber, si el movimiento que se interpone entre los dos reposos es momentáneo o dura un tiempo. La conclusión que Leibniz extrae es clara: si el movimiento interpuesto entre dos reposos es momentáneo, deberían afirmarse saltos en el movimiento; ahora bien, si dicho movimiento dura un tiempo, o se caería en una regresión al infinito o se reconocería que es continuo. En consecuencia, en la explicación del

\footnotetext{
${ }^{113}$ Pacidius Philalethi, A VI 3, 556. "Non possum negare posito motu continuo uniformi, et stabilita quam dixisti, mutationis notione, componi continuum ex punctis. Nam durante motu, ut uni puncto atque [uno] momento aliud proximum sumsimus, ita nulla ratio est cur non et huic secundo aliud tertium proximum assumamus; cumque hoc modo pergendo tandem spatium tempusque absolvantur, utique ex punctis momentisve sibi immediatis constabunt". OFC, 8, 143.

${ }_{114}^{114}$ Pacidius Philalethi, A VI 3, 542. OFC, 8, 140-141. Asimismo, 543-544.

${ }^{115}$ Pacidius Philalethi, A VI 3, 542.
} 
movimiento no hay lugar para negar la continuidad del movimiento. Como se observa, en este caso también vale el principio según el cual 'la grandeza o pequeñez no vienen al caso':

No puedo no confesar esto [a saber, que el movimiento que está entre dos reposos es continuo]; pues si introdujera nuevamente otros reposos, solamente volvería la misma cuestión. Y aunque progresara subdividiendo infinitamente y mezclara reposos indefinidamente exiguos e indesignables con pequeños movimientos de la misma naturaleza, será sin embargo necesario [que se mezcle] con pequeños tiempos y pequeñas líneas, y siempre subsistirían los mismos razonamientos. ${ }^{116}$

En consecuencia, el primero de los supuestos del movimiento examinado no puede ser negado. De esta manera, Leibniz pasa a considerar si el movimiento, además de continuo, puede ser uniforme. Ahora bien, ¿qué entendió Leibniz por 'uniformidad' del movimiento? S. Levey señala que, en el contexto del siglo XVII, se empleó esta noción para referirse a movimientos cuya velocidad es constante. ${ }^{117}$ Esta interpretación parecería ser perfectamente consistente con lo que propone Leibniz en el Pacidius Philalethi, dado que, si se supone la uniformidad de un movimiento continuo, la distancia entre dos puntos cualesquiera sería siempre la misma; en consecuencia, supuestos dos puntos que se siguen inmediatamente, necesariamente habría un tercero inmediatamente posterior, y un cuarto, y así sucesivamente. Más aún, en algunos escritos de los años anteriores puede observarse que Leibniz interpreta la uniformidad de esta manera. Por ejemplo, como hemos visto en el quinto capítulo, en la TMA Leibniz señaló que, mientras puede haber conatos y puntos mayores que otros, no puede haber momentos mayores que otros, “(...) de donde el tiempo se expone por un movimiento uniforme en la misma línea". ${ }^{118}$ De esta manera, la igualdad de los instantes se concibe si el movimiento que recorre un cuerpo es constante. Sin embargo, el texto en el que se muestra más claramente que Leibniz tuvo en mente esta noción de uniformidad es Demonstratio substantiarum incorporearum. Recordemos un pasaje que citamos en la primera sección del cuarto capítulo:

Sea el espacio $a b$. Entiéndase que en él marcha el cuerpo $C$, con un movimiento uniforme, y atraviesa, en el espacio de una hora, de $a$ hasta $b$. Es necesario que,

\footnotetext{
${ }^{116}$ Pacidius Philalethi, A VI 3, 543. "Non possum id diffiteri, nam si alias rursus quietulas introducerem, rediret tantum quaestio eadem; et tametsi indefinite progrederer subdividendo ac quietulas indefinite exiguas atque indesignabiles, motulis ejusdem naturae miscerem, is opus tamen et tempusculis atque lineolis foret, restarentque eaedem semper ratiocinationes".

${ }^{117}$ Levey, 2003: 384.

${ }^{118}$ TMA, A VI 2, 266. “(...) unde tempus exponitur motu uniformi in linea eadem”.
} 
en el espacio de media hora, atraviese hasta $d$, y en el espacio de un cuarto [de hora] hasta $e$, y en un octavo [de hora] hasta $\mathrm{f}$, y así dividiendo continuamente el espacio y el tiempo en la misma razón. ${ }^{119}$

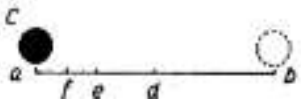

Si el movimiento del cuerpo fuera uniforme, esto es, constante, podría saberse con exactitud a qué distancia está un móvil de su destino en un tiempo determinado. En este sentido, en la mitad del tiempo habría recorrido la mitad del trayecto, y así sucesivamente.

Como dijimos anteriormente, en el Pacidius Philalethi Leibniz observa que si se supone que el movimiento es continuo y uniforme, debe concluirse que el espacio y el tiempo se componen de puntos. A su vez, mostró que el movimiento es continuo, es decir, no está interrumpido por reposos. De esta manera, para evitar la conclusión de que el continuo se compone de puntos, Leibniz buscó mostrar que el movimiento carece de uniformidad. En efecto, a modo de ejemplo considera un móvil $E$ que en el momento $M$ se encuentra en el lugar $A$ y que en el momento $R$ estará en el lugar $C$ :

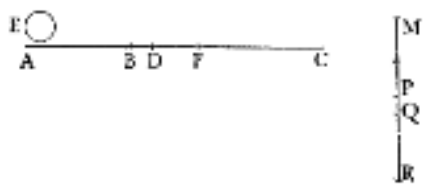

Leibniz señala que se seguirían contradicciones si se supone que existe un punto $B$ en el trayecto del movimiento en el cual el móvil se encontraría en el tiempo intermedio $P$. En efecto, supuesto esto, no habría razones para negar que, en el momento próximo $Q$, el móvil se encontraría en el punto $D$, inmediatamente posterior a $B$, ni tampoco para negar que la misma conclusión podría extraerse nuevamente. En consecuencia, habría un punto inmediatamente posterior a $D$ en el que el cuerpo estaría en un momento próximo a $Q$, y así sucesivamente. Por lo tanto, para evitar una composición de mínimos, Leibniz se ve forzado a concluir que el movimiento no es uniforme:

Pero ha sido demostrado que es absurdo que la línea se componga de puntos. Pero puesto que no puede negarse la uniformidad en el lugar y el tiempo considerados por sí [mismos], resta, por consiguiente, que se niegue en el movimiento mismo. $\mathrm{Y}$ en primer lugar debe negarse que pueda asumirse otro

\footnotetext{
${ }^{119}$ Demonstratio substantiarum incorporearum, A VI 3, 81. "Esto spatium $a b$, in eo ferri intelligatur corpus $C$ motu uniformi et horae spatio pervenire ex $a$ in $b$, necesse est semihorae spatio pervenire in $d$ et spatio quadrantis in $e$ et semiquadrantis in $f$ et sic perpetuo subdividendo in eadem ratione locum et tempus".
} 
punto inmediato al punto $D$, del mismo modo en que [se ha asumido] un punto inmediato $D$ al punto $B .^{120}$

Ahora bien, Leibniz no acepta esta conclusión únicamente por reducción al absurdo. Ella está íntimamente conectada con la distinción explorada en la sección 2.1. de este capítulo entre lo que es un todo y lo que es un agregado, pues la línea en la que se asumirían los puntos $B, D$, etc. no es una 'línea uniforme continua' sino una línea que representa el trayecto de un movimiento. En este sentido, es una línea que ya está dividida en acto en partes. Como el movimiento es un agregado, la línea en la que se expone no puede ser tomada como una línea continua, esto es, un cierto todo que no está aún dividido, en la que los extremos $B$ y $D$ coincidirían. En consecuencia, como los puntos no existen con anterioridad a la división actual, los puntos $B$ y $D$ que se supusieron en la línea que representa el trayecto son, rigurosamente hablando, una hipótesis imposible. ${ }^{121}$ En este sentido, el abordaje sobre el movimiento que Leibniz ha llevado a cabo en el Pacidius Philalethi es radicalmente distinto del que presentó en los escritos anteriores (como son, entre otros, aquellos en los que utilizó el concepto de 'uniformidad del movimiento' mencionados anteriormente). Mientras que en la $T M A$ y en otros textos inmediatamente posteriores Leibniz esbozó una teoría abstracta del movimiento, en el Pacidius Philalethi piensa en la estructura, o mejor dicho, en la filosofía primera del movimiento. ${ }^{122}$ En este sentido, el movimiento real - no el que podríamos imaginarnos como uniforme, sino el que efectivamente sucede en la naturaleza- no solamente no es uniforme sino que tampoco podría serlo. En última instancia, la razón por la cual el movimiento no es uniforme se funda en una de sus más importantes tesis físicas, a saber, se sigue como consecuencia del pleno:

CARINO: Por consiguiente, ¿qué si decimos que el Movimiento de un móvil está en acto dividido en infinitos otros movimientos diversos entre sí, y que no continúa igual y uniforme a lo largo de ningún trecho de tiempo?

PACIDIO: Muy ciertamente, y tú mismo ves que restaba [por decir] está sola cosa. Pero también esto está de acuerdo con la razón; en efecto, no hay ningún

\footnotetext{
${ }^{120}$ Pacidius Philalethi, A VI 3, 563. "Lineam autem ex punctis componi absurdum esse demonstratum est. Quoniam autem negari non potest uniformitas in loco et tempore per se consideratis, superest ergo ut negetur in ipso motu. Et in primis negandum est uti puncto $B$ sumtum est punctum immediatum $D$ ". OFC, 8, 148.

${ }^{121}$ Pacidius Philalethi, A VI 3, 563-564. OFC, 8, 148-149.

${ }^{122}$ Pacidius Philalethi, A VI 3, 529. OFC, 8, 116.
} 
cuerpo que no soporte, en algún momento, alguna pasión de los [cuerpos] vecinos. $^{123}$

De este modo, el influjo que los cuerpos circundantes ejercen sobre un móvil acarrea como consecuencia que su movimiento se vea permanentemente alterado. Precisamente por eso no podría haber un movimiento inercial (esto es, constante o uniforme).

Al comienzo de esta sección mencionamos que en los escritos de 1675-1676, Leibniz extrajo algunas conclusiones novedosas sobre la naturaleza del movimiento, como por ejemplo que no es uniforme. En lo que sigue abordaremos otra conclusión muy importante, a saber, la relatividad del movimiento. Ahora bien, Leibniz omite intencionalmente considerar esta cuestión en el Pacidius Philalethi. ${ }^{124}$ El examen del carácter relativo del movimiento se encuentra en un escrito llamado Principia mechanica que data de entre 1673 y 1676 . Incluso, los presupuestos del examen de la relatividad del movimiento son opuestos a los del Pacidius Philalethi que hemos visto anteriormente, en la medida en que, como veremos, se suponen movimientos uniformes. En este sentido, la relatividad o respectividad del movimiento es una conclusión a la que Leibniz arriba a partir de un examen abstracto del movimiento. ${ }^{125}$

Leibniz llega a afirmar el carácter relativo del movimiento como consecuencia de una profundización de la definición de movimiento que hemos visto anteriormente. En efecto, el movimiento, como adquisición de una nueva posición o de un estado de cosas distinto del que se sentía con anterioridad, puede interpretarse como una modificación en la distancia que el móvil mantiene respecto de otros cuerpos. En este sentido, la posición de un cuerpo se encuentra en relación con otros respecto de los cuales permanece distante. ${ }^{126}$ Así, por ejemplo, decimos que hay un movimiento cuando dos cuerpos que se encontraban juntos pasan a estar distantes. A partir de esto, Leibniz concluye que "es evidente que el conocimiento de la posición se reduce a la distancia y, por lo tanto, el cambio de posición

\footnotetext{
${ }^{123}$ Pacidius Philalethi, A VI 3, 565. "Ch.: Quid si ergo dicemus Motum mobilis actu esse divisum in infinitos alios motus inter se diversos, neque per ullum temporis tractum eundem perseverare atque uniformem. - $\mathrm{Pa}$.: Recte profecto, et vides ipse hoc unum superesse, sed et rationi consentaneum id est, nullum enim corpus est, quod non quolibet momento aliquam passionem subeat a vicinis". OFC, 8, 150.

${ }^{124}$ Pacidius Philalethi, A VI 3, 529. OFC, 8, 116.

125 Arthur, 2015b: 149-152.

${ }^{126}$ Principia mechanica, A VI 3, 102-103. OFC, 8, 98-99.
} 
no se produce sin el cambio de alguna distancia". ${ }^{27}$ Ahora bien, el filósofo de Leipzig reconoce que, supuestas así las cosas, no se tienen suficientes elementos para juzgar a cuál de los cuerpos que cambian de posición debe adscribirse el movimiento. Esta incertidumbre se apoya en que en unas ocasiones atribuimos el movimiento a uno de los cuerpos y en otras decimos que se movieron los dos. En este sentido, en ocasiones interpretamos al movimiento como absoluto y en otras como relativo.

Si el movimiento es tomado como absoluto, se asume que uno de los dos cuerpos permanece inmóvil mientras que el otro se mueve con una velocidad uniforme. Así, en la figura 1 el cuerpo B permanece inmóvil mientras que el cuerpo A se desplaza hacia (A), de manera similar a como inversamente en la figura 2 el cuerpo A permanece inmóvil mientras que B se desplaza hacia $(\mathrm{B}):^{128}$

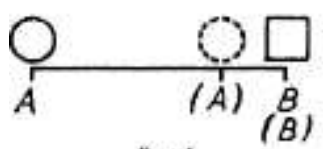

fig. 1

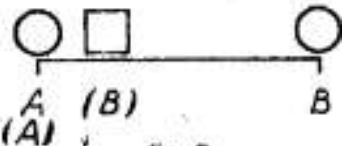

fig. 2

La posibilidad de atribuir el movimiento a un cuerpo se apoya en que a veces es posible detectar ciertas marcas o señales (notae) que justifica dicha atribución. ${ }^{129}$ A modo de ejemplo, Leibniz señala que si algunos hombres caminan hacia una ciudad, no decimos que la ciudad se mueve hacia ellos sino los individuos hacia ella, pues los hombres experimentan cierto esfuerzo y cansancio. No obstante, en otras ocasiones no se dan estas marcas o señales. En estos casos o bien decidimos de acuerdo con lo que parece más simple o con lo que se suele juzgar, o bien se le atribuye el movimiento a las otras cosas más que a uno mismo, como cuando en la astronomía antigua se creía que las estrellas giran alrededor de la tierra en lugar de la tierra sobre su eje.

Ahora bien, para Leibniz la explicación del movimiento de manera absoluta comporta un inconveniente, a saber, que depende de dónde nos posicionemos. En este sentido, la explicación que corresponde a la primera figura sería satisfactoria para quien se posicione en el cuerpo $\mathrm{A}$, mientras que la que corresponde a la segunda figura parecería

\footnotetext{
${ }^{127}$ Principia mechanica, A VI 3, 103. "ideo patet denique situs cognitionem ad distantiam reduci, adeoque mutationem situs non contingere sine distantiae cujusdam mutatione". Traducción de OFC 8, 99.

${ }^{128}$ Estas figuras, así como también las que se mostrarán a continuación, son tomadas de Principia mechanica, A VI 3, 106-107. OFC, 8, 102-103.

${ }^{129}$ Principia mechanica, A VI 3, 104. OFC, 8, 100-101.
} 
verdadera para quien se posicione en B. ${ }^{130}$ Por esta razón, de acuerdo con Leibniz, para explicar el cambio de posición, en ocasiones es necesario atribuir a los dos cuerpos un movimiento compuesto. En este sentido, podría pensarse que el movimiento es algo respectivo o relativo y que, en consecuencia, no podemos saber qué hay que atribuirle a cada cuerpo cuando dos de ellos cambian entre sí de posición. En este caso no se considera que uno de los dos permanezca inmóvil y el otro se desplace sino que de alguna manera se mueven los dos. Así, el movimiento no se atribuye absolutamente a uno de ellos. De este modo, esta alternativa admite infinitas variantes, a saber, tantas como sean las posibilidades de dividir la velocidad entre los dos cuerpos, de modo que la suma total de las velocidades sea igual a la que se daría supuesto que haya un movimiento absoluto. ${ }^{131}$ Las figuras 3 y 4 muestran algunas de las infinitas variantes:

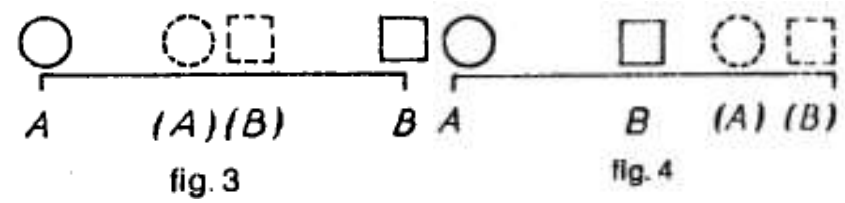

De acuerdo con Leibniz, en sentido estricto el movimiento sería conjunto, de manera tal que "la cuestión del movimiento o el reposo absoluto sería algo inútil y carente de significado". ${ }^{132}$ Para mostrar que un movimiento conjunto y respectivo no puede reducirse a un movimiento absoluto de uno de los agentes, el filósofo de Leipzig postula un tercer cuerpo $\mathrm{C}$ que sea un espectador del fenómeno, de modo que podría dilucidar si A se mueve hacia B o B hacia A. No obstante, para poder hacer esto, ha de suponerse que el cuerpo $\mathrm{C}$ permanece inmóvil mientras es espectador del movimiento de uno de los otros cuerpos. Sin embargo, no habría manera de justificar el reposo en este cuerpo. ${ }^{133}$ Con el mismo derecho podría decirse que $\mathrm{C}$ se mueve mientras que otro de los cuerpos permanece inmóvil, como A, con lo cual se volvería a lo anterior. En este sentido, la cuestión se replicaría incluso si suponemos muchos otros cuerpos. ${ }^{134}$ Ahora bien, la conclusión que Leibniz extrae es un poco más ambiciosa que lo que se ha dicho hasta aquí. En efecto, no se

\footnotetext{
${ }^{130}$ Principia mechanica, A VI 3, 107. OFC, 8, 103.

131 Principia mechanica, A VI 3, 107. OFC, 8, 103.

${ }^{132}$ Principia mechanica, A VI 3, 108. "Quodsi ergo nullus plane esset modus unum ab altero discernendi, ac si ne is quidem qui omnia perspecta atque explorata habet, discrimen aliquod notare posset, sequeretur utrumque esse idem, et quaestionem de motu aut quiete absolutis inanem esse, ac nihil significantem". Traducción: OFC, 8, 104. Garber, 2009: 106-115, presenta el desarrollo de la concepción del movimiento respectivo en la década de 1670 .

${ }^{133}$ Principia mechanica, A VI 3, 108. OFC, 8, 104.

${ }^{134}$ Principia mechanica, A VI 3, 110. OFC, 8, 106.
} 
limitó a decir que no podemos demostrar cuál es el movimiento absoluto de los cuerpos sino, más en general, que no es posible reconocer un movimiento absoluto de un cuerpo. En este sentido, no es posible ni siquiera para Dios, es decir, para quien podría considerar en una mirada infinitos observadores:

En todo caso, es manifiesto que de los meros fenómenos que pertenecen al cambio de posición nunca se puede obtener una ciencia cierta acerca del movimiento y del reposo absolutos. De manera que, si el movimiento absoluto no se puede diagnosticar desde el resto de los fenómenos, ni siquiera por aquél que tuviera explorado todos los fenómenos, se sigue que el movimiento y el reposo entendidos absolutamente son términos vacíos, y todo lo que en ellos hay de real consiste únicamente en el cambio respectivo; y como ninguna hipótesis puede ser refutada con demostración cierta en favor de otras, ni siquiera por un ser omnisciente, se sigue que ninguna es más falsa que las demás, esto es (al no poder ser entre ellas coexistentes), son todas falsas y no pueden admitirse sino como diversas apariencias o juegos ópticos de una misma realidad, en cuanto que el ojo se sitúa en un lugar o en otro. ${ }^{135}$

No obstante, con el objetivo de facilitar nuestros exámenes, Leibniz propone una regla metodológica un tanto pragmática, a saber, elegir la explicación más simple, es decir, la que permite tomar una causa de la que puedan derivarse con facilidad los demás cambios. A modo de ejemplo, es más simple decir que una piedra cae hacia la tierra que decir que la tierra va hacia la piedra, aunque en verdad no haya sino un cambio respectivo. Este criterio aspira a economizar el trabajo humano, como por otra parte también defiende cuando se refiere al uso del lenguaje, como se mostró en la sección 2.1. del sexto capítulo. De un modo similar, Leibniz señala que si puede explicarse una mutación diciendo que muchas cosas cambian un poco cada una o diciendo que hay un gran cambio en una sola cosa, debe optarse por la segunda opción, pues multiplicar los sujetos es algo inútil. ${ }^{136}$

\footnotetext{
${ }^{135}$ Principia mechanica, A VI 3, 110-111. "Hinc ergo patet ex solis phaenomenis mutati situs nullam certam scientiam haberi unquam posse de absoluto motu et quiete. Quodsi motus absolutus nec ex aliis phaenomenis dignosci potest, ne ab eo quidem cui omnia phaenomena sunt explorata, sequitur motum et quietem absolute sumta esse nomen inane, et quicquid in illis reale est in sola mutatione respectiva consistere, cum enim nulla hypothesis prae alia certa demonstratione refutari possit, ne ab omniscio quidem, sequitur nullam prae alia falsam esse; id est (cum consistere non possint) falsas esse omnes; nec admitti posse nisi ut varias eiusdem rei apparentias sive lusus opticos, prout oculus alio atque alio loco constituitur". Traducción: OFC, 8, 106-107.

${ }^{136}$ De materia, de motu, de minimis, de continuo, A VI 3, 470.
} 


\section{La formulación leibniziana de la ley de conservación}

Una de las cosas que más llamó la atención de Leibniz tras su lectura de los Principia Philosophiae de Descartes, ha sido el conocido como 'principio de conservación de la cantidad del movimiento', que antecede a y es soporte de las tres leyes de la naturaleza propuestas por el filósofo francés (a saber, que todo lo que se mueve una vez tiende siempre a moverse, que todo movimiento es recto por naturaleza y que un cuerpo que choca con otro cuya resistencia es mayor no pierde nada de su movimiento, pero que si choca con otro cuya resistencia es menor, pierde tanto movimiento como le transmite al otro cuerpo). ${ }^{137}$ Dicho principio, que Descartes presentó como la causa general del movimiento, fue descrito en la segunda parte de los Principia:

Pues bien, por lo que atañe a la [causa] general [del movimiento], me parece evidente que no es otra que Dios mismo, que creó al principio la materia junto con el movimiento y el reposo, y que conserva ahora en toda ella, por medio de su mero concurso ordinario, tanto movimiento y reposo como puso entonces. Pues aunque el movimiento no sea más que un modo de la materia que se mueve, tiene una cantidad determinada, y entendemos fácilmente que puede ser siempre la misma en todo el universo, aunque cambie sus partes. Por eso, cuando una parte de materia se mueve con el doble de velocidad que otra, siendo ésta el doble de grande que aquélla, juzgamos que hay igual cantidad de movimiento en ambas; y que cuanto más disminuya la velocidad de una parte, tanto más aumentará la de alguna otra igual a ella. ${ }^{138}$

El principio cartesiano puede sintetizarse en una ley de acuerdo con la cual la cantidad total de movimiento en el mundo, medida por la masa de cada cuerpo $(m)$ multiplicada por su velocidad $(v)$, permanece siempre constante (esto es, la cantidad total

\footnotetext{
${ }^{137}$ Principia Philosohpiae, AT, VIII, 2, § 37 ("Prima lex naturae: quod unaquaeque res, quantum in se est, semper in eodem statu perseveret; sicque quod semel movetur, semper moveri pergat"), 39 ("Altera lex naturae: quod omnis motus ex se ipso sit rectus; et ideo quae circulariter moventur, tendere semper ut recedant a centro circuli quem describunt") y $\$ 40$ ("Tertia lex: quod unum corpus, alteri fortiori occurrendo, nihil amittat de suo motu; occurrendo vero minus forti, tantum amittat, quantum in illud transfert").

${ }^{138}$ Principia Philosohpiae, AT, VIII, 2, § 36. "Et generalem quod attinet, manifestum mihi videtur illam non aliam esse, quam Deum ipsum, qui materiam simul eum motu et quiete in principio creavit, iamque, per solum suum concursum ordinarium, tantundem motus et quietis in ea tota quantum tunc posuit conservat. Nam quamvis ille motus nihil aliud sit in materia mota quam ejus modus: certam tamen et determinatam habet quantitatem, quam facile intelligimus eandem semper in tota rerum universitate esse posse, quamvis in singulis eius partibus mutetur. Ita scilicet ut putemus, cum una pars materiae duplo celerius movetur quam altera, et haec altera duplo maior est quam prior, tantundem motus esse in minore quam in majore; ac quanto motus unius partis lentior sit, tanto motum alicuius alterius ipsi sequalis fieri celeriorem". Traducción: Descartes y Leibniz, 1989: 98. Véase Dutton, 1999: 56-58.
} 
de $m v$ no cambia). ${ }^{139}$ No obstante, aunque la cantidad total de movimiento en el universo se conserve, el movimiento se redistribuye entre los cuerpos. ${ }^{140}$ Como es sabido, en su madurez Leibniz cuestionó la ley cartesiana de la conservación de la cantidad de movimiento, apoyándose en el principio según el cual un efecto debe ser igual a su causa y señalando que lo que se conserva no es la cantidad de movimiento $(m v)$, sino una magnitud física diferente, la 'fuerza viva', que se mide como masa por el cuadrado de la velocidad (o sea, $\left.m v^{2}\right) .{ }^{141}$ Si bien Leibniz no tiene en mente este cuestionamiento en los escritos de DSR, es claro que se dio rápidamente cuenta de que la ley cartesiana es insatisfactoria. En lo siguiente examinaremos el cuestionamiento de Leibniz a la formulación cartesiana de la ley, tras lo cual abordaremos la manera como el filósofo de Leipzig entendió la conservación.

Leibniz abordó el examen de la ley de conservación en los escritos que redactó inmediatamente después de haber leído la obra cartesiana. En De materia, de motu, de minimis, de continuo de diciembre de 1675, puede observarse que Leibniz interpretó la ley de Descartes como el principio según el cual "la Naturaleza de la materia o el cuerpo es tal que en los mismos tiempos, ocupa el mismo espacio". ${ }^{142}$ Esta interpretación de Leibniz se funda en la concepción de que el movimiento de un cuerpo es una cierta expansión, esto es, que cuanto más rápido se mueve un cuerpo en un tiempo determinado, más espacio ocupa. En consecuencia, de acuerdo con la ley de conservación, en el pleno debe haber otro u otros cuerpos que, en el mismo tiempo, se contraigan. ${ }^{143}$ Esta interpretación de Leibniz descansa en dos presupuestos, a saber, en primer lugar que el espacio del mundo es definido, es decir, tal que no puede ampliarse por la expansión producida por un cuerpo al aumentar su velocidad o disminuirse en caso de que suceda lo opuesto, así como también se presupone, en segundo lugar, el pleno de cuerpos sin el cual no tendría sentido hablar de la conservación. De esta manera, se conserva la misma cantidad de movimiento $(v)$ en total

\footnotetext{
${ }^{139}$ Seguimos la descripción de Garber, 2001: 136.

${ }^{140}$ Gaukroger, 2002b: 11-12. Descartes ha postulado este principio varios años antes de comenzar la redacción de los Principia Philosophiae, por ejemplo en Le Monde: "No me detengo a buscar la causa de sus movimientos, pues me alcanza con pensar que ellos [esto es, los cuerpos] han comenzado a moverse desde que el mundo comenzó a existir. Y siendo así, encuentro por mis razones que es imposible que sus movimientos cesen e incluso que cambien de otra manera que de sujeto. Es decir que la virtud o el poder de moverse a sí mismo que se encuentra en un cuerpo, puede pasar toda o en parte a otro y así no estar más en el primero, pero no puede no estar más en absoluto en el mundo”. AT, XI, 11. La traducción es nuestra.

${ }^{141}$ Seguimos a Garber, 2001: 139 y 2009: 99-106.

${ }^{142}$ De materia, de motu, de minimis, de continuo, A VI 3, 469. "Illud ergo sufficit pro principio sumi, Naturam materiae sive corporis talem esse, ut iisdem temporibus tantundem spatii occupet".

${ }^{143}$ De materia, de motu, de minimis, de continuo, A VI 3, 469.
} 
dado que ella es igual a la cantidad de espacio ocupado por una cantidad determinada de materia $(m) .{ }^{144}$ En este sentido, Leibniz señala que de esto "[s]e sigue que [decir que] 'la misma cantidad de movimiento siempre se conserva', es lo mismo que [decir que] 'la misma cantidad de materia siempre se conserva'". ${ }^{145}$

Ahora bien, de acuerdo con Leibniz, para que la magnitud compense la velocidad, es necesario que estas dos cosas sean homogéneas, es decir, que haya algo que convenga tanto a la magnitud como a la velocidad. Si bien para Leibniz esta homogeneidad es un 'admirable misterio', reconoce como indicio para ella que tanto la materia como el movimiento se resuelven en una 'intelección general'. ${ }^{146}$ Ante todo, parecería que Leibniz detecta un problema de fundamentos en el planteo cartesiano, en la medida en que considera que Descartes falló al recurrir a la inmutabilidad de Dios para demostrar el origen de la ley de conservación. Como veremos en la siguiente sección de este capítulo, unos meses más tarde Leibniz reconoció la importancia de Dios como sustancia que permanece en la explicación del movimiento. ${ }^{147}$ Sin embargo, esto no significa que deba recurrirse a la inmutabilidad divina para justificar esta ley, sino que debe apelarse "a la armonía de las cosas de Dios"148 que explica por qué cuando un cuerpo se expande, otro debe compensar moviéndose más lentamente. En este sentido, la 'intelección general' que conviene tanto a la magnitud como a la velocidad explica lo que podríamos llamar la 'coordinación' de la compensación (esto es, que uno se mueva más lentamente cuando otro se mueve más rápidamente), cuyo fundamento no podría nunca hallarse en los cuerpos mismos:

Pues cuando dos cuerpos se chocan, es evidente que las mentes de los [cuerpos] singulares no producen que se siga la ley de compensación, sino que [lo que produce que se siga dicha ley es] aquella [intelección] general que asiste del mismo modo a ambos [cuerpos] o, mejor [aún], a todos. ${ }^{149}$

${ }^{144}$ De materia, de motu, de minimis, de continuo, A VI 3, 467-468.

${ }^{145}$ De materia, de motu, de minimis, de continuo, A VI 3, 469. "Sequitur eandem semper motus quantitatem servari, idem esse quod eandem semper materiae servari quantitatem".

${ }^{146}$ De motu et materia, A VI 3, 493.

${ }^{147}$ Pacidius Philalethi, A VI 3, 567. OFC, 8, 153.

${ }^{148}$ De materia, de motu, de minimis, de continuo, A VI 3, 466. "Eandem motus quantitatem servari, sive si corporis movendi magnitudo augeatur celeritatem diminui, quae a Galilaeo et Cartesio et Hobbesio, imo et Archimede observata sunt, res est ex phaenomenis ducta, sed cuius originem in ipsa natura ostendit nemo. (...).Cartesius confugit ad immutabilitatem Dei; debebat appellare harmoniam rerum Dei, simplicissima enim eligere ad maxima praestanda sapientissimi est".

${ }^{149}$ De motu et materia, A VI 3, 493. "nam cum duo corpora colliduntur, patet non singulorum mentes efficere, ut sequatur excompensationis, sed generalem illam, utrique, imo omnibus aeque assistentem”. Arthur, 2015b: 151. 
Sin embargo, esto lleva a Leibniz a reconocer no solamente que la conservación del movimiento no es necesaria, sino incluso que no se da. En efecto, reconoció que la ley de conservación del movimiento no parece ser acorde con la 'armonía de las cosas', ${ }^{150}$ puesto que es posible que un cuerpo se mueva en una dirección a causa del empuje producido por otro, y al mismo tiempo que se mueva proporcionalmente en la dirección contraria por su propia voluntad. De esta manera, el cuerpo reposaría, es decir, no abandonaría su lugar. ${ }^{151}$ No obstante, esto no significa que no haya algo que se conserve. Como este ejemplo muestra claramente, a pesar de que el cuerpo no cambie de lugar, hay una tendencia a moverse. De esta manera, lo que se conserva no es el movimiento sino su causa, es decir, la acción. En efecto, en una anotación al parágrafo 36 de la segunda parte de los Principia Philosophiae, en donde Descartes precisamente presenta su ley de conservación de movimiento, Leibniz señala:

[Descartes dice que] Dios siempre conserva la misma cantidad de movimiento en el universo. Me parece que conserva siempre la misma cantidad de conato, ímpetu o acción. Puesto que, a saber, los conatos nunca son destruidos, pero se componen entre sí; y puede suceder que de dos conatos opuestos iguales se siga el reposo o al menos un movimiento más lento, si no son iguales. Conservada, no obstante, la cantidad de acciones o conatos. ${ }^{152}$

Incluso, en una oportunidad Leibniz se refirió no a la conservación de la misma cantidad de 'conato' 'ímpetu' o 'acción', sino de las fuerzas (vires), como mencionamos al final de la sección 4.2.2. del capítulo anterior. Más allá de estas múltiples denominaciones, por lo general Leibniz se refiere a la conservación de la acción. Ahora bien, como veremos en la siguiente sección, en el Pacidius Philalethi Leibniz concibió que la acción está fuera de los cuerpos, a saber, en Dios. En este sentido, parece haber un cambio en la visión de Leibniz que va desde las anotaciones inmediatamente posteriores a la lectura de la obra cartesiana que datan de finales de 1675 y principios de 1676 (en los que se refirió a 'acciones', es decir, en plural), hacia el Pacidius Philalethi (donde sostuvo que la acción es

${ }^{150}$ De materia, de motu, de minimis, de continuo, A VI 3, 466-467.

${ }^{151}$ De motu et materia, A VI 3, 493.

${ }^{152}$ Zu Descartes' Principia Philosophiae, A VI 3, 215-216. “Cartes. princip. part. 2. n. 36. Deum eandem semper quantitatem motus in universo servare. Mihi videtur ea[n]dem semper quantitatem conatus, impetus sive actionis servare. Quia scilicet conatus nunquam destruuntur, sed componuntur inter se, ac fieri potest, ut ex duobus conatibus oppositis aequalibus sequatur quies vel saltem motus tardior, si non sint aequales. Servata nihilominus quantitate actionum sive conatuum". Similarmente, en De motu et materia, A VI 3, 493. "Unde de actione, sive motu respectivo, quo scilicet corpus ad aliud refertur, aut in aliud agit, enuntianda quantitatis motus conservatio". 
solamente de Dios). Este cambio comienza a detectarse en algunos escritos de abril de 1676, en los que, como veremos, Leibniz enfatiza que la conservación de la acción parecería no querer decir otra cosa sino que 'Dios transcrea'. Como consecuencia, dice:

Supuesto que el Movimiento es la reproducción desde una distancia hacia otra distancia, ahora es manifiestamente claro, mucho más [que antes], cómo Dios es causa inmediata de todas las cosas, cómo la conservación [es] producción continua, cómo no [hay] ninguna otra ley de la naturaleza más que la naturaleza de Él $(\ldots){ }^{153}$

\section{Naturaleza de la acción}

El examen de la naturaleza del movimiento por parte de Leibniz conlleva algunas consecuencias relativas al modo de concebir la acción y su rol en la explicación del movimiento que, también en este caso, difieren de los planteos que propuso en la TMA y en los escritos inmediatamente posteriores. Leibniz nota que, si el movimiento es un agregado de estados, entonces no hay acción en los cuerpos al moverse. En efecto, como no hay un estado de mutación, no sería posible asignar un momento en el que el cuerpo actúe. ${ }^{154}$ En consecuencia, de acuerdo con Leibniz, “(...) de aquí se demuestra que los cuerpos, cuando están en movimiento, no actúan". ${ }^{155}$ Esta conclusión, que es una consecuencia necesaria de concebir el movimiento como un agregado, manifiesta a su vez que Leibniz modificó el modo de entender la relación entre la acción y el movimiento. En efecto, en los capítulos de la segunda parte de nuestra tesis, especialmente el cuarto y el quinto, hemos visto que Leibniz entendió que la acción de un cuerpo es un movimiento. En consecuencia, como entendió que todo lo que actúa es una sustancia, los cuerpos fueron concebidos como sustancias. ${ }^{156} \mathrm{Al}$ mismo tiempo, esta conclusión explica por qué apenas es mencionada la noción de 'conato' en los escritos de $D S R$, incluso en los que aborda especialmente la

\footnotetext{
${ }^{153}$ De motu et materia, A VI 3, 494. "Posito Motum esse reproductionem de distantia in distantiam, iam illud praeclare patet, multo magis, quomodo Deus sit imnediata omnium causa, quomodo conservatio continua productio, quomodo nulla alla Lex naturae, quam natura ipsius (...)". La expresión 'transcreación' aparece en Numeri infiniti de abril de 1676. A VI 3, 500.

${ }_{155}^{154}$ Pacidius Philalethi, A VI 3, 566. OFC, 8, 152.

${ }^{155}$ Pacidius Philalethi, A VI 3, 566. "Sed aliud velim a vobis animadverti, quod hic demonstratur corpora cum in motu sunt non agere". OFC, 8, 152.

${ }^{156}$ A modo de ejemplo, recordemos algunos pasajes citados en los capítulos de la segunda parte: De rationibus motus, A VI 2, 165. "Omnis actio corporis est motus"; Demonstratio substantiarum incorporearum, A VI 3, 74. "Substantia est quicquid agit".
} 
naturaleza del movimiento. Como vimos anteriormente, el conato fue concebido en la TMA y en los escritos inmediatamente posteriores como el 'extremo' de un movimiento, esto es, la tendencia inicial que, propagada, da lugar al movimiento. De esta manera, en síntesis, concebir el movimiento como un agregado llevó a Leibniz a rechazar la idea de un extremo en común, la concepción de un conato por cuya propagación se explica el movimiento y la noción de acción como movimiento. Quizás por eso Leibniz en alguna medida confiesa que, cuando examinó anteriormente el movimiento, no pudo nunca superar el examen del inicio del movimiento, esto es, del conato:

Pero cuando se trataba acerca del movimiento, todo mi cuidado y diligencia era inútil, y nunca pude alcanzar a comprender las razones y causas de las fuerzas con la imaginación, y a poder juzgar con éxito acerca de las máquinas. En efecto, siempre me quedaba atorado en el inicio del comienzo del movimiento, pues observaba que en cierto modo debía suceder ya en el primer momento lo que debía ocurrir en todo el tiempo restante. Pero razonar sobre momentos y puntos, esto, sin duda, confesaba que estaba por encima de mi alcance. ${ }^{157}$

Ahora bien, de acuerdo con lo que hemos visto en el séptimo capítulo, para Leibniz sería imposible concebir el conato, en sus últimos años en París, del mismo modo que lo concibió en la TMA o en los escritos posteriores. En efecto, no solamente no puede ser tomado como un indivisible sino tampoco como el inicio infinitamente pequeño de un movimiento tal como lo entendió en $D M M$, dado que en dicho texto concibió que, aunque el inicio de un cuerpo móvil cualquiera (digamos, el cuerpo $A$ ) se entiende como una línea infinitamente pequeña respecto de la cual existe otra menor, para el movimiento de dicho cuerpo $A$ no puede asumirse un infinitesimal menor. ${ }^{158}$ No obstante, en los escritos de 1675-1676, Leibniz señaló que una cantidad infinitamente pequeña que no admita una menor es una ficción. Quizás esto explica que Leibniz haya señalado que "en otro lado demostré, hace muy poco, que los conatos son verdaderos movimientos, no unos infinitamente pequeños". ${ }^{159}$ En consecuencia, no tendría sentido explicar el movimiento

\footnotetext{
${ }^{157}$ Pacidius Philalethi, A VI 3, 532. "Sed cum de motu agebatur, omnis mea cura atque diligentia irrita fuit, neque unquam assequi potui, ut virium rationes atque causas imaginatione comprehendere, ac de machinarum successu judicare liceret, semper enim in ipso motus inchoandi initio haesi, nam quod toto reliquo tempore evenire debebat, jam in momento primo fieri quodammodo debere animadvertebam. Circa momenta autem atque puncta ratiocinari, id quidem supra meum captum esse fatebar". OFC, 8, 119.

${ }^{158} D M M$, A VI 3, 100.

${ }^{159}$ De motu et materia, A VI 3, 492. “(...) alibi enim demonstravi, nuperrime, conatus esse veros motus, non infinite parvos".
} 
como la propagación de un conato ni, por lo tanto, el movimiento como acción. No obstante, el planteo de Leibniz es incluso más radical: si un cuerpo no actúa cuando se mueve, entonces las acciones son propias de las cosas que no cambian al actuar. Así, la acción por la cual un cuerpo móvil se mueve no es propia del cuerpo que se traslada. ${ }^{160}$ En este sentido, para Leibniz la acción se explica por una causa externa y superior respecto del cuerpo móvil:

Por consiguiente, aquello por lo cual un cuerpo es movido y es trasladado no es el cuerpo mismo sino una causa superior, la cual, actuando, no muta, [y] a la cual llamamos Dios. De donde es evidente que un cuerpo no puede siquiera continuar un movimiento espontáneamente, sino que continuamente necesita del impulso de Dios, quien, sin embargo, actúa constantemente y de acuerdo a ciertas leyes según su suma sabiduría. ${ }^{161}$

El hecho de que la acción provenga de Dios muestra por qué para Leibniz el movimiento se explica como una suerte de creación continua o, como prefiere decir, una 'transcreación'. ${ }^{162}$ En este sentido, el filósofo de Leipzig entiende que, en alguna medida, un cuerpo móvil es 'aniquilado' en un punto y es 'resucitado' en el siguiente, esto es, sin pasar por un estado intermedio de mutación. De esta manera, para Leibniz no hay ninguna diferencia esencial entre decir que un cuerpo se mueve y decir que es transcreado (esto es, 'aniquilado' y 'resucitado'). Estas expresiones solamente difieren en que la primera de ellas no revela cuál es la causa del cambio, mientras que en la segunda se explicita. En consecuencia, como dijimos antes, la causa debe ser algo que no cambia al actuar. Así, Dios permanece como una sustancia que transcrea, esto es, que 'aniquila' y 'resucita' los cuerpos. $^{163}$

\footnotetext{
${ }^{160}$ Pacidius Philalethi, A VI 3, 566. OFC, 8, 152.

${ }^{161}$ Pacidius Philalethi, A VI 3, 567 "Id ergo a quo movetur corpus, et transfertur, non est ipsum corpus, sed causa superior quae agendo non mutatur, quam dicimus Deum. Unde patet corpus ne continuare quidem sponte motum posse; sed continue indigere impulsu Dei, qui tamen constanter et pro sua summa sapientia certis legibus agit”. OFC, 8, 152-153. Garber, 2009: 191-192, señala que Leibniz mantuvo es una variante del ocasionalismo.

${ }^{162}$ Robinet, 1986: 191-193, resalta la importancia de esta doctrina, al punto de señalar que "el laberinto del continuo se desenreda porque se puede hablar de continuidad del movimiento abstracto y de discontinuidad en la transmisión del movimiento por el acto distinto de la creación continua" (193). La traducción es nuestra.

${ }^{163}$ Pacidius Philalethi, A VI 3, 567. OFC, 8, 153. Orio de Miguel, 1994: 504, señala que el neoplatonismo inspirado en Plotino contiene, como un elemento de importancia, un naturalismo teológico, es decir, la idea de que Dios, aunque sea trascendente e innombrable, no dirige el mundo desde fuera, "sino que es introducido como 'lo activo microfísico' en el seno de toda transformación mundana". Como sugerimos en el capítulo anterior, en el pensamiento leibniziano de $D S R$ parecerían haber elementos de platonismo. Esta idea de Leibniz podría ser, quizás, una muestra de ello.
} 
Esta conclusión de Leibniz parecería poner en conexión el examen de la acción con el análisis de las formas que hemos explorado en el capítulo anterior. En la tercera sección de dicho capítulo hemos señalado a la pasada que para Leibniz hay algo divino y eterno en el cuerpo o ente móvil y que es lo que se denomina 'omnipotencia'. Como mencionamos a la pasada en la sección 1.3. de este capítulo, en consonancia con su interpretación de que la materia no debe entenderse como un cierto principio de limitación, Laerke concibe que la puesta en juego de la omnipresencia de Dios corresponde precisamente a la adición de la materia. ${ }^{164}$ De acuerdo con este intérprete, esta idea se remontaría al contexto general de la $T M A$ en el cual Leibniz concibió que la esencia de la materia es el movimiento. En consecuencia, el hecho de que el filósofo de Leipzig haya concebido que la materia se adiciona a las formas, en el contexto de $D S R$, debería entenderse como la adición del principio del movimiento, que no es otra cosa que la omnipotencia de Dios. ${ }^{165}$ No obstante, la interpretación de Laerke acarrea algunas dificultades. En primer lugar, como hemos visto anteriormente, si bien Leibniz no se refiere literalmente a la materia como 'principio de limitación', lo cierto es que cumple esa función. En segundo lugar, no quedaría claro con qué criterio podría decirse que en el pensamiento de $D S R$ persiste la idea leibniziana de los años previos según la cual la esencia de la materia es el movimiento, pero no la consecuencia que Leibniz extrajo de allí, a saber, que un cuerpo es una sustancia cuya acción consiste precisamente en moverse. Laerke debería rechazar esta consecuencia, como deja en evidencia su concepción unisustancialista del pensamiento leibniziano de $D S R$ que mencionamos en la sección 3.2.1. del capítulo anterior. En tercer lugar, es claro que, como vimos en este capítulo, parecería que lo verdaderamente esencial de la materia es ser sentida según ciertas leyes gracias a las que encontramos cierta regularidad en ella, pero no el movimiento. En cuarto lugar, la interpretación de Laerke iría en contra de la explicación

\footnotetext{
${ }^{164}$ Laerke, 2008: 537.

${ }^{165}$ Laerke, 2008: 537, sintetiza su planteo de esta manera: "Si Leibniz insiste tantas veces sobre la necesidad de añadir la materia a las formas, es decir, de añadir este principio de movimiento que es la potencia divina, es por la siguiente razón: sin la potencia, los otros atributos no producirían nada. La potencia divina completa la teoría de la doble causalidad o de las relaciones puras, proporcionando el principio que la hace eficaz. Ya hemos descrito los efectos que causa la extensión en el pensamiento: la extensión presenta al pensamiento una variedad de cosas para pensar, asumiendo la función de una suerte de causa material de la variedad de los pensamientos. Hemos igualmente descrito los efectos que causa el pensamiento en la extensión: dando forma a la variedad, funciona como una suerte de causa formal. Es por esta causación que las cosas están organizadas en agregados o 'torbellinos'. Resta la exigencia de una causa eficiente. Esta causa eficiente es la potencia de Dios, principio de movimiento". La traducción es nuestra.
} 
del movimiento como transcreación que vimos anteriormente, pues significaría que Dios 'aniquila' y 'resucita' su propia omnipotencia. Por eso, para Leibniz la materia es precisamente lo que se extingue perpetuamente, es decir, lo que deviene constantemente una y otra cosa. ${ }^{166}$ En este sentido, la materia no es eterna, como por otra parte sí lo son los atributos divinos, inclusive la omnipotencia. ${ }^{167}$

Ahora bien, aunque la materia de Leibniz no sea la omnipotencia divina, no obstante hay un vínculo entre ellas. Entendemos que dicha vinculación es lo que queda expresado en pasajes en los que Leibniz señala, por ejemplo, que "[d]e algún modo la materia tiene el ser por una forma" o que "[h]ay en la materia, como también en el espacio, algo eterno e indivisible". ${ }^{168}$ En efecto, entendemos que, si la acción no se encuentra en los cuerpos sino en Dios y si, en consecuencia, todo movimiento ha de explicarse como una transcreación, entonces la materia existe a partir de la omnipotencia divina que la 'aniquila' y la 'resucita' constantemente. En ese sentido, aunque la materia no sea eterna, hay algo eterno en ella, a saber, la omnipotencia de Dios que explica su causación. Más aún, esto permite explicar una quinta dificultad que conlleva el planteo de Laerke, a saber, que si la materia fuera la omnipotencia divina, entonces Dios sería una parte de las cosas. No obstante, Leibniz mismo rechazó esto:

Parece que aquellos que creen que Dios mismo es la materia de las cosas entienden esto [a saber, que hay en la materia, como también en el espacio, algo eterno e indivisible]. Sin embargo, esto no se dice propiamente, puesto que Dios no deviene parte de las cosas, sino un principio [de las cosas]. ${ }^{169}$

El hecho de que Dios no sea parte sino principio de las cosas debe querer decir, nuevamente, que por su omnipotencia Dios crea y conserva las cosas. En este sentido, el movimiento se ubica entre la materia (que es constantemente recreada) y las formas (esto es, la omnipotencia, así como también la inmensidad respecto de los lugares ocupados por el cuerpo y la eternidad respecto del tiempo). Quizás esto sea lo que Leibniz tuvo en cuenta al

\footnotetext{
${ }^{166}$ Notizen zur Wissenschaft und Metaphysik, A VI 3, 391.

${ }^{167}$ Notizen zur Wissenschaft und Metaphysik, A VI 3, 392.

${ }^{168}$ Notizen zur Wissenschaft und Metaphysik, A VI 3, 392. "Materia quodammodo esse habet a forma. / Est in materia, ut et in spatio quiddam aeternum; et indivisibile (...)".

${ }^{169}$ Notizen zur Wissenschaft und Metaphysik, A VI 3, 392. “(...) quod illi intellexisse videntur, qui Deum ipsum esse credidere materiam rerum. Quod tamen non dicitur proprie, quia Deus non facit partem rerum: sed principium".
} 
señalar que se echa en falta una ciencia sobre el movimiento que conecte la materia con las formas. $^{170}$

Para finalizar este capítulo, haremos una recopilación de las conclusiones parciales que hemos ido obteniendo. De alguna manera, la física leibniziana de DSR surge como cuestionamiento del pensamiento cartesiano de los Principia Philosophiae. En lo que respecta al examen de la naturaleza de la materia, hemos visto que Leibniz extrajo las siguientes conclusiones. En primer lugar, que la existencia de la materia es una cualidad gracias a la cual se tienen sensaciones coherentes o conformes según ciertas leyes que explican la regularidad de las sensaciones. En segundo lugar, que sería contradictorio afirmar tanto un cuerpo perfectamente líquido como uno perfectamente sólido, de manera tal que todos los cuerpos poseen cierta resistencia a dividirse, al mismo tiempo que son susceptibles de ser subdivididos o flexionados. En este sentido, Leibniz se refiere a la 'flexibilidad' de todos los cuerpos. En tercer lugar, hemos visto que para Leibniz la materia limita lo absoluto de las formas, de tal manera que es aquello por cuyo añadido se explica la variedad de cosas en lo extenso. En lo que respecta al examen de la cohesión de los cuerpos, Leibniz extrajo como conclusión que no puede seguir sosteniéndose que los cuerpos son continuos de acuerdo con la noción aristotélica, en la medida en que la afirmación de un extremo en común contradice el principio de tercero excluido. En este sentido, a diferencia del planteo de TMA y los escritos inmediatamente posteriores, en el período de DSR la unidad o cohesión de los cuerpos no se explica en términos puramente físicos sino por la relación que una porción de materia mantiene con una mente determinada. Esto, una porción de materia unida a una mente, es lo que Leibniz llamó 'átomo'. Este sentido de átomo, a diferencia de lo que sucede con la interpretación de Gassendi, no es para el filósofo de Leipzig contradictorio. En lo que respecta al examen de la naturaleza del movimiento, hemos visto que Leibniz sostuvo que el movimiento, aunque es continuo, no es uniforme. En efecto, como los cuerpos se mueven en el pleno, su movimiento no permanece igual en ningún instante del tiempo. De esta manera, Leibniz presenta un

${ }^{170}$ Pacidius Philalethi, A VI 3, 531. OFC, 8, 118-119. 
examen del movimiento que no es abstracto sino que considera la estructura o la filosofía primera del movimiento. Ahora bien, en el período de $D S R$ Leibniz concibió que la acción no es algo que pertenece a los cuerpos que se mueven sino a Dios que, a saber, transcrea constantemente. Como una consecuencia de eso, el filósofo de Leipzig planteó que se conserva no la misma cantidad de movimiento, como planteó Descartes, sino de acción. 



\section{CONCLUSIONES}

Dividiremos este apartado de nuestro trabajo en dos secciones. En primer lugar, indicaremos las conclusiones generales que, al margen de las conclusiones parciales que se han ido extrayendo en cada uno de los capítulos, recorren transversalmente el análisis leibniziano y que, a nuestro modo de ver, contribuyen o aportan a la discusión actual de los estudios de Leibniz sobre el laberinto del continuo. Ahora bien, somos conscientes de que, aunque el filósofo de Leipzig llevó a cabo la mayoría de sus exámenes sobre el continuo y el infinito en el período de estudio que delimitamos en nuestro trabajo, su vida se extendió por cuarenta años más. De acuerdo con esto, en segundo lugar buscaremos 'trazar puentes' entre los desarrollos presentados en nuestro trabajo y el pensamiento maduro de Leibniz. Naturalmente, realizar esta tarea de manera exhaustiva supera ampliamente el objetivo de esta presentación. En cualquier caso, nos limitaremos a considerar cómo se proyectaron las tesis que examinamos anteriormente en algunos escritos representativos del período en el que el filósofo de Leipzig desarrolló su 'primer sistema'.

\section{Conclusiones generales: la transversalidad del problema del continuo y del infinito}

1. Si nos preguntáramos cuál es el aspecto más importante de todos los que conjuntamente constituyen para Leibniz el problema del continuo, que, al mismo tiempo, atraviese transversalmente todo el período que consideramos, deberíamos señalar, sin dudas, la tesis de que en el continuo hay infinitas partes en acto. Ahora bien, si analizáramos esta tesis desde una perspectiva histórica, encontraríamos algo llamativo, a saber: si bien Leibniz defendió esta tesis al menos desde la TMA, parecería que no ofreció grandes argumentos que la justifiquen positivamente con anterioridad al final del período parisino. En efecto, como vimos en el tercer capítulo, Leibniz enunció la infinitud actual de partes en la TMA para oponerse - tal como había hecho Thomas White- a la concepción cartesiana de que la división de la materia es 'al infinito o indefinida'. No obstante, si nos preguntáramos con qué argumentos Leibniz defendió esto, no encontraríamos una respuesta en la TMA. En este sentido, no es casual que Leibniz presente esta tesis en los dos primeros 'fundamentos predemostrables' de dicho escrito, es decir, para los que no hay una demostración. En 
consecuencia, para responder a esa pregunta, deberíamos remontarnos al final del período parisino. Como vimos en el séptimo capítulo, la clave para poder afirmar infinitas partes en el continuo se encuentra en el argumento de la inconcinnitas, según el cual-tratándose, por ejemplo, de la teoría de la materia- afirmar partes que no estén nuevamente subdividas implicaría una incongruencia o una falta de simetría. Como vimos, con este argumento, Leibniz explica por qué no puede sostenerse una división 'en mínimos' y por qué debemos afirmar, sobre la base de la noción de 'infinito sin término', que el continuo se divide 'sin fin'. Ahora bien, si tuviéramos en cuenta este argumento y volviéramos a los primeros dos fundamentos predemostrables de la TMA, podríamos pensar que hay un argumento implícito. Recordemos las palabras de Leibniz: "(1) Se dan en acto partes en el continuo (...) (2) y ellas son infinitas en acto (...)". En alguna medida, a la luz del argumento de la incongruencia, podríamos pensar que hay una secuencia argumentativa entre estos dos fundamentos: si hay partes en las magnitudes continuas, entonces hay infinitas. En última instancia, como vimos, para Leibniz la noción de magnitud está vinculada con la posesión de partes. En consecuencia, como una magnitud no está condicionada al tamaño, posee partes al margen de su grandeza o pequeñez. Esto es consistente con el hecho de que el argumento de la incongruencia se basa en la propiedad según la cual la grandeza o pequeñez no vienen al caso. De esta manera, es posible generalizar el argumento, de modo tal que, como en el continuo hay partes actuales -al margen de cuán grande o pequeña sea la magnitud continua considerada-, se sigue que son infinitas.

2. En estos razonamientos está implícito otro importante aspecto del análisis leibniziano del continuo, a saber: muchos de los razonamientos que Leibniz empleó son argumentos a base de propiedades estructurales, es decir, argumentos que valen universalmente por haber sido demostrados en un caso general. En este sentido, la universalidad o generalidad de estos razonamientos se obtiene sin tener que examinar todas las instancias posibles. Esto es claro en el argumento de la incongruencia: si una magnitud es continua, sin importar su tamaño, tiene partes todavía más pequeñas. No obstante, hay muchos otros argumentos a base de propiedades estructurales, por ejemplo, la explicación de la cohesión de los cuerpos que exploramos en el quinto capítulo, fundada en la noción de 'continuo' de Aristóteles. En este sentido, como vimos, no importa en qué escala de

\footnotetext{
${ }^{1}$ TMA, A VI 2, 264. “(1.) Dantur actu partes in continuo (...) (2.) eaeque infinitae actu (...)”. OFC, 8, 79.
} 
grandeza o pequeñez estemos considerando a los cuerpos, en el sentido de que, si hay cuerpos unidos o cohesionados, entonces hay un extremo en común. Del mismo modo, en el capítulo noveno hemos visto que la noción de ‘átomo' que Leibniz admite al final de sus días en París, no es la de un cuerpo pequeñísimo físicamente indivisible, como el átomo de Gassendi (que para el filósofo de Leipzig es incongruente), sino la de un cuerpo que se resiste a la disipación, al margen de su dimensión, esto es, “(...) cualquiera que sea su magnitud, siempre que tenga una cierta mente". ${ }^{2}$ Podríamos mencionar muchísimos otros argumentos a base de propiedades estructurales. En todos los casos, parece quedar en evidencia que para Leibniz este tipo de razonamientos es necesario siempre que se vea involucrada la noción de infinito. En última instancia, el empleo de este tipo de argumentos se justifica en que las distintas escalas de grandeza o pequeñez son -siguiendo el ejemplo clásico de Leibniz- como distintas perspectivas de lo mismo. En este sentido, en todas ellas hay una cierta estructura que se presenta invariantemente, esto es, al margen de las dimensiones del caso.

3. Hasta aquí vimos de qué manera Leibniz argumentó que hay infinitas partes en acto en el continuo. Sin embargo, esto no esclarece la cuestión sobre qué implica que en el continuo haya infinitas partes actuales. Hay al menos tres cosas que deben decirse al respecto:

3.1. Que en el continuo haya infinitas partes en acto no significa que el número de partes sea infinito. Como vimos en el sexto capítulo, para Leibniz la tesis de Galileo sobre el número infinito está plagada de dificultades e inconsistencias. El filósofo de Leipzig abordó la cuestión sobre el número infinito desde dos perspectivas, que, aunque son distintas y no poseen los mismos presupuestos, de alguna manera convergen. En este sentido, pareciera que Leibniz considera que las distintas perspectivas son complementarias. Desde un punto de vista filosófico, la estrategia de Leibniz tiene como primer objetivo demostrar el axioma del todo y la parte. Una vez que consigue esto, para Leibniz es claro que el número infinito contradice dicho axioma. Ahora bien, desde el punto de vista aritmético, esta cuestión sobre la imposibilidad del número infinito es irrelevante. Por eso, desde esta perspectiva, el filósofo de Leipzig argumenta que el número infinito no se

\footnotetext{
${ }^{2}$ Notizen zur Wissenchaft und Metaphysik, A VI 3, 393. “(...) cuiuscunque sit magnitudinis, quandocunque aliquam unam habet mentem".
} 
equipara con la unidad, como sostenía Galileo, sino con el cero, es decir, no es nada. Así, que no se equipare con el uno sino con el cero significa para Leibniz que el número infinito no representa un todo. En consecuencia, cuando Leibniz dice que en el continuo hay infinitas partes en acto, no está pensando que hay un número infinito de ellas, sino que el infinito no se equipara con ningún número. Por lo tanto, como explica en la Accessio, la equiparación del número infinito con el cero no conlleva la negación de infinitas partes en el continuo o una magnitud sin término en el espacio o en el tiempo. ${ }^{3}$

3.2. Para Leibniz, la afirmación de infinitas partes actuales no significa que el continuo se componga de partes últimas, es decir, mínimas o indivisibles. Dicho de otra manera, que el continuo tenga infinitas partes no significa que esté dividido en todas las partes posibles. Como vimos en el segundo capítulo, esta concepción de que el continuo no está dividido en todas sus partes posibles es típicamente aristotélica. En el caso de Leibniz, esta tesis se observa en los cuestionamientos a la interpretación de una composición de indivisibles de Galileo, así como también, y especialmente, en las críticas al pensamiento de Descartes acerca de la 'materia perfectamente líquida'. Incluso, como vimos en el séptimo capítulo, tras cuestionar los planteos del célebre filósofo francés, Leibniz señaló que la división del continuo no debe entenderse como una división en mínimos (es decir, 'como la arena en granos') sino como una división sin fin (como 'los pliegues de un papel o una túnica'). En efecto, en una división sin fin, de acuerdo con Leibniz, no habría una parte última, de la misma manera en que en una línea sin término no hay un último punto. Esta indicación pone en evidencia la conexión que hay entre los escritos filosóficos y los escritos matemáticos de Leibniz sobre el infinito. Como vimos, en $D Q A$ Leibniz estableció la distinción, que es fundamental para la tesis que estamos enunciando, entre 'infinito con término' e 'infinito sin término'. En efecto, Leibniz entiende que, desde una perspectiva filosófica o metafísica, una línea infinita con término implica contradicciones, mientras que una línea infinita sin término sirve análogamente para explicar la división del continuo. En este sentido, en el continuo no hay una última parte, así como en una línea sin término tampoco hay un último punto.

3.3. Ahora bien, a pesar de que el continuo no tiene un número infinito de partes y que no está dividido 'en todas partes', la división del continuo no es arbitraria. Como vimos

${ }^{3}$ Leibniz a J. Gallois, A II 1, 352. 
especialmente en el cuarto capítulo, Leibniz se habría representado infinitas partes en acto en el continuo de manera análoga a como se entienden los términos en una serie infinita. En una serie infinita, los términos decrecen siempre de acuerdo con una cierta ley que guía la serie, de tal manera que cada uno de ellos es menor que el anterior y que no hay un último término. Al mismo tiempo, como vimos en el sexto capítulo, la otra cara de esta cuestión es el hecho de que es posible llevar a cabo la suma de una serie infinita de estas características. ${ }^{4}$ En este sentido, propusimos que el modelo que Leibniz tuvo especialmente en cuenta para representarse la infinitud actual de partes del continuo es el de series que decrecen geométricamente al infinito, es decir, series en las que los términos son proporcionales. En nuestra argumentación destacamos que la posibilidad de establecer esta analogía está en el recurso a la exposición en líneas, es decir: Leibniz expone visualmente el continuo que esté considerando en una línea geométrica, de la misma manera que expone en líneas las series infinitas. En este sentido, podríamos decir que hay un cierto isomorfismo entre las magnitudes físicas, las geométricas y las series infinitas de la aritmética. Ahora bien, la afirmación de que en el continuo las partes son proporcionales no es una tesis especialmente novedosa de Leibniz. Como vimos, Libert Froidmont, cuya obra sobre el laberinto del continuo Leibniz conocía al menos desde 1671, afirmó infinitas partes proporcionales. Más aún, esta concepción, que estaba bastante extendida entre los escolásticos del siglo XVII, tiene sus raíces en la Edad Media, por ejemplo, en Guillermo de Ockham. ${ }^{5}$

Estas cuestiones nos muestran que la manera como Leibniz entendió el problema del continuo, en términos generales, sigue los lineamientos fundamentales de la tradición aristotélica. Esto no significa que Leibniz sea un fiel seguidor de Aristóteles, pues como vimos, el filósofo griego sostuvo que el número de partes actuales en el continuo es siempre

\footnotetext{
${ }^{4}$ Téngase en cuenta que hablamos solamente de series decrecientes.

${ }^{5}$ Ockham, Quaestiones in libros Physicorum Aristotelis, Q. 66. En efecto, allí (1984: 583) señala: "Sin embargo, naturalmente sucede esta división de la línea por un acto del alma, a través de la que el alma en verdad y sin excepción dice que 'en todo este continuo hay dos mitades, y en ambas mitades hay dos mitades, y en ambas de estas dos mitades hay dos mitades', de modo que nunca sucede que el alma acceda a alguna parte en todo el continuo en la que no pueda verazmente afirmar siempre que hay dos mitades de esta parte". Esta descripción se complementa con la afirmación de infinitas partes actuales (1984: Q. 70, 591): "A esto cuestión [a saber, si en el continuo existen o no infinitas partes en acto] digo brevemente que sí. La razón de esto es que (...) una línea no se compone de puntos ni de partes indivisibles; se compone, por consiguiente, de partes divisibles, y éstas siempre existen en acto en el continuo -de acuerdo con las cosas [dichas] anteriormente. Por consiguiente, en el continuo existen infinitas partes". Las traducciones son nuestras.
} 
finito, mientras que el infinito es sólo en potencia. No obstante, los planteos de Leibniz son afines a algunas ideas de naturaleza aristotélica, lo que puede observarse, por ejemplo, en el hecho de sostener partes proporcionales, en las críticas a las variantes atomistas (esto es, al atomismo geométrico de Galileo o al atomismo físico de Gassendi), así como también en la visión defendida en la TMA según la cual hay extremos indivisibles. Aunque luego Leibniz haya abandonado la noción de extremo indivisible, siguió cuestionando las variantes atomistas y sosteniendo partes proporcionales.

4. Esta concepción de que el continuo está compuesto de infinitas partes actuales proporcionales encuentra una de sus primeras expresiones en los escritos físicos de 1672. No obstante, en esos escritos Leibniz fue más allá, pues afirmó que en el continuo hay cosas infinitamente pequeñas. Como dijimos, esta visión difiere de la de TMA en que ya no se admite la existencia de extremos indivisibles del continuo, pues incluso los inicios y finales son cosas infinitamente pequeñas. Estas cosas infinitamente pequeñas no son mínimas, esto es, respecto de las cuales no podemos imaginarnos nada menor, sino que, dado que son divisibles, pueden ser concebidas como fracciones infinitamente pequeñas. Ahora bien, como vimos en el séptimo capítulo, en los últimos años en París, Leibniz se refirió a cantidades ficticias infinitas e infinitamente pequeñas, lo que ha llevado a algunos intérpretes a pensar que hay un paso de la actualidad a la ficcionalidad de los infinitesimales. A pesar de lo anterior, hemos visto que Leibniz distinguió dos sentidos de la noción de lo infinitamente pequeño en los escritos del período de DSR. Por una parte, esta noción fue concebida por Leibniz como un término categoremático, es decir, como una expresión que se refiere a cantidades que tienen la propiedad de ser menores que las cuales no hay otras, esto es, cantidades últimas o mínimas, que como tales son ficciones, a saber, metafísicamente imposibles, aunque no obstante sean útiles para la geometría. Por otra parte, la noción de lo infinitamente pequeño fue también concebida como un término sincategoremático, esto es, tal que se refiere a una cosa infinitamente pequeña en relación con otra, aunque no obstante haya cosas que sean incluso más pequeñas que ella. De esta manera, lo infinitamente pequeño como relación puede ser entendido sincategoremáticamente porque, en última instancia, no importa cuán pequeña sea una cosa que es infinitamente pequeña en relación con otra, con tal que haya otras cosas menores que ella. Como vemos, aquí hay, nuevamente, un argumento a base de propiedades estructurales. 
De esta manera, en este sentido podríamos decir que Leibniz no abandonó la concepción del continuo como compuesto de cosas infinitamente pequeñas, con tal que se entiendan estas cosas en un sentido relacional, esto es, no como cantidades ficticias sino respecto de las cuales hay otras menores. Si esta interpretación es correcta, entonces, a pesar de que el pensamiento de Leibniz evoluciona notablemente entre el comienzo y el final del período parisino, la manera como habría concebido la composición del continuo no habría cambiado sustancialmente.

5. Dentro de la multiplicidad de novedades que Leibniz expuso en los escritos de $D S R$, el planteo de los atributos divinos o formas simples implicó una originalidad especialmente significativa para el problema del continuo. En efecto, tras llevar a cabo importantes reflexiones en el dominio de la metafísica, Leibniz entendió que hay una relación entre las formas simples y las cosas con las que dichas formas se vinculan en términos de eminencia o ejemplaridad. En este sentido, por ejemplo, la extensión, como atributo de Dios por el cual las cosas extensas se dicen tales, está vinculada con los lugares ocupados por los cuerpos particulares, el agregado de los cuales es llamado por Leibniz 'espacio universal'. Ahora bien, la originalidad de esta propuesta leibniziana queda especialmente en evidencia si se la compara con las concepciones que el filósofo de Leipzig sostuvo con anterioridad. Por ejemplo, como vimos en el tercer capítulo, en 1669 Leibniz concibió al espacio como el ente extenso en primer grado, esto es, como el cuerpo matemático que contiene tres dimensiones y "que es aquel lugar universal de todas las cosas". ${ }^{6}$ De alguna manera, en estos escritos Leibniz parecería haber concebido al espacio, objeto de la geometría, como si fuera una sustancia anterior a los cuerpos en el cual ellos se ubican. ${ }^{7}$ Esta visión de Leibniz parece haber cambiado apenas arribó a la capital francesa, pues consideró que la concepción relativamente intuitiva del espacio, como de "una cierta sustancia inmóvil parecida a un vaso universal", ${ }^{8}$ no es acorde con la visión de que el cuerpo se define por el movimiento. En este sentido, como vimos en el cuarto capítulo, el espacio es la trayectoria realizada por un cuerpo al moverse. Ahora bien, el examen del atributo de la extensión en el período de $D S R$ conlleva nuevas variaciones en la visión de

\footnotetext{
${ }^{6}$ Leibniz a Thomasius, A II 1, 34. "Spatium (...) estque locus ille universalis omnium rerum".

${ }^{7}$ Leibniz a Thomasius, A II 1, 30. Similarmente, Specimen demonstrationum de natura rerum corporearum ex phaenomenis, A VI 2, 305.

${ }^{8}$ Propositiones quaedam physicae, A VI 3, 55-56. “(...) spatium esse substantiam quandam immobilem, instar vasis universalis".
} 
Leibniz. Aunque también plantea el problema de la anterioridad de la extensión, no obstante, lo hace en un sentido radicalmente distinto del que fue sostenido en 1669. En efecto, Leibniz concibe que la forma simple de la extensión es anterior a sus modificaciones, esto es, a los lugares particulares; no obstante, la extensión no es un lugar universal, pues el atributo de Dios no es algo extenso sino una idea o naturaleza. Ahora bien, el espacio universal, que es el agregado de todos los lugares, tampoco se corresponde con el 'lugar universal' que defendió anteriormente, pues, mientras que el lugar universal fue visto como un cierto todo dado con anterioridad a los cuerpos, el espacio universal es un ente por agregación, esto es, posterior a los lugares ocupados por los cuerpos. En última instancia, la evolución del pensamiento de Leibniz muestra un progresivo alejamiento de la visión sustancialista del espacio.

6. El hecho de que para Leibniz el continuo tenga infinitas partes actuales, aunque no esté dividido en todas partes, tiene algunas implicancias especialmente importantes en el marco de la teoría del cuerpo. En alguna medida, las tesis que desarrollamos anteriormente tratan sobre la multiplicidad de partes (por ejemplo, en este caso, de la materia); no obstante, para Leibniz es también necesario dar razón de la cohesión o unidad que dicha pluralidad supone como la otra cara de la misma moneda. Ahora bien, en nuestra tesis hemos visto que, a lo largo de los años, los planteos de Leibniz presentan una evolución significativa. En efecto, hemos visto que, en los escritos del período de DSR, Leibniz cuestionó la idea de que los cuerpos están cohesionados por tener un extremo en común. En otras palabras, en el período de $D S R$ el filósofo de Leipzig habría concebido que la explicación de la cohesión de los cuerpos que mantuvo entre 1670 y 1672 es insuficiente. Como vimos, en el Pacidius Philalethi Leibniz argumenta que la noción de un 'extremo en común' contradice el principio de tercero excluido. En este sentido, los cuerpos -y lo mismo vale para los restantes continuos en la acepción genérica de la expresión-, rigurosamente hablando, no son continuos, en el sentido aristotélico del término, sino solamente contiguos. En consecuencia, son agregados de partes, pero no totalidades dadas con anterioridad a ellas. Así, en el período de $D S R$, la explicación que Leibniz dio entre los años 1670 y 1672, que de alguna manera se fundaba en principios más bien mecánicos, es reemplazada por una justificación cuyo soporte se encuentra en un elemento no corpóreo, es decir, en el hecho de que cada porción de materia mantiene una relación con una mente. 
Ante todo, esto no significa que, en los escritos de 1670-1672, Leibniz haya concebido que las mentes no cumplen ninguna función en absoluto. Como mencionamos en el quinto capítulo, las mentes fueron concebidas como un principio no corporal de movimiento. En este sentido, ellas fueron importantes para la explicación del movimiento. No obstante, no lo fueron para explicar la cohesión de los cuerpos, al menos no directamente. Recordemos que Leibniz había defendido que los cuerpos que se comprimen mutuamente comienzan a unirse, esto es, de modo que sus extremos dejan de ser distintos y pasan a ser el mismo. No obstante, en el período de $D S R$, la unidad o solidez de los cuerpos es debida directamente a las mentes. De esta manera, ahora las mentes son vistas como un principio no corpóreo que explica la cohesión de los cuerpos. Como vimos en el último capítulo de nuestro trabajo y señalamos anteriormente en la segunda conclusión general, uno de los sentidos con los que Leibniz utilizó la palabra 'átomo' en el final de sus días en París, se refiere precisamente a un cuerpo sólido, es decir, que mantiene una unidad, de manera que no está dividido en todas partes. Como vimos, para Leibniz todo cuerpo es flexible, esto es, admite una nueva subdivisión o flexión, al mismo tiempo que conserva una cierta resistencia a la dispersión de las partes. De esta manera, un cuerpo implica una unidad en la multiplicidad de partes, no porque la materia no esté dividida, sino por el hecho de que hay una mente implantada en ella. En este sentido, en lo que respecta al problema de la cohesión de los cuerpos, podríamos decir que Leibniz pasa de una concepción más bien mecanicista a otra más bien metafísica. En cualquier caso, es importante destacar que, en lo que respecta a la teoría de la materia, la explicación de la unidad o cohesión de los cuerpos se complementa con la tesis de la infinitud actual de partes.

7. El problema de la unidad o cohesión de los cuerpos no fue el único que sufrió de cambios constantes en el pensamiento de juventud de Leibniz. Más aún, otro caso de este tipo especialmente relevante, también enmarcado en el estudio de la realidad corpórea, es el de la teoría de la acción y del movimiento. En efecto, parece claro que en sus escritos juveniles, el filósofo de Leipzig no logró sistematizar una concepción de la acción que esté libre de dificultades. Resumamos los momentos más significativos de la evolución de Leibniz respecto de la teoría del movimiento y de la acción. En primer lugar, en los últimos años de la década de 1660, Leibniz mantuvo que las únicas notas que definen al cuerpo son la extensión y la impenetrabilidad, de manera que el movimiento no solamente no es una de 
las notas esenciales, sino que tampoco se deduce de ellas. Ahora bien, en la TMA, Leibniz defendió que el inicio del movimiento es el conato, que, como vimos especialmente en el quinto capítulo, es aquello que, propagado, da lugar al movimiento. No obstante, en los escritos físicos del comienzo del período parisino, el filósofo de Leipzig introdujo varias modificaciones en su teoría del cuerpo a partir de un examen riguroso del concepto de indivisible, llegando a la conclusión de que ser cuerpo es estar en movimiento. Como una sustancia es algo activo, Leibniz consideró que un cuerpo es una sustancia cuya acción es el movimiento. En este contexto, el filósofo de Leipzig asocia estrechamente las nociones de acción y de movimiento, lo que no es claro que sostuviera anteriormente. No obstante, hacia el final del período parisino, Leibniz vuelve a modificar su visión, e incluso más radicalmente. En efecto, sostuvo que no hay acción en el cuerpo que se mueve, sino solamente un padecer el influjo de un cuerpo colindante. En este sentido, el movimiento es una pasión, pero no una acción. En última instancia, la acción estaría en Dios, lo que se explicaría a partir del atributo divino de la omnipotencia. De esta manera, el movimiento se explica como una creación continua o una transcreación. Como vemos, es claro que en su pensamiento de juventud Leibniz no arribó a una concepción consistente y definitiva sobre estas cuestiones. Ahora bien, hay algo que se destaca en los cambios en la teoría del movimiento y de la acción durante estos años, que es especialmente relevante si se lo considera en relación con el pensamiento de madurez de Leibniz, a saber, que no parece estar seguro de si el movimiento y la acción deben identificarse o no.

8. Como vemos, en buena medida la transversalidad del problema del continuo y del infinito, que es parte central del carácter laberíntico de la cuestión, se justifica en la naturaleza interdisciplinar del tratamiento llevado a cabo por Leibniz. Quizás podríamos decir, incluso más rigurosamente, que el abordaje leibniziano es transdisciplinar, en la medida en que el filósofo de Leipzig lleva constantemente a cabo los dos movimientos que describiremos a continuación. Por una parte, fundamenta algunas tesis que pertenecen a un ámbito del saber por medio de razonamientos que pertenecen a otro dominio del conocimiento. Esto lo mostramos, por ejemplo, al señalar la conexión entre los exámenes sobre series infinitas y la tesis de la infinitud actual de partes del continuo. Por otra parte, Leibniz analiza un mismo problema o una misma noción desde enfoques distintos pero complementarios. Un ejemplo de esto lo vimos al examinar la distinción entre infinito 
terminado e infinito sin término y las consecuencias que dicha diferenciación tiene para la geometría y para la metafísica, así como también al examinar la cuestión sobre el número infinito. De esta manera, la transversalidad del problema del continuo y del infinito se entiende en el sentido de que hay una cierta matriz común que consiste en determinados problemas y conceptos, y que recorre los abordajes físicos, metafísicos y matemáticos de Leibniz.

\section{Trazando puentes: de la multiplicidad a la unidad}

A lo largo de nuestro trabajo, hemos mostrado cómo y por qué Leibniz halló en las nociones de continuo y de infinito -siguiendo las palabras de Beeley referidas en la introducción general- la clave fundamental para armonizar la matemática, la física y la metafísica. ${ }^{9}$ Ahora bien, en nuestro tratamiento quedó también de manifiesto que las reflexiones del filósofo de Leipzig acerca de la multiplicidad actualmente infinita de partes en el continuo se complementan con profundas consideraciones sobre la unidad que se corresponde con dicha pluralidad. No obstante, hay una diferencia esencial entre los tratamientos de Leibniz centrados en la multiplicidad y aquellos otros enfocados en la unidad: mientras que, a lo largo de los años, el filósofo de Leipzig mantuvo la tesis de la infinitud actual de partes en el continuo (a pesar de haber ido sucesivamente profundizando en ella), cambió constantemente la manera de abordar la cuestión de la unidad. Esto es claro, por ejemplo, en el caso del problema de la unidad o cohesión de los cuerpos. Si quisiéramos explicar en pocas palabras cómo fluye el pensamiento de Leibniz desde los escritos de juventud hacia los de madurez, podríamos decir que transita desde el problema del infinito hacia el de la unidad. De acuerdo con esto, en esta sección analizaremos la evolución de los exámenes del problema del continuo en conexión con el período en el que se constituye la primera formulación madura del cuerpo filosófico de Leibniz, esto es, los escritos de la década de 1680. En estos años se consolidaron las ideas que, tras un importante desarrollo, culminaron, entre otras cosas, en la concepción monadológica y en la dinámica de Leibniz. En buena medida, el núcleo del pensamiento leibniziano de la década de 1680 se estructura en torno a la noción de 'sustancia'. El texto más emblemático en este

\footnotetext{
${ }^{9}$ Beeley, 2015: 23. Véase la introducción general.
} 
sentido fue el Discours de métaphysique, que se complementa con la correspondencia con Arnauld. Naturalmente, un análisis exhaustivo excedería la intención de este apartado de la conclusión. Por este motivo, nuestra presentación es simplemente a título ilustrativo.

Ahora bien, si quisiéramos hacer una aproximación general, casi comparativa, entre lo que Leibniz dijo en el final del período parisino y en los textos de la década de 1680, veríamos que hay algunas cuestiones sobre las que mantuvo las mismas ideas y otras sobre las que sucede lo contrario. Sin embargo, en este segundo caso podemos observar que, aunque no haya una coincidencia, en los escritos de $D S R$ se encuentran antecedentes o, al menos, indicios que llevaron a los planteos de madurez, aunque muchas veces carentes de orden y faltos de profundización. En este sentido, veremos que, en algunos casos, las ideas de la primera formulación madura están en germen en el pensamiento del período parisino, aunque a Leibniz le haya faltado llevar sus planteos hasta sus últimas consecuencias. Naturalmente, esto no significa que el primer sistema esté en su integridad germinalmente en el período de $D S R$, sino solamente algunos aspectos. De acuerdo con esto, a continuación haremos dos cosas. En primer lugar, intentaremos dejar en evidencia algunas de las tesis que Leibniz elaboró en su período parisino y que se conservan en la década de 1680. En siguiente lugar, analizaremos la otra cara de la cuestión, esto es, aquellas tesis que evolucionaron.

En buena medida, muchas de las tesis que Leibniz conserva del período de DSR en el pensamiento posterior están vinculadas con la tesis del infinito actual. A continuación pondremos algunos ejemplos que ilustran esto, sobre la base de la teoría leibniziana del cuerpo.

1. Leibniz continúa defendiendo que no hay átomos, esto es, cuerpos tan exiguos que no estén nuevamente subdivididos en acto. Más aún, hacia el final de la década de 1680, Leibniz recuerda el argumento de la incongruencia, a saber, que “(...) no puede darse ninguna razón para que un cuerpo de pequeñez determinada no sea ulteriormente divisible". ${ }^{10}$ Por la misma razón, Leibniz insiste en que no hay cuerpos perfectamente

\footnotetext{
${ }^{10}$ Principia logico-metaphysica, A VI 4, 1648. "Ut taceam rationem nullam reddi posse, cur corpora certae parvitatis non amplius sint divisibilia”. Traducción: De Olaso, 397.
} 
líquidos o fluidos, de modo que todos los cuerpos son flexibles, esto es, tienen algún grado de firmeza y algún grado de fluidez. ${ }^{11}$

2. Ahora bien, como un corolario del punto anterior, Leibniz también continúa defendiendo que hay un mundo de infinitas criaturas en cada partícula del universo. ${ }^{12}$ Más aún, cuando el filósofo de Leipzig describe esta tesis, emplea expresiones que se corresponden casi a la perfección con las notas que señalamos en la primera sección de esta conclusión:

Sin embargo, el continuo no se divide en puntos, ni se divide de todas las maneras posibles; en puntos no, pues los puntos no son partes, sino límites; ni de todas las maneras posibles, pues no todas las criaturas están contenidas en lo mismo, sino sólo una cierta progresión infinita de las mismas. ${ }^{13}$

El hecho de que Leibniz continúe defendiendo la tesis del infinito actual implica el reconocimiento de que hay cosas que son muy pequeñas respecto de nosotros, pero que pueden considerarse como muy grandes respecto de otras cosas aún más pequeñas (así, según como lo describimos en el capítulo séptimo, son infinitesimales como relación). ${ }^{14}$ Ahora bien, de alguna manera, Leibniz extrae de aquí una consecuencia muy significativa para su pensamiento maduro, a saber: si se entiende que la naturaleza del cuerpo consiste en la extensión, no habría ninguna unidad genuina. ${ }^{15}$ Como vimos en nuestro trabajo, desde el período de $D S R$ Leibniz entendió que todo cuerpo es un agregado de cuerpos, es decir, está dividido al infinito en partes menores. El problema que Leibniz observa es serio, pues reconoce que no podemos decir que hay 'entes' donde no hay un ente que sea verdaderamente uno. En consecuencia, todo ser por agregación supone seres dotados de una verdadera unidad. Como queda claro, esta unidad no puede sustentarse en la noción de

\footnotetext{
${ }^{11}$ Actu infinitae sunt creaturae; A VI 4, 266; De mundo praesenti, A VI 4, 1510; Specimen inventorum de admirandis arcanis naturae, A VI 4, 1623, 1627-1628; Principia logico-metaphysica, A VI 4, 1648.

${ }^{12}$ Leibniz a Arnauld, A II 2, 171; OFC, 14, 93-94; A II 2, 237; OFC, 14, 125.

${ }^{13}$ Principia logico-metaphysica, A VI 4, 1648. "Non tamen continuum in puncta dividitur, nec dividitur omnibus modis possibilibus. Non in puncta, quia puncta non sunt partes sed termini; non omnibus modis possibilibus, quia non omnes creaturae insunt in eodem, sed certus tantum earum in infinitum progressus". Traducción: De Olaso, 397.

${ }^{14}$ De mundo praesenti, A VI 4, 1511.

${ }^{15}$ Reconstruiremos el hilo de la argumentación de Leibniz sobre la extensión teniendo en cuenta los siguientes textos: Definitiones cogitationesque metaphysicae, A VI 4, 1393-1405; An Corpora sint mera phaenomena, A VI 4, 1464-1465; Mira de natura substantiae corporeae, A VI 4, 1465-1466; De resolvenda notione extensionis contra cartesianos, A VI 4, 1468; Leibniz a Arnauld, A II 2, 59-60; 120-122; 169-171; 184-188; Specimen inventorum de admirandis arcanis naturae, A VI 4, 1615-1630; Principia logicometaphysica, A VI 4, 1643-1649.
} 
extensión: por una parte, como vimos, para Leibniz no hay partículas atómicas; por otra, no puede decirse que constituyen una unidad cosas que estén muy cerca una de la otra, e incluso en contacto. En cualquier caso, ellas no serían más que contiguas, y por lo tanto, no constituirían más que un agregado. Que estén en contacto, es decir, muy cerca una de otra, o que estén a una distancia mayor, en última instancia no cambia nada respecto de la unidad: "el más y el menos no influye nada aquí". 16

Como vemos, en este punto de su examen, hay un cambio muy importante en el pensamiento de Leibniz en lo que respecta a la noción de extensión. Más aún, el filósofo de Leipzig es consciente de que “(...) las dificultades sobre la composición del continuo no se resolverán nunca, mientras que se considere la extensión como constituyendo la sustancia de los cuerpos, y nos confundamos con nuestras propias quimeras". ${ }^{17}$ En este sentido, Leibniz reconoce que caeríamos en una equivocación si concibiéramos a la extensión como una noción primitiva. Si se lo compara con el pensamiento de $D S R$, en esta cuestión hay un cambio de perspectiva muy significativo: que la extensión deje de ser concebida como una noción primitiva, implica que deja de ser tenida por una forma simple inteligible por sí, esto es, por un atributo de Dios. Que no sea 'simple' o 'primitiva' significa, ante todo, que el examen del problema del continuo revela que la noción de extensión no es tan clara como parecía. En efecto, Leibniz reconoce que, si en los cuerpos no hubiera más que extensión y sus modificaciones (esto es, figura y movimiento), los cuerpos serían meros fenómenos, pero no entes reales. En este sentido, serían algo análogo a los colores o a los sonidos, que en parte dependen de nosotros para ser. Como no hay un cuerpo tan pequeño que no esté dividido en partes, no es posible asignar una figura determinada a un cuerpo. De esta manera, las figuras son algo imaginario, en el sentido de que, rigurosamente hablando, no es posible hallar en los cuerpos una línea exacta, un círculo perfecto, una elipse u otra figura cualquiera. Dicho de otra manera, la figura no es una cualidad enteramente real y determinada fuera del pensamiento. Algo similar puede decirse del movimiento. Como vimos en el último capítulo, desde el período parisino Leibniz sostiene que el movimiento

\footnotetext{
${ }^{16}$ Leibniz a Arnauld, A II 2, 170. "Le plus et le moins ne faisant rien icy, et mêmes quand on viendra jusqu'à l'attouchement". Traducción: OFC, 14, 95.

${ }^{17}$ Leibniz a Arnauld, A II 2, 187. “(...) et même les difficultés de compositione continui ne se resoudront jamais, tant qu'on considerera l'etendue comme faisant la substance des corps, et nous nous embarrassons de nos propres chimeres”. Traducción: OFC, 14, 105.
} 
consiste en un respecto. Como corolario (que analizaremos con mayor profundidad más adelante), el espacio y el tiempo son también concebidos como fenómenos.

Estas reflexiones de Leibniz muestran que, en consecuencia, si se quisiera dar razón de la unidad de los cuerpos, no debería atenderse exclusivamente a la materia. Así, si hubiera en el cuerpo un principio de unidad, debería ser pensado como algo carente de extensión. Esto no significa que el principio de unidad sea, por ejemplo, como los indivisibles de la TMA. En efecto, como vimos, dichos indivisibles fueron concebidos en términos físicos. El problema del continuo le mostró a Leibniz que no puede haber algo físico e indivisible, es decir una unidad de naturaleza física. Para explicar el principio de unidad de los cuerpos, Leibniz introduce en su pensamiento la noción metafísica de forma sustancial y, en consecuencia, de sustancia. Más aún, Leibniz nota que esto es consistente con el hecho de que en el cuerpo hay cosas que no pueden derivarse de la extensión ni de sus modos, como la fuerza o potencia:

Por consiguiente, la esencia del cuerpo no debe colocarse en la extensión y sus modificaciones, a saber, la figura y el movimiento (que envuelven algo imaginario no menos que el calor, el color y otras cualidades sensibles), sino sólo la fuerza de actuar y resistir, que percibimos no con la imaginación, sino con el entendimiento. ${ }^{18}$

Hay muchas cosas que decir sobre las nociones de sustancia y de forma sustancial. Ante todo, notemos la novedad que supone en el pensamiento de Leibniz, especialmente si se lo compara con las reflexiones de DSR. Como vimos, hacia el final del período parisino, Leibniz parece haberse decidido conscientemente por evitar la introducción de sustancias particulares en su sistema del mundo. En última instancia, había entendido que la única cosa que puede verdaderamente ser llamada 'sustancia' es Dios. Más aún, como vimos en el último capítulo, Leibniz entendió que no hay acción en los cuerpos que se mueven y, en consecuencia, que la potencia es propia solamente de Dios. La introducción de sustancias particulares significa, al menos, la asignación de un fundamento real de la unidad de los cuerpos que es, al mismo tiempo, la fuente de su actividad, esto es, la fuerza motriz o

\footnotetext{
18 Specimen inventorum de admirandis arcanis naturae, A VI 4, 1623. "Itaque essentia corporis non in extensione et ejus modificationibus, figura scilicet et motu (quae imaginarii aliquid involvunt non minus quam calor, et color, et aliae qualitates sensibiles), sed in sola vi agendi resistendique collocanda est, quam non imaginatione, sed intellectu percipimus". La traducción es de Oscar Esquisabel.
} 
potencia de actuar. ${ }^{19}$ Ahora bien, en cada sustancia puede distinguirse -tal como distinguía Aristóteles- entre materia y forma. Leibniz explica estos términos valiéndose de múltiples descripciones, detrás de las cuales se esconde una clara armonía que se estructura a la manera de una oposición: mientras la materia es principio de naturaleza limitada, la forma es principio de naturaleza ilimitada o infinita; así como la primera es principio multiplicidad y cambio, la segunda es principio de unidad y duración; una es fuerza primitiva de resistencia (llamada mole o antitipia), la otra es fuerza primitiva del obrar. Todas estas oposiciones reflejan aspectos de las sustancias:

En primer lugar, para Leibniz en toda criatura está tanto lo infinito como lo limitado: toda criatura es omnisciente y omnipotente, aunque ninguna de ellas lo sea de manera absoluta. En este sentido, una sustancia tiene algo de infinito, es decir, tiene algún vestigio o una participación de la omnisciencia y la omnipotencia, en cuanto que involucra a su causa, esto es, a Dios. De esta manera, las criaturas son omniscientes, aunque confusamente, y poseen una fuerza infinita, aunque ejercen dicha fuerza dentro de sí mismas. Como vimos en el capítulo octavo, esta tesis de Leibniz se encuentra germinalmente en el período de $D S R$, aunque no precisamente por las mismas razones (cuestión en la que nos detendremos más adelante). No obstante, hay un claro anticipo de ella, tanto en la noción de forma simple, respecto de lo infinito, como en la de materia, mole o masa, en tanto principio de limitación.

En segundo lugar, en toda criatura hay un principio de multiplicidad y un principio de unidad: "[1]a unidad se ha de juntar con la multitud tanto como sea posible". ${ }^{20}$ Esta es, sin dudas, la gran novedad de Leibniz en lo que respecta a la resolución del problema del continuo: la forma sustancial hace la unidad sustancial independiente de la unión exterior. Por esta razón, el cuerpo, si se lo considerara al margen de la forma sustancial, no es una sustancia sino un ser por agregación. En efecto, como vimos, desde este punto de vista, todo cuerpo tiene infinitas partes actuales. Ahora bien, como toda parte de un cuerpo es

\footnotetext{
${ }^{19}$ Sintetizaremos la concepción de Leibniz sobre la sustancia basándonos en los siguientes textos: Definitiones cogitationesque metaphysicae, A VI 4, 1393-1405; Mira de natura substantiae corporeae, A VI 4, 1465-1466; De mundo praesenti, A VI 4, 1505-1513; Discours de métaphysique, A VI 4, 1529-1588; Leibniz a Arnauld, A II 2, 113-116; 120-122; 172; 233-234; 248-250; 273-274; Specimen inventorum de admirandis arcanis naturae, A VI 4, 1615-1630; Principia logico-metaphysica, A VI 4, 1643-1649; Communicata ex disputationibus cum Fardella, A VI 4 1666-1671.

${ }^{20}$ Definitiones cogitationesque metaphysicae, A VI 4, 1401. "Semper unitas multitudini jungenda est quantum licet”. Traducción de Oscar Esquisabel.
} 
también un cuerpo, no sería posible señalar una parte de materia, por pequeña que sea, que no contenga un cuerpo animado, es decir, que no esté dotada de una forma sustancial que le de unidad verdadera. Esto implica, en consecuencia, que un cuerpo es efectivamente un agregado, pero de sustancias. De esta manera, Leibniz señala que todo cuerpo es o bien un cuerpo organizado, o bien un montón de cuerpos organizados. A partir de esto, es claro por qué para Leibniz, si no se afirmaran sustancias, los cuerpos no serían más que meros fenómenos, pues el continuo está actualmente dividido en otras partes, de modo que nunca podría alcanzarse por división un verdadero ser. Por esto, como decíamos antes, una sustancia, como unidad real, debe ser indivisible, y la extensión, al margen de estas unidades reales, no podría constituir un ser completo, esto es, sería un mero fenómeno. ${ }^{21}$ Esto explica por qué para Leibniz las formas sustanciales son tan importantes: “(...) es la forma la que da el ser determinado a la materia, y los que no toman en cuenta esto, no saldrán nunca del laberinto de la composición del continuo, si es que han entrado en ello alguna vez". ${ }^{22}$ Ahora bien, que un cuerpo sea un agregado de sustancias no significa que las sustancias sean partes del cuerpo. En la materia hay sustancias en todas partes, del mismo modo que hay puntos en una línea: así como no hay ninguna porción de una línea en la que no haya infinitos puntos, así también no hay porción de materia en la que no haya infinitas sustancias. En efecto, las partes de una línea no son puntos, sino líneas en la que están los puntos, del mismo modo que las partes de la materia no son las sustancias, sino cuerpos en los que están las formas sustanciales. Por esta razón, Leibniz señala que “(...) las almas son tantas como los Átomos sustanciales o sustancias corpóreas". ${ }^{23}$ Es claro que los átomos sustanciales a los que el filósofo de Leipzig se refiere en esta cita no son los cuerpos perfectamente duros. En alguna medida, pareciera haber una proximidad (aunque no

\footnotetext{
${ }^{21}$ No es mi intención introducirme en la discusión actual sobre la relación entre forma, materia y fenómeno en el pensamiento maduro de Leibniz. Esta cuestión fue abordada, entre otros, por Adams, 1994 (quien sostuvo una interpretación idealista), Phemister, 2005 (quien acentúa el carácter esencialmente real de los cuerpos), Garber, 2009 (quien defiende una interpretación realista, acentuando la importancia de la sustancia corpórea, compuesta de materia y forma, para entender el pensamiento leibniziano del período medio), Hartz, 2007 (quien, centrándose en el pensamiento maduro del autor, sostiene que Leibniz fue tanto realista como idealista) y Smith, 2011a (quien señala que el cambio fundamental en el pensamiento maduro de Leibniz se encuentra en la concepción de la naturaleza del cuerpo como compuesto no ya de partes homogéneas, sino de sustancias corpóreas, es decir, vivientes).

${ }^{22}$ Leibniz a Arnauld, A II 2, 250. "Aussi les philosophes ont reconnu que c'est la forme qui donne l'estre determiné à la matiere, et ceux qui ne prennent pas garde à cela ne sortiront jamais du labyrinthe de compositione continui, s'ils y entrent une fois". OFC, 14, 133.

${ }^{23}$ Mira de natura substantiae corporeae, A VI 4, 1466. "Quot sunt animae Tot sunt Atomi substantiales seu substantiae corporeae".
} 
identidad) entre los átomos sustanciales que Leibniz describe en la década de 1680 y la noción de 'átomo' mantenida en el período de DSR que describimos en el último capítulo. En este sentido, en el pensamiento de la época parisina encontramos, por lo menos, un anticipo de la visión de madurez.

En tercer lugar, para Leibniz toda sustancia envuelve una fuerza primitiva de resistencia y una fuerza primitiva de obrar. El carácter pasivo está dado por la materia, mientras que el activo por la forma. Precisamente por esto, el filósofo de Leipzig es consciente de que no es erróneo decir que la forma es 'acto primero', es decir, la primera facultad activa. Ahora bien, como señalamos en la sección anterior, en su pensamiento de juventud, Leibniz osciló entre identificar y distinguir el movimiento y la acción. El hecho de que en el período parisino haya considerado que el movimiento es respectivo y que no hay acción en el cuerpo que se mueve, revela que en los escritos de $D S R$ ya concebía una distinción bastante clara entre dichas nociones. En el pensamiento maduro, esta distinción alcanza una dimensión aún mayor. Mientras que el movimiento, como cambio de lugar, no es algo real, de manera que cuando varios cuerpos se mueven no podemos decidir a cuál de ellos debe atribuírsele el movimiento, la fuerza sí lo es, de manera que es posible atribuírsela a un cuerpo y no a otro. El movimiento, como un modo de la extensión, es fenoménico, es decir, envuelve algo imaginario; la acción, por el contrario, pertenece al plano de lo real. A diferencia de lo que había mantenido en el período de $D S R$, en donde señaló que la acción está en Dios, en la década de 1680, Leibniz entendió que la fuerza o la potencia está en las sustancias, lo que lo llevó al restablecimiento de las formas sustanciales. En este sentido, si el movimiento, a pesar de ser fenoménico, no es un mero fenómeno, es porque tiene un fundamento real. Con esto, Leibniz da razón de algo de lo que ya había tomado conciencia en el período parisino, a saber, que no hay que sorprenderse de que Dios conserve siempre la misma cantidad de fuerza aunque no la misma cantidad de movimiento.

La distinción entre lo fenoménico y lo real, entre movimiento y fuerza, es posiblemente uno de los aspectos más destacados de la resolución del problema del continuo por parte de Leibniz. Ahora bien, en algún sentido, esta distinción se corresponde con la diferenciación entre regiones de conocimiento, a saber, la física y la metafísica. En este sentido, Leibniz es consciente de que los escolásticos han fallado al no reconocer que las formas sustanciales no sirven en nada en los pormenores de la física; no obstante, 
también fallaron aquellos que, por la misma razón, las rechazan en la metafísica. Para Leibniz esto significa que un físico puede dar razón de las experiencias sin necesidad de consideraciones que pertenecen a la esfera de la metafísica, del mismo modo en que "(...) los Geómetras no se preocupan por la composición del continuo". ${ }^{24}$ Como vimos en el séptimo capítulo, en $D Q A$ Leibniz señaló que un geómetra puede extraer conclusiones acertadas admitiendo en su procedimiento cantidades infinitas e infinitamente pequeñas, a pesar de que, desde un punto de vista metafísico, pueda concluirse que dichas cantidades son imposibles. Entre la física y la metafísica sucede algo análogo: podemos decir que toda sustancia creada ejerce acción y pasión física sobre todas las otras (en el sentido, por ejemplo, de que, cuando una de ellas se mueve, se produce un desplazamiento correspondiente en todas las otras), a pesar de que ninguna ejerza una acción metafísica sobre las demás (por razones que explicaremos más adelante). En este sentido, desde el punto de vista de la filosofía natural, es posible explicar todos los fenómenos suponiendo algunos principios de la mecánica, a pesar de que, desde una perspectiva metafísica, estemos forzados a reconocer que la naturaleza del cuerpo no puede consistir en la extensión. Incluso, Leibniz señala que en la física puede fingirse que todo consta de glóbulos muy pequeños de una firmeza infinita y de un fluido intersticial (es decir, los presupuestos de la física corpuscular mecanicista), “(...) como fingimos en la geometría líneas infinitas e infinitamente pequeñas". ${ }^{25}$ En consecuencia, la física, al igual que la geometría, puede prescindir de las consideraciones metafísicas. Esta concepción de Leibniz no deja de ser una manera de ver el perspectivismo desde un punto de vista epistemológico.

A partir de lo anterior podemos extraer la conclusión de que para Leibniz una sustancia individual cumple, por lo menos, con los siguientes requisitos: debe ser una unidad, indivisible, algo idéntico y sujeto de acciones y pasiones. No obstante, esto no responde a la pregunta por cuál es la naturaleza de una sustancia singular. Para esto, Leibniz señala un requisito más: una sustancia individual posee un ser completo. De acuerdo con esto, el filósofo de Leipzig señala que "la naturaleza de la sustancia singular es que tenga una noción completa, en la cual estén envueltos todos los predicados del

\footnotetext{
${ }^{24}$ Leibniz a Arnauld, A II 2, 116. "A peu près comme les Geometres ne se soucient pas de compositione continui, et les physiciens ne se mettent point en peine, si une boule pousse l'autre, ou si c'est Dieu”. OFC, 14, 77.

${ }^{25}$ Specimen inventorum de admirandis arcanis naturae, A VI 4, 1628. “(...) uti in Geometria fingimus lineas infinitas et infinite parvas”. Traducción de Oscar Esquisabel. Sobre esta cuestión, ver Santi, 2016.
} 
sujeto". ${ }^{26}$ Esta idea de la noción completa de una sustancia singular fue una de las primeras novedades inmediatamente posteriores al período parisino. En efecto, en 1677 Leibniz ya había reconocido que se llama 'sustancia' al ente que envuelve todos los predicados necesarios del mismo sujeto. ${ }^{27}$ En los años siguientes, el filósofo de Leipzig ha ido profundizando en esta idea. Por ejemplo, señaló que en la noción perfecta de una sustancia individual se contienen todos los predicados no sólo necesarios sino también contingentes. Esto explica que la noción completa no se refiera a las especies (que contienen solamente verdades eternas y necesarias), sino a las sustancias singulares. Esto marca una gran diferencia en relación con lo que había defendido en el período de $D S R$, pues luego, si bien no niega la sustancia perfecta y absoluta, reconoce también a la sustancia limitada y creada. Ahora bien, los predicados que están involucrados en la noción completa de una sustancia singular son pasados, presentes y futuros. En este sentido, en el concepto de la sustancia singular se contiene virtualmente todo lo que puede entenderse en ella, desde el punto de vista del estado de posibilidad, de acuerdo a como está en Dios. En consecuencia, para Leibniz toda predicación verdadera o es una identidad o puede reducirse a ella, en la medida en que en el sujeto, como dijimos, se incluyen todos sus predicados. En última instancia, aquí yace el fundamento último de por qué la extensión no puede constituir la naturaleza de una sustancia, a saber, porque la extensión expresa solamente un estado presente, pero no pasado o futuro. La extensión es, simplemente, el orden de coexistencia posible.

Ahora bien, hay una multiplicidad de consecuencias que Leibniz extrae a partir de esta idea de la noción completa de una sustancia singular. Por un lado, que, en el caso de los hombres, un alma piensa confusamente todo lo que alguna vez pensará de manera distinta. Dicho en otras palabras, esto explica por qué toda sustancia creada es omnisciente, aunque de manera confusa: "[p]ues expresa aunque confusamente todo lo que sucede en el universo, pasado, presente o futuro, lo que tiene cierta semejanza con una percepción o un

\footnotetext{
${ }^{26}$ Specimen inventorum de admirandis arcanis naturae, A VI 4, 1625. "substantiae enim singularis natura est ut habeat notionem completam, cui omnia ejusdem subjecti praedicata involvantur". Traducción de Oscar Esquisabel. Examinaremos sintéticamente los fundamentos de la concepción de Leibniz sobre la noción completa de sustancia singular sobre la base de estos textos: De perfecta notione substantiarum, A VI 4, 1530-1351; De mundo praesenti, A VI 4, 1505-1513; Discours de métaphysique, A VI 4, 1529-1588; Specimen inventorum de admirandis arcanis naturae, A VI 4, 1615-1630; Leibniz a Arnauld, A II 2, 42-53; 54-60; 111-116; 230-238; 239-261; Principia logico-metaphysica, A VI 4, 1643-1649; Communicata ex disputationibus cum Fardella, A VI 4, 1666-1671.

${ }^{27}$ Nos referimos a De perfecta notione substantiarum, A VI 4, 1530-1351.
} 
conocimiento infinito". ${ }^{28}$ Ahora bien, esto implica, en segundo lugar, que en la noción de una sustancia no solamente está contenido lo que le sucederá a ella, sino también a toda la serie de cosas del mundo. En este sentido, todas las operaciones, acciones y pasiones de una sustancia, metafísicamente hablando, son espontáneas, de manera que, al margen de la dependencia de las creaturas de Dios, no hay ningún influjo real de las sustancias entre sí. Incluso, el filósofo de Leipzig señala que, por esta razón, de alguna manera Dios produce las cosas por una suerte de emanación, como nosotros producimos nuestros pensamientos. Desde este punto de vista, no hay ningún influjo verdadero de una sustancia sobre otras. Más bien, cada sustancia singular expresa el universo en su totalidad desde su perspectiva, esto es, a su manera. ${ }^{29}$ Para graficar el hecho de que una sustancia es como un mundo entero y un espejo de Dios, Leibniz se vale de una imagen que, como vimos, ya se encuentra presente en los escritos de $D S R$ : cada una de ellas expresa el universo como una misma ciudad es expresada desde distintas perspectivas. Es claro que en parte la idea que está detrás de esta imagen es la misma en los escritos parisinos y en los de la década de 1680, aunque en parte también difiere. Como mostramos a lo largo de esta segunda sección de la conclusión, la clave de esta diferencia es la noción de sustancia.

Este hecho de que no haya un influjo real de una sustancia sobre las restantes, es decir, que en su noción estén incluidos todos los acontecimientos que le sucederán a ella y a toda la serie de cosas, es explicado por Leibniz de esta manera: así como al estado de un cuerpo en un momento A le sigue el estado en el momento B, así también al estado A del alma le sigue el estado B. Eso implica, por ejemplo, que a un acontecimiento en el cuerpo, que se explica como un movimiento, le corresponde en el alma una sensación (por ejemplo, de dolor, de picor, etc.). De esta manera, las sustancias tienen entre sí una conexión y una armonía, en virtud de que cada una de ellas expresa el mismo universo y la misma causa universal. Si fuera de otro modo, los fenómenos no concordarían entre sí, de modo que habría tantos sistemas como sustancias. En este sentido, detrás de esta concepción de Leibniz se esconde el argumento que justifica el carácter de fenómeno bien fundado del tiempo y del espacio, lo que conlleva, como vimos, un cambio notable respecto de sus

\footnotetext{
${ }^{28}$ Discours de métaphysique, $\S 9$, A VI 4, 1542. "Car elle exprime quoyque confusement tout ce qui arrive dans l'univers, passé, present ou avenir, ce qui a quelque ressemblance à une perception ou connoissance infinie". Traducción: De Olaso, 334.

${ }^{29}$ Para una visión del planteo de Leibniz sobre la noción de expresión y de las discusiones actuales en torno a dicha noción, véase Esqusabel, 2016.
} 
concepciones del período de DSR: "[t]oda la noción que tenemos del tiempo y del espacio está fundada en esta correspondencia (...)".30 Más aún, a partir de estas reflexiones, Leibniz soluciona uno de los problemas que más le había preocupado, a saber, el de la unión del alma y el cuerpo. No obstante, la idea de la noción completa de una sustancia singular y la manera de entender la expresión como una especie de concordancia o correspondencia entre las sustancias y los fenómenos respectivos, le abre un nuevo horizonte en el que inspeccionar esta cuestión que es muy diferente del que planteó en el pensamiento de juventud. En efecto, al igual que lo que ocurre entre dos sustancias cualesquiera, la unión del alma con el cuerpo consiste en la concordancia o concomitancia por medio de la cual la serie de los movimientos del cuerpo se corresponde con la serie de los pensamientos del alma. De esta manera, Leibniz rechaza, por un lado, la hipótesis según la cual entre el alma y el cuerpo se produce un influjo real. Pareciera que el filósofo de Leipzig defendió esta visión en los escritos físicos del comienzo del período parisino, cuando sostuvo que el alma es el principio del movimiento no corporal, e incluso en $D S R$, donde, como dijimos antes, explicó la unidad en un cuerpo por las mentes implantadas. No obstante, también rechaza, por la misma razón, la hipótesis de las causas ocasionales, que, nuevamente, pareciera haber sostenido transitoriamente mientras mantuvo que el movimiento es una transcreación.

Como vemos, en la evolución del pensamiento leibniziano son bastante manifiestas tanto las continuidades como las rupturas. Leibniz halló una salida al laberinto del continuo una vez que introdujo en sus reflexiones la idea de sustancias particulares. Gracias a ellas pudo explicar por qué la extensión no constituye una verdadera unidad, así como también pudo mostrar que el movimiento se explica por la fuerza motriz. Estas tesis de Leibniz se conectan, como vimos, con la concepción de la sustancia singular como lo que posee una noción completa. Sea como fuere, esta breve síntesis de los planteos que constituyen la primera formulación madura de Leibniz nos sirve de advertencia para notar la importancia que tienen los exámenes sobre el continuo y el infinito, al mismo tiempo que nos muestra que en su pensamiento de juventud ya había arribado al núcleo central de su concepción sobre estas nociones. Por eso, como vimos, en los años siguientes, Leibniz dejó de

\footnotetext{
${ }^{30}$ Leibniz a Arnauld, A II 2, 245. "Toute la notion que nous avons du temps et de l'espace est fondée sur cet accord". OFC, 14, 129-130.
} 
dedicarle una atención primordial al laberinto del continuo, no porque haya dejado de considerarlo como relevante, sino porque arribó a la conclusión de que no es posible hallar una unidad puramente física dada, precisamente, la infinitud actual de partes del continuo. Por eso, podemos decir que, entre la concepción de la infinita multiplicidad de partes del continuo a la que arribó en su pensamiento juvenil y la de la necesidad de una unidad sustancial distintiva de su filosofía madura, hay una cierta armonía. 



\section{BIBLIOGRAFÍA}

\section{Fuentes}

\subsection{Obras de G. W. Leibniz}

Leibniz, G. W. (1846): Historia et Origo Calculi Differentialis (C. I. Gerhardt ed.), Hannover.

[GM] Leibniz, G. W. (1849-1863): Leibnizen Mathematische Schriften (C. I. Gerhardt ed.), Berlin; La Haya, A. Ascher \& Comp; H.W. Schmidt. [Seguido del número de volúmen (en números romanos) y del número de página].

[GP] Leibniz, G. W. (1875-1890): Die Philosophischen Schriften von Gottfried Wilhelm Leibniz (C. I. Gerhardt ed.), Weidmann, Berlin. [Seguido del número de volúmen (en números romanos) y del número de página].

[A] Leibniz, G. W. (1923 y ss.): Sämtliche Schriften und Briefe (Deutsche Akademie der Wissenschaften ed.), Akademie-Verlag, Darmstadt; Leipzig; Berlin. [Seguido de la serie (en números romanos), del tomo (en números arábigos) y del número de página. Ej.: A VI 3, 555].

Leibniz, G. W. (1996): “Geschichte des Kontinuumproblems” (M. Luna Alcoba ed.), Studia Leibnitiana, 28:2, 1996, 183-198.

[DQA] Leibniz, G. W. (2004): Quadrature arithmétique du cercle, de l'ellipse et de l'hyperbole et la trigonométrie sans tables trigonométriques qui en est le corollaire (introducción, traducción y notas de Marc Parmentier, texto latino editado por Eberhard Knobloch), Vrin, París. [Seguido del número de proposición (en números romanos) y del número de página].

\subsection{Traducciones de las obras de Leibniz}

[Loemker] Leibniz, G.W. (1989): Philosophical Papers and Letters (edición, traducción e introducción de L. E. Loemker), Kluwer Academic Publishers, Dordecht; Boston; London (segunda edición). 
[PDSR] Leibniz, G. W. (1992): De summa rerum. Metaphysical Papers, 1675-1676 (traducción e introducción de G. H. R. Parkinson), Yale University Press, New Haven \& London.

Leibniz, G. W. (2001): The Labyrinth of the Continuum. Writings on the Continuum Problem, 1672-1686 (textos seleccionados, traducidos y editados e introducción elaborada por Richard T. W. Arthur), Yale University Press, New Haven \& London.

[de Olaso] Leibniz, G. W. (2003): Escritos filosóficos (edición de Ezequiel de Olaso, notas de Ezequiel de Olaso y Roberto Torretti, traducciones de Roberto Torretti, Tomás E. Zwanck y Ezequiel de Olaso), A. Machado, Madrid.

[OFC] Leibniz, G. W. (2007 y ss.): Obras filosóficas y científicas, Editorial Comares, Granada.

Leibniz, G. W. (2014): "Introducción a la aritmética de los infinitos (1672)" (comentario introductorio y traducción de Federico Raffo Quintana), Notae Philosophicae Scientiae Formalis, 3:1, 2014, 47-69.

\subsection{Obras de otros autores}

\subsubsection{En idioma original}

Aristóteles (1936): Aristotle's Physics (texto revisado, introducción y comentarios de W. D. Ross), Clarendon Press, Oxford.

Cavalieri, Bonaventura (1653): Geometria indivisibilibus continuorum quadam nova ratione promota, Bononiae.

De Arriaga, Rodrigo (1632): Cursus Philosophicus, Imp. Moretti, Anvers.

de Saint-Vincent, Grégoire (1647): Opus geometricum quadraturae circuli et sectionum coni, Anvers, vol. 2.

[AT] Descartes, René (1897-1910): Oeuvres de Descartes (publicadas por Charles Adam y Paul Tannery), Vrin, París. [Seguido del tomo (en números romanos), parte y parágrafo (en caso que nos refiramos a los Principia Philosophiae) y del número de página].

Digby, Kenelm (1664): Demonstratio immortalitatis animae rationalis (prólogo de Thomas White), Frankfurt. 
Froidmont, Libert (1631): Labyrinthus sive de compositione continui, Anvers.

[EN] Galilei, Galileo (1898): Le opere di Galileo Galilei, Edizione Nazionale, Florencia, vol. VIII. [Seguido del volumen (en números romanos) y del número de página].

Gassendi, Pierre (1658): Opera omnia in sex tomos divisa, Lvgdvni: Sumptibus Lavrentii Anisson \& Ioan. Bapt., Devenet, tomo primero.

Hobbes, Thomas (1839-1845a): The English Works of Thomas Hobbes (William Molesworth ed.), London, Bohn.

Hobbes, Thomas (1839-1845b): Opera Philosophica quae latina scripsit omnia (William Molesworth ed.), London.

Ockham, Guilliemi de (1984): Opera Philosophica et Theologica (St. Brown ed.), St. Bonaventure University, St. Bonaventure N.Y. Tomo: Opera Philosophica VI.

Pascal, Blaise (1665): Traité du triangle arithmétique, avec quelques autres petits traitez sur la mesme matière, G. Desprez, París.

[Eth./EP] Spinoza, Baruch (1925): Spinoza Opera (C. Gebhardt ed.), Carl Winters, Heidelberg. [Ethica: Eth., número de parte, indicación de que se refiere a una proposición, definición, escolio, etc. número respectivo $\mathrm{y}$, entre paréntesis, tomo $\mathrm{y}$ número de página. Por ejemplo: Eth. 1 esc15 (II, 57-60); para la correspondencia, EP, seguido del número de carta en números romanos $\mathrm{y}$, entre paréntesis, tomo y número de página. Por ejemplo: EP XII (IV, 56-57)].

Suárez, Francisco (1861): Opera omnia, vol. XXVI, Apud Ludovicum Vives, Bibliopolam Editores, París. [Indicaremos el número disputación, sección y página]

\subsubsection{Traducciones}

Aristóteles (1983 [1978]): Acerca del alma (introducción, traducción y notas de Tomás Calvo Martínez), Gredos, Madrid.

Aristóteles (1987): Acerca de la generación y la corrupción. Tratados breves de historia natural (introducciones, traducciones y notas de Ernesto La Croce y Alberto Bernabé Pajares), Gredos, Madrid.

Aristóteles (1994): Metafísica (introducción, traducción y notas de Tomás Calvo Martínez), Gredos, Madrid. 
Aristóteles (1995a): Física (introducción, traducción y notas de Guillermo R. de Echandía), Gredos, Madrid.

Aristóteles (1995b): Tratados de lógica (Órganon) II. Sobre la interpretación, Analíticos primeros, Analíticos segundos (introducción, traducción y notas de Miguel Candel Sanmartín), Gredos, Madrid.

Aristóteles y Euclides (2000): Aristóteles: Sobre las líneas indivisibles. Mecánica. Euclides: Óptica, Catóptrica. Fenómenos (introducción, traducción y notas de Paloma Ortiz García), Gredos, Madrid.

Aristóteles (2009): Categorías (traducción, introducción y notas de Eduardo Sinnott), Colihue, Buenos Aires.

Averroes (2003): "Averroes, Tafsir del De Anima: Sobre el Intelecto" (introducción, traducción y notas de Andrés Martínez Lorca), en ÉNDOXA: Series Filosóficas, 17, pp. $9-61$.

Descartes, René (2004): The World and Other Writings (traducción y edición de Stephen Gaukroger), Cambridge University Press, Cambridge.

Descartes y Leibniz (1989): Sobre los principios de la filosofía (traducción y notas por E. López y M. Graña), Gredos, Madrid.

Euclides (1991): Elementos. Libros I-IV (introducción de Luis Vega, traducción y notas de María Luisa Puertas Castaños), Gredos, Madrid.

Euclides (1996): Elementos. Libros X-XIII (traducción y notas de María Luisa Puertas Castaños), Gredos, Madrid.

Galilei, Galileo (2003): Diálogos acerca de dos nuevas ciencias (traducción de José San Román Villasante), Losada, Buenos Aires.

Platón (1988): Diálogos V. Parménides, Teeteto, Sofista, Político (traducción, introducción y notas de Ma. Isabel Santa Cruz, Álvaro Vallejo Campos y Néstor Luis Cordero), Gredos, Madrid.

Spinoza, Baruch (2007): Epistolario (introducción y notas: Diego Tatián; traducción y prólogo a la edición de 1950: Oscar Cohan; introducción a la edición de 1950: Carl Gebhardt; traducción de las cartas no incluidas en la edición de 1950: Diego Tatián y Javier Blanco), Colihue, Buenos Aires. 
Spinoza, Baruch (2011): Ética demostrada según el orden geométrico (introducción, traducción y notas de Vidal Peña), Alianza, Madrid (tercera edición).

\section{Bibliografía secundaria:}

Adams, Robert M. (1994): Leibniz. Determinist, Theist, Idealist, Oxford University Press, New York \& Oxford.

Alonso Matos, Juana del Carmen (2001) (ed.): Galileo y la gestación de la ciencia moderna (Acta IX), Fundación Canaria Orotava de Historia de la Ciencia, Canarias.

Andersen, Kirsti (1985): “Cavalieri's Method of Indivisibles", en Archive for History of Exact Sciences, 31, pp. 291-367.

Andersen, Kirsti (1986): "The Method of the Indivisibles: Changing Understandings", en Studia Leibnitiana, Sonderheft 14, pp. 14-25.

Andersen, Kirsti, Giusti, Enrico y Jullien, Vincent (2015): “Cavalieri’s Indivisibles”, en Jullien, Vincent (ed.), pp. 31-55.

Arthur, Richard T. W. (1986): "Leibniz on Continuity", en PSA: Proceedings of the Biennial Meeting of the Philosophy of Science Association, 1, pp. 107-115.

Arthur, Richard T. W. (1998): "Cohesion, Division and Harmony: Physical Aspects of Leibniz's Continuum Problem (1671-1686)", en Perspectives of Science, 6/1\&2, pp. 110-135.

Arthur, R., Mercer, C., Smith, J. y Wilson, C. (1997): "Symposium on Philip Beeley's Kontinuität und Mechanismus" (reseñas de la obra por dichos autores), Leibniz Society Review, 7, pp. 25-64.

Arthur, Richard T. W. (2000): “Leibniz's Inversion of Zeno: Continuity of Motion, Substantial Action and Plurality", en http://www.humanities.momaster.ca/ rarthur/papers/LIZ.pdf

Arthur, Richard T. W. (2001): "Leibniz on Infinite Number, Infinite Wholes and the Whole World: A Reply to Gregory Brown”, en Leibniz Review, 11, pp. 103-116.

Arthur, Richard T. W. (2004): “The Enigma of Leibniz's Atomism”, en Garber, Daniel y Nadler, Steven (eds.), pp. 183-228. 
Arthur, Richard T. W. (2008): "Leery Bedfellows: Newton and Leibniz on the Status of Infinitesimals”, en Goldenbaum, Ursula y Jesseph, Douglas (eds.), pp. 7-30.

Arthur, Richard T. W. (2009): “Actual Infinitesimals in Leibniz's Early Thought”, en Kulstad, Mark, Laerke, Mogens y Snyder, David (eds.), pp. 11-28.

Arthur, Richard T. W. (2013): "Leibniz's syncategorematic infinitesimals", en Archive for History of Exact Sciences, 67, pp. 553-593.

Arthur, Richard T. W. (2014): Leibniz, Polity Press, Classic Thinkers, Cambridge.

Arthur, Richard T. W. (2015a): "Leibniz's Actual Infinite in Relation to his Analysis of Matter", en Goethe, Norma B., Beeley, Philip y Rabouin, David (eds.), pp. 137-156.

Arthur, Richard T. W. (2015b): "The Relativity of Motion as a Motivation for Leibnizian Substantial Forms", en Nita, Adrian (ed.), pp. 143-160.

Barnes, Jonathan (ed.) (1999a [1995a]): The Cambridge Companion to Aristotle, Cambridge University Press, Cambridge.

Barnes, Jonathan (1999b [1995b]): “Metaphysics”, en Barnes, Jonathan, (ed.), pp. 66-108.

Bassler, Otto Bradley (1998a): "The Leibnizian Continuum in 1671", en Studia Leibnitiana, 30/1, pp. 1-23.

Bassler, Otto Bradley (1998b): "Leibniz on the Indefinite as Infinite", en The Review of Metaphysics, 51/4, pp. 849-874.

Beeley, Philip (1996): Kontinuität und Mechanismus. Zur Philosphie des jungen Leibniz in ihrem Ideengeschichtlichen Kontext (Studia Leibnitiana Supplementa, 30), Franz Steiner Verlag, Stuttgart.

Beeley, Philip (1999): "Mathematics and nature in Leibniz's early philosophy”, en Brown, Stuart (ed.), pp. 123-145.

Beeley, Philip (2008): "Infinity, Infinitesimals and the Form of Cavalieri: John Wallis and his Critics", en Goldenbaum, Ursula y Jesseph, Douglas (eds.), pp. 31-52.

Beeley, Philip (2009): “Approaching Infinity. Philosophical Consequences of Leibniz's Mathematical Investigations in Paris and Thereafter", en Kulstad, Mark, Laerke, Mogens y Snyder, David (eds.), pp. 29-48.

Beeley, Philip (2015): "Leibniz, Philosopher Mathematician and Mathematical Philosopher", en Goethe, Norma B., Beeley, Philip y Rabouin, David (eds.), pp. 23-48. 
Berlioz, Dominique y Nef, Frédéric (eds.) (1999): L'actualité de Leibniz: les deux labyrinthes: décade de Cerisy la Salle, 15-22 juin 1995 (Studia Leibnitiana Supplementa 34), Franz Steiner Verlag, Stuttgart.

Bernstein, Howard (1980): "Conatus, Hobbes, and the young Leibniz", en Studies in History and Philosophy of Science, 11/1, pp. 25-37.

Blank, Andreas (2001): “Substance Monism and Substance Pluralism in Leibniz's Metaphysical Papers 1675-1676”, en Studia Leibnitiana, 33/2, pp. 216-223.

Blank, Andreas (2009): “The Analysis of Reflection and Leibniz's Early Response to Spinoza”, en Kulstad, Mark, Laerke, Mogens y Snyder, David (eds.), pp. 161-175.

Blank, Andreas (2011): "Sennert and Leibniz on Animate Atoms", en Smith, Justin E. y Nachtomy, Ohad (eds.), pp. 115-130.

Blank, Andreas (2014): "Leibniz, Spinoza y el intelecto agente", en Cabañas, Leticia y Esquisabel, Oscar M. (eds.), pp. 231-244.

Bostock, David (2006): Space, Time, Matter, and Form. Essays on Aristotle's Physics, Clarendon Press, Oxford.

Boyer, Carl B. (1949): The history of the calculus and its conceptual development, Dover Publications, New York.

Breger, Herbert (1990): “Das Kontinuum bei Leibniz”, en Lamarra, Antonio (ed.), pp. 5367.

Breger, Herbert (2016): “Kontinuum, Analysis, Informales - Beiträge zur Mathematik und Philosophie von Leibniz", Springer, Heidelberg / Berlin.

Brown, Stuart (ed.) (1999a): The young Leibniz and his philosophy (1646-76), Kluwer Academic Publishers, Dordrech; Boston; London.

Brown, Stuart (1999b): “Leibniz's formative years (1646-76): an overview”, en Brown, Stuart (ed.), pp. 1-18.

Brown, Stuart (1999c): "The proto-monadology of the De Summa Rerum", Brown, Stuart (ed.), pp. 123-145.

Brundell, Barry (1987): Pierre Gassendi. From Aristotelianism to a New Natural Philosophy, Dordretch, Reidel.

Cabañas, Leticia y Esquisabel, Oscar M. (eds.) (2014): Leibniz frente a Spinoza. Una interpretación panorámica, Comares, Granada. 
Castañeda, Hector-Neri (1978), “Leibniz’s Meditation on April 15, 1676 about Existence, Dreams and Space", en Symposion de la G. W. Leibniz-Gesellschaft (Hannover) et du Centre National de la Recherche Scientifique (Paris) a Chantilly (France) du 14 au 18 Novembre 1976. Tome II. La Philosophie de Leibniz, Franz Steiner Verlag, Chantilly, pp. 91-129.

Charlton, William (2003 [1991]): “Aristotle's Potential Infinities”, en Judson, Lindsay (ed.), pp. 129-149.

Clarke, Desmond (1979): "Physics and Metaphysics in Descartes' Principles", en Studies in History and Philosophy of Science, Part A, 10:2, pp. 89-112.

De Tommaso, Emilio M. (2014): "From the flos substantiae to the vortex: a shift in Leibniz's early philosophy”, en Pacific Philosophical Quarterly, 95, pp. 87-108.

De Jong, Willem R. (1986): “Hobbes's logic: language and scientific method", en History and Philosophy of Logic, 7:2, pp. 123-142.

Di Bella, Stefano (2014): “Leibniz, Spinoza y el argumento ontológico", en Cabañas, Leticia y Esquisabel, Oscar M. (eds.), pp. 239-250.

Duhem, Pierre (1908): $\Sigma \Omega Z E I N ~ T A ~ \Phi A I N O M E N A$. Essai sur la notion de théorie physique de Platon a Galilée, Herman et Fils, Paris.

Dutton, Blake D. (1999): "Physics and Metaphysics in Descartes and Galileo", en Journal of the History of Philosophy, 37:1, pp. 49-71.

Earman, John (1975): "Infinities, Infinitesimals and Indivisibles: the Leibnizian Labyrinth", en Studia Leibnitiana, 8/2, pp. 236-251.

Edamura, Shohei (2016): "Can We Unify Theories of the Origin of Finite Things in Leibniz's De Summa Rerum?”, en Li, Wenchao et al. (eds.), vol. I, pp. 393-406.

Escribano Cabeza, Miguel (2016): Complejidad y dinámica en la filosofía natural y la metafisica de G.W. Leibniz, Universidad de Granada, Tesis doctoral.

Esquisabel, Oscar M. (1992-1993): “Los argumentos a posteriori para la noción leibniziana de sustancia”, en Cuadernos del Sur, 25, pp. 71-81.

Esquisabel, Oscar M. (1999a): "Perspectivas leibnizianas sobre el análisis y la síntesis”, en THEORIA - Segunda Época, 14/2, pp. 303-329.

Esquisabel, Oscar M. (1999b): “Leibniz sobre la verdad y la coherencia”, en Revista de Filosofía y Teoría Política, 33, pp. 167-199. 
Esquisabel, Oscar M. (2012a): “Representing and Abstracting. An analysis of Leibniz's concept of symbolic knowledge", en Lassalle Casanave, Abel (comp.), pp. 1-49.

Esquisabel, Oscar M. (2012b): "Leibniz: las bases semióticas de la characteristica universalis", en Representaciones, 8/1, pp. 5-32.

Esquisabel, Oscar M. (2012c): “Infinitesimales y conocimiento simbólico en Leibniz”, en Notae Philosophicae Scientiae Formalis, 1/1, pp. 66-79.

Esquisabel, Oscar M. (2016): "Perspectivism, Expression, and Logic in Leibniz. A Foundational Essay”, en Li, Wenchao et al. (eds.), vol. III, pp. 73-87.

Fazio, Rodolfo E. (2012): "Mecánica y metafísica en el joven Leibniz", en Revista de Filosofia de la Universidad de Costa Rica, 51/129-131, pp. 159-166.

Fazio, Rodolfo E. (2014): Dinámica y Metafísica. Un estudio de la sustancia corpórea en la filosofía de Leibniz a través de sus distintos períodos, Universidad de Buenos Aires, tesis doctoral.

Garber, Daniel (1995): “Leibniz: Physics and philosophy”, en Jolley, Nicholas (ed.), pp. 270-352.

Garber, Daniel (2000): "A different Descartes: Descartes and the programme for a mathematical physics in his correspondence", en Gaukroger, Stephen, Schuster, John y Sutton, John (eds.), pp. 113-130.

Garber, Daniel (2001): Descartes Embodied. Reading Cartesian Philosophy through Cartesian Science, Cambridge University Press, Cambridge.

Garber, Daniel (2002): "Descartes, Mechanics, and the Mechanical Philosophy", en Midwest Studies in Philosophy, 26, pp. 185-204.

Garber, Daniel y Nadler, Steven (eds.) (2004): Oxford Studies in Early Modern Philosophy. Volume 1, Oxford University Press, New York.

Garber, Daniel (2009): Leibniz: Body, Substance, Monad, Oxford University Press, Oxford.

Gaukroger, Stephen, Schuster, John y Sutton, John (eds.) (2000): Descartes' Natural Philosophy, Routledge, London \& New York.

Gaukroger, Stephen (2002a [1995]): Descartes. An intelectual biography, Oxford University Press, Oxford.

Gaukroger, Stephen (2002b): Descartes' System of Natural Philosophy, Cambridge University Press, Cambridge. 
Gavroglu, Kostas, Christianidis, Jean y Nicolaidis, Efthymios (eds.) (1994): Trends in the historiography of science, Kluwer Academic Publishers, Dordrecht; Boston; London.

Gilbert, Neal W. (1963): Renaissance Concepts of Method, Columbia University Press, New York \& London.

Giusti, Enrico (2001): "Los discursos sobre dos nuevas ciencias” (traducción de Joaquín Gutiérrez Calderón), en Alonso Matos, Juana del Carmen (ed.), pp. 245-265.

Goethe, Norma B., Beeley, Philip y Rabouin, David (eds.) (2015): G. W. Leibniz, interrelations between Mathematics and Philosophy (Serie Archimedes, 41), Springer, Dordrecht, Heidelberg, New York, London.

Goldenbaum, Ursula y Jesseph, Douglas (eds.) (2008): Infinitesimal Differences: Controversies between Leibniz and his Contemporaries, Walter de Gruyter, Berlin \& New York.

Goldenbaum, Ursula (2014): "La fascinación de Leibniz por Spinoza”, en Cabañas, Leticia y Esquisabel, Oscar M. (eds.), pp. 31-50.

Gracia, Jorge E. y Noone, Timothy B. (eds.) (2002): A Companion to Philosophy in the Middle Ages, Blackwell Publishing, Malden.

Grant, Hardy (1996): “Hobbes and mathematics”, en Sorell, Tom (ed.), pp. 108-128.

Grosholz, Emily R. (2015): “Leibniz’s Mathematical and Philosophical Analysis of Time”, en Goethe, Norma B., Beeley, Philip y Rabouin, David (eds.), pp. 75-88.

Hartz, Glenn A. (2007): Leibniz' Final System. Monads, Matter and Animals, Routledge, London \& New York.

Hasper, Pieter Sjoerd (2006): “Aristotle’s Diagnosis of Atomism”, en Apeiron, 39:2, 121156.

Hofmann, Joseph E. (1974): Leibniz in Paris, 1672-1676. His growth to mathematical maturity, Cambridge University Press, Cambridge \& New York.

Ishiguro, Hidé (1990): Leibniz's Philosophy of Logic and Languaje, Cambridge University Press, Cambridge.

Jaeger, Werner (1923): Aristoteles: Grundlegung einer Geschichte seiner Entwicklung, Weidgmann, Berlin.

Jesseph, Douglas (1996): "Hobbes and the method of natural science", en Sorell, Tom (ed.), pp. 86-107. 
Jesseph, Douglas (1998): "Leibniz on the Foundations of the Calculus: The Question of the Reality of Infinitesimal Magnitudes”, en Perspectives of Science, 6:1\&2, 6-40.

Jesseph, Douglas (1999): Squaring the Circle. The War between Hobbes and Wallis, The University of Chicago Press, Chicago \& London.

Jesseph, Douglas (2008): “Truth in Fiction: Origins and Consequences of Leibniz's Doctrine of Infinitesimal Magnitudes", en Goldenbaum, Ursula y Jesseph, Douglas (eds.), pp. 215-233.

Jesseph, Douglas (2015): "Leibniz on The Elimination of Infinitesimals", en Goethe, Norma B., Beeley, Philip y Rabouin, David (eds.), pp. 189-205.

Jolley, Nicholas (ed.) (1995): The Cambridge Companion to Leibniz, Cambridge University Press, Cambridge.

Judson, Lindsay (ed.) (2003 [1991]): Aristotle's Physics. A Collection of Essays, Oxford, Clarendon Press.

Jullien, Vincent (ed.) (2015a): Seventeenth-Century Indivisibles Revisited, Dordrecht, Birkäuser (Science Networks. Historical Studies, 49).

Jullien, Vincent (2015b): "Explaining the Sudden Rise of Methods of Indivisibles", en Jullien, Vincent (ed.), pp. 1-18.

Jullien, Vincent (2015c): "Indivisibles in the work of Galileo", en Jullien, Vincent (ed.), pp. 87-103.

Jullien, Vincent (2015d): “Archimedes and Indivisibles”, en Jullien, Vincent (ed.), pp. 451457.

Katz, Mikhail y Sherry, David (2012): "Infinitesimals, Imaginaries, Ideals, and Fictions", en Studia Leibnitiana, 44/2, pp. 166-192.

Katz, Mikhail y Sherry, David (2013): “Leibniz's infinitesimals: their fictionality, their modern implementations, and their foes from Berkeley to Russell and beyond", en Erkenntnis, 78/3, pp. 571-625.

Knobloch, Eberhard (1990): "L’infini dans les matématiques de Leibniz", en Lamarra, Antonio (ed.), pp. 33-51.

Knobloch, Eberhard (1993): "Les courbes analytiques simples chez Leibniz”, en Sciences et techniques en perspective, 26, pp. 74-96. 
Knobloch, Eberhard (1994): “The infinite in Leibniz's mathematics - the historiographical method of comprehension in context", en Gavroglu, Kostas, Christianidis, Jean y Nicolaidis, Efthymios (eds.), pp. 265-278.

Knobloch, Eberhard (1999): "Galileo and Leibniz: Different Approaches to Infinity", en Archive for History of Exact Sciences, 54, pp. 87-99.

Knobloch, Eberhard (2002): “Leibniz's rigorous foundation of infinitesimal geometry by means of Riemannian sums", en Synthese, 133, pp. 59-73.

Knobloch, Eberhard (2015): "Analyticité, équipollence et théorie des courbes chez Leibniz”, en Goethe, Norma B., Beeley, Philip y Rabouin, David (eds.), pp. 89-110.

Kulstad, Mark A. (1999a): "Leibniz, Spinoza and Tschirnhaus: multiple worlds, possible worlds", en Brown, Stuart (ed.), pp. 246-262.

Kulstad, Mark A. (1999b): "Leibniz's De summa rerum. The origin of the variety of things, in connection with the Spinoza-Tshirnhaus correspondence”, en Berlioz, Dominique y Nef, Frédéric (eds.), pp. 69-85.

Kulstad, Mark A. (2000): "Pantheism, Harmony, Unity and Multiplicity: a Radical Suggestion of Leibniz's De summa rerum", en Lamarra, Antonio y Palaia, Roberto (eds.), pp. 97-105.

Kulstad, Mark, Laerke, Mogens y Snyder, David (eds.) (2009): The Philosophy of the Young Leibniz (Studia Leibnitiana Sonderheft 35), Franz Steiner Verlag, Stuttgart.

Kulstad, Mark A. (2014): “Leibniz, Spinoza y Tschirnhaus. Metafísica «a tres manos», 1675-1676”, en Cabañas, Leticia y Esquisabel, Oscar M. (eds.), pp. 51-70.

Laerke, Mogens (2008): Leibniz lecteur de Spinoza. La genèse d'une opposition complexe, Honoré Champion Éditeur, Paris.

Laerke, Mogens (2009): “De Origine Rerum ex Formis (April 1676): A Quasi-Spinozistic Parallelism in De Summa Rerum", en Kulstad, Mark, Laerke, Mogens y Snyder, David (eds.), pp. 203-220.

Lamarra, Antonio (ed.) (1990): L' infinito in Leibniz: problemi e terminologia: Simposio internazionale del Lessico intellettuale europeo e della Gottfried-Wilhelm-LeibnizGesellschaft: Roma, 6-8 novembre 1986, Edizioni dell'Ateneo, Roma.

Lamarra, Antonio y Palaia, Roberto (eds.) (2000): Unità e molteplicità nel pensiero filosofico e scientifico di Leibniz, Olschki, Roma. 
Lassalle Casanave, Abel (comp.) (2012): Symbolic Knowledge from Leibniz to Husserl, College Publications, London.

Lawrenz, Jürgen (2010): The Nature of Reality and the Reality of Nature. A Study of Leibniz's Double-Aspect Ontology and the Labyrinth of the Continuum, Cambridge Scholars Publishing, Cambridge.

Levey, Samuel (1998): "Leibniz on Mathematics and the Actually Infinite Division of Matter", en The Philosophical Review, 107/1, pp. 49-96.

Levey, Samuel (1999): "Matter and Two Concepts of Continuity in Leibniz", en Philosophical Studies, 94, pp. 81-118.

Levey, Samuel (2003): “The Interval of Motion in Leibniz's Pacidius Philalethi”, en NOÛS, 47/3, pp. 371-416.

Levey, Samuel (2007): "On Unity and Simple Substance in Leibniz", en The Leibniz Review, 17, pp. 61-106.

Levey, Samuel (2008): "Archimedes, Infinitesimals and the Law of Continuity: On Leibniz's Fictionalism", en Goldenbaum, Ursula y Jesseph, Douglas (eds.), pp. 107133.

Levey, Samuel (2011): "On Two Theories of Substance in Leibniz: Critical Notice of Daniel Garber, Leibniz: Body, Substance, Monad”, en Philosophical Review, 120/2, pp. 285-320.

Levey, Samuel (2015): "Comparability of Infinities and Infinite Multitude in Galileo and Leibniz”, en Goethe, Norma B., Beeley, Philip y Rabouin, David (eds.), pp. 157-187.

Li, Wenchao et al. (eds.) (2016): „Für unser Glück oder das Glück Anderer“ - Vorträge des X. Internationalen Leibniz-Kongress, Olms, Hildesheim/Zürich/New York (5 volúmenes)

Lison, Elad (2006): “The Philosophical Assumptions Underlying Leibniz's Use of the Diagonal Paradox in 1672", en Studia Leibnitiana, 38/2, pp. 197-208.

Lodge, Paul (2001): “Leibniz's notion of an Aggregate”, en British Journal for the History of Philosophy, 9/3, 467-486.

LoLordo, Antonia (2007): Pierre Gassendi and the Birth of Early Modern Philosophy, Cambridge University Press, Cambridge. 
Look, Brandon C. (2014): "Perfección, poder y pasiones en Spinoza y Leibniz", en Cabañas, Leticia y Esquisabel, Oscar M. (eds.), pp. 131-146.

Luna Alcoba, Manuel (1994): "El problema del continuo en la escolástica española: Rodrigo de Arriaga", en Fragmentos de Filosofía, 4, pp. 137-150.

Luna Alcoba, Manuel (1996): La ley de continuidad en G. W. Leibniz, Universidad de Sevilla, Sevilla.

MacDonald Ross, George (2007): “Leibniz's Debt to Hobbes”, en Phemister, Pauline y Brown, Stuart (eds.), pp. 19-33.

Mercer, Christia (1999): “The young Leibniz and his teachers”, en Brown, Stuart (ed.), pp. $19-40$.

Mercer, Christia (2000): "God as Both the Unity and the Multiplicity in the World", en Lamarra, Antonio y Palaia, Roberto (eds.), pp. 71-95.

Mercer, Christia (2004): Leibniz's Metaphysics. Its origins and development, Cambridge University Press, Cambridge.

Montesinos Sirera, José y Solís Santos, Carlos (eds.) (2001): Largo campo di filosofare. Eurosymposium Galileo 2001, Fundación Canaria Orotava de Historia de la Ciencia, Canarias.

Montesinos Sirera, José L. (2009): "Fluxiones, infinitesimales y fuerzas vivas. Un panorama leibniziano", en Thémata. Revista de Filosofía, 42, pp. 77-106.

Morfino, Vittorio (2014): "Modo o mónada: La puesta en juego de una alternativa", en Cabañas, Leticia y Esquisabel, Oscar M. (eds.), pp. 97-112.

Nadler, Steven (2014): "Spinoza, Leibniz y los dioses de la filosofía”, en Cabañas, Leticia y Esquisabel, Oscar M. (eds.), pp. 251-265.

Nachtomy, Ohad (2014): “Unidad, singularidad e infinito en Spinoza y Leibniz”, en Cabañas, Leticia y Esquisabel, Oscar M. (eds.), pp. 147-166.

Nita, Adrian (ed.) (2015): Leibniz's Metaphysics and Adoption of Substantial Forms. Between Continuity and Transformation, Springer, Dordrecht, Heidelberg, New York, London.

Orio de Miguel, Bernardino (1994): "Leibniz y la tradición neoplatónica", en Revista de Filosofía, 7:12, pp. 493-517. 
Osler, Margaret J. (2002): "New Wine in Old Bottles: Gassendi and the Aristotelian Origin of Physics", en Midwest Studies in Philosophy, 36, pp. 167-184.

Owens, Joseph (1978): The Doctrine of Being in the Aristotelian Metaphysics: A Study in the Greek Background of Mediaeval Thought, Pontifical Institute of Mediaeval Studies, $3^{\mathrm{a}}$. ed., Toronto.

Palmerino, Carla R. (2011): "The Isomorphism of Space, Time and Matter in Seventeenthcentury Natural Philosophy”, en Early Science and Medicine, 16/4, pp. 296-330.

Pantin, Isabelle (2001): "Libert Froidmont et Galilée: L'impossible dialogue”, en Montesinos Sirera, José y Solís Santos, Carlos (eds.), pp. 615-635.

Pasini, Enrico (2014): "Leibniz tras los pasos de Spinoza", en Cabañas, Leticia y Esquisabel, Oscar M. (eds.), pp. 71-96.

Phemister, Pauline (2005): Leibniz and the Natural World. Activity, Passivity and Corporeal Substances in Leibniz’ Philosophy, Springer, Dordrech.

Phemister, Pauline y Brown, Stuart (eds.) (2007): Leibniz and the English-Speaking World, Springer, Dordrech.

Piro, Francesco (2014): "Spinoza y Leibniz: Dos historias diferentes sobre atributos, sustancias y esencias”, en Cabañas, Leticia y Esquisabel, Oscar M. (eds.), pp. 113-129.

Probst, Siegmund (2008): "Indivisibles and infinitesimals in Early Mathematical Texts of Leibniz”, en Goldenbaum, Ursula y Jesseph, Douglas (eds.), pp. 95-106.

Rabouin, David (2015): “Leibniz's Rigorous Foundations of the Method of indivisibles", en Jullien, Vincent (ed.), pp. 347-364.

Racionero, Quintín (1980): “La filosofía del joven Leibniz: La génesis de los conceptos y la función de la lógica", en Revista de Filosofía, 3, 39-125.

Reale, Giovanni (1985): Introducción a Aristóteles, Herder, Barcelona.

Reale, Giovanni (1993): Il concetto di filosofia prima e l'unità della metafisica di Aristotele, Vita e Pensiero, $5^{\mathrm{a}}$. ed., Milán.

Robinet, André (1986): Architectonique disjonctive automates systémiques et idéalité transcendantale dans l'œuvre de G. W. Leibniz, Vrin, Paris.

Santi, Marco (2016): “On Leibniz' Reappraisal of Material Atomism”, en Li, Wenchao et al. (eds.), vol. I, pp. 89-103. 
Sellés García, Manuel (2001): “La teoría de los indivisibles de Galileo y su geometrización del movimiento", en Montesinos Sirera, José y Solís Santos, Carlos (eds.), pp. 445457.

Sellés García, Manuel (2006): "La paradoja de Galileo", en Asclepio. Revista de Historia de la Medicina y de la Ciencia, 58/1, 113-148.

Shapin, Steven (2000): La revolución científica. Una interpretación alternativa (traducción de José Romo Feito), Paidós, Barcelona.

Shapin, Steven y Schaffer, Simon (2005): el Leviathan y la bomba de vacío. Hobbes, Boyle y la vida experimental (traducción de Alfonso Buch), Universidad Nacional de Quilmes, Bernal.

Shea, William R. (2001): “Galileo e l'atomismo”, en Acta Philosophica, 10/2, 257-272.

Slowik, Edward (2001): "Descartes and Individual Corporeal Substance", en British Journal for the History of Philosophy, 9:1, pp. 1-15.

Smith, Justin E. (2011a): Divine Machines. Leibniz and the Sciences of Life, Princeton University Press, Princeton \& Oxford.

Smith, Justin E. y Nachtomy, Ohad (eds.) (2011b): Machines of Nature and Composite Substances in Leibniz (serie New Synthese Historical Library, 67), Springer, Dordrecht.

Solis Santos, Carlos (2007): "El atomismo inane de Galileo", en Theoria, 59, pp. 213-231.

Sorabji, Richard (1983): Time, Creation and the Continuum. Theories in antiquity and the early middle ages, Duckworth, London.

Sorell, Tom (ed.) (1996): The Cambridge Companion to Hobbes, Cambridge University Press, Cambridge.

Sumida Joy, Lynn (2002 [1987]): Gassendi the Atomist. Advocate of history in an age of science, Cambridge University Press, Cambridge.

Taliaferro, R. Catesby (1964): “The concept of matter in Descartes and Leibniz”, en Notre Dame Mathematical Lectures, Number 9, Notre Dame, Indiana: University of Notre Dame. 33 páginas.

White, Michael J. (2002 [1992]): The Continuous and the Discrete. Ancient Physical Theories from a Contemporary Perspective, Oxford, Clarendon Press. 
Wilson, Catherine (1999): “Atoms, Minds and Vortices in De summa rerum: Leibniz vis-avis Hobbes and Spinoza", en Brown, Stuart (ed.), pp. 224-243.

Zarka, Yves Charles (1996): "First Philosophy and the foundations of knowledge", en Sorell, Tom (ed.), pp. 62-85.

Zupko, Jack (2002): “Gregory of Rimini”, en Gracia, Jorge E. y Noone, Timothy B. (eds.), pp. 283-290. 